Production of Working Reference Materials for the Capability Evaluation Project

Phillip D. Noll, Jr.

Robert S. Marshall 


\section{DISCLAIMER}

Portions of this document may be illegible in electronic image products. Images are produced from the best available original document. 


\section{Contents}

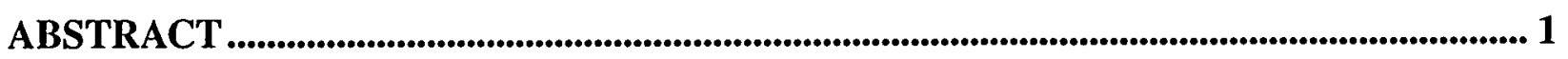

I. INTRODUCTION .................................................................................................................... 2

II. STARTING MATERIALS ........................................................................................................... 3

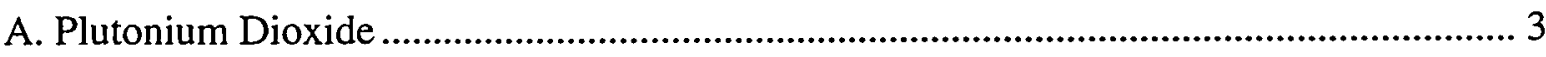

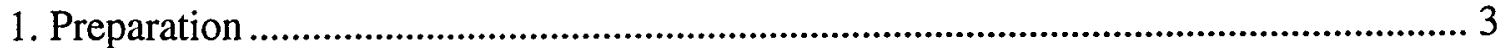

a. Blending and Calcining .......................................................................................... 3

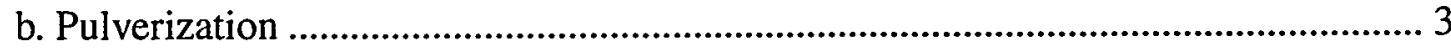

c. Screening ............................................................................................................. 3

d. Documentation and Records ..................................................................................... 3

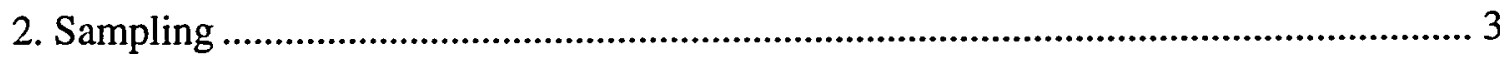

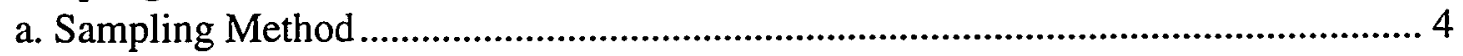

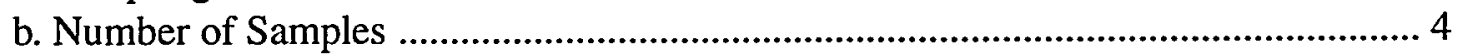

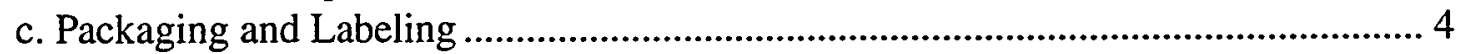

d. Documentation and Records ................................................................................ 4

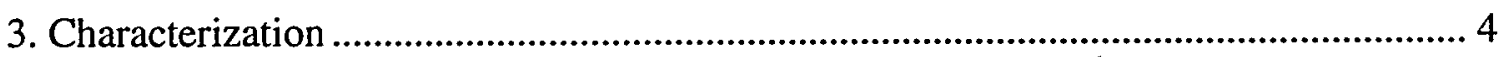

a. Particle Size Distribution ...................................................................................... 4

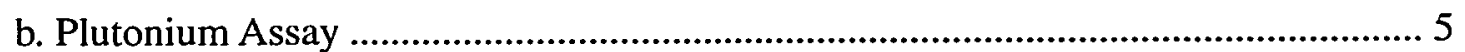

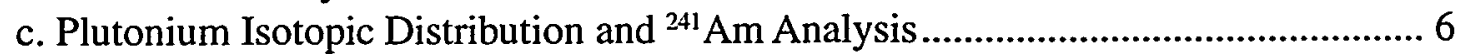

d. DC Arc Emission Spectroscopy Determination of Impurities ..................................... 8

e. Inductively-Coupled Plasma Mass Spectrometry Determination of

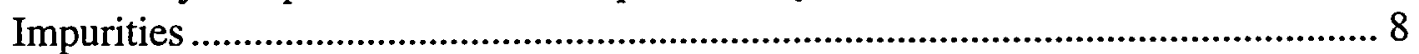

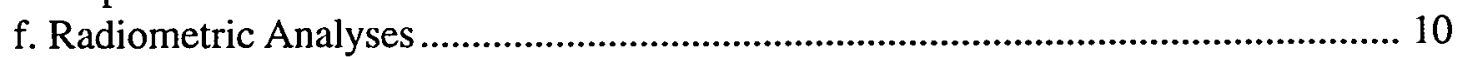

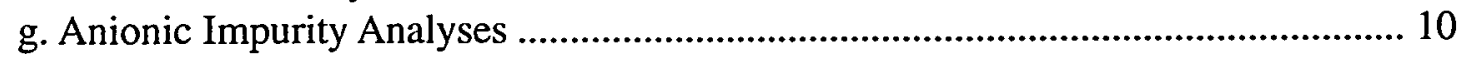

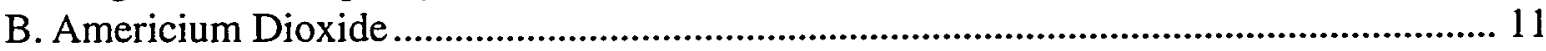

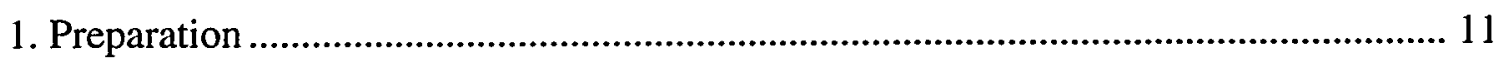

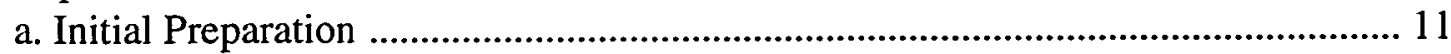

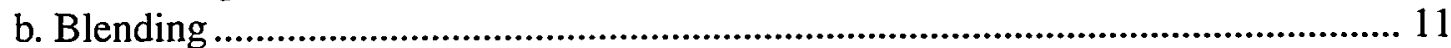

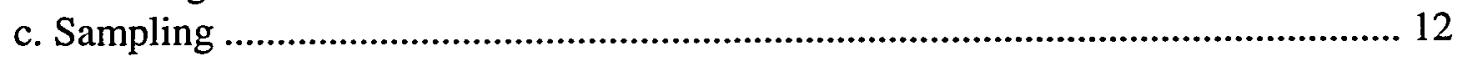

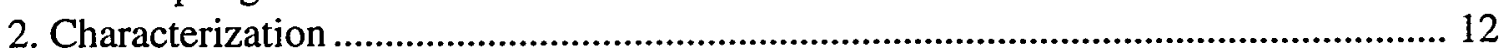

a. Sampling for Analytical Chemistry ........................................................................ 12

b. Particle Size Distribution ................................................................................ 12

c. Americium Assay, Pu and U Content, and Isotopic Distribution ............................... 13

d. Inductively-Coupled Plasma Mass Spectrometry Determination of Impurities ........................................................................................................... 15

e. Radiometric Analysis ........................................................................................ 17

f. Loss on Ignition ................................................................................................... 18

g. Anionic Impurity Analyses .................................................................................. 18

C. Depleted Uranium Oxide ………................................................................................. 19

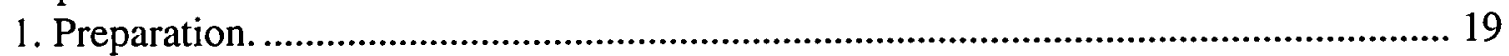

a. Initial Preparation ........................................................................................ 19

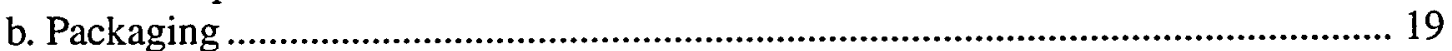

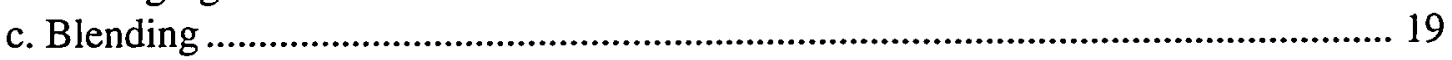




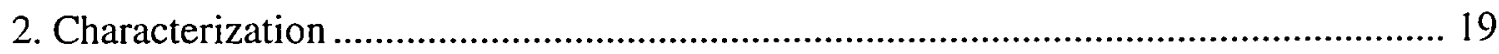

a. Sampling for Analytical Chemistry .............................................................. 19

b. Particle Size Distribution …………………………….................................... 20

c. Uranium Assay and Isotopic Distribution ................................................................ 20

d. ICP-AES Determination of Impurities .............................................................. 21

e. ICP-MS Determination of Impurities .............................................................. 22

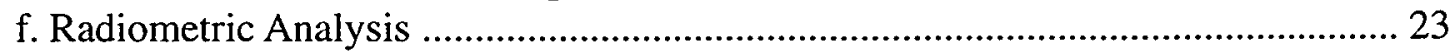

g. Anionic Impurity Anlayses ........................................................................... 24

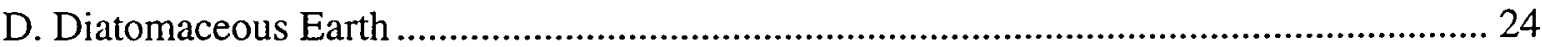

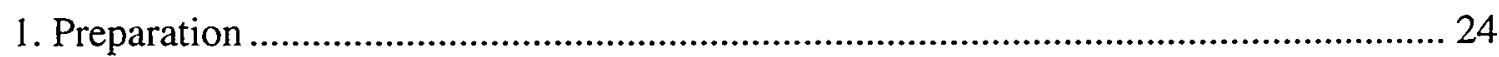

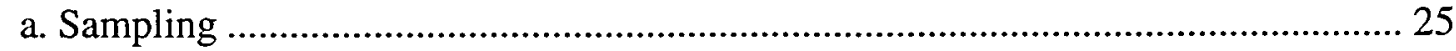

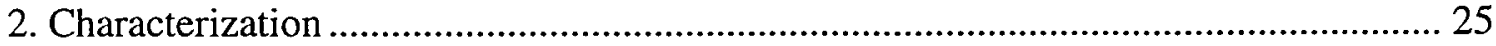

a. Glow Discharge Mass Spectrometry ……………………................................... 25

b. Loss on Ignition .................................................................................................. 26

III. BLENDING ...................................................................................................................................... 26

A. Blending Parameters and Blend Evaluations ……….................................................... 27

1. Summary of Initial Tests for PDP .......................................................................... 27

2. Alpha-Neutron Yield of $\mathrm{AmO}_{2}$-DE Blends ............................................................... 27

3. Gas-Generation Evaluation of the IAP WRMs ............................................................. 27

B. IAP WRM Blend Preparation ………………………................................................ 27

1. Nuclear Material and DE Addition ..................................................................... 28

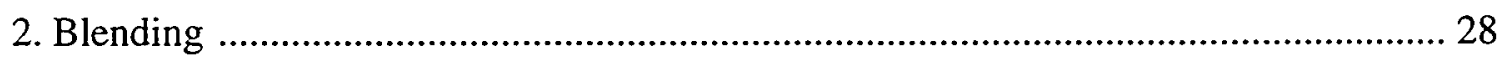

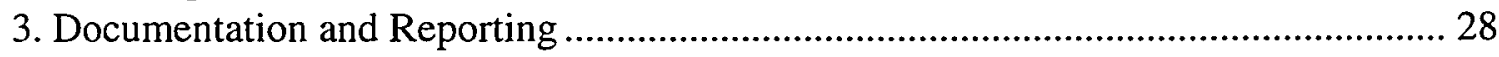

C. DU WRM Blend Preparation ................................................................................. 28

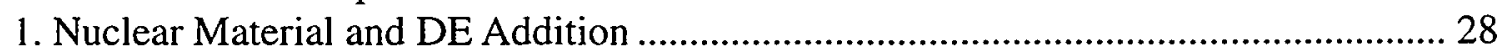

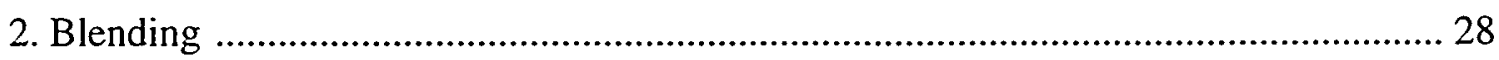

3. Documentation and Reporting ................................................................................. 29

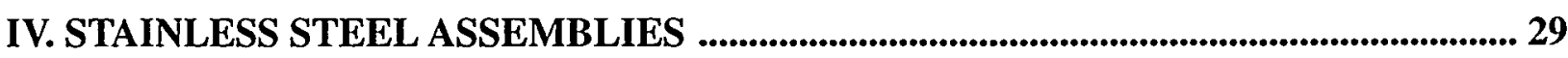

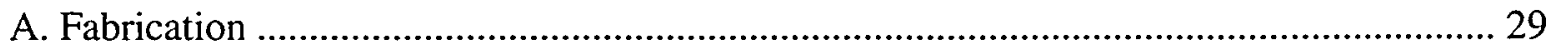

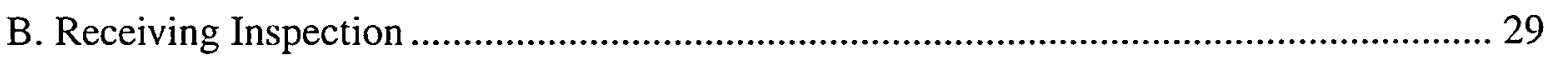

V. STAINLESS STEEL CYLINDER FILLING .............................................................................. 30

A. Cylinder Preparation ............................................................................................... 30

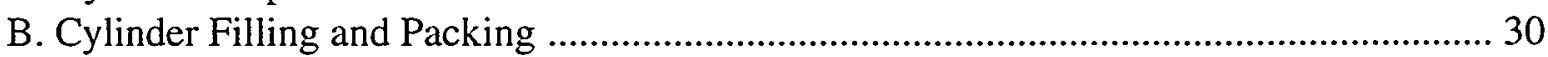

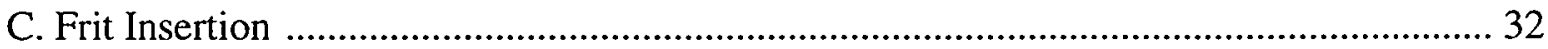

D. Waste Materials Measurement ........................................................................................ 32

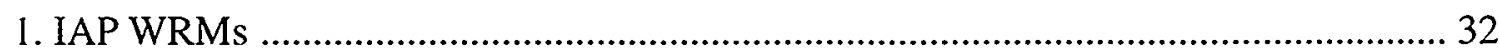

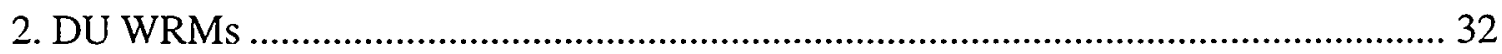

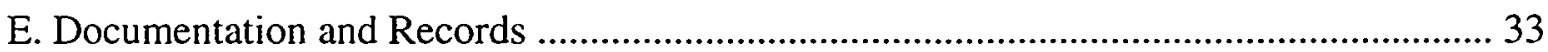

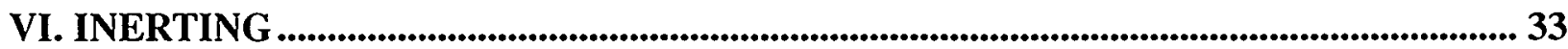

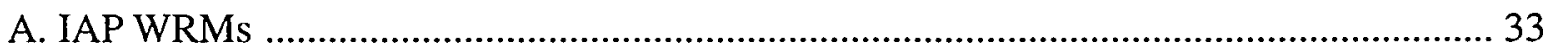

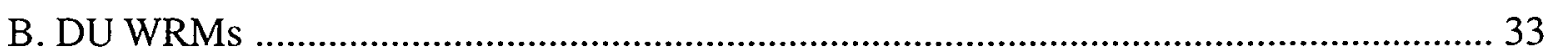


VII. WELDING ................................................................................................................................ 34

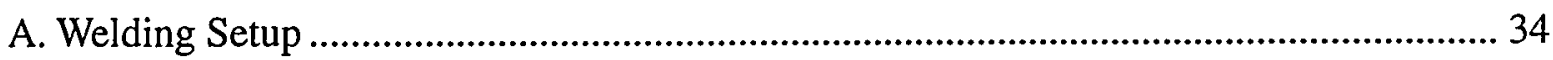

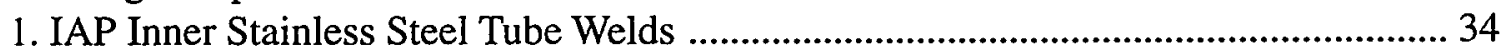

2. IAP Outer Stainless Steel Tube Welds ......................................................................... 34

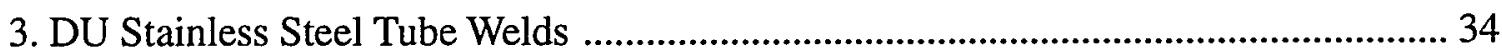

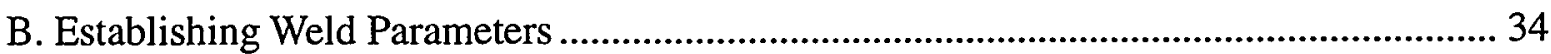

C. Welding Qualification ................................................................................................. 35

D. Documentation and Records ....................................................................................... 35

VIII. DECONTAMINATION OF THE IAP INNER CYLINDERS ......................................... 36

IX. LEAK CHECKING ............................................................................................................................ 36

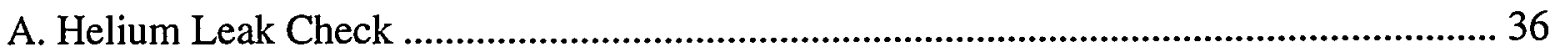

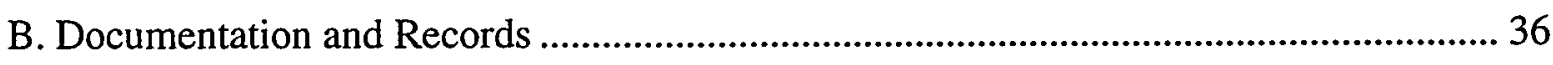

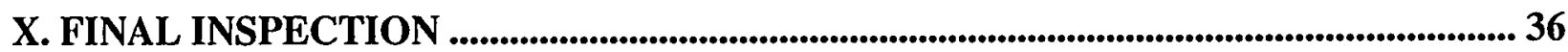

A. Alpha Contamination Checks ........................................................................................ 36

B. Dimensional and Identification Checks ............................................................................. 37

C. Nuclear Material Uniformity Checks and Verification ....................................................... 37

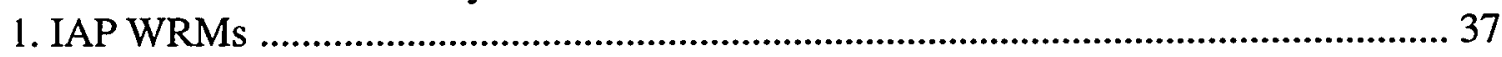

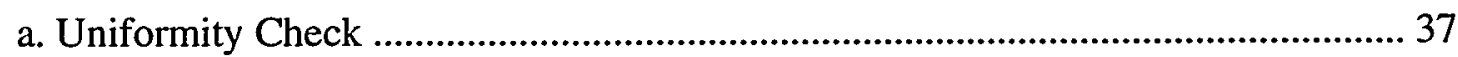

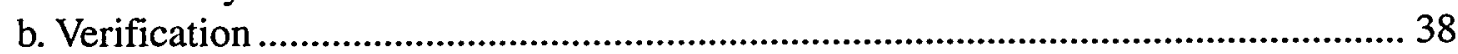

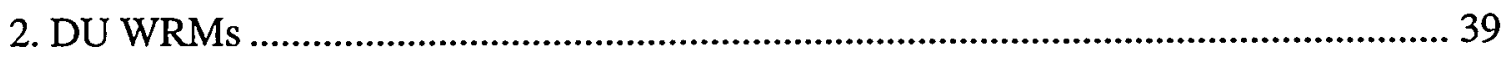

a. Uniformity Check ……….................................................................................... 39

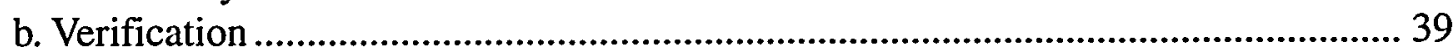

XI. PACKAGING AND SHIPPING ......................................................................................................... 40

XII. WRM CERTIFICATION ................................................................................................................ 41

A. Nuclide Mass and Alpha Activity Calculations ………................................................... 41

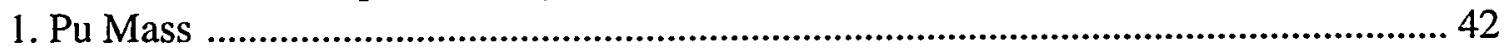

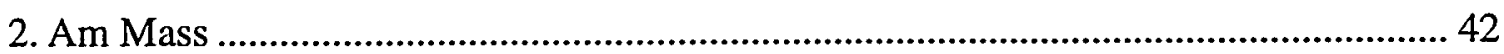

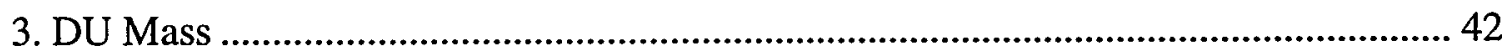

4. Alpha Activity ............................................................................................................... 42

B. Uncertainty Data and Calculations .................................................................................. 43

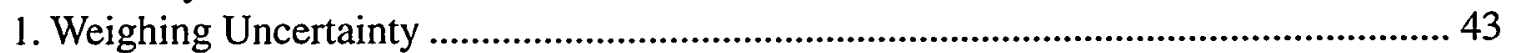

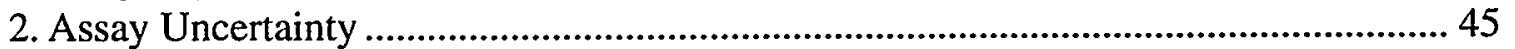

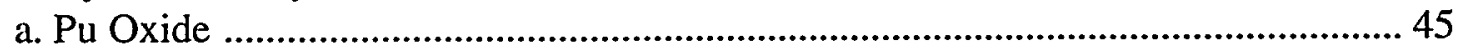

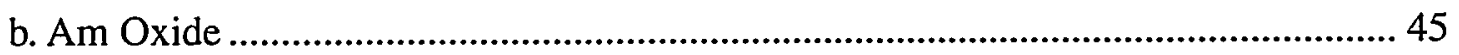

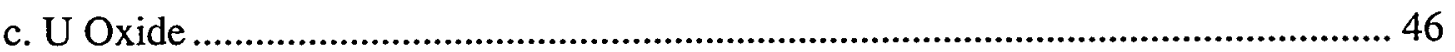

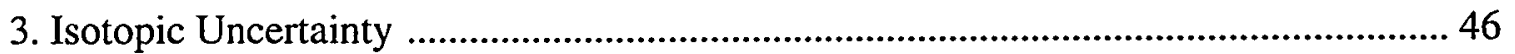

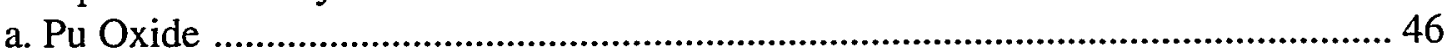

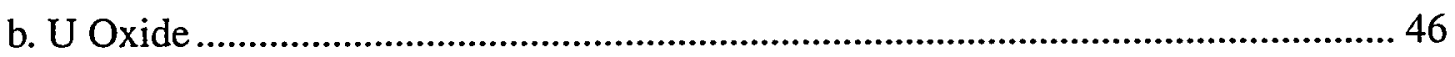

4. Transfer and Hold-Up Loss ............................................................................................. 47

5. Alpha Activity Uncertainty ............................................................................................ 47

6. Combined Uncertainty for Mass and Alpha Activity .................................................... 48

C. WRM Certification ........................................................................................................ 48

XIII. REFERENCES .................................................................................................................. 49 


\section{Appendices}
A. CEP SOW
B. Pu Preparation at TA-55
C. Final Chemical Analysis Report
D. Am Preparation at TA-55
E. AmO2 Particle Size Distribution
F. UO2 Particle Size Distribution
G. Am + DE Neutron Shuffler Measurements
H. Gas-Generation Report
I. Final Weights (IAP)
J. Final Weights (DU)
K. Hold-up Measurements
L. IAP Uniformity/Verification Measurements
M. DU Uniformity/Verification Measurements
N. Shipping Information
O. Uncertainty Calculations on Mass and Alpha Activity
P. Alpha Activity for Each WRM through 2001
Q. Weighing Data
R. Certificates for All Standards Used
S. NBS 948 and NBS U005 Standard Data
T. Description of Hold-up Measurements and Uncertainty
U. Description of Uncertainty Propagation
V. WRM Certificates 


\section{List of Tables}

Table 1. Pu Assay Results, Wt. \% Pu ................................................................................... 5

Table 2. Summary of Pu Isotopic Distribution As Weight Percent ............................................ 7

Table 3. ${ }^{241} \mathrm{Am} / \mathrm{Pu}$ Analysis Results ……................................................................................ 7

Table 4. Emission Spectroscopic Analysis Results in Micrograms Impurity per Gram $\mathrm{PuO}_{2} \ldots 8$

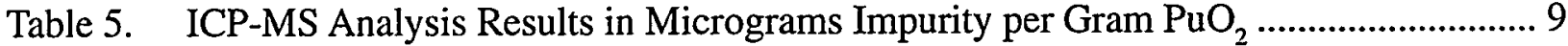

Table 6. Gamma Radiometric Analysis of $\mathrm{PuO}_{2}$ for ${ }^{241} \mathrm{Am}$..................................................... 10

Table 7. Ion Chromatographic Analyses of $\mathrm{PuO}_{2}$ for $\mathrm{Cl}$ and $\mathrm{F}$.............................................. 11

Table 8. Results of the ${ }^{241} \mathrm{Am}$ Assay of the $\mathrm{AmO}_{2}$................................................................ 13

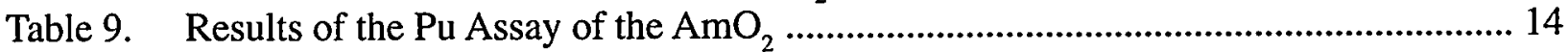

Table 10. Summary of Pu Isotopic Distribution of the $\mathrm{AmO}_{2}$ As Weight Percent ...................... 14

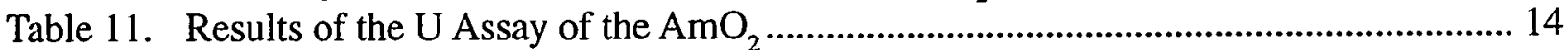

Table 12. Summary of $U$ Isotopic Distribution of the $\mathrm{AmO}_{2}$ As Weight Percent ....................... 14

Table 13. ICP-MS Analysis Results in Micrograms Impurity per Gram $\mathrm{AmO}_{2}$......................... 16

Table 14. Liquid Scintillation and Gamma Radiometric Analysis of $\mathrm{AmO}_{2}$ for ${ }^{241} \mathrm{Am}$............... 17

Table 15. Ion Chromatographic Analyses of $\mathrm{AmO}_{2}$ for $\mathrm{Cl}$ and $\mathrm{F}$............................................ 18

Table 16. Summary of U Isotopic Distribution As Weight Percent .............................................. 20

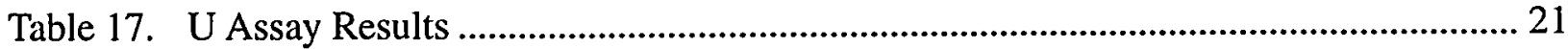

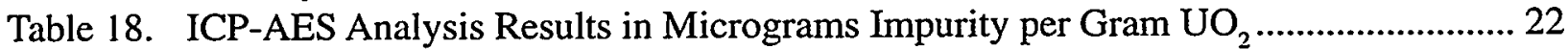

Table 19. ICP-MS Analysis Results in Micrograms Impurity per Gram $\mathrm{UO}_{2}$ …...................... 23

Table 20. Ion Selective Electrode Analyses of $\mathrm{UO}_{2}$ for $\mathrm{Cl}$ and $\mathrm{F}$................................................ 24

Table 21. GDMS Analysis Results on Kieselguhr Diatomaceous Earth .................................... 25

Table 22. Uniformity Measurement Data Summary ................................................................... 37

Table 23. Verification Measurement Data Summary .................................................................... 38

Table 24. Uniformity Measurement Data Summary for the DU WRMs................................... 40

Table 25. Verification Measurement Data Summary for DU WRMs ......................................... 40

Table 26. Atomic Masses, Half-Lives, and Alpha Activities of the Isotopes Present in the CEP WRMs ....................................................................................................... 43

Table 27. Precision on Standard-Control Weight Weighings ...................................................... 44

Table 28. Upper Bound Error Estimates for Mass Spectrometric Pu Isotopic Distribution........ 46

Table 29. Upper Bound Error Estimates for Mass Spectrometric U Isotopic Distribution ......... 47

Table 30. Components Included in Uncertainty Calculations ...................................................... 48 


\section{List of Figures}

Figure 1. Turbula Blender with Blend Bottle ............................................................... 26

Figure 2. Packaged Assemblies with Inspection Forms .................................................. 29

Figure 3. Labeled Assembly with Endcaps .......................................................... 30

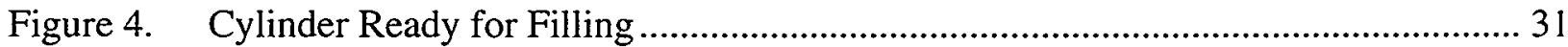

Figure 5. Fully Loaded and Tap-Packed ...................................................................... 31

Figure 6. Packaged Wasted and Filled Cylinder Ready for Bagout .................................... 32

Figure 7. The Six DU WRMs in the Desiccator for Inerting ............................................ 33

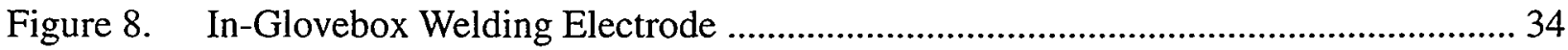

Figure 9. Completed IAP WRM after Welding and Inspection ......................................... 35

Figure 10. Inner Cylinder-Endcap Weld Cross-section .................................................... 35

Figure 11. IAP WRM Undergoing Uniformity/Verification Measurement ............................ 38

Figure 12. DU WRM (In Gray Can) Undergoing Uniformity/Verification Measurement on a Segmented Gamma Scanner ........................................................................ 39

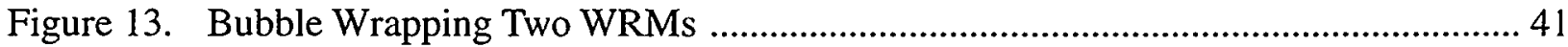

Figure 14. Inserting WRMs into a 2R Cylinder for Shipment ........................................ 41 


\title{
PRODUCTION OF WORKING REFERENCE MATERIALS \\ FOR THE CAPABILITY EVALUATION PROJECT
}

Phillip D. Noll, Jr. and Robert S. Marshall

\begin{abstract}
Nondestructive waste assay (NDA) methods are employed to determine the mass and activity of waste-entrained radionuclides as part of the National TRU (Trans-Uranic) Waste Characterization Program. In support of this program the Idaho National Engineering and Environmental Laboratory Mixed Waste Focus Area developed a plan to acquire capability/performance data on systems proposed for NDA purposes. The Capability Evaluation Project (CEP) was designed to evaluate the NDA systems of commercial contractors by subjecting all participants to identical tests involving 55 gallon drum surrogates containing known quantities and distributions of radioactive materials in the form of sealed-source standards, referred to as working reference materials (WRMs). Although numerous Pu WRMs already exist, the CEP WRM set allows for the evaluation of the capability and performance of systems with respect to waste types/configurations which contain increased amounts of ${ }^{241} \mathrm{Am}$ relative to weapons grade $\mathrm{Pu}$, waste that is dominantly ${ }^{241} \mathrm{Am}$, as well as wastes containing various proportions of depleted uranium. The CEP WRMs consist of a special mixture of $\mathrm{PuO}_{2} / \mathrm{AmO}_{2}$ (IAP) and diatomaceous earth (DE) or depleted uranium (DU) oxide and DE and were fabricated at Los Alamos National Laboratory. The IAP WRMs are contained inside a pair of welded inner and outer stainless steel containers. The DU WRMs are singly contained within a stainless steel container equivalent to the outer container of the IAP standards. This report gives a general overview and discussion relating to the production and certification of the CEP WRMs.
\end{abstract}




\section{INTRODUCTION}

This Nondestructive Waste Assay (NDA) Capability Evaluation Project (CEP) Production Plan addresses the key elements in the production of 16 Working Reference Materials (WRMs) as defined in the LITCO Statement of Work (SOW, see Appendix A). Guidelines in the ASTM Standard Guide C1128-89 were used to ensure that this plan addresses all the subjects appropriate to a production plan. This document serves two purposes: first, it defines all the operations required to meet the SOW objectives, task requirements, and technical specifications as envisioned prior to the start of WRM production; and second, it provides a record of the actual production and certification of the WRMs after they were produced. The SOW specified the WRM nuclear material masses, traceability to Certified Reference Materials, physical, chemical, and isotopic ranges, and total uncertainty. Additionally, specifications addressed the matrix material, matrix uniformity, containment, verification measurements, WRM shipping, and records disposition. The sixteen WRMs fabricated for the CEP project are analogous to those fabricated for the Performance Demonstration Program (PDP) Phase I (See LA-UR-96-2277, "NDA PDP Working Reference Materials Production Plan-Phase I") and PDP Phase II WRMs with the following exceptions: 1) eight of the WRMs contain both $\mathrm{AmO}_{2}$ and $\mathrm{PuO}_{2}$ in an Increased $\mathrm{Am} / \mathrm{Pu}$ (IAP) ratio; 2) two of the WRMs contain Am only (these two are also considered "IAP" WRMs); 3) six of the WRMs contain Depleted Uranium oxide $\left(\mathrm{UO}_{2}\right)$; and 4$)$ the six DU WRMs are encapsulated within a single layer of stainless steel (the PDP and IAP WRMs are encased in two layers of stainless steel). Since the fabrication of the CEP WRMs is nearly identical to that of previous PDP WRMs, some of the documentation associated with the production of the CEP WRMs was originally created during the production of the PDP WRMs. This being the case, there are numerous references within this document to data and/or documentation that is located within the PDP Phase I files and/or the PDP Phase I Production Plan (LA-UR-96-2277) rather than contained within the CEP files. Even though WRMs meeting the specifications of the SOW had been produced before (PDP Phase I, II), the SOW was continually updated during the course of WRM production and certification. Throughout the WRM production, the production plan was also updated to provide a complete and accurate description of the production and certification processes used to meet the SOW objectives.

This production plan was written to provide a general description of processes, steps, files, quality control, and certification measures. This plan identifies the files where detailed procedures, data, quality control and certification documentation, and forms are retained. The first several sections of this production plan describe the production and distribution of the WRMs, including starting materials, blending, loading, packaging, and shipping. The final sections address WRM certification, including WRM plutonium, americium, and depleted uranium content calculations, uncertainties and propagation of bias and precision, components, and the WRM certification certificates. Appendices for this production plan include extensive, detailed data that is identified and often summarized in the text. Four other documents complement the production plan: a quality assurance plan defining those quality assurance measures implemented to ensure the WRMs meet all the quality objectives stated in the SOW; a management plan which defines the management methods and tools used to ensure the WRMs are produced in a cost effective manner while meeting all milestones; a document control/records management plan that defines those measures taken to ensure that all procedures, records, and data required to document the production and demonstrate the pedigree of the WRMs are properly generated, documented, retained, and protected until delivered to LITCO; and finally, PERT Charts showing all tasks (with start and finish dates) that facilitate the scheduling and management of the project. 


\section{STARTING MATERIALS}

\section{A. Plutonium Dioxide}

Specifications for the plutonium dioxide $\left(\mathrm{PuO}_{2}\right)$ to be used for the CEP WRM production are listed in sections 5.6-5.8 of the SOW. Characteristics of the $\mathrm{PuO}_{2}$ used for the WRM production are typical of material used in the fabrication of nuclear weapons. Since waste materials currently being measured were typically generated on the order of ten to twenty years ago, the $0.085-0.25$ weight percent ${ }^{241}$ Am specified in the CEP WRM Production SOW (section 5.6) corresponds to a high purity $\mathrm{PuO}_{2}$ starting material purified in 1986 that now contains about ten years of daughter product in-growth. The $\mathrm{PuO}_{2}$ batch initially selected and used for the production of NDA PDP Phase I WRMs (LANL PEOR3258) was also used for the NDA CEP WRM production. This material (see LA-UR-96-2277 "NDA PDP Working Reference Materials Production Plan-Phase One") was initially prepared by the anion exchange purification of a plutonium nitrate solution, followed by precipitation as plutonium oxalate. The resultant $\mathrm{Pu}$ oxalate was calcined to $\mathrm{PuO}_{2}$ and packaged in hermetically sealed food-pack cans. The $1988 \mathrm{Pu}$ assay, plutonium isotopic, and impurity analyses records on this material indicates a suitable starting material. Approximately 120 grams was prepared, sampled, and characterized as described below.

1. Preparation. Appendix B contains a detailed report describing all preparation steps taken at the Los Alamos National Laboratory (LANL) TA-55 Plutonium Facility on the $\mathrm{PuO}_{2}$ used for the WRM production. These steps are summarized as follows:

a. Blending and Calcining. The $\mathrm{PuO}_{2}$ batch was calcined during initial $\mathrm{Pu}$ oxalate-to- $\mathrm{PuO}_{2}$ production; however, the calcination was not sufficiently rigorous to generate a stable (low surface area) material. Therefore, the batch was further calcined between $900^{\circ} \mathrm{C}$ and $960^{\circ} \mathrm{C}$ for nine hours. Prior to calcining, the $\mathrm{PuO}_{2}$ was blended in a $\mathrm{V}$ blender for approximately 30 minutes and then screened through a \#40 mesh sieve to eliminate any coarse $\mathrm{PuO}_{2}$ particles. The blended $\mathrm{PuO}_{2}$ was placed in a fused silica furnace boat and calcined. Furnace temperature history and calcining time was recorded, and is detailed in Appendix B.

b. Pulverization. The $\mathrm{PuO}_{2}$ was a uniform, finely divided powder when initially produced. The $\mathrm{PuO}_{2}$ was examined after calcining to determine whether the material homogeneity might be enhanced by grinding. The material appeared highly uniform; hence, no grinding was required.

c. Screening. The calcined $\mathrm{PuO}_{2}$ was screened through a \#80 mesh sieve. All the material passed through the sieve.

d. Documentation and Records. Records of the calcining time and temperature history, Loss-On-Ignition (LOI) analysis, and particle size analysis were generated and initialed upon completion of the calcining operation. The original report on the calcining, final screening, LOI, and particle size analyses are in the NDA PDP Phase I WRM files.

2. Sampling. Quality assurance and quality control are incorporated into the procedures used to characterize the $\mathrm{PuO}_{2}$. The accuracy and precision of these methods have been established via ongoing quality control programs, and maintained through the routine practice of 
analyzing control standards along with samples. Hence, multiple sampling of the selected $\mathrm{PuO}_{2}$ batch was not required to establish analytical method precision. However, multiple sampling was performed to verify batch homogeneity.

a. Sampling Method. The entire 120 gram batch of $\mathrm{PuO}_{2}$ was placed in a container of sufficient diameter to allow removal of five samples from different areas throughout the volume of $\mathrm{PuO}_{2}$. A spatula of suitable size was used to withdraw samples of the desired mass. The spatula was inserted into the $\mathrm{PuO}_{2}$ to obtain samples from different vertical and horizontal regions of the $\mathrm{PuO}_{2}$ batch.

b. Number of Samples. The number of samples selected for the measurement of each attribute was based on SOW quality objectives, and on the demonstrated performance of the instrument and method used to measure the attribute. Statistical considerations were used to assure that the samples taken for particle size determination, $\mathrm{Pu}$ assay, $\mathrm{Pu}$ isotopic distribution, Am Assay, and impurity analyses provided the desired level of confidence in the data and its subsequent application and propagation.

Three samples were taken for each of the following analysis methods: particle size distribution, DC Arc Emission Spectroscopy of metallic impurities, Inductively-Coupled Plasma (ICP)Mass Spectrometry (MS) of metallic impurities, and Ion Chromatography of anionic impurities. Five samples were taken for each of the following determinations: Pu Assay, Pu isotopic distribution, and ${ }^{241} \mathrm{Am}$ assay (sample dissolution for $\mathrm{Pu}$ assay provides aliquots for $\mathrm{Pu}$ isotopic distribution and ${ }^{241} \mathrm{Am}$ assay). Samples taken for Pu Assay and for blend preparation were taken from the batch only after the batch equilibrated in the glovebox inert-gas atmosphere for at least 24 hours. This precaution assured that the batch $\mathrm{PuO}_{2}$ samples taken for critical analyses and for blend preparation had exactly the same moisture content.

c. Packaging and Labeling. All samples were promptly sealed in glass or plastic screw-cap vials after removal from the $\mathrm{PuO}_{2}$ batch and before removal from the inert-gas atmosphere glovebox. The vials removed from the sample distribution room were clearly labeled with barcoded labels containing sequential numbers that uniquely defined each individual sample. Sample tracking was provided by the NMT-1 Analytical Laboratory Information Management System (LIMS).

d. Documentation and Records. Records were made showing sample identification, sample mass, date, and requested analyses. These records are retained in the NDA PDP Phase I WRM file.

\section{Characterization.}

\section{a. Particle Size Distribution.}

Method. A LAB-TEC 1000 Particle Size Analyzer was used to determine the sample particle size distribution. This instrument is a scanning laser microscope that measures particles suspended in a liquid medium. The procedure used for particle size determination is NMT-3-281MRD-R00. The particle count fraction and mass fraction were determined for particle size distributions with resolution of $<1$ micron in 28 increments over the 0.5 to 250 micron range. 
Calibration. Quartz certified reference materials BCR Nos. 67 and 69 were used for the particle size analyzer calibration and performance checks. The instrument laser, detectors, and focal point are fixed in position and cannot be manipulated or adjusted. This very stable instrument is checked using the BCR quartz certified reference materials on a biweekly basis. The performance check was performed on the same day as, and prior to, the $\mathrm{PuO}_{2}$ particle size determination.

Documentation and Reporting. The particle size distribution was a technical HOLD POINT. The particle size distribution data was reviewed by the NDA CEP Technical Team prior to using the $\mathrm{PuO}_{2}$ for preparing the WRMs. The Spherical Equivalent Mean Diameter of the three samples ranged from 32.5 to 34.4 microns. On a mass basis, the mean particle size was 125 microns for all three samples. Tables showing the detailed particle size data on both a particle count and mass basis can be found in the PDP Phase I file and in LA-UR-96-2277, "NDA PDP Working Reference Materials Production Plan-Phase I." A copy of procedure NMT-3 281-MRDR00 and a brief description of the instrument operation and calibration are retained in the NDA PDP Phase I WRM file. The particle size distribution determined for each sample and the instrument calibration control data are retained in the NDA PDP Phase I WRM file.

\section{b. Plutonium Assay.}

Dissolution. The five sample aliquots taken for Pu assay were independently dissolved. Each sample aliquot was weighed to the nearest 0.01 milligram and the weight recorded. The dissolution method was ASTM C1 168-90 "Standard Practice for Preparation and Dissolution of Plutonium Materials for Analyses," which required a sealed reflux tube dissolution incorporating a mixture of $\mathrm{HCl}, \mathrm{HNO}_{3}$, and $\mathrm{HF}$ under pressure to ensure complete dissolution.

Solution Preparation. After dissolution, each aliquot was quantitatively transferred to a tarred dispensing bottle. Multiple rinses of the dissolution vessel were performed to ensure quantitative transfer. After transfer, the dispensing bottle was weighed to the nearest 0.1 milligram, and the net weight of the solution was recorded. The solution was then thoroughly mixed by swirling and shaking the dispensing bottle for at least 30 seconds.

Coulometric Titration. Two aliquots of each of the five samples were weight dispensed from the dispensing bottle for coulometric assay as described in procedure ANC125, "ControlledPotential Coulometric Determination of Plutonium in Sulfuric Acid Electrolyte." The average analysis results for the five samples are summarized in Table 1.

Standards and Calibration. As described in procedure ANC125, "Controlled-Potential Coulometric Determination of Plutonium in Sulfuric Acid Electrolyte" the coulometric titrator was calibrated with NBS Standard Reference Material (SRM) \#949f or NBL Certified Reference Material (CRM) 126 (see Appendix R), which provides SRM traceability for sample analysis. Further, titration of the sample aliquots were preceded and followed by titrations of aliquots of a well characterized, high purity $\mathrm{PuO}_{2}$ control material. The analyses of the control material

Table 1. Pu Assay Results, Wt. \% Pu.

\begin{tabular}{|l|c|c|c|c|c|}
\hline \multicolumn{1}{|c|}{ Sample } & $\mathbf{1}$ & $\mathbf{2}$ & $\mathbf{3}$ & $\mathbf{4}$ & $\mathbf{5}$ \\
\hline Wt. \% Pu & 87.8317 & 87.8466 & 87.7717 & 87.7817 & $\mathbf{8 7 . 7 8 6 7}$ \\
\hline Ave. \% Pu: 87.8036 & \multicolumn{5}{l}{ Effective: $6 / 1 / 97$} \\
\hline
\end{tabular}


aliquots were recorded and used as quality control samples to determine the analysis precision on the five samples. The control material assays fell within the $0.5 \%$, three relative standard deviation, coulometric assay control limit. The historical precision of the method is $0.07 \%$ at one relative standard deviation. The overall method relative random uncertainty is $0.08 \%$. Interlaboratory studies have shown that the method has no significant bias. The mean replicate assay result $(87.804 \% \mathrm{Pu})$ for the five samples had a one relative standard deviation precision (RSD) of $0.038 \%$ on $6 / 1 / 97$. The mean assay values for all five samples fell within the one standard deviation range of all five samples; hence, the batch homogeneity can be bounded by a RSD of $0.038 \%$.

Documentation and Reporting. The sample aliquots' weights, dissolution date, net solution weights, coulometric assay results and dates, certified reference material aliquot assay results, and operator and supervisor initials are recorded in formal LANL notebooks with appropriate page copies introduced into NDA PDP Phase I WRM files. The results of the replicate assays for the five samples are summarized in Table 1 and presented in Appendix C. These data were a technical HOLD POINT and were reviewed by the NDA CEP Technical Team prior to preparing the WRM blends.

c. Plutonium Isotopic Distribution and ${ }^{241}$ Am Analysis. The same sample preparation and mass spectrometer operations were used for both $\mathrm{Pu}$ isotopic distribution and ${ }^{241} \mathrm{Am}$ analysis. The sample preparation and mass spectrometer operations are described in LANL procedures ANC 131, "U \& Pu Isotopic Distribution and Assay by Isotope Dilution Mass Spectrometry," ANC 1312, "Operation of the VG-2 Mass Spectrometer," and ANC 130, "Purification of Plutonium for Mass Spectrometric Analysis by Ion Exchange Separation."

Samples. Aliquots of the five solutions prepared for $\mathrm{Pu}$ assay (see section II.A.3.B., "Plutonium Assay") were used for the Pu isotopic distribution and for the ${ }^{241} \mathrm{Am}$ assay.

Sample Preparation. For the Pu isotopic distribution determinations, aliquots of the dissolved samples were purified by ion exchange chromatography to remove interfering uranium isotopes. The ${ }^{241} \mathrm{Am}$ analysis was performed by Isotope Dilution Mass Spectrometry (IDMS), and a weight aliquot of each sample was spiked with a known quantity of ${ }^{243} \mathrm{Am}$ (spike). Using ion exchange chromatography, the Pu fraction and Am fraction were separated, and an aliquot of the Am fraction was mounted on filaments for the ${ }^{241} \mathrm{Am} /{ }^{243} \mathrm{Am}$ ratio determination.

Pu Isotopic Distribution Analysis. The Pu fraction filaments containing approximately $20 \mathrm{ng}$ of $\mathrm{Pu}$ were mounted in the VG-354 instrument (a.k.a. VG-2). This instrument is equipped with a multicollector (5) Faraday system which permits the simultaneous collection of up to five isotopes. The entire Pu aliquot is evaporated (Total Evaporation Mass Spectrometry), and the subsequent ion signal is collected, thereby yielding a very high precision, high accuracy analysis (see Ref. 2). The relative gain of the five measuring channels was determined at the start of each analysis with a built-in constant current source. The integrated intensity from each isotope was proportional to the abundance of that isotope. The results of these analyses are summarized in Table 2.

${ }^{241}$ Am Assay. The Am fraction filaments were mounted in the VG-354 Mass Spectrometer and processed as described in II.A.3.C., above. The ${ }^{241} \mathrm{Am} /{ }^{243} \mathrm{Am}$ mass ratio was measured and the ${ }^{241} \mathrm{Am}$ concentration in the dissolved sample was calculated using the ${ }^{241} \mathrm{Am} /{ }^{243} \mathrm{Am}$ ratio and the ${ }^{243} \mathrm{Am}$ concentration of the spike. Since the Pu concentration in the dissolved sample was known from the $\mathrm{Pu}$ assay of the same solution, the ${ }^{241} \mathrm{Am} / \mathrm{Pu}$ mass ratio could be calculated. The ${ }^{241} \mathrm{Am} / \mathrm{Pu}$ assay and $\mathrm{g}{ }^{241} \mathrm{Am} / \mathrm{g} \mathrm{PuO}_{2}$ results are summarized in Table 3. 


\begin{tabular}{|c|c|c|c|c|c|c|}
\hline \hline \multicolumn{7}{|c|}{ Table 2. Summary of Pu Isotopic Distribution As Weight Percent.* } \\
\hline Sample & ${ }^{238} \mathbf{P u}$ & ${ }^{239} \mathbf{P u}$ & ${ }^{240} \mathbf{P u}$ & ${ }^{241} \mathbf{P u}$ & ${ }^{242} \mathbf{P u}$ & ${ }^{244} \mathbf{P u}$ \\
\hline 1 & 0.0148 & 93.7806 & 5.9448 & 0.2037 & 0.0561 & 0.0000 \\
\hline 2 & 0.0138 & 93.7821 & 5.9443 & 0.2040 & 0.0558 & 0.0000 \\
\hline 3 & 0.0147 & 93.7812 & 5.9446 & 0.2037 & 0.0558 & 0.0000 \\
\hline 4 & 0.0141 & 93.7812 & 5.9451 & 0.2036 & 0.0560 & 0.0000 \\
\hline 5 & 0.0141 & 93.7804 & 5.9455 & 0.2038 & 0.0562 & 0.0000 \\
\hline Average & 0.0143 & 93.7811 & 5.9448 & 0.2038 & 0.0560 & 0.0000 \\
\hline \multicolumn{7}{|c|}{} \\
\hline \hline
\end{tabular}

\begin{tabular}{|l|c|c|c|c|c|}
\hline \hline \multicolumn{1}{|c|}{ Table 3. ${ }^{241} \mathrm{Am} /$ Pample Analysis Results. } & $\mathbf{1}$ & $\mathbf{2}$ & $\mathbf{3}$ & $\mathbf{4}$ & $\mathbf{5}$ \\
\hline$\mu \mathrm{g}{ }^{241} \mathrm{Am} / \mathrm{g} \mathrm{PuO}_{2}$ & 938.9 & 939.5 & 938.8 & 939.1 & 939.0 \\
\hline$\mu \mathrm{g}{ }^{241} \mathrm{Am} / \mathrm{g} \mathrm{Pu}$ & 1069.0 & 1069.5 & 1069.6 & 1069.8 & 1069.7 \\
\hline $\begin{array}{l}\text { Mean } \mu \mathrm{g}{ }^{241} \mathrm{Am} / \mathrm{g} \text { PuO } \\
\text { One standard deviation: } 039.1 *\end{array} 0.27$ & \multicolumn{5}{c|}{ Mean $\mu \mathrm{g}{ }^{241} \mathrm{Am} / \mathrm{g}$ Pu: $1069.5 *$} \\
\hline \hline
\end{tabular}

Standards and Calibration. The Mass Spectrometer is calibrated using NBS SRM-948 (see Appendix R) aliquots run with every batch of samples receiving Pu isotopic distribution and ${ }^{241} \mathrm{Am}$ assay analysis. These data have formed the basis for control charts and were used to assure the method is meeting performance criteria, and to determine the method's historical performance. Historical quality check (QC) data demonstrates that this method (sample preparation and instrument performance) is superior to the manufacture's stated precision of $0.05 \%$ at one standard deviation.

Documentation and Reporting. The SRM and sample replicate $\mathrm{Pu}$ isotopic distribution (both as atomic percent and weight percent) and ${ }^{241} \mathrm{Am}$ assay results, analysis dates, SRM aliquot, and operator and supervisor initials are recorded in formal LANL notebooks with copies introduced into NDA PDP Phase I WRM files. The Pu isotopic distribution results and ${ }^{241} \mathrm{Am} / \mathrm{Pu}$ ratio results for the five samples are summarized in Tables 2 and 3 above and are contained in the "Final Chemical Analysis Report," included as Appendix C. Copies of procedures ANC 130, ANC 131, ANC 1312 are in the NDA CEP WRM file. The ${ }^{241} \mathrm{Am} / \mathrm{Pu}$ ratio and Pu isotopic distribution results were a technical HOLD POINT and were reviewed by the NDA CEP Technical Team prior to using the $\mathrm{PuO}_{2}$ to prepare $\mathrm{AmO}_{2}-\mathrm{PuO}_{2}-\mathrm{DE}$ WRM blends. 
d. DC Arc Emission Spectroscopy Determination of Impurities. The DC Arc Emission Spectroscopy (ES) method is well suited for, and was used to determine, the concentration of aluminum, calcium, iron, nickel, and silicon impurities in the $\mathrm{PuO}_{2}$. The LANL procedure ANCDE-1-SC-2S;R3 was used for sample preparation and emission spectroscopic analyses.

Sample Preparation. Single aliquots of $\mathrm{PuO}_{2}$ from each of three samples were mixed with gallium and cobalt (internal standards) and transferred into cupped graphite electrodes.

Emission Spectroscopic Analysis. The electrodes were placed in a Jarrell-Ash emission spectrograph and ionized. The resulting spectra were analyzed to determine the $\mathrm{PuO}_{2}$ impurity concentrations.

DC Arc ES Impurity Analysis Results. The analysis results for $\mathrm{Al}, \mathrm{Ca}, \mathrm{Fe}, \mathrm{Ni}$, and $\mathrm{Si}$ for the three samples are listed in Table 4 below.

Standards and Calibration. The emission spectrograph was calibrated with a standard prepared from a high purity $\mathrm{PuO}_{2}$ matrix spiked with known quantities of elemental impurities from NIST-traceable emission spectroscopy standards. The precision and accuracy of the LANL DC Arc Emission Spectroscopic method has been established through a large number of control checks using the $\mathrm{PuO}_{2}$ based in house standard $\mathrm{Pu}-\mathrm{U}-\mathrm{H}-\mathrm{RMP} 2323$ and verified through LANL participation in interlaboratory studies.

Documentation and Reporting. The emission spectroscopic data for the three samples, the instrument calibration data, calibration and sample analysis dates, and operator and supervisor initials are recorded in formal LANL notebook 26648, p. 96, and the analytical results are recorded in the LANL NMT LIMS under sample \#200016529. A copy of the "Final Chemical Analysis Report" is included in Appendix C. A copy of LANL procedure ANC-DE-1-SC-2S;R3 is contained in the NDA PDP Phase I WRM file. The results for all three samples were reviewed by the NDA CEP Technical Team to ensure the impurity levels and batch homogeneity were satisfactory. This review was a technical HOLD POINT prior to using the $\mathrm{PuO}_{2}$ to prepare WRM AmO $2-\mathrm{PuO}_{2}-\mathrm{DE}$ blends.

e. Inductively-Coupled Plasma Mass Spectrometry Determination of Impurities. The ICPMS method is well suited for, and was used to determine, the concentration of the following impurities in the $\mathrm{PuO}_{2}: \mathrm{B}, \mathrm{Be}, \mathrm{Cd}, \mathrm{Ga}, \mathrm{Gd}, \mathrm{Mg}, \mathrm{Li},{ }^{235} \mathrm{U},{ }^{237} \mathrm{~Np},{ }^{244} \mathrm{Cm}$, and ${ }^{252} \mathrm{Cf}$. The LANL procedure ANC102, "Inductively Coupled Plasma-Mass Spectrometry Using the VG Plasma Quad" was used for sample preparation and ICP-MS analyses.

\begin{tabular}{|c|c|c|c|c|}
\hline Impurity & Sample 1 & Sample 2 & Sample 3 & Average \\
\hline $\mathrm{Al}$ & 35 & 19 & 19 & 24 \\
\hline $\mathrm{Ca}$ & 1000 & 770 & 750 & 840 \\
\hline $\mathrm{Fe}$ & 99 & 89 & 100 & 96 \\
\hline $\mathrm{Ni}$ & 245 & 280 & 285 & 270 \\
\hline $\mathrm{Si}$ & 205 & 130 & 155 & 163 \\
\hline
\end{tabular}


Sample Preparation. Three samples of the $\mathrm{PuO}_{2}$ were dissolved in concentrated nitric acid using procedure ANC142, "Trace-Element Analysis Microwave Assisted Sample Preparation." The dissolved samples were aspirated into the ICP-MS for elemental and isotopic analyses.

ICP-MS Analysis. The samples were atomized and ionized in the plasma, which is sampled by a mass spectrometer. Mass detection and concentration measurements were made, relative to external calibration for each element. The analysis results for the three samples are summarized in Table 5.

Standards and Calibration. Standard Reference Materials traceable to the National Institute of Standards and Technology (NIST) standards for each element were used to calibrate the ICPMS instrument and to assess instrument performance. The precision and accuracy of this method, based on ongoing calibration and verification standards, is $\pm 10 \%$. Neptunium, $\mathrm{Cm}$, and $\mathrm{Cf}$ are reported as semiquantitative values, due to lack of NIST standards for these elements. Analyses for ${ }^{242} \mathrm{Cm}$ and ${ }^{238} \mathrm{U}$ were performed, but were of limited value because ${ }^{242} \mathrm{Pu}$ and ${ }^{238} \mathrm{Pu}$ interfere directly with these mass values.

Documentation and Reporting. The sample handling, weights, and dissolution volumes are recorded in formal LANL notebook 10733, pp. 11 and 120, and in the LANL NMT LIMS system. Appendix C contains copies of the "Final Chemical Analysis Report." A memorandum discussing the analysis results for elements measured by ICP-MS is contained within the NDA

\begin{tabular}{|l|c|c|c|c|}
\hline \hline \multicolumn{5}{|c|}{ Table 5. ICP-MS Analysis Results in Micrograms Impurity per Gram PuO } \\
\hline Impurity & Sample 1 & Sample 2 & Sample 3 & Average \\
\hline $\mathrm{B}$ & $<8$ & $<8$ & $<8$ & $<8$ \\
\hline $\mathrm{Be}$ & $<2$ & $<2$ & $<2$ & $<2$ \\
\hline $\mathrm{Cd}$ & 8.5 & 0.4 & 7.7 & 5.5 \\
\hline $252 \mathrm{Cf}$ & $<4$ & $<4$ & $<4$ & $<4$ \\
\hline $244 \mathrm{Cm}$ & 0.10 & 0.095 & 2.3 & 0.8 \\
\hline $\mathrm{Ga}$ & 18 & 17 & 17 & 17 \\
\hline $\mathrm{Gd}$ & 0.6 & $<0.4$ & $<0.4$ & $<0.6$ \\
\hline $\mathrm{Li}$ & 8.5 & $<6$ & $<7$ & $<8.5$ \\
\hline $\mathrm{Mg}$ & 34 & 33 & 32 & 33 \\
\hline $237 \mathrm{~Np}$ & 94 & 96 & 96 & 95 \\
\hline $\mathrm{Th}$ & 1.1 & 2.8 & 0.95 & 1.6 \\
\hline $235 \mathrm{U}$ & 310 & 310 & 320 & 313 \\
\hline Note: values preceded by the symbol $<$ represent ICP-MS limits of detection & \\
\hline \hline
\end{tabular}


PDP Phase I WRM files. Copies of procedures ANC102 and ANC142 are contained in the NDA CEP WRM files. The sample impurity analysis results were reviewed by the NDA CEP Technical Team. The impurity levels, analysis data, and batch homogeneity were found to be satisfactory. This review was a technical HOLD POINT prior to using the $\mathrm{PuO}_{2}$ to prepare $\mathrm{AmO}_{2}-$ $\mathrm{PuO}_{2}-\mathrm{DE}$ WRM blends.

f. Radiometric Analyses. Radiometric analyses were performed to verify that the ${ }^{244} \mathrm{Cm}$ and ${ }^{252} \mathrm{Cf}$ levels were not high enough to adversely effect neutron or gamma based measurements of the WRMs, and to confirm the Mass Spectrometric/IDMS assay of ${ }^{241} \mathrm{Am}$.

Sample Preparation. An aliquot of each of the five $\mathrm{PuO}_{2}$ samples dissolved for $\mathrm{Pu}$ Assay (see section II.A.3.B, "Plutonium Assay") were pipetted onto glass slides and evaporated to dryness for alpha spectra analysis. To determine the ${ }^{241}$ Am concentration, an aliquot from each of the dissolved samples was diluted to $10.0 \mathrm{ml}$ with nitric acid. Gamma spectroscopy analysis was performed on the resultant solutions.

Radiometric Analyses. The alpha spectra from five sample aliquots showed no alpha peaks in the energy region 5.7 to $6.5 \mathrm{meV}$. Based on the alpha background in this energy region and the alpha peak from ${ }^{239} \mathrm{Pu}$ and ${ }^{240} \mathrm{Pu}$ at $5.155 \mathrm{meV}$, the measurement established that the ${ }^{244} \mathrm{Cm}$ was $<0.5 \mu \mathrm{g} / \mathrm{g} \mathrm{Pu}$ and the ${ }^{252} \mathrm{Cf}$ was $<0.1 \mu \mathrm{g} / \mathrm{g} \mathrm{Pu}$. The gamma analysis of the five sample aliquots showed the ${ }^{241} \mathrm{Am} /$ $\mathrm{PuO}_{2}$ ratios listed in Table 6. The mean value of the five analyses is $934.4 \mu \mathrm{g}{ }^{241} \mathrm{Am} / \mathrm{g} \mathrm{PuO}_{2}$. This value confirms the more precise and accurate mass spectrometric value of $939.1 \mu \mathrm{g}{ }^{241} \mathrm{Am} / \mathrm{g} \mathrm{PuO}$.

Standards and Calibration. The alpha spectrometer was energy calibrated with a source prepared from weapons grade $\mathrm{Pu}$ and ${ }^{244} \mathrm{Cm}$. This energy calibration was validated with NIST Standard

\begin{tabular}{|c|c|}
\hline \multicolumn{2}{|c|}{$\begin{array}{l}\text { Table 6. Gamma Radiometric } \\
\text { Analysis of } \mathbf{P u O}_{\mathbf{2}} \text { for }{ }^{241} \text { Am. }\end{array}$} \\
\hline Sample & $\boldsymbol{\mu g}^{241} \mathbf{A m} / \mathbf{~ P u O}_{2}$ \\
\hline 1 & 936 \\
\hline 2 & 936 \\
\hline 3 & 934 \\
\hline 4 & 930 \\
\hline 5 & 936 \\
\hline Average & 934 \\
\hline & Effective: $6 / 1 / 97$ \\
\hline \hline
\end{tabular}
Reference Material 4906-C-9, a ${ }^{238} \mathrm{Pu}$ source. The gamma spectrometer was energy calibrated using an Amersham QCY.44 mixed radionuclide gamma-ray reference solution (see Appendix R).

Documentation and Reporting. The results of the ${ }^{244} \mathrm{Cm}$ and ${ }^{252} \mathrm{Cf}$ alpha spectrometric analysis and the ${ }^{241} \mathrm{Am}$ assay are contained in the Appendix C "Final Chemical Analysis Report" and are recorded in the LANL NMT LIMS system. The alpha spectrometric results for ${ }^{244} \mathrm{Cm}$ and ${ }^{252} \mathrm{Cf}$ were reported to the NDA CEP Technical team and was a technical HOLD POINT prior to using the $\mathrm{PuO}_{2}$ to preparing $\mathrm{AmO}_{2}-\mathrm{PuO}_{2}-\mathrm{DE}$ WRM blends.

g. Anionic Impurity Analyses. Chlorine and fluorine potentially add random uncertainty to neutron based waste assays; hence, analyses were performed to determine their concentration in the $\mathrm{PuO}_{2}$.

Sample Preparation. The chlorine and fluorine constituents of three representative samples of $\mathrm{PuO}_{2}$ were separated from each $\mathrm{PuO}_{2}$ sample by pyrohydrolysis and collected in a condensate. The pyrohydrolysis procedure is ANC115, "Determination of Chloride and Fluoride in UraniumPlutonium Fuel Materials and Boron Carbide." 
Ion Chromatography Analysis. The chloride and fluoride concentrations were determined in the condensates using a Dionex DX-100 ion-chromatography instrument with a sensitivity of better than 1 microgram analyte per milliliter of solution. The three $\mathrm{PuO}_{2}$ sample analyses for chloride and fluoride are listed in Table 7.

\begin{tabular}{|c|c|c|}
\hline Sample & $\mathrm{Cl}, \mu \mathrm{g} / \mathrm{g} \mathrm{PuO}_{2}$ & $\mathrm{~F}, \mu \mathrm{g} / \mathrm{g} \mathrm{PuO}_{2}$ \\
\hline 1 & 31.9 & 36.3 \\
\hline 2 & 23.6 & 28.3 \\
\hline 3 & 51.6 & 54.6 \\
\hline Average & 35.7 & 39.7 \\
\hline
\end{tabular}

Standards and Calibration. The Dionex-100 instrument was calibrated using a three point calibration curve with VHG standards that are traceable to NIST. The instrument was calibrated the day it was used.

Documentation and Reporting. The sample aliquots' weights and volumes, solution volume adjustments, sample preparation and analysis dates, VHG standards assay results, calculations, and operator and supervisor initials were recorded in formal LANL notebook \#10733, pp. 117 and 120, and copies of these pages are in NDA PDP Phase I WRM files. Final data results are recorded in the LANL NMT LIMS system and found in the Appendix C "Final Chemical Analysis Report." A copy of procedure ANC115 is in the NDA CEP WRM file. The data was reviewed by the NDA CEP Technical Team and was a technical HOLD POINT prior to using the $\mathrm{PuO}_{2}$ to prepare $\mathrm{WRM} \mathrm{AmO}_{2}-\mathrm{PuO}_{2}-\mathrm{DE}$ blends.

\section{B. Americium Dioxide}

Specifications for the americium oxide $\left(\mathrm{AmO}_{2}\right)$ to be used for the CEP WRM production are listed in sections 5.9-5.14 of the SOW. The material (LANL FZG45-AMP138-2) was initially prepared at the LANL TA-55 Plutonium Facility as described below. A copy of the TA-55 report is included as Appendix D.

\section{Preparation}

a. Initial Preparation. Am (and any accompanying $\mathrm{Pu}$ ) was separated from solution using a hydrogen peroxide precipitation. The hydroxide was redissolved in $7 \mathrm{M} \mathrm{HNO}_{3}$. Am was then separated from $\mathrm{Pu}$ via ion exchange. Am in the eluate was precipitated using oxalic acid. The Am oxalate was calcined to $\mathrm{AmO}_{2}$ and screened through a 100 mesh screen and then packaged. Approximately 32 grams $\mathrm{AmO}_{2}$ was prepared.

b. Blending. The $\mathrm{AmO}_{2}$ was placed within a 1 pint container and blended using a rod mill without the rods. The material was blended for 1 hour. 
c. Sampling. A 2 gram sample (LANL FZG45-AMP138-2S2) was used for production of the CEP WRMs and for characterization (described below). In addition, a 3 gram sample (LANL FZG45-AMP138-2S1) was sent out for particle size distribution analysis (also described below). Two additional 2 gram samples (LANL FZG45-AMP138-2S3 and LANL FZG45-AMP138-2S4) were placed in storage.

\section{Characterization}

a. Sampling for Analytical Chemistry. Quality assurance and quality control are incorporated into the procedures used to characterize the $\mathrm{AmO}_{2}$. The accuracy and precision of these methods have been established via ongoing quality control programs, and maintained through the routine practice of analyzing control standards along with samples. Hence, multiple sampling of the selected $\mathrm{AmO}_{2}$ batch was not required to establish analytical method precision. However, multiple sampling was performed to verify batch homogeneity.

Four $50 \mathrm{mg}$ samples were taken from the vial containing the $2 \mathrm{~g}$ of $\mathrm{AmO}_{2}$. These were dissolved and diluted (first dilution). From this, one sample from each bottle was taken for trace element analysis by ICP-MS (roughly $5 \mathrm{mg}$ of $\mathrm{AmO}_{2}$ in each sample) and two samples from each bottle were taken for mass spectral analysis (roughly $2 \mathrm{mg}$ of $\mathrm{AmO}_{2}$ in each sample) of the $\mathrm{Pu}$ fraction and $\mathrm{Pu}$ isotopic distribution of the $\mathrm{AmO}_{2}$. In addition, one sample from each bottle was placed into $250 \mathrm{~mL}$ plastic bottles for a second dilution. From each of these four bottles (second dilution), one sample each was taken for radiochemistry. In addition, two samples were taken from each of the four bottles for mass spectrometric determination of total Am as well as two samples from one of the bottles for $\mathrm{U}$ assay and $\mathrm{U}$ isotopic distribution of the $\mathrm{AmO}_{2}$.

b. Particle Size Distribution. A particle size distribution was performed on a separate 3 gram sample (LANL FZG45-AMP138-2S1) of $\mathrm{AmO}_{2}$. Two portions of this material were analyzed and the reports are included in Appendix $\mathrm{E}$.

Method. A LAB-TEC 1000 Particle Size Analyzer was used to determine the sample particle size distribution. This instrument is a scanning laser microscope that measures particles suspended in a liquid medium. The procedure used for particle size determination is NMT-3-281MRD-R00. The particle count fraction and mass fraction were determined for particle size distributions with resolution of $<1$ micron in 28 increments over the 0.5 to 250 micron range.

Calibration. Quartz certified reference materials BCR Nos. 67 and 69 were used for the particle size analyzer calibration and performance checks. The instrument laser, detectors, and focal point are fixed in position and cannot be manipulated or adjusted. This very stable instrument is checked using the BCR quartz certified reference materials on a biweekly basis.

Documentation and Reporting. The particle size distribution was a technical HOLD POINT. The particle size distribution data was reviewed by the NDA CEP Technical Team prior to using the $\mathrm{AmO}_{2}$ for preparing WRMs. The Spherical Equivalent Mean Diameter of the two samples ranged from 5.7 to 6.1 microns. Appendix E contains tables showing the detailed particle size data on both a particle count and mass basis.

A copy of procedure NMT-3 281-MRD-R00 and a brief description of the instrument operation and calibration are retained in the NDA PDP Phase I WRM file. The particle size distribution determined for each sample and the instrument calibration control data are retained in the NDA CEP WRM file. 
c. Americium Assay, Pu and $U$ Content, and Isotopic Distribution. The mass spectrometer operations are described in LANL procedure ANC 1312, "Operation of the VG-2 Mass Spectrometer." Procedures ANC 130, "Purification of Plutonium for Mass Spectrometric Analysis by Ion Exchange Separation" and ANC 141, "Separation of Trace Quantities of Uranium From Plutonium" describe the separation of Am from $\mathrm{Pu}$ and the separation of $\mathrm{U}$ from $\mathrm{Pu}$ by ion exchange. The principles discussed in procedure ANC 131, "U \& Pu Isotopic Distribution and Assay by Isotope Dilution Mass Spectrometry" are directly applicable to the determination of $\mathrm{Am}$ in $\mathrm{AmO}_{2}$ by IDMS except that the isotopic spike in this case would be ${ }^{243} \mathrm{Am}$.

Samples. Aliquots of the four $\mathrm{AmO}_{2}$ solutions (second dilution) prepared for characterization were used for Am assay. Aliquots from one of the four solutions (second dilution) was used to determine the $U$ content and $U$ isotopic distribution of the $\mathrm{AmO}_{2}$. Aliquots from the four $\mathrm{AmO}_{2}$ solutions (first dilution) were used to determine the total $\mathrm{Pu}$ content and $\mathrm{Pu}$ isotopic distribution of the $\mathrm{AmO}_{2}$.

Sample Preparation. The ${ }^{241} \mathrm{Am}$ analysis was performed by IDMS, and a weight aliquot of each sample was spiked with a known quantity of ${ }^{243} \mathrm{Am}$. Using ion exchange chromatography, the $\mathrm{Pu}$ fraction and Am fraction were separated, and an aliquot of the Am fraction was mounted on $\mathrm{Re}$ filaments for the ${ }^{241} \mathrm{Am} /{ }^{243} \mathrm{Am}$ ratio determination. For the $\mathrm{Pu}$ isotopic distribution determinations, aliquots of the dissolved samples were purified by ion exchange chromatography to remove interfering uranium and americium isotopes. Samples used for Pu assay by IDMS were spiked with a known quantity of ${ }^{244} \mathrm{Pu}$ and then interfering $\mathrm{U}$ and Am isotopes were removed by ion exchange. The resulting Pu fractions were mounted on Re filaments for analysis. For $U$ isotopic distribution determinations, an aliquot of the dissolved sample was purified by removing interfering $\mathrm{Pu}$ isotopes by ion exchange. For $\mathrm{U}$ assay by IDMS, the sample was spiked with a known quantity of ${ }^{233} \mathrm{U}$ followed by ion exchange as above. The $U$ fractions were mounted on Re filaments for the analysis.

${ }^{24 I}$ Am Assay. The Am fraction filaments were mounted in the VG-354 Mass Spectrometer. This instrument is equipped with a multicollector (5) Faraday system which permits the simultaneous collection of up to five isotopes. The entire Am aliquot is evaporated (Total Evaporation Mass Spectrometry), and the subsequent ion signal is collected, thereby yielding a very high precision, high accuracy analysis. The relative gain of the five measuring channels was determined at the start of each analysis with a built-in constant current source. The integrated intensity from each isotope was proportional to the abundance of that isotope. The ${ }^{241} \mathrm{Am} /{ }^{243} \mathrm{Am}$ mass ratio was measured and the ${ }^{241} \mathrm{Am}$ concentration in the dissolved sample was calculated using the $241 / 243$ ratio and the known ${ }^{243}$ Am concentration of the spiked sample. ${ }^{241}$ Am assay results are summarized in Table 8.

Pu Assay and Isotopic Distribution Analysis. The Pu fraction filaments containing approximately $20 \mathrm{ng}$ of $\mathrm{Pu}$ (mostly ${ }^{239} \mathrm{Pu}$ ) were mounted in the VG-354 instrument and analyzed by Total Evaporation Mass Spectrometry as described above for Am. The integrated intensity from

Table 8. Results of the ${ }^{241} \mathrm{Am}$ Assay of the $\mathrm{AmO}_{2}$ **

\begin{tabular}{|c|c|c|c|c|c|}
\hline Sample & $\mathbf{1}$ & $\mathbf{2}$ & $\mathbf{3}$ & $\mathbf{4}$ & Mean \\
\hline Wt. \% Am & 78.605 & 79.045 & 78.543 & 78.718 & 78.728 \\
\hline * Effective: $6 / 1 / 97$
\end{tabular}


each isotope was proportional to the abundance of that isotope. The total Pu concentration in the dissolved sample was calculated using the $\mathrm{Pu}$ isotopic ratios and the known ${ }^{244} \mathrm{Pu}$ concentration of the spiked sample. The results of these analyses are summarized in Tables 9 and 10.

$U$ Assay and Isotopic Distribution Analysis. The $U$ fraction filaments containing approximately $200 \mathrm{ng}$ of $\mathrm{U}$ were mounted in the VG-354 instrument and analyzed by Total Evaporation Mass Spectrometry as described above for $\mathrm{Am}$ and $\mathrm{Pu}$. The total U concentration in the dissolved sample was calculated using the $U$ isotopic ratios and the known ${ }^{233} U$ concentration of the spiked sample. The results of these analyses are summarized in Tables 11 and 12.

\begin{tabular}{|c|c|c|c|c|c|}
\hline Sample & 1 & 2 & 3 & 4 & Mean \\
\hline Wt. \% Pu & 0.403 & 0.414 & 0.421 & 0.421 & 0.415 \\
\hline
\end{tabular}

Table 10. Summary of Pu Isotopic Distribution of the $\mathrm{AmO}_{2}$ As Weight Percent.*

\begin{tabular}{|c|c|c|c|c|c|c|}
\hline Sample & $238 \mathbf{P u}$ & ${ }^{239} \mathbf{P u}$ & ${ }^{240} \mathbf{P u}$ & ${ }^{241} \mathbf{P u}$ & ${ }^{242} \mathbf{P u}$ & ${ }^{244} \mathbf{P u}$ \\
\hline 1 & 0.0438 & 89.3626 & 9.9459 & 0.4623 & 0.1854 & 0 \\
\hline 2 & 0.0457 & 89.1017 & 10.1855 & 0.4784 & 0.1887 & 0 \\
\hline 3 & 0.0459 & 89.1031 & 10.1839 & 0.4778 & 0.1894 & 0 \\
\hline 4 & 0.0453 & 89.0381 & 10.2437 & 0.4821 & 0.1908 & 0 \\
\hline Mean & 0.0451 & 89.1514 & 10.1398 & 0.4751 & 0.1886 & 0 \\
\hline
\end{tabular}

\begin{tabular}{|c|c|}
\hline \multicolumn{2}{|c|}{$\begin{array}{l}\text { Table 11. Results of the } \\
\text { U Assay of the } \mathrm{AmO}_{2} \text {. }\end{array}$} \\
\hline Sample & 1 \\
\hline Wt. \% U & 0.0035 \\
\hline
\end{tabular}

Table 12. Summary of $U$ Isotopic Distribution of the $\mathrm{AmO}_{2}$ As Weight Percent.

\begin{tabular}{|c|c|c|c|c|c|}
\hline Sample & $233 \mathbf{U}$ & ${ }^{234} \mathbf{U}$ & $235 \mathbf{U}$ & $\mathbf{2 3 6} \mathbf{U}$ & $\mathbf{2 3 8} \mathbf{U}$ \\
\hline 1 & 0.1904 & 5.3044 & 42.8841 & 17.1893 & 34.4319 \\
\hline \hline
\end{tabular}


Standards and Calibration. For Pu and U, the mass spectrometer is calibrated using NBS Standard Reference Materials (SRMs) which are run with every batch of samples. These data have formed the basis for control charts and were used to assure the method is meeting performance criteria and to determine the method's historical performance. Historical QC data demonstrates that this method (sample preparation and instrument performance) is superior to the manufacture's stated precision of $0.05 \%$ at one standard deviation. For Pu and U, the standards used include NBS 948 (Pu standard) and NBS U005 (U standard), respectively (Appendix R). However, since there are no SRMs for Am, NBS 948 is used. This is acceptable because the isotopic range measured for Am (241-243 a.m.u.) overlaps that of the Pu measurements (238-244 a.m.u.). In addition, because of the use of the total evaporation method, the measurements are near absolute, i.e., no correction factors for mass discrimination are needed (see Ref. 2).

Documentation and Reporting. The SRM and sample replicate $\mathrm{Pu}$ and $\mathrm{U}$ isotopic distribution (both as atomic percent and weight percent), $\mathrm{Pu}$ and $\mathrm{U}$ assay, and ${ }^{241} \mathrm{Am}$ assay results, analysis dates, SRM aliquots, and operator and supervisor initials are recorded in formal LANL notebooks with copies introduced into NDA CEP WRM files. The Pu and U isotopic distribution and assay results and ${ }^{241} \mathrm{Am}$ assay ratio results for the five samples are summarized in Tables 8-12 above, and are contained in the "Final Chemical Analysis Report," included as Appendix C. Copies of procedures ANC 1312, ANC 130, ANC 141, and ANC 131 are included in the NDA CEP WRM file. The ${ }^{241} \mathrm{Am}$ assay, $\mathrm{Pu}$ isotopic distribution and assay, and the $\mathrm{U}$ isotopic distribution and assay results were technical HOLD POINTS and were reviewed by the NDA CEP Technical Team prior to using the $\mathrm{AmO}_{2}$ to prepare $\mathrm{AmO}_{2}-\mathrm{PuO}_{2}-\mathrm{DE}$ WRM blends.

d. Inductively-Coupled Plasma Mass Spectrometry Determination of Impurities. The ICPMass Spectrometry (MS) method is well suited for, and was used to determine the concentration of the following impurities in the $\mathrm{AmO}_{2}: \mathrm{Fe}, \mathrm{Ni}, \mathrm{Ca}, \mathrm{Th}, \mathrm{Al}, \mathrm{Be}, \mathrm{Ga}, \mathrm{Mg},{ }^{235} \mathrm{U}$ (semi-quantitative), ${ }^{238} \mathrm{U}$, and ${ }^{237} \mathrm{~Np}$. The LANL procedures ANC102, "Inductively Coupled Plasma-Mass Spectrometry Using the VG Plasma Quad" and ANC142, "Trace Element Analysis-MicrowaveAssisted Sample Preparation" were used for sample preparation and ICP-MS analyses. In addition, $\mathrm{Bi}, \mathrm{K}, \mathrm{La}, \mathrm{Na}, \mathrm{Pb}, \mathrm{Np}$, and $\mathrm{Y}$ were determined, for information only, using full quality assurances.

Sample Preparation. Three samples of the $\mathrm{AmO}_{2}$ were dissolved in concentrated nitric acid. The dissolved samples were diluted and aspirated into the ICP-MS for elemental and isotopic analyses.

ICP-MS Analysis. The samples were atomized and ionized in the plasma, which is sampled by a mass spectrometer. Mass detection and concentration measurements were made, relative to external calibration for each element. The analysis results for the three samples are summarized in Table 13 below.

Standards and Calibration. Standard Reference Materials, traceable to NIST standards, for each element were used to calibrate the ICP-MS instrument and to assess instrument performance. The precision and accuracy of this method, based on ongoing calibration and verification standards, is $+/-10 \%$. 


\begin{tabular}{|c|c|c|c|c|}
\hline Impurity & Sample 1 & Sample 2 & Sample 3 & Average \\
\hline $\mathrm{Fe}$ & 287 & 264 & 259 & 270 \\
\hline $\mathrm{Ni}$ & 97 & 95 & 87 & 83 \\
\hline $\mathrm{Be}$ & $<0.5$ & $<0.5$ & $<0.5$ & $\cdots$ \\
\hline $\mathrm{Mg}$ & 58 & 52 & 45 & 52 \\
\hline $\mathrm{Ca}$ & 1298 & 1257 & 1277 & 1277 \\
\hline $\mathrm{Np}$ & 19976 & 20201 & 19150 & 19776 \\
\hline Th & 35 & 36 & 35 & 35 \\
\hline $\mathrm{Ga}$ & 3.2 & 3.3 & 3.0 & 3.0 \\
\hline $\mathrm{Al}$ & 144 & 121 & 102 & 122 \\
\hline${ }^{235} \mathrm{U}$ & $18^{*}$ & $20^{*}$ & $18^{*}$ & $19^{*}$ \\
\hline $238 \mathrm{U}$ & 18 & 20 & 19 & 19 \\
\hline $\mathrm{Bi}$ & 576 & 584 & 552 & 571 \\
\hline $\mathrm{K}$ & 4821 & 5640 & 4124 & 4862 \\
\hline $\mathrm{La}$ & 190 & 198 & 180 & 189 \\
\hline $\mathrm{Na}$ & 2981 & 2223 & 1438 & 2214 \\
\hline $\mathrm{Pb}$ & $4385 * * *$ & 1761 & 1619 & 1690 \\
\hline $\mathrm{Np}^{* *}$ & 19590 & 19631 & 18718 & 19313 \\
\hline Y & 43301 & 45056 & 42890 & 43749 \\
\hline \multicolumn{5}{|c|}{$\begin{array}{l}\text { Note: values preceded by the symbol < represent ICP-MS limits of detection; } \\
*=\text { Semi-quant. } \\
* * \text { Repeat Np analysis to verify original results. } \\
* * * \text { Suspect result }- \text { not included in average. }\end{array}$} \\
\hline
\end{tabular}

Documentation and Reporting. The sample handling, weights, and dissolution volumes are recorded in formal LANL notebook ANC52, p.115, and in the LANL NMT LIMS system. Appendix C contains copies of the "Final Chemical Analysis Report." Copies of procedures ANC102 and ANC142 are contained in the NDA CEP WRM file. The sample impurity analysis results were reviewed by the NDA CEP Technical Team. The impurity levels, analyses data, and batch homogeneity were found to be satisfactory. This review was a technical HOLD POINT prior to using the $\mathrm{AmO}_{2}$ to prepare $\mathrm{AmO}_{2}-\mathrm{PuO}_{2}$ - $\mathrm{DE}$ WRM blends. 
e. Radiometric Analysis. Radiometric analyses were performed to verify that the ${ }^{244} \mathrm{Cm}$ and ${ }^{252} \mathrm{Cf}$ levels were not high enough to adversely effect neutron or gamma based measurements of the WRMs, and to confirm the Mass Spectrometric/IDMS assay of the Am.

Sample Preparation. $100 \mu \mathrm{L}$ of the ${ }^{241}$ Am sample solution ( $2^{\text {nd }}$ dilution) was diluted with $1 \mathrm{~N} \mathrm{HNO}_{3}$ to $10 \mathrm{~mL}$. Two cuts of $25 \mu \mathrm{L}$ of diluted solutions were analyzed for total alpha (assume all alpha activity is due to ${ }^{241} \mathrm{Am}$ ) by liquid scintillation counting. Two cuts of $25 \mu \mathrm{L}$ of the ${ }^{241} \mathrm{Am}$ sample solution were diluted with $2 \mathrm{~mL} 1 \mathrm{~N} \mathrm{HNO}_{3}$ for ${ }^{241} \mathrm{Am}^{2}$ determination by gamma ray spectrometry.

Radiometric Analyses. The amount of ${ }^{241} \mathrm{Am}$ isotope within the sample was determined by radiochemical methods. Duplicate analyses were performed on each cut of sample. The total alpha activity was determined by liquid scintillation counting and ${ }^{241} \mathrm{Am}$-gamma activity was determined by gamma spectrometry.

The wt. \% Am determined by radiochemistry, 79.27\%, is slightly larger than the more precise IDMS value 78.73\% (see Table 14). This is likely due to the assumption that all alpha activity in the sample is due to Am decay. The presence of small amounts of $\mathrm{Pu}, \mathrm{Np}$, and $\mathrm{U}$ in the $\mathrm{AmO}_{2}$ (Tables $9,11,13$ ) add slightly to the total alpha activity thus increasing the radiochemistry assay value. The amounts of ${ }^{244} \mathrm{Cm}$ and ${ }^{252} \mathrm{Cf}$ in the sample were estimated based on their half-lives, and activity ratio to the ${ }^{241} \mathrm{Am}$ isotope using alpha spectrometry. This method provides a rough upper limit estimate of ${ }^{244} \mathrm{Cm}$ and ${ }^{252} \mathrm{Cf}$ concentrations. No actual peaks were observed in the 5.7 to $7.5 \mathrm{MeV}$ region so an integrated background area (5 counts) in this energy region was used to bound the ${ }^{244} \mathrm{Cm}$ and ${ }^{252} \mathrm{Cf}$ concentrations. The estimated ${ }^{244} \mathrm{Cm}$ concentration in the sample was less than $2 \mathrm{ppm}$ based on the half-lives and activity ratio of ${ }^{244} \mathrm{Cm}$ to ${ }^{241} \mathrm{Am}$. The estimated ${ }^{252} \mathrm{Cf}$ concentration in the sample was less than $3 \mathrm{ppm}$ based on the halflives and activity ratio of ${ }^{252} \mathrm{Cf}$ to ${ }^{241} \mathrm{Am}$.

\begin{tabular}{|c|c|c|c|c|c|}
\hline \hline \multicolumn{2}{|c|}{ Table 14. Liquid Scintillation and Gamma Radiometric Analysis of AmO for $^{241}$ Am. } \\
\hline Cut & $\begin{array}{c}\text { Sample wt., } \\
\text { mg }\end{array}$ & $\begin{array}{c}\text { LSC, Am } \\
\text { mg* }\end{array}$ & Wt. \% Am & $\begin{array}{c}\text { Gamma, Am } \\
\text { mg }\end{array}$ & Wt. \% Am \\
\hline $14 \mathrm{a}$ & 21.09 & 16.69 & 79.14 & 16.63 & 78.85 \\
\hline $14 \mathrm{~b}$ & 21.09 & 16.54 & 78.43 & 16.60 & 78.71 \\
\hline $15 \mathrm{a}$ & 17.37 & 13.83 & 79.62 & 13.77 & 79.27 \\
\hline $15 \mathrm{~b}$ & 17.37 & 13.83 & 79.62 & 13.91 & 80.08 \\
\hline $16 \mathrm{a}$ & 24.33 & 19.46 & 79.98 & 19.19 & 78.87 \\
\hline $16 \mathrm{~b}$ & 24.33 & 19.19 & 78.87 & 19.28 & 79.24 \\
\hline $17 \mathrm{a}$ & 17.82 & 14.09 & 79.07 & 14.26 & 80.02 \\
\hline $17 \mathrm{~b}$ & 17.82 & 14.15 & 79.41 & 14.18 & 79.57 \\
\hline \multicolumn{7}{|c|}{} & AVG & $79.27 \pm 0.49$ & AVG & $79.33 \pm 0.53$ \\
\cline { 2 - 6 } & & $\%$ RSD & 0.62 & \% RSD & 0.66 \\
\hline \hline
\end{tabular}


The half-life ratios of ${ }^{244} \mathrm{Cm}$ and ${ }^{252} \mathrm{Cf}$ to ${ }^{241} \mathrm{Am}$ were very small due to small magnitude differences in the isotope half-lives. Therefore, the estimated detection limits for ${ }^{244} \mathrm{Cm}$ and ${ }^{252} \mathrm{Cf}$ were higher than the expected or real concentrations. If the detection limits were estimated based on ${ }^{239,240} \mathrm{Pu}$ alpha peak, then the estimated ${ }^{244} \mathrm{Cm}$ was less than $0.02 \mathrm{ppm}$ and ${ }^{252} \mathrm{Cf}$ was less than $0.003 \mathrm{ppm}$. However, the counting statistics of the Pu peak was poor due to the tailing effect of high ${ }^{241} \mathrm{Am}$ alphas.

Standards and Calibration. Alpha spectrometry was performed using the surface barrier silicon detectors in an Oxford alpha spectrometry system (OASIS). The alpha spectrometers were energy calibrated with a source prepared from ${ }^{239} \mathrm{Pu},{ }^{241} \mathrm{Am}$, and ${ }^{244} \mathrm{Cm}$. The energy calibrations were validated with a NIST ${ }^{238}$ Pu source (SRM 4906-C-9; see Appendix R). The liquid scintillation counter (Packard Tri-Carb 2200C) was calibrated using a NIST traceable in-house Radiochemistry Primary plutonium oxide standard (PEOR3258-STD1). The NaI based gammaray spectrometer was calibrated using an NIST traceable ${ }^{241} \mathrm{Am}$ standard solution (Amersham, AMP10040, batch 95/241/49; see Appendix R).

Documentation and Reporting. The results of the ${ }^{244} \mathrm{Cm}$ and ${ }^{252} \mathrm{Cf}$ alpha spectrometric analysis and the ${ }^{241}$ Am assay are contained in Appendix C "Final Chemical Analysis Report," recorded in notebook AW-RC-5, pp. 91-102, and are recorded in the LANL NMT LIMS system. The alpha spectrometric results for ${ }^{244} \mathrm{Cm}$ and ${ }^{252} \mathrm{Cf}$ were reported to the NDA CEP Technical team and was a technical HOLD POINT prior to using the $\mathrm{AmO}_{2}$ to prepare $\mathrm{AmO}_{2}-\mathrm{PuO}_{2}-\mathrm{DE}$ WRM blends.

f. Loss on Ignition. LOI was determined for mass balance considerations. A Pt dish was prepared by washing in water, dried, and heated to approximately $950^{\circ} \mathrm{C}$, cooled $0.5 \mathrm{hr}$. in oven, and then placed into a desiccator for approximately $2 \mathrm{hr}$. A nominally $1.7 \mathrm{~g}$ aliquot of $\mathrm{AmO}_{2}$ was weighed into this $\mathrm{Pt}$ dish. The $\mathrm{AmO}_{2}$ and $\mathrm{Pt}$ dish were then heated to $950^{\circ} \mathrm{C}$ for $2 \mathrm{hrs}$. After cooling in a desiccator, the $\mathrm{AmO}_{2}$ and $\mathrm{Pt}$ dish were reweighed and the weight difference recorded. The percent LOI was calculated as $2.19 \%$.

g. Anionic Impurity Analyses. Chlorine and fluorine potentially add random uncertainty to neutron based waste assays; hence, analyses were performed to determine their concentration in the $\mathrm{AmO}_{2}$.

Sample Preparation. The chlorine and fluorine constituents of a $99 \mathrm{mg}$ sample of $\mathrm{AmO}_{2}$ were separated from the $\mathrm{AmO}_{2}$ sample by pyrohydrolysis and collected in a condensate. The pyrohydrolysis procedure is ANC115, "Determination of Chloride and Fluoride in UraniumPlutonium Fuel Materials and Boron Carbide."

Ion Chromatography Analysis. The chloride and fluoride concentrations were determined in the condensates using a Dionex DX-100 ion-chromatography instrument with a sensitivity of better than 1 microgram analyte per milliliter of solution. The results of the $\mathrm{AmO}_{2}$ sample analysis for chloride and fluoride are listed in Table 15.

\begin{tabular}{|c|c|c|}
\hline \hline Table 15. Ion Chromatographic Analyses of $\mathrm{AmO}_{2}$ for $\mathrm{Cl}$ and F. \\
\hline Sample & $\mathbf{C l}, \mu \mathrm{g} / \mathrm{g} \mathrm{AmO}_{2}$ & $\mathrm{~F}, \mu \mathrm{g} / \mathbf{g} \mathrm{AmO}_{\mathbf{2}}$ \\
\hline 1 & 40 & 654 \\
\hline \hline
\end{tabular}


Standards and Calibration. The Dionex-100 instrument was calibrated using a three point calibration curve with VHG or SPEX standards that are traceable to NIST. The instrument was calibrated the day it was used.

Documentation and Reporting. The sample aliquot weight and volume, solution volume adjustments, sample preparation and analysis dates, VHG or SPEX standards assay results, calculations, and operator and supervisor initials were recorded in formal LANL notebook 4070, pp. 142-143. Final data results are recorded in the LANL NMT LIMS system and found in Appendix C "Final Chemical Analysis Report." A copy of procedure ANC115 is in the NDA CEP WRM file. The data was reviewed by the NDA CEP Technical Team and was a technical HOLD POINT prior to using the $\mathrm{AmO}_{2}$ to prepare WRM $\mathrm{AmO}_{2}-\mathrm{PuO}_{2}-\mathrm{DE}$ blends.

\section{Depleted Uranium Oxide}

Specifications for the Depleted Uranium (DU) oxide $\left(\mathrm{UO}_{2}\right)$ to be used for the CEP WRM production are listed in sections 5.15-5.19 of the SOW. The material (LANL LOT 0907-43 and 0907-44) was initially prepared at LANL. Two, nominally $3 \mathrm{~kg}$ each, bottles of the DU were delivered for CEP WRM production.

\section{Preparation.}

a. Initial Preparation. This material was initially prepared at Los Alamos in 1986 as fuel feedstock. $\mathrm{U}_{3} \mathrm{O}_{8}$ was dissolved in demineralized water. $\mathrm{UO}_{4}$ was then precipitated using $\mathrm{H}_{2} \mathrm{O}_{2}$ $\mathrm{NH}_{4} \mathrm{OH}$. The precipitate was then filtered and dried to "yellow cake." The yellow cake was then calcined at $900^{\circ} \mathrm{C}$ for 16 hours in air to oxidize the material to $\mathrm{U}_{3} \mathrm{O}_{8}$. The $\mathrm{U}_{3} \mathrm{O}_{8}$ was then reduced to $\mathrm{UO}_{2}$ by heating to $700^{\circ} \mathrm{C}$ for 1 hour in an $\mathrm{H}_{2}$ atmosphere. The temperature was then decreased to $400^{\circ} \mathrm{C}$ and the material oxidized in air for 6 hours. Further reduction of the $\mathrm{U}$ oxide was accomplished by heating the material to $700^{\circ} \mathrm{C}$ for 1 hour in $\mathrm{H}_{2}$ then sintering for 1 hour in $\mathrm{CO}_{2}$ and allowed to cool in $\mathrm{CO}_{2}$.

b. Packaging. A total of $6 \mathrm{~kg}$ were requested for production of the CEP WRMs. The material was packaged in two plastic bottles each containing nominally $3 \mathrm{~kg}$.

c. Blending. To ensure homogeneity of the total $6 \mathrm{~kg}$ of DU, the entire batch was blended in a Turbula Model T2C blender. Approximately half of the contents of the two bottles were placed within a blending bottle and blended for 30 minutes. The same was done with the remainder of the material. Next, one half of the material blended first is combined with one half of the material blended second and this was blended for $30 \mathrm{~min}$. The same was done with the remainder of the material. The DU was then left in the blending bottles.

\section{Characterization}

a. Sampling for Analytical Chemistry. Aliquots of the DU oxide were weighed for analytical chemistry as follows: four $250 \mathrm{mg}$ samples for trace element analysis, one $30 \mathrm{mg}$ sample for particle size distribution, three $100 \mathrm{mg}$ samples for pyrohydrolysis/ion selective electrode analysis, and eight $150 \mathrm{mg}$ samples (total) for mass spectrometry and radiochemistry. 
b. Particle Size Distribution. A particle size distribution was performed on a $30 \mathrm{mg}$ sample of DU oxide. The report is included in Appendix F.

Method. An Olympus Vanox microscope (reflected light) was used to determine the sample particle size distribution. The optical images were collected and digitized by a Scion video capture board. The digital images were processed and sized using NIH Image software.

Calibration. The calibration was done using a B\&L optical standard.

Documentation and Reporting. The particle size distribution was a technical HOLD POINT. The particle size distribution data was reviewed by the NDA CEP Technical Team prior to using the DU for preparing WRMs. The Spherical Equivalent Mean Diameter is 11 microns with a maximum diameter of 43 microns. See Appendix F for details.

c. Uranium Assay and Isotopic Distribution. The same sample preparation and mass spectrometer operations described previously for the $\mathrm{PuO}_{2}$ and $\mathrm{AmO}_{2}$ analyses were used for $\mathrm{U}$ assay and $\mathrm{U}$ isotopic distribution of the $\mathrm{UO}_{2}$. The sample preparation and mass spectrometer operations are described in LANL procedures ANC 131, "U \& Pu Isotopic Distribution and Assay by Isotope Dilution Mass Spectrometry," ANC 1312, "Operation of the VG-2 Mass Spectrometer," and ANC 130, "Purification of Plutonium for Mass Spectrometric Analysis by Ion Exchange Separation."

Samples. Five $150 \mathrm{mg}$ aliquots of the DU oxide powder were dissolved in concentrated $\mathrm{HNO}_{3}$ with a few drops of dilute $\mathrm{HF}$ and diluted with $1 \mathrm{~N} \mathrm{HNO}_{3}$ for mass spectrometric determination of total $\mathrm{U}$ and $\mathrm{U}$ isotopic distribution.

Sample Preparation. For the $\mathrm{U}$ isotopic distribution determinations, aliquots of the dissolved samples were purified by ion exchange chromatography to remove any interfering plutonium isotopes. The U assay analysis was performed by IDMS, and a weight aliquot of each sample was spiked with a known quantity of ${ }^{233} \mathrm{U}$. Using ion exchange chromatography, the $U$ sample plus spike was purified, and an aliquot of the $U$ sample plus spike fraction was mounted on Re filaments for the isotopic ratio determinations.

U Isotopic Distribution Analysis. The U fraction filaments containing approximately $200 \mathrm{ng}$ of $\mathrm{U}$ were mounted in the VG-354 instrument. This instrument is equipped with a multicollector (5) Faraday system which permits the simultaneous collection of up to five isotopes. The entire $U$ aliquot is evaporated (Total Evaporation Mass Spectrometry), and the subsequent ion signal is collected, thereby yielding a very high precision, high accuracy analysis (see Ref. 2). The relative gain of the five measuring channels was determined at the start of each analysis with a built-in current source. The integrated intensity from each isotope was proportional to the abundance of that isotope. Results of these analyses are summarized in Table 16.

\begin{tabular}{|c|c|c|c|c|c|}
\hline Sample & ${ }^{233} U$ & ${ }^{234} \mathrm{U}$ & ${ }^{235} \mathbf{U}$ & ${ }^{236} \mathbf{U}$ & ${ }^{238} \mathbf{U}$ \\
\hline 1 & 0.0000 & 0.0008 & 0.1901 & 0.0035 & 99.8057 \\
\hline 2 & 0.0000 & 0.0008 & 0.1906 & 0.0034 & 99.8053 \\
\hline 3 & 0.0000 & 0.0002 & 0.1899 & 0.0036 & 99.8064 \\
\hline 4 & 0.0000 & 0.0014 & 0.1898 & 0.0029 & 99.8060 \\
\hline 5 & 0.0000 & 0.0008 & 0.1905 & 0.0037 & 99.8051 \\
\hline Average & 0.0000 & 0.0008 & 0.1902 & 0.0034 & 99.8057 \\
\hline
\end{tabular}


U Assay. The U fraction (plus spike) filaments were mounted in the VG-354 Mass Spectrometer and processed as described above. The $\mathrm{U}$ isotope ratios were measured and the total $\mathrm{U}$ concentration in the dissolved sample was calculated using the $238 / 233$ ratio and the ${ }^{233} \mathrm{U}$ concentration of the spike. The $U$ assay results are summarized in Table 17.

\begin{tabular}{|c|c|c|c|c|c|}
\hline \hline Table 17. U Assay Results. \\
\hline Sample & $\mathbf{1}$ & $\mathbf{2}$ & $\mathbf{3}$ & $\mathbf{4}$ & $\mathbf{5}$ \\
\hline Wt. \% U & 87.464 & 87.497 & 87.496 & 87.525 & 87.485 \\
\hline Average: 87.493 \\
\hline \hline
\end{tabular}

Standards and Calibration. The Mass Spectrometer is calibrated using NBS SRM-U005 (Appendix $\mathrm{R}$ ) aliquots run with every batch of depleted uranium samples receiving $\mathrm{U}$ isotopic distribution analysis. These data have formed the basis for control charts and were used to assure the method is meeting performance criteria, and to determine the method's historical performance. Historical QC data demonstrates that this method (sample preparation and instrument performance) is superior to the manufacture's stated precision of $0.05 \%$ at one standard deviation.

Documentation and Reporting. The SRM and sample replicate U isotopic distribution (both as atomic percent and weight percent) and $U$ assay results, analysis dates, SRM aliquot, and operator and supervisor initials are recorded in formal LANL notebooks with copies introduced into NDA CEP WRM files. The U isotopic distribution results and $U$ isotopic ratio results for the five samples are summarized in Tables 16 and 17 above and are contained in the "Final Chemical Analysis Report," included as Appendix C. Copies of procedures ANC 130, ANC 131, ANC 1312 are in the NDA CEP WRM file. The total $U$ and $U$ isotopic distribution results were a technical HOLD POINT and were reviewed by the NDA CEP Technical Team prior to using the $\mathrm{UO}_{2}$ to prepare $\mathrm{UO}_{2}$-DE WRM blends.

d. ICP-AES Determination of Impurities. The ICP Atomic Emission Spectroscopy (AES) method is well suited for, and was used to determine, the concentration of the following impurities in the $\mathrm{UO}_{2}$ : $\mathrm{Al}, \mathrm{Ca}, \mathrm{Fe}, \mathrm{Mg}$, and $\mathrm{Na}$. The LANL procedure ANC189, "Inductively Coupled Plasma-Atomic Emission Spectroscopy Using the Thermo Jarrell-Ash IRIS Spectrometer" was used for sample preparation and ICP-AES analyses.

Sample Preparation. Three samples of the $\mathrm{UO}_{2}$ were dissolved in concentrated nitric acid with a few drops of dilute HF following LANL procedure ANC142, "Trace-Element AnalysisMicrowave-Assisted Sample Preparation." The dissolved samples were diluted and aspirated into the ICP-AES for elemental analyses.

ICP-AES Analysis. The samples were atomized and ionized in the plasma; atomic emission lines were detected optically and intensities measured by a charge injection device. Elemental concentration measurements were made, relative to external calibration for each element. The analysis results for the three samples are summarized in Table 18 below.

Standards and Calibration. Standard Reference Materials (e.g., SPEX) traceable to NIST standards for each element were used to calibrate the ICP-AES instrument and to assess instrument performance. The precision and accuracy of this method, based on ongoing calibration and verification standards, is $5-10 \%$. 


\begin{tabular}{|l|c|c|c|c|}
\hline \hline \multicolumn{5}{|c|}{ Table 18. ICP-AES Analysis Results in Micrograms Impurity per Gram UO } \\
\hline Impurity & Sample 1 & Sample 2 & Sample 4 & Average \\
\hline $\mathrm{Al}$ & 99 & 108 & 102 & 103 \\
\hline $\mathrm{Ca}$ & 21 & 23 & 25 & 23 \\
\hline $\mathrm{Fe}$ & 46 & 50 & 49 & 48 \\
\hline $\mathrm{Mg}$ & 4.1 & 5.4 & 4.5 & 4.7 \\
\hline $\mathrm{Na}$ & 171 & 175 & 157 & 168 \\
\hline \hline
\end{tabular}

Documentation and Reporting. The sample handling, weights, and dissolution volumes are recorded in formal LANL notebooks ANC52, p. 116, ANC6, p. 211, and F1994, p. 129, and in the LANL NMT LIMS system. Appendix C contains copies of the "Final Chemical Analysis Report." Copies of the procedures ANC189 and ANC142 are contained in the NDA CEP WRM file. The sample impurity analysis results were reviewed by the NDA CEP Technical Team. The impurity levels, analyses data, and batch homogeneity were found to be satisfactory. This review was a technical HOLD POINT prior to using the $\mathrm{UO}_{2}$ to prepare $\mathrm{UO}_{2}-\mathrm{DE} W \mathrm{WR}$ blends.

e. ICP-MS Determination of Impurities. The ICP-MS method is well suited for, and was used to determine, the concentration of the following impurities in the $\mathrm{UO}_{2}: \mathrm{B}, \mathrm{Be}, \mathrm{Cd}, \mathrm{Ni}, \mathrm{Cr}$, $\mathrm{Li}, \mathrm{Pb}, \mathrm{W}, \mathrm{V}$. The LANL procedure ANC102, "Inductively Coupled Plasma-Mass Spectrometry Using the VG Plasma Quad" was used for sample preparation and ICP-MS analyses.

Sample Preparation. Three samples of the $\mathrm{UO}_{2}$ were dissolved in concentrated nitric acid with a few drops of dilute HF following LANL procedure ANC142, "Trace-Element AnalysisMicrowave-Assisted Sample Preparation." The dissolved samples were diluted and aspirated into the ICP-MS for elemental and isotopic analyses.

ICP-MS Analysis. The samples were atomized and ionized in the plasma, which is sampled by a mass spectrometer. Mass detection and concentration measurements were made, relative to external calibration for each element. The analysis results for the three samples are summarized in Table 19.

Standards and Calibration. Certified Reference Materials (e.g., SPEX) traceable to NIST standards for each element were used to calibrate the ICP-MS instrument and to assess instrument performance. The precision and accuracy of this method, based on ongoing calibration and verification standards, is $+/-10 \%$.

Documentation and Reporting. The sample handling, weights, and dissolution volumes are recorded in formal LANL notebooks ANC52, p. 116, ANC6, p. 211, and F1994, p. 129, and in the LANL NMT LIMS system. Appendix C contains copies of the "Final Chemical Analysis Report." Copies of procedures ANC102 and ANC142 are contained in the NDA CEP WRM file. The sample impurity analysis results were reviewed by the NDA CEP Technical Team. The impurity levels, analyses data, and batch homogeneity were found to be satisfactory. This review was a technical HOLD POINT prior to using the $\mathrm{UO}_{2}$ to prepare $\mathrm{UO}_{2}-\mathrm{DE} W \mathrm{WR}$ blends. 


\begin{tabular}{|l|c|c|c|c|}
\hline \hline \multicolumn{5}{|c|}{ Table 19. ICP-MS Analysis Results in Micrograms Impurity per Gram UO ${ }_{2}$. } \\
\hline \multicolumn{1}{|c|}{ Impurity } & Sample 1 & Sample 2 & Sample 4 & Average \\
\hline $\mathrm{B}$ & 297 & 307 & 307 & 304 \\
\hline $\mathrm{Be}$ & $<0.5$ & $<0.5$ & $<0.5$ & \\
\hline $\mathrm{Cd}$ & 0.22 & 0.13 & 0.31 & 0.22 \\
\hline $\mathrm{Ni}$ & 7.7 & 5.7 & 4.9 & 6.1 \\
\hline $\mathrm{Cr}$ & 1.6 & 1.7 & 2.0 & 1.8 \\
\hline $\mathrm{Li}$ & $<0.5$ & $<0.5$ & $<0.5$ & \\
\hline $\mathrm{Pb}$ & 7.2 & 5.5 & 5.4 & 6.0 \\
\hline $\mathrm{W}$ & 3.0 & 2.8 & 3.1 & 3.0 \\
\hline $\mathrm{V}$ & 1.6 & 1.4 & 1.6 & 1.5 \\
\hline Note: Values preceded by the symbol < represent ICP-MS limits of detection. \\
\hline \hline
\end{tabular}

f. Radiometric Analysis. Radiometric analyses were performed to verify that the ${ }^{244} \mathrm{Cm}$ and ${ }^{252} \mathrm{Cf}$ levels were not high enough to adversely effect neutron or gamma based measurements of the WRMs.

Sample Preparation. Two cuts ( $200 \mu \mathrm{L}$ each) of the DU sample solution were analyzed for ${ }^{244} \mathrm{Cm}$ and ${ }^{252} \mathrm{Cf}$ by alpha spectrometry.

Radiometric Analyses. The amounts of ${ }^{244} \mathrm{Cm}$ and ${ }^{252} \mathrm{Cf}$ in the sample were estimated based on their half-lives and activity ratio to the ${ }^{238} \mathrm{U}$ isotope using alpha spectrometry. This method provides a rough upper limit estimate of ${ }^{244} \mathrm{Cm}$ and ${ }^{252} \mathrm{Cf}$ concentrations. No actual peaks were observed in the 5.7 to $7.5 \mathrm{MeV}$ region so an integrated background area (5 counts) in this energy region was used to bound the ${ }^{244} \mathrm{Cm}$ and ${ }^{252} \mathrm{Cf}$ concentrations. The estimated ${ }^{244} \mathrm{Cm}$ concentration in the sample was less than $1 \times 10^{-5} \mathrm{ppm}$ based on the half-lives and activity ratio of ${ }^{244} \mathrm{Cm}$ to ${ }^{238} \mathrm{U}$. The estimated ${ }^{252} \mathrm{Cf}$ concentration in the sample was less than $1 \times 10^{-6} \mathrm{ppm}$ based on the half-lives and activity ratio of ${ }^{252} \mathrm{Cf}$ to ${ }^{238} \mathrm{U}$.

The half-life ratios of ${ }^{244} \mathrm{Cm}$ and ${ }^{252} \mathrm{Cf}$ to ${ }^{238} \mathrm{U}$ were very large due to a very long half-life of ${ }^{238} \mathrm{U}$. Therefore, conservative estimates of detection limits for ${ }^{244} \mathrm{Cm}$ and ${ }^{252} \mathrm{Cf}$ were reported. If the detection limits were estimated based on ${ }^{234} \mathrm{U}$ alpha peak, then the estimated ${ }^{244} \mathrm{Cm}$ was less than $0.001 \mathrm{ppm}$ and ${ }^{252} \mathrm{Cf}$ was less than $0.001 \mathrm{ppm}$.

Standards and Calibration. Alpha spectrometry was performed using the surface barrier silicon detectors in an OASIS. The alpha spectrometers were energy calibrated with a source prepared from ${ }^{238} \mathrm{Pu},{ }^{239} \mathrm{Pu}$ and ${ }^{244} \mathrm{Cm}$. The energy calibrations were validated with an NIST ${ }^{238} \mathrm{Pu}$ source (SRM 4906-C-9; see Appendix R).

Documentation and Reporting. The results of the ${ }^{244} \mathrm{Cm}$ and ${ }^{252} \mathrm{Cf}$ alpha spectrometric analysis are contained in the Appendix C "Final Chemical Analysis Report" and are recorded in the LANL NMT LIMS system. The alpha spectrometric results for ${ }^{244} \mathrm{Cm}$ and ${ }^{252} \mathrm{Cf}$ were reviewed by the NDA CEP Technical team and was a technical HOLD POINT prior to using the DU to prepare DU WRM blends. 
g. Anionic Impurity Analyses. Chlorine and fluorine potentially add random uncertainty to neutron based waste assays; hence, analyses were performed to determine their concentration in the $\mathrm{UO}_{2}$.

Sample Preparation. The chlorine and fluorine constituents of three representative samples of $\mathrm{UO}_{2}$ were separated from each $\mathrm{UO}_{2}$ sample by pyrohydrolysis and collected in a condensate. The pyrohydrolysis procedure is ANC115, "Determination of Chloride and Fluoride in UraniumPlutonium Fuel Materials and Boron Carbide."

Ion-Selective Electrode Analysis. The chloride and fluoride concentrations were determined in the condensates using ion-selective electrodes. Either a fluoride or chloride ISE is plugged into a pH/ISE meter and calibration curve standards are directly read and recorded into computer memory followed by sample analysis. The three $\mathrm{UO}_{2}$ sample analyses for chloride and fluoride are listed in Table 20.

Standards and Calibration. The ISEs are calibrated using a three point calibration curve with VHG or SPEX standards that are traceable to NIST. The instruments were calibrated the day they were used.

Documentation and Reporting. The sample aliquots' weights and volumes, solution volume adjustments, sample preparation and analysis dates, VHG or SPEX standards assay results, calculations, and operator and supervisor initials were recorded in formal LANL notebook \#4070, pp. 142-143. Final data results are recorded in the LANL NMT LIMS system and found in Appendix C "Final Chemical Analysis Report." A copy of ANC115 is in the NDA CEP WRM file. The data was reviewed by the NDA CEP Technical Team and was a technical HOLD POINT prior to using the $\mathrm{UO}_{2}$ to prepare $\mathrm{WRM} \mathrm{UO}_{2}-\mathrm{DE}$ blends.

\begin{tabular}{|l|c|c|}
\hline \hline \multicolumn{3}{|c|}{ Table 20. Ion Selective Electrode Analyses of $\mathbf{U O}_{\mathbf{2}}$ for $\mathbf{C l}$ and F. } \\
\hline Sample & $\mathbf{C l}, \boldsymbol{\mu g} / \mathbf{g} \mathbf{U O}_{\mathbf{2}}$ & $\mathbf{F}, \boldsymbol{\mu g} / \mathbf{g} \mathbf{U O}_{\mathbf{2}}$ \\
\hline 1 & 6 & 4 \\
\hline 2 & 3 & 4 \\
\hline 3 & 3 & $<1$ \\
\hline Mean & 4 & 4 \\
\hline \hline
\end{tabular}

\section{Diatomaceous Earth}

J.T. Baker Co. \#2244-05 diatomaceous earth (DE) (Kieselguhr) was obtained in eleven, one $\mathrm{kg}$ batches. This type of DE was selected because previous analyses demonstrated that Kieselguhr contained the lowest chloride and fluoride content of the four types of DE evaluated.

\section{Preparation}

The diatomaceous earth (DE) batches were sealed inside a clean, 55 gallon steel drum. The $\mathrm{DE}$ was blended for ten hours with a rotating drum mixer. 
a. Sampling. After blending, the DE was poured into three plastic containers. While the DE was being poured, two samples were taken from each receiving container. The first sample was taken when the receiving container was $1 / 5$ full, and the second sample was taken when the receiving container was full. The blending and sampling are described in further detail in the August 17, 1995 memo, "Don Vance to File," which is contained in Appendix D of LA-UR-96-2277, "NDA PDP Working Reference Materials Production Plan-Phase I."

\section{Characterization}

Characterization of the DE was important for two reasons: to ensure that the material was adequately blended, and to ensure that the concentration of elements interfering with neutron and gamma based analyses were at or below levels which might introduce significant interference via alpha-n reactions.

a. Glow Discharge Mass Spectrometry. The constituents of the DE were determined by Glow Discharge Mass Spectrometry (GDMS), with the procedure described (in Ref. 3). The GDMS analysis involved quantification of 29 constituents, including the alkaline metals $\mathrm{Be}, \mathrm{B}, \mathrm{Si}, \mathrm{S}, \mathrm{Cl}$, $\mathrm{F}, \mathrm{Fe}, \mathrm{Al}, \mathrm{Th}$, and U.

Sample Preparation. Each DE sample (and the SRM materials) was blended with high purity tantalum metal and mounted in the Glow Discharge Mass Spectrometer. Two of the DE samples were prepared in duplicate to provide analysis precision data.

Glow-Discharge Mass Spectrometry Analysis. Glow discharge mass spectrometry is a sputtering technique whereby atoms from an electrically conducting sample are introduced into a highenergy argon plasma, ionized and mass analyzed. The GDMS instrument at LANL is a double focusing, magnetic sector, high resolution instrument capable of quantification to the ppb level. The complete report of GDMS data is contained in Appendix E of LA-UR-96-2277 (Ref. 1). Table 21 contains a summary of GDMS analysis results on constituents with potential neutronic interference. Most elements are reported as weight percent oxides which is a geological convention. This does not mean that the oxides listed in Table 21 are actually present in the DE.

Table 21 lists a F content of 0.2 weight percent. This content is probably biased high; analysis of F on the NIST SRM 278 was biased almost a factor of 10 high. However, the F content for the SRM is listed as a semiquantitative value. Hence, we cannot unequivocally bias correct the GDMS $F$ value.

\begin{tabular}{|l|c|c|c|}
\hline \hline Table 21. GDMS Analysis Results on Kieselguhr Diatomaceous Earth. \\
\hline Constituent & Wt $\%$ & Constituent & $\mu \mathrm{g} / \mathrm{g}$ (ppm) \\
\hline $\mathrm{SiO}$ & 88 & $\mathrm{BeO}$ & $<0.1$ \\
\hline $\mathrm{Fe}_{2} \mathrm{O}_{3}$ & 1.7 & $\mathrm{~B}_{2} \mathrm{O}_{3}$ & 18 \\
\hline $\mathrm{CaO}$ & 4.2 & $\mathrm{ThO}_{2}$ & $<0.2$ \\
\hline $\mathrm{Na}{ }_{2} \mathrm{O}$ & 1.2 & $\mathrm{UO}_{2}$ & $<0.3$ \\
\hline $\mathrm{Cl}$ & $<0.006$ & & \\
\hline $\mathrm{F}$ & 0.2 & & \\
\hline
\end{tabular}


Standards and Calibration. The high purity tantalum binder is routinely analyzed for impurities to provide background correction data. NIST SRMs 89, 91, 92, and 98b (Appendix R) were combined with the tantalum binder and analyzed to provide calibration sensitivity factors. Further, NIST SRM 278 (Appendix R) was analyzed along with the DE samples as a QC check. To ensure that the instrument precision was adequate, two of the six DE samples were analyzed in duplicate.

Documentation and Reporting. All pertinent data, including calibration, sample weights, sample identification, sample preparation and analysis dates, and QC sample identification and sample analyses results are recorded on both the GDMS hard disk and the backup floppy disks of the LANL Analytical Chemistry Group (NMT-1). A copy of the procedure described in Ref. 3 is contained in the NDA PDP Phase I WRM file. A copy of the complete analytical results for all six samples and the control samples is found in Appendix E of LA-UR-96-2277 (Ref. 1). The DE impurity analysis results were reviewed by the NDA CEP Technical Team to ensure the DE homogeneity and impurity content were satisfactory. This review was a technical HOLD POINT prior to usage of the DE for preparing WRM blends.

b. Loss on Ignition. To ensure that the $\mathrm{DE}$ did not contain appreciable adsorbed moisture or other volatile species, two samples of the $\mathrm{DE}$ were heated to $102^{\circ} \mathrm{C}$ for 16 hours. The resulting LOI was $0.29 \%$ and $0.17 \%$, indicating that the DE was relatively free of moisture or volatile materials. This measurement data and calculation is found in both Appendix F of LA-UR-962277 (Ref. 1) and the NDA PDP Phase I WRM file.

\section{BLENDING}

A Turbula Model T2C blender, shown in Figure 1, was used for blending. Separate blends were prepared for each individual WRM to ensure that the amount of nuclear material in each WRM was known with maximum certainty.

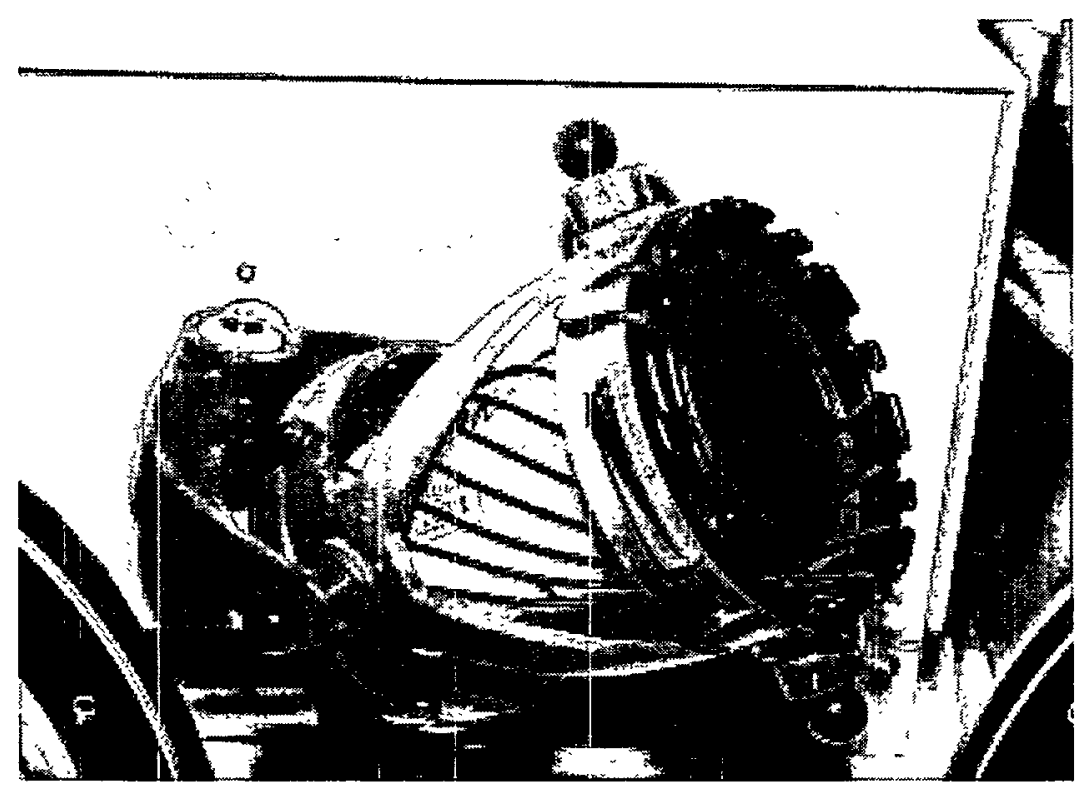

Figure 1. Turbula Blender with Blend Bottle. 


\section{A. Blending Parameters and Blend Evaluations}

Blending parameters were determined and blend evaluations carried out during the initial stages of the PDP WRM production (PDP Phase I) and these results are directly applicable to the CEP WRM production. The following summary is based on detailed descriptions that are found in LA-UR-96-2277, “NDA PDP Working Reference Materials Production Plan-Phase I” (see Ref. 1).

\section{Summary of Initial Tests for PDP}

To establish the blender speed and length of time required to produce homogeneous blends of nuclear material with $\mathrm{DE}$, cold tests were initially performed using iron powder as a surrogate for the nuclear material. Following this, actual test blends using $\mathrm{PuO}_{2}$ and $\mathrm{DE}$ were prepared following procedure ANC1412, "Blending the Nuclear Material and Matrix for the Nondestructive Assay Standards." The homogeneity of these blends was determined via gamma-ray spectrometry following procedure ANC1413, "Nuclear Material-Diatomaceous Earth Homogeneity Determination." The homogeneity of the blends was better than $2 \% \mathrm{RSD}$. Concerns of nuclear material particle agglomeration during blending were evaluated by performing a particle size distribution analysis of the $\mathrm{PuO}_{2}$ and of the $\mathrm{PuO}_{2}-\mathrm{DE}$ blend. No indication of agglomeration of the nuclear material particles was found. The alpha-neutron yield of the blend was also evaluated employing a Shuffler neutron assay instrument (passive mode). The total neutron flux ratio of the $\mathrm{PuO}_{2}-\mathrm{DE}$ blend divided by the flux for $\mathrm{PuO}_{2}$ alone was found to be 1.37 indicating some increased neutron flux from the blend. However, this level of added random neutron flux would not appreciably degrade the neutron-based assay system's precision.

\section{Alpha-Neutron Yield of $\mathrm{AmO}_{2}-\mathrm{DE}$ Blends}

A prototype IAP WRM (58 mg Am) was analyzed on the Shuffler neutron assay instrument. The counts per second of the WRM were indistinguishable from background implying that the alpha-neutron yield from $\mathrm{AmO}_{2}$ blends is insignificant. The data (see Appendix G) were reviewed by the NDA CEP Technical Team and was a technical HOLD POINT prior to the preparation of IAP WRMs.

\section{Gas-Generation Evaluation of the IAP WRMs}

Gas generation within the WRMs due to alpha radiolysis of hydrogenous material was evaluated through computational studies. These studies reveal that the pressure within the WRMs will rise to 22.6 psig within 27.9 years due primarily to the radiolysis of residual water. After 27.9 years the water will be consumed and the pressure will continue to rise very slowly due to formation of helium gas formed by the decay of alpha-emitting radionuclides. The pressure within the stainless steel WRMs will reach the maximum design and failure (yield) pressures within 83 and 176 years, respectively. These values are affected by assumptions made for the evaluations. A full report on the gas generation evaluation is included in Appendix $H$. These data were reviewed by the NDA CEP Technical Team and was a technical HOLD POINT prior to the preparation of IAP WRMs.

\section{B. IAP WRM Blend Preparation}

The blending procedure ANC1412, "Blending the Nuclear Material and Matrix for the Nondestructive Assay Standards" was followed to produce homogeneous blends with Am and Pu masses within the ranges listed in the SOW section 4.1.a-4.1.e (see Appendix A). 


\section{Nuclear Material and DE Addition}

Prior to producing the first blend, the quantity of $\mathrm{DE}$ required to fill a tap-packed stainless steel container to within $0.5+/-0.05$ inches of the top was determined in cold testing to be 134.0 grams. The DE was weighed out to the nearest 0.1 gram and recorded. The DE was placed in a uniquely identified blend container. The containers were introduced into the glovebox train and transferred into the weighing glovebox. Weighed quantities of $\mathrm{PuO}_{2}$ and $\mathrm{AmO}_{2}$ were transferred to the blend bottle containing the $\mathrm{DE}$.

\section{Blending}

After $\mathrm{DE}, \mathrm{AmO}_{2}$, and $\mathrm{PuO}_{2}$ addition, the blend container lid was secured, and the container was removed from the weighing glovebox, transferred into the blending glovebox, and introduced into the blender. The blending was performed for 60 minutes at the medium rotational speed of the Turbula Blender, under the conditions established in LANL procedure ANC1412, "Blending the Nuclear Material and Matrix for the Nondestructive Assay Standards."

\section{Documentation and Reporting}

Diatomaceous earth weight, $\mathrm{AmO}_{2}$ weight, $\mathrm{PuO}_{2}$ weight, blend identification, blend time, date, and operator signature were recorded on the work form from procedure $\mathrm{ANC1412}$. These forms are retained in the NDA CEP WRM file. A summary of the DE, $\mathrm{AmO}_{2}$, and $\mathrm{PuO}_{2}$ weights for each of the 16 blends is found in Appendix I.

\section{DU WRM Blend Preparation}

The blending procedure ANC1412, "Blending the Nuclear Material and Matrix for the Nondestructive Assay Standards" was followed to produce homogeneous blends with DU masses within the ranges listed in the SOW section 4.1.f-4.1.h (see Appendix A).

\section{Nuclear Material and DE Addition}

Prior to producing the first blend, the quantity of $\mathrm{DE}$ to be mixed with the nuclear material required to fill a tap-packed stainless steel container to within $0.5+/-0.05$ inches of the top was estimated based on experience with $\mathrm{PuO}_{2}$ PDP WRMs and was adjusted for each mass range. Since the DU WRMs have such large mass ranges for $U$, the amount of DE in these WRMs is far less than the amount of nuclear material (opposite from the PDP and IAP WRMs). Thus, errors were encountered in terms of the proper amount of $\mathrm{DE}$ to use. These errors will be discussed below in the section pertaining to filling the cylinders and WRM certification. The DE was weighed out to the nearest 0.1 gram and recorded. The DE was placed in a uniquely identified blend container. The containers were then introduced into the glovebox train and transferred into the weighing glovebox. Weighed quantities of $\mathrm{UO}_{2}$ were transferred to the blend bottles containing the $\mathrm{DE}$. The total weight of the blend bottle plus the blend was then recorded on the blend preparation form.

\section{Blending}

After $\mathrm{DE}$ and $\mathrm{UO}_{2}$ addition, the blend container lid was secured, and the container was removed from the weighing glovebox, transferred into the blending glovebox, and introduced into the blender. The blending was performed for 60 minutes at the medium rotational speed of the Turbula Blender, under the conditions established in LANL procedure ANC1412, "Blending the Nuclear Material and Matrix for the Nondestructive Assay Standards." 


\section{Documentation and Reporting}

Diatomaceous earth weight, DU weight, blend bottle tare, blend identification, blend time, date, and operator signature were recorded on the work form from procedure ANC1412. These forms are retained in the NDA CEP WRM file. A summary of the DE and DU weights for each of the 16 blends is found in Appendix J.

\section{STAINLESS STEEL ASSEMBLIES}

\section{A. Fabrication}

Sixteen stainless steel assemblies were fabricated from \#304 stainless steel tubing (seamless) and sheet and bar stock in the same manner as those prepared for PDP Phases I and II. The fabrication was performed at the Los Alamos National Laboratory main machine shop as described in the Statement of Work PLA-STD-103/1 (Appendix K in LA-UR-96-2277; Ref. 1). The Statement of Work and all QA documentation (manufacture certificates, initial assembly inspection, test component inspection, welder certification, and leak check records) are contained in the NDA PDP Phase I WRM file.

\section{B. Receiving Inspection}

The 16, \#304 stainless steel tubing assemblies and upper endcaps were inspected for cleanliness, identification marks, dimensions (wall thickness, length, diameter), endcap fit, damage, and weld quality. Inspection was performed using LANL procedure ANC1408, "Receiving Inspection of NDA Standard Containers" which includes an inspection form. A copy of this procedure and the initialed and dated inspection forms for all assembly inspections are retained in the NDA CEP WRM files. Figure 2 shows several of the as-received assembly packages for the PDP Phase I WRMs with inspection documentation. Those received for the CEP WRMs were similar.

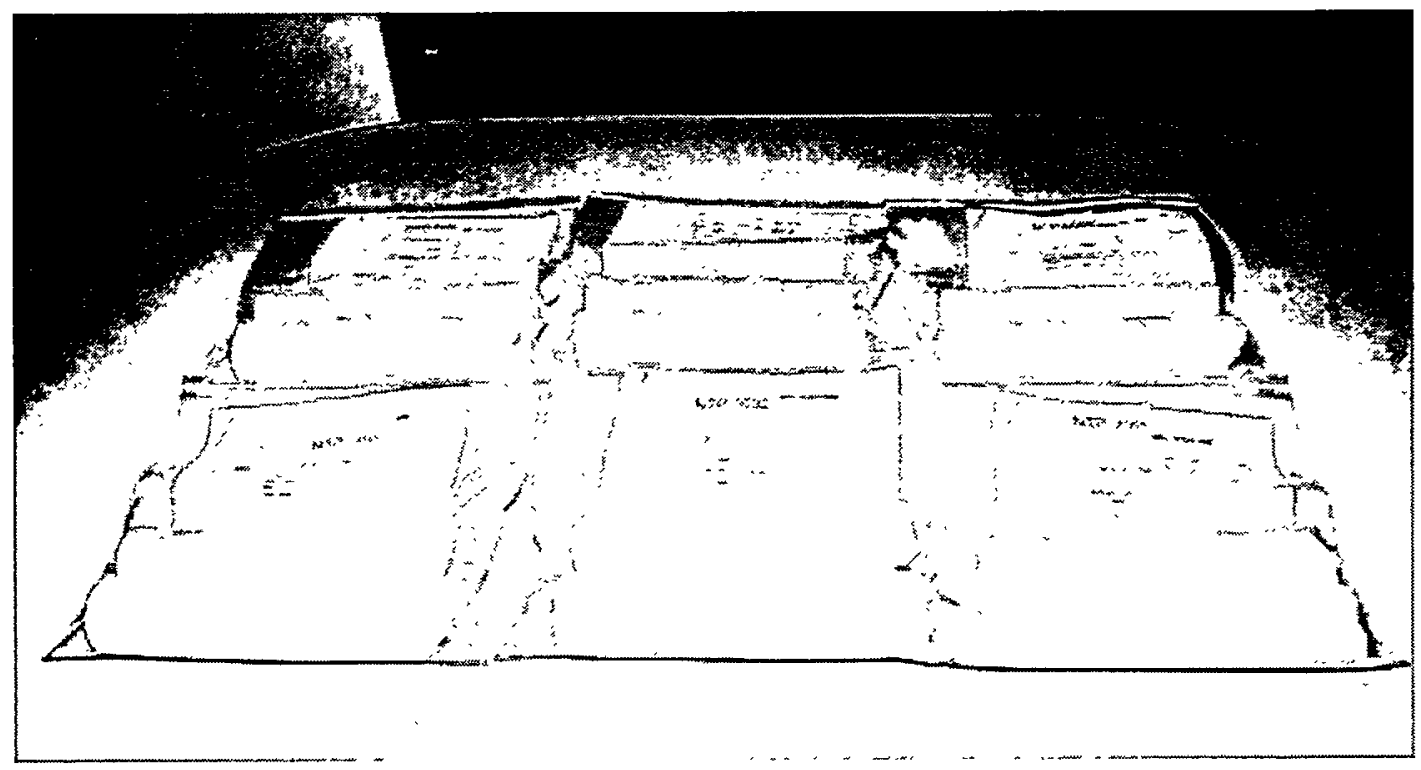

Figure 2. Packaged Assemblies with Inspection Forms. 
The 16 assemblies were identified with the following sequential alpha-numeric system: CEP-001,..., CEP-010, ...CEP-016. The identification was laser-etched into both the assembly inner and outer cylinder endcaps for the IAP WRMs and the outer assembly and endcap for the DU WRMs (Note: the DU WRMs are singly contained). Figure 3 shows a labeled DU WRM assembly with endcaps.

\section{STAINLESS STEEL CYLINDER FILLING}

The WRM cylinder preparation (inner cylinder for IAP WRMs), filling, packing, frit insertion, bagout for

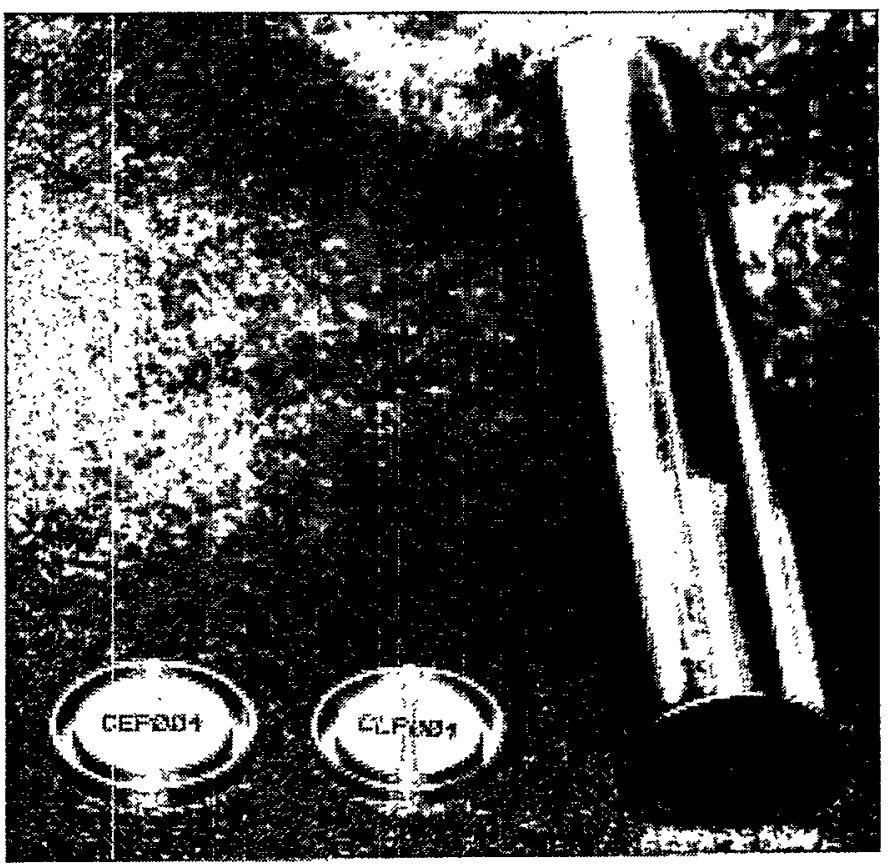

Figure 3. Labeled Assembly with Endcaps. transfer, and cleanup operations are fully described in LANL procedures ANC1410, "Filling the Containers with the Reference Materials" and ANC1411, "Decontaminating Containers for NDA Standards."

\section{A. Cylinder Preparation}

To minimize the spread of contamination, the cylinders were wrapped in aluminum foil and taped in a manner to cover all the cylinder outer surfaces while leaving the open end of the tube exposed for filling. The tube was then placed in the filling glovebox. The cylinder was fitted with a plastic sleeve which covered the lip of the open end and extended $12 \mathrm{~mm}$ down into the cylinder. This sleeve prevented blend powder from contacting the upper $12 \mathrm{~mm}$ of the cylinder, where the graphite frit and endcap would be placed.

\section{B. Cylinder Filling and Packing}

For stability, the cylinders were placed inside an approximately six cm (ID) graduated cylinder of about $15 \mathrm{~cm}$ in height. An approximately $30 \mathrm{X} 30 \mathrm{~cm}$ sheet of brown paper was positioned under the graduated cylinder so that any spillage could be readily detected and recovered. Tests with $\mathrm{DE}$ demonstrated that one $\mathrm{mg}$ of $\mathrm{DE}(<0.001 \%$ of the blend mass) was highly visible when spilled on this paper. All implements used in the loading process were kept on the paper. A paper funnel was then inserted into the open cylinder and the designated blend powder was added incrementally via a spatula into the cylinder. Figure 4 shows a cylinder ready for filling, an opened blend bottle, filling implements and a graphite frit on spillage-catch paper.

After each incremental addition, the cylinder was repetitively tapped against the glovebox floor to firmly pack the powder. Figure 5 shows a fully loaded cylinder. 
Figure 4. Cylinder Ready for Filling.
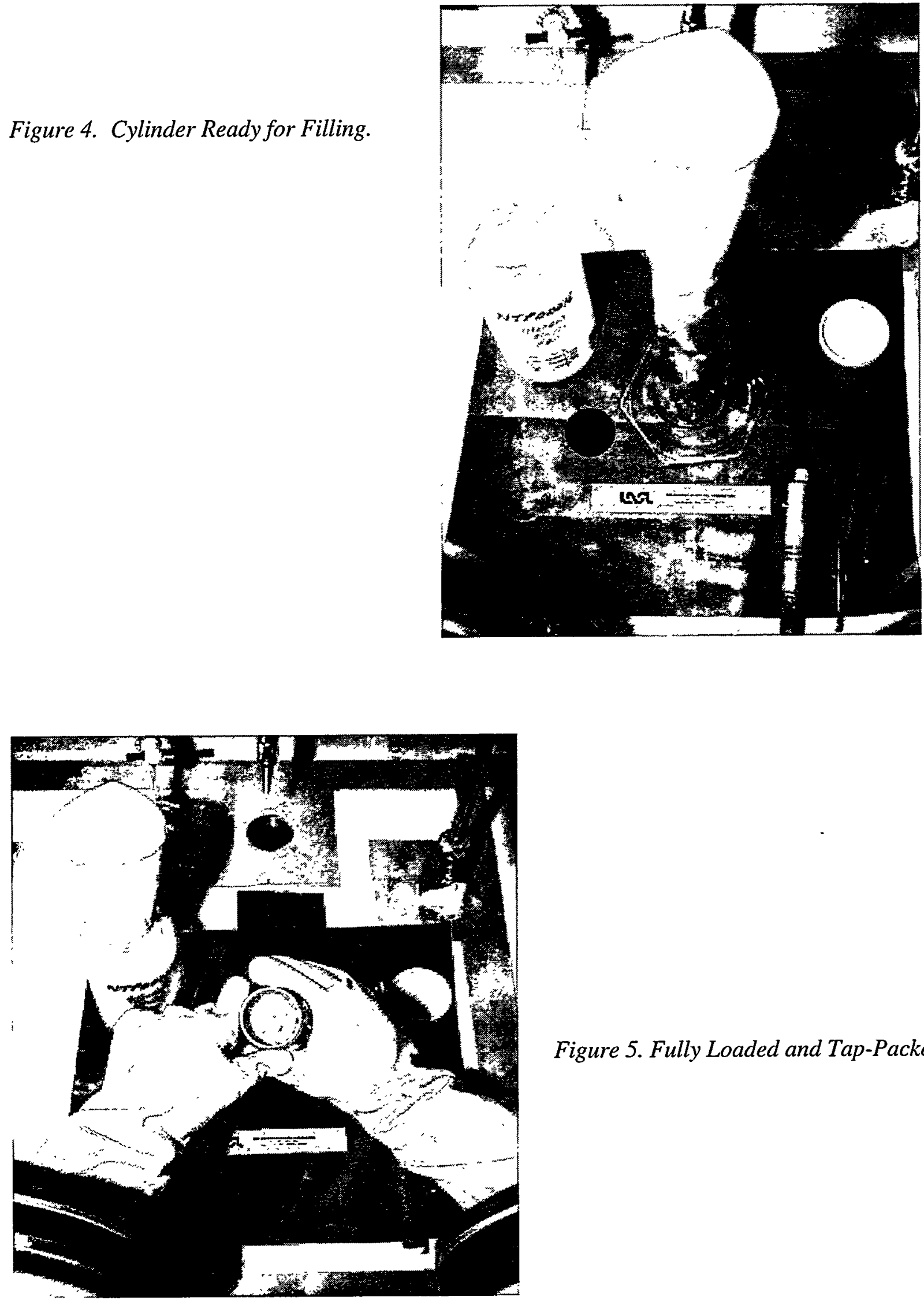

Figure 5. Fully Loaded and Tap-Packed. 
To prevent loss of blend powder during tap-packing, a small watch glass was held over the open end of the cylinder. Any detected spillage was immediately returned to the blend bottle or the cylinder. The incremental addition and tap packing steps were continued until all the blend powder was introduced into the cylinder (Note: For some of the DU WRMs, not all of the blend was transferred into the cylinder due to errors in determining the proper amount of DE to use for blending. Since not all of the blend is incorporated into the WRM, the total mass of DU in the WRM was adjusted and the homogeneity of the blend was determined and incorporated into the total uncertainty calculations discussed in the section on WRM Certification.). The cylinder was finally tap packed until the surface of the powder was just below the bottom lip of the plastic sleeve insert (see Figure 5).

\section{Frit Insertion}

After the blend powder was transferred into the cylinder, the plastic sleeve was removed and a precut graphite felt frit was carefully inserted and gently pressed down onto the surface of the powder. The loaded WRM cylinder was now ready for bagout.

\section{Waste Materials Measurement}

\section{IAP WRMs}

After each cylinder was fully loaded, the paper funnel, paper tissues used to clean the plastic sleeve, watch glass, and spatula, and the paper sheet under the loading area were inserted into the now-empty blending bottle (see Figure 6). These materials were bagged out of the filling glovebox and submitted to radiochemistry to determine the amount of nuclear material adhering to these materials. This measurement was performed using the far-field gamma counting method. Appendix $\mathrm{K}$ describes the measurement of the waste materials.

\section{DU WRMs}

After each cylinder was fully loaded, the paper funnel, paper tissues used to clean the plastic sleeve, watch glass, and spatula, and the paper sheet under the loading area were inserted into a CLEAN blending bottle (except for CEP01 1 which was handled like the IAP WRMs discussed above). These materials were bagged out of the filling glovebox and submitted to radiochemistry to

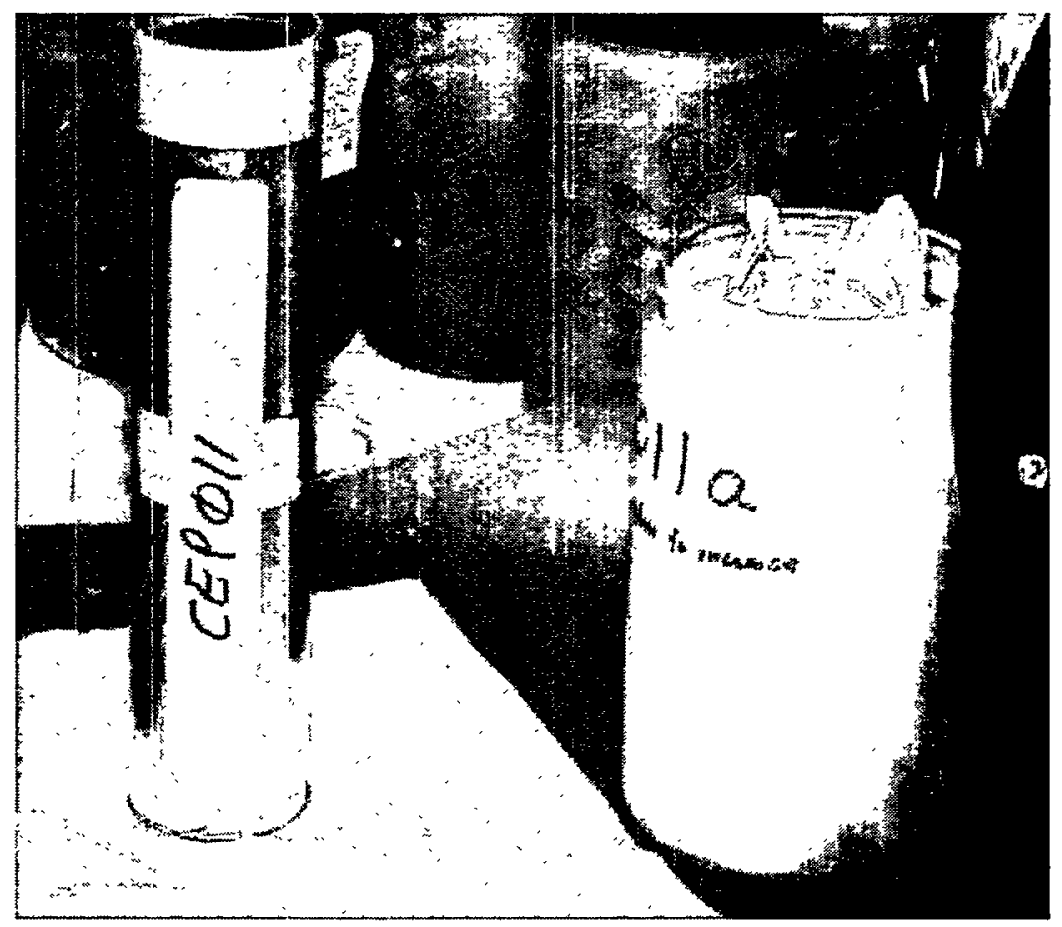

Figure 6. Packaged Wasted and Filled Cylinder Ready for Bagout. 
determine the amount of nuclear material adhering to these materials. This measurement was performed using the far-field gamma counting method. Appendix K describes the measurement of the waste materials.

Since, in most cases, not all of the DU-DE blend was delivered into the steel cylinder, the remaining blend in the blend bottle was reweighed and the amount of DU remaining was subtracted from the total DU in the blend. This correction was then applied to the total mass of DU in the WRM.

\section{E. Documentation and Records}

Records were prepared showing that all the steps pertaining to the cylinder preparation, filling, frit insertion, and cleanup were performed. These records list blend and cylinder identification numbers, and they were initialed and dated by the operator performing the operations. The final calculated quantity of nuclear material in the WRMs, including the weight of the nuclear materials and corrections for the amount of nuclear material in the waste materials, are contained in the NDA CEP WRM files and summarized in Appendices I and J. The cylinder filling records are retained in the NDA CEP WRM files.

\section{INERTING}

\section{A. IAP WRMs}

The prepared IAP WRM cylinders (10) were transferred into the inert gas airlock of the welding glovebox. The airlock was gently evacuated and backfilled with helium gas. The evacuation and backfilling operation was repeated twice. This operation replaced the air in the cylinders with helium, which prevented oxidation of the stainless steel cylinders during TIG welding and acted as a fill gas for leak inspection after welding.

\section{B. DU WRMs}

The prepared DU WRM cylinders (6) were transferred into a large desiccator which was then evacuated using a rotary pump. The desiccator was then backfilled with helium gas. The evacuation and back filling was

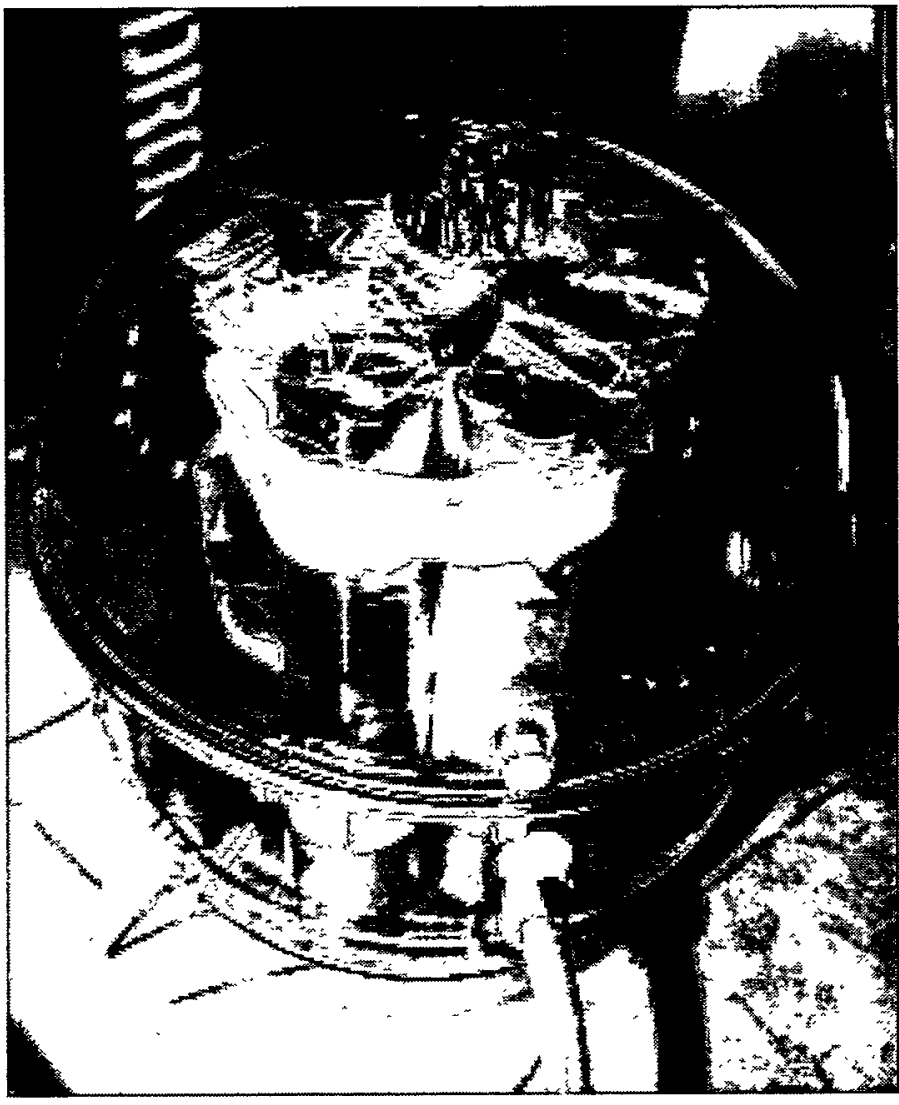

Figure 7. The Six DU WRMs in the Desiccator for Inerting. repeated twice. This operation replaced the air in the cylinders with helium which acted as a fill gas for leak inspection. Figure 7 shows the desiccator with the DU WRMs. 


\section{WELDING}

\section{A. Welding Setup}

A Programmable TIG welder located within an inert atmosphere glovebox was used to perform the TIG welds on both the inner and outer stainless steel tubes for the IAP WRMs. A similar TIG welder mounted on a bench top was used to seal the DU WRMs.

\section{IAP Inner Stainless Steel Tube Welds}

The power supply was located outside of the welding glovebox, and the welding cables fed into the welding glovebox. Located inside the glovebox was a speed-controlled rotational chuck and a stand holding the welding torch. The stand allowed precise, three directional positioning of the welding electrode. Since the welding was performed in an inert-gas glovebox, no additional inert cover gas was required. Figure 8 shows the in-glovebox welding electrode being positioned for an IAP inner cylinder endcap weld.

\section{IAP Outer Stainless Steel Tube Welds}

The IAP outer tube welds were performed outside the glovebox. A speed-controlled rotational chuck and a

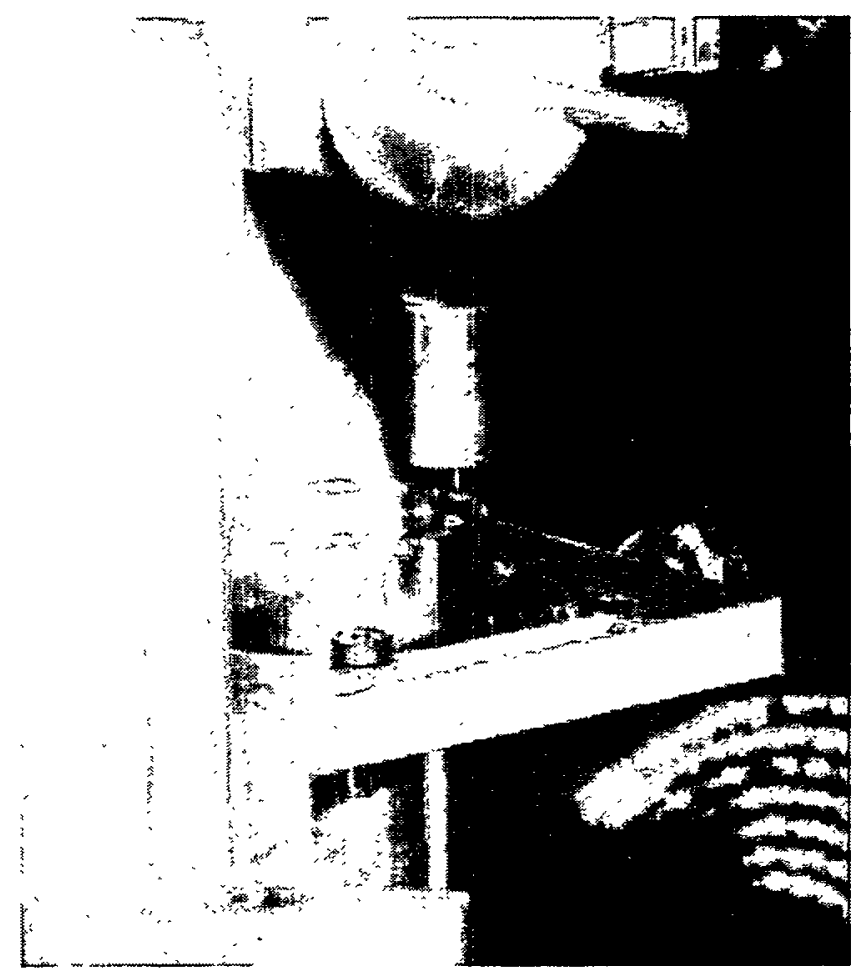

Figure 8. In-Glovebox Welding Electrode. stand holding the welding torch was used to ensure reproducible welds. An inert cover gas was used to minimize oxidation of the stainless steel during welding. Figure 9 shows a completed WRM after outer cylinder-endcap welding.

\section{DU Stainless Steel Tube Welds}

The DU tube welds were performed outside the glovebox. A speed-controlled rotational chuck and a stand holding the welding torch was used to ensure reproducible welds. An inert cover gas was used to minimize oxidation of the stainless steel during welding.

\section{B. Establishing Weld Parameters}

Using the \#304 stainless steel cylinders and end caps that comprised the test components (see Appendix K of LA-UR-96-2277; Ref. 1), practice welds were performed to establish welding power supply amperage, program cylinder rotational speed, and welding electrode-to-cylinder distance and position following procedure ANC1404, "Weld Development Procedure-NDA Standards." To ensure acceptable welds, end cap welds were performed at different current levels, and a current operating range was established. These parameters were established for both 
the inner and outer cylinders and end caps.

\section{Welding Qualification}

The welding equipment, welding parameters, welding procedure and weld operators were qualified as detailed in LANL procedure ANC1402, "Weld Qualifications Procedure-NDA Standards." Once they had demonstrated operational welding parameters by performing test welds, the two welding operators performed qualification welds on both the inner and outer cylinders with appropriate end caps. The welds extended $360^{\circ}$ around the cylinders, with adequate over-run to assure a complete seal and controlled arc break. The weld qualification acceptance criteria includes visual examination at $10 \mathrm{X}$ magnification, helium leak testing, and metallographic examination as defined in LANL procedure CST-STD-005/0. Figure 10 shows a photomicrograph of an innercylinder endcap weld cross-section with $0.040^{\prime \prime}$ penetration.

\section{Documentation and Records}

Dated and signed records were prepared on the weld qualification visual inspection and leak testing. Metallographic examination records include dated and signed photomicrographs of various sections of the qualification weld specimens. These evaluations were performed as part of PDP Phase I and the records are retained in the NDA PDP Phase I WRM files. The visual inspection and leak testing results, and the photomicrographs were reviewed to assess weld quality. A weld qualification report was prepared and is included in the NDA PDP Phase I WRM files. These reviews were a technical HOLD POINT prior to welding of the blend-filled CEP WRM cylinders.

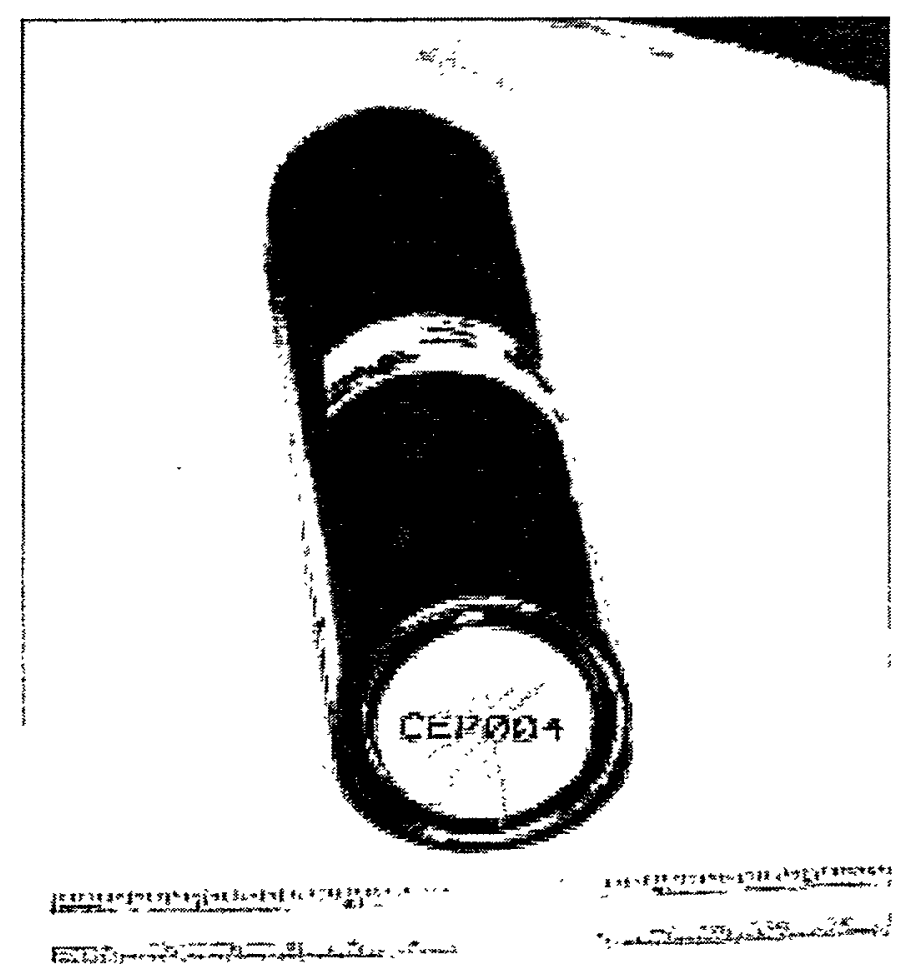

Figure 9. Completed IAP WRM after Welding and Inspection.

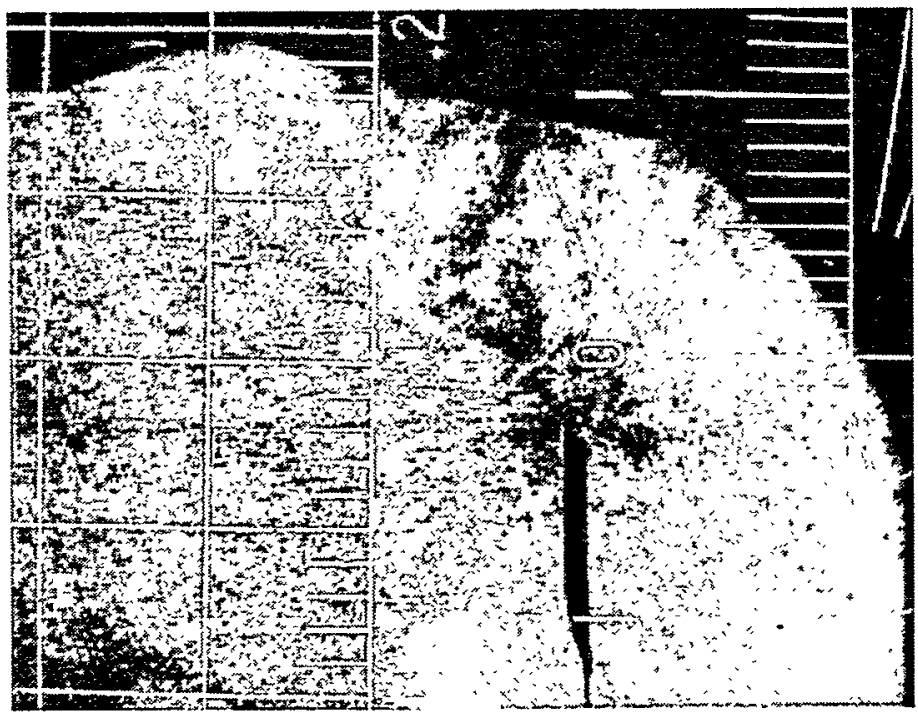

Figure 10. Inner Cylinder-Endcap Weld Crosssection. 


\section{DECONTAMINATION OF THE IAP INNER CYLINDERS}

After the inner cylinder end caps were welded in the inert atmosphere glovebox, the cylinders were removed from the glovebox through a series of cleaning operations. The cleaning was assessed by smearing the cylinders with a Health Physics swipe cloth, and then counting the swipe with a portable alpha survey instrument. Once the cylinders were cleaned to $<20 \mathrm{dpm}$ smearable alpha contamination, they were removed from the open-front glovebox and placed in plastic bags. The cleaning and contamination monitoring procedure was ANC1411, "Decontaminating Containers for NDA Standards." This procedure and records of the decontamination assessment are retained in the NDA CEP WRM files.

\section{LEAK CHECKING}

\section{A. Helium Leak Check}

Helium leak checks were performed on the welder qualification welds for the inner and outer test cylinders, and for the inner cylinder welds for every IAP WRM and the cylinder welds for the DU WRMs. The helium leak checks were performed following LANL procedure ANC1401, "Leak-Checking the NDA Standard Containers," with a leak rate pass criteria of $<1 \times 10^{-6}$ atm$\mathrm{cc} / \mathrm{sec}$ - All . cylinders demonstrated a helium leak rate of $<1 \times 10^{-8} \mathrm{~atm}-\mathrm{cc} / \mathrm{second}$, meeting Department of Transportation requirements for shipping in Class B containment.

\section{B. Documentation and Records}

Dated and initialed leak check records including leak detector calibration data and leak rate data for each WRM are retained in the NDA CEP WRM files. These records were a technical HOLD POINT and were reviewed prior to WRM shipment.

\section{FINAL INSPECTION}

Final WRM inspection included alpha contamination checks, dimensional checks, and gamma-ray measurements to both evaluate WRM nuclear material uniformity and verify WRM nuclear material loadings. Each WRM was placed in a plastic bag and sealed after final inspection. The bags were identified using a flow-pen with the same alphanumeric identifier as the WRM.

\section{A. Alpha Contamination Checks}

Thorough alpha contamination measurements were made on every WRM using both swipe methods sensitive to $6 \mathrm{dpm} / 100 \mathrm{~cm}^{2}$ removable alpha activity and direct alpha surveys sensitive to $300 \mathrm{dpm} / 100 \mathrm{~cm}^{2}$. No detectable alpha contamination was found on any WRM. These survey results were recorded, signed, and dated for every WRM and are contained in the NDA CEP WRM files. 


\section{B. Dimensional and Identification Checks}

Every WRM was checked for length and diameter to ensure a length of 8.99 to 9.01 inches and a diameter of $<1.947$ inches. The final weld on the endcap of the outer cylinder added up to 0.04 inches to the length of some of the WRMs. With permission from the Idaho National Engineering and Environmental Laboratory (INEEL) technical manager, this increased length was accepted as being preferable to machining the weld down to the 9.01 inch specification length. Further, every WRM was visually inspected for any obvious defects such as dents or scratches, and to ensure the identification markings were clear and robust. These data are recorded, dated, signed, and retained in the NDA CEP WRM files.

\section{Nuclear Material Uniformity Checks and Verification}

Each WRM was subjected to collimated gamma-ray intensity measurements focused on either a $4.5 \mathrm{~cm}$ zone of the left and right (upper and lower if the cylinder is vertically oriented) segments of the cylinder (IAP WRMs) or three $5 \mathrm{~cm}$ segments near the center of the WRM (DU WRMs). These measurements were used to determine the uniformity of the nuclear material within the WRM and to verify the contents of the WRM.

\section{IAP WRMs}

a. Uniformity Check. Peak areas for the $59.5 \mathrm{keV}$ gamma peak of ${ }^{241} \mathrm{Am}$ and the $129 \mathrm{keV}$ peak of ${ }^{239} \mathrm{Pu}$ of were integrated. Table 22 contains representative uniformity data for the WRMs at $59.5 \mathrm{keV}$ and $129 \mathrm{keV}$. All counting data (including multiple runs for certain WRMs) are included in Appendix L.

\begin{tabular}{|c|c|c|c|c|}
\hline \hline \multicolumn{6}{|c|}{ Table 22. Uniformity Measurement Data Summary. } \\
\hline WRM & mg Am & $\begin{array}{c}\text { L/R Ratio } \\
\text { @59.5keV }\end{array}$ & g Pu & $\begin{array}{c}\text { L/R Ratio } \\
\text { @129keV }\end{array}$ \\
\hline CEP001 & 10.4778 & 0.98 & 0.0854 & 1.09 \\
\hline CEP002 & 9.9121 & 1.00 & 0.0788 & 1.09 \\
\hline CEP003 & 54.1621 & 0.99 & 1.9880 & 1.01 \\
\hline CEP004 & 54.7379 & 1.01 & 2.0089 & 1.03 \\
\hline CEP005 & 92.2422 & 1.00 & 1.9934 & 0.98 \\
\hline CEP006 & 93.2348 & 1.06 & 1.9915 & 1.02 \\
\hline CEP007 & 54.7680 & 1.01 & 0.3957 & 0.99 \\
\hline CEP008 & 52.1327 & 1.01 & 0.4136 & 1.02 \\
\hline CEP009 & 103.3964 & 1.02 & ----- & ---- \\
\hline CEP010 & 99.7750 & 1.01 & ----- & ---- \\
\hline \hline
\end{tabular}


Figure 11 shows a verification/uniformity measurement being performed with the IAP WRM positioned behind lead bricks with a $4.5 \mathrm{~cm}$ wide aperture. Appendix L summarizes the measurement details and contains a complete compilation of the left-right zone counting data for each WRM. This record showing WRM identification and two-zone gamma count data is also contained in the NDA CEP WRM files.

b. Verification. The same measurements used above for uniformity were also applied to the verification of the nuclear material content of the WRMs. The left and right side counts are added together which is then divided by the total mass of Am or Pu as the case may be. By dividing the total peak areas by the mass of nuclear material, one would expect a constant count rate/mass value for all the WRMs. In no case was the Count Rate/Mass significantly different from the mean (Appendix L). Table 23 displays this data for both Am and Pu.

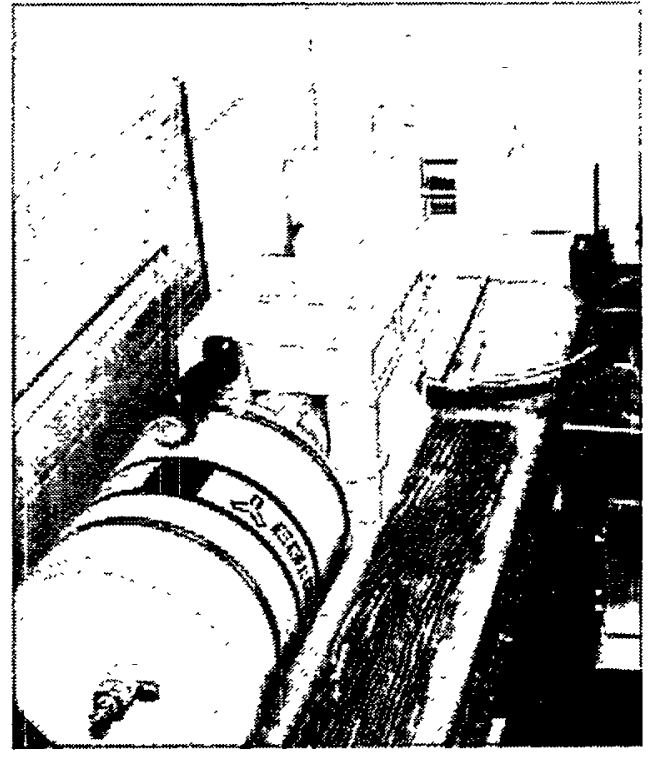

Figure 11. IAP WRM Undergoing Uniformity/Verification Measurement.

Table 23. Verification Measurement Data Summary.

\begin{tabular}{|c|c|c|c|c|}
\hline WRM & $\begin{array}{c}\text { Am } \\
\mathbf{L}+\mathbf{R} \text { Counts } \\
59.9 \mathrm{keV}\end{array}$ & $\begin{array}{c}\text { Count } \\
\text { Rate/Mass }\end{array}$ & $\begin{array}{c}\text { Pu } \\
\mathbf{L}+\mathbf{R} \text { Counts } \\
129 \mathrm{keV}\end{array}$ & $\begin{array}{c}\text { Count } \\
\text { Rate/Mass }\end{array}$ \\
\hline CEP001 & 23787 & 2270 & 750 & 8786 \\
\hline CEP002 & 21597 & 2179 & 545 & 6921 \\
\hline CEP003 & 119288 & 2202 & 14316 & 7201 \\
\hline CEP004 & 107893 & 1971 & 14001 & 6970 \\
\hline CEP005 & 205095 & 2223 & 14445 & 7247 \\
\hline CEP006 & 190381 & 2042 & 13966 & 7013 \\
\hline CEP007 & 137330 & 2507 & 2906 & 7343 \\
\hline CEP008 & 117226 & 2249 & 3295 & 7966 \\
\hline CEP009 & 233310 & 2256 & & \\
\hline CEP010 & 252694 & 2533 & & \\
\hline
\end{tabular}




\section{DU WRMs}

The DU WRMs were counted on a segmented gamma scanner (Figure 12). Instead of counting the left and right halves of each WRM as was done for the IAP WRMs, three $5 \mathrm{~cm}$ segments were counted (2 hours/segment) and compared for each DU WRM. Acquiring accurate data for the DU WRMs was problematic due to the weak gamma signal from the ${ }^{235} \mathrm{U}$ coupled with an excessive attenuation correction applied to the count data. The attenuation correction in most cases was $>90 \%$ thus rendering the quality of the data suspect. With this in mind, the uniformity and verification data are presented below.

Figure 12. DU WRM (In Gray Can) Undergoing Uniformity/ Verification Measurement on a Segmented Gamma Scanner.

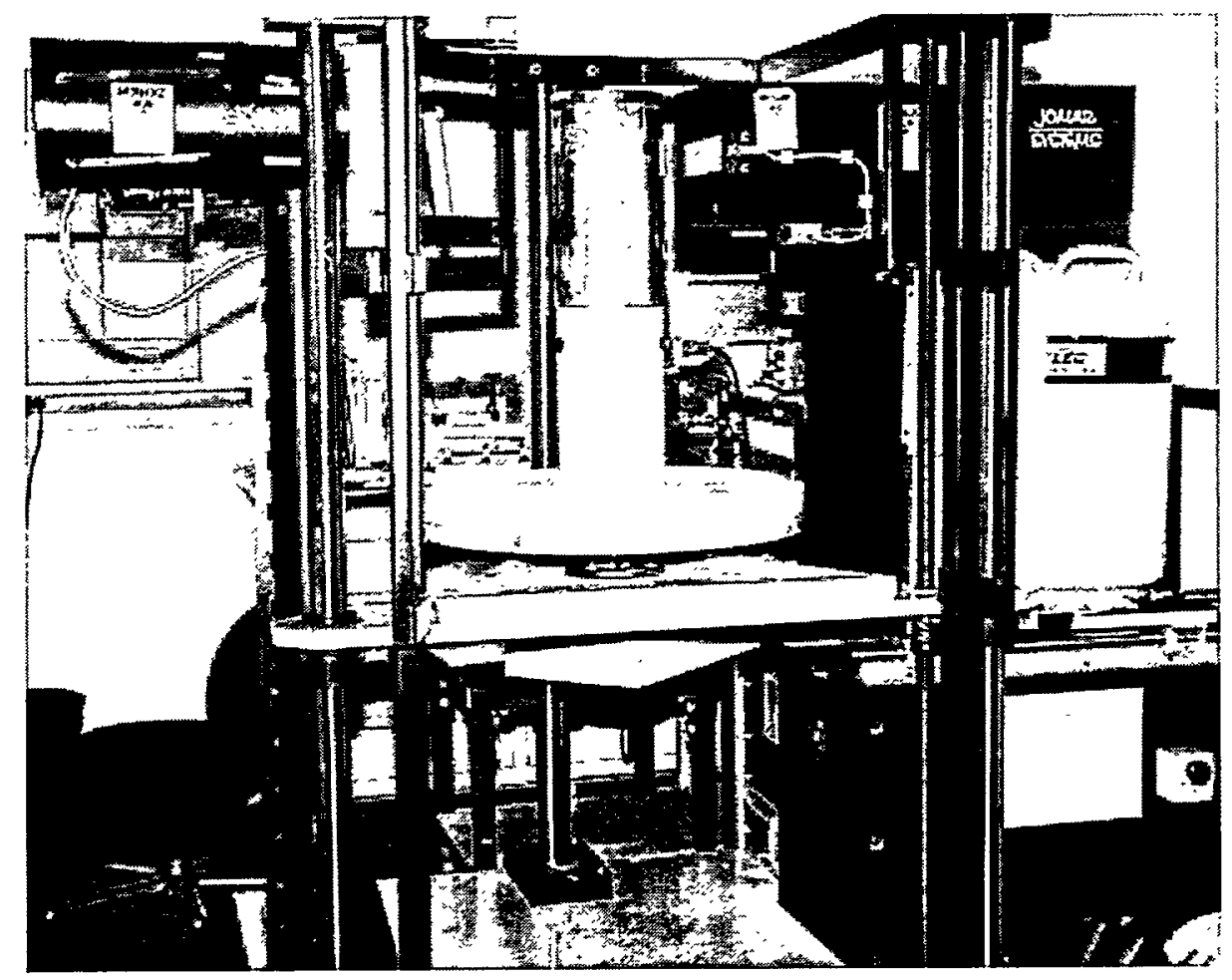

a. Uniformity Check. Peak areas for the $186 \mathrm{keV}$ gamma peak of ${ }^{235} \mathrm{U}$ were integrated. Table 24 contains representative uniformity data for the WRMs at $186 \mathrm{keV}$. All counting data (including multiple runs for certain WRMs) are included in Appendix M.

Even with the poor quality count data it is evident that the WRMs are uniform to better than $18 \%$ (worst case). Higher quality gamma count data would likely show uniformity to better than $10 \%$.

Appendix M summarizes the measurement details and contains a complete compilation of the segmented gamma scanner data for each WRM. This record showing WRM identification and three-zone gamma count data is also contained in the NDA CEP WRM files.

b. Verification. The same measurements used above for uniformity were also applied to the verification of the uranium content of the WRMs. The three segment counts are added together and then divided by the total mass of U. Table 25 displays this data for the U WRMs.

In only one case (CEP011) was the Count Rate/Mass apparently (not statistically significant) different from the mean (Appendix M). This was to be expected as this WRM has the highest $\mathrm{DE} / \mathrm{DU}$ ratio and thus less attenuation of the $186 \mathrm{keV}$ gamma due to self-shielding. The other 


\begin{tabular}{|c|c|c|c|c|}
\hline \hline Table 24. Uniformity Measurement Data Summary for the DU WRMs. \\
\hline WRM & g U & $\begin{array}{c}\text { Seg. 1/Seg. 2 } \\
\text { Ratio }\end{array}$ & $\begin{array}{c}\text { Seg. 1/Seg. 3 } \\
\text { Ratio }\end{array}$ & $\begin{array}{c}\text { Seg. 2/Seg. 3 } \\
\text { Ratio }\end{array}$ \\
\hline CEP011 & 499.18 & 0.98 & 1.04 & 1.06 \\
\hline CEP012 & 883.94 & 0.85 & 0.93 & 1.09 \\
\hline CEP013 & 957.60 & 1.00 & 1.13 & 1.14 \\
\hline CEP014 & 959.51 & 0.85 & 1.01 & 1.19 \\
\hline CEP015 & 972.64 & 0.88 & 0.98 & 1.11 \\
\hline CEP016 & 948.66 & 0.99 & 0.97 & 0.98 \\
\hline & \multicolumn{5}{|l}{} \\
\hline \hline
\end{tabular}

\begin{tabular}{|c|c|c|}
\hline \hline Table 25. Verification Measurement Data Summary for DU WRMs. \\
\hline WRM & $\begin{array}{c}\text { U } \mathbf{1}+\mathbf{2}+\mathbf{3} \text { Counts } \\
\mathbf{1 8 6} \mathbf{~ k e V}\end{array}$ & Count Rate/Mass \\
\hline CEP011 & 40104 & 80 \\
\hline CEP012 & 41472 & 47 \\
\hline CEP013 & 42192 & 44 \\
\hline CEP014 & 45000 & 47 \\
\hline CEP015 & 40824 & 42 \\
\hline CEP016 & 45360 & 48 \\
\hline \hline
\end{tabular}

five DU WRMs, taken as a group, show no significant deviation from the mean which verifies the $U$ content of the WRMs.

\section{PACKAGING AND SHIPPING}

Each WRM was sealed in a plastic bag, and each bag was marked with the WRM identification number, plus an "OK" sticker signifying the WRM had passed all inspection and verification steps. The WRMs were wrapped in bubble wrap, inserted into the $2 R$ inner container of a certified DOT 6M shipping container, and shipped via authorized commercial carriers Appendix $\mathrm{N}$ is a record of the WRMs sent to INEEL. Also included in Appendix $\mathrm{N}$ is a listing of the NDA CEP Program site personnel, including the individual designated for receiving the WRMs.

Figures 13 and 14 show WRMs being protected by bubble wrap and inserted into a $2 \mathrm{R}$ cylinder. 


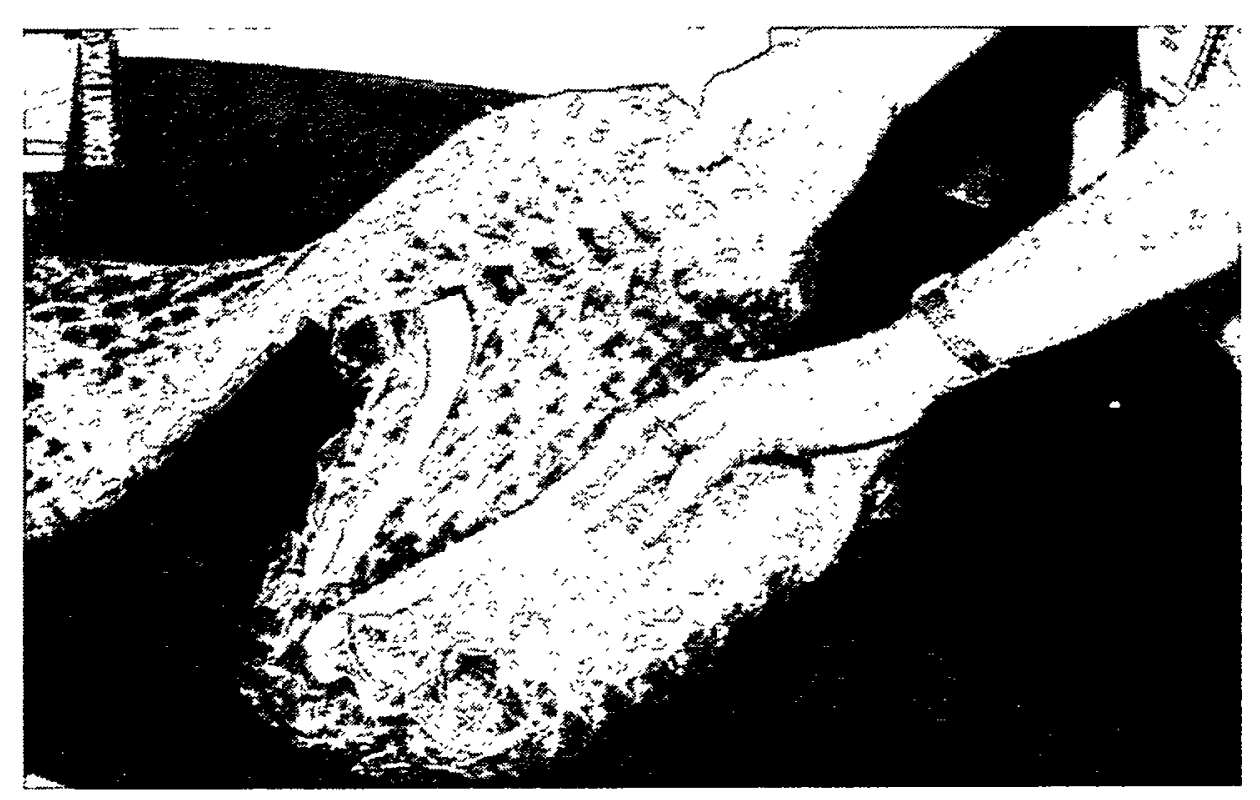

Figure 13. Bubble Wrapping Two WRMs.

\section{WRM CERTIFICATION}

The WRM production process was designed to meet all SOW specified design attributes. To certify the WRMs, critical information and data generated during the WRM production process was formally documented, filed and reduced through appropriate calculations to determine the $\mathrm{Pu}, \mathrm{Am}$, and $\mathrm{U}$ mass values and the total alpha activity for each WRM. Further, uncertainty data for the critical information and data was propagated to determine the statistical uncertainties of the calculated masses and alpha activities of each completed WRM. Finally, for certification purposes, all critical measurements are traceable to nationally recognized reference materials.

\section{A. Nuclide Mass and Alpha Activity Calculations}

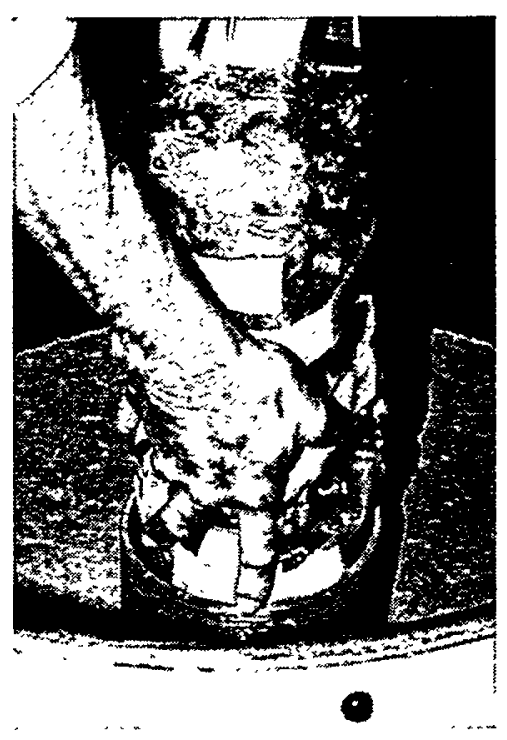

Figure 14. Inserting WRMs into a $2 R$ Cylinder for Shipment.

The calculation algorithms for $\mathrm{Pu}, \mathrm{Am}$, and $\mathrm{U}$ mass and alpha activity for the WRMs are presented below. These calculations were executed in the spreadsheet format contained in Appendix O. Also listed in Appendix $\mathrm{O}$ are the calculated Pu, Am, $\mathrm{U}$ mass, and alpha activities for all $16 \mathrm{WRMs}$. It should be noted that the $\mathrm{AmO}_{2}$ used for CEP WRM production does contain minor amounts of $\mathrm{Pu}, \mathrm{U}$, and $\mathrm{Np}$ (see Appendix $\mathrm{C}$ ). The small concentration of these elements in the $\mathrm{AmO}_{2}$ result in negligible contributions to the total alpha activity and are hence ignored in the mass and alpha activity calculations. 


\section{Pu Mass}

The Pu mass for each WRM is calculated as follows:

Pu Mass (g) $=($ Wt. PuO $(\mathrm{g}) \times$ Pu assay) - T\&H Loss (g Pu)

where: Wt. $\mathrm{PuO}_{2}$ is the weight of $\mathrm{PuO}_{2}(\mathrm{~g})$ weighed out for the specific WRM.

$\mathrm{Pu}$ assay is the mean value of the $\mathrm{Pu}$ content of the $\mathrm{PuO}_{2}$ in $\mathrm{g} \mathrm{Pu} / \mathrm{g} \mathrm{PuO}$ (decay corrected to 6/1/97).

T\&H Loss is the transfer and holdup loss as determined by the gamma spectroscopy assay of the transfer container, the blending container, funnel, cleaning tissues, and the transfer spillage catch paper.

\section{Am Mass}

The ${ }^{241} \mathrm{Am}$ mass for each WRM is calculated as follows:

${ }^{241} \mathrm{Am}$ Mass $(\mathrm{g})=\left[\left(\mathrm{Wt} . \mathrm{AmO}_{2}(\mathrm{~g}) \times\right.\right.$ Am assay1) + ( Wt. Pu (g) x Am assay2)] - T\&H

Loss (g Am)

where: Wt. $\mathrm{AmO}_{2}$ is the weight of $\mathrm{AmO}_{2}$ weighed out for the specific WRM.

Am assay 1 is the mean value of the Am content of the $\mathrm{AmO}_{2}$ in $\mathrm{g} \mathrm{Am} / \mathrm{g} \mathrm{AmO}_{2}$ (decay corrected to 6/1/97).

Wt. $\mathrm{Pu}$ is the weight of elemental $\mathrm{Pu}$ in the WRM (i.e., Wt. $\mathrm{PuO}_{2}(\mathrm{~g}) \times \mathrm{Pu}$ assay).

Am assay 2 is the mean value of the $\mathrm{Am}$ content of the $\mathrm{PuO}_{2}$ in $\mathrm{g} \mathrm{Am} / \mathrm{g} \mathrm{Pu}$ (decay corrected to $6 / 1 / 97)$.

T\&H Loss is the transfer and holdup loss as determined by the gamma spectroscopy assay of the transfer container, the blending container, funnel, cleaning tissues, and the transfer spillage catch paper.

\section{DU Mass}

The DU mass for each WRM is calculated as follows:

DU Mass $=\left(\right.$ Wt. $\mathrm{UO}_{2} \times \mathrm{U}$ assay $)-\mathrm{T} \& \mathrm{H}$ Loss $(\mathrm{g} \mathrm{U})$

where: Wt. $\mathrm{UO}_{2}$ is the weight of $\mathrm{UO}_{2}$ weighed out for the specific WRM.

$\mathrm{U}$ Assay is the mean value of the $\mathrm{U}$ content of the $\mathrm{UO}_{2}$ in $\mathrm{g} \mathrm{U} / \mathrm{g} \mathrm{UO}_{2}$.

T\&H Loss is the transfer and holdup loss as determined by the gamma spectroscopy assay of the transfer container, the blending container, funnel, cleaning tissues, and the transfer spillage catch paper.

\section{Alpha Activity}

The WRM alpha activity is the summation of the alpha activity contribution from each of the $\mathrm{Pu}, \mathrm{Am}$, and $\mathrm{U}$ isotopes in the WRM. To determine the alpha activity for each WRM, the alpha specific activity (alpha curies per gram $\mathrm{Pu}, \mathrm{Am}$, or $\mathrm{U}$ multiplied by the $\mathrm{g} \mathrm{Pu}, \mathrm{Am}$, or $\mathrm{U}$, respectively) for the nuclear material feed stock was calculated, effective 6/1/97 (see Table 26). Each WRM alpha activity was calculated by multiplying the WRM Pu, Am, or U isotopic mass times the appropriate factor (see Table 26). Appendix P lists the WRM's alpha specific activity for the initial date of 6/1/97, plus annual calculations from 6/1/97 through 6/1/2001. 


\begin{tabular}{|c|c|c|c|c|c|c|c|c|}
\hline Isotope & $\begin{array}{l}\text { At. Mass } \\
\text { (a.m.u.) }\end{array}$ & $\begin{array}{c}\text { At. Mass } \\
\text { Uncert. } \\
\text { (a.m.u.) }\end{array}$ & $\mathrm{T}_{1 / 2}(\mathrm{yrs})$ & $\begin{array}{c}\mathrm{T}_{1 / 2} \\
\text { Uncert. } \\
\text { (yrs) }\end{array}$ & $\mathrm{T}_{1 / 2}(\mathrm{~s})$ & $\begin{array}{c}\text { Total } \\
\text { Specific } \\
\text { Activity } \\
\text { (Ci/g) }\end{array}$ & $\begin{array}{c}\text { Branching } \\
\text { Ratio \% } \\
\text { Alpha }\end{array}$ & $\begin{array}{c}\text { Alpha } \\
\text { Activity } \\
\text { (Ci/g) }\end{array}$ \\
\hline $23 \hat{3} \mathrm{U}$ & 233.03963 & $3.006 \mathrm{E}-06$ & $1.592 E \div 05$ & $2.0 \mathrm{E} \div 02$ & $5.021 E \div 12$ & $9.644 \mathrm{E}-03$ & 100 & $9.644 \mathrm{E}-03$ \\
\hline $234 \mathrm{U}$ & 234.04095 & 2.147E-06 & $2.455 \mathrm{E} \div 05$ & $6.0 E \div 02$ & $7.742 \mathrm{E} \div 12$ & $6.227 \mathrm{E}-03$ & 100 & $6.227 \mathrm{E}-03$ \\
\hline $235 \mathrm{U}$ & 235.04392 & $2.147 E-06$ & $7.038 E \div 08$ & $5.0 E \div 05$ & $2.220 E \div 16$ & $2.163 \mathrm{E}-06$ & 100 & $2.163 \mathrm{E}-06$ \\
\hline $236 \mathrm{U}$ & 236.04556 & $2.040 \mathrm{E}-06$ & $2.342 E \div 07$ & $3.0 E \div 04$ & $7.386 E \div 14$ & $6.472 \mathrm{E}-05$ & 100 & 6.472E-05 \\
\hline $238 \mathrm{U}$ & 238.05078 & 2.147E-06 & $4.468 \mathrm{E} \div 09$ & $3.0 E \div 06$ & $1.409 E \div 17$ & $3.364 \mathrm{E}-07$ & 100 & $3.364 \mathrm{E}-07$ \\
\hline $238 \mathrm{Pu}$ & 238.04955 & $2.147 \mathrm{E}-06$ & $8.770 E \div 01$ & $3.0 \mathrm{E}-01$ & $2.766 E \div 09$ & $1.714 \mathrm{E} \div 01$ & 100 & $1.714 \mathrm{E} \div 01$ \\
\hline $239 \mathrm{Pu}$ & 239.05216 & 2.147E-06 & $2.411 E \div 04$ & $3.0 \mathrm{E} \div 01$ & $7.603 \mathrm{E} \div 11$ & 6.208E-02 & 100 & $6.208 \mathrm{E}-02$ \\
\hline $240 \mathrm{Pu}$ & 240.05381 & $2.040 \mathrm{E}-06$ & $6.563 \mathrm{E} \div 03$ & $7.0 E \div 00$ & $2.070 E \div 11$ & 2.271E-01 & 100 & $2.271 E-01$ \\
\hline $241 \mathrm{Pu}$ & 241.05685 & $2.040 \mathrm{E}-06$ & $1.435 \mathrm{E} \div 0 !$ & $1.0 \mathrm{E}-01$ & $4.525 E \div 08$ & $1.034 E \div 02$ & 0.0025 & $2.534 \mathrm{E}-03$ \\
\hline $242 \mathrm{Pu}$ & 242.05874 & 2.147E-06 & $3.733 \mathrm{E} E \div 05$ & $1.2 E \div 03$ & $1.177 \mathrm{E} \div 13$ & $3.960 \mathrm{E}-03$ & 100 & $3.960 \mathrm{E}-03$ \\
\hline $241 \mathrm{Am}$ & 241.05682 & 2.147E-06 & $4.322 E \div 02$ & $7.0 \mathrm{E}-0 !$ & $1.363 E \div 10$ & $3.434 \mathrm{E} \div 00$ & 100 & $3.434 \mathrm{E} \div 00$ \\
\hline Ref: & 4 & 4 & 5 & 5 & 5 & & 5 & \\
\hline
\end{tabular}

\section{B. Uncertainty Data and Calculations}

To meet the SOW (Appendix A) section 4.1 criteria for alpha activity and uncertainty, the following information was collected and data reduction performed.

\section{Weighing Uncertainty}

Random uncertainties for weighing were estimated from repeated weighings using a standard weight that most closely matched the weight of the target quantity of nuclear material. These weighings were performed before each set of same-target-mass nuclear material were weighed. The balance performance is summarized in Table 27 below and full control weighing data is listed in Appendix Q.

All but one of the standard weight sets used for control weighings were certified against NIST traceable weights. Copies of the certifications for the weight sets and analytical balances are also contained in Appendix $Q$. The observed control weight checks (Table 27) show no statistically significant bias from the certified mass. Hence, the WRM nuclear material weights were considered free of significant bias. 


\begin{tabular}{|c|c|c|c|c|}
\hline \multicolumn{5}{|c|}{ Diatomaceous Earth Weighings } \\
\hline \multicolumn{5}{|c|}{$\begin{array}{l}\text { Balance: } 13045 \text { (Certified) } \\
\text { Check Wts: Cenco Class S (Certified) }\end{array}$} \\
\hline Standard Wt. & Number of Measurements & Mean & Std. Dev. & \% Uncert. \\
\hline $30 \mathrm{~g}$ & 15 & 29.99853 & $5.16 \mathrm{E}-04$ & 0.009 \\
\hline $50 \mathrm{~g}$ & 3 & 50.001 & 0.002 & 0.014 \\
\hline $100 \mathrm{~g}$ & 20 & 99.993 & 0.004 & 0.018 \\
\hline \multicolumn{5}{|c|}{ Diatomaceous Earth Adjustment Weighings (DU WRMs) } \\
\hline \multicolumn{5}{|c|}{$\begin{array}{l}\text { Balance: } 015233 \text { (Certified) } \\
\text { Check Wts: Not Certified }\end{array}$} \\
\hline Standard Wt. & Number of Measurements & Mean & Std. Dev. & \% Uncert. \\
\hline $10 \mathrm{~g}$ & 15 & 10.00094 & $1.46 \mathrm{E}-05$ & 0.010 \\
\hline $200 \mathrm{~g}$ & 12 & 200.0143 & 4.93E-05 & 0.007 \\
\hline \multicolumn{5}{|c|}{ Pu Oxide and Am Oxide Weighings } \\
\hline \multicolumn{5}{|c|}{$\begin{array}{l}\text { Balance: } 013599 \text { (Certified) } \\
\text { Check Wts: } 15082 \text { (Certified) }\end{array}$} \\
\hline Standard Wt. & Number of Measurements & Mean & Std. Dev. & \% Uncert. \\
\hline $10 \mathrm{mg}$ & 5 & 0.01001 & $4.47 \mathrm{E}-06$ & 0.204 \\
\hline $50 \mathrm{mg}$ & 5 & 0.05002 & $5.48 \mathrm{E}-06$ & 0.062 \\
\hline $100 \mathrm{mg}$ & 10 & 0.10002 & $6.75 \mathrm{E}-06$ & 0.032 \\
\hline $\lg$ & 6 & 1.00001 & $5.16 \mathrm{E}-06$ & 0.003 \\
\hline $2 \mathrm{~g}$ & 10 & 2.00003 & $6.75 \mathrm{E}-06$ & 0.002 \\
\hline \multicolumn{5}{|c|}{ U Oxide Weighings } \\
\hline \multicolumn{5}{|c|}{$\begin{array}{l}\text { Balance: } 016834 \text { (Certified) } \\
\text { Check Wts: } 4482,3648 \text { (Certified) }\end{array}$} \\
\hline Standard Wt. & Number of Measurements & Mean & Std. Dev. & \% Uncert. \\
\hline $500 \mathrm{~g}$ & 41 & 499.954 & $5.91 \mathrm{E}-03$ & 0.012 \\
\hline $1 \mathrm{~kg}$ & 38 & 999.899 & $6.49 \mathrm{E}-03$ & 0.012 \\
\hline
\end{tabular}




\section{Assay Uncertainty}

\section{a. Pu Oxide}

$P u$ Assay. $\mathrm{Pu}$ assay values on five samples of the $\mathrm{PuO}_{2}$ starting material are listed in Table 1 . The assays were performed by coulometry. The individual assay values on the five samples can be found in Appendix $C$ and a copy of the certificate of the SRM used is in Appendix R.

The mean assay of the five samples was 0.87804 grams Pu/gram $\mathrm{PuO}_{2}$ (6/1/97). The observed standard deviation of the five assays was $0.00033(6 / 1 / 97)$. This value was deemed too small for the uncertainty to be associated with the plutonium assay, for two reasons. First, it does not reflect systematic errors that can effect an assay; and second, it probably does not capture anything other than short-term variation (repeatability). Because this $\mathrm{PuO}_{2}$ was made to be a standard material, extra care was taken during analyses to ensure homogeneity and representative sampling. Based on the analysis of SRMs, it was believed that a standard deviation value in the range 0.0006 to 0.0008 (0.07-0.09\%RSD) would be more reasonable. To be conservative, values at the high end of this interval were chosen. (Experience with propagation of variation (POV) has shown that in spite of efforts to include all sources of uncertainty, POV estimates are often understatements.) Since assays from five independent samples were averaged to get the 0.87804 value, the standard deviation of the average was taken as the standard deviation of SRM control data from a 2 year period divided by the square root of five. This was then multiplied by the student's $\mathrm{t}$ corresponding to $\mathrm{n}=5$ to get the $95 \%$ confidence bounds. This error was then propagated $(\mathrm{n}=5)$ to result in an overall uncertainty on the Pu assay of $0.036 \%$.

Am Assay. The ${ }^{241} \mathrm{Am}$ assay values for the five samples of $\mathrm{PuO}_{2}$ analyzed are listed in Table 3. The mean assay value of $939.1 \mu \mathrm{g}{ }^{241} \mathrm{Am} / \mathrm{g} \mathrm{PuO} \mathrm{Pu}_{2}(6 / 1 / 97)$ has a one random standard deviation uncertainty of $0.028 \%$. The isotope dilution mass spectrometric (IDMS) method uses a ${ }^{243}$ Am spike as an internal standard. Since no nationally traceable mass spectrometry (isotopic) standards exist for Am, the relative uncertainty of the ${ }^{243} \mathrm{Am}$ spike solution concentration has been conservatively estimated as $0.25 \%$ at $95 \%$ confidence. This estimate was made based on (1) the original calibration of the ${ }^{243} \mathrm{Am}$ spike using a high purity ${ }^{241} \mathrm{Am}$ material which itself was assayed by EDTA titration and (2) comparative studies on EURATOM samples (PIDIE) (Ref. 6). The $0.25 \%$ uncertainty serves as a systematic error, as applied to the ${ }^{241} \mathrm{Am}$ assay. The random error associated with the Am assay is $0.028 \%$ as obtained from multiple determinations (five by IDMS) of the Am content of the $\mathrm{PuO}_{2}$ (see Appendix C). The random error (0.028\%) is added after using the systematic error $(0.25 \%)$ to bound the expected value resulting in an overall error of $2.8 \mathrm{mg} / \mathrm{g} \mathrm{Pu}$. For details see Appendices $\mathrm{O}$ and $\mathrm{U}$.

\section{b. Am Oxide}

Am Assay. Four samples of Am oxide were assayed by IDMS. The mean assay value of $78.728 \% \mathrm{Am}(6 / 1 / 97)$ has a one random standard deviation uncertainty of $0.284 \%$. Again, since no nationally traceable mass spectrometry (isotopic) standards exist for Am, the relative uncertainty of the ${ }^{243} \mathrm{Am}$ spike solution concentration has been conservatively estimated as $0.25 \%$ at $95 \%$ confidence as described above. The random uncertainty associated with this assay is $0.28 \%$ as obtained from multiple determinations (four by DMS) of the Am content of the $\mathrm{AmO}_{2}$ (see Appendix C). The random error (0.28\%) is added after using the systematic error $(0.25 \%)$ to bound the expected value resulting in an overall error of $0.6 \%$. More details can be found in Appendices $\mathrm{O}$ and $\mathrm{U}$. 


\section{c. $U$ Oxide}

$U$ Assay. The uncertainty on the $U$ assay $(87.493 \% \mathrm{U})$ at the $95 \%$ confidence level is taken the standard deviation of the five assay values $(0.022)$ divided by the square root of five. This is then multiplied by the corresponding student's $\mathrm{t}$ value for $\mathrm{n}=5$ to obtain the $95 \%$ confidence bounds. The overall error on the $\mathrm{U}$ assay is calculated as $0.03 \%$.

\section{Isotopic Uncertainty}

a. Pu Oxide. The Total Evaporation Mass Spectrometric method used for the Pu isotopic distribution and ${ }^{241} \mathrm{Am}$ assay analyses is an absolute method with no known bias. The method was calibrated with the Plutonium Isotopic Standard NBS SRM 948 (Appendix R), which has a $\mathrm{Pu}$ distribution similar to the $\mathrm{PuO}_{2}$ starting material. The ${ }^{239} \mathrm{Pu}$ weight percents of the NBS SRM 948 and the $\mathrm{PuO}_{2}$ are $91.8284 \%$ and $93.7811 \%$, respectively (on 6/1/97).

The five samples analyzed for total plutonium were also analyzed for Pu isotopic fraction using Thermal Ionization Mass Spectrometry. The summary statistics provide estimates of isotopic standard deviations that were 25 to $67 \%$ less than the standard deviations obtained on the measurement control standard (NBS 948), measured over a four month period immediately prior to the date of the $\mathrm{PuO}_{2}$ isotopic measurements (Appendix S). To be conservative, it was decided to use the isotopic averages of the five samples and the standard deviations calculated from the measurement control data. To obtain the standard deviations of the averages, the measurement control standard deviations were divided by the square root of five, the sample size. These estimates of uncertainties for the stated $\mathrm{PuO}_{2}$ isotope weight percents are then multiplied by the corresponding student's t value for $n=5$ to provide $95 \%$ confidence bounds, and are listed in Table 28.

\begin{tabular}{|c|c|c|c|c|c|}
\hline \hline \multicolumn{6}{|c|}{ Table 28. Upper Bound Error Estimates for Mass Spectrometric Pu Isotopic Distribution. } \\
\hline Isotope & 238Pu & 239Pu & 240Pu & 241 Pu & 242 Pu \\
\hline Mean & 0.0143 & 93.7811 & 5.9448 & 0.2038 & 0.0560 \\
\hline Std. Dev & 0.0014 & 0.0022 & 0.0008 & 0.0015 & 0.0003 \\
\hline 95\% C.B. & $+/-0.0018$ & $+/-0.0028$ & $+/-0.0010$ & $+/-0.0019$ & $+/-0.0003$ \\
\hline \hline
\end{tabular}

b. U Oxide. The Total Evaporation Mass Spectrometric method used for the U isotopic distribution is an absolute method with no known bias. The method was calibrated with the Uranium Isotopic Standard NBS SRM U005 (Appendix R), which has a U distribution similar to the $\mathrm{UO}_{2}$ starting material. The ${ }^{238} \mathrm{U}$ weight percents of the NBS SRM U005 and the $\mathrm{UO}_{2}$ are $99.504 \%$ and $99.806 \%$, respectively (on 6/1/97).

The five samples analyzed for total uranium were also analyzed for $U$ isotopic fraction using Thermal Ionization Mass Spectrometry. The summary statistics provide estimates of isotopic standard deviations that were generally similar to the standard deviations obtained on the measurement control standard (NBS U005), measured over a 1.5 year period immediately prior to the date of the $\mathrm{UO}_{2}$ isotopic measurements (Appendix S). It was decided to use the isotopic averages of the five samples along with their standard deviations. These estimates of uncertainties for the stated $\mathrm{UO}_{2}$ isotope weight are divided by the square root of five and then multiplied by the 
corresponding student's $\mathrm{t}$ value for $\mathrm{n}=5$ to provide the $95 \%$ confidence bound and are listed in Table 29.

\begin{tabular}{|l|c|c|c|c|c|}
\hline \hline \multicolumn{6}{|c|}{ Table 29. Upper Bound Error Estimates for Mass Spectrometric U Isotopic Distribution. } \\
\hline \multicolumn{1}{|c|}{ Isotope } & ${ }^{\mathbf{2 3 3}} \mathbf{U}$ & $\mathbf{2 3 4}_{\mathbf{U}}$ & ${ }^{235} \mathbf{U}$ & ${ }^{236} \mathbf{U}$ & $\mathbf{2 3 8} \mathbf{U}$ \\
\hline Mean & 0.0000 & 0.0008 & 0.1902 & 0.0034 & 99.8057 \\
\hline Std. Dev & 0.0000 & 0.0004 & 0.0004 & 0.0003 & 0.0005 \\
\hline $95 \%$ C.B. & $+/-0.0000$ & $+/-0.0005$ & $+/-0.0004$ & $+/-0.0004$ & $+/-0.007$ \\
\hline \hline
\end{tabular}

\section{Transfer and Hold-Up Loss}

Transfer and holdup loss quantities were measured by counting the $59.5 \mathrm{keV}$ peak of the ${ }^{241} \mathrm{Am}$ (IAP WRMs) and the $63.32 \mathrm{keV}$ peak of ${ }^{234} \mathrm{Th}$ (DU WRMs) contained in the funnels, cleaning tissues, and spillage catch paper used to transfer the blend material into the stainless steel cylinder. For the IAP WRMs, since all of the blend produced was incorporated into the steel cylinders, the blending bottle was also counted to determine the amount of $\mathrm{Am}$ and $\mathrm{Pu}$ that was adhered to the blending bottle. For the DU WRMs, The blending bottle was not counted (except for CEP011). This is because there was always a portion of the blend that was not incorporated into the WRMs (except for CEP011 in which all of the blend was incorporated into the WRM), and this excess amount of blend was determined gravimetrically and the amount of $U$ in the WRM was adjusted accordingly. These loss corrections were relatively small; the largest loss was $0.063 \%$ for WRM CEP003.

Uncertainty terms for these waste item measurements include the preparation of the Am and Th standards, the gamma spectroscopy instrumentation calibration, and the uncertainty associated with the counting of each waste item. From a positional/rotational study, the uncertainty in the counts appeared to be the dominating term, especially for those items with the smallest amount of $\mathrm{Pu}$.

The uncertainty associated with the gamma spectroscopy counter calibration includes uncertainty in the standard value used for calibration, uncertainty in the calibration curve shape, and uncertainty in the calibration short-term variability. From prior studies on pipette calibration, weighing, and the calibration curve fit, the calibration short-term random variability was estimated to be less than $1.6 \%$. The relative effect of the uncertainty on the calibration curve shape and the standard value depends on the count rate of the waste item, and was assumed to be a systematic error. Both the random variation and the systematic error are thought to act as a bias effect on the final calculation of the grams of ${ }^{241} \mathrm{Am}, \mathrm{Pu}$, or $\mathrm{U}$ in the WRM.

The WRM waste item uncertainty terms used for calculating the final $\mathrm{Pu}, \mathrm{Am}$, and $\mathrm{U}$ content, and alpha activity for each WRM are listed in Appendix K. Appendix T includes a detailed description and discussion of the waste item uncertainty terms.

\section{Alpha Activity Uncertainty}

Alpha half-life values for converting $\mathrm{Pu}, \mathrm{Am}$, and $\mathrm{U}$ isotope quantities in the WRMs to alpha activity are those presented in Table 26. The total alpha activity for the various WRMs has two uncertainty components, the alpha half-life and the isotopic abundance. These uncertainty terms 
are incorporated into the total uncertainty associated with the total alpha activity of each WRM (see Appendix O).

\section{Combined Uncertainty for Mass and Alpha Activity}

Standard uncertainty estimation methods were used to calculate individual random and systematic uncertainties for $\mathrm{Pu}, \mathrm{PuO}_{2}, \mathrm{Am}, \mathrm{AmO}_{2}, \mathrm{U}, \mathrm{UO}_{2}$ mass, total alpha activity, and $\mathrm{Pu}$ and $\mathrm{U}$ isotope ratios. POV techniques were used to appropriately combine the uncertainties for all the components used to calculate nuclear quantities. Where well-supported estimates on uncertainties for components were not available, a conservative approach was taken to use values that are believed to exceed the actual values. Therefore the $95 \%$ confidence intervals (bounds) presented in this plan and listed on the WRM Certificates are believed to be larger than they would be if exhaustive data was available for every uncertainty component.

Identified in Table 30 are uncertainty components included in estimates of the $95 \%$ confidence interval for the nuclear quantities listed on the WRM Certificates.

Appendix $U$ presents all the equations used to estimate the $95 \%$ confidence limits for the quantities listed in Table 30. Appendix $U$ provides values for all the parameters used in the propagated uncertainty calculations listed in Appendix $\mathrm{O}$.

\section{WRM Certification}

The WRMs are formally certified by a combination of the multiple analyses characterizing the $\mathrm{PuO}_{2}$ and DE starting materials, the calibration and check of measurement methods with Certified or Standard Reference Materials, the Project Quality Assurance Plans, the numerous signed and dated QA forms used to document inspections and completion of fabrication steps, the review of calculations and critical documents, the statistical analysis of data using standard

\begin{tabular}{|c|c|c|c|c|c|c|}
\hline \multicolumn{7}{|c|}{ Source of Uncertainty } \\
\hline & Weighing & $\begin{array}{c}\mathbf{P u}, \mathbf{A m}, \\
\text { or } \mathbf{U} \\
\text { Assay }\end{array}$ & $\begin{array}{c}\text { Pu or U } \\
\text { Isotopic } \\
\text { Ratio }\end{array}$ & Transfer & Homogeneity & Counting \\
\hline $\mathrm{PuO}_{2}$ Mass & $X$ & & & & & \\
\hline Pu Mass & $\mathrm{X}$ & $\mathrm{X}$ & & $\mathrm{X}$ & & $\mathrm{X}$ \\
\hline Pu Isotopic & & & $\mathrm{X}$ & & & \\
\hline $\mathrm{AmO}_{2}$ Mass & $\mathrm{X}$ & & & & & \\
\hline Am Mass & $\mathrm{X}$ & $\mathrm{X}$ & & $X$ & & $\mathrm{X}$ \\
\hline $\mathrm{UO}_{2}$ Mass & $X$ & & & & $\mathrm{X}$ & \\
\hline U Mass & $\mathrm{X}$ & $\mathrm{X}$ & & $\mathrm{X}$ & $\mathrm{X}$ & $\mathrm{X}$ \\
\hline U Isotopic & & & $X$ & & $\mathrm{X}$ & \\
\hline Alpha Activity & $\mathrm{X}$ & $X$ & $X$ & $X$ & $\mathrm{X}$ & $\mathrm{X}$ \\
\hline
\end{tabular}


data reduction methods, the qualification and training of persons responsible for analysis and fabrication operations, and the formal control and filing of documents. To provide a single document attesting to the formal certification of the 16 WRMs, Certificates of Content and Traceability for each WRM were prepared, signed, and dated by the LANL Analytical Chemistry (NMT-1) Group Leader, Bill J. McKerley and the LANL Project Leader for NDA CEP WRM production, Robert S. Marshall. Copies of the WRM Certificates are included as Appendix V.

The reduction of $\mathrm{PuO}_{2}, \mathrm{AmO}_{2}$, and $\mathrm{UO}_{2}$ characterization, mass transfer data, and control data generated during the production of the WRMs produces $\mathrm{Pu}, \mathrm{Am}$, and $\mathrm{U}$ isotope mass and alpha activity, as well as uncertainty data required for the WRM certification. These data and calculations are formally recorded, signed and stored in the NDA CEP WRM file. Certification also requires that the critical characterization measurements ( $\mathrm{Pu}$ assay, $\mathrm{Pu}$ isotopic distribution, $\mathrm{Am}$ assay, $\mathrm{PuO}_{2}, \mathrm{AmO}_{2}$, and $\mathrm{UO}_{2}$ weighings, $\mathrm{U}$ assay, and $\mathrm{U}$ isotopic distribution) be traceable to nationally recognized reference materials. This traceability has been demonstrated by identifying these reference materials in this production plan (Appendix $\mathrm{R}$ ) and in the analytical procedures used. In addition, the DOE site that received WRMs also received Certificates of Control and Traceability for those WRMs. Copies of these reference materials' certificates are retained in the NDA CEP WRM reference file. To the highest degree possible, traceability to nationally recognized reference materials was established for less critical parameters, including particle size analysis, impurity analyses, isotope half-life and alpha specific activity, and helium leak check. Certificates or statements addressing traceability are retained in the NDA CEP WRM file for the less critical parameters.

\section{REFERENCES}

1. Marshall, "NDA PDP Working Reference Materials Production Plan-Phase I," Los Alamos National Laboratory document LA-UR-96-2277, (1996).

2. Callis \& Abernathy, High-Precision Isotopic Analyses of Uranium and Plutonium by Total Sample Volatilization and Signal Integration., International Journal of Mass Spectrometry and Ion Processes, 103, pp. 93-105, (1991).

3. Duckworth, Borshick \& Smith, Analysis of Soils by Glow-Discharge Mass-Spectrometry, Journal of Analytical Atomic Spectrometry, Vol. 8, pp. 875-879, (1993).

4. Audi \& Wapstra, The 1995 Update to the Atomic Mass Evaluation, Nuclear Physics, A595, p. $409,(1995)$.

5. Firestone, Table of Isotopes, Vol. II, $8^{\text {th }}$ ed., John Wiley \& Sons, New York, (1996).

6. Chauvenet \& Morel, "Intercomparaison des mesures de Composition Isotopique du Plutonium par Spectrometrie X et Gamma Resultats de L'action 'Pidie,' Raport Final," report CEA-R-5582. 


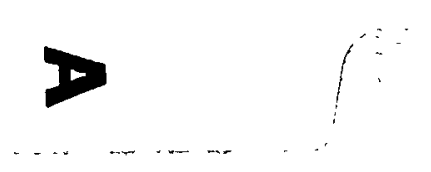




\title{
Statement of Work
}

\author{
Idaho National Engineering and Environmental Laboratory \\ Nondestructive Waste Assay \\ Capability Evaluation Project \\ Working Reference Material \\ Production \\ Increased Am/Pu and DU WRMs
}

Revision 1.15

July 24,1997

1. Introduction

Non-destructive waste assay (NDA) methods are used in the National TRU Waste Characterization Program to determine the mass and associated alpha activity of waste entrained radionuclides. The capability and performance of waste NDA systems employed in the Program must comply with requirements as set forth in the TRU Waste Characterization Program Quality Assurance Program Plan (QAPP) ${ }^{1}$. As part of the overall effort to assess waste NDA system utility and capability, the Idaho National Engineering and Environmental Laboratory (INEEL) Mixed Waste Focus Area (MWFA) has developed a plan to acquire capability/performance data on systems proposed for nondestructive assay characterization purposes. Such systems include those purveyed by commercial entities as well as Department of Energy (DOE) developed systems. The INEEL waste NDA system Capability Evaluation Project (CEP), scheduled to commence in August of 1997, is not designed to certify waste NDA systems per QAPP waste NDA requirements. Rather the goal of the CEP is to acquire objective data/information useful for determining the potential utility of a given system benchmarked to QAPP quality assurance objectives for specified waste type subpopulations.

The CEP test sequence subjects all participants to identical test sample configurations thereby allowing an assessment of NDA system performance relative to a common basis. The common basis is derived from test sample configurations comprised of surrogate and/or actual 


\section{Statement of Work \\ INEEL NDA Capability Evaluation Project Increased Am/Pu \& DU WRM Production}

Revision 1.15

July 24, 1997

Page 2 of 17

waste containers selected from the inventory at the INEEL Radioactive Waste Management Complex (RWMC). The surrogates are specified, and the actual RWMC waste from drums are selected, to test fundamental waste NDA system properties and performance relative to actual waste form attributes.

A fraction of the test samples are derived from surrogate waste matrices combined with known quantities and distributions of radioactive material. Due to limited radioactive standard set present at the INEEI RWMC, additional standards are required to meet the objective of the INEEL Capability Evaluation Project. These standards, hereafter referred to as Working Reference Materials (WRMs), are specified to complement both existing and scheduled fabrication of standards made available through the Nondestructive Assay Performance Demonstration Program².

\section{Objectives}

The objective of this work statement is to support implementation of the INEEL Nondestructive Waste Assay CEP project through the production of an Increased $\mathrm{Am} / \mathrm{Pu}$ mass ratio (IAP) and depleted uranium (DU) WRM set. The CEP IAP/DU WRM set provides radioactive material standards for use in combination with 55 gallon drum waste matrix surrogates. The CEP IAP/DU WRM set allows an assessment of system capability and performance specific to waste types/configurations containing increased amounts of ${ }^{241} \mathrm{Am}$ relative to weapons grade $\mathrm{Pu}$, (i.e. ${ }^{241} \mathrm{Am} / W G$ Pu mass ratios greater than $0.2 \%$ ), wastes containing principally ${ }^{241} \mathrm{Am}$, and wastes containing $\mathrm{DU}$ of varying weight proportions relative to other radionuclides. The specifications for the enhanced ratios and americium masses used to fabricate the CEP IAP/DU WRM set are derived from knowledge of radionuclidic compositions of actual waste forms. The CEP IAP/DU WRM set can be utilized in combination with other NDA PDP WRM types, e.g. NDA PDP Phase I/II.A weapons grade specification WRMs to achieve a variety of source configurations thereby enhancing the assessment variable range of the INEEL CEP program.

\section{Scope}

A total of sixteen CEP IAP/DU WRMs are to be produced to achieve the objectives of and support implementation of the INEEL Capability Evaluation Project. Ten of the CEP WRMs are of an IAP composition 
Statement of Work
INEEL NDA Capability Evaluation Project
Increased Am/Pu \& DU WRM Production

Revision 1.15

July 24, 1997

Page 3 of 17

designed to complement the WRM attributes specified for the NDA PDP Phase III.A production campaign. The remaining six CEP WRMs are of a DU composition provided to assess system capability and performance for waste forms which contain radionuclidic compositions comprised of DU in various combinations with other radionuclides and waste forms of a predominantly DU composition.

The CEP IAP/DU WRM production techniques and procedures are analogous to those prepared and employed in the NDA PDP Phase I WRM set in that the principle attribute varied for the CEP IAP Project WRM set is the addition of ${ }^{241} \mathrm{Am}$ to WG Pu. The DU WRMs are also similar to the Phase I WRMs in that the principle attribute varied is the type of the radioactive material. To this extent the CEP IAP/DU WRM production specifications and task outline is similar in content and structure to the PDP WRM Phase I statement of work ${ }^{3}$.

A fundamental requirement of all phases of the CEP IAP/DU WRM production project driving scope definition and the associated project task specification, is the need to ensure the completed WRMs have pedigrees specifying a primary attribute traceable to a recognized reference base. The precision and accuracy of the attribute value is to be commensurate with the intended application, i.e. qualification of measurement methods/systems. To this end all pertinent aspects of the production of the CEP IAP/DU WRM set requires carefully specified quality assurance and control measures to ensure data supporting attribute quantification, uncertainty and traceability are produced, analyzed and documented in an auditable form.

The overall project scope is delineated as a set of general tasks as follows:

(1) review CEP IAP/DU WRM data quality objectives,

(2) production of the Phase CEP IAP/DU WRMs,

(3) assignment of a CEP IAP/DU WRM mass/alpha activity values and uncertainties,

(4) documentation of the CEP IAP/DU WRM production plan,

(5) preparation of CEP IAP/DU WRM content and traceability certificates,

(6) waste NDA physics support/review of fabrication process and resulting CEP IAP/DU WRMS,

(7) packaging/transportation of the CEP IAP/DU WRMs to the INEL RWMC facility. 
Statement of Work

INEEL NDA Capability Evaluation Project Increased Am/Pu \& DU WRM Production

Revision 1.15

July 24,1997

Page 4 of 17

The capability to produce the CEP IAP/DU WRM set requires expertise in the area of waste NDA expert and the objectives of the capability evaluation project. Successful completion of the project necessitates that an individuals of this capacity interface with the LANI CST-8 technical production team as issues regarding waste NDA measurements arise. The scope of work for this preselected complement of personnel and resources is outlined in the general task tabulation above.

LMITCO will specify WRM data quality objectives and is responsible for coordination, technical/managerial review of subcontractor performed activities, and completion of the indicated tasks.

\section{Technical Tasks}

The technical tasks address the completion of the sixteen CEP IAP/DU WRM set. The technical tasks are dependent on the data quality objectives (DQOs) specified for the project. For this reason the DQOs are presented first. followed by the task breakdown.

Data Quality Objectives

4.1 Produce sixteen CEP IAP/DU WRMs of the following quantity/mass denominations:

IAP WRMS

4.1.a) two WRMs with an ${ }^{241} \mathrm{Am}$ mass in the range of $(8$ - 11) milligrams combined with WG $\mathrm{Pu}$ in the mass range of $(60$ - 110) milligrams,

4.1.b) two WRMs with an ${ }^{241}$ Am mass in the range of (45 - 55) milligrams combined with WG Pu in the mass range of $(1.50-2.50)$ grams,

4.1.c) two WRMs with an ${ }^{241} \mathrm{Am}$ mass in the range of (85 - 95) milligrams combined with WG $\mathrm{Pu}$ in the mass range of $(1.50-2.50)$ grams,

4.1.d) two WRMs with an ${ }^{241} \mathrm{Am}$ mass in the range of (45 - 55) milligrams combined with WG Pu in the mass range of $(0.3-0.5)$ grams,

4.1.e) two WRMs with an ${ }^{241} \mathrm{Am}$ mass in the range of (95 - 105) milligrams. 
Statement of Work

INEEL NDA Capability Evaluation Project Increased Am/Pu \& DU WRM Production

Revision 1.15

July 24, 1997

Page 5 of 17

Note: maximum allowable total uncertainty at the $95 \%$ confidence level per CEP IAP WRM as specified in items 4.1 .b through 4.1 .e is $\pm 0.5 \%$ in terms of WRM alpha activity. Due to limitations in mass determinations for $4.1 . \mathrm{a}{ }^{241} \mathrm{Am}$ and $\mathrm{Pu}$ components of the WRM the allowable alpha activity uncertainty is relaxed to $\pm 0.75 \%$ at the $95 \%$ confidence level.

DU WRMS
4.I.f)
one WRM with a DU mass in the range of $(490$
$4.1 .9)$ - 510) grams,
4.1.h)
one WRM with a DU mass in the range of $(850$ - 900) grams,
four WRM with a DU mass in the range of $(925$ - 1000) grams.

Note: maximum allowable total uncertainty at the $95 \%$ confidence level per DU WRM as specified in items 4.1.f through $4.1 . \mathrm{h}$ is $\pm 0.5 \%$ in terms of WRM DU mass.

4.2 Item (4.1) criteria is provided to specify an acceptable range within which a suitable ${ }^{241} \mathrm{Am}$, WG $\mathrm{Pu}$ and $\mathrm{DU}$ mass value can be realized in consideration of production procedures. The ${ }^{241} \mathrm{Am}$, WG $\mathrm{Pu}$ and DU mass ranges are not to be construed as the allowable uncertainty per IAP or DU WRM.

4.3 For Project purposes, the CEP IAP/DU WRMs must be traceable to a certificate or other documentation that is issued by a technically competent certifying body such as the New

Brunswick Laboratory. The waste NDA CEP project need is for traceable standards in accordance with the reference material hierarchy level classified as WRMs. The WRM level specification is based on the intended application, i.e., qualification of a measurement method. ${ }^{4}$ The IAP/DU WRMs are not intended to be used for calibration purposes. Hence all aspects of the planning, preparation, fabrication, packaging, characterization, statistical analyses, and documentation shall be consistent with the rigor and completeness typical of establishing and demonstrating traceability for WRMs. It is the responsibility of IMITCO to ensure that project production procedures, quality assurance measures, and documentation are adequate to demonstrate that degree of WRM credibility needed to support 
Statement of Work

INEEL NDA Capability Evaluation Project Increased Am/Pu \& DU WRM Production

Revision 1.15

July 24,1997

Page 6 of 17

the intended application, measurement system qualification.

\section{Project Tasks/Requirements}

Project tasks/requirements/documentation to be performed by the LANL CST-8 group are largely based on techniques developed and approved for the Phase I PDP WRM production project. The CEP IAP/DU WRM Production Plan will detail the indicated tasks and fully document the embedded activities and derived data. Where indicated, documented procedures or descriptions necessary to sufficiently detail the indicated tasks must be prepared and submitted by LANL to LMITCO for review and concurrence prior to commencement of the activity.

5.1 General - Establish in advance required resources and personnel to complete the production and delivery of the CEP IAP/DU WRMs in accordance with the specified completion date; July 21, 1997. Ensure contingency plans have been considered in the event of unanticipated delays.

Notification of IMITCO of the occurrence of delays impacting the completion date is required. Production unknowns and open-ended technical issues to be identified and resolved by production team prior to commencement of fabrication activities.

5.2 Prepare and submit a short form project quality assurance plan in accordance with requirements as provided by LMITCO.

5.3 Prepare and submit a short form project management plan, requires IMITCO concurrence.

5.4 Prepare and submit documentation control and records management plan. Records repository at CEP IAP/DU WRM project completion is the MWFA at IMITCO.

5.5 Develop CEP IAP/DU WRM Production Plan complete with all ${ }^{241} \mathrm{Am}, \mathrm{Pu}$ and DU feedstock characterization, chemical and physical manipulations to support the process of feedstock fixation/encapsulation, completed assembly characterization and documentation/quality control measures. The production plan shall accommodate the following IAP/DU WRM material attribute requirements: 
Statement of Work INEEL NDA Capability Evaluation Project Increased Am/Pu \& DU WRM Production

Revision 1.15

July 24, 1997

Page 7 of 17

\section{WRM Attribute Requirements}

\section{IAP WRMS}

5.6 Isotopic/radionuclidic composition of the Pu feedstock component of the IAP WRM at the time of incorporation into the WRM must be within the following nominal ranges:

Table 1. Allowable Pu Isotopic/nuclidic Composition Range

\begin{tabular}{|c|c|}
\hline Radionuclide & Mass fraction range (\%) \\
\hline${ }^{238} \mathrm{Pu}$ & $0.01-0.02$ \\
\hline${ }^{239} \mathrm{Pu}$ & $93.0-94.0$ \\
\hline${ }^{240} \mathrm{Pu}$ & $5.0-6.0$ \\
\hline${ }^{241} \mathrm{Pu}$ & $0.1-0.25$ \\
\hline${ }^{242} \mathrm{Pu}$ & $0.02-0.06$ \\
\hline${ }^{241} \mathrm{Am}$ & $0.085-0.25$ \\
\hline
\end{tabular}

5.7 Chemical composition of $\mathrm{Pu}$ feedstock to be $\mathrm{PuO}_{2}$.

Certification of elemental impurity concentration must be provided and consistent with Table 2 limits below. Other impurity elements will be considered on a case by case basis.

Table 2. Allowable $\mathrm{PuO}_{2}$ Feedstock Impurity Iimits

\begin{tabular}{|c|c|}
\hline Impurity Element & Concentration Limit (ppm) \\
\hline \hline $\mathrm{Fe}+\mathrm{Ni}$ & $<400$ \\
\hline $\mathrm{Be}$ & $<2$ \\
\hline $\mathrm{Mg}$ & $<500$ \\
\hline $\mathrm{Ca}$ & $<1000$ \\
\hline $\mathrm{Np}$ & $<100$ \\
\hline $\mathrm{Th}$ & $<50$ \\
\hline
\end{tabular}


Statement of Work

INEEL NDA Capability Evaluation Project Increased Am/Pu \& DU WRM Production

Revision 1.15 July 24, 1997

Page 8 of 17

\begin{tabular}{|c|c|}
\hline $\mathrm{Ga}$ & $<25$ \\
\hline $\mathrm{F}$ & $<85$ \\
\hline $\mathrm{Cl}$ & $<70$ \\
\hline $\mathrm{Si}$ & $<300$ \\
\hline $\mathrm{Al}$ & $<50$ \\
\hline $\mathrm{U}$ & $<500$ \\
\hline${ }^{244} \mathrm{Cm}$ & $<1$ \\
\hline${ }^{252} \mathrm{Cf}$ & $<0.5$ \\
\hline $\begin{array}{c}\text { any significant } \\
\text { individual remaining } \\
\text { impurity }\end{array}$ & $<100$ \\
\hline
\end{tabular}

5.8 WG $\mathrm{PuO}_{2}$ physical form to be particulate with a particle size distribution mean less than 100 microns and no more than $2 \%$ of the $\mathrm{PuO}_{2}$ particle population exceeding 250 microns in diameter. An evaluation of the $\mathrm{PuO}_{2}$ particle size data is required prior to continuance of the fabrication process. ( $Q A$ documentation required).

5.9 Isotopic/radionuclidic composition of the Am feedstock component of the IAP WRM at the time of incorporation into the WRM must be within the following nominal ranges:

Table 3. Allowable Am Isotopic/nuclidic Composition Range

\begin{tabular}{|c|c|}
\hline Radionuclide & Mass fraction range $(\%)$ \\
\hline \hline${ }^{241} \mathrm{Am}$ & $99.9-100$ \\
\hline${ }^{242} \mathrm{Am}$ & $<0.001$ \\
\hline${ }^{243} \mathrm{Am}$ & $<0.001$ \\
\hline
\end{tabular}

5.10 Pu component of Am feedstock to be accounted for in complying with WRM data quality objective specifications 
Statement of Work INEEL NDA Capability Evaluation Project increased Am/Pu \& DU WRM Production Revision 1.15

July 24,1997

Page 9 of 17

item 4.1 .

5.11 Chemical composition of Am feedstock to be Am oxide. Certification of elemental impurity concentration must be provided and consistent with Table 4 limits below. Other impurity elements will be considered on a case by case basis.

Table 4. Allowable Am Oxide Feedstock Impurity Limits

\begin{tabular}{|c|c|}
\hline Impurity Element & Concentration Limit (ppm) \\
\hline $\mathrm{Ee}+\mathrm{Ni}$ & $<400$ \\
\hline $\mathrm{Be}$ & $<2$ \\
\hline $\mathrm{Mg}$ & $<500$ \\
\hline $\mathrm{Ca}$ & $<1500$ \\
\hline $\mathrm{Np}$ & $N / A^{1}$ \\
\hline Th & $<50$ \\
\hline $\mathrm{Ga}$ & $<25$ \\
\hline $\mathrm{F}$ & $<85$ \\
\hline $\mathrm{Cl}$ & $<70$ \\
\hline $\mathrm{Si}$ & $<300$ \\
\hline $\mathrm{Al}$ & $<150$ \\
\hline $\mathrm{U}$ & $<500$ \\
\hline${ }^{244} \mathrm{Cm}$ & $<1$ \\
\hline${ }^{252} \mathrm{Cf}$ & $<0.5$ \\
\hline $\begin{array}{c}\text { any significant } \\
\text { individual remaining } \\
\text { impurity }\end{array}$ & $<100$ \\
\hline
\end{tabular}

1 - the fraction of the total alpha activity in any given WRM

attributable to $\mathrm{Np}^{237}$ is on the order of $10^{-6}$ and hence does not affect performance assessment considerations; additionally its concentration varies with time as it is a daughter of $\mathrm{Am}^{241}$ making it difficult to specify an impurity limit on concentration. 
Statement of Work

INEEL NDA Capability Evaluation Project Increased Am/Pu \& DU WRM Production

Revision 1.15

July 24, 1997

Page 10 of 17

5.12 Am oxide physical form to be particulate with no more than $2 \%$ of the Am oxide particle population exceeding 250 microns in diameter. This specification may be met by sieving the Am oxide through an appropriate sized sieve.

5.13 The Am/Pu diluent is to be comprised of diatomaceous earth of the same quality and composition as utilized in the fabrication of the NDA PDP Phase II.A WRM set.

5.14 Uniformity of the IAP WRM Am/Pu diluent mixture throughout inner cylinder stainless steel encapsulation volume to be within $\pm 2.5 \%$ of mean concentration for any given $30 \mathrm{~cm}^{3}$ volume for each mass range delineated in item 4.1. (QA checkpoint)

\section{DU WRMS}

5.15 Isotopic/radionuclidic composition of the DU feedstock at the time of incorporation into the WRM must be within the following nominal ranges:

Table 5. Allowable DU Isotopic/nuclidic Composition Range

\begin{tabular}{|c|c|}
\hline Radionuclide & Mass fraction range $(\%)$ \\
\hline \hline${ }^{234} \mathrm{U}$ & $0.000-0.001$ \\
\hline${ }^{235} \mathrm{U}$ & $0.10-0.30$ \\
\hline${ }^{236} \mathrm{U}$ & $0.001-0.006$ \\
\hline${ }^{238} \mathrm{U}$ & $99.6-99.2$ \\
\hline
\end{tabular}

5.16 Chemical composition of DU feedstock to be $U$ oxide. Certification of elemental impurity concentration must be provided and consistent with Table 6 limits below. Other impurity elements will be considered on a case by case basis.

Table 6. Allowable DU Oxide Feedstock Impurity Limits

\begin{tabular}{|c|c|}
\hline Impurity Element & Concentration Limit (ppm) \\
\hline $\mathrm{Al}$ & $<200$ \\
\hline
\end{tabular}


Statement of Work INEEL NDA Capability Evaluation Project Increased Am/Pu \& DU WRM Production

Revision 1.15 July 24, 1997

Page 11 of 17

\begin{tabular}{|c|c||}
\hline $\mathrm{B}$ & $<350$ \\
\hline $\mathrm{Be}$ & $<1$ \\
\hline $\mathrm{Ca}$ & $<200$ \\
\hline $\mathrm{Cl}$ & $<70$ \\
\hline $\mathrm{F}$ & $<85$ \\
\hline $\mathrm{Cd}$ & $<2$ \\
\hline $\mathrm{Fe}+\mathrm{Ni}+\mathrm{Cr}$ & $<250$ \\
\hline $\mathrm{Li}$ & $<1$ \\
\hline $\mathrm{Mg}$ & $<50$ \\
\hline $\mathrm{Na}$ & $<200$ \\
\hline $\mathrm{Si}$ & $<300$ \\
\hline $\mathrm{Pb}$ & $<20$ \\
\hline $\mathrm{W}$ & $<350$ \\
\hline $\mathrm{V}$ & $<100$ \\
\hline${ }^{244} \mathrm{Cm}$ & $<1$ \\
\hline${ }^{252} \mathrm{Cf}$ & $<0.5$ \\
\hline any significant & $<100$ \\
\hline individual remaining & \\
\hline impurity & \\
\hline
\end{tabular}

5.17 DU oxide physical form to be particulate with a particle size distribution mean less than 100 microns and no more than $2 \%$ of the DU oxide particle population exceeding 250 microns in diameter. An evaluation of the DU oxide particle size data is required prior to continuance of the fabrication process. (QA documentation required).

5.18 The DU oxide diluent is to be comprised of diatomaceous earth of the same quality and composition as utilized in the fabrication of the NDA PDP Phase II.A WRM set. 
Statement of Work

INEEL NDA Capability Evaluation Project Increased Am/Pu \& DU WRM Production

Revision 1.15

July 24, 1997

Page 12 of 17

5.19 Uniformity of the DU oxide/diluent mixture throughout inner cylinder stainless steel encapsulation volume to be within $\pm 5.0 \%$ of mean concentration for any given $30 \mathrm{~cm}^{3}$ volume for each mass range delineated in item 4.I. (QA checkpoint)

\section{WRM Production Requirements}

Prior to commencing the production of the as specified IAP WRMs, scoping studies regarding WRM configuration gas generation and $(\alpha, n)$ reaction yields are required. Gas generation data can be acquired through computational studies and from existing studies where an appropriate margin of safety is represented in the data relative to the IAP WRM configuration. The gas generation data shall be reviewed by LMITCO and concurrence acquired before commencing production. The data may require supplemental experimental data to conclusively ensure gas generation does not compromise the value and safety of the IAP WRMs. Such being the case, IANL CST-8 will collaborate with the IMITCO technical representative to devise an appropriate test.

In addition to gas generation considerations, the IAP WRM design may complicate the the CEP NDA capability evaluation process due to the potential for high $(\alpha, n)$ yields resulting from the blend process. In order to assess the magnitude of this effect in the specified WRM configuration, measurements of a test blend is required. A technical review of the resulting measurement data is required. Based on the results of such measurements, modification to the radioactive $\mathrm{Am} / \mathrm{Pu}$ substrate may be required in some of the IAP WRM mass ranges.

The following is the general production sequence with specific quality assurance or test case holdpoints for technical review.

5.20 Process $\mathrm{PuO}_{2}$, Am oxide and DU oxide feedstock as appropriate and characterize isotopic, chemical, and elemental impurity homogeneity throughout the batch. Accepted methods of establishing these parameters for $\mathrm{PuO}_{2}$ and $\mathrm{Am}$ oxide are as determined during the Phase I WRM production project as documented in the Phase I NDA PDP WRM Production Plan ${ }^{5}$. Similar methods are required for DU characterization per LMITCO concurrence. Documentation of the quantitation procedure and results is to be provided in the CEP IAP/DU WRM Production Plan. Requirements itemized below: 


\title{
Statement of Work \\ INEEL NDA Capability Evaluation Project Increased Am/Pu \& DU WRM Production \\ Revision 1.15 \\ July 24,1997 \\ Page 13 of 17
}

\begin{abstract}
5.20.I Pu, $\mathrm{Am}$ and $\mathrm{DU}$ feedstock isotopic/radionuclidic composition analysis, traceable documentation required, technical and $Q A$ checkpoint.
\end{abstract}

5.20.2 Pu, $\mathrm{Am}$ and DU feedstock chemical composition analysis, traceable documentation required, technical and $\mathrm{QA}$ checkpoint.

5.20.3 Pu, $\mathrm{Am}$ and DU feedstock elemental impurities analysis, traceable documentation required, technical and $\mathrm{QA}$ checkpoint.

5.20.4 Pu, Am oxide and DU oxide feedstock particle size characterization, documentation required, technical and $\mathrm{QA}$ checkpoint.

5.21 Determine blend parameters required to achieve the acceptable Am/Pu/diatomaceous earth uniformity as specified in 5.14. Determine blend parameters for the DU/diatomaceous earth mixture per item 5.19. Acquire samples to validate compliance, documentation required - (QA checkpoint).

5.22 Procure stainless steel WRM encapsulation assemblies per Phase II NDA PDP WRM Statement of Work for Stainless Steel Assemblies ${ }^{6}$.

5.23 Determine weld configuration and associated parameters and perform test weld analyses to assure weld integrity. Documentation of weld integrity analysis results required.

5.24 A unique indelible identification number is to be marked on the outer stainless steel encapsulation assembly endcaps. The identification number is to be a physical attribute of the material, e.g. chemically etched or embedded, into the external surface of the selected endcaps. The height of the identification numbers/characters are to occupy a maximum area on the outer cylinder endcaps without compromising endcap weld regions. The identification serial numbers of the thirteen IAP/DU WRM encapsulation assemblies are as follows: CEP001, CEP002, ... CEP016. WRM specific identifications are as tabulated below: 
Statement of Work INEEL NDA Capability Evaluation Project Increased Am/Pu \& DU WRM Production

Revision 1.15

July 24, 1997

Page 14 of 17

Table 7. CEP WRM Identification

\begin{tabular}{|c|c|c|}
\hline CEP SOW & WRM Specification Item & Identification \\
\hline & 4.1.a -- WRM 1 & CEP001 \\
\hline & $4.1 . \mathrm{a}--$ WRM 2 & CEP002 \\
\hline & $4.1 . b-W R M 1$ & CEP003 \\
\hline & $4 \cdot 1 \cdot b-W R M 2$ & CEPO0 4 \\
\hline & 4.1.C - WRM 1 & CEPO05 \\
\hline & $4.1 . C-W R M 2$ & CEP006 \\
\hline & $4.1 . d-W R M 1$ & CEP007 \\
\hline & $4.1 . d-W R M 2$ & CEPO0 8 \\
\hline & 4.1.e - WRM 1 & CEPOO9 \\
\hline & 4.1.e - WRM 2 & CEP010 \\
\hline & 4.1.f - WRM 1 & CEP011 \\
\hline & $4.1 . g-W R M 1$ & CEP012 \\
\hline & $4.1 . h-W R M 1$ & CEP013 \\
\hline & $4.1 . h-W R M 2$ & CEP014 \\
\hline & $4.1 . h-W R M 3$ & CEP015 \\
\hline & $4.1 . h-W R M 4$ & CEP016 \\
\hline
\end{tabular}

5.25 Quantitatively dispense IAP/diatomaceous earth prepared blend into inner stainless steel cylinder/endcap assembly (QA documentation required), install graphite felt pad, and weld inner top endcap in place. Deburr and smooth external surface of welded inner cylinder to specified dimensions.

5.26 Quantitatively dispense DU/diatomaceous earth prepared blend into stainless steel cylinder/endcap assembly (QA documentation required), install graphite felt pad, and weld top endcap in place. The exterior surface of the DU WRM encapsulation cylinder is then finished with particular 
INEEL NDA Capability Evaluation of Work

Increased Am/Pu \& DU WRM Production

Revision 1.15

July 24, 1997

Page 15 of 17

attention being given to the weld point to ensure the O.D. of the tube does not exceed 1.955 inches.

5.27 Perform helium leak test on IAP inner cylinder at $10^{-8} \mathrm{~atm}-$ $\mathrm{cc} / \mathrm{sec}, \mathrm{QA}$ documentation required. Data generated during weld parameter determinations, associated evaluations and any nondestructive testing is to be maintained to support proof of seal integrity.

5.28 Perform helium leak test on DU single encapsulation cylinder at $10^{-8} \mathrm{~atm}-\mathrm{cc} / \mathrm{sec}, Q A$ documentation required. Data generated during weld parameter determinations, associated evaluations and any nondestructive testing is to be maintained to support proof of seal integrity.

5.29 Insert IAP assembled inner stainless steel cylinder into outer cylinder and weld top outer endcap in place. The exterior surface of the outer tube is then finished at the weld point to ensure the O.D. of the tube at the weld location does not exceed 1.955 inches.

5.30 Determine Am and Pu mass and alpha activity values and associated uncertainties for each radionuclidic/isotopic feedstock component, i.e. Am and $\mathrm{Pu}$, individually and combined for each IAP WRM. Assemble all pertinent $Q A$ records and statistical analyses used in the mass/activity value/uncertainty determination, and establish traceability of assigned WRM values to recognized reference base.

5.31 Determine DU mass and associated uncertainty for each radionuclidic/isotopic feedstock component individually and combined. Assemble all pertinent $Q A$ records and statistical analyses used in the mass value/uncertainty determination, and establish traceability of assigned WRM values to recognized reference base.

5.32 Perform WRM attribute verification measurements on the completed units as specified by LANI and concurred with by LMITCO. Attributes to be verified will be specified by LANL and IMITCO, i.e., vertical IAP and DU WRM uniformity. Include results of verification in CEP IAP/DU WRM Production document. 
Statement of Work

INEEL NDA Capability Evaluation Project Increased Am/Pu \& DU WRM Production

Revision 1.15

July 24, 1997

Page 16 of 17

5.33 Prepare WRM Certificates of Content and Traceability and SNM accountability documentation.

5.34 Perform internal independent physics review of completed WRMS .

5.35 Acquire transport containers, package and ship CEP WRMs to the INEEL RWMC site contact.

5.36 Formally transmit all records and documentation to the INEEL MWFA IMITCO project management office.

5.37 Prepare a CEP IAP/DU WRM Production document providing details of the production/fabrication process, mass value determination method and data and traceability process. Method and document is to be reviewed and concurred with by LMITCO and to serve as the source of certification for the CEP IAP/DU WRMS .

6. Delivery/Schedule

6.1 Submit QAPJP to LMITCO for review and concurrence by February 14, 1997.

6.2 Submit Project Management Plan to LMITCO for review and concurrence by February 14, 1997.

6.3 Submit Records Management Plan to LMITCO for review and concurrence by February 14, 1997.

6.4 Complete CEP IAP/DU WRM characterization, fabrication, and corresponding $Q A$ check-point documentation of the IAP/DU WRM set by June $27,1997$.

6.5 Complete draft WRM certificates of traceability and transmit to LMITCO contact on or before July 15, 1997.

6.6 Complete transportation of CEP IAP/DU WRMs to IMITCO specified facility before July 21, 1997.

6.7 Submit Draft CEP IAP/DU WRM Production Plan to IMITCO for review and concurrence by August 18, 1997. 
Statement of Work INEEL NDA Capability Evaluation Project Increased Am/Pu \& DU WRM Production

Revision 1.15

July 24, 1997

Page 17 of 17

6.8 Transmit Final CEP IAP/DU WRM Production Plan and documentation to LMITCO before september 17, 1997.

\section{References}

7.1 Transuranic Waste Characterization Quality Assurance Program Plan, Revision 0, CAO-94-1010, April 30, 1995, U.S. Department of Energy, Carlsbad Area Office, National TRU Program Office.

7.2 Performance Demonstration Program Plan for Nondestructive Assay for the TRU Waste Characterization Program, Revision 0, CAO-941045, March 1995, U.S. Department of Energy, Carlsbad Area Office.

7.3 Statement of Work, Non-Destructive Assay Performance Demonstration Plan, Phase I Working Reference Material Production, Revision 1.3, October, 1995, Lockheed Martin Idaho Technologies Company.

7.4 Standard Guide for Preparation of Working Reference Materials for Use in the Analysis of Nuclear Cycle Materials, ASTM Designation: C 1128-89, American Society for Testing and Materials, Philadelphia, PA.

7.5 Phase I NDA PDP WRM Production Plan, CST-8-PLA-STD-1-1/Rev2, June 24, 1996 version, Los Alamos National Laboratory.

7.6 Phase II NDA PDP WRM Statement of Work for Seamless Stainless Steel Tubing Assemblies, LANL/CST-8, Document \# PLA-STD-203/0. November 8, 1995. 


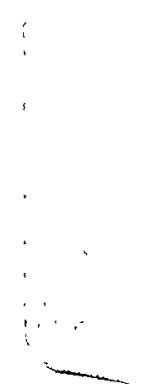

B 
To/MS: R. Marshall, CST-8 G740

Los Alamos

WATIONAL LABOAATOAY

memorandum

Nuclear Matoitals Procioseling -

Actinlde Process Chemistry

NMT-2
Thru: J. D. Williams, NMT-2 Group Ld

T. A. Hayes, Team Idr. ateaj

From/MS: T. E. Ricketts, NMT-2 E511 1ER wes

\section{SUBJECT: PLUTONIUM DIOXIDE PREPARATION PROCEDURE} AND CHARACTERIZATION RESULTS

I have attached a comprehensive data package which discusses the procedures and operating parameters used to prepare the selected plutonium dioxide item to the agreed upon specifications. I have also included the loss-on-ignition (LOI) and particle size/surface area results as part of the characterization efforts by CST-15 and NMT-2i. analytical capability. To complete the data package, I have included a spreadsheet that calculates the mass percent of the individual particles, as well as cumulative, from the particle size distribution analysis.

Due to the dedicated efforts of NMT-2 processing personnel in room 208 , we were able to meet the extremely short deadlines associated with this project. Efforts put forth by Charlie Davis, CST-15, and Greg Bird, NMT-2, should also be acknowledged. Their hard work provided almost real-time analysis capability for the samples submitted for LOI and particle size/surface area analysis.

I have enjoyed working with you on this project and if you should have any questions or comments regarding the attached information, please do not hesitate to contact me. I look forward to our future interactions under phase II of this project.

Distribution: $w / o$ attachments
B. McKerley, CST-8 G740
C. Leasure, CST-15 E531
C. Davis, CST-15 E531
G. Bird, NMT-2 E511
M. Romero, NMT-2 E511
Author 
June 23, 1995

\section{PLUTONIUM DIOXIDE PREPARATION}

The information presented in this document discusses the procedure and operating parameters used in the processing and characterization of selected plutonium dioxide item (52/PEOR3258). The procedure and parameters for this project were agreed upon in a meeting with $R$. Marshall, CST-8, on May 22, 1995. This material is going to be used to fabricate standards which will be used to certify NDA instruments measuring waste items destine for WIPP.

All work, associated with the processing of this material, was performed in Room 208, P/S RBJ in glovebox G221.

May 22, 1995:

- Item 52/PEOR3258 was selected for processing and characterization based upon three factors: 1) the purity of material ( 86.9 weight $\% \mathrm{Pu}) ; 2)$ the quantity of material ( $1.7 \mathrm{Kgs}$ net weight); and 3 ) the age of the item ( 7 yrs old).

\section{May 23, 1995:}

- Retrieved selected item from the vault. See attachment I for item status.

- Introduced item in-line.

- Transferred item to glovebox G221.

- The material was initially screened using a 40 mesh sieve - Tyler Equivalent 35 . The sieve openings are $0.0165 \mathrm{in} . / 425 \mu \mathrm{m}$. 
- To assure homogeneity the material was V-blended for approximately 30 minutes.

- The material was then transferred to a fused silica furnace boat for calcination.

The typical composition of a fused silica furnace boat is:

$$
\begin{array}{ll}
\mathrm{SiO}_{2}-86.7 \% & \mathrm{Al}_{2} \mathrm{O}_{3}-10.4 \% \\
\mathrm{Fe}_{2} \mathrm{O}_{3}-0.34 \% & \mathrm{TiO}_{2}-0.05 \% \\
\mathrm{CaO}+\mathrm{MgO}-0.15 \% & \mathrm{NA}_{2} \mathrm{O}+\mathrm{K}_{2} \mathrm{O}-0.41 \%
\end{array}
$$

- The boat and material were placed into a Lindberg furnace (Model 51894) and the following furnace controller program was usectfor calcination.

\begin{tabular}{ccc} 
Set Pt & Temperature & Time \\
\cline { 2 - 3 } & $75^{\circ} \mathrm{C}$ & - \\
1 & $200^{\circ} \mathrm{C}$ & $1 \mathrm{Hr}$ \\
2 & $400^{\circ} \mathrm{C}$ & $1 \mathrm{Hr}$ \\
3 & $600^{\circ} \mathrm{C}$ & $1 \mathrm{Hr}$ \\
4 & $800^{\circ} \mathrm{C}$ & $1 \mathrm{Hr}$ \\
5 & $980^{\circ} \mathrm{C}$ & $1 \mathrm{Hr}$ \\
6 & $980^{\circ} \mathrm{C}$ & $2 \mathrm{Hr}$ \\
7 & $700^{\circ} \mathrm{C}$ & $2 \mathrm{Hr}$ \\
8 & $500^{\circ} \mathrm{C}$ & $2 \mathrm{Hr}$ \\
& OFF &
\end{tabular}

Furnace Started at 3:30 PM and allowed to run overnight.

\section{May 24, 1995:}

- $\quad$ Appeared to have a furnace malfunction. See attachment II for printout of furnace temperature profile. 
June 23, 1995

The malfunction was such that the material was calcined between 900 and $960^{\circ} \mathrm{C}$ for approximately nine hours instead of the programmed $980^{\circ} \mathrm{C}$ for two hours. After a brief consultation with R. Marshall, it was agreed that the increased time of calcination had no detrimental effect upon the material, perhaps, it even was beneficial considering the intended use of this material.

Evaluation: Ramp-up to $800^{\circ} \mathrm{C}$ was as anticipated ( $\sim 5 \mathrm{Hrs}$ ). Ramp-up from 800 to $900^{\circ} \mathrm{C}$ took $~ 2 \mathrm{Hrs}$. Ramp-up from 900 to $950^{\circ} \mathrm{C}$ took $\sim 3 \mathrm{Hrs}$. Ramp-up from 950 to $960^{\circ} \mathrm{C}$ took $\sim 6 \mathrm{Hrs}$.

Furnace was turned off at 7:20 am after roüghly 16 hours in the calcination cycle. Nine of those hours were at $900^{\circ} \mathrm{C}$ or greater.

- Opened door on furnace to allow rapid heat dissipation. This allowed adequate cooling such that the boat and material was cool enough to be handled in a relatively short period of time ( $4-6$ Hrs).

- Approximately half of the material (roughly $1.0 \mathrm{Kg}$ ) was screened using a 80 mesh sieve - Tyler Equivalent 80 and collected in a clean catch pan. The sieve openings are $0.007 \mathrm{in} . / 180 \mu \mathrm{m}$. The material screened relatively easy which indicated that the majority of the particles were $\sim 200 \mu \mathrm{m}$ or less.

NOTE: The portion of the material selected for the screening was obtained by taking four large scoops of material from different locations in the furnace boat. The material was transferred to the sieve, "mixed" and screened.

- The screened material was then sampled:

* A ten gram sample (PEOR3258-S2) was collected and sent for LOI analysis by G. Bird and C. Davis. 
* A three gram sample (PEOR3258-S3) was collected and sent for particle size and suriace area analysis by $G$. - Bird and C. Davis.

NOTE: Any material which touched the glovebox floor was . treated as sweepings.

- After the material was sampled, 120 gms (net weight) was obtained and packaged to be sent to R. Marshall for use as standard material. The item was created as 52/PEOR3258-STD1.

The conditions of the glovebox in which the handling of the material occurred was:

Atmosphere: Air

Relative Humidity: $\sim 8.0 \%$

Temperature: $77.6^{\circ} \mathrm{F} / 24.8^{\circ} \mathrm{C}$

Dew Point: $13.3^{\circ} \mathrm{F} /-10.4^{\circ} \mathrm{C}$

\section{May 25, 1995:}

- Item PEOR3258-STD1 was removed from the glovebox line and sent to the sample room.

- The parent item was sent down to the vault (P/S ST - Standards) with the following comments added to item remarks (see attachment III):

* Oxide calcined at greater than $900^{\circ} \mathrm{C}$ for approximately 9 hours.

* Standard material save for Ricketts/Marshall. 
June 23, 1995

\section{RESULTS:}

- The ten gram sample (PEOR3258-S2) was split into two five gram aliquots and each aliquot had a IOI analysis. The average LOI for the two aliquots was $0.004 \%$. See attachment IV.

- The three gram sample (PEOR3258-S3) was split, using a riffler, into three 0.2 gram aliquots. Each aliquot had a particle size and surface area analysis.

* Particle Size

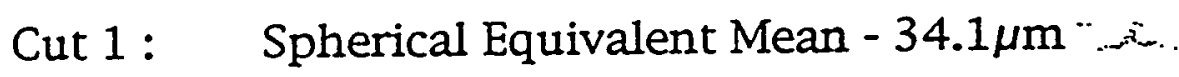

Cut 2: Spherical Equivalent Mean - $34.4 \mu \mathrm{m}$

Cut 3 : $\quad$ Spherical Equivalent Mean $-32.5 \mu \mathrm{m}$

* $\quad$ Surface Area (3 point BET)

Cut 1: $\quad 2.45$ sq. m./gm

Cut 2: 2.25 sq. m./gm

Due to time constraints, Cut 3 was not able to be analyzed.

See attachment $V$ for detailed particle size and surface area results.

- The spreadsheet in Attachment VI converts the particle size distribution information to a mass percent. As one might expect, there is a relatively large percentage of particles under the 30 $\mu \mathrm{m}$ size, however, the bulk of the mass consist of particles greater than $30 \mu \mathrm{m}$.

Past experiments with similar material (oxide from a nitrate based ion exchange process) indicate that the maximum adsorption after calcination to $\sim 950^{\circ} \mathrm{C}$ in a glovebox of less than $\sim 30-40 \% \mathrm{RH}$ would be $\sim 0.2 \mathrm{mg} \mathrm{H} \mathrm{H}_{2} \mathrm{O} / \mathrm{gm} \mathrm{PuO}_{2}$ or $0.02 \%$ LOI. 
June 23, 1995

\author{
Attachment I
}

Item Status of PEOR3258 as Retrieved from the

Vault (Acct 700)

$-$

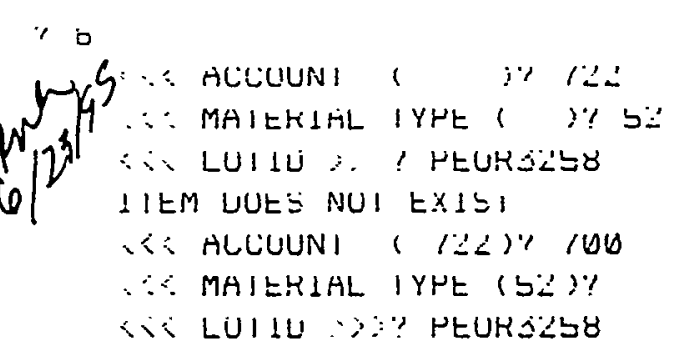

897.

Gwt-2241.3

$T$

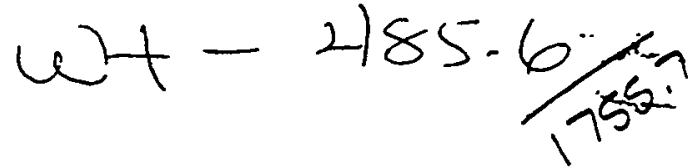

LNUENIUKY IIEM

ALL"I MI LUT-1UENIIFILAIIUN

10022 HESHSZSZ

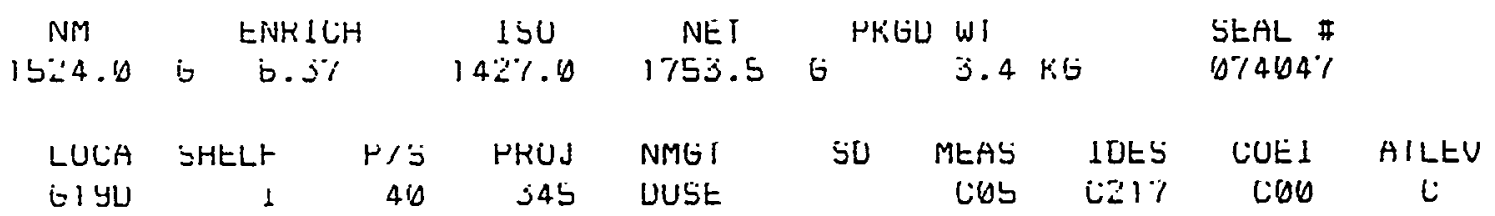

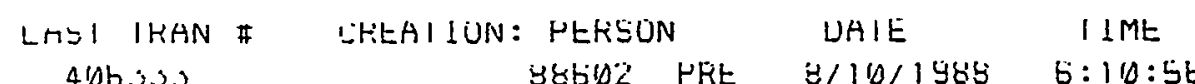

I! LM FIEMAKIT'

$1 \% F U=8 b . J ; N T=400 ; S 1=180 ; M U=300-3000 ;(H=250(\mu H M) \quad$ UNKNUWN $\quad U / \quad U$

$\therefore$ ACLUUNI 
June 23, 1995

\title{
Attachment I
}

\section{Item Status of PEOR3258 as Retrieved from the}

\author{
Vault (Acct 700)
}
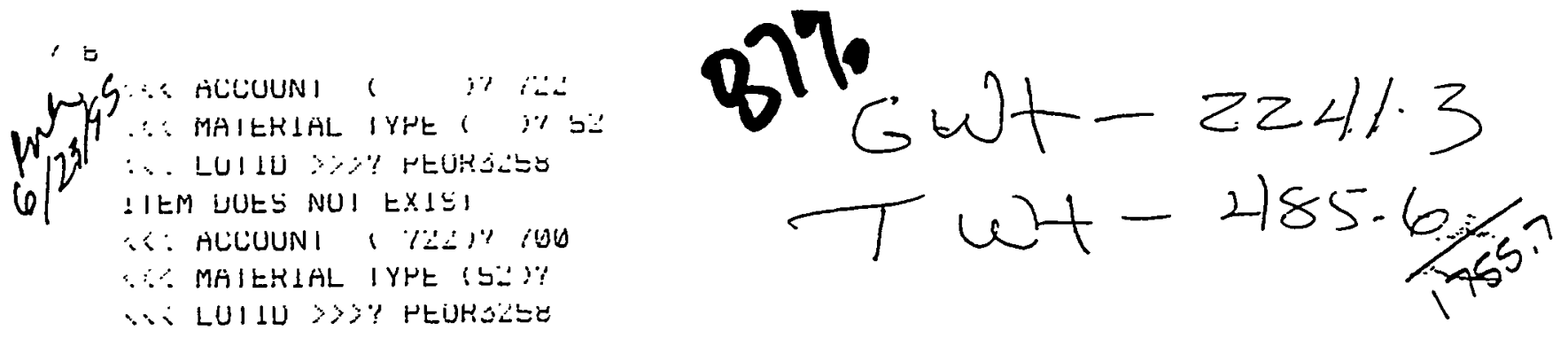

$$
\begin{aligned}
& \begin{array}{l}
\text { INUENIUKY IILM } \\
\text { ALUI MI LUI-IULMIIFILAIIUN UUNIAINER-IU }
\end{array}
\end{aligned}
$$

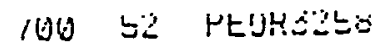

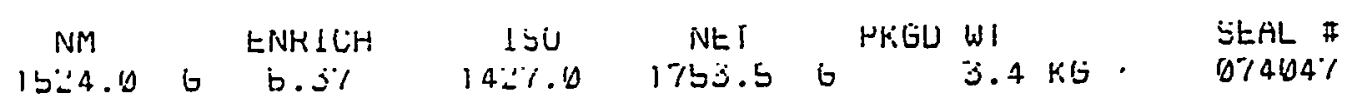

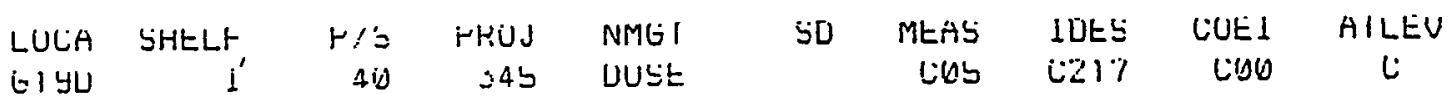

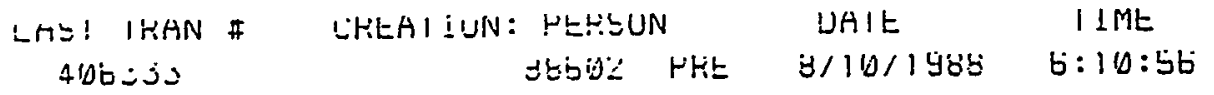

1 ! LM HEMAKIK'S

1 \%HJ= 


\section{Attachment II}

\section{Furnace Temperature Profile}

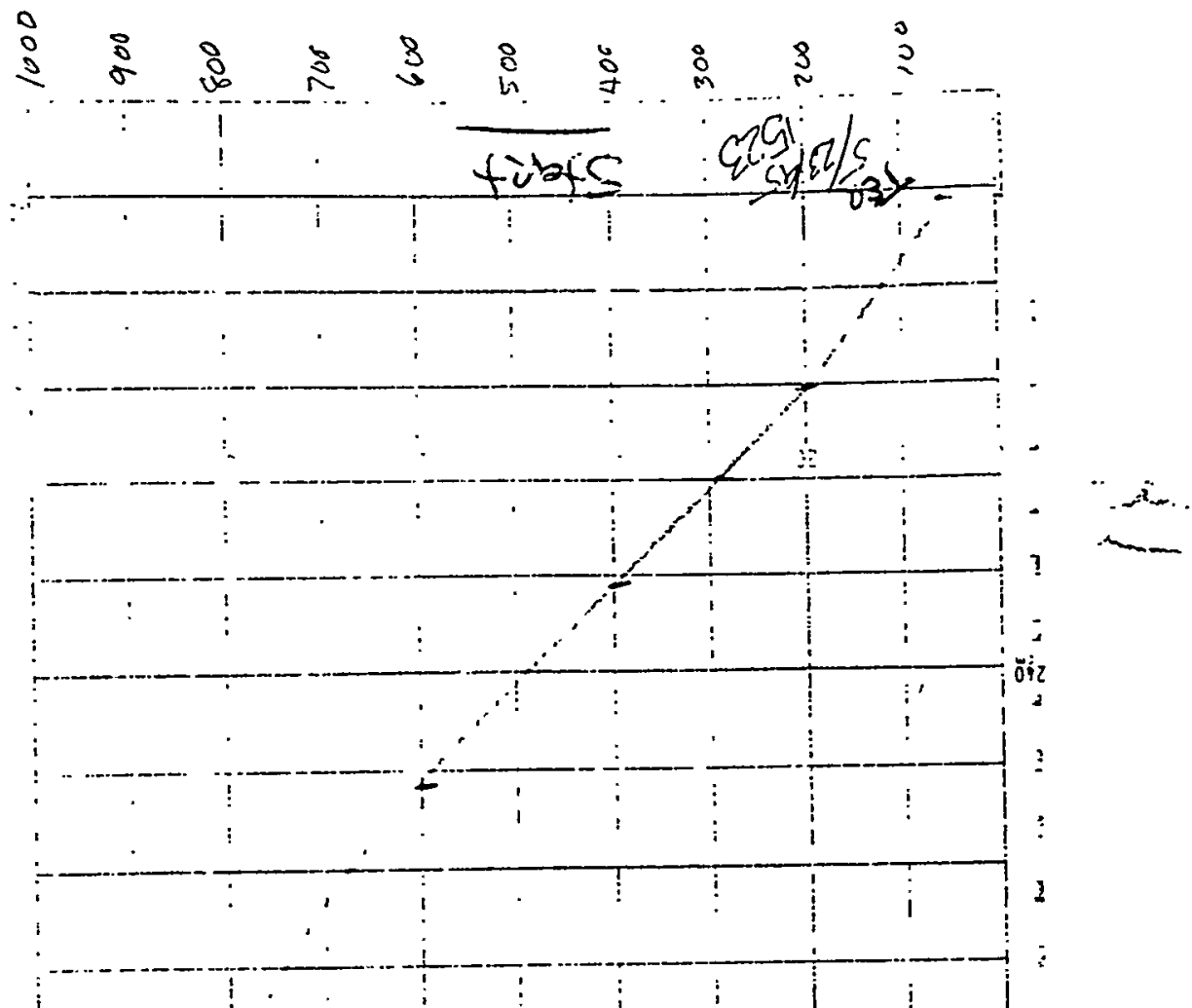




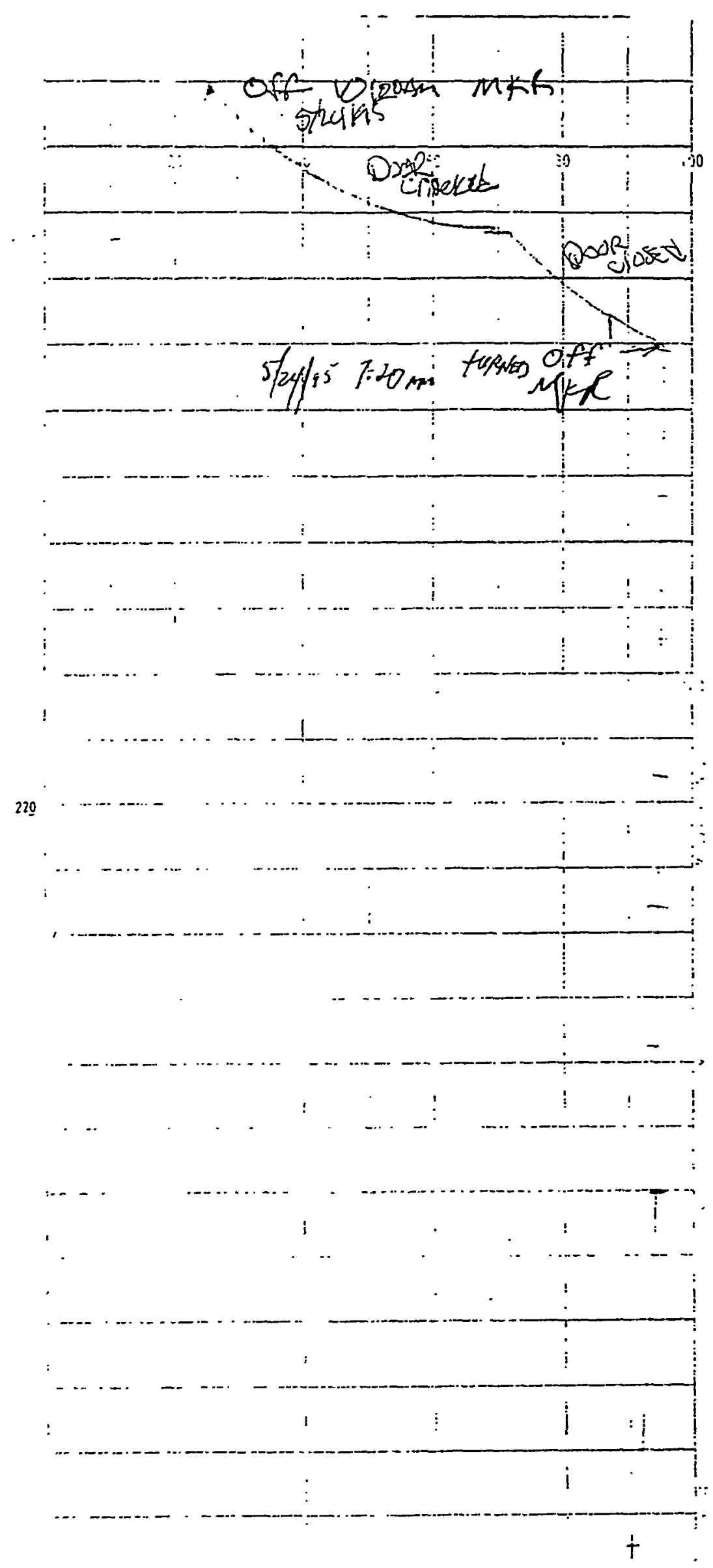

-

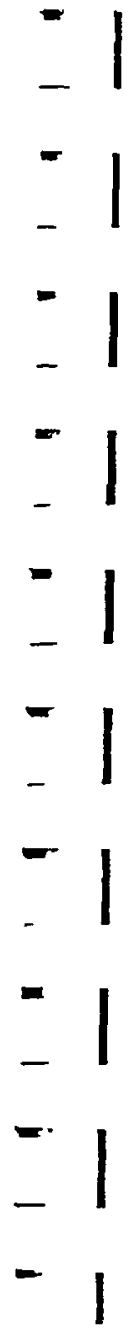




\section{Attachment III}

\section{Item Status of PEOR3258 as Sent to the}

Vault (Acct 700)

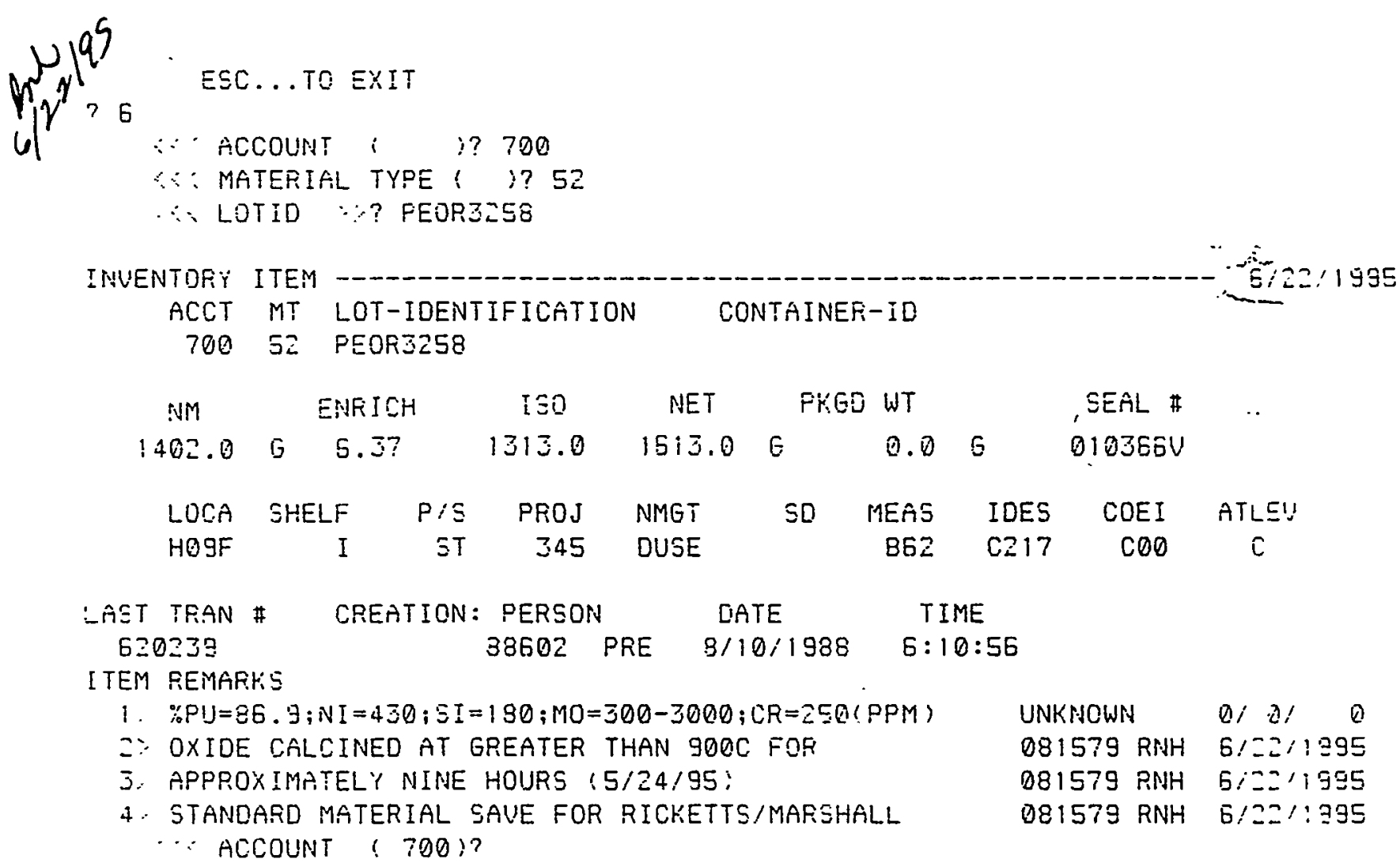




\section{DETERMINATION OF LOSS-ON-IGNITION OF PLUTONIUM DIOXIDE OR OTIER} PLUTONIUM-CONTAINING POWDERS - DATA RECORD

SAMPIED PEOR 3258-52 . DATE_ 5/25/95

FURNACE CALIBRATION NO. 638783

CALIBRATION EXPIRATION DATE $4 / 27 / 96$

IGNITION TEMPERATURE 950

C IGNITION TIME

HRS.

ALIQUOT \#1

CRUCIBLENO.

ALIQUOT \#2

CRUCIBLENO.

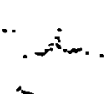

\section{SAMPLE WEIGHT \& TARE}

'EFORE IGNTION
TARE (T1) $\frac{32.3021 \mathrm{~g}}{27.27} .27 .2854$

INITIAL SAMPLE WEIGH'T (B1) 5,0167

(B2T2) 32.6708

$27.6468 \quad g$.

5.0240 g.

SAMPLE WEIGHT \& TARE

$\begin{array}{r}\text { AFTER IGNITION (AIT1) } \frac{32,3020}{27.2854} \text { G. } \\ \text { TARE (T1) } \\ \text { FINAL SAMPLE WEIGHT (A1) } \\ \hline \text { g.0166 }\end{array}$

(A2T2) $\frac{32.6705}{27.6468}$
(A2)

PERCENT LOSS

(L1) $=00199$

AVERAGE LOSS ON IGNITION .00398 $\%$

(12)

.00597 $\%$

OPERATOR SIGNATURE Q vee Sinds CHECKED BY ALIQUOT SPREAD _.003\%8 $\%$

DATE $5 / 25195$

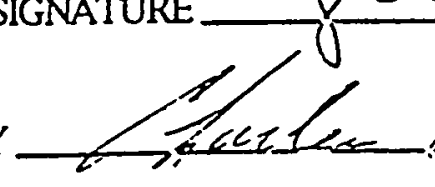




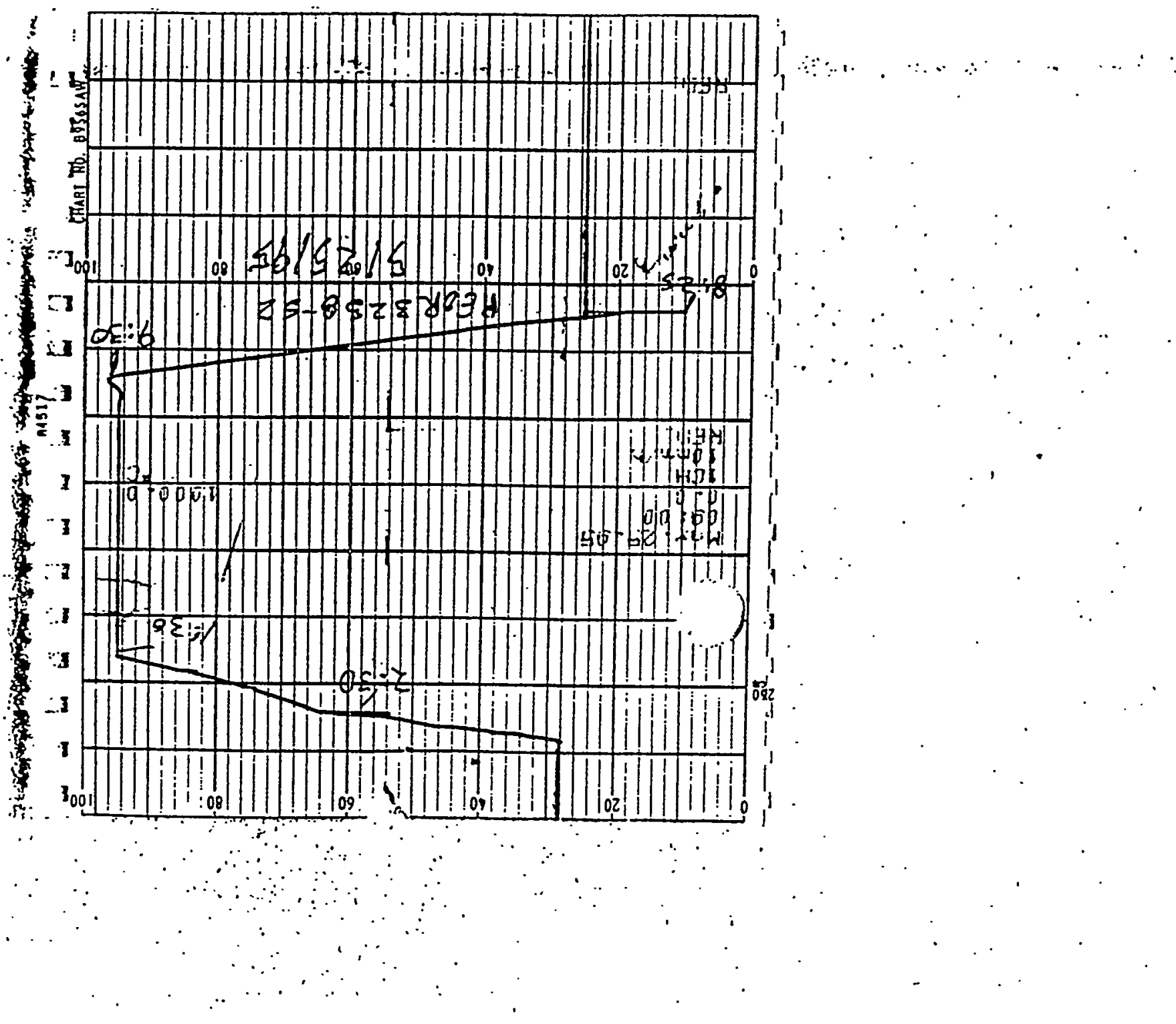




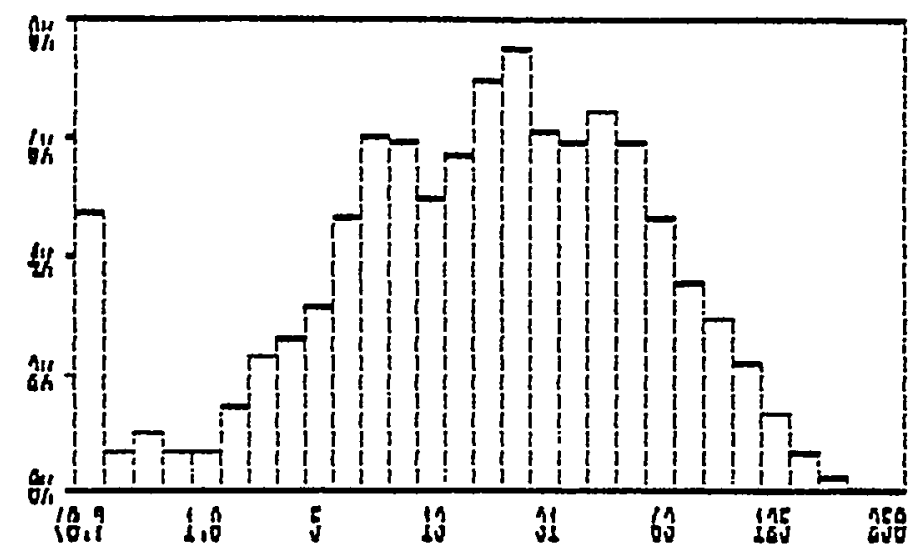

Sampje II CF Code

Dalc

IImo

Spherjcal Equyvajent iscan

Standard Deriation.

Skouness

Xurtosis

Cocffs. of Varfance $(\not)$

Counts

Cycles : 10

scaling $: 1.00$

\section{Channel Slac}

(miarons)

$$
10.7
$$

0.7

1.0

1.3

1.8

2.3

2.0

4.0

E. 0

6.5

8

10

13

17

20
: PFOR2258-S2 CUI 1

:

: 01/03/80

: $12: 52: 49$

: $3 \xi .1$

: 34.2

$: 0.3$

$: 7.9$

$: 100.5$

: 12632
M.Cyclo I'jme: $1.0 \mathrm{Gcc}$. Aroraged last 5 oyclc(s)

dichanne]

4.7770

0.7280

1.0493

0.7393

0.7440

1. 1872

2.3218

2.5732

$3.100 \%$

4.6832

6.0118

5. 3624

4. 9940

5.6222

6.8732

\section{Channc] Size \\ (microns)}

25

31

37

션

53

63

75

98

$\$ 05$

125

149

177

210

250
didChanne]

7.5508

6.0979

5.0798

5.4852

5.9660

4.6656

3.5228

3.0044

2.1969

1.3944

$0.6\{? 2$

0.2581

0.1126

0.0583 

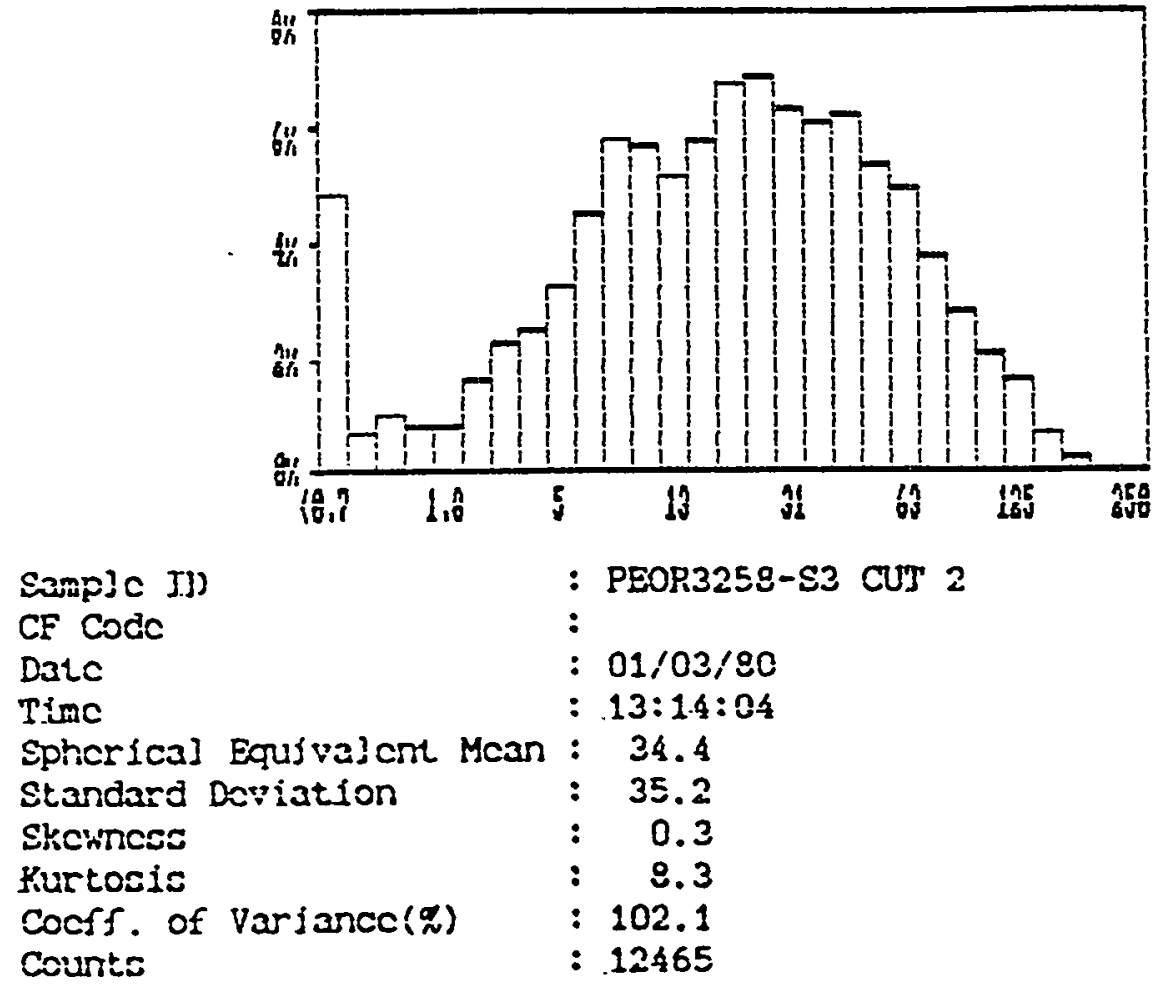

2.3

3.0

4.0

5.0

6.5

\section{8}

10

12

17

20

w'Channcl

4.0393

0.7777

1.0566

0.8441

0.8525

1.6496

2.3033

2.5011

3.3432

4.5332

5.8849

5.7095

5.2201

5.7226

6.8015
M. Cycle I'smc: 1.0 scc. Avaragad last 5 cyclo(s) Channc] Sjzc
(mlarona)

25

31

37

44

53

63

75

89

105

125

149

177

210

250
do'Channc]

6.9553

6.3888

6.1243

6.2782

5.3691

4.9755

3. 2224

2. 8734

2.1527

1:6220

0.7387

0.2593

0.0979

0.1201

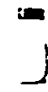

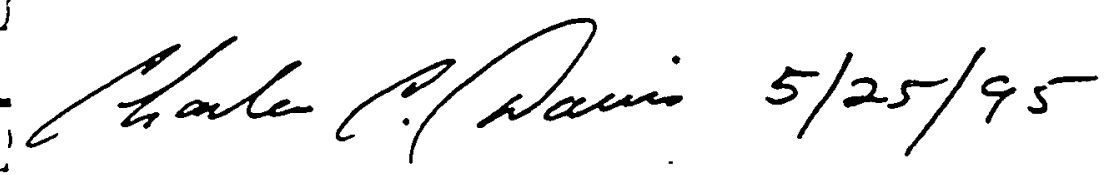




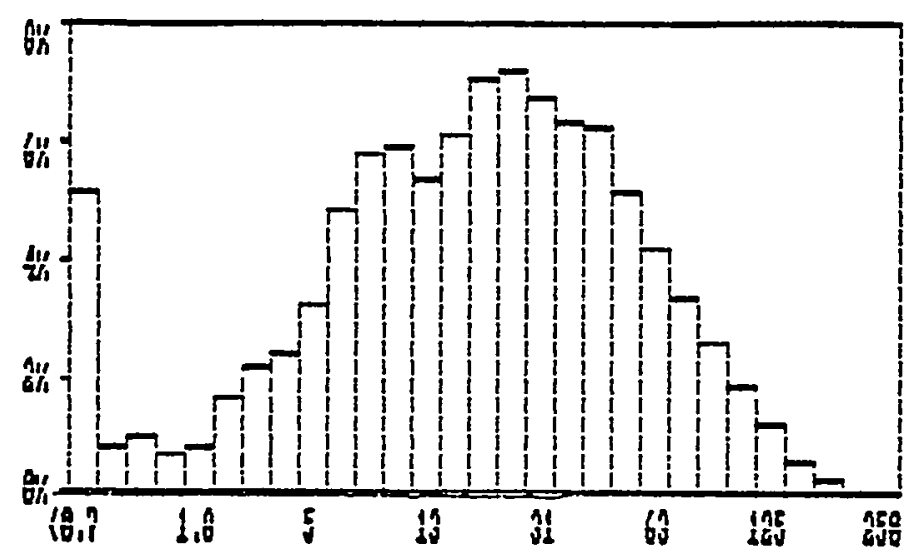

\begin{tabular}{|c|c|}
\hline $\begin{array}{l}\text { Sampje Jנ) } \\
C F \text { Code }\end{array}$ & $\begin{array}{l}\text { : PEOK3 } \\
\text { : }\end{array}$ \\
\hline $\begin{array}{l}\text { CE Code } \\
\text { Datc }\end{array}$ & \\
\hline Time & \\
\hline Sphorlcal Equjuaj cnt Mcan & : \\
\hline Standard Doviation & 32. \\
\hline Skernese & : \\
\hline Murtosis & \\
\hline Cocff. of Vartance $(\mathscr{d})$ & $: 101$. \\
\hline Courite & \\
\hline
\end{tabular}

$\begin{array}{ll}\text { Cycles } & : 20 \\ \text { Scalins } & : 1.00\end{array}$

Channel Stac (ntarons)

$<0.7$

0.7

1.0

1.3

1.8

2.3

3.0

4.0

5.0

6.5

8

10

12

17

20
\#/Channc]

5.1558

0.8020

0.3293

0.7997

0.82 .73

1.7379

2.2006

2.435 多

3.3165

4.2379

5.9003

5.0371

5.3685

6.2354

7.0961
M. Cycle IIsmc: $1.0 \mathrm{ecc}$. Averised last 5 cycle(s)

Channcl. Sfze
(microns)
25
31
37
44
52
63
75
88
105
125
159
177
290
250

didChanne?

7.2602

6.71365

6.3975

6.2628

5.1573

4. 2923

2. 3680

2.7182

1.8458

1.2385

$0.52 \&$ ?

0.2732

0.0523

0.01366

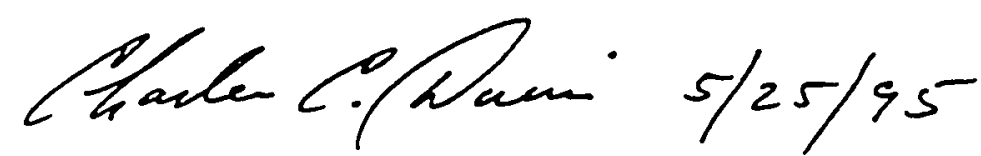


Quartachrome Corporation

BOVA-1000 BET SUrface Arca Analyzar

Tarcion $2.10 \quad 21$ Apri] $\$ 992$

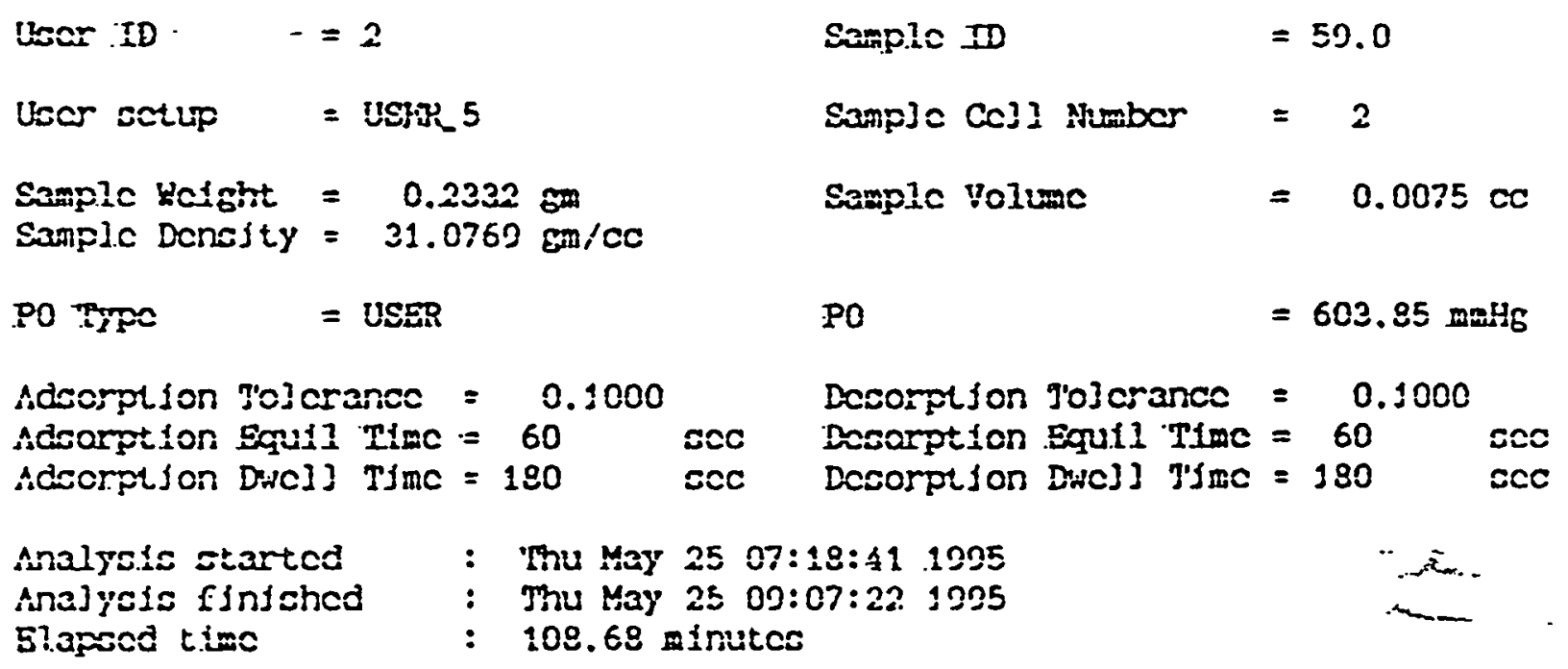

3 Pojnt BLF'

\begin{tabular}{|c|c|c|c|}
\hline $\begin{array}{l}\text { Target } \\
\text { licjatjuc } \\
\text { Procsuro }\end{array}$ & $\begin{array}{l}\text { Actual } \\
\text { Relative } \\
\text { Pxoseurc }\end{array}$ & $\begin{array}{l}\text { Potal } \\
\text { Volume } \\
\text { Adeorbod } \\
\text { (ccí) }\end{array}$ & $\begin{array}{c}\text { BET } \\
\text { Trans } \\
1,(\text { HIPO } / \text { P }-1])\end{array}$ \\
\hline \multicolumn{4}{|c|}{ 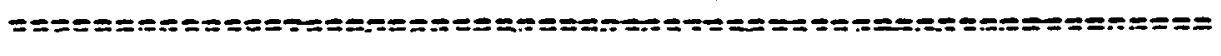 } \\
\hline $\begin{array}{l}0.1000 \\
0.2000 \\
0.3000\end{array}$ & $\begin{array}{l}0.1021 \\
0.1945 \\
0.2944\end{array}$ & $\begin{array}{l}0 . \$ 536 \\
0.5794 \\
0.71 .52 .\end{array}$ & $\begin{array}{l}207.3983 \\
333.5587 \\
466.722 .7\end{array}$ \\
\hline
\end{tabular}

\begin{tabular}{|c|c|c|}
\hline $\begin{array}{l}\text { Surfaco Area } \\
\text { Specjfis Surface Arca }\end{array}$ & & $\begin{array}{l}0.5703 \text { sq. . } \\
2.4 \$ 56 \text { sq. m. Igm }\end{array}$ \\
\hline Slope & & 1355.655185 \\
\hline Intcrcopt & $=$ & 68.361156 \\
\hline Corrolation Coaffiaiont & $=$ & 0.323953 \\
\hline DIFI $C$ & $=$ & 20.830782 \\
\hline
\end{tabular}

Single Paint EFI

\begin{tabular}{|c|c|c|}
\hline Tarect & Actual & T'otal \\
\hline Prossure & yrcssurc & $\begin{array}{l}\text { Adeorbed } \\
\text { (cciss) }\end{array}$ \\
\hline \multicolumn{3}{|c|}{ 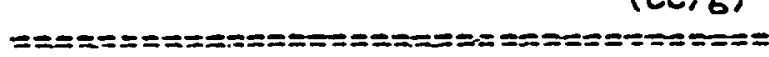 } \\
\hline 0.3000 & 0.2948 & 0.7152 \\
\hline
\end{tabular}

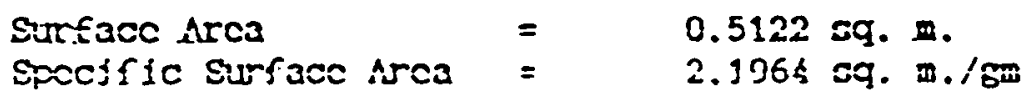




\section{Quamachrome Corporation \\ HoVA-1000 DET Surface Arca Anazyzar \\ Vorston 2.10 2f Aprf] 1993}

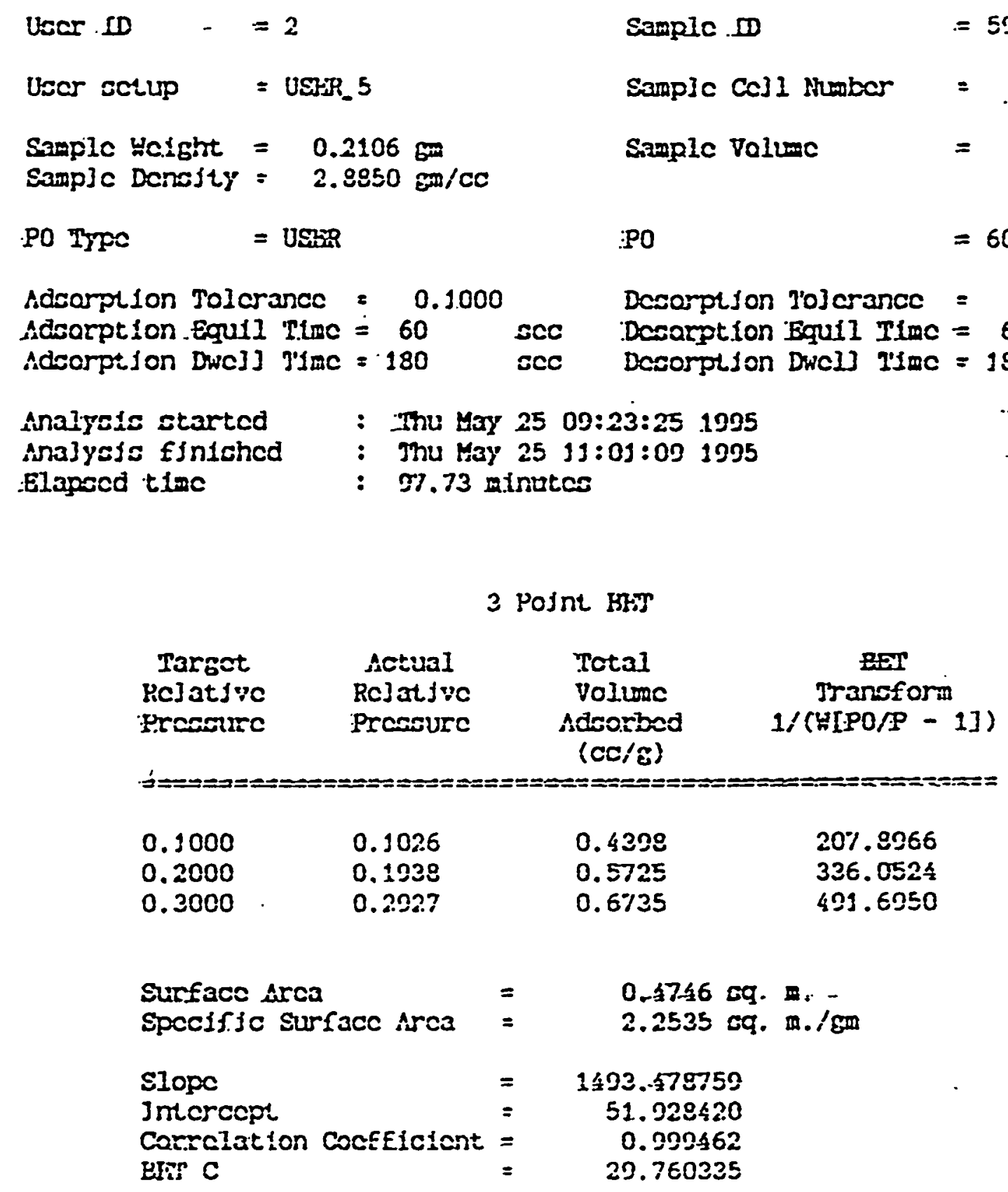

Singlc Polnt urit

\begin{tabular}{|c|c|c|}
\hline $\begin{array}{l}\text { Target } \\
\text { Relatife }\end{array}$ & $\begin{array}{l}\text { Actual } \\
\text { Rclative }\end{array}$ & $\begin{array}{l}\text { Tolal } \\
\text { Polume }\end{array}$ \\
\hline Proscurc & Prcasurc & $\begin{array}{c}\text { Adsorbod } \\
\left(\text { ccl' }^{\prime} g\right)\end{array}$ \\
\hline
\end{tabular}

$\begin{array}{lll}0.3000 & 0.2237 & 0.6 \% 25\end{array}$ 


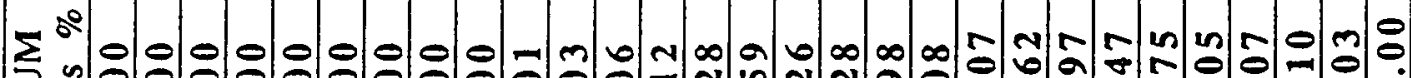

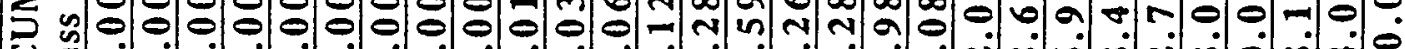
U

ڤే :

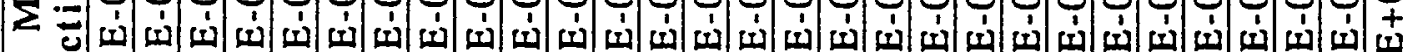
$\Sigma$ m

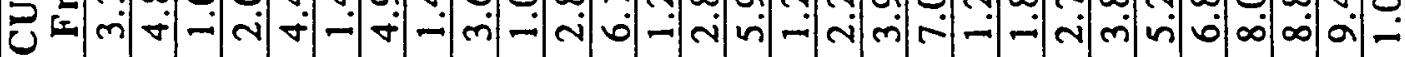

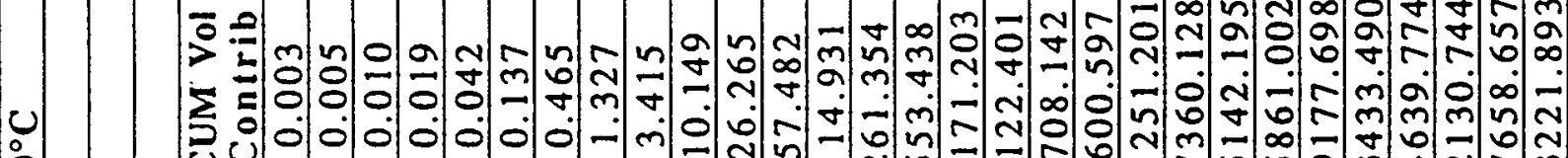
气ิ

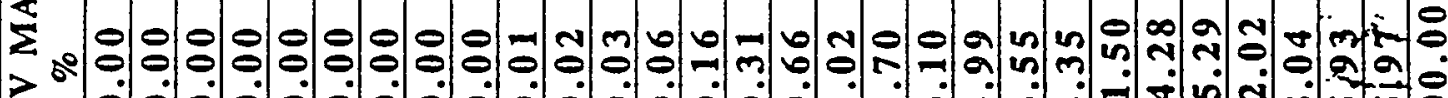

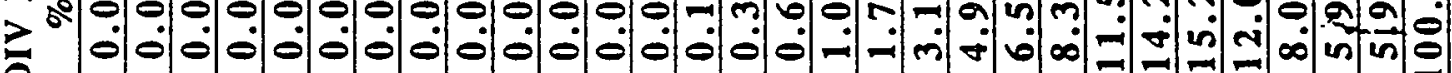

要

Z

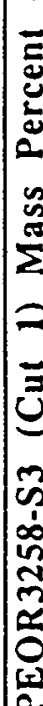

$\div$

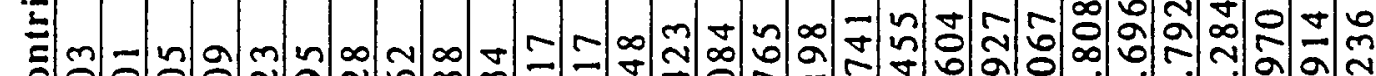

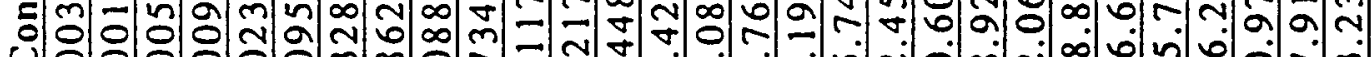

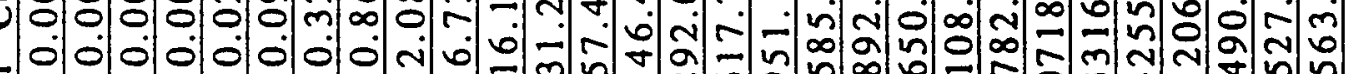

n.

- $\infty$ o $\infty-1000$

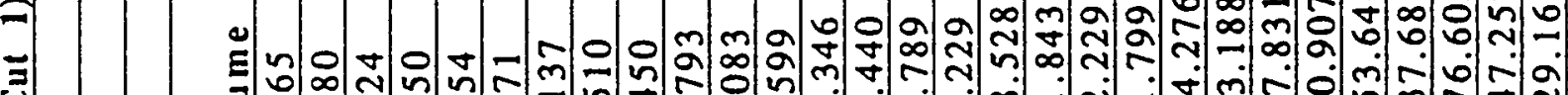

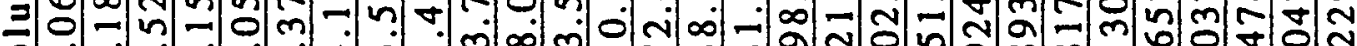

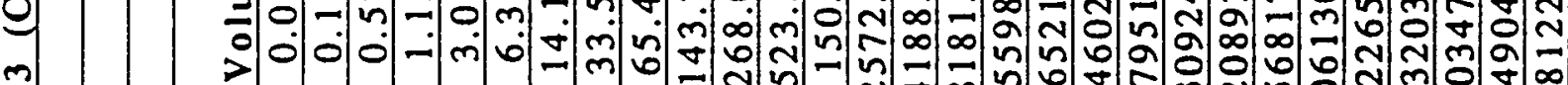

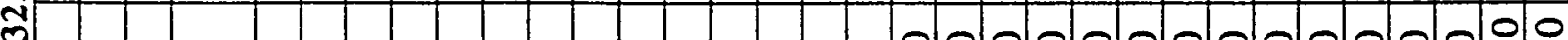

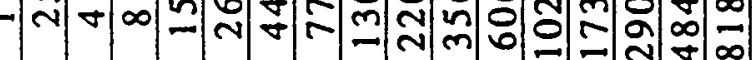

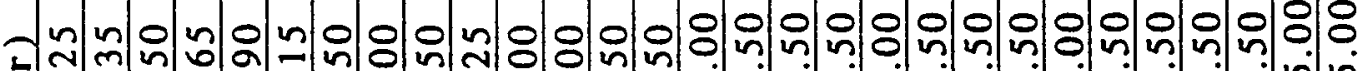

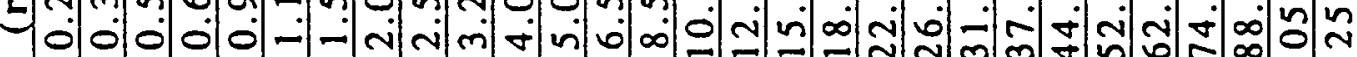

a. $=$

- $\infty$ om nm

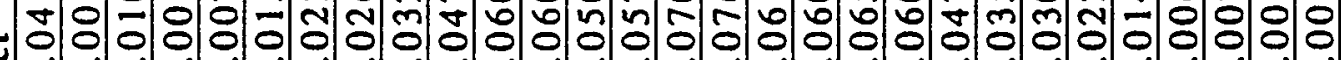
च $\frac{2}{0}$

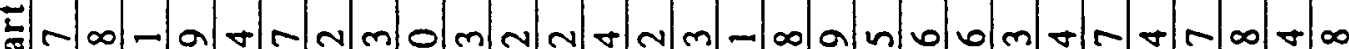

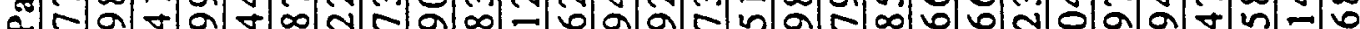

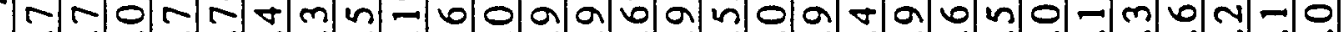

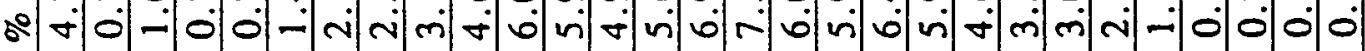

के

vi

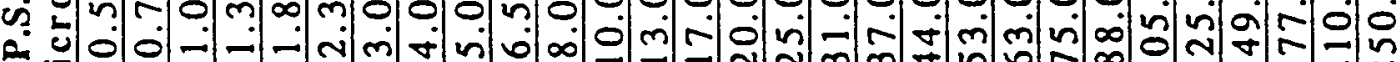
E. 


\begin{tabular}{|c|c|c|c|c|c|c|c|c|c|}
\hline & & & \multicolumn{5}{|c|}{ PEOR3258-S3 (Cut 2) Mass Percent - Calcined to $\sim 950^{\circ} \mathrm{C}$} & & \\
\hline \multicolumn{10}{|c|}{ Assume: Spherical particles } \\
\hline & & & & & & & & & \\
\hline $\begin{array}{c}\text { P.S. } \\
\text { (microns) }\end{array}$ & \% Part & Fract Par & $(\mathbf{r})$ & Volume & Vol Contrib & $\begin{array}{c}\text { INDIV MASS } \\
\%\end{array}$ & $\begin{array}{l}\text { CUM Vol } \\
\text { Contrib }\end{array}$ & $\begin{array}{c}\text { CUM Mass } \\
\text { Fraction }\end{array}$ & $\begin{array}{c}\text { CUM } \\
\text { Mass \% }\end{array}$ \\
\hline 0.5 & 4.939 & 0.049 & 0.25 & 0.065 & 0.003 & 0.00 & 0.003 & $3.19 \mathrm{E}-08$ & 0.00 \\
\hline 0.7 & 0.777 & 0.008 & 0.35 & 0.180 & 0.001 & 0.00 & 0.005 & $4.58 \mathrm{E}-08$ & 0.00 \\
\hline 1.0 & 1.056 & 0.011 & 0.50 & 0.524 & 0.006 & 0.00 & 0.010 & $1.01 \mathrm{E}-07$ & 0.00 \\
\hline 1.3 & 0.844 & 0.008 & 0.65 & 1.150 & 0.010 & 0.00 & 0.020 & $1.97 \mathrm{E}-07$ & 0.00 \\
\hline 1.8 & 0.858 & 0.009 & 0.90 & 3.054 & 0.026 & 0.00 & 0.046 & $4.58 \mathrm{E}-07$ & 0.00 \\
\hline 2.3 & 1.649 & 0.016 & 1.15 & 6.371 & 0.105 & 0.00 & 0.151 & $1.50 \mathrm{E}-06$ & 0.00 \\
\hline 3.0 & 2.303 & 0.023 & 1.50 & 14.137 & 0.326 & 0.00 & 0.477 & $4.75 \mathrm{E}-06$ & 0.00 \\
\hline 4.0 & 2.501 & 0.025 & 2.00 & 33.510 & 0.838 & 0.00 & 1.315 & $1.31 \mathrm{E}-05$ & 0.00 \\
\hline 5.0 & 3.343 & 0.033 & 2.50 & 65.450 & 2.188 & 0.00 & 3.503 & $3.49 \mathrm{E}-05$ & 0.00 \\
\hline 6.5 & 4.533 & 0.045 & 3.25 & 143.793 & 6.518 & 0.01 & 10.021 & $9.98 \mathrm{E}-05$ & 0.01 \\
\hline 8.0 & 5.885 & 0.059 & 4.00 & 268.083 & 15.777 & 0.02 & 25.798 & $2.57 \mathrm{E}-04$ & 0.03 \\
\hline 10.0 & 5.709 & 0.057 & 5.00 & 523.599 & 29.892 & 0.03 & 55.690 & $5.55 \mathrm{E}-04$ & 0.06 \\
\hline 13.0 & 5.220 & 0.052 & 6.50 & 1150.346 & 60.048 & 0.06 & 115.738 & $1.15 \mathrm{E}-03$ & 0.12 \\
\hline 17.0 & 5.793 & 0.058 & 8.50 & 2572.440 & 149.021 & 0.15 & 264.759 & $2.64 \mathrm{E}-03$ & 0.26 \\
\hline 20.0 & 6.801 & 0.068 & 10.00 & 4188.789 & 284.880 & 0.28 & 549.639 & $5.47 \mathrm{E}-03$ & 0.55 \\
\hline 25.0 & 6.956 & 0.070 & 12.50 & 8181.229 & 569.086 & 0.57 & 1118.725 & $1.11 \mathrm{E}-02$ & 1.11 \\
\hline 31.0 & 6.388 & 0.064 & 15.50 & 15598.528 & 996.434 & 0.99 & 2115.159 & $2.11 \mathrm{E}-02$ & 2.11 \\
\hline 37.0 & 6.124 & 0.061 & 18.50 & 26521.843 & 1624.198 & 1.62 & 3739.357 & $3.72 \mathrm{E}-02$ & 3.72 \\
\hline 44.0 & 6.279 & 0.063 & 22.00 & 44602.229 & 2800.574 & 2.79 & 6539.931 & $6.51 \mathrm{E}-02$ & 6.51 \\
\hline 53.0 & 5.369 & 0.054 & 26.50 & 77951.799 & 4185.232 & 4.17 & 10725.163 & $1.07 \mathrm{E}-01$ & 10.68 \\
\hline 63.0 & 4.975 & 0.050 & 31.50 & 130924.276 & 6513.483 & 6.49 & 17238.646 & $1.72 \mathrm{E}-01$ & 17.16 \\
\hline 75.0 & 3.822 & 0.038 & 37.50 & 220893.188 & 8442.538 & 8.41 & 25681.183 & $2.56 \mathrm{E}-01$ & 25.57 \\
\hline 88.0 & 2.879 & 0.029 & 44.00 & 356817.831 & 10272.785 & 10.23 & 35953.969 & $3.58 \mathrm{E}-01$ & 35.80 \\
\hline 105.0 & 2.153 & 0.022 & 52.50 & 606130.907 & 13049.998 & 12.99 & 49003.967 & $4.88 \mathrm{E}-01$ & 48.79 \\
\hline 125.0 & 1.622 & 0.016 & 62.50 & 1022653.646 & 16587.442 & 16.52 & 65591.409 & $6.53 \mathrm{E}-01$ & 65.31 \\
\hline 149.0 & 0.739 & 0.007 & 74.50 & 1732037.686 & 12799.758 & 12.74 & 78391.168 & $7.81 \mathrm{E}-01$ & 78.05 \\
\hline 177.0 & 0.259 & 0.003 & 88.50 & 2903476.605 & 7520.004 & 7.49 & 85911.172 & $8.55 \mathrm{E}-01$ & 85.54 \\
\hline 210.0 & 0.097 & 0.001 & 105.00 & 4849047.252 & 4703.576 & 4.68 & 90614.748 & $9.02 \mathrm{E}-01$ & 90.22 \\
\hline \multirow[t]{3}{*}{250.0} & 0.120 & 0.001 & 125.00 & 8181229.167 & 9817.475 & 9.78 & 100432.223 & $1.00 \mathrm{E}+00$ & 100.00 \\
\hline & & & & & & 100.00 & & & \\
\hline & & & & Total & 100432.223 & & & & \\
\hline
\end{tabular}




\begin{tabular}{|c|c|c|c|c|c|c|c|c|c|}
\hline & & & \multicolumn{5}{|c|}{ PEOR3258-S3 (Cut 3) Mass Percent - Calcined to $\sim 950^{\circ} \mathrm{C}$} & & \\
\hline \multirow{2}{*}{\multicolumn{10}{|c|}{ Assume: Spherical particles }} \\
\hline & & & & & & & & & \\
\hline $\begin{array}{c}\text { P.S. } \\
\text { (microns) }\end{array}$ & \% Part & Fract Par & (r) & Volume & Vol Contrib & $\underset{\%}{\text { INDIV MASS }}$ & $\begin{array}{l}\text { CUM Vol } \\
\text { Contrib }\end{array}$ & $\begin{array}{l}\text { CUM Mass } \\
\text { Fraction }\end{array}$ & $\begin{array}{c}\text { CUM } \\
\text { Mass \% }\end{array}$ \\
\hline 0.5 & 5.156 & 0.052 & 0.25 & 0.065 & 0.003 & 0.00 & 0.003 & $4.15 \mathrm{E}-08$ & 0.00 \\
\hline 0.7 & 0.809 & 0.008 & 0.35 & 0.180 & 0.001 & 0.00 & 0.005 & $5.93 E-08$ & 0.00 \\
\hline 1.0 & 0.999 & 0.010 & 0.50 & 0.524 & 0.005 & 0.00 & 0.010 & $1.23 \mathrm{E}-07$ & 0.00 \\
\hline 1.3 & 0.789 & 0.008 & 0.65 & 1.150 & 0.009 & 0.00 & 0.019 & $2.34 \mathrm{E}-07$ & 0.00 \\
\hline 1.8 & 0.827 & 0.008 & 0.90 & 3.054 & 0.025 & 0.00 & 0.044 & $5.43 E-07$ & 0.00 \\
\hline 2.3 & 1.738 & 0.017 & 1.15 & 6.371 & 0.111 & 0.00 & 0.155 & $1.90 \mathrm{E}-06$ & 0.00 \\
\hline 3.0 & 2.201 & 0.022 & 1.50 & 14.137 & 0.311 & 0.00 & 0.466 & $5.70 \mathrm{E}-06$ & 0.00 \\
\hline 4.0 & 2.435 & 0.024 & 2.00 & 33.510 & 0.816 & 0.00 & 1.282 & $1.57 \mathrm{E}-05$ & 0.00 \\
\hline 5.0 & 3.317 & 0.033 & 2.50 & 65.450 & 2.171 & 0.00 & 3.453 & $4.22 \mathrm{E}-05$ & 0.00 \\
\hline 6.5 & 4.938 & 0.049 & 3.25 & 143.793 & 7.101 & 0.01 & 10.554 & $1.29 \mathrm{E}-04$ & 0.01 \\
\hline 8.0 & 5.900 & 0.059 & 4.00 & 268.083 & 15.817 & 0.02 & 26.371 & $3.22 E-04$ & 0.03 \\
\hline 10.0 & 5.937 & 0.059 & 5.00 & 523.599 & 31.086 & 0.04 & 57.457 & $7.02 E-04$ & 0.07 \\
\hline 13.0 & 5.369 & 0.054 & 6.50 & 1150.346 & 61.762 & 0.08 & 119.219 & $1.46 \mathrm{E}-03$ & 0.15 \\
\hline 17.0 & 6.235 & 0.062 & 8.50 & 2572.440 & 160.392 & 0.20 & 279.610 & $3.42 E-03$ & 0.34 \\
\hline 20.0 & 7.096 & 0.071 & 10.00 & 4188.789 & 297.236 & 0.36 & 576.847 & $7.05 \mathrm{E}-03$ & 0.70 \\
\hline 25.0 & 7.261 & 0.073 & 12.50 & 8181.229 & 594.039 & 0.73 & 1170.886 & $1.43 \mathrm{E}-02$ & 1.43 \\
\hline 31.0 & 6.746 & 0.067 & 15.50 & 15598.528 & 1052.277 & 1.29 & 2223.163 & $2.72 \mathrm{E}-02$ & 2.72 \\
\hline 37.0 & 6.397 & 0.064 & 18.50 & 26521.843 & 1696.602 & 2.07 & 3919.765 & $4.79 E-02$ & 4.79 \\
\hline 44.0 & 6.263 & 0.063 & 22.00 & 44602.229 & 2793.438 & 3.41 & 6713.203 & $8.20 \mathrm{E}-02$ & 8.20 \\
\hline 53.0 & 5.157 & 0.052 & 26.50 & 77951.799 & 4019.974 & 4.91 & 10733.177 & $1.31 \mathrm{E}-01$ & 13.11 \\
\hline 63.0 & 4.292 & 0.043 & 31.50 & 130924.276 & 5619.270 & 6.87 & 16352.447 & $2.00 E-01$ & 19.98 \\
\hline 75.0 & 3.368 & 0.034 & 37.50 & 220893.188 & 7439.683 & 9.09 & 23792.129 & $2.91 \mathrm{E}-01$ & 29.07 \\
\hline 88.0 & 2.718 & 0.027 & 44.00 & 356817.831 & 9698.309 & 11.85 & 33490.438 & $4.09 \mathrm{E}-01$ & 40.92 \\
\hline 105.0 & 1.846 & 0.018 & 52.50 & 606130.907 & 11189.177 & 13.67 & 44679.614 & $5.46 \mathrm{E}-01$ & 54.59 \\
\hline 125.0 & 1.239 & 0.012 & 62.50 & 1022653.646 & 12670.679 & 15.48 & 57350.293 & $7.01 \mathrm{E}-01$ & 70.07 \\
\hline 149.0 & 0.594 & 0.006 & 74.50 & 1732037.686 & 10288.304 & 12.57 & 67638.597 & $8.26 \mathrm{E}-01$ & 82.64 \\
\hline 177.0 & 0.273 & 0.003 & 88.50 & 2903476.605 & 7926.491 & 9.68 & 75565.088 & $9.23 \mathrm{E}-01$ & 92.32 \\
\hline 210.0 & 0.052 & 0.001 & 105.00 & 4849047.252 & 2521.505 & 3.0 .8 & 78086.593 & $9.54 \mathrm{E}-01$ & 95.40 \\
\hline \multirow[t]{3}{*}{250.0} & 0.046 & 0.000 & 125.00 & 8181229.167 & 3763.365 & 4.60 & 81849.958 & $1.00 \mathrm{E}+00$ & 100.00 \\
\hline & & & & & & 100.00 & & & \\
\hline & & & & Total & 81849.958 & & & & \\
\hline
\end{tabular}


011897 62785 705

All numbers as of 6/27/95 (measured)

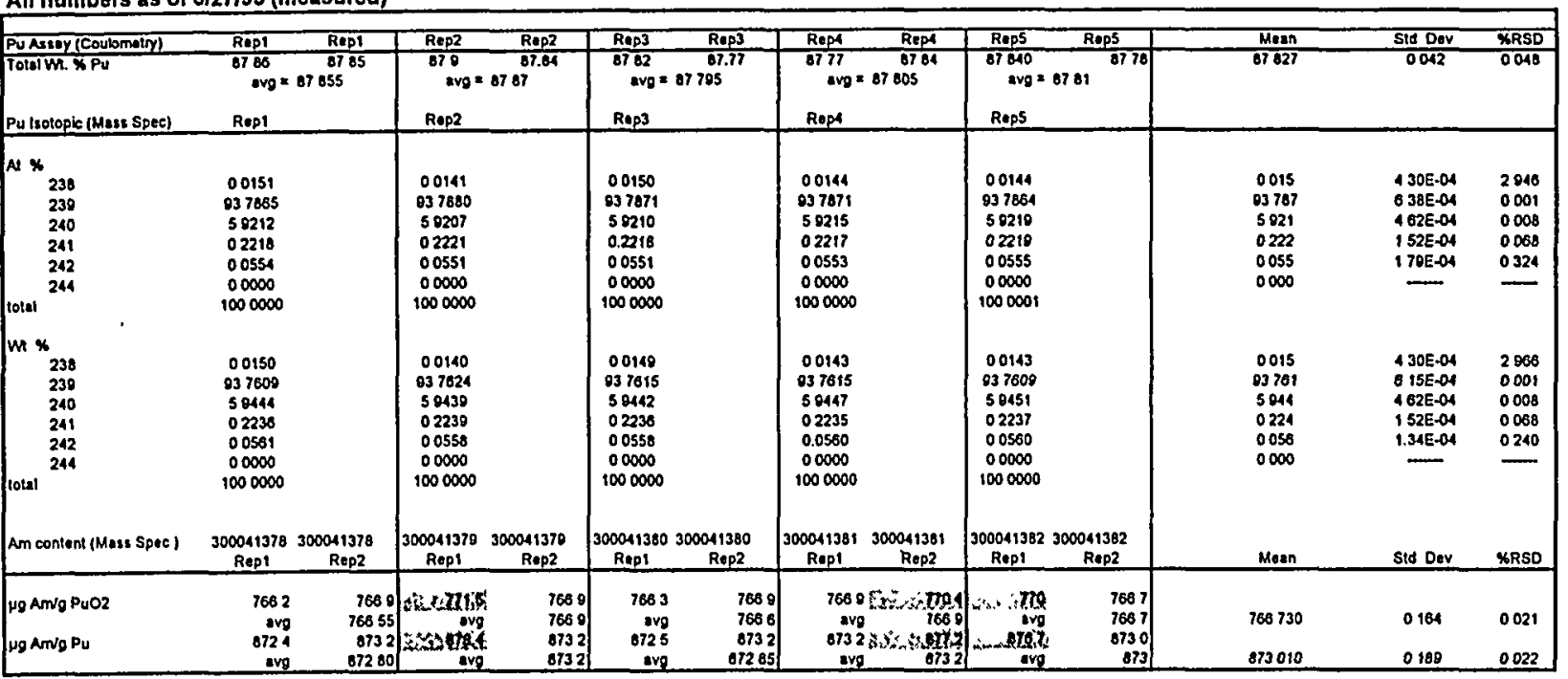

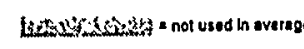

\begin{tabular}{|c|c|c|c|c|c|c|c|c|c|c|c|c|c|}
\hline \\
\hline \multicolumn{13}{|c|}{ 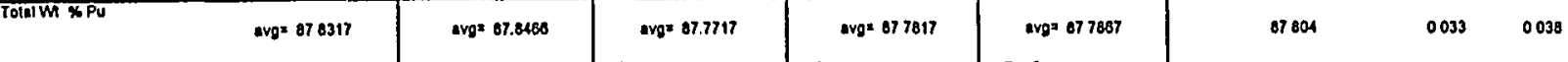 } & 0038 \\
\hline \multirow{2}{*}{$\begin{array}{l}\text { At. } x \\
238 \\
230 \\
240 \\
241 \\
242 \\
244 \\
\text { iotal } \\
m \times x \\
238 \\
230 \\
240 \\
241 \\
242 \\
244 \\
\text { totat }\end{array}$} & $\begin{array}{c}\text { decay } \\
00149 \\
037713 \\
039200 \\
50200 \\
02020 \\
00554 \\
00000 \\
800736\end{array}$ & 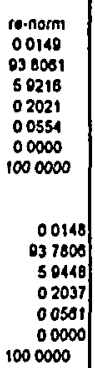 & $\begin{array}{c}\text { decay } \\
0.0130 \\
03.7928 \\
50105 \\
02023 \\
00551 \\
00000 \\
890730\end{array}$ & $\begin{array}{c}\text { ronnorm } \\
00130 \\
03.0076 \\
5.9211 \\
02024 \\
00551 \\
000000 \\
1000000\end{array}$ & 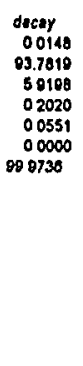 & $\begin{array}{l}10 \text {-norm } \\
00118 \\
038007 \\
50214 \\
02021 \\
000551 \\
00000 \\
0000000 \\
1000000\end{array}$ & $\begin{array}{c}\text { docedy } \\
0.0112 \\
037810 \\
50203 \\
02020 \\
00553 \\
000000 \\
09.9730\end{array}$ & 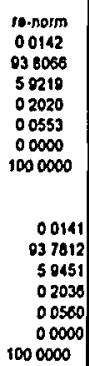 & 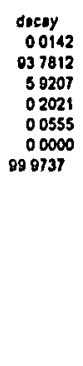 & $\begin{array}{c}\text { ron-norm } \\
00142 \\
038050 \\
50222 \\
02022 \\
00555 \\
00000 \\
1000000\end{array}$ & $\begin{array}{c}001430 \\
0300686 \\
802104 \\
802015 \\
020215 \\
005520 \\
000000 \\
10000000\end{array}$ & 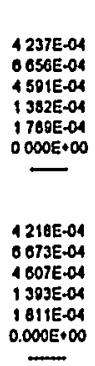 & $\begin{array}{l}2048 \\
0001 \\
0008 \\
00068 \\
0324 \\
0000 \\
\end{array}$ \\
\hline & & & & & & & & & & & & & \\
\hline \multicolumn{2}{|l|}{ 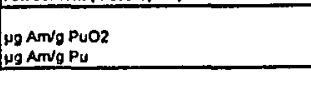 } & $\begin{array}{c}83889140 \\
100898645\end{array}$ & & 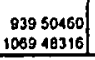 & & $\left.\begin{array}{r}93882193 \\
106961803\end{array}\right]$ & & $\begin{array}{r}93906272 \\
10697057\end{array}$ & & $\begin{array}{r}93902954 \\
106967177\end{array}$ & 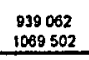 & $\begin{array}{r}2663 E-01 \\
31698-01 \\
\end{array}$ & $\begin{array}{l}0.028 \\
0030 \\
0.030\end{array}$ \\
\hline
\end{tabular}

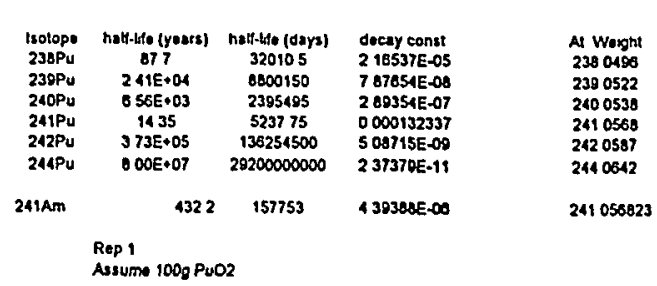

Assume loog PuOS

$\begin{array}{ccc} & 627195 & 01197 \\ & 095 & 09 \\ 238 & 00123 & 00924 \\ 239 & 823328 & 823282 \\ 240 & 52103 & 52183 \\ 241 & 01068 & 01701 \\ 242 & 00490 & 00490 \\ 244 & 00000 & 00000 \\ & & \\ & 878900 & 877887\end{array}$

Dolespu 
TO:

B. MARSHALL GROUP CST - 8

MAILSTOP G740

DATE : 31-Oct-1995

FROM: CST-3 Sample Management

SUBJECT: Final Chemical Analysis Report and Certification

CST-3 Sample Number: 200016529

Your Sample identification: PEOR3258-STD 1 Sample description: PU OXIDE

Program Code: SAll

Methods Requested: MSAM-S, MSPUISO, PACPU-S, PSDCA-S, PSMPU-S, RCAM, RCESS, TECL-S, TEF-S

The chemical analyses listed above have been compleced. The attached report package contains the analyses for all requested work. 
Analytical Chemistry Report

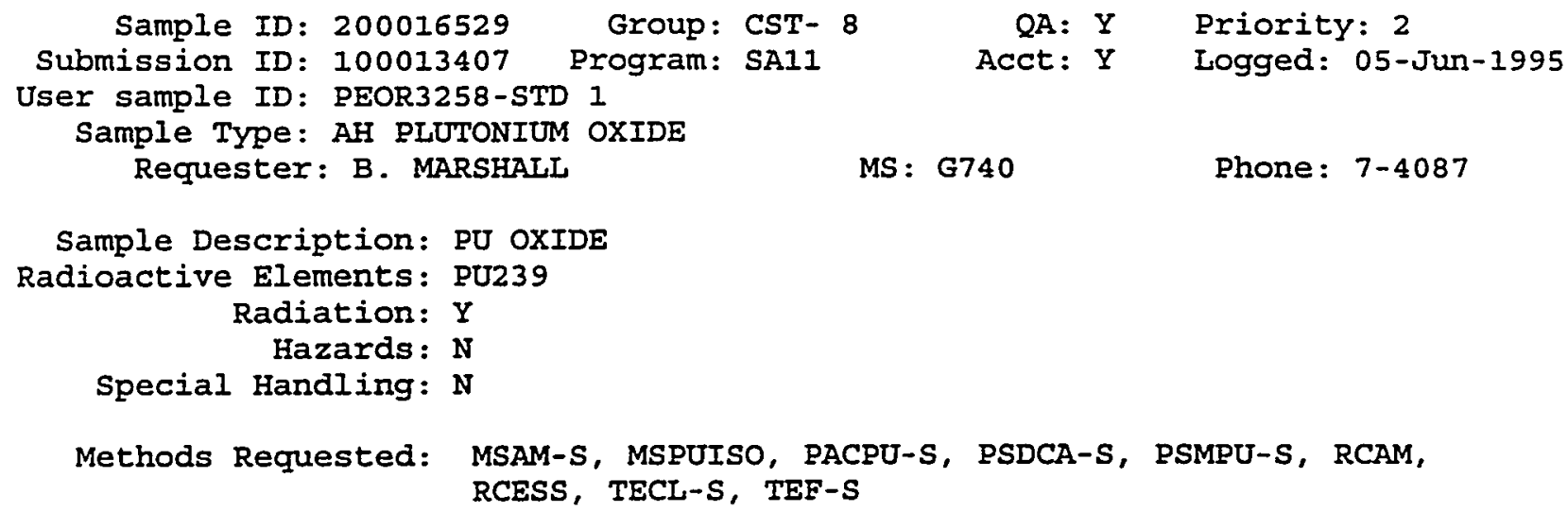

\begin{tabular}{lcccl} 
Component & \multicolumn{2}{l}{ Results } & & Units \\
\hline- PSDCA- ANALYSIS & CBC, RDA & & ANAIYST (S) \\
PLATE NUMBER & 498606 & AND & 498607 & \\
ALUMINUM & 35 & 19 & 19 & $\mathrm{ug} / \mathrm{g}$ \\
CHROMIUM & 130 & 130 & 150 & $\mathrm{ug} / \mathrm{g}$ \\
IRON & 99 & 89 & 100 & $\mathrm{ug} / \mathrm{g}$ \\
NICKEL & 245 & 280 & 285 & $\mathrm{ug} / \mathrm{g}$ \\
SILICON & 205 & 130 & 155 & $\mathrm{ug} / \mathrm{g}$ \\
CAICIUM & 1000 & 770 & 750 & $\mathrm{ug} / \mathrm{g}$ \\
LEAD & 23 & 16 & 15 & $\mathrm{ug} / \mathrm{g}$ \\
TIN & $<5$ & $<5$ & $<5$ & $\mathrm{ug} / \mathrm{g}$ \\
ZINC & $<5$ & $<5$ & $<5$ & $\mathrm{ug} / \mathrm{g}$ \\
SILVER & $<1$ & $<I$ & 1 & $\mathrm{ug} / \mathrm{g}$ \\
BISMUTH & 3 & 2 & 2 & $\mathrm{ug} / \mathrm{g}$ \\
CADMIUM & $<10$ & $<10$ & $<10$ & $\mathrm{ug} / \mathrm{g}$ \\
MAGNESIUM & 34 & 26 & 26 & $\mathrm{ug} / \mathrm{g}$ \\
MANGANESE & 2 & 3 & 4 & $\mathrm{ug} / \mathrm{g}$ \\
MOLYBDENUM & $<20$ & $<20$ & $<20$ & $\mathrm{ug} / \mathrm{g}$ \\
BORON & $<5$ & $<5$ & $<5$ & $\mathrm{ug} / \mathrm{g}$ \\
BERYLLIUM & $<1$ & $<1$ & $<1$ & $\mathrm{ug} / \mathrm{g}$ \\
COPPER & 3 & 3 & 4 & $\mathrm{ug} / \mathrm{g}$ \\
SODIUM & 100 & 50 & 50 & $\mathrm{ug} / \mathrm{g}$
\end{tabular}

Our standards are based on trace impurities in pure PuO2. Experience has shown that if any one impurity level exceeds $2000 \mathrm{ug} / \mathrm{g}$ or the summption of impurity levels for several impurities exceeds $3000 \mathrm{ug} / \mathrm{g}$, results for other impurities may be biased.

Result is based on sample as received and is expressed as ug/g or ug/ml unless indicated otherwise. Result preceded by a s symbol represents our present limit of detection. 
Notebook reference: 26648 PG 96

Analyst: Olivares, Jose

Approved by: Olivares, Jose 28-Jun-1995 15:13

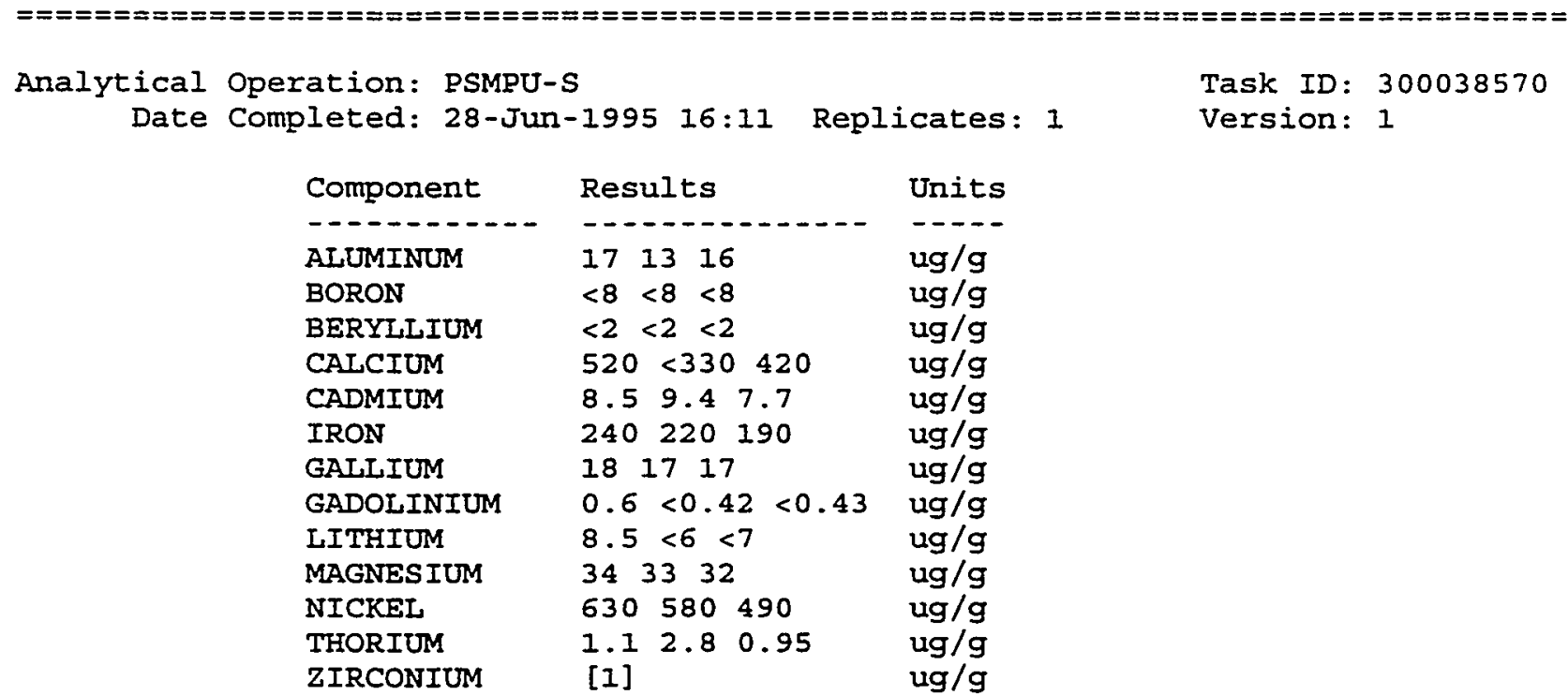

[1] ZIRCONIUM:

URANIUM 238

CURIUM 242

CURIUM 244

CALIFORNIUM
$263269416 \mathrm{ug} / \mathrm{g}$

$157016401620 \mathrm{ug} / \mathrm{g}$ (Intefered by $\mathrm{Pu}-242$ )

$0.100 .0952 .3 \mathrm{ug} / \mathrm{g}$

Notebook reference: LNA12793 PG94-97

Analyst: $\mathrm{CB}$

Approved by: Olivares, Jose 28-Jun-1995 16:48

Notebook reference: 10733, PP. 117, 120

Task ID: 300038572

version: 1 
Analyst: JAK, TRH

Approved by: Marshal1, Thomas K. 06-Sep-1995 14:48

\begin{tabular}{|c|c|c|c|c|c|c|c|}
\hline $\begin{array}{r}\text { Analytical } \\
\text { Date }\end{array}$ & $\begin{array}{l}\text { Operation: } \\
\text { Completed: }\end{array}$ & $\begin{array}{l}\text { PACPU-S } \\
\text { 30-Jun-1995 }\end{array}$ & $11: 53$ & Replicates: & 5 & $\begin{array}{l}\text { Task ID: } \\
\text { Version: }\end{array}$ & $\begin{array}{l}300038573 \\
1\end{array}$ \\
\hline Component & Rep 1 & Rep 2 & Rep & Rep 4 & 4 & Rep 5 & Units \\
\hline PLUTONIUM & $87.85[1]$ & $87.86 \quad[2]$ & 87.7 & $9[3]$ & $0[4]$ & $87.81[5]$ & percent \\
\hline
\end{tabular}

Assay Method: Coulometry

Estimated Precision: $0.1 \%$

[1] PLUTONIUM, Rep I:

Analyzed five separate dissolutions of the sample. Two analyses were performed for each dissolution and the average for each dissolution is reported. The following results were obtained for Rep 1: 87.86\% and $87.85 \%$.

[2] PLUTONIUM, Rep 2 :

Analyzed five separate dissolutions of the sample. Two analyses were performed for each dissolution and the average for each dissolution is reported. The following results were obtained for Rep 2: 87.90\% and $87.84 \%$.

[3] PLUTONIUM, Rep 3 :

Analyzed five separate dissolutions of the sample. Two analyses were performed for each dissolution and the average for each dissolution is reported. The following results were obtained for Rep 3: $87.82 \%$ and $87.77 \%$.

[4] PLUTONIUM, Rep 4 :

Analyzed five separate dissolutions of the sample. Two analyses were performed for each dissolution and the average for each dissolution is reported. The following results were obtained for Rep 4: 87.77\% and $87.84 \%$.

[5] PLUTONIUM, Rep 5:

Analyzed five separate dissolutions of the sample. Two analyses were performed for each dissolution and the average for each dissolution is reported. The following results were obtained for Rep 5: $87.84 \%$ and $87.78 \%$.

$\begin{array}{ll}\text { Notebook references: } & \text { Rep 1: LANB } 9237 \text { PP. 120-121 } \\ \text { Rep 2: SAME } \\ \text { Rep 3: SAME } \\ \text { Rep 4: SAME } \\ \text { Rep 5: SAME }\end{array}$

Analyst: IMS, EL, WJB

Approved by: Temer, Donald J. 30-Jun-1995 14:04

\begin{tabular}{|c|c|c|c|c|c|c|c|}
\hline \multirow[t]{2}{*}{$\begin{array}{r}\text { Analytical } \\
\text { Date }\end{array}$} & $\begin{array}{l}\text { Operation: } \\
\text { Completed: }\end{array}$ & $\begin{array}{l}\text { RCAM } \\
12-J u I-1995\end{array}$ & $11: 55$ & Replicates: & 1 & $\begin{array}{l}\text { Task ID: } \\
\text { Version: }\end{array}$ & $\begin{array}{l}300040775 \\
1\end{array}$ \\
\hline & $\begin{array}{l}\text { Compon } \\
\text { AMERIC } \\
\text { \%RSD + } \\
\text { COMMEN }\end{array}$ & $\begin{array}{l}\text { ent } \\
\text { IUM-241 } \\
/- \\
\text { TS }\end{array}$ & ults & $\begin{array}{l}\text { Units } \\
----- \\
\text { ppm }\end{array}$ & & & \\
\hline
\end{tabular}


Results for Sample 200016529 31-Oct-1995 10:58

\section{[1] COMMENTS: FIVE CUTS WERE ANALYZED}

Analyst: Stalnaker, Nelson D.

Approved by: Stalnaker, Nelson D. 23-Aug-1995 07:39

Analytical operation: RCESS

Date Completed: 12-Jul-1995 11:55 Replicates: 1

Task ID: 300040776

Component Result Units

C....... -.... -...-

SURVEY [I]

COMMENTS [2]

[1] SURVEY:

ALPHA SPECTROSCOPY DID NOT REVEAL ANY ACTIVITY DUE TO CM-244 OR CF-252. THE DETECTION LIMIT FOR CM-244 IS LESS THAN 0.5 PQM AND THE DETECTION IIMIT FOR CE-252 IS LESS THAN 0.1 PPM.

\section{[2] COMMENTS: FIVE CUTS WERE ANALYZED}

Analyst: stalnaker, Nelson D.

Approved by: Stalnaker, Nelson D. 23-Aug-1995 07:39

Analytical Operation: MSAM-S

Date Completed: 17-Jul-1995 11:22 Replicates: 2

Task ID: 300041378

\begin{tabular}{llll} 
Component & $\operatorname{Rep} 1$ & Rep 2 & Units \\
\hdashline AMERICIUM & 766.2 & 766.9 & $\mathrm{ug} / \mathrm{g}$
\end{tabular}

Notebook reference: VG-2, CUTS AI \& A2, SEPARATION DATE: 6/26/95, 238PU BY RADIO CHEMISTRY.

Analyst: $\mathrm{CH}, \mathrm{LC}, \mathrm{PN}$

Approved by: Callis, Larry 18-Jul-1995 08:52

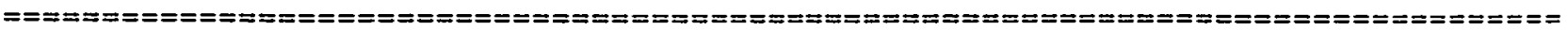

Analytical Operation: MSAM-S

Task ID: 300041379

Date Completed: 17-Jul-1995 11:37 Replicates: 2 Version: 1

\begin{tabular}{llll} 
Component & Rep 1 & Rep 2 & Units \\
\hdashline AMERICIUM & 771.5 & 766.9 & $\mathrm{ug} / \mathrm{g}$
\end{tabular}

Notebook reference: VG-2, CUTS BI \& B2, SEPARATION DATE: 6/26/95, 238PU BY RADIO CHEMISTRY.

Analyst: $\mathrm{CH}, \mathrm{LC}, \mathrm{PN}$

Approved by: Callis, Larry 18-Jul-1995 08:52 
Analytical Operation: MSAM-S

Date Completed: 13-Jul-1995 11:52 Replicates: 2

Task ID: 300041380

Version: 1

\begin{tabular}{llll} 
Component & Rep 1 & Rep 2 & Units \\
\hline AMERICIUM & 766.3 & 766.9 & $\mathrm{ug} / \mathrm{g}$
\end{tabular}

Notebook reference: VG-2, CUTS C1 \& C2, SEPARATION DATE: 6/26/95, 238PU BY RADIO CHEMISTRY.

Analyst: CH, LC, PN

Approved by: Callis, Larry 18-Jul-1995 08:52

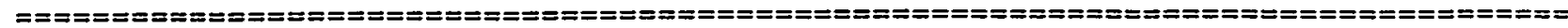

Analytical Operation: MSAM-S

Date Completed: 13-Jul-1995 11:56 Replicates: 2

Task ID: 300041381

Version: 1

\begin{tabular}{llll} 
Component & $\operatorname{Rep} 1$ & $\operatorname{Rep} 2$ & Units \\
\hdashline AMERICIUM & 766.9 & 770.4 & $\mathrm{ug} / \mathrm{g}$
\end{tabular}

Notebook reference: VG-2, CUTS D1 \& D2, SEPARATION DATE: 6/26/95, 238PU BY RADIO CHEMISTRY.

Analyst: $\mathrm{CH}, \mathrm{LC}, \mathrm{PN}$

Approved by: Callis, Larry 18-Jul-1995 08:52

Analytical Operation: MSAM-S

Date Completed: 13-Jul-1995 11:59 Replicates: 2

Task ID: 300041382

Version: 1

\begin{tabular}{llll} 
Component & Rep 1 & Rep 2 & Units \\
\hdashline AMERICIUM & 770.0 & 766.7 & $\mathrm{ug} / \mathrm{g}$
\end{tabular}

Notebook reference: VG-2, CUTS EI \& E2, SEPARATION DATE: 6/26/95, 238PU BY RADIO CHEMISTRY.

Analyst: $\mathrm{CH}, \mathrm{LC}, \mathrm{PN}$

Approved by: Callis, Larry 18-Jul-1995 $08: 52$

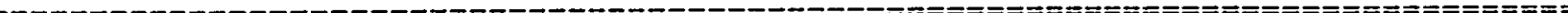

Analytical Operation: MSPUISO

Date Completed: 13-Jul-1995 11:31 Replicates: 5

Componen
PU-238
PU-239
PU-240
PU-241
PU-242
PU-244
SUM
PU-238
PU-239
PU-240
PU-241

$\begin{array}{rr}\text { Rep 1 } & \text { Rep 2 } \\ -0.0151 & 0.0141 \\ 0.0151 & 93.7880 \\ 93.7865 & 5.9207 \\ 5.9212 & 0.2221 \\ 0.2218 & 0.051 \\ 0.0554 & 0.0551 \\ 0.0000 & 0.0000 \\ 100.0000 & 100.0000 \\ 0.0150 & 0.0140 \\ 93.7609 & 93.7624 \\ 5.5444 & 5.9439 \\ 0.2236 & 0.2239\end{array}$

Rep 4
0.0144
93.7871
5.9215
0.2217
0.0553
0.0000
100.0000
0.0143
93.7615
5.9447
0.2235

Task ID: 300041383

Version: 1

\begin{aligned} Rep 5 & Units \\ \hline 0.0144 & atom percent \\ 93.7864 & atom percent \\ 5.9219 & atom percent \\ 0.2219 & atom percent \\ 0.0558 & atom percent \\ 0.0000 & atom percent \\ 99.9999 & atom percent \\ 0.0143 & weight percent \\ 93.7609 & weight percent \\ 5.9451 & weight percent \\ 0.2237 & weight percent \end{aligned}


Results for Sample $200016529 \quad 31$-Oct-1995 10:58

Page 6

\begin{tabular}{|c|c|c|c|}
\hline $\begin{array}{l}P U-242 \\
P U-244\end{array}$ & $\begin{array}{l}0.0561 \\
0.0000\end{array}$ & $\begin{array}{l}0.0558 \\
0.0000\end{array}$ & $\begin{array}{l}0.0 \\
0.0\end{array}$ \\
\hline omponent & Average & \multicolumn{2}{|c|}{ Units } \\
\hline & & \multicolumn{2}{|c|}{$----1----1-1$} \\
\hline $\mathrm{J}-238$ & 0.0146 & \multicolumn{2}{|c|}{ atom percent } \\
\hline $0-239$ & 93.7870 & \multicolumn{2}{|c|}{ atom percent } \\
\hline$P U-240$ & 5.9213 & \multicolumn{2}{|c|}{ atom percent } \\
\hline PU -24 & 0.2219 & \multicolumn{2}{|c|}{ atom percent } \\
\hline$P U-242$ & 0.0552 & \multicolumn{2}{|c|}{ atom percent } \\
\hline PU-244 & 0.0000 & \multicolumn{2}{|c|}{ atom percent } \\
\hline SUM & 100.0000 & \multicolumn{2}{|c|}{ atom percent } \\
\hline $\mathrm{PU}-238$ & 0.0145 & \multicolumn{2}{|c|}{ weight percent } \\
\hline PU-239 & 93.7614 & \multirow{2}{*}{\multicolumn{2}{|c|}{$\begin{array}{l}\text { weight percent } \\
\text { weight percent }\end{array}$}} \\
\hline $\mathrm{PO}-240$ & 5.9445 & & \\
\hline PU-241 & 0.2237 & \multicolumn{2}{|c|}{ weight percent } \\
\hline $\mathrm{PO}-242$ & 0.05 & \multirow{2}{*}{\multicolumn{2}{|c|}{ weight percent }} \\
\hline PU-244 & 0.0000 & & \\
\hline
\end{tabular}

Notebook reference: VG-2

Analyst: CH, LC, PN

Approved by: Callis, Larry 18-Jul-1995 08:52

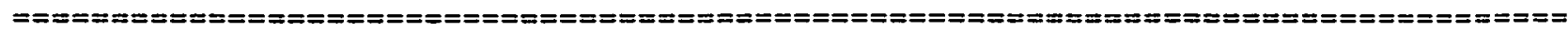




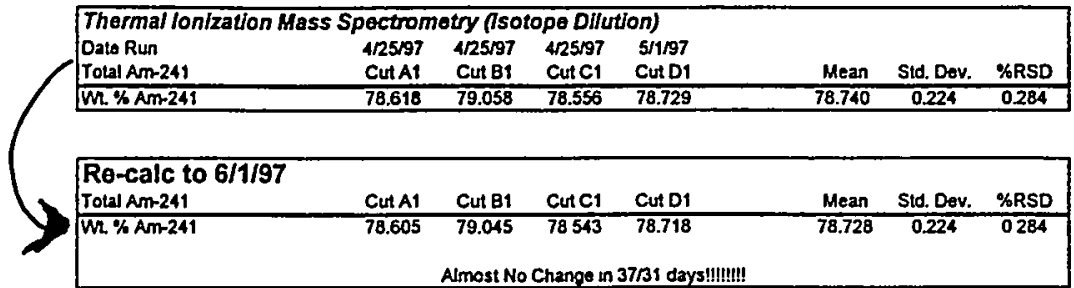

\begin{tabular}{|c|c|c|c|c|c|c|c|}
\hline Pu in the AmO2 & $\begin{array}{c}5 / 12297 \\
\text { Cut A1 }\end{array}$ & $\begin{array}{c}5 / 12997 \\
\text { Cut Bt }\end{array}$ & $\begin{array}{l}5 / 12997 \\
\text { Cut C1 }\end{array}$ & $\begin{array}{l}5 / 12 / 97 \\
\text { Cut D1 }\end{array}$ & Mean & Std. Dev. & \%RSD \\
\hline TotalW. \% Pu & 0.403 & 0.414 & 0.421 & 0.421 & 0.415 & 0.008 & 2.049 \\
\hline AL. $\%$ & $5 / 15 / 97$ & $5 / 15 / 97$ & $5 / 15 / 97$ & $5 / 15 / 97$ & & & \\
\hline 238 & 0.0440 & 0.0459 & 0.0461 & 0.0455 & 0.0454 & 0.001 & 2.094 \\
\hline 239 & 89.4040 & 89.1441 & 89.1455 & 89.0807 & 89.1936 & 0.144 & 0.161 \\
\hline 240 & 9.9090 & 10.1479 & 10.1463 & 10.2059 & 10.1023 & 0.132 & $\$ .305$ \\
\hline 241 & 0.4597 & 0.4757 & 0.4751 & 04794 & 0.4725 & 0009 & 0.847 \\
\hline 242 & 0.1832 & 0.1864 & 0.1871 & 0.1885 & 0.1863 & 0.002 & 1.204 \\
\hline 244 & 0.0000 & 0.0000 & 0.0000 & 0.0000 & 0.0000 & 0.000 & 0.000 \\
\hline Total & 99.9999 & 100.0000 & $100.000 t$ & 100.0000 & 100.0000 & & \\
\hline$m . \%$ & 5/15/97 & $5 / 15 / 97$ & $5 / 15 / 97$ & $5 / 15 / 97$ & & & \\
\hline 238 & 0.0438 & 0.0457 & 0.0459 & 0.0453 & 0.0452 & 0.001 & 2.103 \\
\hline 239 & 89.3616 & 89.1007 & 89.1021 & 89.0371 & 89.1504 & 0.144 & 0.162 \\
\hline 240 & 9.9450 & 10.1855 & 10.1839 & 10.2437 & 10.1397 & 0.132 & 1.304 \\
\hline 261 & 0.4633 & 0.4795 & 0.4789 & 0.4832 & 0.4762 & 0.009 & 1.853 \\
\hline 242 & 0.1854 & 0.1837 & 0.1894 & 0.1908 & 0.1886 & 0.002 & 1.214 \\
\hline 244 & 0.0000 & 0.0000 & 0.0000 & 0.0000 & 0.0000 & 0.0000 & 0.0000 \\
\hline Total & 99.9561 & 100.0001 & 100.0002 & 100.0001 & 100.0001 & & \\
\hline
\end{tabular}

\begin{tabular}{|c|c|c|c|c|}
\hline & $\begin{array}{l}6 / 1 / 97 \\
6 / 1 / 97 \\
6 / 1 / 97\end{array}$ & $\begin{array}{r}4 / 25 / 97 \\
5 / 15 / 97 \\
5 / 1 / 97\end{array}$ & $\begin{array}{l}37 \\
17 \\
31\end{array}$ & \\
\hline $\begin{array}{l}\text { Isotope } \\
238 \mathrm{Pu} \\
239 \mathrm{Pu}\end{array}$ & $\begin{array}{c}\text { 1F-rfe (yea } \\
87.7 \\
2.41 E+04\end{array}$ & $\begin{array}{l}\text { HHtifo (day } \\
32010.5 \\
8800150\end{array}$ & $\begin{array}{l}\text { ecay const } \\
2.17 E-05 \\
7.88 E-08\end{array}$ & $\begin{array}{l}\text { At Weight } \\
2380496 \\
2390522\end{array}$ \\
\hline $\begin{array}{l}240 \mathrm{Pu} \\
241 \mathrm{Pu}\end{array}$ & $\begin{array}{c}6.56 \mathrm{E}+03 \\
14.35\end{array}$ & $\begin{array}{l}2395495 \\
5237.75\end{array}$ & $\begin{array}{l}2.89 E-07 \\
0.000132\end{array}$ & $\begin{array}{l}2400538 \\
2410568\end{array}$ \\
\hline $\begin{array}{l}242 \mathrm{Pu} \\
244 \mathrm{Pu}\end{array}$ & $\begin{array}{l}3.75 E+05 \\
8.00 E+07\end{array}$ & $\begin{array}{l}1.37 E+08 \\
2.92 E+10\end{array}$ & $\begin{array}{l}5.06 E-09 \\
2.37 E-11\end{array}$ & $\begin{array}{l}242.0587 \\
244.0642\end{array}$ \\
\hline $\begin{array}{l}241 \mathrm{Am} \\
237 \mathrm{~Np}\end{array}$ & $\begin{array}{r}432.7 \\
2.14 E+06\end{array}$ & $\begin{array}{l}157935.5 \\
7.81 E+08\end{array}$ & $\begin{array}{l}4.39 E-06 \\
8.87 E-10\end{array}$ & $\begin{array}{l}2410568 \\
2370482\end{array}$ \\
\hline
\end{tabular}

Rep 1

Assume $100 \mathrm{gAmO2}$

$0.414 \mathrm{OPU}$

$\begin{array}{cccc} & 5 / 1297 & 6 / 1197 & 20 \\ 238 & 0.0002 & 0.0002 & \\ 239 & 0.3689 & 0.3689 \\ 240 & 0.0422 & 0.0422 \\ 241 & 0.0020 & 0.0020 \\ 242 & 0.0008 & 0.0008 \\ 244 & 0.0000 & 0.0000\end{array}$

totzl Pu $=0.4140 \quad 0.4140$

\begin{tabular}{|c|c|c|c|c|c|c|c|c|c|c|c|}
\hline $\begin{array}{l}\text { Recalc to } 6 / 1 / 97 \\
\text { Pu in tho AmO2 }\end{array}$ & Cut A1 & & Cut BI & & Cut C1 & & Cut D1 & & Moan & Sid Dev. & \%RSD \\
\hline Total L $_{\text {\% }}$ Pu & 0.403 & & 0414 & & 0421 & & 0.421 & & $\overline{0.415}$ & 0.008 & 2.089 \\
\hline Al. $\%$ & decay & ronnom & docay & ronom & decey & ro-nom & decay & renorm & & & \\
\hline 238 & 0.0440 & 00440 & 0.0459 & 00459 & 0.0461 & 0.0461 & 00455 & 0.0455 & 0.0454 & 0.0009 & 2.0936 \\
\hline 239 & 89.4039 & $89.405 t$ & 89.1440 & 89.1451 & 89.1454 & 89.1464 & 89.0806 & 89.0817 & 89.1946 & 0.1435 & 0.1609 \\
\hline 240 & 9.9090 & 9.9098 & 10.1479 & 10.1480 & 10.1463 & 10.1464 & 10.2058 & 10.2060 & 10.1024 & 0.1318 & 1.3046 \\
\hline 241 & 0,4587 & 0.4587 & 0.4746 & 0.4746 & 0.4740 & 0.4740 & 0.4783 & 0.4783 & 0.4714 & 0.0087 & 1.8469 \\
\hline 242 & 0.1832 & 0.1832 & 0.1854 & 0.1864 & 0.1871 & 0.1871 & 0.1885 & 0.1885 & 0.1863 & 0.0022 & 1.2042 \\
\hline 244 & 0.0000 & 0.0000 & 0.0000 & 0.0000 & 0.0000 & 0.0000 & 0.0000 & 0.0000 & 0.0000 & 0.0000 & 0.0000 \\
\hline Total & 99.9987 & 100.0000 & 99.9987 & 100.0000 & 99.9988 & 100.0000 & 99.9987 & 100.0000 & 100.0000 & & \\
\hline \multicolumn{12}{|l|}{$W_{L} *$} \\
\hline 238 & & 0.0438 & & 0.0457 & & 0.0459 & & 0.0453 & 0.0451 & 0.0009 & 2.0930 \\
\hline 239 & & 89.3626 & & 89.1017 & & 89.1031 & & 89.0381 & 89.1514 & 0.1440 & 0.1616 \\
\hline 240 & & 9.9459 & & 10.1855 & & 10.1839 & & 10.2437 & 10.1398 & 0.1322 & 1.3010 \\
\hline 241 & & 0.4623 & & 0.4784 & & 0.4778 & & 0.4821 & 0.4751 & 0.0088 & 1.8463 \\
\hline 242 & & 0.1854 & & 0.1887 & & 0.1894 & & 0.1908 & 0.1886 & 0.0023 & 1.2036 \\
\hline 244 & & 0.0000 & & 0.0000 & & 0.0000 & & 0.0000 & 0.0000 & 0.0000 & 0.0000 \\
\hline Tous & & 100.0000 & & 100.0000 & & 100.0000 & & 100.0000 & 100.0000 & & \\
\hline
\end{tabular}

\begin{tabular}{|c|c|c|}
\hline $\mathrm{U}$ in the AmO2 & $5 / 16 / 97$ & \\
\hline Total W. \%U & 0.0035 & (35 $\mu g$ g-compares well to ICP-MS data) \\
\hline At. $\%$ & $5 / 16 / 97$ & \\
\hline 233 & 0.1930 & \\
\hline 234 & 5.3530 & \\
\hline 235 & 43.0924 & \\
\hline 236 & 17.1905 & \\
\hline 238 & 34.1621 & \\
\hline Total & 100.0000 & $\begin{array}{l}\text { NOTE: Decay corrections for Uranium are not necessary } \\
\text { Due to the long hattives of the isotopes. }\end{array}$ \\
\hline wh. \% & $5 / 16 / 97$ & \\
\hline 233 & 0.1904 & \\
\hline 234 & 5304 & \\
\hline 235 & 42.8841 & \\
\hline 236 & 17.1893 & \\
\hline 238 & 34.4319 & \\
\hline Total & 99.8097 & \\
\hline
\end{tabular}


CEP WRMs

Am Feedstock Anal. Chem Results (200023528)

\begin{tabular}{|c|c|c|c|c|c|c|c|}
\hline \multicolumn{8}{|c|}{ ICPANS (Full QA) } \\
\hline Eement & Cone. Limt ( $\mu / g)$ & Cut $6(\mu g / g)$ & $\operatorname{Cut} 7(\mu \mathrm{g} / \mathrm{g})$ & Cut $8(\mu / g)$ & Mean & Std Dev. & \%RSD \\
\hline$F e+N_{h}$ & $<400$ & 384 & 359 & 346 & 363 & 19.31 & 5.32 \\
\hline Fe & - & 287 & 264 & 259 & 270 & 1493 & 553 \\
\hline$N_{t}$ & & 97 & 95 & 87 & 93 & 5.29 & 569 \\
\hline $\mathrm{Be}$ & 2 & $<0.5$ & $=0.5$ & $<05$ & & & \\
\hline $\mathbf{M g}_{\mathrm{g}}$ & $<500$ & 58 & 52 & 45 & 52 & 651 & 12.59 \\
\hline co & $<1000$ & 1298 & 1257 & 1277 & 1277 & 20.50 & 9.61 \\
\hline$N_{p}$ & $<100$ & 19976 & 20201 & 19150 & 19776 & 553.40 & 2.80 \\
\hline Th & $<0$ & 35 & 36 & 35 & 35 & 0.58 & 1.63 \\
\hline Ga & 25 & 3.2 & 3.3 & 3 & 3 & 015 & 4.02 \\
\hline A & $<50$ & 144 & $12 t$ & 102 & 122 & 2103 & 17.19 \\
\hline $\mathbf{u}$ & $<500$ & 36 & 40 & 37 & 38 & 2.08 & 5.53 \\
\hline U-235 & - & $18^{\circ}$ & $20^{\circ}$ & $18^{\circ}$ & $187^{*}$ & 1.15 & 6.15 \\
\hline u-23s & - & 18 & 20 & 19 & 19 & 100 & 5.26 \\
\hline \multicolumn{8}{|c|}{ ICPAMS (Ro-analyzed with full QA) } \\
\hline Element & Conc. Lumit $(\mu g / g)$ & Cut $6(\mu g / 9)$ & $\cot 7(\mu g / g)$ & Cut $8(u g / a)$ & Mean & Sta.Dev. & \%RSD \\
\hline $\mathrm{B}$ & - & 576 & 58 & 552 & 579 & 1665 & 2.92 \\
\hline $\mathbf{K}$ & - & 4821 & 5640 & $\$ 124$ & 4862 & 75882 & 15.61 \\
\hline La & - & 190 & 198 & 180 & 189 & 9.02 & 4.76 \\
\hline Na & - & 2981 & 2223 & 1438 & 2214 & 771.54 & 3685 \\
\hline $\mathbf{p o}_{\mathbf{b}}$ & - & 4385 & 1761 & 1619 & 2588 & 1557.58 & 60.18 \\
\hline$y$ & - & 43301 & 45056 & $\$ 2890$ & 43749 & 1150.40 & 2.63 \\
\hline Np & - & 19590 & 19631 & 18718 & 19313 & 515.69 & 2.67 \\
\hline
\end{tabular}

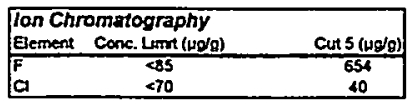

\begin{tabular}{|c|c|c|c|c|c|c|c|}
\hline \multicolumn{8}{|c|}{ Thermal lonization Mass Spectrometry (sotope Dilution) } \\
\hline Totas Anr-241 & CutÁl & cut 81 & Cutc1 & Cut os & Mean & Std. Dev. & \%RSO \\
\hline$m \times A \sqrt{m}-261$ & 70.618 & 79.058 & 78.556 & 78.729 & 78.740 & 0.224 & 0.234 \\
\hline Pun the AmO2 & Cuta1 & Cut 81 & Cut C1 & Cut 0 : & Mean & Std. Dev. & \%RSD \\
\hline Total $\mathrm{W} \times \mathrm{Pu}$ & 0403 & 0.414 & 0.421 & 0.421 & $0 ., 15$ & 0000 & 2.049 \\
\hline \multicolumn{8}{|l|}{ At. $\%$} \\
\hline 238 & 0.0460 & 00459 & 00461 & 0.0455 & 0045 & 0008 & 2.094 \\
\hline 239 & 894040 & 89.144t & 89.1455 & 89.0807 & 89.196 & 0.14 & 0.161 \\
\hline 260 & 9.9090 & 10.1479 & 10.1463 & 10.2059 & 10.102 & 0.132 & 1.305 \\
\hline 241 & 0.4597 & 04757 & 04751 & 04794 & 0.472 & 0.009 & $\$ .247$ \\
\hline 242 & 0.1832 & 01854 & 0.1871 & 01885 & 0.186 & 0.002 & 1.204 \\
\hline 24 & 0.0000 & 00000 & 00000 & 0.0000 & 0.000 & 0.000 & 0000 \\
\hline Total & 999999 & 1000000 & 1000001 & 1000000 & 100.0000 & & \\
\hline \multicolumn{8}{|l|}{$m \%$} \\
\hline 238 & 0.0438 & 00457 & 0.0459 & 00453 & 00452 & 0001 & 2.103 \\
\hline 239 & 89.3616 & 89.1007 & 89.1021 & 89.0371 & 89.1504 & 0.144 & 0.162 \\
\hline 240 & 99458 & 10.1855 & 10.1839 & 10.2437 & 10.1397 & 0.132 & 1.304 \\
\hline 241 & 04633 & 0.4795 & 0.4789 & 0.4832 & 0.4762 & 0009 & 1.853 \\
\hline 242 & 0.1854 & 0.1887 & 0.1894 & 0.1908 & 0.1885 & 0.002 & 1.214 \\
\hline 24 & 00000 & 00000 & 0.0000 & 0.0000 & 0.0000 & 0.0000 & 0.0000 \\
\hline Total & 99.9561 & 100.0001 & 1000002 & 1000001 & 100.0001 & & \\
\hline \multicolumn{8}{|l|}{ Un the AmO2 } \\
\hline Tots $W \mathrm{Ku}$ & 00035 & (35 $\left.\mu g^{\prime} g-\infty\right)$ & Dares well & (CP-MS data) & & & \\
\hline \multicolumn{8}{|l|}{ At: $x$} \\
\hline 233 & 01930 & & & & & & \\
\hline 234 & 53530 & & & & & & \\
\hline 235 & 43.0924 & & & & & & \\
\hline 236 & 17.1995 & & & & & & \\
\hline 238 & 34.1621 & & & & & & \\
\hline Totes & 1000000 & & & & & & \\
\hline \multicolumn{8}{|l|}{$m *$} \\
\hline 233 & 0.1904 & & & & & & \\
\hline 234 & 5.3044 & & & & & & \\
\hline 235 & 42.8841 & & & & & & \\
\hline 236 & 17.1893 & & & & & & \\
\hline 238 & 34.4319 & & & & & & \\
\hline Toted & 99.8097 & & & & & & \\
\hline
\end{tabular}

\begin{tabular}{|c|c|}
\hline \multicolumn{2}{|c|}{ Totw Mass Baisnce (W/t Y) } \\
\hline $\operatorname{Am} 241$ & 78.74 \\
\hline Nip237 & 1.93 \\
\hline$Y$ & 4.37 \\
\hline$P D$ & 0.17 \\
\hline Nata & 0.22 \\
\hline$c_{a}$ & 0.13 \\
\hline $\mathrm{K}$ & 049 \\
\hline Bi & 005 \\
\hline La & 002 \\
\hline LOI (HZO) & 2.19 \\
\hline Pu (total) & 042 \\
\hline Lotal & 8873 \\
\hline $\begin{array}{l}\text { Stoic. An = } \\
\text { Stoic. 02 = }\end{array}$ & $\begin{array}{l}88.28 \\
11.72\end{array}$ \\
\hline $\begin{array}{l}\% \text { dift }= \\
\text { (stac. Amnot }\end{array}$ & $\begin{array}{l}\text { O } 50 \\
\text { constovents } \\
\text { ks } 0 \text { ) }\end{array}$ \\
\hline $\begin{array}{l}\text { assume } 117 \\
\text { equats. }\end{array}$ & $\begin{array}{l}\% 0 \text { then total } \\
0045 \%\end{array}$ \\
\hline
\end{tabular}

\begin{tabular}{|c|c|c|c|c|c|c|c|c|c|c|c|c|}
\hline \multicolumn{13}{|c|}{ Radiochemistry } \\
\hline \multicolumn{2}{|c|}{ 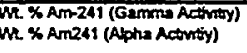 } & $\begin{array}{l}78.55 \\
79.14\end{array}$ & $\begin{array}{l}78.71 \\
78.43\end{array}$ & $\begin{array}{l}79.27 \\
79.62\end{array}$ & $\begin{array}{l}80.08 \\
79.62\end{array}$ & $\begin{array}{l}78.07 \\
79.98\end{array}$ & $\begin{array}{l}79.24 \\
78.87\end{array}$ & $\begin{array}{l}80.02 \\
7907\end{array}$ & $\begin{array}{l}79.57 \\
79.41\end{array}$ & $\begin{array}{l}79.33 \\
79.27\end{array}$ & $\begin{array}{l}0.53 \\
0.49\end{array}$ & $\begin{array}{l}066 \\
062\end{array}$ \\
\hline Eement & Conc. Lumt (ug/g) & AmO2 & & & & & & & & & & \\
\hline $\begin{array}{l}\mathrm{C}_{\mathrm{m}} 244 \\
\mathrm{Cr}-252\end{array}$ & $<4$ & $\begin{array}{l}<0.02 \\
<0.003\end{array}$ & & $\begin{array}{l}\text { estriat } \\
\text { Acovity rab } \\
\text { (no actial }\end{array}$ & $\begin{array}{l}\text { based on } \\
\text { do } 239.2 \\
\text { iks were }\end{array}$ & $\begin{array}{l}\text { Hives and } \\
\text { Pu dphis } \\
\text { enved for }\end{array}$ & $\begin{array}{l}\text { vity rabo. } \\
m \text { or } 252 \mathrm{C}\end{array}$ & the cones & ntratons : & & & \\
\hline
\end{tabular}

Loss On lgnition Performed on remanang AmO2 to be used in WRM fabncaton (nom. 1.70)

\begin{tabular}{|c|c|c|c|c|}
\hline \multirow{3}{*}{$\begin{array}{l} \\
\text { Groess.... } \\
\text { Troos } \\
\text { Net }\end{array}$} & \multirow{3}{*}{$\begin{array}{l}\text { Before (g) } \\
14.0158 \\
12.65575 \\
1.74583\end{array}$} & \multirow{3}{*}{$\begin{array}{l}\text { Ater (g) } \\
14.3634 \\
12.6558 \\
1.70165\end{array}$} & \multicolumn{2}{|c|}{$\cdots$ AmO2 + Pt Dish } \\
\hline & & & & \\
\hline & & & W. $\cos 8(9)$ & 0.03817 \\
\hline LOO WL & 2.19 & & & \\
\hline
\end{tabular}


Analytical Chemistry Report

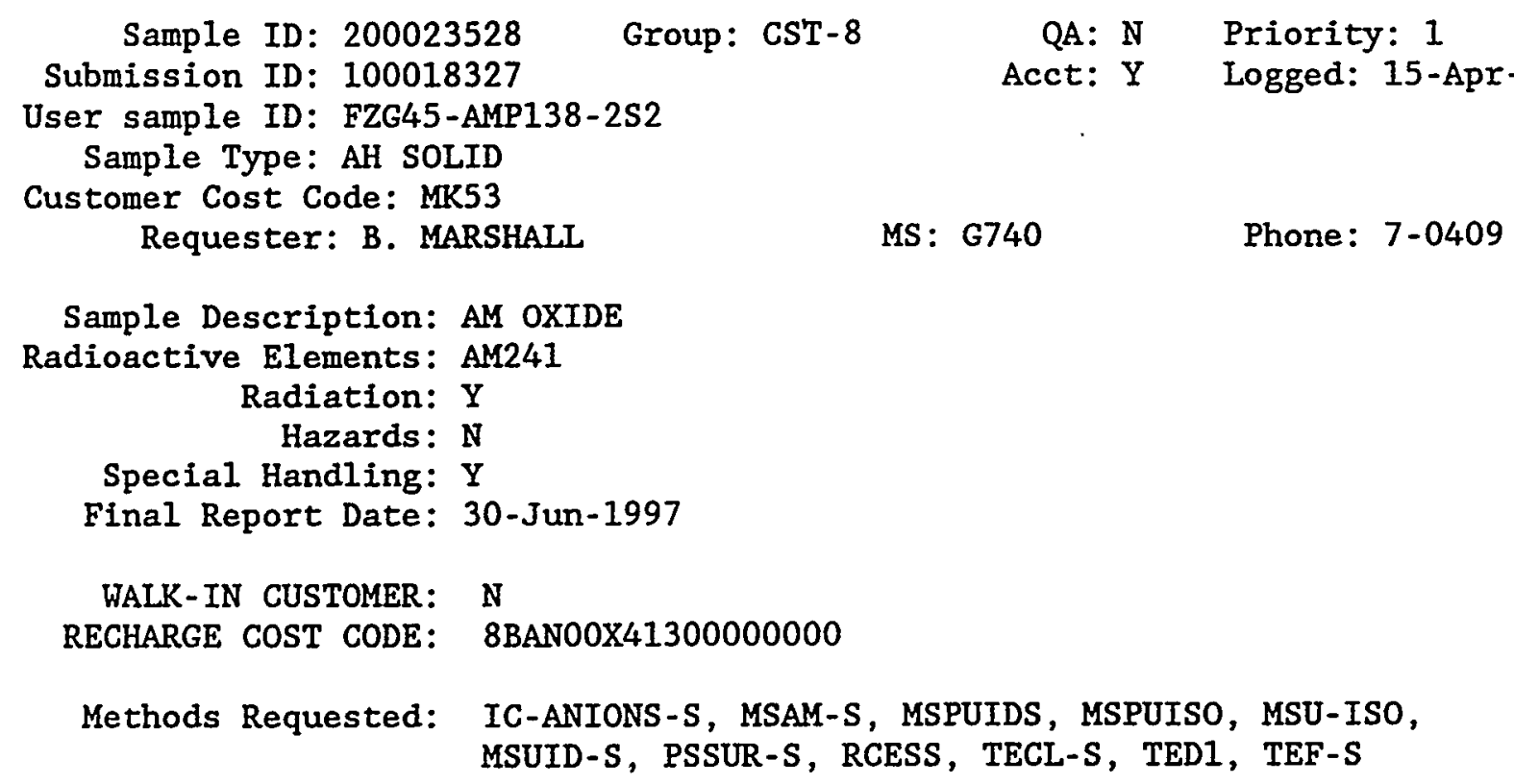


Analytical Operation: TED1

Date Completed: 20-May-1997 08:50 Replicates: 1

Task ID: 300081860

Version: 1

WALK-IN QUOTED COST:

WAIK-IN CHARGE BALNC: 0

DESCRIPTION: DISSOLUTION

\begin{tabular}{lll} 
Component & Result & Units \\
\hdashline DISSOLUTION & $\mathrm{Y}$ & $\mathrm{Y} / \mathrm{N}$
\end{tabular}

Notebook reference: 4040, P. 141

Analyst: TRH

Approved by: Marshall, Thomas K. 20-May-1997 08:50

Analytical Operation: MSU-ISO

Date Completed: 20-May-1997 14:12 Replicates: 1

Task ID: 300084888

Version: 1

WALK-IN QUOTED COST:

WALK-IN CHARGE BALNC: 0

DESCRIPTION: MS-MSU ISO

\begin{tabular}{lrrl} 
Component & Results & Average & Units \\
\hline $\mathrm{U}-233$ & 0.1930 & 0.1930 & atom percent \\
$\mathrm{U}-234$ & 5.3530 & 5.3530 & atom percent \\
$\mathrm{U}-235$ & 43.0924 & 43.0924 & atom percent \\
$\mathrm{U}-236$ & 17.1995 & 17.1995 & atom percent \\
$\mathrm{U}-238$ & 34.1621 & 34.1621 & atom percent \\
SUM & 100.0000 & 100.0000 & atom percent \\
$\mathrm{U}-233$ & 0.1904 & 0.1904 & weight percent \\
$\mathrm{U}-234$ & 5.3044 & 5.3044 & weight percent \\
$\mathrm{U}-235$ & 42.8841 & 42.8841 & weight percent \\
$\mathrm{U}-236$ & 17.1893 & 17.1893 & weight percent \\
$\mathrm{U}-238$ & 34.4319 & 34.4319 & weight percent
\end{tabular}

Notebook reference: VG-2

Analyst: NMS, CH, JA

Approved by: Callis, Larry 21-May-1997 10:38

Analytical Operation: MSPUISO

Date Completed: 20-May-1997 14:27 Replicates: 4
Task ID: 300084889

Version: 1

WALK-IN QUOTED COST:

WALK-IN CHARGE BALNC: 0

DESCRIPTION: MS-MASS SPEC PU ISOTOPIC 


\begin{tabular}{lrrrrrl} 
Component & Rep 1 & Rep 2 & Rep 3 & Rep 4 & Average & Units \\
\hline PU-238 & 0.0440 & 0.0459 & 0.0461 & 0.0455 & 0.0454 & atom percent \\
PU-239 & 89.4040 & 89.1441 & 89.1455 & 89.0807 & 89.1936 & atom percent \\
PU-240 & 9.9090 & 10.1479 & 10.1463 & 10.2059 & 10.1023 & atom percent \\
PU-241 & 0.4597 & 0.4757 & 0.4751 & 0.4794 & 0.4725 & atom percent \\
PU-242 & 0.1832 & 0.1864 & 0.1871 & 0.1885 & 0.1863 & atom percent \\
PU-244 & 0.0000 & 0.0000 & 0.0000 & 0.0000 & 0.0000 & atom percent \\
SUM & 99.9999 & 100.0000 & 100.0001 & 100.0000 & 100.0000 & atom percent \\
PU-238 & 0.0438 & 0.0457 & 0.0459 & 0.0453 & 0.0452 & weight percent \\
PU-239 & 89.3616 & 89.1007 & 89.1021 & 89.0371 & 89.1504 & weight percent \\
PU-240 & 9.9458 & 10.1855 & 10.1839 & 10.2437 & 10.1397 & weight percent \\
PU-241 & 0.4633 & 0.4795 & 0.4788 & 0.4832 & 0.4762 & weight percent \\
PU-242 & 0.1854 & 0.1887 & 0.1894 & 0.1908 & 0.1886 & weight percent \\
PU-244 & 0.0000 & 0.0000 & 0.0000 & 0.0000 & 0.0000 & weight percent
\end{tabular}

Notebook reference: VG-2

Analyst: NMS, $\mathrm{CH}, \mathrm{JA}$

Approved by: Callis, Larry 21-May-1997 10:38

Analytical Operation: MSPUIDS

Date Completed: 20-May-1997 14:30 Replicates: 4

WALK-IN QUOTED COST:

WALK-IN CHARGE BALNC: 0

DESCRIPTION: MS-PLUTONIUM IN SOLIDS OR LIQUIDS

Notebook reference: VG-2

Analyst: NMS, $\mathrm{CH}, \mathrm{JA}$

Approved by: Callis, Larry 21-May-1997 10:38

Analytical Operation: MSUID-S

Date Completed: 20-May-1997 14:18 Replicates: 1

Task ID: 300084890

Version: 1

\begin{tabular}{llllll} 
Component & $\operatorname{Rep} 1$ & $\operatorname{Rep} 2$ & $\operatorname{Rep~3}$ & $\operatorname{Rep~4}$ & Units \\
\hdashline PLUTONIUM & 0.403 & 0.414 & 0.421 & 0.421 & weight percent
\end{tabular}

WALK-IN QUOTED COST:

WALK-IN CHARGE BALNC: 0

DESCRIPTION: MS-URANIUM IN SOLIDS

$\begin{array}{lll}\text { Component } & \text { Result Units } \\ \text { URANIUM } & .0035 & \text { weight percent }\end{array}$

Task ID: 300084891

Version: 1 
Results for Sample 200023528 26-Jan-1998 10:57

Notebook reference: VG-2

Analyst: NMS, $\mathrm{CH}, \mathrm{JA}$

Approved by: Callis, Larry 21-May-199? 10:38

Analytical Operation: PSSUR-S

Date Completed: 27-May-1997 00:00 Replicates: 1 Version: 1

WAIK-IN QUOTED COST:

WALK-IN CHARGE BALNC: 0

DESCRIPTION: PS-ELEMENTAL ANALYSIS IN SOLIDS

\begin{tabular}{|c|c|c|c|c|c|}
\hline Component & Result & Units & Component & Result & Units \\
\hline - & $\cdots$ & $\ldots$ & 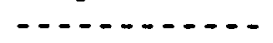 & $\ldots$ & $\ldots$ \\
\hline ALUMINUM & 144. & ug/g & BERYLLIUM & $<0.5$ & $\mathrm{ug} / \mathrm{g}$ \\
\hline BISMUTH & $570 *$ & $\mathrm{ug} / \mathrm{g}$ & CALCIUM & 1298 & $\mathrm{ug} / \mathrm{g}$ \\
\hline IRON & 287 & $\mathrm{ug} / \mathrm{g}$ & GALLIUM & 3.2 & $\mathrm{ug} / \mathrm{g}$ \\
\hline POTASSIUM & $1743 *$ & ug/g & LANTHANUM & $180 *$ & $\mathrm{ug} / \mathrm{g}$ \\
\hline MAGNESIUM & 58 & ug/g & SODIUM & $2016 *$ & $\mathrm{ug} / \mathrm{g}$ \\
\hline NICKEL & 97 & $\mathrm{ug} / \mathrm{g}$ & LEAD & $1796 *$ & $\mathrm{ug} / \mathrm{g}$ \\
\hline THORIUM & 35 & $\mathrm{ug} / \mathrm{g}$ & YTTRIUM & $42300 *$ & $\mathrm{ug} / \mathrm{g}$ \\
\hline ZIRCONIUM & $302 *$ & $\mathrm{ug} / \mathrm{g}$ & COMMENTS & [1] & \\
\hline URANIUM 235 & $18 * *$ & $\mathrm{ug} / \mathrm{g}$ & NEPTUNIUM & 19976 & $\mathrm{ug} / \mathrm{g}$ \\
\hline URANIUM 238 & 18 & $u g / g$ & CUT_ID & CUT - 6 & \\
\hline
\end{tabular}

\section{[1] COMMENTS: *LIMITED QA $/ * *$ SEMI -QUANT}

Notebook reference: ANC52 PG .115

Analyst: TMY/AAM/CAB

Approved by: Yoshida, Thomas M 27-May-1997 10:08

Analytical Operation: PSSUR-S

Date Completed: 27-May-1997 00:00 Replicates: 1 Version: 1

WALK-IN QUOTED COST:

WALK-IN CHARGE BALNC: 0

DESCRIPTION: PS-ELEMENTAL ANALYSIS IN SOLIDS

\begin{tabular}{|c|c|c|c|c|c|}
\hline Component & Results & Units & Component & Results & Units \\
\hline - & - & $-\cdots$ & - - - - - - - - - - - - & - & \\
\hline ALUMINUM & 121 & $\mathrm{ug} / \mathrm{g}$ & BERYLLIUM & $<0.5$ & ug/g \\
\hline CALCIUM & 1257 & $\mathrm{ug} / \mathrm{g}$ & IRON & 264 & $\mathrm{ug} / \mathrm{g}$ \\
\hline GALLIUM & 3.3 & $u g / g$ & MAGNESIUM & 52 & $\mathrm{ug} / \mathrm{g}$ \\
\hline NICKEL & 95 & $u g / g$ & THORIUM & 36 & $\mathrm{ug} / \mathrm{g}$ \\
\hline COMMENTS & **SEMI-QUANT & & URANIUM 235 & $20 * *$ & $\mathrm{ug} / \mathrm{g}$ \\
\hline NEPTUNIUM & 20201 & ug/g & URANIUM 238 & 20 & $u g / g$ \\
\hline
\end{tabular}


Notebook reference: ANC52 PG 115

Analyst: TMY/AAM/CAB

Approved by: Yoshida, Thomas M 27-May-1997 10:08

Analytical Operation: PSSUR-S

Date Completed: 27-May-1997 00:00 Replicates: 1 Version: 1

WALK-IN QUOTED COST:

WALK-IN CHARGE BALNC: 0

DESCRIPTION: PS-ELEMENTAL ANALYSIS IN SOLIDS

\begin{tabular}{|c|c|c|c|c|c|}
\hline Component & Results & Units & Component & Results & Units \\
\hline - & מ & $\ldots$ & - & מ & \\
\hline ALUMINUM & 102 & $\mathrm{ug} / \mathrm{g}$ & BERYLLIUM & $<0.5$ & ug/g \\
\hline CALCIUM & 1277 & $\mathrm{ug} / \mathrm{g}$ & IRON & 259 & $\mathrm{ug} / \mathrm{g}$ \\
\hline GALIIUM & 3.0 & $\mathrm{ug} / \mathrm{g}$ & MAGNESIUM & 45 & $\mathrm{ug} / \mathrm{g}$ \\
\hline NICKEL & 87 & $\mathrm{ug} / \mathrm{g}$ & THORIUM & 35 & $\mathrm{ug} / \mathrm{g}$ \\
\hline COMMENTS & $* *$ SEMI -QUANT & & URANIUM 235 & $18 * *$ & $\mathrm{ug} / \mathrm{g}$ \\
\hline NEPTUNIUM & 19150 & $\mathrm{ug} / \mathrm{g}$ & URANIUM 238 & 19 & ug/g \\
\hline CUT_ID & CUT - 8 & & & & \\
\hline
\end{tabular}

Notebook reference: ANC52 PG 115

Analyst: TMY/AAM/CAB

Approved by: Yoshida, Thomas M 27-May-1997 10:08

Analytical Operation: RCESS

Date Completed: 27-May-1997 11:02 Replicates: 1 Version: 1

WALK-IN QUOTED COST:

WALK-IN CHARGE BALNC: 0

\begin{tabular}{lll} 
Component & Results & Units \\
\hline SURVEY & {$[1]$} & \\
COMMENTS & AW-RC-5 PP91-102
\end{tabular}

\section{[1] SURVEY:}

sample were received. Several Radiochemical analyses were performed as part of analytical survey on this sample.

(1) The amount of 241Am isotope in the sample was determine by the liquid scintillation and gamma ray spectroscopy. The average $\%$ of Am in the sample was $79.34+/-0.57 \%$ by LSC and $79.40+/-0.57 \%$ by gamma ray analysis. The calculations were based on the assumption of all alpha and gamma activities were from Am241. 
(2) Direct gamma scan of the Am oxide sample could not provide information on other radionuclides in the sample due to high level Am activity. The half-life of $241 \mathrm{Am}$ isotope is about 5000 times shorter than 237Np. Based on the gamma analysis, we could not confirm if there is any $237 \mathrm{~Np}$ in the sample.

(3) $244 \mathrm{Cm}$ and $252 \mathrm{Cf}$ concentrations: Based on alpha spectrometry data, the estimated amount of $244 \mathrm{~cm}$ in the sample is less than $0.02 \mathrm{ppm}$ and the amount of $252 \mathrm{Cf}$ in the sample is less than $0.003 \mathrm{ppm}$.

Analyst: Wong, Amy

Approved by: Wong, Amy 27-May-1997 11:02

Analytical Operation: MSAM-S

Date Completed: 30-May-1997 14:36 Replicates: 4

Task ID: 300087631

Version: 1

WALK-IN QUOTED COST:

WALK-IN CHARGE BALNC: 0

DESCRIPTION: MS-AMERICIUM IN SOLIDS

\begin{tabular}{|c|c|c|c|c|}
\hline ponent & Rep 1 & Rep 2 & Rep 3 & $\operatorname{Rep} 4$ \\
\hline AMERICIUM & 786180 & 790580 & 785560 & 787290 \\
\hline
\end{tabular}

Notebook reference: VG-2

Analyst: NMS, $\mathrm{CH}, \mathrm{JA}$

Approved by: Callis, Larry 02-Jun-1997 17:42

Analytical Operation: PSSUR-S

Date Completed: 19-Jun-1997 00:00 Replicates: 1

WALK-IN QUOTED COST:

WALK-IN CHARGE BAINC: 0

DESCRIPTION: PS-ELEMENTAL ANALYSIS. IN SOLIDS

$\begin{array}{llllll}\text { Component } & \text { Results } & \text { Units } & \text { Component } & \text { Results } & \text { Units } \\ \text { BISMUTH } & 576 & \text { ug/g } & \text { POTASSIUM } & 4821[1] & \mathrm{ug} / \mathrm{g} \\ \text { LANTHANUM } & 190 & \text { ug/g } & \text { SODIUM } & 2981 & \mathrm{ug} / \mathrm{g} \\ \text { LEAD } & 4385 & \text { ug/g } & \text { YTTRIUM } & 43301 & \mathrm{ug} / \mathrm{g} \\ \text { COMMENTS } & \text { SEMI -QUANT } & & \text { NEPTUNIUM } & 19590 & \mathrm{ug} / \mathrm{g}\end{array}$

Notebook reference: ANC52 PG 122

Analyst: TMY/AAM/CAB 
Analytical Operation: PSSUR-S

Date Completed: 19-Jun-1997 00:00 Replicates: 1 Version: 1

WALK-IN QUOTED COST:

WALK-IN CHARGE BALNC: 0

DESCRIPTION: PS-ELEMENTAL ANALYSIS IN SOLIDS

\begin{tabular}{llllll} 
Component & Results & Units & Component & Results & Units \\
\hdashline BISMUTH & 584 & ug/g & POTASSIUM & $5640[1]$ & ug/g \\
LANTHANUM & 198 & ug/g & SODIUM & 2223 & $\mathrm{ug} / \mathrm{g}$ \\
LEAD & 1761 & ug/g & YTTRIUM & 45056 & $\mathrm{ug} / \mathrm{g}$ \\
COMMENTS & SEMI-QUANT & & NEPTUNIUM & 19631 & $\mathrm{ug} / \mathrm{g}$ \\
CUT_ID & CUT-7 & & & &
\end{tabular}

Notebook reference: ANC52 PG 122

Analyst: TMY/AAM/CAB

Approved by: Yoshida, Thomas M 19-Jun-1997 09:46

Analytical Operation: PSSUR-S

Date Completed: 19-Jun-1997 00:00 Replicates: 1

WALK-IN QUOTED COST:

WALK-IN CHARGE BALNC: 0

DESCRIPTION: PS-ELEMENTAL ANALYSIS IN SOLIDS

\begin{tabular}{llllll} 
Component & Results & Units & Component & Results & Units \\
\hdashline BISMUTH & 552 & ug/g & POTASSIUM & $4124[1]$ & $\mathrm{ug} / \mathrm{g}$ \\
LANTHANUM & 180 & ug/g & SODIUM & 1438 & $\mathrm{ug} / \mathrm{g}$ \\
LEAD & 1619 & ug/g & YTTRIUM & 42890 & $\mathrm{ug} / \mathrm{g}$ \\
COMMENTS & SEMI-QUANT & & NEPTUNIUM & 18718 & $\mathrm{ug} / \mathrm{g}$ \\
CUT_ID & CUT-8 & & & &
\end{tabular}

Notebook reference: ANC52 PG 122

Analyst: TMY/AAM/CAB

Approved by: Yoshida, Thomas M 19-Jun-1997 09:46
Task ID: 300092948

Version: 1 
Analytical Operation: TEF-S

Date Completed: 20-Jun-1997 16:44 Replicates: 1

WALK-IN QUOTED COST:

WALK-IN CHARGE BALNC: 0

DESCRIPTION: TE-F
Task ID: 300093804

Version: 1

Notebook reference: 4070, PP. 142, 143

Analyst: TRH

Approved by: Marshall, Thomas K. 20-Jun-1997 16:54

Analytical Operation: TECL-S

Date Completed: 20-Jun-1997 16:44 Replicates: 1.Version: 1

WALK-IN QUOTED COST:

WALK-IN CHARGE BALNC: 0

DESCRIPTION: TE-CL IN SOLID

\begin{tabular}{lll} 
Component & Result & Units \\
\hdashline$-\ldots . .-1$ & $-\ldots .--$ & $\ldots$. \\
CHLORIDE & 40 & $\mathrm{ug} / \mathrm{g}$
\end{tabular}

Notebook reference: 4070, PP. 142,143

Analyst: TRH

Approved by: Marshall, Thomas K. 20-Jun-1997 16:54 


\section{CEP WRMs}

\section{Depleted Uranium Feedstock Anal. Chem Results (200023256)}

\begin{tabular}{|c|c|c|c|c|c|c|c|}
\hline \\
\hline Element & Conc. Limit $(\mu g / g)$ & \multicolumn{5}{|c|}{ ICP-MS (Full QA) } & \%RSD \\
\hline Al & $<200$ & 99 & 108 & 102 & 103 & 5 & 4 \\
\hline$B$ & $<30$ & 297 & 307 & 307 & 303.666667 & 5.773502692 & 1.901263 \\
\hline $\mathrm{Be}$ & $<1$ & $<0.5$ & $<0.5$ & $<0.5$ & & & \\
\hline $\mathrm{Ca}$ & $<200$ & 21 & 23 & 25 & 23 & 2 & 9 \\
\hline Cd & $<2$ & 0.22 & 0.13 & 0.31 & 0.22 & 0.09 & 40.91 \\
\hline $\mathrm{Fe}+\mathrm{Ni}+\mathrm{Cr}$ & $<250$ & 55.3 & 57.4 & 55.9 & 56.2 & 1.1 & 1.9 \\
\hline $\mathrm{Fe}$ & $\ldots$ & 46 & 50 & 49 & 48 & 2 & 4 \\
\hline $\mathrm{Ni}$ & - & 7.7 & 5.7 & 4.9 & 6.1 & 1.4 & 23.6 \\
\hline $\mathrm{Cr}$ & - & 1.6 & 1.7 & 2.0 & 1.8 & 0.2 & 11.8 \\
\hline $\mathrm{Li}$ & $<1$ & $<0.5$ & $<0.5$ & $<0.5$ & & & \\
\hline $\mathrm{Mg}$ & $<50$ & 4.1 & 5.4 & 4.5 & 4.7 & 0.7 & 14.3 \\
\hline $\mathrm{Na}$ & $<200$ & 171 & 175 & 157 & 168 & 1 & 6 \\
\hline $\mathrm{Si}$ & $<300$ & - & 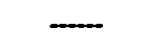 & $\longrightarrow$ & & & \\
\hline $\mathrm{Pb}$ & $<20$ & 7.2 & 5.5 & 5.4 & 6.0 & 1.0 & 16.8 \\
\hline$w$ & $<350$ & 3.0 & 2.8 & 3.1 & 3.0 & 0.2 & 5.1 \\
\hline $\mathrm{v}$ & $<100$ & 1.6 & 1.4 & 1.6 & 1.5 & 0.1 & 7.5 \\
\hline
\end{tabular}

\begin{tabular}{|c|c|c|c|c|c|c|c|}
\hline \multicolumn{8}{|c|}{ Pyrohydrolysis/lon Selective Electrode } \\
\hline Element & Conc. Limit ( $\mu \mathrm{g} / \mathrm{g})$ & Cut a & Cut b & Cut $\mathrm{c}$ & Mean & Std. Dev. & $\%$ RSD \\
\hline$F$ & $<85$ & 4 & 4 & $<1$ & 4.0 & 0.0 & 0.0 \\
\hline $\mathrm{Cl}$ & $<70$ & 6 & 3 & 3 & 4.0 & 1.7 & 43.3 \\
\hline
\end{tabular}

\begin{tabular}{|c|c|c|c|c|c|c|c|c|}
\hline \multicolumn{9}{|c|}{ Thermal Ionization Mass Spectrometry (Isotope Dilution) } \\
\hline U Assay & Cut 12 & Cut 13 & Cut 14 & Cut 15 & Cut 16 & Mean & Std. Dev. & \%RSD \\
\hline Total Wt. \%U & 87.464 & 87.497 & 87.496 & 87.525 & 87.485 & 87.493 & 0.022 & 0.025 \\
\hline \multicolumn{9}{|l|}{ At. $\%$} \\
\hline 233 & 0.0000 & 0.0000 & 0.0000 & 0.0000 & 0.0000 & 0.000 & 0.000 & $\ldots$ \\
\hline 234 & 0.0008 & 0.0008 & 0.0002 & 0.0014 & 0.0008 & 0.001 & 4.24E-04 & 53.033 \\
\hline 235 & 0.1925 & 0.1930 & 0.1923 & 0.1922 & 0.1929 & 0.193 & $3.56 E-04$ & 0.185 \\
\hline 236 & 0.0035 & 0.0034 & 0.0036 & 0.0029 & 0.0037 & 0.003 & $3.11 E-04$ & 9.107 \\
\hline 238 & 99.8031 & 99.8028 & 99.8039 & 99.8036 & 99.8027 & 99.803 & 5.17E-04 & 0.001 \\
\hline Total & 99.9999 & 100.0000 & 100.0000 & 100.0001 & 100.0001 & 100.000 & & \\
\hline \multicolumn{9}{|l|}{ Wt. \% } \\
\hline 233 & 0.0000 & 0.0000 & 0.0000 & 0.0000 & 0.0000 & 0.000 & 0.000 & - \\
\hline 234 & 0.0008 & 0.0008 & 0.0002 & 0.0014 & 0.0008 & 0.001 & 4.24E-04 & 53.033 \\
\hline 235 & 0.1901 & 0.1906 & 0.1899 & 0.1898 & 0.1905 & 0.190 & $3.56 E-04$ & 0.187 \\
\hline 236 & 0.0035 & 0.0034 & 0.0036 & 0.0029 & 0.0037 & 0.003 & 3.11E-04 & 9.107 \\
\hline 238 & 99.8057 & 99.8053 & 99.8064 & 99.8060 & 99.8051 & 99.806 & 5.24E-04 & 0.001 \\
\hline Total & 100.0001 & 100.0001 & 100.0001 & 100.0001 & 100.0001 & 100.000 & & \\
\hline
\end{tabular}

\begin{tabular}{|lll|}
\hline \multicolumn{2}{|l|}{ Radiochemistry } & \\
Element & Conc. Limit $(\mu \mathrm{g} / \mathrm{g})$ & Depleted UO2 \\
\hline Cm-244 & $<1$ & $<0.000005^{*}$ \\
$\mathrm{Cf}-252$ & $<0.5$ & $<0.0000007^{*}$
\end{tabular}


Rep 8: SAME

Analyst: EL

Approved by: Temer, Donald J. 22-Apr-1997 14:37

Analytical Operation: MSU-ISO

Date Completed: 28-Apr-1997 09:54 Replicates: 5
Task ID: 300081170

Version: 1

WALK-IN QUOTED COST:

WALK-IN CHARGE BALNC: 0

DESCRIPTION: MS-MSU ISO

\begin{tabular}{|c|c|c|c|c|c|c|}
\hline Component & $\operatorname{Rep} 1$ & $\operatorname{Rep} 2$ & Rep 3 & $\operatorname{Rep} 4$ & $\operatorname{Rep} 5$ & Units \\
\hline$\ldots . .$. & $\ldots . .$. & $\ldots \ldots$ & & & $\ldots$ & $\ldots$ \\
\hline$U-233$ & 0.0000 & 0.0000 & 0.0000 & 0.0000 & 0.0000 & atom percent \\
\hline$U-234$ & 0.0008 & 0.0008 & 0.0002 & 0.0014 & 0.0008 & atom percent \\
\hline$U-235$ & 0.1925 & 0.1930 & 0.1923 & 0.1922 & 0.1929 & atom percent \\
\hline$U-236$ & 0.0035 & .0 .0034 & 0.0036 & 0.0029 & 0.0037 & atom percent \\
\hline $\mathrm{U}-238$ & 99.8031 & 99.8028 & 99.8039 & 99.8036 & 99.8027 & atom percent \\
\hline SUM & 99.9999 & 100.0000 & 100.0000 & 100.0001 & 100.0001 & atom percent \\
\hline $\mathrm{U}-233$ & 0.0000 & 0.0000 & 0.0000 & 0.0000 & 0.0000 & weight percent \\
\hline $\mathrm{U}-234$ & 0.0008 & 0.0008 & 0.0002 & 0.0014 & 0.0008 & weight percent \\
\hline$U-235$ & 0.1901 & 0.1906 & 0.1899 & 0.1898 & 0.1905 & weight percent \\
\hline $\mathrm{U}-236$ & 0.0035 & 0.0034 & 0.0036 & 0.0029 & 0.0037 & weight percent \\
\hline$U-238$ & 99.8057 & 99.8053 & 99.8064 & 99.8060 & 99.8051 & weight percent \\
\hline Component & Average & Units & & & & \\
\hline$-\ldots$ & $\ldots$ & $\cdots \cdots$ & $\ldots$ & & & \\
\hline U-233 & 0.0000 & atom per & cent & & & \\
\hline$U-234$ & 0.0008 & atom per & cent & & & \\
\hline $\mathrm{U}-235$ & 0.1926 & atom per & cent & & & \\
\hline$U-236$ & 0.0034 & atom per & cent & & & \\
\hline$U-238$ & 99.8032 & atom per & cent & & & \\
\hline SUM & 100.0000 & atom per & cent & & & \\
\hline$U-233$ & 0.0000 & weight & ercent & & & \\
\hline$U-234$ & 0.0008 & weight & ercent & & & \\
\hline$U-235$ & 0.1902 & weight & ercent & & & \\
\hline$U-236$ & 0.0034 & weight & ercent & & & \\
\hline $\mathrm{U}-238$ & 99.8057 & weight & ercent & & & \\
\hline
\end{tabular}

Notebook reference: VG-2

Analyst: NMS, $\mathrm{CH}, \mathrm{JA}$

Approved by: Callis, Larry 02-May-1997 17:12 
Analytical Operation: MSUID-S

Date Completed: 29-Apr-1997 08:20 Replicates: 5

Task ID: 300081171

Version: 1

WALK-IN QUOTED COST:

WALK-IN CHARGE BALNC: 0

DESCRIPTION: MS-URANIUM IN SOLIDS

\begin{tabular}{|c|c|c|c|c|c|c|}
\hline Compo & Rep 1 & $\operatorname{Rep} 2$ & Rep 3 & Rep & $\operatorname{Rep} 5$ & Units \\
\hline URANIUM & 87.464 & 87.497 & 87.496 & 87.525 & 87.485 & weight \\
\hline
\end{tabular}

Notebook reference: VG-2

Analyst: NMS, $\mathrm{CH}, \mathrm{JA}$

Approved by: Callis, Larry 02-May-1997 17:12

Analytical Operation: XAEPMA

Date Completed: 22-May-1997 07:23 Replicates: 1 Version: 1

WALK-IN QUOTED COST:

WALK-IN CHARGE BALNC: 0

DESCRIPTION: XA-MICROPROBE ANALYSIS

\begin{tabular}{lll} 
Component & Results & Units \\
\hline XAEPMA REPORT & SEE REPORT
\end{tabular}

Notebook reference: EPMA-4 P 39

Distribution:R. Marshall (original) MS G740

W. Hutchinson

File

Analyst: Hutchinson, William B.

Approved by: Hutchinson, William B. 22-May-1997 07:27

Analytical Operation: PSSUR-S

Date Completed: 27-May-1997 00:00 Replicates: 1 Version: 1

WALK-IN QUOTED COST:

WALK-IN CHARGE BALNC: 0

DESCRIPTION: PS-ELEMENTAL ANALYSIS IN SOLIDS

\begin{tabular}{|c|c|c|c|c|c|}
\hline Component - & Result & Units & Component & Result & Units \\
\hline - & $\ldots . .$. & $\ldots$ & - & & \\
\hline ALUMINUM & 99 & $=u g / g$ & BORON & 297 & $u g / g$ \\
\hline BERYLLIUM & $<0.5$ & ug/g & CALCIUM & 21 & $\mathrm{ug} / \mathrm{g}$ \\
\hline CADMIUM & 0.22 & $\mathrm{ug} / \mathrm{g}$ & CHROMIUM & 1.6 & $\mathrm{ug} / \mathrm{g}$ \\
\hline IRON & 46 & ug/g & LITHIUM & $<0.5$ & ug/g \\
\hline
\end{tabular}


Results for Sample 200023256 26-Jan-1998 11:02

Page 4

$\begin{array}{llllll}\text { MAGNESIUM } & 4.1 & \mathrm{ug} / \mathrm{g} & \text { SODIUM } & 171 & \mathrm{ug} / \mathrm{g} \\ \text { NICKEL } & 7.7 & \mathrm{ug} / \mathrm{g} & \text { LEAD } & 7.2 & \mathrm{ug} / \mathrm{g} \\ \text { VANADIUM } & 1.6 & \mathrm{ug} / \mathrm{g} & \text { TUNGSTEN } & 3.0 & \mathrm{ug} / \mathrm{g} \\ \text { CUT_ID } & \text { CUT-1 } & & & & \end{array}$

Notebook reference: ANC52 PG 116/ANC6 PG 211/F1994 PG129

Analyst: TMY/AAM/CAB/RDA/PEC/DLG/BJH/DJG/AKS

Approved by: Yoshida, Thomas M 27-May-1997 10:08

Analytical Operation: PSSUR-S

Date Completed: 27-May-1997 00:00 Replicates: 1

Task ID: 300086272

Version: 1

WALK-IN QUOTED COST:

WALK-IN CHARGE BALNC: 0

DESCRIPTION: PS-ELEMENTAL ANALYSIS IN SOLIDS

\begin{tabular}{llllll} 
Component & Result & Units & Component & Result & Units \\
\hline ALUMINUM & 108 & ug/g & BORON & 307 & $\mathrm{ug} / \mathrm{g}$ \\
BERYLIUM & $<0.5$ & $\mathrm{ug} / \mathrm{g}$ & CALCIUM & 23 & $\mathrm{ug} / \mathrm{g}$ \\
CADMIUM & 0.13 & $\mathrm{ug} / \mathrm{g}$ & CHROMIUM & 1.7 & $\mathrm{ug} / \mathrm{g}$ \\
IRON & 50 & $\mathrm{ug} / \mathrm{g}$ & LITHIUM & $<0.5$ & $\mathrm{ug} / \mathrm{g}$ \\
MAGNESIUM & 5.4 & $\mathrm{ug} / \mathrm{g}$ & SODIUM & 175 & $\mathrm{ug} / \mathrm{g}$ \\
NICKEL & 5.7 & $\mathrm{ug} / \mathrm{g}$ & LEAD & 5.5 & $\mathrm{ug} / \mathrm{g}$ \\
VANADIUM & 1.4 & $\mathrm{ug} / \mathrm{g}$ & TUNGSTEN & 2.8 & $\mathrm{ug} / \mathrm{g}$ \\
CUT_ID & CUT -2 & & & &
\end{tabular}

Notebook reference: ANC52 PG 116/ANC6 PG 211/F1994 PG129

Analyst: TMY/AAM/CAB/RDA/PEC/DLG/BJH/DJG/AKS

Approved by: Yoshida, Thomas M 27-May-1997 10:08

Analytical Operation: PSSUR-S

Date Completed: 27-May-1997 00:00 Replicates: 1

WALK-IN QUOTED COST:

WALK-IN CHARGE BALNC: 0

DESCRIPTION: PS-ELEMENTAL ANALYSIS IN SOLIDS

\begin{tabular}{llllll} 
Component & Result & Units & Component & Result & Units \\
\hline ALUMINUM & 102 & ug/g & BORON & 307 & $\mathrm{ug} / \mathrm{g}$ \\
BERYLIIUM & $<0.5$ & $\mathrm{ug} / \mathrm{g}$ & CALCIUM & 25 & $\mathrm{ug} / \mathrm{g}$ \\
CADMIUM & 0.31 & $\mathrm{ug} / \mathrm{g}$ & CHROMIUM & 2.0 & $\mathrm{ug} / \mathrm{g}$ \\
IRON & 49 & $\mathrm{ug} / \mathrm{g}$ & LITHIUM & $<0.5$ & $\mathrm{ug} / \mathrm{g}$ \\
MAGNESIUM & 4.5 & $\mathrm{ug} / \mathrm{g}$ & SODIUM & 157 & $\mathrm{ug} / \mathrm{g}$ \\
NICKEL & 4.9 & $\mathrm{ug} / \mathrm{g}$ & LEAD & 5.4 & $\mathrm{ug} / \mathrm{g}$ \\
VANADIUM & 1.6 & $\mathrm{ug} / \mathrm{g}$ & TUNGSTEN & 3.1 & $\mathrm{ug} / \mathrm{g}$
\end{tabular}

Task ID: 300086273

Version: 1 
CUT_ID CUT-4

Notebook reference: ANC52 PG 116/ANC6 PG 211/F1994 PG129

Analyst: TMY/AAM/CAB/RDA/PEC/DLG/BJH/DJG/AKS

Approved by: Yoshida, Thomas M 27-May-1997 10:08

Analytical Operation: RCESS

Date Completed: 27-May-1997 11:24 Replicates: 1 Version: 1

WALK-IN QUOTED COST:

WALK-IN CHARGE BALNC: 0

\begin{tabular}{lll} 
Component & Results & Units \\
\hdashline SURVEY & {$[1]$} & \\
COMMENTS & AW-RC-5 PP91-102 &
\end{tabular}

[1] SURVEY:

CST非23526 depleted uranium sample was analyzed by radiochemistry team. Three cuts of sample were received (Cuts $9,10,11$ ).

(1) Typical spectra of depleted uranium sample were obtained for this sample. No other noticeable radionuclide was obserbed by gamma ray analysis.

(2) Based on alpha spectrometry, the estimated $244 \mathrm{Cm}$ level in the sample was less than 5E-6 ppm and the estimated 252Cf level in the sample was less than $7 \mathrm{E}-7 \mathrm{ppm}$. The estimated concentrations were calculated based on the half-life, activity ratio of $234 \mathrm{U}, 238 \mathrm{U}, 244 \mathrm{Cm}$ and $252 \mathrm{Cf}$.

Analyst: Wong, Amy

Approved by: Wong, Amy 27-May-1997 11:28

Analytical Operation: TEF-S

Date Completed: 20-Jun-1997 16:51 Replicates: 1 Version: 1

WALK-IN QUOTED COST:

WALK-IN CHARGE BALNC: 0

DESCRIPTION: - TE-F

\begin{tabular}{|c|c|}
\hline Component & Results \\
\hline FLUORIDE & \\
\hline
\end{tabular}

Notebook reference: 4070, PP. 142,143 
Results for Sample 200023256 26-Jan-1998 11:02

Analyst: TRH

Approved by: Marshal1, Thomas K. 20-Jun-1997 16:54

Analytical Operation: TECL-S

Date Completed: 20-Jun-1997 16:51 Replicates: 1

WALK-IN QUOTED COST:

WALK-IN CHARGE BAINC: 0

DESCRIPTION: TE-CL IN SOLID

\begin{tabular}{lll} 
Component & Results & Units \\
\hdashline CHLORIDE & $6,3,3$ & ug/g
\end{tabular}

Notebook reference: 4070, PP. 142,143

Analyst: TRH

Approved by: Marshall, Thomas K. 20-Jun-1997 16:54
Task ID: 300093816

Version: 1 
D 
NMT-2

Americium item, FZG45-AMP138-2, 27.0 grams NM, 32.3 grams net, was taken from the vault and samples drawn for particle size determination and standards. The process sheet attached lists the samples and sample weights.

History of the item:

1. Am separation using $\mathrm{H} 2 \mathrm{O} 2$ precipitation filtrate containing Am241 and trace plutonium was sent to $\mathrm{OH}$ precipitation.

2. Am hydroxide was desolved in $\mathrm{HNO} 3$ (7M).

3. Am separation from residual $\mathrm{Pu}$ by ion exchange.

4. Am in ion exchange eluate precipitated using oxalic acid.

5. Am oxalate calcined to $\mathrm{AmO} 2$.

6. Item screened through 100 mesh screen.

7. Item was sampled and packaged for shipment to Oak Ridge (Isotope Sales Pool).

Processing of Item by NMT-2:

1. The item was introduced into the glovebox line and taken to location G264. The material was contained in a small stainless steel container.

2. The oxide was transfered to a 1 pint container and blended in this container using a rod mill without the rods. The item was blended for 1 hour on $4 / 3 / 97$.

3. The item was sampled immediately after blending using the an accountablility balance accurate to 0.1 gram. Three 2.0 gram samples were taken for standards. One sample, FZG45-AMP138-2S2, was sent to CST-8, Bob Marshall, and the remaining two were placed in the vault as Lot ID's FZG45-AMP138-2S3 and FZG45-AMP138-2S4. A 3 gram sample, FZG45-AMP138-2S1, was provided to CST-15 for particle size determination.

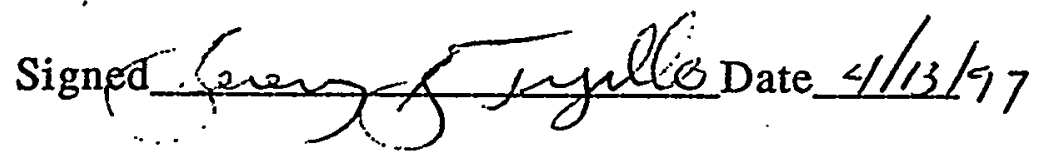


FZG 45-AMP $138-2$

\begin{tabular}{|c|c|c|c|c|c|c|c|c|c|c|c|c|c|c|}
\hline \multicolumn{15}{|c|}{ PROCESS SHEET } \\
\hline \multicolumn{15}{|c|}{ INCOMING ITEMS } \\
\hline \begin{tabular}{|c|c} 
VAULT & PU \\
LOC & MT \\
\end{tabular} & LOTID & SEAL & PROJ.\#P & 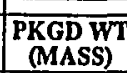 & WT & $\begin{array}{l}\text { NET } \\
\text { (MESS) }\end{array}$ & $\begin{array}{l}\text { VERTFED } \\
\text { NET WT }\end{array}$ & $\begin{array}{l}\text { Pu } \\
\text { (MASS) }\end{array}$ & $\begin{array}{ll}\text { MEAS } \\
\text { CODE }\end{array}$ & $\begin{array}{l}\text { WEIGHEI } \\
\text { BY }\end{array}$ & CHECKED & DATE & & COMMENTS \\
\hline$\frac{1}{\text { NOTE: } R \text { Record R }}$ & lative Humidity res & ading in proce & sing glove & box. & & $\mathrm{RH}=$ & $\frac{1}{F_{0} / \text { Temp. }=}$ & ${ }_{\mathrm{FQ}}$ & & & & & & Mencel \\
\hline & Frods-An & & & 261.6 & 229.1 & & 33.5 & & 833 & & $2 a$ & $4 / 3 / 97$ & & $210: 15$ tol1:15 $4 / 3197$ \\
\hline & & & & 258.3 & 229.1 & & 24.2 & & 833 & & $2 a$ & $x / 3 / 9$ & $\leftleftarrows$ & After Samplimg \\
\hline & & & & & & & & & & & & & & \\
\hline & & 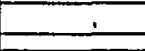 & & & & & & & & & & & & \\
\hline & & & & & & & & & & & & & & \\
\hline & & & $\mathrm{Net}$ & weight affer & roasting: & & & & & & & & & \\
\hline OUTGOING ITEI & S: & & & & & & & & & & & & & \\
\hline LOTID & GROSS WT & TARE WT & NET WT & FACTOR & SNM & $\begin{array}{l}\text { NEIGHED } \\
\text { BX }\end{array}$ & $\begin{array}{l}\text { CHECKED } \\
\text { BY }\end{array}$ & $\begin{array}{l}\text { MEDS } \\
\text { CODE }\end{array}$ & $\begin{array}{l}\text { CODED } \\
\text { BY } \\
\text { BY }\end{array}$ & TRANS\# & DATE & DES & PROJ.A & COMMENTS \\
\hline $52645-A m P 138-2$ & (5) $\quad 9.4$ & 6.4 & 3.0 & & & $\sqrt{5}$ & $2 a$ & 833 & & 8419.83 & $4 / 3 / 97$ & & & Char lic Davis-Particlesire \\
\hline 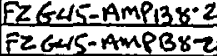 & $\begin{array}{ll}52 & 8.4 \\
53 & 8.3 \\
\end{array}$ & 6.4 & $\frac{20}{2.0}$ & & & 5 & $-\frac{2 a}{2 a}$ & $\frac{133}{833}$ & & 1841986 & $4 / 8 / 172$ & & & To Bob Maeshall-CUR-ADEL STD \\
\hline$F Z G 4 S-A M P B r^{2}$ & $54 \quad 8.4$ & 6.4 & 20 & & & 4 & $2 a$ & $\frac{33}{833}$ & & 242010 & $443 / 192$ & & & 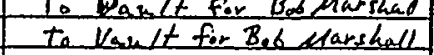 \\
\hline & & & & & & & & & & & & & & \\
\hline & & & & & & & & & & & & & & \\
\hline & & & & & & & & & & & & & & \\
\hline SCRAP TTEMS: & & & & & & & & & & & & & & \\
\hline ITEMID & MASS CT & SNM UNMS & 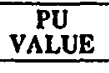 & NET WT & \begin{tabular}{|l} 
MEAS \\
CODE \\
\end{tabular} & $\begin{array}{c}\text { CODED } \\
\text { BY }\end{array}$ & TRANS\# & DATE & & & & & & \\
\hline & & & & & & & & & & & & & & \\
\hline & & & & & & & & & & & & & & \\
\hline & & & & & & & & & & & & & & \\
\hline & N & & & & & & & & & & & & & \\
\hline & & & & & & & & & & & & & & \\
\hline & & & & & & & & & & Supervisor & Approval// & & & \\
\hline
\end{tabular}




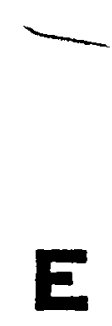

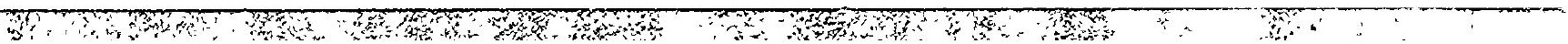




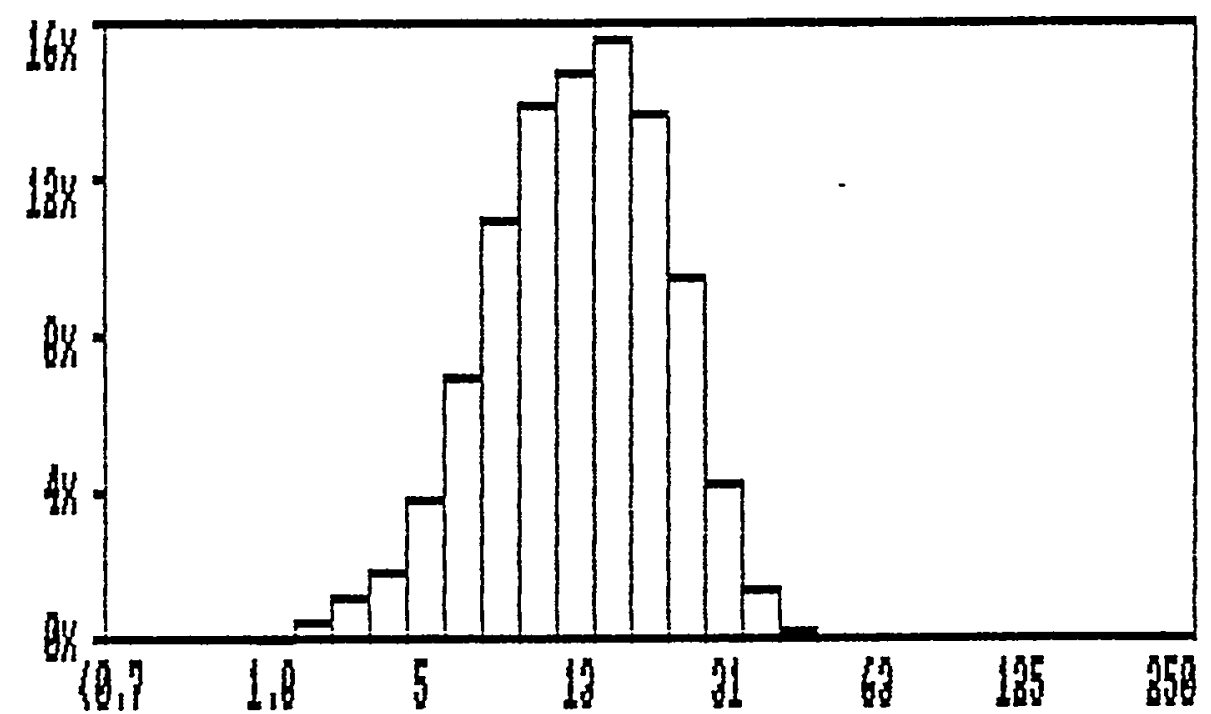

Sample ID

CF code

Date

Time

Diameter by Volume Mean

Standard Deviation

Skewness

Kurtosis

Coeff. of Variance (\%)

counts

$$
\begin{gathered}
\text { : CUT \# 2 } \\
: \text { 01/03/80 } \\
: 13: 29: 01 \\
: 16.7 \\
: \quad 8.5 \\
: 0.1 \\
: \quad 3.8 \\
: 51.0 \\
: 44062
\end{gathered}
$$

Cycles : 20
scaling : 1.00
Channel size
(microns)
$<0.7$
0.7
1.0
1.3
1.8
2.3
3.0
4.0
5.0
6.5
8
10
13
17
20

M.Cycle Time: 2.0 sec.

Averaged last 5 cycle(s)

$$
\begin{aligned}
& \% / \text { Channel } \\
& 0.0123 \\
& 0.0354 \\
& 0.0865 \\
& 0.1196 \\
& 0.2187 \\
& 0.5969 \\
& 1.1932 \\
& 1.8850 \\
& 3.7011 \\
& 7.0054 \\
& 11.0746 \\
& 13.9221 \\
& 14.9617 \\
& 15.7722 \\
& 13.7813
\end{aligned}
$$

$\% / C h a n n e l$

9.4432

4.2566

1.4809

0.3726

0.0724

0.0078

0.0005

0.0000

0.0000

0.0000

0.0000

0.0000

0.0000

0.0000 


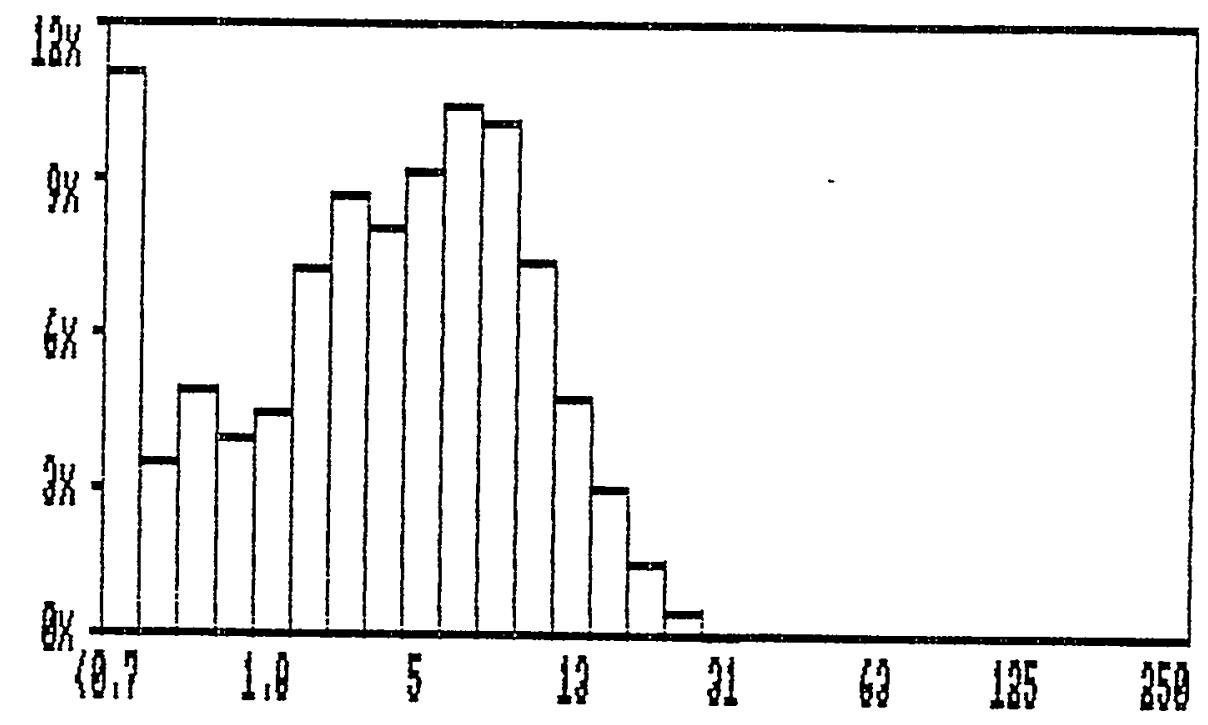

Sample ID

CF Code

Date

: CUT \# 2

Time

: $01 / 03 / 80$

Spherical Equivalent Mean :

standard Deviation

: $13: 23: 32$

skewness

Kurtosis

Coeff. of Variance $(\%)$

$: 6.1$

$: \quad 5.5$

$: \quad 0.3$

$: \quad 6.4$

counts

Cycles : 20
scaling : 1.00
Channel size
(microns)
$<0.7$
0.7
1.0
1.3
1.8
2.3
3.0
4.0
5.0
6.5
8
10
13
17
20

$\begin{array}{cc} & \begin{array}{c}\text { M.Cycle Time: } 2.0 \\ \text { Averaged last } 5\end{array} \\ \% / \text { Channel } & \begin{array}{c}\text { Channel size } \\ \text { (microns) }\end{array} \\ 11.0993 & 25 \\ 3.4089 & 31 \\ 4.9924 & 37 \\ 4.0585 & 44 \\ 4.4266 & 53 \\ 7.3006 & 63 \\ 8.7905 & 75 \\ 8.0763 & 88 \\ 9.2564 & 105 \\ 10.4908 & 125 \\ 10.3009 & 149 \\ 7.5468 & 177 \\ 4.7510 & 210 \\ 2.9809 & 250 \\ 1.6332 & \end{array}$

$\% /$ Channel

0.6706

0.1758

0.0343

0.0056

0.0007

0.0001

0.0000

0.0000

0.0000

0.0000

0.0000

0.0000

0.0000

1.6332

0.0000 


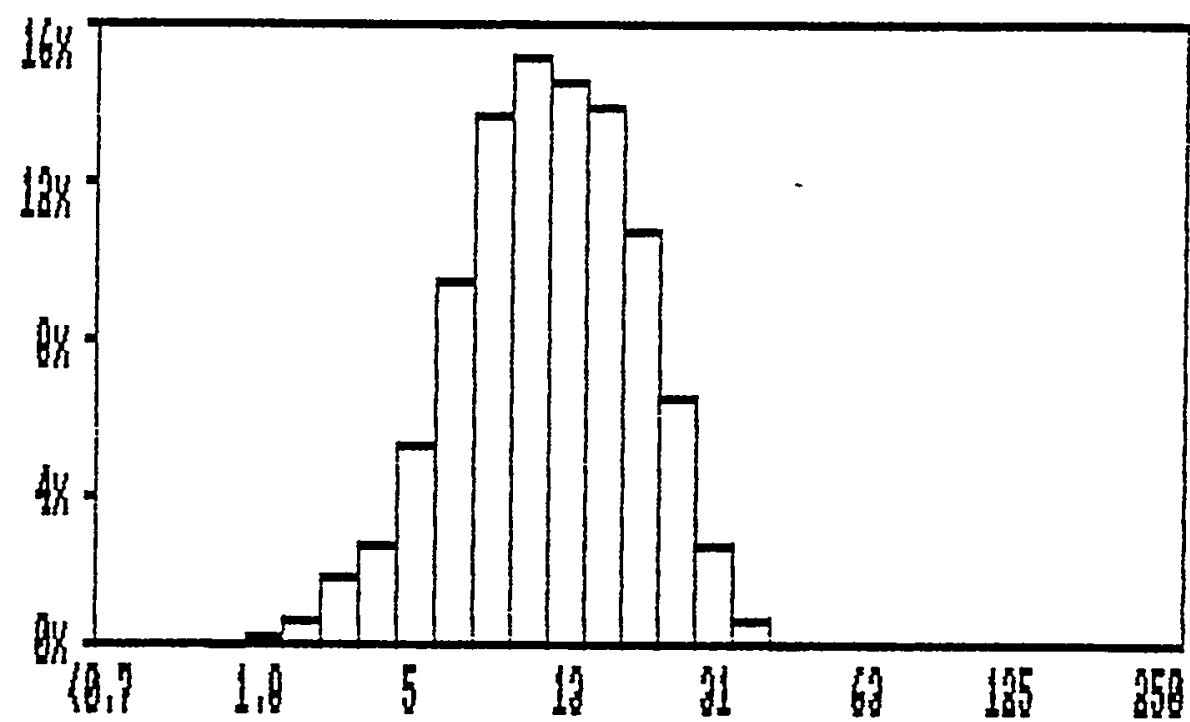

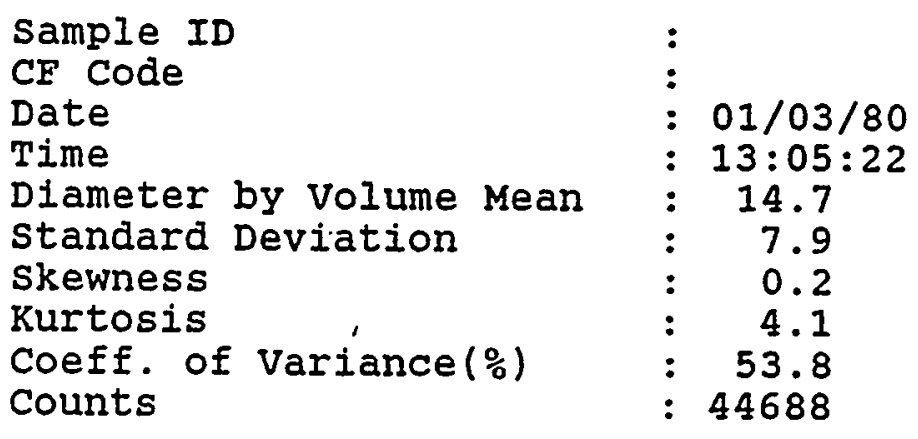

Cycles : 20

scaling : 1.00

Channel size
(microns)
$<0.7$
0.7
1.0
1.3
1.8
2.3
3.0
4.0
5.0
6.5
8
10
13
17
20

\section{$\% /$ Channel}

0.0122

0.0425

0.1129

0.1646

0.3242

0.9236

1.8112

2.7656

5.1316

9.5716

13.8209

15.2693

14.6603

14.0332

10.8630
M.Cycle Time: 2.0 sec.

Averaged last 5 cycle(s)

Channel size
(microns)
25
31
37
44
53
63
75
88
105
125
149
177
210
250

$\% /$ Channel

6.6179

2.7350

0.9020

0.2004

0.0329

0.0045

0.0005

0.0000

0.0000

0.0000

0.0000

0.0000

0.0000

0.0000 


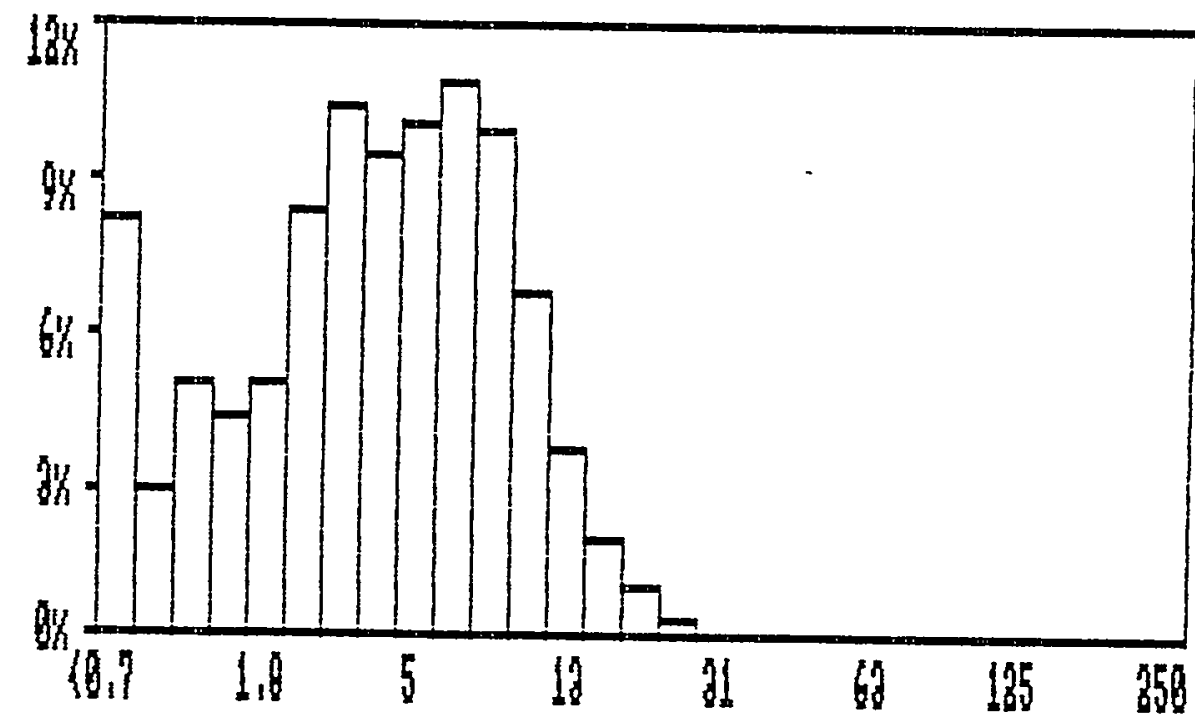

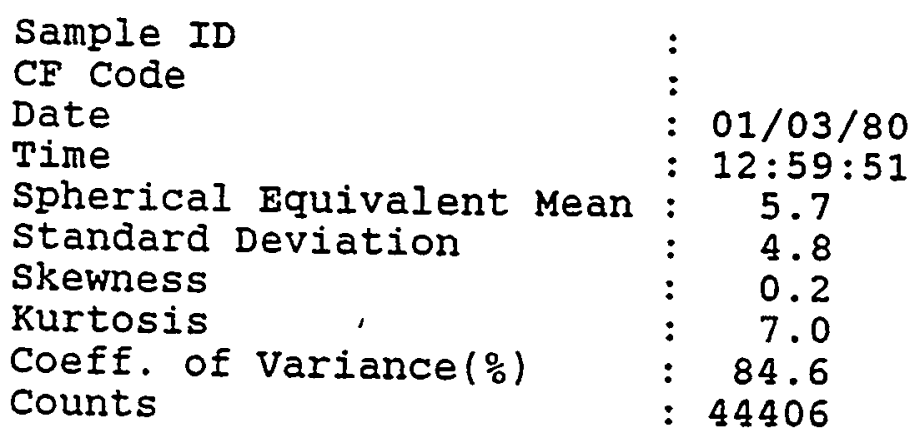

Cycles : 20
Scaling 1.00
Channel size
(microns)
$<0.7$
0.7
1.0
1.3
1.8
2.3
3.0
4.0
5.0
6.5
8
10
13
17
20

$\% /$ Channel
8.3469
3.1013
5.1506
4.5005
5.0798
8.5120
10.4549
9.4943
10.2237
10.9499
10.0163
6.7283
3.8034
2.0963
1.0420

M.Cycle Time: $2.0 \mathrm{sec}$. Averaged last 5 cycle(s)
Channel size (microns)

25

31

37

44

53

63

75

88

105

125

149

177

210

250
$\% /$ Channel

0.3859

0.0945

0.0168

0.0024

0.0002

0.0000

0.0000

0.0000

0.0000

0.0000

0.0000

0.0000

0.0000

0.0000 


\section{7}




\section{CST-8}

Microanalysis EPMA/SEM

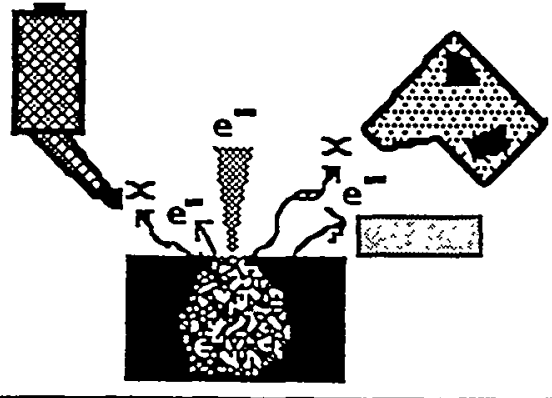

Sample Description.

A small portion of U oxide powder was submitted for particle sizing (ID \# 0907-43).

Analysis and results.

A few tens of milligrams of the powder was sonicated for about 20 minutes in distilled water and then transferred to a graphite planchet for sizing. Optical examination revealed some agglomeration and that only a small fraction of the particles were less than 1 micron in diameter. Based on these observations optical sizing was selected. Ten frames were collected and stored (see a typical example in Fig. 1). Each of the 10 images were loaded into the particle sizing software (NIH Image), a binary image created and then sized. When completed over 10,000 particles were sized. The average area was $98 \mu \mathrm{m}^{2}$. Assuming spherical particles this would translate to an average diameter of 11 microns. The range of areas sized was 2 to $1460 \mu \mathrm{m}^{2}$. A lower limit of 2 microns in diameter was set based on the attainable resolution. 

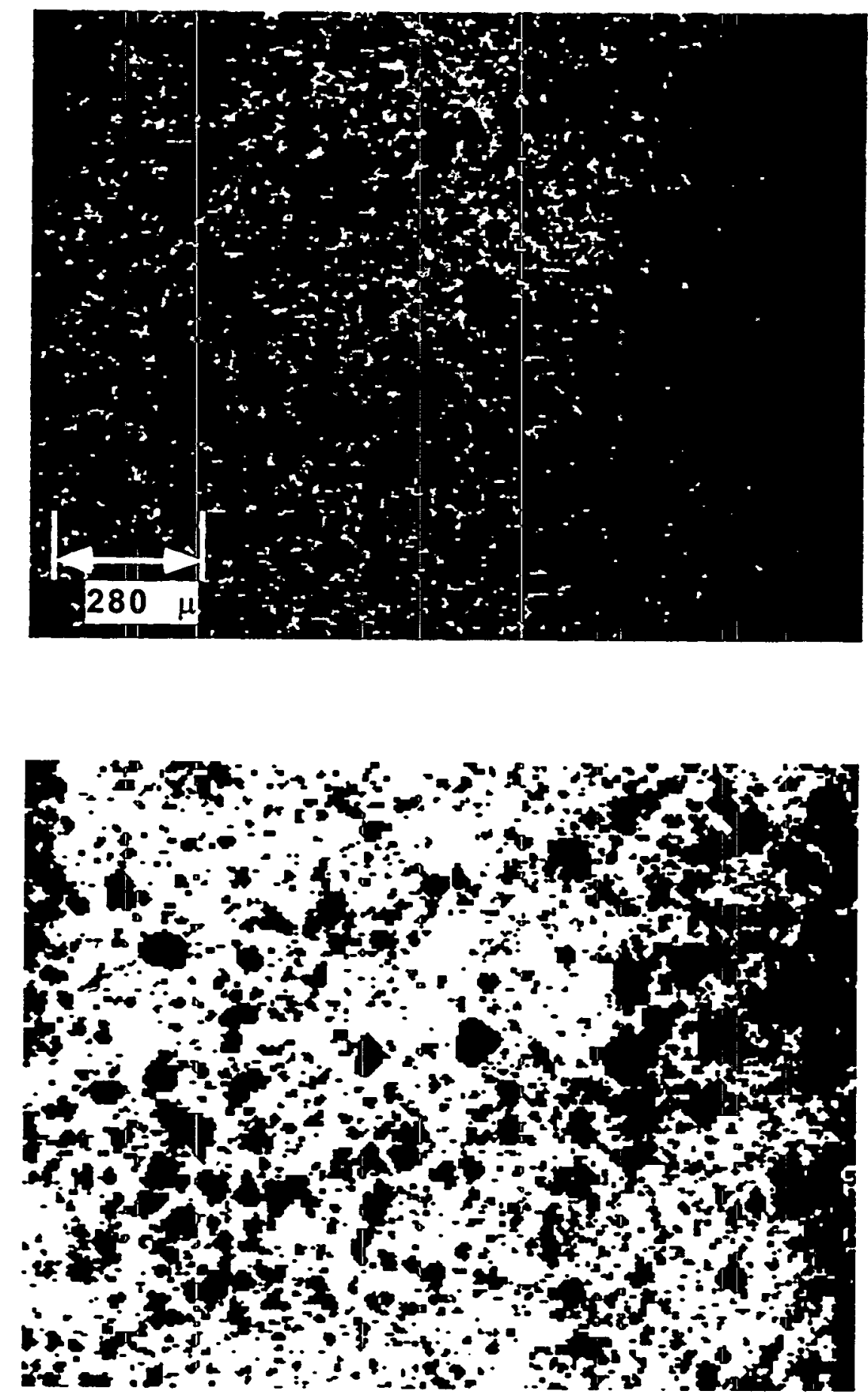

Fig. 1. Photomicrograph showing the grey scale and binary images from a typical region. 


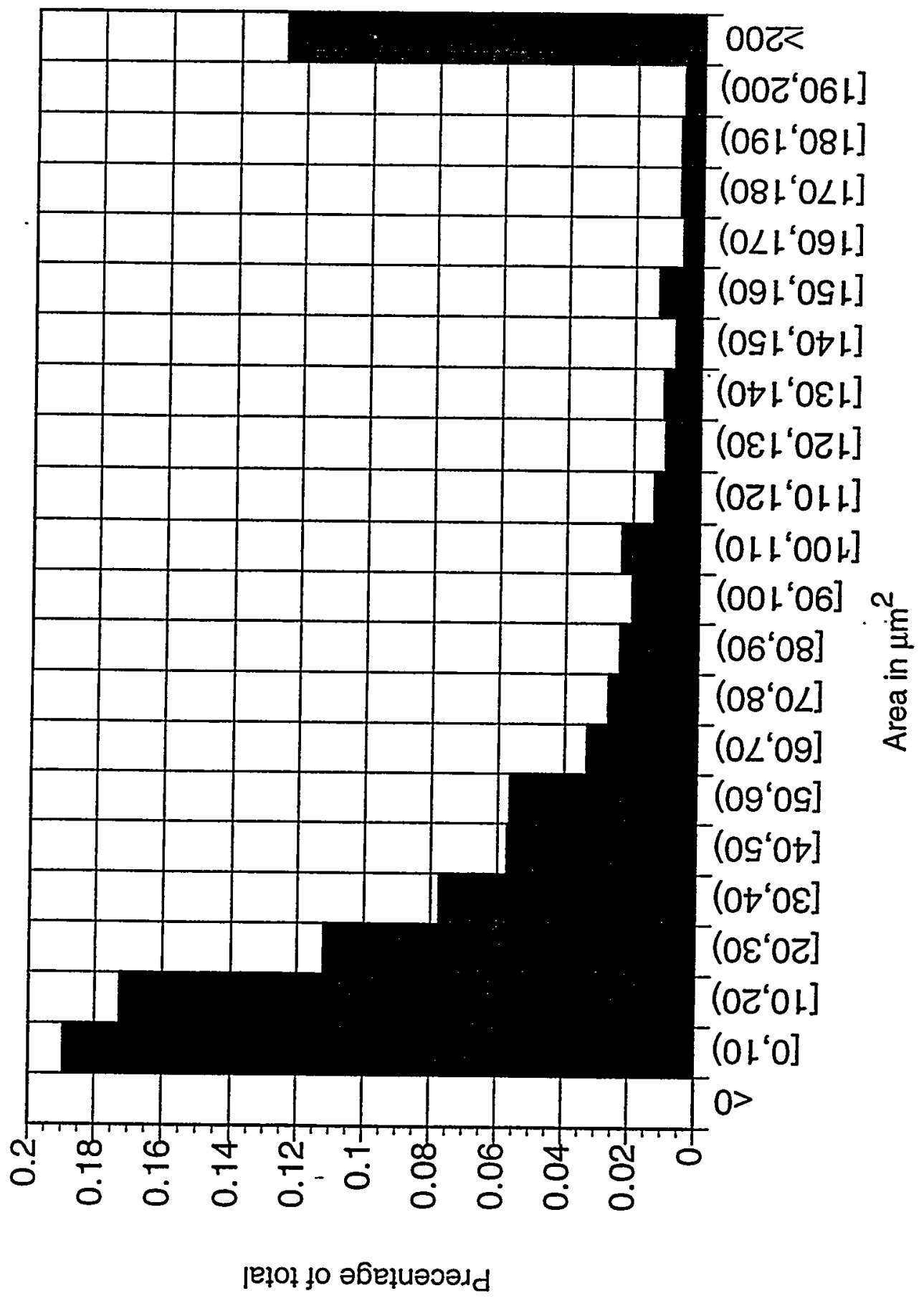

문 


\section{Du Oxide Part. Size dist.}

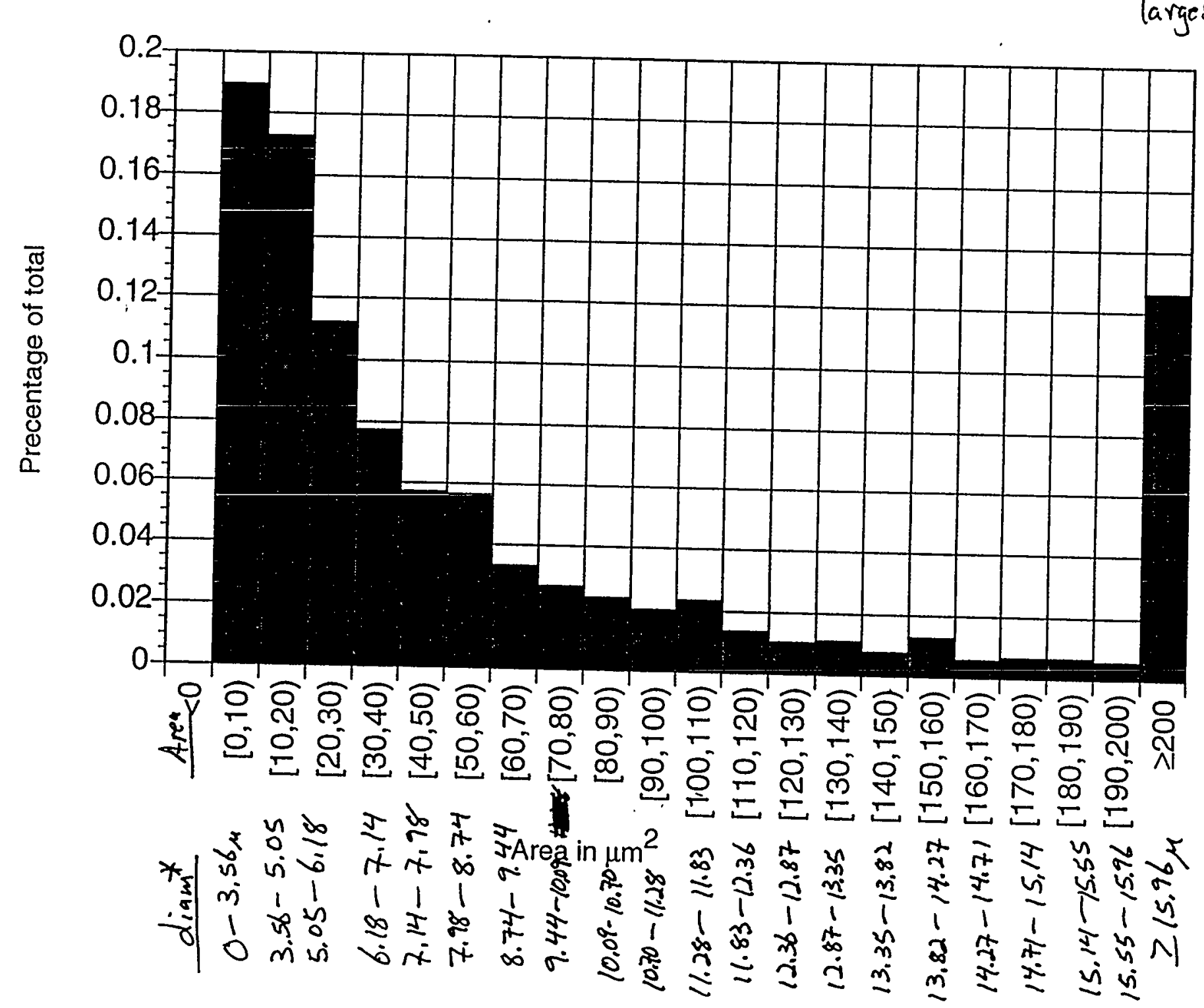

Fig. 2.

$\begin{array}{ll}\text { mean }=11 \mu & \frac{\text { Spec }}{\angle 100 \mu} \\ & \begin{array}{l}\text { Nomore } \\ \text { than } 2 \%\end{array} \\ \text { largest }=43 \mu \quad & \geq 250 \mu\end{array}$ * assumes spherical particles 


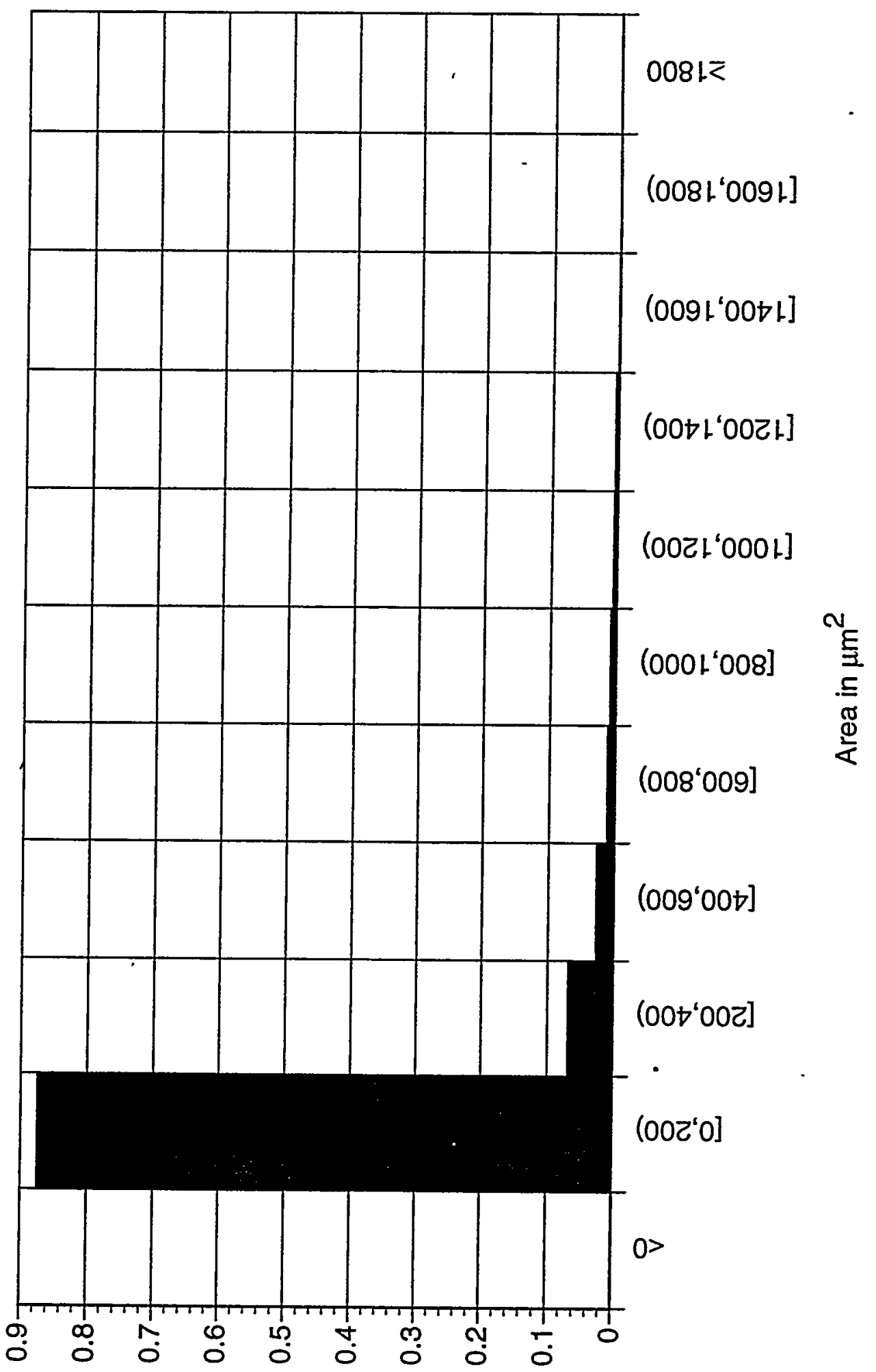

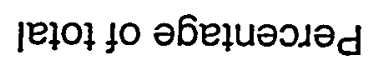

$\dot{\infty}$ i⿺辶) 

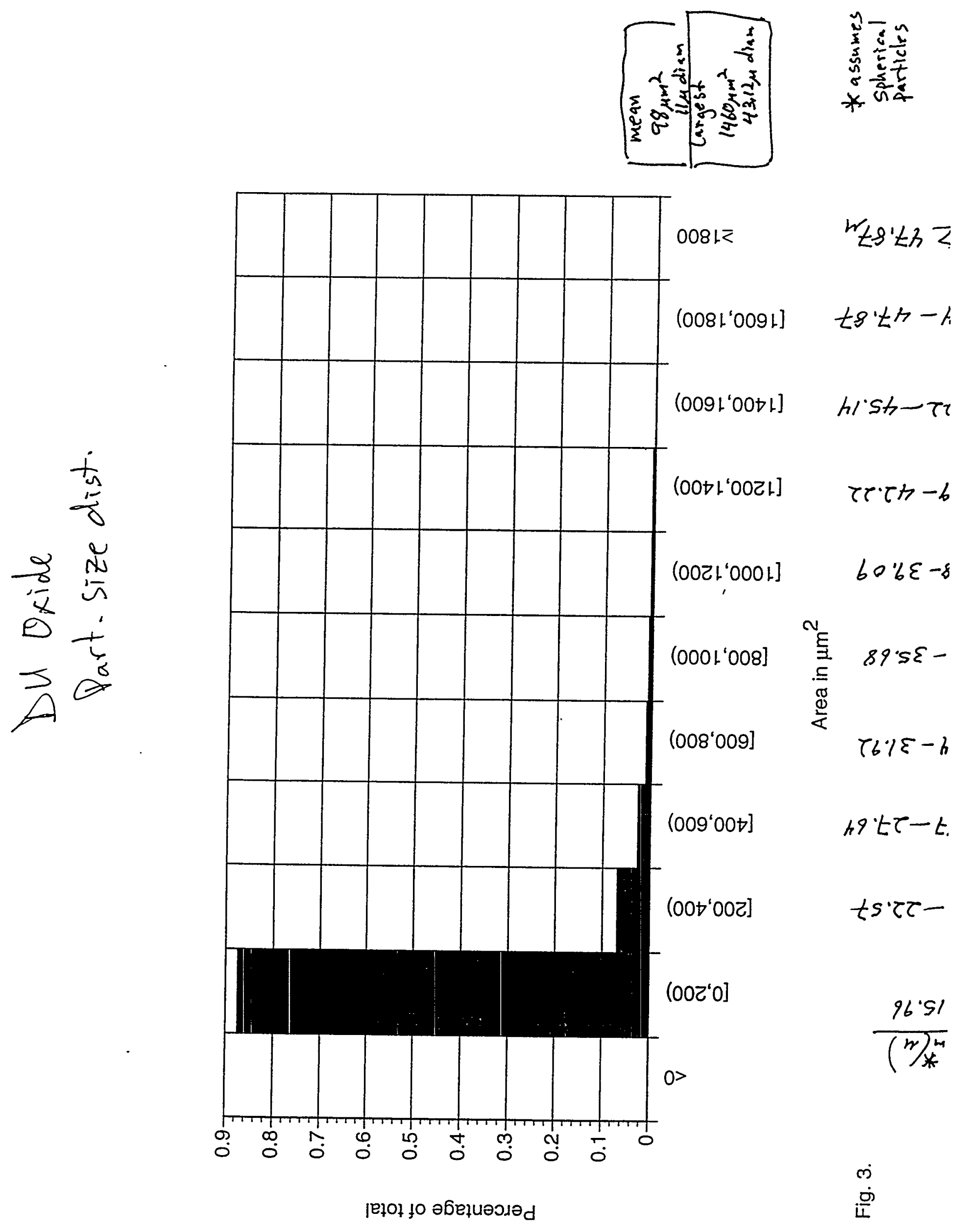
DATA FAXED TO G.BECKER 6/7/97

FULFILLS 6/2/97 CEP SOW NEUTRON

COUNT REQUIREMENT, PR.

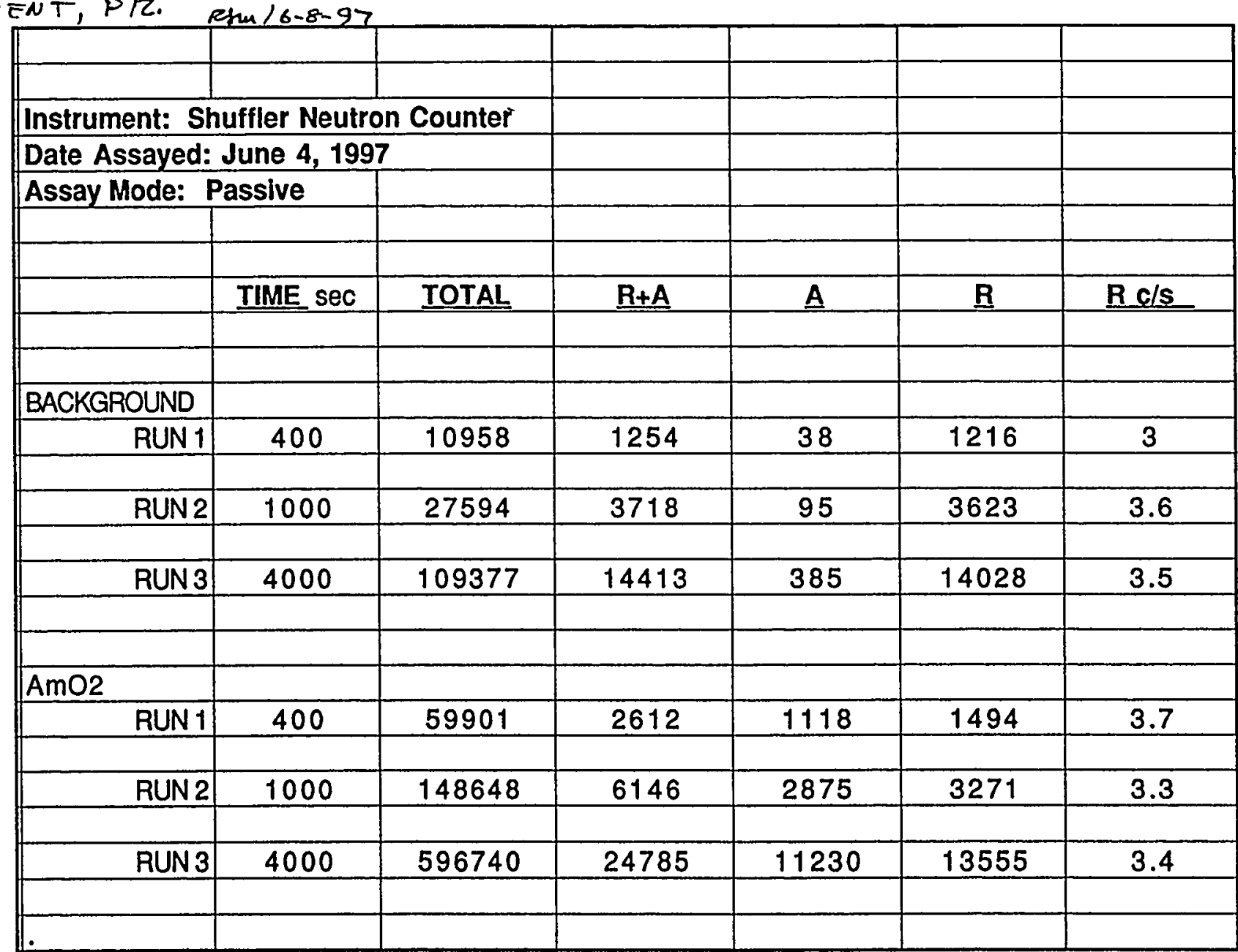





\section{$\square$ BENCHMARK \\ ENVIRONMENTAL CORPORATION}

September 24, 1997

Project Nos. 5061.06.0201 and 5061.06.0203

Subcontract No. B45370007-8N

Document No. AL-7286

Dr. Robert Marshall

Los Alamos National Laboratory

P.O. Box 1663, MS G740

Los Alamos, New Mexico 87545

Transmittal of the Letter Reports, "Pressurization of the PDP DE-Plutonium/Americium

Matrix Cylinder Due to the Buildup of Hydrogen, Oxygen, and Helium Gases" and

"Maximum Internal Allowable (Design) and Failure (Yield) Stresses on Stainless Steel and Zirconium Test Cylinders"

Dear Dr. Marshall:

Please find enclosed for your review the letter report entitled "Pressurization of the PDP DE-Plutonium/ Americium Matrix Cylinder Due to the Buildup of Hydrogen, Oxygen, and Helium Gases," which summarizes the results of calculations performed by Benchmark Environmental Corporation (Benchmark). The calculation results estimate the pressure buildup in the Performance Demonstration Program (PDP) diatomaceous earth (DE)-plutonium/americium matrix cylinders that is likely to occur over the course of the PDP DE-plutonium/americium matrix cylinder experiment. This letter report also considers the radiolytic depletion of the residual water trapped in the test matrix.

Also enclosed is the letter report entitled "Maximum Internal Allowable (Design) and Failure (Yield) Stresses on Stainless Steel and Zirconium Test Cylinders," which documents the results of Benchmark's evaluation of the maximum internal allowable (design) pressures and the expected failure (yield) pressures for the cylinders used in the above-noted experiment. As seen in the attached letter of certification, this evaluation was reviewed by an independent registered professional engineer. This letter report incorporates your comments on the prior report (dated July 22, 1997).

Based upon the evaluations presented in the attached letter reports, the pressure inside the test cyliner rises to reach 22.6 psig after the experiment has proceeded for 27.9 years. This pressure increase is primarily due to the radiolysis of the residual water in the PDP DE-plutonium/americium matrix. The residual water is completely consumed at $\mathbf{2 7 . 9}$ years. After the residual water has been consumed, the pressure inside the test cylinder continues to rise very slowly as a result of the helium gas formed by the decay of alphaemitting radionuclides. The pressure inside the inner stainless steel cylinders will reach the material's maximum design and failure (yield) pressures within 83 and 176 years, respectively. The pressure inside the inner zirconium cylinders will reach the material's maximum design and failure (yield) pressures within 494 and 1,022 years, respectively. These values represent the length of time the experiment may run before the cylinders begin to experience plastic deformation, resulting in bulging and subsequent failure. The values presented above are affected by the assumptions that were made in the attached evaluations. No credit was given to fatigue, creep, corrosion, or hydrogen embrittlement impacting the cylinder's operating life; or to the outer cylinders providing extra strength or resistance to the internal cylinders. 
Please contact Sinisa Djordjevic or Monika Kinker at (505) 262-2694 with any comments or concerns you may have regarding the enclosed.

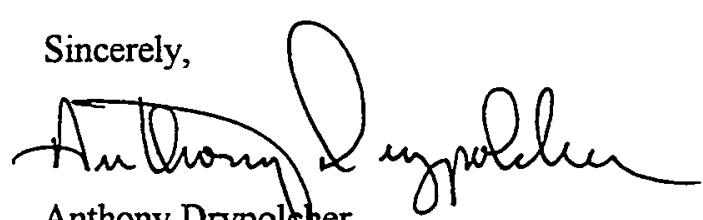

Anthony Drypoldher

Project Manager

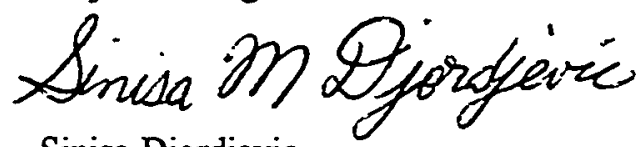

Sinisa Djordjevic

Task Leader

\section{$\mathrm{AD} / \mathrm{TK} / \mathrm{PBS}$}

Enclosures

cc with enclosures:

Greg Becker, LMITCO

William F. Lyon, Applied Sciences Laboratory, Albuquerque

Sinisa Djordjevic, Benchmark, Albuquerque

Monika Kinker, Benchmark, Albuquerque

Terry Kraus, Benchmark, Albuquerque

Central Files, Benchmark, Albuquerque

cc without enclosures:

Pete Ayala, LANL, BUS2, MS P274

Kenneth Hargis, LANL, EM/WM, MS J552 


\title{
PRESSURIZATION OF THE PDP DE-PLUTONIUM/AMERICIUM MATRIX CYLINDER DUE TO THE BUILDUP OF HYDROGEN, OXYGEN, AND HELIUM GASES
}

\author{
September 24, 1997 \\ Project No. B45370007-8N \\ Sinisa Djordjevic \\ Chemical Engineer \\ Terry Kraus \\ Health Physicist

\begin{abstract}
Benchmark Environmental Corporation 4501 Indian School Road NE, Suite 105

Albuquerque, New Mexico 87110
\end{abstract}

This report summarizes the results of calculations (Benchmark 1997a and 1997b) made by Benchmark Environmental Corporation to estimate the gas pressure build-up that occurs, over time, in the PDP DEPlutonium ( $\mathrm{Pu}$ /Americium (Am) test cylinders as the radionuclides in the waste matrix undergo radioactive decay. This paper investigates two gas generation processes that result in the pressurization of sealed waste containers. The processes are (a) the formation of hydrogen and oxygen gas by the radiolysis of water and (b) the formation of helium gas by radionuclides that decay via alpha emission. It is assumed that the radiolytically generated hydrogen and oxygen gas do not recombine to form water. Therefore, this report presents the worst case pressure buildup scenario.

The first gas generation process investigated in this analysis was the radiolysis of water by alpha particles resulting in the formation of hydrogen and oxygen gas. The waste matrix used in this analysis was contained in an air-tight test cylinder, and consisted of $65 \mathrm{~g}$ of a Pu blend (i.e., $73.70 \mathrm{~g} \mathrm{PuO}_{2}$ ) and $6.5 \times 10^{-2}$ $\mathrm{g}$ of ${ }^{241} \mathrm{Am}$ intermixed within $128 \mathrm{~g}$ of diatamaceous earth (DE) (LANL 1997). Table 1 indicates the isotopic composition of the Publend, by weight, and the decay heat of the plutonium isotopes. The effective (total) decay heat of the $\mathrm{Pu}$ blend is calculated in the fourth column of Table 1 by multiplying the weight percent of each plutonium isotope by the isotope's decay heat and then summing the decay heat contributions of each isotope to derive the total decay heat of the $\mathrm{Pu}$ blend. The decay heat of ${ }^{241} \mathrm{Am}$ is $1.16 \times 10^{-1} \mathrm{~W} / \mathrm{g}$ (NRC 1997). The total decay heat of the Pu/Am mixture is calculated to be $0.16 \mathrm{~W}$ using Equation 1:

$$
\begin{gathered}
P u / \text { Am decay heat }=P u \text { blend decay heat } \times \text { Publend mass }+ \\
241 \text { Am decay heat } \times{ }^{241} \text { Am mass }
\end{gathered}
$$

where

$\begin{array}{lll}P u \text { blend decay heat } & = & 2.34 \times 10^{-3} \mathrm{~W} / \mathrm{g} \\ P u \text { blend mass } & = & 65 \mathrm{~g} \\ { }^{241} \text { Am decay heat } & =1.16 \times 10^{-1} \mathrm{~W} / \mathrm{g} \\ { }^{241} \text { Am mass } & =6.52 \times 10^{-2} \mathrm{~g}\end{array}$


Table 1. Isotopic Composition and Decay Heat of Pu Blend

\begin{tabular}{lccc}
\hline Radionuclide & $\begin{array}{c}\text { Weight } \\
\text { Fraction }^{\mathrm{a}}\end{array}$ & ${\text { Decay Heat }(\mathrm{W} / \mathrm{g})^{\mathrm{b}}}^{\mathrm{b}}$ & $\begin{array}{c}\text { Decay Heat Contribution (W/g) } \\
\text { (Column 2 } \text { Column 3) }\end{array}$ \\
\hline Pu-238 & $1.46 \times 10^{-4}$ & $5.73 \times 10^{-1}$ & $8.3658 \times 10^{-5}$ \\
Pu-239 & $9.37722 \times 10^{-1}$ & $1.95 \times 10^{-3}$ & $1.8286 \times 10^{-3}$ \\
Pu-240 & $5.9460 \times 10^{-2}$ & $7.16 \times 10^{-3}$ & $4.2573 \times 10^{-4}$ \\
Pu-241 & $2.093 \times 10^{-3}$ & $3.31 \times 10^{-3}$ & $6.9278 \times 10^{-6}$ \\
Pu-242 & $5.78 \times 10^{-4}$ & $1.17 \times 10^{-4}$ & $6.7626 \times 10^{-8}$ \\
Totals & 1.0 & - & $2.34 \mathrm{E}-3$ \\
\hline LANL 1997. & & & \\
b NRC 1997. & & & \\
\hline
\end{tabular}

Although DE is included in the chemical lists for the TRUPACT-II content codes, DE is not considered to generate gas as a result of radiolysis, and therefore, the oxygen incorporated into the constituents comprising $\mathrm{DE}$ is not considered to be a source of radiolytically generated oxygen gas. Residual water trapped within the $\mathrm{PuO}_{2}$ and the $\mathrm{DE}$ serves as the source of hydrogen and oxygen. The residual water content of $\mathrm{PuO}_{2}$ is 0.2 percent by weight and the residual moisture content of DE is 0.11 percent by weight (LANL 1997). It was necessary to quantitate the amount of water in the waste matrix in order to determine the rate of hydrogen and oxygen gas formation. The weighted average residual water content of the waste matrix was calculated to be $1.43 \times 10^{-3} \mathrm{~g} \mathrm{H}_{2} \mathrm{O}$ per $\mathrm{g}$ waste matrix (i.e., 0.143 percent by weight) using Equation 2 :

$$
\begin{gathered}
\text { Wtd.av. water content }=\left(\frac{0.002 \mathrm{~g} \mathrm{H}_{2} \mathrm{O}}{\mathrm{gPuO_{2 }}} \times 73.70 \mathrm{gPuO} \mathrm{O}_{2}+\frac{0.0011 \mathrm{~g} \mathrm{H}_{2} \mathrm{O}}{\mathrm{gDE}} \times 128 \mathrm{~g} \mathrm{DE}\right) / \\
201.7 \mathrm{~g} \text { test matrix }
\end{gathered}
$$

where

Wtd $a v$. water content $=$ weighted average number of grams of $\mathrm{H}_{2} \mathrm{O}$ per gram of waste matrix

and all other terms are as previously defined.

The total amount of residual water trapped in the test matrix was determined to be $0.29 \mathrm{~g}$, or 0.016 moles. It was necessary to determine the total void volume in the test cylinder before the pressure buildup in the test cylinder could be evaluated. The inside volume of the test cylinder was calculated to be $19.243 \mathrm{in}^{3}$ $\left(315.3 \mathrm{~cm}^{3}\right)$ using Equation 3:

$$
\text { Volume }=\pi r^{2} h
$$


where:

$$
\begin{aligned}
& \pi=3.141 \\
& r=\text { test cylinder radius, } 0.855 \text { in INEEL } 1997 \\
& h=\text { test cylinder height, 8.379 in INEEL } 1997
\end{aligned}
$$

The volume of the waste matrix placed in each test cylinder was $315 \mathrm{~cm}^{3}$ (LANL 1997), leaving a headspace (void) volume of $315.3 \mathrm{~cm}^{3}-315.0 \mathrm{~cm}^{3}=0.3 \mathrm{~cm}^{3}$ in each test cylinder. However, the waste matrix is porous and also has a void volume that must be considered. Therefore, it was necessary to calculate the density of $\mathrm{DE}$ to determine the true volume occupied by the DE. Table 2 lists the weight fraction, the normalized weight fraction that takes into account the residual water in the DE matrix, the density, and the volume contribution of each constituent comprising $\mathrm{DE}$. The density of the $\mathrm{DE}$ was calculated from Equation 4 (Butcher and Mendenhall 1993):

$$
\begin{aligned}
& \operatorname{Density~}(\text { solid })=\rho(D E)=\frac{1}{V_{D E}}=\frac{1}{\sum \frac{w_{i}}{\rho_{i}}}= \\
& \frac{\frac{1}{{ }^{w_{S i O}}}}{\rho_{\mathrm{SiO}_{2}}}+\frac{1}{{ }_{\mathrm{Fe}_{2} \mathrm{O}_{3}}}+\frac{1}{\rho_{\mathrm{Fe}_{2} \mathrm{O}_{3}}}+\frac{1}{{ }^{w_{\mathrm{CaO}}}}+\frac{1}{\rho_{\mathrm{CaO}}}+\frac{1}{{ }^{w} \mathrm{Na}_{2} \mathrm{O}} \frac{1}{\rho_{\mathrm{Na}_{2} \mathrm{O}}}+\frac{1}{{ }_{\mathrm{Al}_{2} \mathrm{O}_{3}}}=\frac{1}{\rho_{\mathrm{Al}_{2} \mathrm{O}_{3}}}
\end{aligned}
$$

where

$$
\begin{aligned}
\rho(D E)= & \text { the calculated density of } \mathrm{DE}\left(2.364 \mathrm{~g} / \mathrm{cm}^{3}\right) \\
V_{\mathrm{DE}}= & \text { the volume occupied by } \mathrm{DE} \\
w_{\mathrm{i}}= & \text { the normalized weight fraction, listed in Table } 2 \text {, of the } i \text { th constituent comprising the } \\
& \mathrm{DE}\left(\mathrm{g}_{\mathrm{i}} / \mathrm{g} \mathrm{DE}\right) \\
\rho_{\mathrm{i}}= & \text { the crystalline density, listed in Table } 2, \text { of the } i \text { th constituent comprising the } \mathrm{DE} \\
& \left(\mathrm{g} / \mathrm{cm}^{3}\right)
\end{aligned}
$$

Table 2. Composition of DE (LANL 1997)

\begin{tabular}{lcccc}
\hline Constituent & $\begin{array}{c}\text { Weight } \\
\text { Fraction }\end{array}$ & $\begin{array}{c}\text { Normalized Weight } \\
\text { Fraction, } \mathrm{w}_{\mathrm{i}} \\
(\mathrm{g} \mathrm{i} / \mathrm{g} \mathrm{DE})\end{array}$ & $\begin{array}{c}\text { Crystalline Density, } \\
\mathrm{Y}_{\mathrm{i}} \\
\left(\mathrm{g} \mathrm{i} / \mathrm{cm}^{3} \mathrm{i}\right)^{\mathrm{a}}\end{array}$ & $\begin{array}{c}\text { Volume Contribution } \\
\mathrm{W}_{\mathrm{i}} / \mathrm{Y}_{\mathrm{i}} \\
\left(\mathrm{cm}^{3} \mathrm{I} / \mathrm{g} \mathrm{DE}\right)\end{array}$ \\
\hline $\mathrm{SiO}_{2}$ & $8.77 \times 10^{-1}$ & $9.04 \times 10^{-1}$ & 2.3 & $3.93 \times 10^{-1}$ \\
$\mathrm{Fe}_{2} \mathrm{O}_{3}$ & $1.31 \times 10^{-2}$ & $1.4 \times 10^{-2}$ & 5.24 & $2.7 \times 10^{-3}$ \\
$\mathrm{CaO}$ & $3.5 \times 10^{-3}$ & $4.0 \times 10^{-3}$ & 3.32 & $1.2 \times 10^{-3}$ \\
$\mathrm{Na}_{2} \mathrm{O}$ & $3.2 \times 10^{-2}$ & $3.3 \times 10^{-2}$ & 2.27 & $1.45 \times 10^{-2}$ \\
$\mathrm{Al}_{2} \mathrm{O}_{3}$ & $4.4 \times 10^{-2}$ & $4.5 \times 10^{-2}$ & 4.0 & $1.12 \times 10^{-2}$ \\
Totals & $9.696 \times 10^{-1}$ & 1.000 & - & $4.23 \times 10^{-1}$ \\
\hline
\end{tabular}

Weast 1978. 
The density of the solid waste matrix was calculated to be $3.33 \mathrm{~g} / \mathrm{cm}^{3}$ using Equation 5 :

$$
\operatorname{Density}(\text { solid })=\rho(\text { solid waste matrix })=\frac{1}{V_{D E}}=\frac{1}{\sum \frac{w_{i}}{\rho_{i}}}=\frac{1}{\frac{{ }_{P u O_{2}}}{\rho_{P u O_{2}}}}+\frac{1}{\frac{w_{D E}}{\rho_{D E}}}
$$

where

$\rho$ (solid waste matrix) $=$ the calculated density of the solid waste matrix (i.e., DE plus $\mathrm{PuO}_{2} / \mathrm{Am}$ source material) $\left(3.33 \mathrm{~g} / \mathrm{cm}^{3}\right)$

$w_{\mathrm{PrO} 2}=$ the mass of $\mathrm{PuO}_{2}$ per gram of waste matrix $\left(73.70 \mathrm{~g} \mathrm{PuO}_{2} / 201.70 \mathrm{~g}\right.$ waste matrix $=0.365 \mathrm{~g} \mathrm{Pu} / \mathrm{g}$ waste matrix)

$\rho_{\text {PuO2 }} \quad=$ the density of $\mathrm{PuO}_{2}\left(11.46 \mathrm{~g} / \mathrm{cm}^{3}\right)$

$w_{\mathrm{DE}} \quad=$ the mass of $\mathrm{DE}$ per gram of waste matrix $(128 \mathrm{~g} \mathrm{DE} / 201.70 \mathrm{~g}$ waste matrix $=0.635 \mathrm{~g} \mathrm{DE} / \mathrm{g}$ waste matrix)

PDE $\quad=$ the density of $\operatorname{DE}\left(2.364 \mathrm{~g} / \mathrm{cm}^{3}\right)$

Equation 6 is used to calculate the porosity of the waste matrix (Butcher and Mendenhall 1993):

$$
\text { Porosity }=1-\frac{\text { actual density }}{\text { solid } \text { matrix density }}=0.808
$$

where

actual density $=$ actual density of the waste matrix $\left[\left(73.70 \mathrm{~g} \mathrm{PuO}_{2}+128 \mathrm{~g} \mathrm{DE}\right) / 315 \mathrm{~cm}^{3}\right.$ $\left.=0.640 \mathrm{~g} / \mathrm{cm}^{3}\right]$

solid matrix density = solid matrix density of the waste matrix $\left(3.33 \mathrm{~g} / \mathrm{cm}^{3}\right)$

The pore void volume of the waste matrix was calculated using Equation 7:

Waste matrix pore void volume $=$ porosity $\times$ total volume

where

$$
\begin{array}{ll}
\text { Waste matrix pore void volume } & =254.5 \mathrm{~cm}^{3} \\
\text { porosity } & =\text { porosity of the waste matrix }(0.808) \\
\text { total volume } & =\text { total volume of the waste matrix }\left(315 \mathrm{~cm}^{3}\right)
\end{array}
$$

Therefore, the total void volume in the test cylinder was determined to be $254.8 \mathrm{~cm}^{3}$ by summing the headspace volume $\left(0.3 \mathrm{~cm}^{3}\right)$ and the pore void volume $\left(254.5 \mathrm{~cm}^{3}\right)$.

The effectiveness at which alpha particles decompose water (i.e., radiolysis) is described by the G-value. The effective G-value for hydrogen formation is calculated using Equation 8 (Table A2-5, NRC 1997):

$$
\begin{gathered}
G_{e f f}(H)=G(H-\text { water radiolysis }) \times w t . \text { frac. water in sample } \times \\
\text { fraction of alpha energy }
\end{gathered}
$$


where:

$$
\begin{aligned}
& G_{\text {eff }}(H) \quad=\text { effective G-value for hydrogen formation }\left(7.32 \times 10^{-4}\right. \text { molecules } \\
& \mathrm{H}_{2} / 100 \mathrm{eV} \text { alpha energy) } \\
& G(H \text {-water radiolysis })=1.6 \text { molecules } \mathrm{H}_{2} \text { formed/100 eV alpha energy } \\
& \text { wt. frac. water in sample }=\text { the fraction of water in the waste matrix }\left(1.43 \times 10^{-3}\right) \\
& \text { fraction of alpha energy }=\text { the fraction of alpha energy that escapes a } 30 \mu \mathrm{m} \mathrm{PuO}_{2} \text { particle } \\
& \text { (0.32) (Table A2-5, NRC 1997) }
\end{aligned}
$$

The effective G-value for oxygen formation is calculated using Equation 9 (NRC 1997):

$$
G_{\text {eff }}(O)=G(O-\text { water radiolysis }) \times \text { wt. frac. water in sample } \times \text { fraction of alpha energy }
$$

where:

$$
\begin{aligned}
& \mathrm{G}_{\mathrm{eff}}(\mathrm{O})=\begin{array}{l}
\text { effective } \mathrm{G} \text {-value for oxygen formation }\left(3.66 \times 10^{-4} \text { molecules } \mathrm{O}_{2} / 100 \mathrm{eV}\right. \\
\text { alpha energy) }
\end{array} \\
& \mathrm{G}(\mathrm{O} \text {-water radiolysis })=0.8 \text { molecules } \mathrm{O}_{2} \text { formed } / 100 \mathrm{eV} \text { alpha energy }
\end{aligned}
$$

and all other terms are as previously defined.

The net gas generation rate is calculated using Equation 10:

$$
G_{\text {eff }}(\text { net gas })=G_{e f f}(H)+G_{e f f}(O)=1.10 \times 10^{-3} \text { molecules } / 100 \mathrm{eV}
$$

where all terms are as previously defined.

Equation 11 (NRC 1977) is used to calculate the gas generation rate in the waste matrix due the radiolysis of water by alpha particles:

$$
C_{g}=\frac{Q_{i} G_{e f f}}{N_{A} 1.602 \times 10^{-19} \frac{W \mathrm{sec}}{e V}}
$$

where

$$
\begin{aligned}
& C_{\mathrm{B}}=\text { gas generation rate in the test cylinder due to radiolysis }\left(1.82 \times 10^{-11} \mathrm{~mole} / \mathrm{sec}\right) \\
& Q_{\mathrm{i}}=\text { decay heat }(0.16 \mathrm{~W}) \\
& G_{\text {eff }}=\text { effective net } \mathrm{G}-\mathrm{value}\left(1.10 \times 10^{-3} \mathrm{molecules} / 100 \mathrm{eV}\right) \\
& N_{\mathrm{A}}=\text { Avogadro's number }\left(6.0225 \times 10^{23} \text { molecules } / \mathrm{mole}\right)
\end{aligned}
$$

Equation 12 (BEC 1997a) is used to calculate the test cylinder pressure, at time $t$, due to the hydrogen and oxygen formed by the radiolysis of residual water in the waste matrix:

$$
P_{(t)}=\frac{P_{o} V+C_{g} t R T}{V} \times K
$$


where

$P_{(t)}=$ the test cylinder pressure (psi) at time $t$

$P_{\mathrm{o}}=$ initial test cylinder (ambient) pressure at Los Alamos, New Mexico (0.7755 atm)

$V=$ void volume in test cylinder $\left(254.8 \mathrm{~cm}^{3}\right)$

$C_{g}=$ gas generation rate $\left(1.82 \times 10^{-31} \mathrm{~mole} / \mathrm{sec}\right)$

$t \quad=$ elapsed time (sec)

$R=$ Gas Law Constant (82.057 atm $\mathrm{cm}^{3} / \mathrm{mol} \mathrm{K}$ ) (Weast 1978)

$T=$ absolute temperature of test cylinder $(298.15 \mathrm{~K})$

$K=$ conversion factor (14.696 psi/atm) (Weast 1978)

The pressure profile of the test cylinder was calculated, using Equation 12, from the time the experiment started (time zero) to 78.5 years. The results from Equation 12, in units of psi, absolute, were converted to psi, gauge (psig) by subtracting the ambient pressure (11.4 psi) at Los Alamos, New Mexico. The calculated pressure profile (psig versus time) of the test cylinder is graphed in Figure 1. Inspection of Figure 1 reveals that the pressurization of the test cylinder that results from the radiolysis of water, represented by the solid line, reaches a maximum value of 22.6 psig at 27.9 years. The pressure profile becomes flat after 27.9 years because the total amount of residual water (i.e., 0.016 moles) trapped in the test matrix has been consumed by radiolysis at this point in time.

The second gas generation process investigated in this analysis considered the pressure buildup in the test cylinder due to the formation of helium gas. Helium gas is formed by alpha-emitting radionuclides because the alpha particles will eventually acquire two electrons from the surrounding matter to form neutral helium atoms. It is assumed that one helium atom is formed each time an alpha-emitting radionuclide undergoes radioactive decay. Table 3 lists the characteristics of the radionuclides comprising the Pu/Am source material.

The mass of each plutonium isotope in $65 \mathrm{~g}$ of the $\mathrm{Pu}$-Am alpha source material is calculated in the sixth column of Table 3 by dividing the weight percent by 100 to get the mass of each isotope in one gram of source material and then multiplying the mass per gram by 65 to derive the mass of each radionuclide per $65 \mathrm{~g}$ of source material. The mass of the individual plutonium isotopes comprising the source material was calculated from Equation 13:

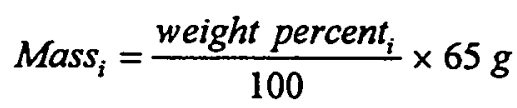

where .

$$
\begin{array}{ll}
\text { Mass }_{\mathrm{i}} & =\text { mass of the } i \text { th radionuclide }(\mathrm{g}) \\
\text { weight percent } & =\text { weight percent of the } i \text { th radionuclide (from Table 3) } \\
100 & =\text { conversion factor to convert percentage values to fractional values } \\
65 \mathrm{~g} & =\text { mass of the Pu/Am source material. }
\end{array}
$$

The alpha-specific activity of each radionuclide comprising the source material is taken from the LANL RAD_CODE Table (LANL 1995) and is listed in Table 3. The alpha activity ( $\mathrm{Ci}$ ) of each radionuclide comprising the source material is calculated using Equation 14:

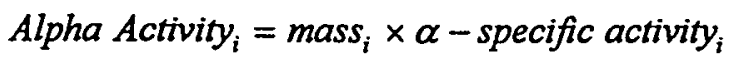




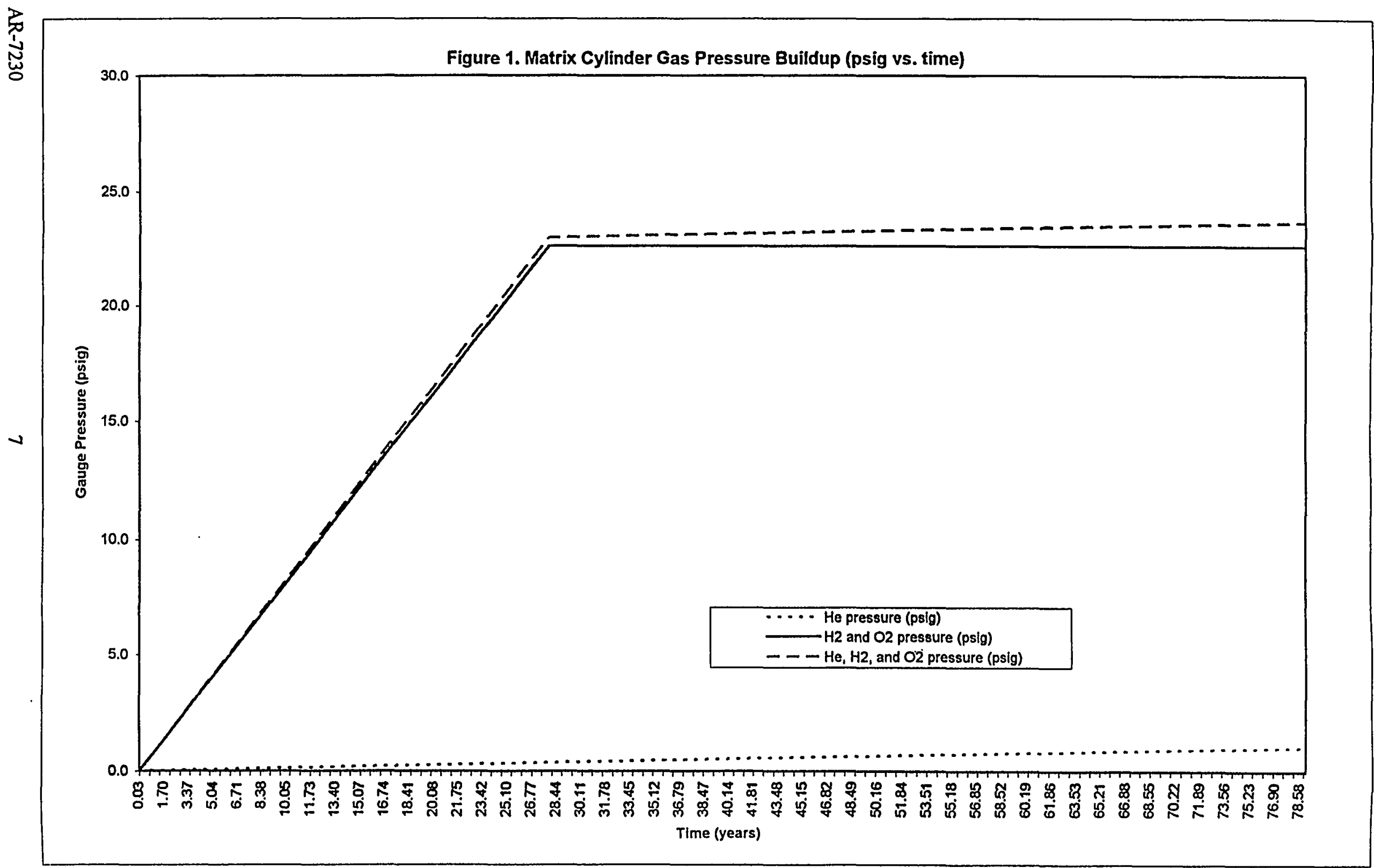


where

$$
\begin{aligned}
& \text { Alpha Activity } y_{\mathrm{i}}=\text { the alpha radioactivity }(\mathrm{Ci}) \text { of the } i \text { th radionuclide comprising the source } \\
& \text { material } \\
& \text { mass }_{\mathrm{i}} \quad=\text { the mass of the } i \text { th radionuclide comprising the source material }(\mathrm{g}) \\
& \alpha \text {-specific activity }=\text { the } \alpha \text {-specific activity of the } i \text { th radionuclide comprising the source } \\
& \text { material (Ci/g) }
\end{aligned}
$$

Table 3. Characteristics of Pu/Am Source Material

\begin{tabular}{lcccccc}
\hline & $\begin{array}{c}\alpha \text {-Specific } \\
\text { Radio- } \\
\text { nuctivity } \\
(\mathrm{Ci} / \mathrm{g})^{\mathrm{a}}\end{array}$ & $\begin{array}{c}\text { Half-life } \\
(\mathrm{yr})^{\mathrm{a}}\end{array}$ & $\begin{array}{c}\text { Decay } \\
\text { Constant } \\
\left(\mathrm{s}^{-1}\right)\end{array}$ & $\begin{array}{c}\text { Weight } \\
\text { Percent per } \\
\mathrm{Pu}^{\mathrm{b}}\end{array}$ & $\begin{array}{c}\text { Mass per } \\
65 \mathrm{~g} \mathrm{Pu} \\
(\mathrm{g})\end{array}$ & $\begin{array}{c}\alpha \text { Activity } \\
\text { per } 65 \mathrm{~g} \mathrm{Pu}(\mathrm{Ci})\end{array}$ \\
\hline Pu238 & $1.7119 \times 10^{1}$ & $8.77 \times 10^{1}$ & $2.51 \times 10^{-10}$ & $1.46 \times 10^{-2}$ & $9.49 \times 10^{-3}$ & $1.624 \times 10^{-1}$ \\
Pu239 & $6.204 \times 10^{-2}$ & $2.41 \times 10^{4}$ & $9.12 \times 10^{-13}$ & $9.377 \times 10^{1}$ & $6.095 \times 10^{1}$ & 3.781 \\
Pu240 & $2.2696 \times 10^{-1}$ & $6.56 \times 10^{3}$ & $3.35 \times 10^{-12}$ & 5.946 & 3.865 & $8.772 \times 10^{-1}$ \\
Pu241 & $2.48 \times 10^{-3}$ & $1.44 \times 10^{1}$ & $1.53 \times 10^{-9}$ & $2.093 \times 10^{-1}$ & $1.360 \times 10^{-1}$ & $3.37 \times 10^{-4}$ \\
Pu242 & $3.926 \times 10^{-3}$ & $3.76 \times 10^{5}$ & $5.84 \times 10^{-14}$ & $5.78 \times 10^{-2}$ & $3.757 \times 10^{-2}$ & $1.47 \times 10^{-4}$ \\
Am241 & 3.428 & $4.33 \times 10^{2}$ & $5.08 \times 10^{-11}$ & $1.0 \times 10^{-1}$ & $6.52 \times 10^{-2}$ & $2.234 \times 10^{-1}$ \\
\hline LANL 1995. & & & & & \\
LANL 1997. & & & & & \\
\hline
\end{tabular}

The number of alpha decays (transformations) each radionuclide undergoes during a time interval (time integrated decay) is calculated from Equation 15:

$$
\text { Number of decays } i_{i}=C \frac{A_{o, i}}{\lambda_{i}}\left(1-e^{-\lambda_{i} t}\right)
$$

where

$$
\begin{aligned}
& \text { Number of decays } s_{\mathrm{i}}=\text { the number of transformations the ith radionuclide undergoes during the } \\
& C \quad=\text { the constant } 3.7 \times 10^{10} \text { decays } / \mathrm{sec}(\mathrm{dps}) \text { per curie, used to convert } \mathrm{Ci} \text { to } \mathrm{dps} \\
& A_{0, i}=\text { the alpha activity of the } i \text { th radionuclide at the beginning of the interval } \\
& \text { (Ci) } \\
& \lambda_{i} \quad=\text { the decay constant of the ith radionuclide }\left(\sec ^{-1}\right) \\
& e \quad=\text { base of the natural } \log \\
& t \quad=\text { length of the interval (sec) }
\end{aligned}
$$


The number of alpha decays, as calculated above, is equivalent to the number of atoms of helium formed during the time interval in question. The number of moles of helium atoms formed during a time interval is calculated using Equation 16:

$$
\text { moles He }=\frac{\text { atoms of } \mathrm{He}}{6.0225 \times 10^{23} \frac{\text { atoms }}{\text { mole }}}
$$

where

moles $\mathrm{He}=$ the number of moles of helium formed during the specified time interval $6.0225 \times 10^{23}$ atoms $/$ mole $=$ Avogadro's number

The Ideal Gas Law (Equation 17) is used to determine the pressure created by the helium formed by the decay of the ith radionuclide:

$$
P=\frac{n R T}{V} \times K
$$

where

$P=$ the calculated gas pressure created by the helium (psi)

$n=$ the number of moles of helium formed by the radioactive decay of the $i$ th radionuclide

$R=$ the Gas Law constant (82.057 atm $\mathrm{cm}^{3} /$ mole K) (Weast 1978)

$T=$ the absolute temperature of the test cylinder $(298.15 \mathrm{~K})$

$\mathrm{V}=$ the void volume in the test cylinder $\left(254.8 \mathrm{~cm}^{3}\right)$

$K=$ conversion factor (14.696 psi/atm) (Weast 1978)

The gas pressure created by the helium, formed from the radioactive decay of the $i$ th radionuclide comprising the source material, was calculated for time intervals ranging from 10 days to 78.5 years. The total gas pressure created by the radioactive decay of the radionuclides comprising the source material is calculated by summing the pressures created by the helium from the decay of each radionuclide. The results from Equation 17 were converted into units of psig as described above.

Figure 1 graphically presents the buildup of pressure (psig) in the test cylinder versus time for the following cases: (a) helium plus atmospheric pressure; (b) hydrogen and oxygen plus atmospheric preșsure; and (c) helium, hydrogen, and oxygen plus atmospheric pressure. Inspection of Figure 1 indicates that the test cylinder pressure profile is dominated by the radiolysis gas generation process until all of the residual water in the test matrix has been consumed by radiolysis after the experiment has proceeded for 27.9 years. The pressure profile continues to slowly rise, after all the residual water has been consumed, as a result of the pressurization created by the buildup of helium gas, formed by the decay of alpha emitting radionuclides. The pressurization created by the buildup of helium gas is negligible when compared to the pressurization created by the buildup of hydrogen and oxygen gas, formed by radiolysis. The test cylinder reaches a pressure of $23.6 \mathrm{psig}$ at 78.5 years. 


\section{REFERENCES}

BEC, 1997a PDP-DE-Plutonium/Americium Matrix Cylinder Gas Pressure Build-Up, Benchmark Environmental Corporation. Albuquerque, New Mexico.

BEC, 1997b. PDP-DE-Plutonium/Americium Matrix Cylinder Helium Pressure Build-Up, Benchmark Environmental Corporation. Albuquerque, New Mexico.

Butcher and Mendenhall, 1993. A Summary of the Models Used for the Mechanical Response of Disposal Rooms in the Waste Isolation Pilot Plan with regard to CompHance with 40 CFR 191, Subpart B, SAND92-0427, Sandia National Laboratories, Albuquerque, New Mexico

INEEL, 1997. Fax from Greg Becker, March 31, 1997, Idaho National Engineering and Environmental Laboratory, Idaho Falls, Idaho.

LANL, 1995. RAD_CODE Table, Los Alamos National Laboratory, Los Alamos, New Mexico.

LANL, 1997. Fax from Dr. Robert Marshall, March 28, 1997, Los Alamos National Laboratory, Los Alamos, New Mexico.

NRC, 1997. Safety Analysis Report for the TRUPACT-II Shipping Package, Revision 16, NRC Docket No. 9218, U.S. Nuclear Regulatory Commission, Washington, D.C.

Weast, R. C., 1978. Handbook of Chemistry and Physics, 58th edition, CRC Press, West Palm Beach, Florida. 


\title{
MAXIMUM INTERNAL ALLOWABLE (DESIGN) AND FAILURE (YIELD) STRESSES ON STAINLESS STEEL AND ZIRCONIUM TEST CYLINDERS
}

\author{
September 24, 1997 \\ Project No. B45370007-8N \\ Monika Kinker \\ Materials Engineer \\ John Kinker, P.E. \\ Environmental Engineer \\ Benchmark Environmental Corporation \\ 4501 Indian School Road NE, Suite 105 \\ Albuquerque, New Mexico 87110
}

\subsection{INTRODUCTION}

Benchmark Environmental Corporation (Benchmark) performed an evaluation of the maximum internal allowable (design) operating pressures and the expected failure (yield) pressures for the cylinders used in the diatomaceous earth (DE)-plutonium (Pu)/americium (Am) matrix gas cylinder experiment. The evaluation was based on information supplied to Benchmark by the Los Alamos National Laboratory Inorganic Elemental Analysis Group, which is attached for reference. The evaluated cylinders are seamless stainless steel and seamless zirconium cylinders with flat endcaps welded onto each cylinder's ends. Inner and outer cylinders of the same material were designed and assembled so that the inner cylinder would fit snugly within the outer cylinder. Benchmark performed this evaluation, which (as seen in the attached letter of certification) was reviewed by an independent registered professional engineer, to determine: 1) the maximum design internal pressures the cylinders are expected to withstand, and 2) the internal pressure at which the cylinders are expected to fail. The methodology used and the results are presented herein.

\subsection{CALCULATION}

The attached calculation note, "Allowable Stresses of PDP DE-Pu/Am Matrix Test Cylinders," evaluates the maximum design and yield pressures using standard analytical techniques for designing thin-walled pressure vessels, which are broken down into the pressure on the cylindrical shell and the pressure on the endcaps. The internal pressure on the cylindrical shell was determined using hoop stress analysis for thinwalled cylindrical vessels, while internal pressure on the endcaps was determined for uniformly-loaded, flat circular plates. Dimensional tolerances were incorporated so that the most limiting internal pressure would result. Applicable safety factors for hoop stress and endcap stress were based on and applied to the yield strength of each material type to obtain the maximum design pressures. No safety factor was used to determine yield pressures. 
This evaluation used the following input data and assumptions:

- Yield strengths of 30,000 psig for the stainless steel AISI type 304 and 66,000 psig for the zirconium UNS R60802

- Weld joint efficiencies were not considered (cylinder tubes are seamless and endcaps are electronbeam, tungsten-inert gas, or laser welded with 100 percent weld penetration required)

- High temperature effects, including creep, were not considered (the test was assumed to be conducted at ambient temperature)

- Corrosion was not considered (DE matrix is not expected to contribute to corrosion of the assemblies)

- Hydrogen embrittlement was not considered (radioactivity levels are not expected to be sufficient enough to contribute to hydrogen embrittlement of the tubing assemblies)

- Fatigue of the material (failure of the material due to repeated application of stress below the material's yield strength) was not considered

- Contribution of outer cylinder to strength of inner cylinder was not considered

\subsection{RESULTS}

Table 3-1 lists the allowable (design) and maximum (yield) intérnal pressures calculated for the tubes and endcaps for both the inner and outer cylinders for each material. Table 3-1 also shows maximum design internal pressures for the inner stainless steel and zirconium assemblies of 25 and 149 psig, respectively. These values represent the maximum operating pressures at or below which the cylinders are expected to operate continuously without failing. Above this value, the cylinders have an increasing probability of plastic deformation and subsequent mechanical failure that approaches 100 percent at the yield pressure. The pressures at which the inner stainless steel and zirconium cylinders will exceed their yield strengths are 53 and 308 psig, respectively. Table 3-1 shows the weakest component for both the stainless steel and zirconium cylinders as being the top endcap, with the zirconium cylinders having six times greater strength than the stainless steel cylinders.

\subsection{DISCUSSION}

Figure 4-1 shows a stress-strain diagram, which illustrates the response (stress) of a metal to an applied force (strain). Below the yield strength, the bonds between the atoms are stretched but not broken. Thus, the assembly experiences elastic, or recoverable, deformation as the internal pressure increases, so that the material returns to its original shape once the applied force is removed. This elastic deformation accounts for the linear relationship between the stress experienced by the material and the applied force. At the yield strength of the material, plastic deformation begins to take place so that the component permanently deforms from its original shape. 
Table 3-1. Design and Failure (Yield) Internal Pressure on Tubing and Top and Bottom Endcaps

\begin{tabular}{|c|c|c|c|c|c|c|}
\hline \multirow[t]{2}{*}{$\begin{array}{l}\text { Material } \\
\text { Type }\end{array}$} & \multicolumn{2}{|c|}{$\begin{array}{c}\text { Cylinder Pressure } \\
\text { (psig) }\end{array}$} & \multicolumn{2}{|c|}{$\begin{array}{c}\text { Top Endcap Pressure } \\
\text { (psig) }\end{array}$} & \multicolumn{2}{|c|}{$\begin{array}{c}\text { Bottom Endcap Pressure } \\
\text { (psig) }\end{array}$} \\
\hline & design & yield & design & yield & design & yield \\
\hline $\begin{array}{c}\text { Stainless Steel } \\
\text { Inner Tube } \\
\text { Outer Tube }\end{array}$ & $\begin{array}{c}826 \\
1,161\end{array}$ & $\begin{array}{l}1,364 \\
1,915\end{array}$ & $\begin{array}{l}25 \\
38\end{array}$ & $\begin{array}{l}53 \\
78\end{array}$ & $\begin{array}{l}288 \\
257\end{array}$ & $\begin{array}{l}596 \\
533\end{array}$ \\
\hline $\begin{array}{l}\text { Zirconium } \\
\text { Inner Tube } \\
\text { Outer Tube }\end{array}$ & $\begin{array}{l}2,043 \\
2,530\end{array}$ & $\begin{array}{l}3,371 \\
4,175\end{array}$ & $\begin{array}{l}149 \\
130\end{array}$ & $\begin{array}{l}308 \\
269\end{array}$ & $\begin{array}{l}183 \\
216\end{array}$ & $\begin{array}{l}380 \\
447\end{array}$ \\
\hline
\end{tabular}

PART ॥ CONTROLLING THE MICROSTRUCTURE AND MECHANICAL PROPERTIES OF MATERIALS

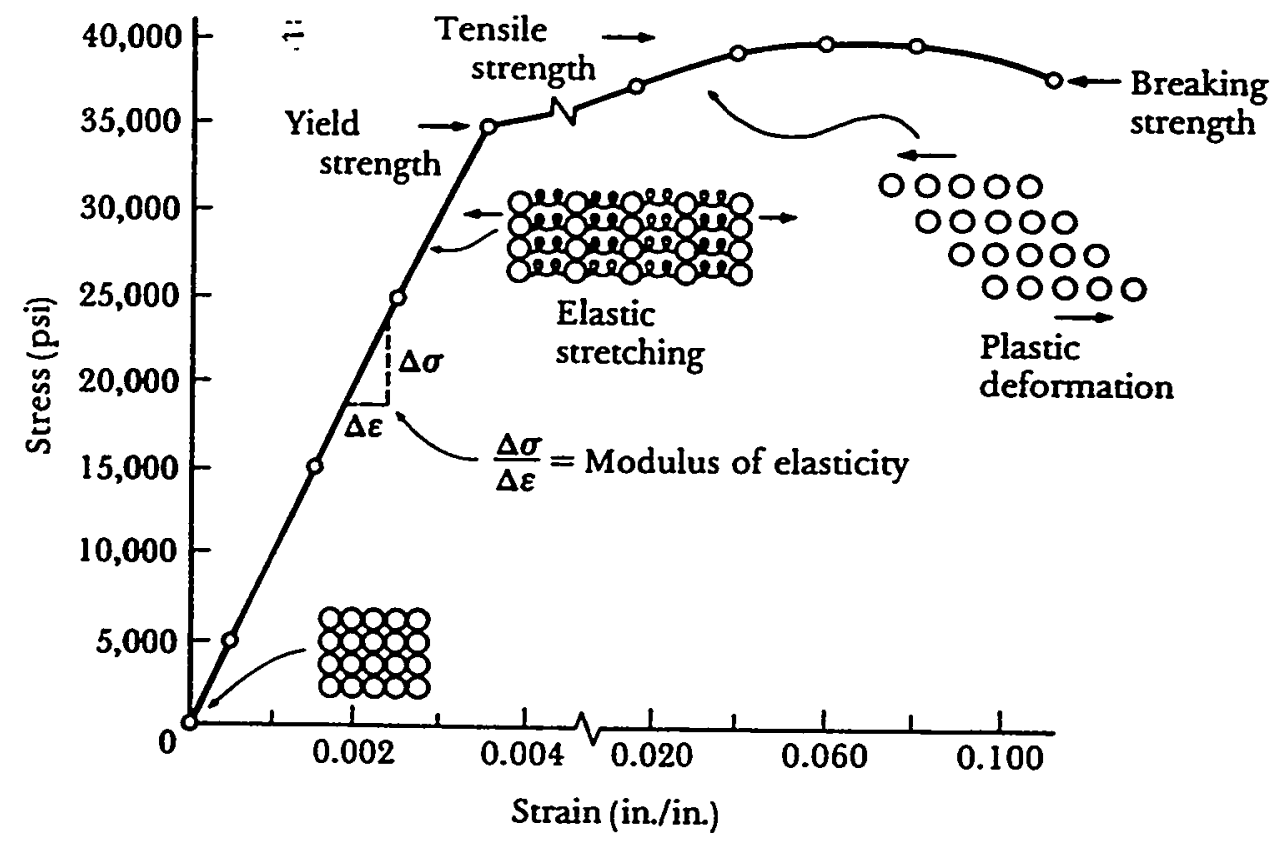

Figure 4-1. Stress-Strain Diagram for an Aluminum Alloy (Askeland 1985) 
The tensile strength is the stress obtained at the highest applied force and thus is the maximum stress on the stress-strain curve. The tensile strength is the easiest value to obtain and is therefore the most reported for most materials, but is less useful than the yield strength in the design and manufacturing of materials.

As the pressure increases, the material eventually fails. The breaking strength is the value at which the material fails. However, in the case of the evaluated assemblies, the yield strength is considered the failure strength, because the internal pressure on the assemblies is modeled to rise continuously. No pressure relief is expected because the assemblies are welded shut; thus, the applied force will continue to increase, and eventually, the material will fail.

In the case of the evaluated assemblies, failure will most likely occur at or near the welded region of the endcaps. Generally, the high temperatures associated with welding causes the physical properties of the localized region of the weld to change, resulting in the weld region to potentially be the weakest region of the assembly. This potential should be minimized by the types of welding specified (i.e., electron beam, etc.), which exhibit high cooling rates and may preclude major or serious alteration of the material's microstructure. An additional consideration is the location of the welded zone in proximity to increased mechanical strain.

The top endcaps of the stainless steel cylinders have a groove machined near the perimeter to allow for deflection and an interference fit into the outer cylinder. The reduced thickness of the grooved area of the endcap resides in the area of highest stress; therefore, this thickness was used as the dimension of the top inner and outer endcaps in determining the maximum design and yield pressures for the stainless steel cylinders. 
Date: July 9.1997 Project Number: 5061.06.0203 Sheet No. 1 of 3 Prepared By: Monika Kinker. Checked By: Check Date: 2-8-77 Calculation Title: Allowable Stresses of PDPDE-Pu/Am Matrix Test Cylinders

Purpose:

The purpose of this calculation is to evaluate the internal design stresses on stainless steel and zirconium cylinders used in the Performance Demonstration Project (PDP) diatomaceous earth (DE) -Plutonium (Pu)/Americium(Am) Matrix Gas Cylinder project. More specifically, this calculation estimates the maximum internal allowable pressure, and the pressure that would result in failure of the cylindrical structures and the endcaps of the cylinders.

Approach:

The evaluation of the maximum allowable intemal pressure is broken down into pressure on the cylindrical shell and the pressure on the endcaps. The internal design pressure for the shell is obtained by the following equation for hoop stress in thin-walled cylindrical vessels:

$$
\sigma=\frac{p d}{2 t} \rightarrow p=\frac{2 t \sigma}{d} ; \quad \sigma_{\text {allow }}=\frac{\sigma}{n}
$$

(Askeland 1985)

where $p=$ internal pressure (psi)

d $=$ inside diameter (in.)

$t \quad=$ thickness (in.)

$\sigma \quad=$ circumferential or hoop stress (psi)

$n=$ safety factor

The safety factor $\eta_{y}$ for yield strength is recommended by Azbel et al. as 1.65.

The design of the endcaps for the stainless steel and zirconium cylindrical vessels being reviewed in this calc note is similar to what Azbel et al calls a flat head closure. The maximum internal pressure is obtained by the following equation for a uniformly loaded flat circular plate that is clamped at the edges Idue to circumferential weld):

$$
\sigma=0.49 p(r / s)^{2} \rightarrow p=\frac{\sigma\left(s / r^{2}\right.}{0.49}
$$

(Azbel et al 1982)

where $s=$ thickness of plate (in.)

$r \quad=$ radius of plate (in.)

Under the same conditions, the maximum internal pressure at the edge of the endcaps is:

$$
\sigma=0.75 p(n / s)^{2} \rightarrow p=\frac{\sigma\left(s / r^{2}\right.}{0.75}
$$

Azbel et al recommends smaller allowable stresses for flat heads than for cylindrical shells, with $\eta_{y}=2.07$. 
Date: July 2.1997 Project Number: 5061.06.0203 Sheet No. 2 of 3 Prepared By: Monika Kinker. Checked By: Check Date: 7-8 -97 Calculation Title: Allowable Stresses of PDP DE-Pu/Am Matrix Test Cylinders Input Data:

Input data on material specifications (wall thickness, diameter, etc.) are obtained from the attached statements of work.

The properties for the stainless steel and zirconium tubing and endcaps are as follows:

\begin{tabular}{|l|l|c|}
\hline Material & Specification & Yield $\sigma$ (psi) \\
\hline Stainless Steel & SAE type 30404 or AISI type 304 & $30,000^{\circ}$ \\
\hline Zirconium & ASTM Designation B353-91: R60001, R60802, or R60804 UNS & $66,000^{\circ}$ \\
\hline
\end{tabular}

Source: Askeland, 1985

'Rust, 1979

Assumptions:

The following assumptions are made in this calculation:

- Cylinder tubes are seamless

- Endcaps are electron-beam, tungsten-inert gas, or laser welded with $100 \%$ penetration and certification of He leak testing provided to client

- Cylinders will not be heated above ambient

- Thickness allowances for corrosion are ignored

- Hydrogen embrittlement will not occur

\section{Computation:}

All computations are performed in the attached spreadsheet "Pressure Calculation." All equations used to calculate hoop stress and stress on the flat circular endcaps are as described earlier. The smallest dimension in the endcap design was used to provide a conservative estimate. Dimensional tolerances for the stainless steel and zirconium tubes were incorporated in the hoop stress and center and edge endplate stress equations so that the most limiting (smallest) internal pressure would result.

Results:

The attached spreadsheet shows the allowable and maximum (based on yield strength of material) internal pressures on the cylinder and endcaps for both the inner and outer tube for each material. Table 1 lists results of the attached calculations.

As seen in the attached spreadsheet, the pressure on the edge of the endcaps was the most limiting value, most likely because for this type of shape (cylindrical vessel with flat end) the stress is concentrated at the edge of the end plate. 
Date: July 9.1997 Project Number: 5061.06.0203 Sheet No. 3 of 3 Prepared By: Monika Kinker Checked By: Check Date: $7-8-\$ 7$ Calculation Title: Allowable Stresses of PDPDE-Pu/Am Matrix Test Cylinders

Table 1. Maximum Internal Allowable and Yield Pressures

\begin{tabular}{|l|c|c|c|c|c|c|}
\hline & \multicolumn{2}{|c|}{$\begin{array}{c}\text { Maximum Cylinder } \\
\text { Design pressure } \\
\text { (psi) }\end{array}$} & \multicolumn{2}{c|}{$\begin{array}{c}\text { Maximum Top Endcap } \\
\text { Design Pressure at Edge } \\
\text { (psi) }\end{array}$} & $\begin{array}{c}\text { Maximum Bottom Endcap } \\
\text { Design Pressure at Edge } \\
\text { (psi) }\end{array}$ \\
Material Type & allowable & yield & allowable & yield & allowable & yield \\
\hline $\begin{array}{l}\text { Stainless Steel } \\
\text { Inner Tube } \\
\text { Outer Tube }\end{array}$ & 826 & 1364 & 25 & 53 & 288 & 596 \\
\hline & 1161 & 1915 & 38 & 78 & 257 & 533 \\
\hline $\begin{array}{l}\text { Zirconium Tubing } \\
\text { Inner Tube } \\
\text { Outer Tube }\end{array}$ & 2043 & 3371 & 149 & 308 & 183 & 380 \\
\hline
\end{tabular}

As seen above, the limiting design pressure for both the stainless steel and zirconium tubings is the top endcap. The entire thickness of the bottom endcaps for both material types, which had machined insets on the inner and outer bottom endcaps, and the entire thickness of the zirconium top endcaps, which had no machined insets, was used in the evaluation of maximum internal pressure; however, the top endcaps for the stainless steel tubing had deep grooves near the outer edge to assist in the insertion of the endcaps into the tubing, with the inner tubing endcap machined to provide an interference fit inside the inner tubing and the outer tubing endcap machined to provide a clearance fit inside the outer tubing. Because the groove was so close to the edge of the endcap and is therefore in the area of stress concentration, both from the strain induced by the interference fit of the end cap and by deflection caused by internal pressure, the groove was considered for the evaluation of maximum internal pressure at the edge of the endcap. Therefore, the effective thickness of the endcap was equated to the original thickness minus the groove depth.

\section{References:}

Askeland, Donald. 1985. The Science and Engineering of Materials. Boston, Massachusetts, PWS Publishers.

Azbel, David S. et al. 1982. Chemical and Process Equipment Design. Ann Arbor, Michigan, Ann Arbor Science Publishers.

LANL. 1995/6. Statements of Work for the tubing and endcap components and assemblies. Los Alamos, New Mexico, Los Alamos National Laboratory.

Rust, James H. 1979. Nuclear Power Plant Engineering. Atlanta, Georgia, Haralson Publishing Company. 
Pressure Calculation

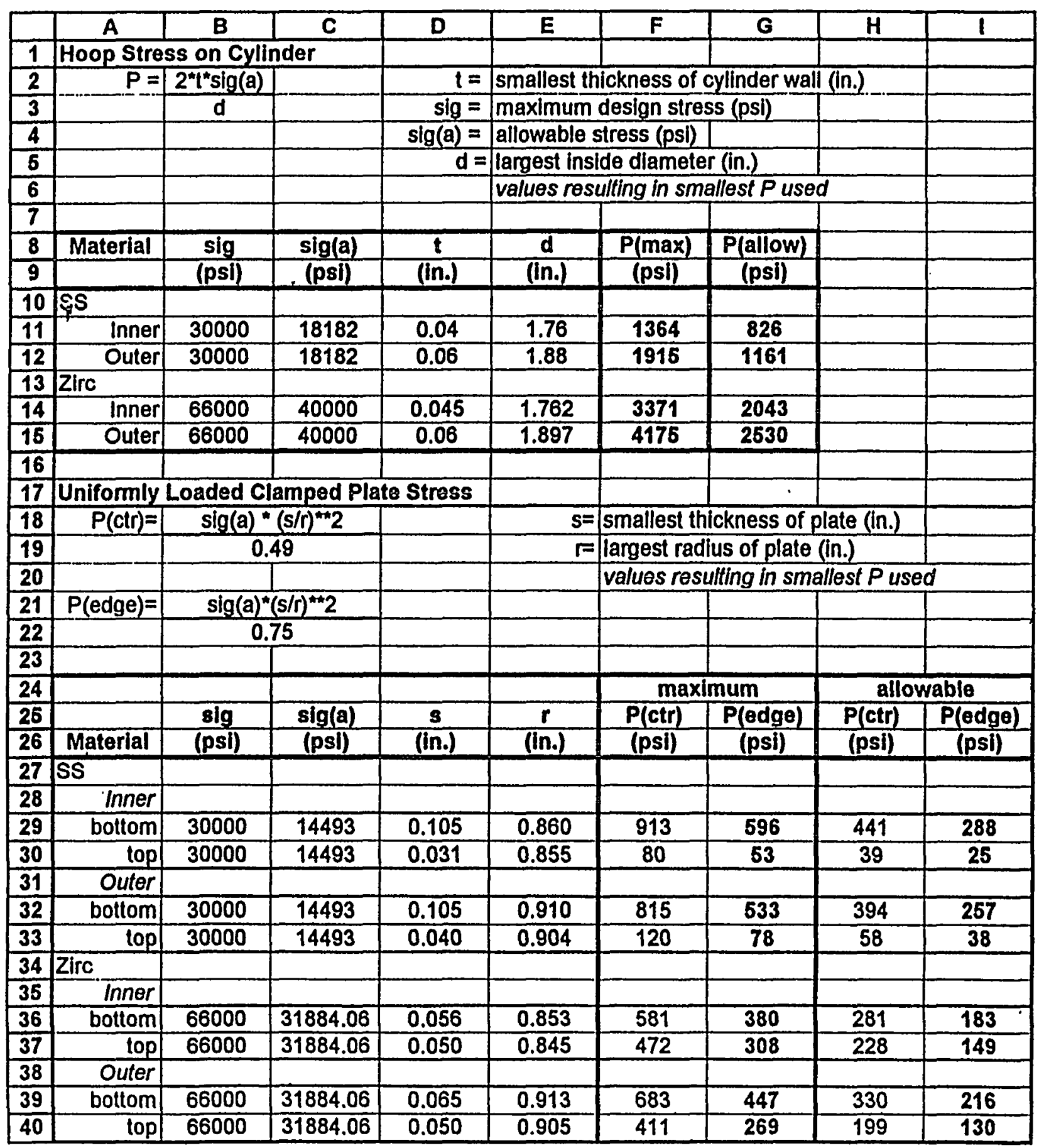

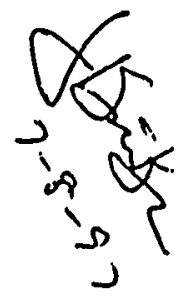





\section{CEP WRMs}

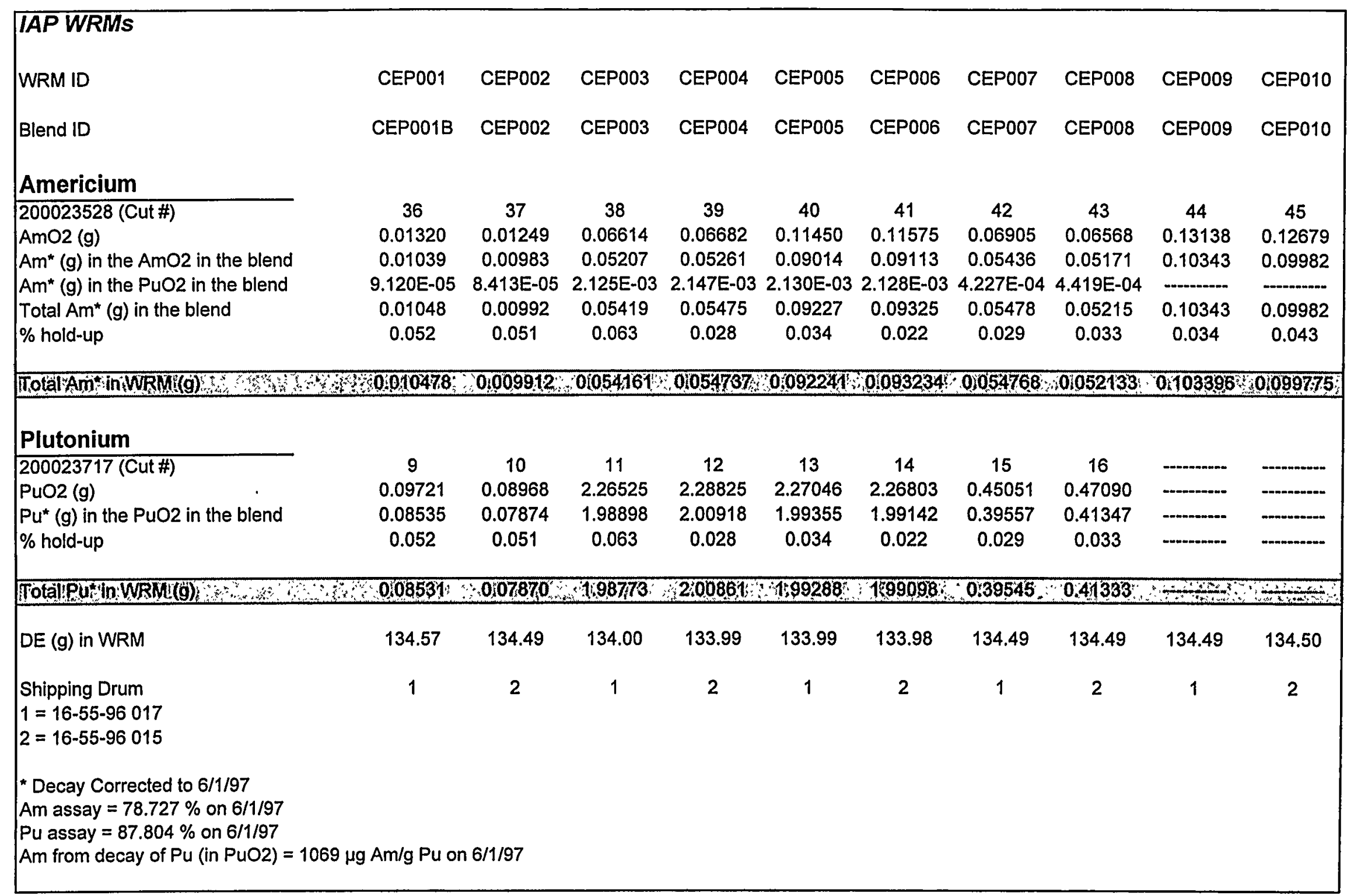




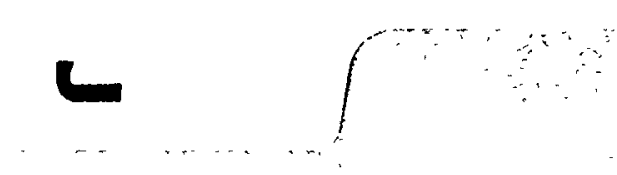




\section{CEP WRMs}

\begin{tabular}{|c|c|c|c|c|c|c|}
\hline \multicolumn{7}{|l|}{$\overline{D U}$ WRMs } \\
\hline WRM ID & CEP011 & CEP012 & CEP013 & CEP014 & CEP015 & CEP016 \\
\hline Blend ID & CEP011a & CEP012 & CEP013 & CEP014 & CEP015 & CEP016 \\
\hline \multicolumn{7}{|l|}{ Uranium } \\
\hline 200023256 (Cut \#) & 26 & 27 & 28 & 29 & 30 & 31 \\
\hline UO2 (g) & 570.61 & 1010.37 & 1094.58 & 1097.25 & 1111.82 & 1084.47 \\
\hline$U(g)$ & 499.24 & 884.00 & 957.68 & 960.01 & 972.76 & 948.84 \\
\hline$\%$ hold-up & 0.013 & 0.007 & 0.008 & 0.053 & 0.012 & 0.018 \\
\hline \multicolumn{7}{|l|}{ UThWRM(g) } \\
\hline$D E(g)$ in WRM & 113.49 & 41.95 & 30.14 & 30.48 & 30.71 & 30.62 \\
\hline Shipping Drum & 1 & 2 & 1 & 2 & 1 & 2 \\
\hline \multicolumn{7}{|l|}{$\begin{array}{l}1=16-55-96017 \\
2=16-55-96015\end{array}$} \\
\hline
\end{tabular}


$\pi$ 
Waste Item Measurements for CEP Uranium Waste Items (7/97)

$\begin{array}{llrl}\text { STANDARD } & \text { STD\#2 } & 67.4 & \mathrm{mg} \text { DU } \\ & \text { STD\#1 } & 168.5 & \mathrm{mg} \text { DU }\end{array}$

\begin{tabular}{ccccccccc}
\multicolumn{3}{c}{ Count } & & & \multicolumn{4}{c}{$63.32 \mathrm{keV}, 234 \mathrm{Th}$} \\
DATE & Time (s) & ID & SPEC & CT & cpm & ERR & $\%$ ERR & cpm/mg DU \\
\hline $7 / 11 / 97$ & 30000 & STD\#2 & DUSTD2 & 1484 & 2.968 & 188 & 12.67 & 0.044 \\
$7 / 16 / 96$ & 30000 & STD\#2 & DUSTD2b & 1401 & 2.802 & 187 & 13.35 & 0.042 \\
$7 / 14 / 97$ & 10000 & STD\#1 & DUSTD1 & 1331 & 7.986 & 110 & 8.26 & 0.047 \\
$7 / 16 / 97$ & 10000 & STD\#1 & DUSTD1b & 1120 & 6.72 & 110 & 9.82 & 0.040 \\
& & & & & & & AVG & 0.043 \\
& & & & & & & STD & 0.003 \\
& & & & & & & \%RSD & 7.55 \\
\hline
\end{tabular}

\begin{tabular}{|c|c|c|c|c|c|c|c|c|c|c|}
\hline \multirow[b]{2}{*}{ DATE } & \multirow[b]{2}{*}{ Time (s) } & \multirow[b]{2}{*}{ ID } & \multirow[b]{2}{*}{ SPEC } & \multicolumn{5}{|c|}{$63.32 \mathrm{keV}, 234 \mathrm{Th}$} & \multirow[b]{2}{*}{ Total U } & \multirow[b]{2}{*}{$\%$ Hold-Up* } \\
\hline & & & & CT & $\mathrm{cpm}$ & ERR & $\%$ ERR & $\mathrm{mg} D U$ in waste & & \\
\hline $7 / 11 / 97$ & 10000 & CEP011a & CEP11-W & 1170 & 7.02 & 109 & 9.32 & 162.42 & 499.01 & 0.033 \\
\hline $7 / 11 / 97$ & 10000 & CEP012 & CEP12-W & 432 & 2.592 & 107 & 24.77 & 59.97 & 884.00 & 0.007 \\
\hline 7/14/97 & 10000 & CEP013 & CEP13-W & 546 & 3.276 & 107 & 19.60 & 75.80 & 957.68 & 0.008 \\
\hline $7 / 15 / 97$ & 10000 & CEP014 & CEP14-W & 3664 & 21.984 & 121 & 3.30 & 508.64 & 960.01 & 0.053 \\
\hline $7 / 15 / 97$ & 10000 & CEP015 & CEP15-W & 871 & 5.226 & 108 & 12.40 & 120.91 & 972.76 & 0.012 \\
\hline $7 / 11 / 97$ & 10000 & CEP016 & CEP16-W & 1259 & 7.554 & 113 & 8.98 & 174.78 & 948.84 & 0.018 \\
\hline
\end{tabular}




\begin{tabular}{|c|c|c|c|c|c|c|c|c|c|c|}
\hline \multicolumn{11}{|c|}{ Waste Item Measurements for CEP Am Waste Items (6/97) } \\
\hline & & & & & & & & & & \\
\hline \multirow[t]{6}{*}{ STANDARD } & $\operatorname{Am} 241=$ & 27.015 & $\mu \mathrm{Ci}$ or & 7.873 & $\mu \mathrm{g}$ & $4 / 27 / 97$ & 51.00 & days & & \\
\hline & $\operatorname{Am} 241=$ & 27.009 & $\mu \mathrm{Ci}$ or & $\mathbf{7 . 8 7 9}$ & ng & $6 / 17 / 97$ & & & & \\
\hline & & & & & & & & & & \\
\hline & & & & & & & & & & \\
\hline & & & & & & & & & & \\
\hline & Couns & & & Am241 & & Counting & & & & \\
\hline DATE & Timo (s) & ID & SPEC & ROI & ERR & $\%$ ERR & $\mu \mathrm{Ci}$ & $\mathrm{cpm} / \mu \mathrm{Ci}$ & & \\
\hline $6 / 17 / 97$ & 1200 & 4197 High STD & STD06178 & 98430 & 353 & 0.36 & 27.009 & 182.22 & $\cdot$ & \\
\hline $6 / 17 / 97$ & 1200 & 4/97 High STD & STD0617b & 103697 & 369 & 0.36 & 27.009 & 191.97 & & \\
\hline $6 / 17 / 97$ & 1200 & 4/97 High STD & STD0617e & $102594^{\circ}$ & 359 & 0.35 & 27.009 & 189.93 & & \\
\hline \multirow[t]{3}{*}{$6 / 18 / 97$} & 1200 & 4/97 High STD & STD0618a & 102946 & 359 & 0.35 & 27.009 & 190.58 & & \\
\hline & & & & & & & AVG, $\mathrm{cpm} / \mu \mathrm{Ci}$ & 188.67 & & \\
\hline & & & & & & & STD & 3.80 & & \\
\hline \multirow[t]{3}{*}{ Blending Bottles } & & & & & & & $\%$ RSD & 2.01 & & \\
\hline & & & & & & & & & & \\
\hline & Count & & & $\operatorname{Am} 241$ & & Counting & & & Total & \\
\hline DATE & Time (s) & ID & \begin{tabular}{|l|} 
SPEC \\
\end{tabular} & ROI & ERR & $\% \mathrm{ERR}$ & $\mu \mathrm{Ci}$ & $\mu g$ & $\mathrm{Am}, \mathrm{mg}$ & $\%$ left in waste \\
\hline $6 / 17 / 97$ & 1200 & CEP001-Pro & CEP001-Pro & 148216 & 427 & 0.29 & 39.28 & 11.45 & 58.0 & 0.020 \\
\hline $6 / 17 / 97$ & 1200 & CEPOOL-B & CEPOOI-B & 70866 & 299 & 0.42 & 18.78 & 5.47 & 105 & 0.052 \\
\hline $6 / 17 / 97$ & 1200 & CEPOO2 & CEP002.W & 66096 & 290 & 0.44 & 17.52 & 5.10 & 9.9 & 0.051 \\
\hline $6 / 17 / 97$ & 1200 & CEPO03 & CEPOO3-W & 444003 & 740 & 0.17 & 117.67 & 34.29 & 54.2 & 0.063 \\
\hline $6 / 17 / 97$ & 1200 & CEPOO4 & CBPOO4-W & 198572 & 496 & 0.25 & 52.62 & 15.34 & 54.8 & 0028 \\
\hline $6 / 17 / 97$ & 1200 & CBPOOS & CEPO05.W & 408645 & 712 & 0.17 & 108.29 & 31.56 & 22.3 & 0.034 \\
\hline $6 / 17 / 97$ & 1200 & CBPO06 & CEP006-W & 263178 & 571 & 0.22 & 69.74 & 20.33 & 93.3 & 0.022 \\
\hline $6 / 17 / 97$ & 1200 & CEP007 & CEPO07-W & 209350 & 508 & 0.24 & 55.48 & 16.17 & 54.8 & 0.030 \\
\hline $6 / 18 / 97$ & 1200 & CEPO08 & CEPOO8-W & 222826 & 525 & 0.24 & 59.05 & 17.21 & 52.2 & 0.033 \\
\hline $6 / 18 / 97$ & 1200 & CBPOOO9 & CEP009.W & 458186 & 751 & 0.16 & 121.42 & 35.39 & 103.4 & 0.034 \\
\hline $6 / 18 / 97$ & 1200 & CEP010 & CEP010-W & 550938 & 825 & 0.15 & 146.00 & 42.55 & 99.8 & 0.043 \\
\hline $6 / 18 / 97$ & 1200 & CEPO05-Vial & CEPOOS-V & 109957 & 373 & 0.34 & 29.14 & 8.49 & 92.3 & 0.009 \\
\hline
\end{tabular}


Decay Corr. for Hold-up

\begin{tabular}{|c|c|c|c|c|c|c|c|c|c|c|}
\hline Total Am in the Blends & CEP001 & CEP002 & CEP003 & CEP004 & CEP005 & CEP006 & CEP007 & CEP008 & CEP009 & CEP010 \\
\hline grams as of $6 / 1 / 97$ & 0.010500 & 0.009930 & 0.054490 & 0.055050 & 0.092570 & 0.093550 & 0.054840 & 0.052210 & 0.103430 & 0.099820 \\
\hline grams as of $6 / 17 / 97$ & 0.010499 & 0.009929 & 0.054486 & 0.055046 & 0.092563 & 0.093543 & 0.054836 & 0.052206 & 0.103423 & 0.099813 \\
\hline grams as of $6 / 18 / 97$ & 0.010499 & 0.009929 & 0.054486 & 0.055046 & 0.092563 & 0.093543 & 0.054836 & 0.052206 & 0.103422 & 0.099813 \\
\hline$\mu \mathrm{g} \mathrm{Am}$ in hold-up & 5.47 & 5.1 & 34.29 & 15.34 & 31.56 & 20.33 & 16.17 & 17.21 & 35.39 & 42.55 \\
\hline$\%$ Hold-up & 0.052 & 0.051 & 0.063 & 0.028 & 0.034 & 0.022 & 0.029 & 0.033 & 0.034 & 0.043 \\
\hline & & $\begin{array}{l}\text { Isotope } \\
\text { 241Am }\end{array}$ & $\begin{array}{l}\text { half-life } \\
\text { (years) } \\
\qquad 432.7\end{array}$ & $\begin{array}{l}\text { half-life } \\
\text { (days) } \\
157935.5\end{array}$ & $\begin{array}{l}\text { decay } \\
\text { const. } \\
4.39 E-06\end{array}$ & & $\begin{array}{r}\text { At. Weight } \\
241.0568\end{array}$ & 1 & & \\
\hline & & & $\begin{array}{l}35598 \\
35599\end{array}$ & $\begin{array}{l}35582 \\
35582\end{array}$ & $\begin{array}{l}16 \\
17\end{array}$ & & & & & \\
\hline
\end{tabular}




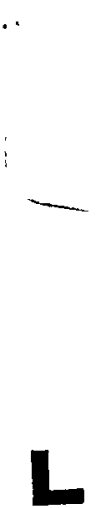

L 

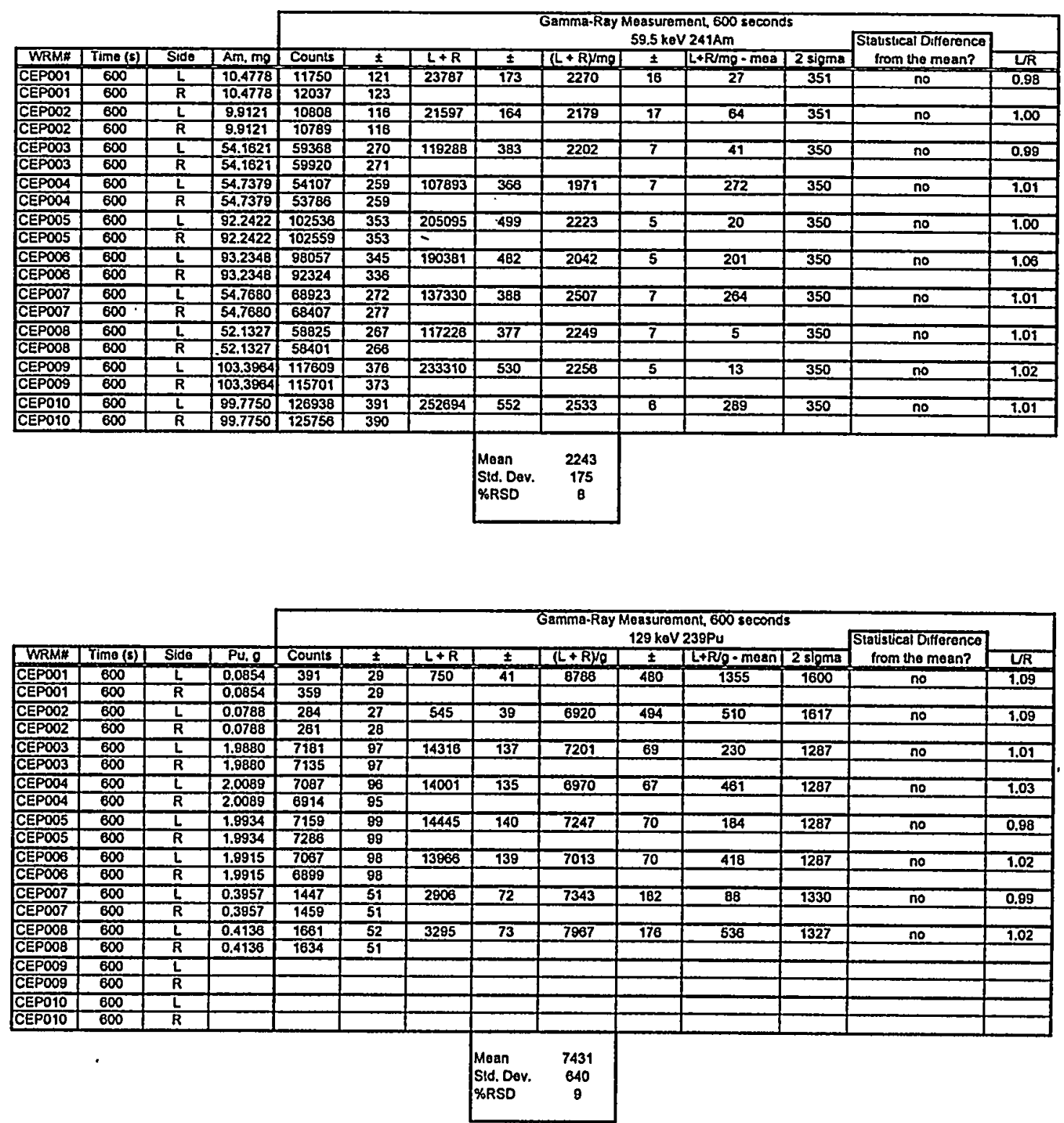
$\mathrm{CEP}^{241} \mathrm{Am}$ WRMs Homogeneity Measurements

\begin{tabular}{|c|c|c|c|c|c|c|c|c|c|c|c|c|}
\hline \multirow{3}{*}{ WRM\# } & \multirow[b]{3}{*}{ Time (s) } & \multirow[b]{3}{*}{ Side } & \multirow[b]{3}{*}{$\mathrm{Am}, \mathrm{mg}$} & \multirow[b]{3}{*}{$\mathrm{Pu}, \mathrm{g}$} & \multicolumn{8}{|c|}{ Gamma-Ray Measurement, 600 seconds, 7/11/97, 7/15/97, 7/17/97 } \\
\hline & & & & & \multicolumn{4}{|c|}{$59.5 \mathrm{keV} 241 \mathrm{Am}$} & \multicolumn{4}{|c|}{$129 \mathrm{keV} 239 \mathrm{Pu}$} \\
\hline & & & & & count & $+\%$ & LR & $\mathrm{ct} / \mathrm{mg}$ & count & $+1-$ & LR & $c / / B$ \\
\hline CEP001 & 600 & L1 & 10.48 & 0.09 & 11750 & 121 & 1.000 & 1112 & 391 & 29 & & 4134 \\
\hline CEPOOI & 600 & $\overline{R 1}$ & & & 12037 & 123 & & & 359 & 29 & & \\
\hline CEPOOI & 600 & L2 & & & 11545 & 119 & & & 363 & 29 & & \\
\hline CEPO01 & 600 & $\overline{R 2}$ & & & 11857 & 121 & & & 330 & 29 & & \\
\hline CEPOOI & 1800 & $\mathrm{L3}$ & & & 12009 & & & & 322 & & & \\
\hline CEP001 & $7200^{*}$ & CEN & & & 10911 & & & 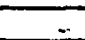 & 307 & & 0.976 & 3642 \\
\hline CEPOOI & $7200^{\circ}$ & $\overline{\mathrm{L}} 4$ & & & 11512 & & & & 315 & & & \\
\hline CEPOO2 & 600 & $\mathrm{Il}$ & 9.92 & 0.08 & 10808 & 116 & 1.002 & 1089 & 284 & 27 & 1.088 & 3460 \\
\hline CEPO02 & 600 & $\overline{\mathrm{R} 1}$ & & & 10789 & 116 & & & 261 & 28 & & \\
\hline CEP003 & 600 & LI & 54.21 & 1.99 & 59368 & 270 & 0.991 & 1100 & 7181 & 97 & 1.006 & 3598 \\
\hline CEPO03 & 600 & RI & & & 59920 & 271 & & & 7135 & 97 & & \\
\hline CEP004 & 600 & II & 54.76 & 2.01 & 54107 & 259 & 1.006 & 985 & 7087 & 96 & 1.025 & 3484 \\
\hline CEP004 & 600 & $\overline{R I}$ & & & 53786 & 259 & & & 6914 & 95 & & \\
\hline CEPOOS & 600 & $\mathrm{~L} 1$ & 92.29 & 1.99 & 102536 & 353 & 1.000 & 1111 & 7159 & 99 & 0.983 & 3622 \\
\hline CEPOOS & 600 & $\overline{\mathrm{RI}}$ & & & 102559 & 353 & & & 7286 & 99 & & \\
\hline CEP006 & 600 & $\mathrm{L1}$ & 93.27 & 1.99 & 98057 & 345 & 1.045 & 1021 & 7067 & 98 & 1.004 & 3537 \\
\hline CEP006 & 600 & R1 & & & 92324 & 336 & & & 6899 & 98 & & \\
\hline CEPO06 & 600 & $\overline{R 2}$ & & & 95400 & 341 & & & 7172 & 90 & & \\
\hline CEP007 & 600 & $\mathrm{LI}$ & 54.79 & 0.40 & 68923 & 272 & 1.021 & 1198 & 1447 & 51 & 1.035 & 3855 \\
\hline CEP007 & 600 & $\mathrm{RI}$ & & & 68407 & 277 & & & 1459 & 51 & & \\
\hline CEP007 & 600 & L2 & & & 63690 & 276 & & & 1656 & 53 & & \\
\hline CEP007 & 600 & $\overline{\mathrm{R} 2}$ & & & 61498 & 271 & & & 1539 & 51 & & \\
\hline CEP008 & 600 & $\overline{\mathrm{LI}}$ & 52.16 & 0.41 & 58825 & 267 & 1.011 & 1128 & 1661 & 52 & 1.016 & 3883 \\
\hline CEP008 & 600 & R1 & & & 58401 & 266 & & & 1634 & 51 & & \\
\hline CEP008 & 600 & $\overline{L 2}$ & & & 58637 & 266 & & & 1565 & 50 & & \\
\hline CEP008 & 600 & $\overline{R 2}$ & & & 58180 & 258 & & & 1607 & 52 & & \\
\hline CEP008 & 600 & $\mathrm{L3}$ & & & 60003 & 267 & & & 1630 & 51 & & \\
\hline CEPO08 & 600 & R3 & & & 58923 & 261 & & & 1539 & 52 & & \\
\hline CEP009 & 600 & $\mathrm{Ll}$ & 103.45 & & 117609 & 376 & 1.018 & 1118 & & & & \\
\hline CEPOO9 & 600 & $\mathrm{L2}$ & & & 115701 & 373 & & & & & & \\
\hline CEPOO9 & 600 & $\overline{\mathbf{R I}}$ & & & 114137 & 372 & & & & & & \\
\hline CEP009 & 600 & $\mathrm{R} 2$ & & & 114976 & 373 & & & & & & \\
\hline CEPO10 & 600 & L1' & 99.83 & & 126938 & 391 & 0.999 & 1189 & & & & \\
\hline CEP010 & 600 & R1 & & & 125756 & 390 & & & & & & \\
\hline CEPO10 & 600 & L2 & & & 110417 & 362 & & & & & & \\
\hline CEPO10 & 600 & $R 2$ & & & 111864 & 363 & & & $\therefore$ & $\because$ & $\because \because$ & \\
\hline & & & & & & & $\begin{array}{c}\text { AVG } \\
\text { STD } \\
\% \text { RSD }\end{array}$ & $\begin{array}{c}1105 \\
65 \\
5.89\end{array}$ & & & $\begin{array}{c}\text { AVG** } \\
\text { STD } \\
\text { \%RSD }\end{array}$ & $\begin{array}{l}3635 \\
158 \\
4.35\end{array}$ \\
\hline
\end{tabular}

The counts in 59.5-keV and 129-keV peaks were expressed as $600 \mathrm{~s}$ counts.

** The short counts $(600,1800 \mathrm{~s})$ on CEP001 WRM wẹre not included in the average of normalized 129-keV peak area due to poor peak shape and counting statistics. 



\begin{tabular}{|c|c|c|c|c|c|c|c|c|c|c|c|c|c|c|c|}
\hline \multirow[b]{2}{*}{ WRM\# } & \multirow[b]{2}{*}{ Time (s) } & \multirow[b]{2}{*}{ Segment } & \multirow[b]{2}{*}{$U, g$} & \multicolumn{8}{|c|}{$\begin{array}{l}\text { Ganma-Ray Measurement, } 600 \text { seconds } \\
\qquad 186 \mathrm{keV} 235 \mathrm{U}\end{array}$} & \multirow{2}{*}{$\begin{array}{l}\text { Statistical Difference } \\
\text { from the mean? }\end{array}$} & \multicolumn{3}{|c|}{ Segments } \\
\hline & & & & Counts & \pm & $1+2+3$ & \pm & $(1+2+3) / g$ & \pm & $1+2+3 / \mathrm{g}-$ mean & 2 sigma & & $1 / 2$ & $1 / 3$ & $2 / 3$ \\
\hline CEP011 & 7200 & 1 & 499.18 & 13464 & 648 & 40104 & 1122 & 80 & 2 & 29 & 29 & no? & 0.98 & 1.04 & 1.06 \\
\hline CEP011 & 7200 & 2 & 499.18 & 13680 & 648 & & & & & & & & & & \\
\hline CEP011 & 7200 & 3 & 499.18 & 12960 & 648 & & & & & & & & & & \\
\hline CEP012 & 7200 & 1 & 883.94 & 12744 & 720 & 41472 & 1247 & 47 & 1 & 4 & 29 & no & 0.85 & 0.93 & 1.09 \\
\hline CEP012 & 7200 & 2 & 883.94 & 14976 & 720 & & & & & & & & & & \\
\hline CEP012 & 7200 & 3 & 883.94 & 13752 & 720 & & & & & & & & & & \\
\hline CEP013 & 7200 & 1 & 957.60 & 14616 & 720 & 42192 & 1247 & 44 & 1 & 7 & 29 & no & 1.00 & 1.13 & 1.14 \\
\hline CEP013 & 7200 & 2 & 957.60 & 14688 & 720 & & & & & & & & & & \\
\hline CEP013 & 7200 & 3 & 957.60 & 12888 & 720 & & & & & & & & & & \\
\hline CEP014 & 7200 & 1 & 959.51 & 14184 & 720 & 45000 & 1247 & 47 & 1 & 4 & 29 & no & 0.85 & 1.01 & 1.19 \\
\hline CEP014 & 7200 & 2 & 959.51 & 16776 & 720 & & & & & & & & & & \\
\hline CEP014 & 7200 & 3 & 959.51 & 14040 & 720 & & & & & & & & & & \\
\hline CEP015 & 7200 & 1 & 972.64 & 12960 & 720 & 40824 & 1247 & 42 & 1 & 9 & 29 & no & 0.88 & 0.98 & 1.11 \\
\hline CEP015 & 7200 & 2 & 972.64 & 14688 & 720 & & & & & & & & & & \\
\hline CEP015 & 7200 & 3 & 972.64 & 13176 & 720 & & & & & & & & & & \\
\hline CEP016 & 7200 & 1 & 948.66 & 14904 & 720 & 45360 & 1247 & 48 & 1 & 4 & 29 & no & 0.99 & 0.97 & 0.98 \\
\hline CEP016 & 7200 & 2 & 948.66 & 15048 & 720 & & & & & & & & & & \\
\hline CEP016 & 7200 & 3 & 948.66 & 15408 & 720 & & & & & & & $!$ & & & \\
\hline & & & & & & & $\begin{array}{l}\text { Mean } \\
\text { Std. Dev. } \\
\% \text { RSD }\end{array}$ & $\begin{array}{l}51 \\
14 \\
28\end{array}$ & & & & & & & \\
\hline
\end{tabular}


*** U-235 LONG FEFOFT/G5O1 *** Uncorrected Eounts/sec B8 keV FEAK 136 kEV FEAK 186 kEV FEAK 279 keV FEAK

$\begin{array}{lll}\text { SEIVIENT \# } 1 & \text { DFEN } & 133.37 \\ & +/- & 0.32 \\ & \text { CLOSED } & 751.98 \\ & +/- & 1.32\end{array}$

SEIIMENT \# 2 OFEN ET3.59 $+1-\quad 1.29$ CLOSED 753.80 $+1-\quad 1.32$

SEISMENT \# 3 OFEN $71 E .68$ $+1-\quad 1.31$ ELOSED 754.46 $+1-\quad 1.32$

$\begin{array}{rlr}\text { SEGMENT \# } 4 & \text { OFEN } & 718.84 \\ & +/- & 1.31 \\ & \text { LLOSED } & 754.13 \\ & +/- & 1.32\end{array}$

SEGMENT \# 5 OFEN' 722.92 $+1-\quad 1.31$

CLLSED 754.72 $+1-\quad 1.32$

$\begin{array}{ccc}\text { SEISMENT \# } E & \text { OFEN } & 490.35 \\ & +/- & 1.5 \\ & \text { DLOSED } & 756.89 \\ & +/- & 1.32\end{array}$

SEGMENT \# 7 OFEN 476.29 $+1-\quad 1.19$ CLOSED 758.78 $+1-\quad 1.32$

1973.88
2.19
0.49
0.07
15.67
0.47
0.40
0.05
136. 21
0.62
0.64
0.08

7.10

0.26

0.53

0.09

\subsection{6}

0.25

0.75

0.09

E. 27

0.24

0.72

0.09

7.14

0.32

1. 22

0.07

$\begin{array}{ll}4.86 & 122.77 \\ 0.23 & 0.52 \\ 1.87 & 0.127 \\ 0.09 & 0.06\end{array}$

4.72

0.23

$1.50-$

0.09

107.12

0.49

0.26

0.06

$\begin{array}{ll}4.55 & 100.53 \\ 0.23 & 0.47 \\ 1.80 & 0.32 \\ 0.09 & 0.06\end{array}$

\subsection{5}

1.90

0.32

0.08

10.61

0.41

1. $.21-$

1121.88

1.54

0.19

0.04

1624.08
1.90
0.60
0.07

1.1. 63

0.42

0.34

0.05
1193.95

1.59

$0.0 \epsilon$

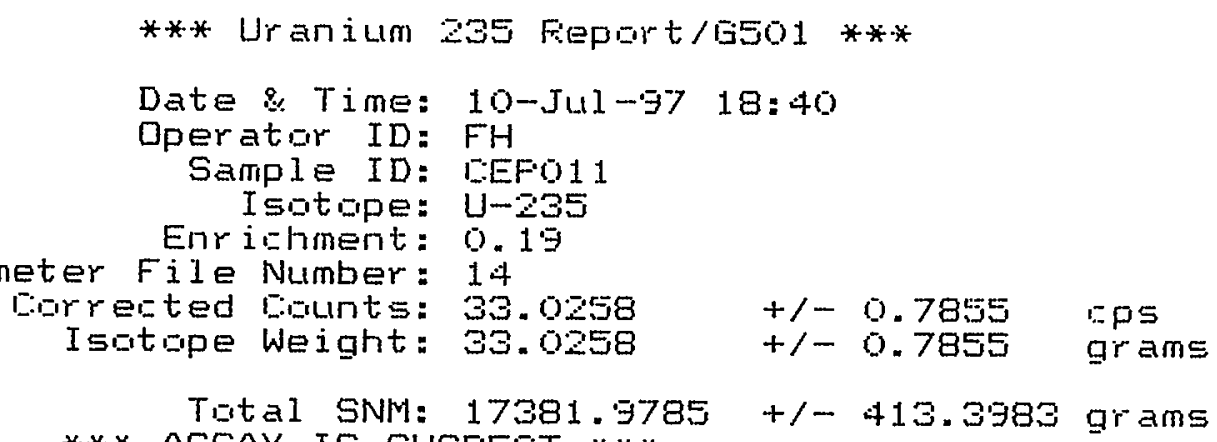




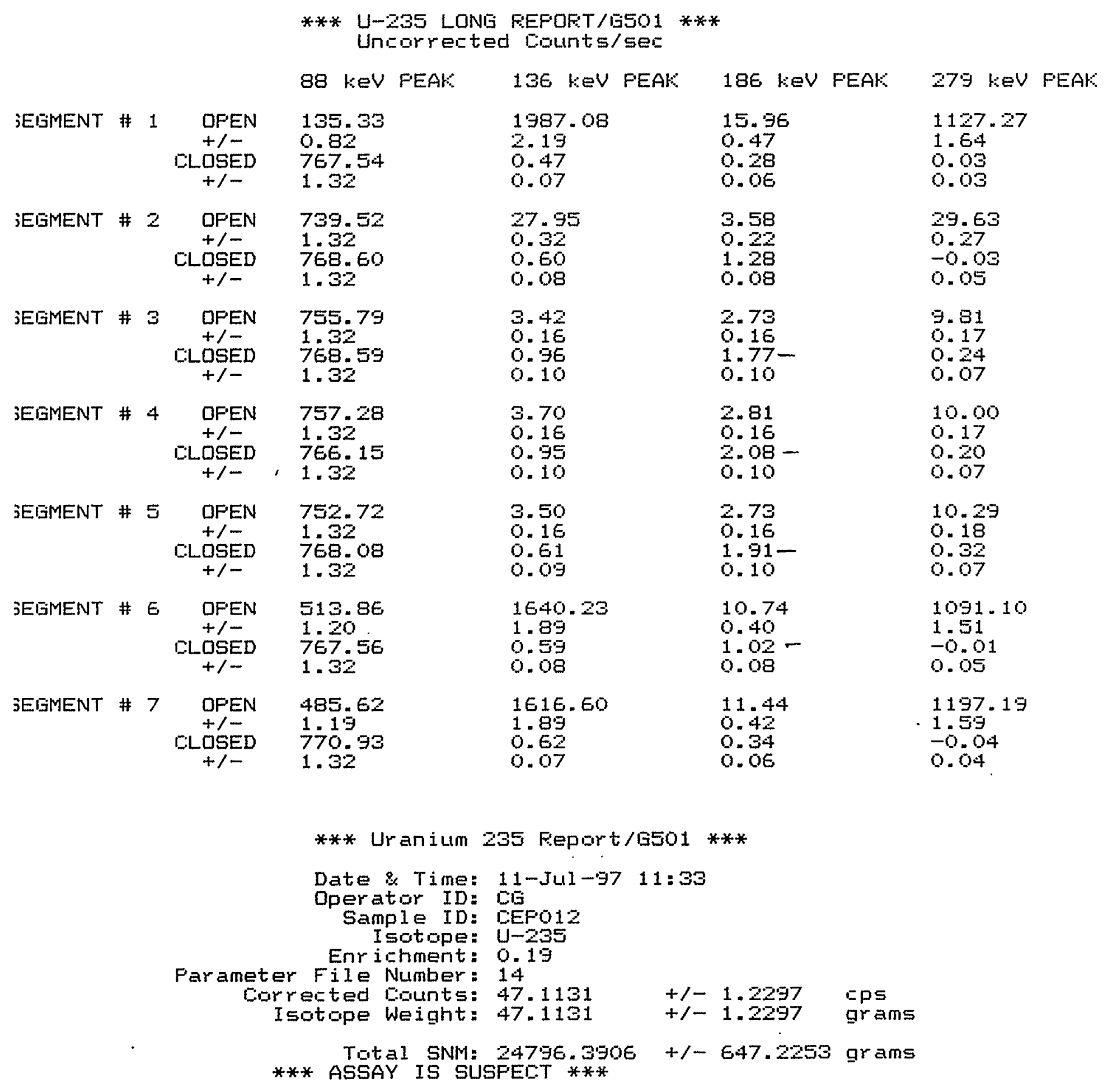




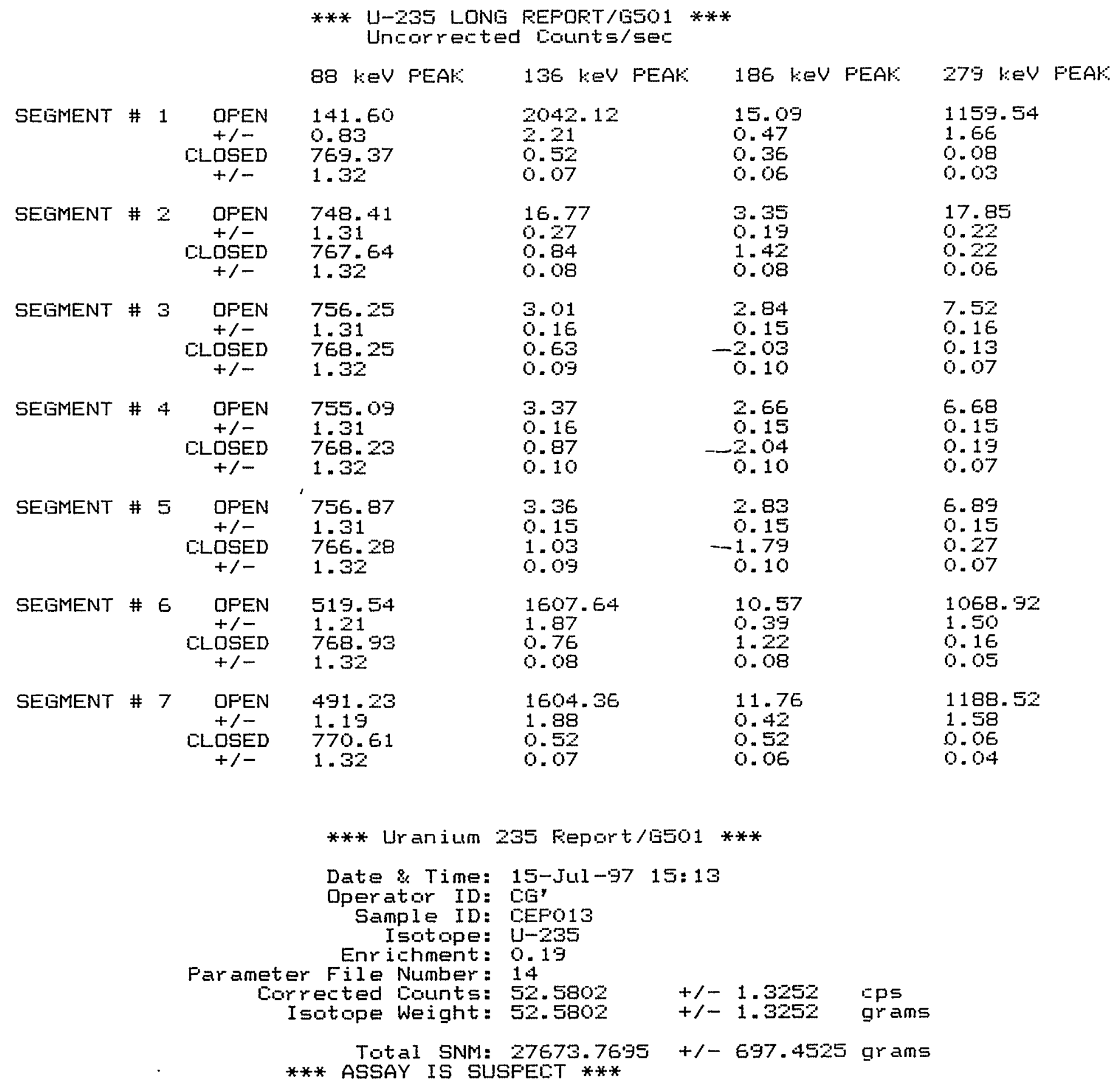




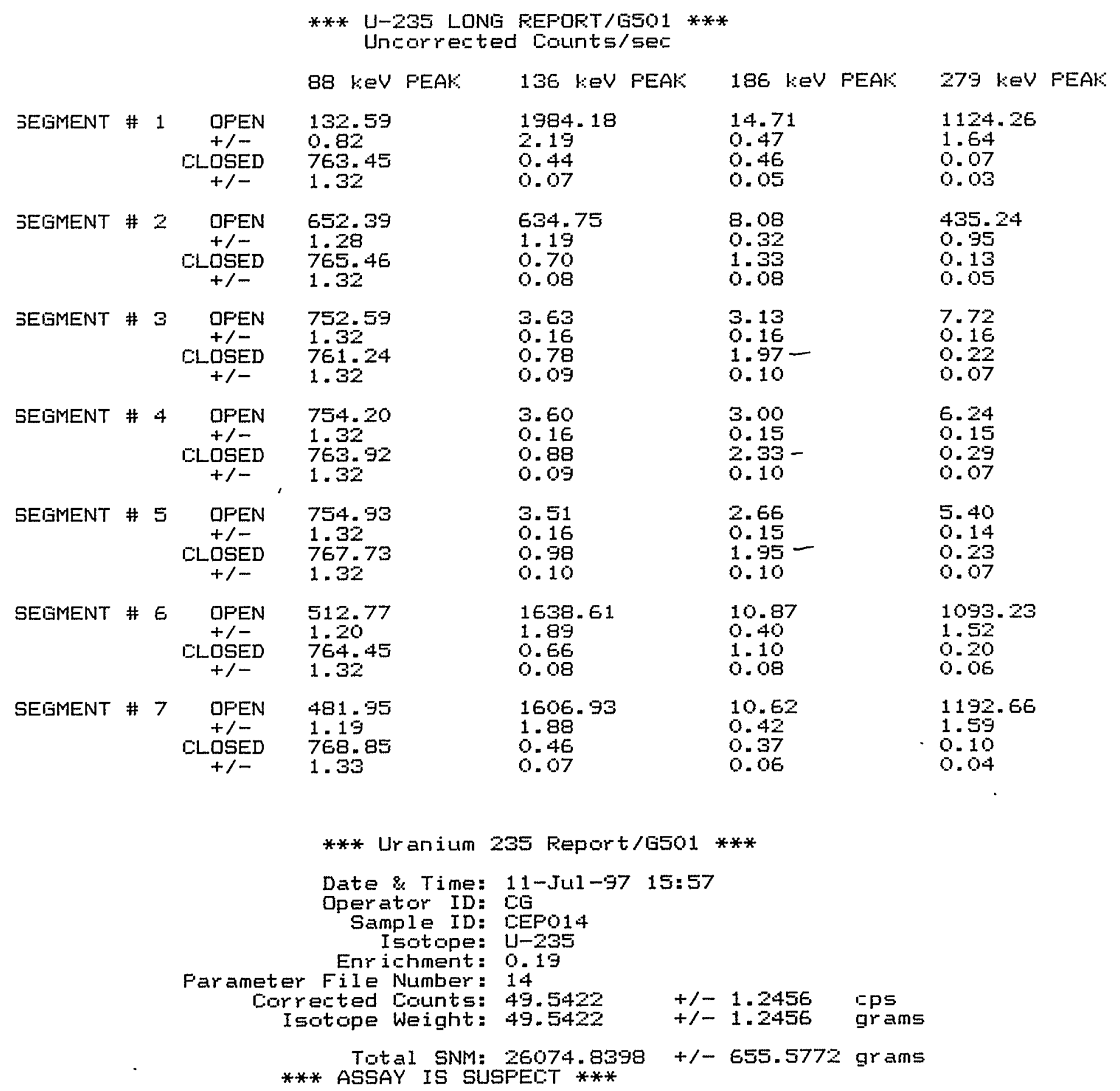




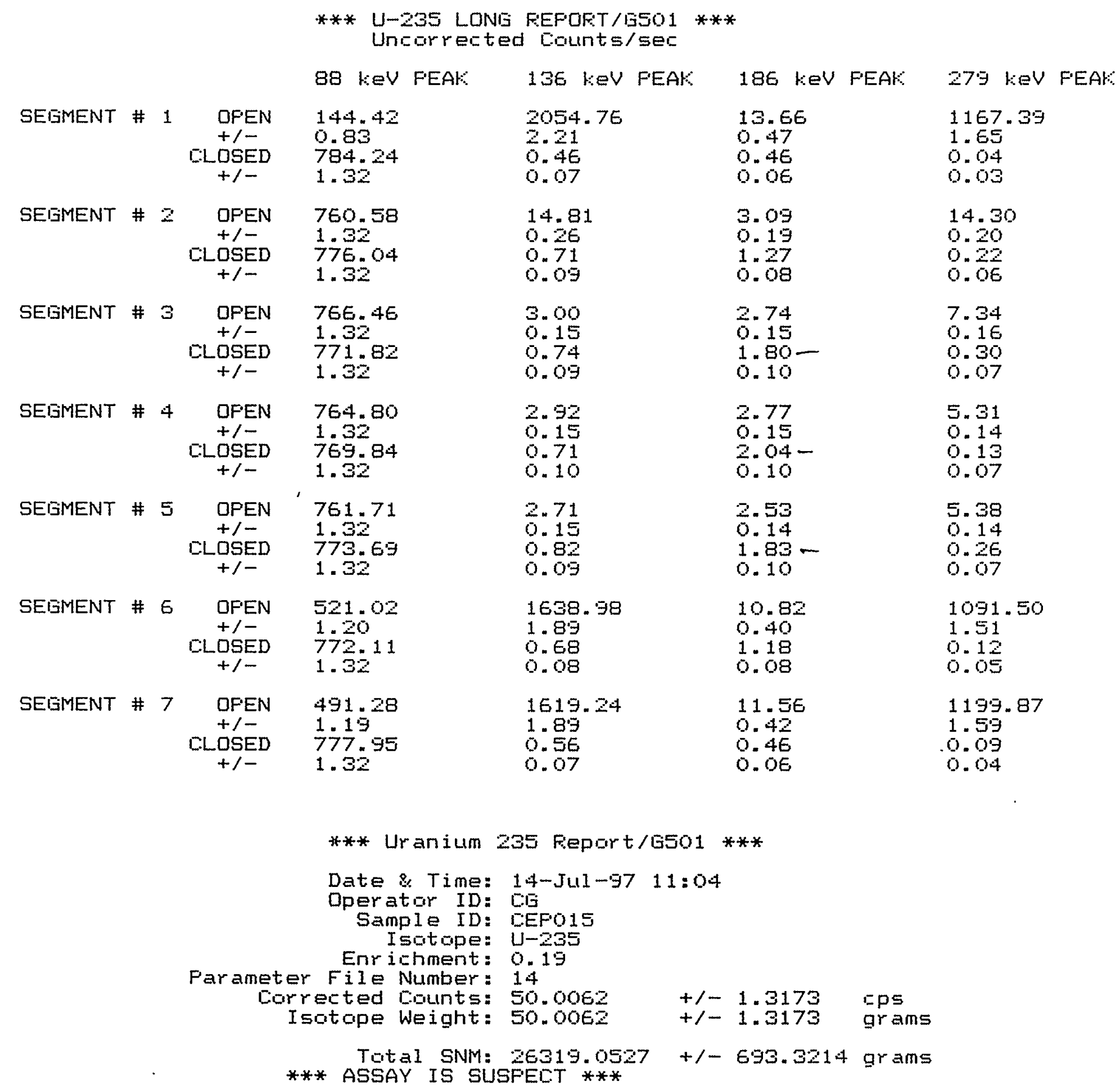




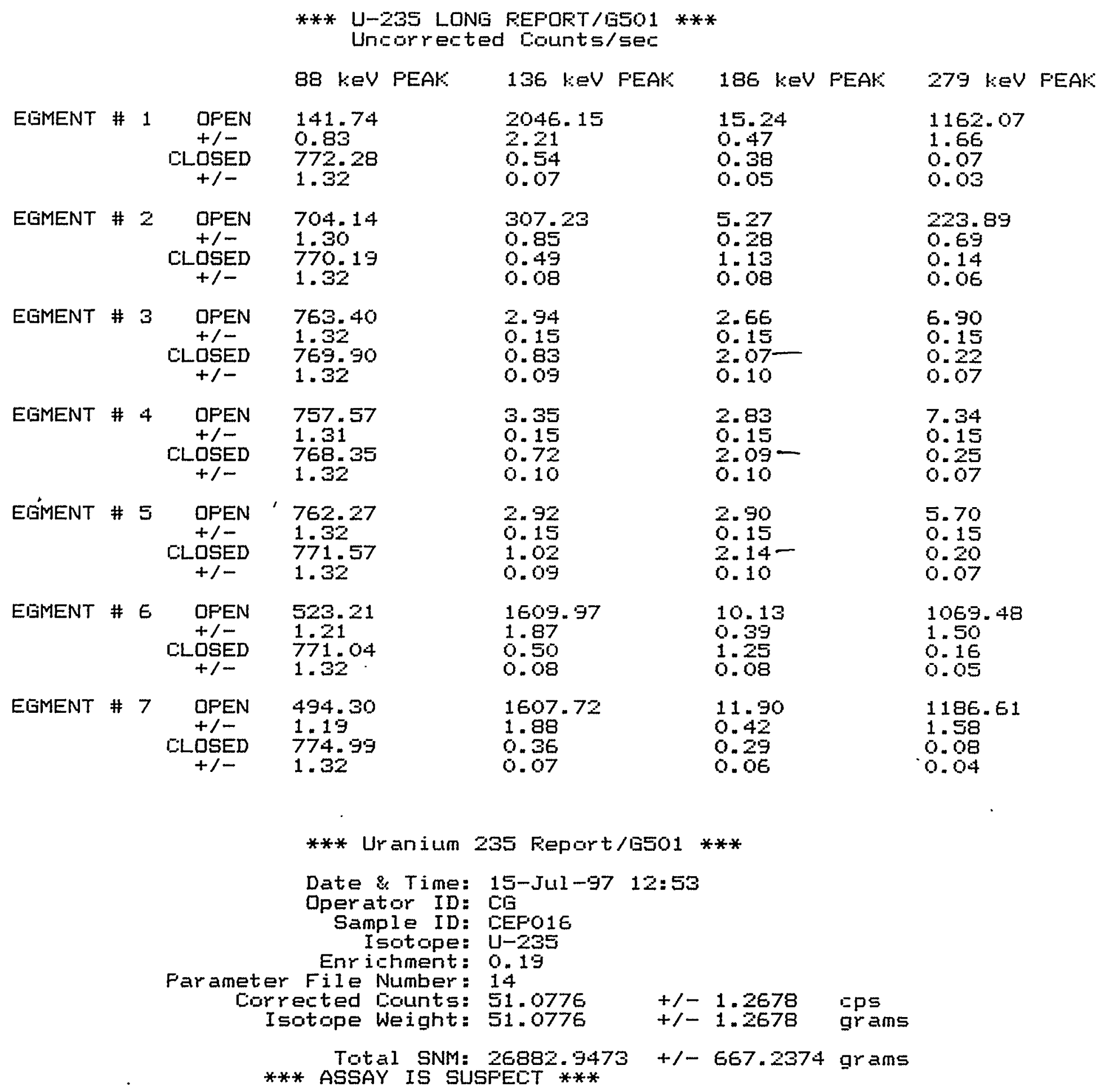


$z$ 


\section{LOS ALAMOS}

NATIONAL LABORATORY

\section{SHIPPING MANIFEST \#}

\section{8}

IMPORTANT: SEE INSTRUCTIONS FOR COMPLETING THE SHIPPING MANIFEST. THIS FORM MUST BE TYPED. REPRODUCE A COPY FOR YOUR FILES.

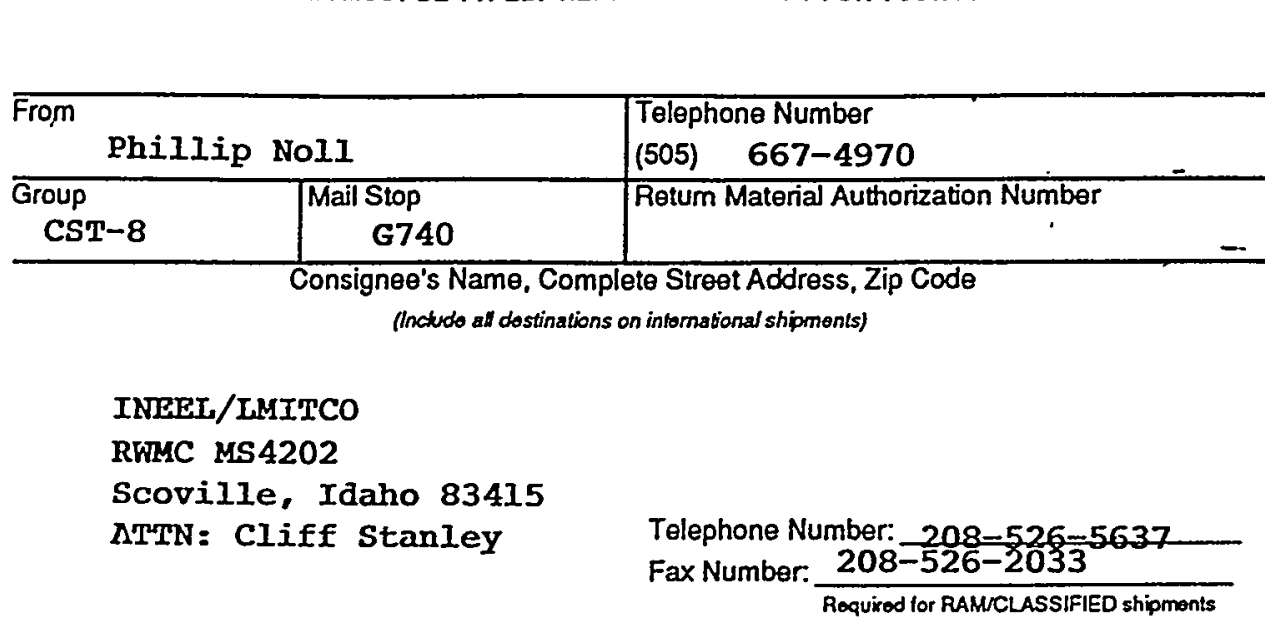

ALL PACKAGES AND CORRESPONDENCE MUST BE IDENTIFIEO WITH LABORATORY REFERENCE NUMBER

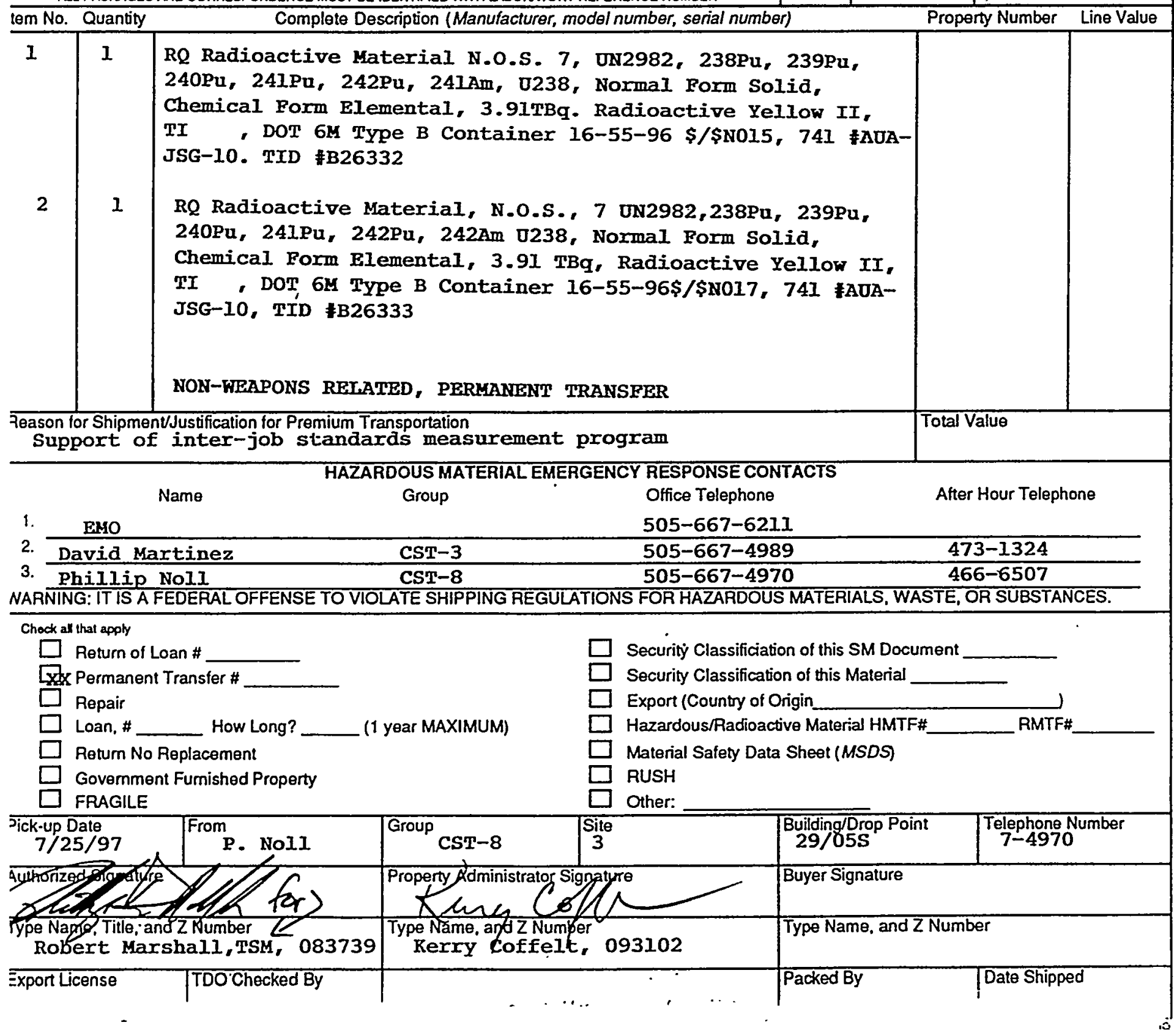




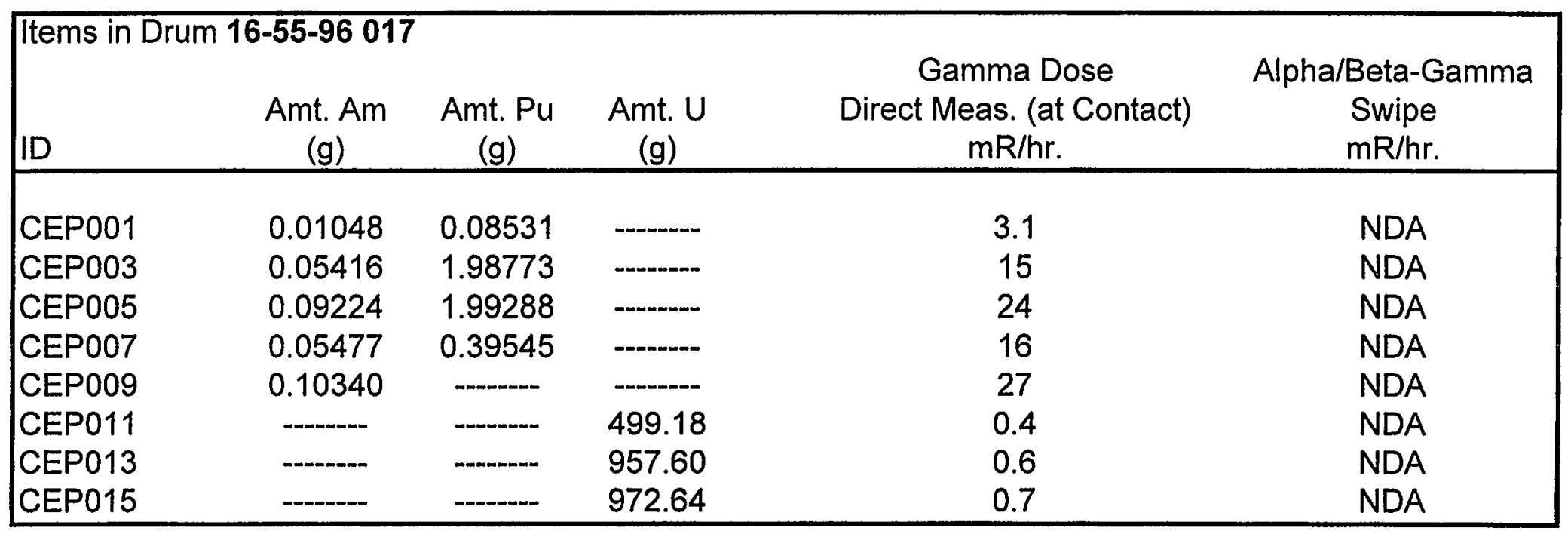

\begin{tabular}{|c|c|c|c|c|c|}
\hline \multicolumn{6}{|c|}{ Items in Drum 16-55-96 015} \\
\hline ID & $\begin{array}{c}\text { Amt. Am } \\
\text { (g) }\end{array}$ & $\begin{array}{l}\text { Amt. Pu } \\
\text { (g) }\end{array}$ & $\begin{array}{c}\text { Amt. U } \\
\text { (g) }\end{array}$ & $\begin{array}{c}\text { Gamma Dose } \\
\text { Direct Meas. (at Contact) } \\
\mathrm{mR} / \mathrm{hr} \text {. }\end{array}$ & $\begin{array}{c}\text { Alpha/Beta-Gamma } \\
\text { Swipe } \\
\mathrm{mR} / \mathrm{hr} .\end{array}$ \\
\hline CEP002 & 0.00991 & 0.07870 & -.--.-- & 3.0 & NDA \\
\hline CEP004 & 0.05474 & 2.00861 & -......... & 15 & NDA \\
\hline CEPO06 & 0.09323 & 1.99098 & -...-.-. & 23 & NDA \\
\hline CEP008 & 0.05213 & 0.41333 & ב...-... & 14 & NDA \\
\hline CEP010 & 0.09978 & -...- & -------- & 28 & NDA \\
\hline CEP012 & -------- & -........ & 883.94 & 0.7 & NDA \\
\hline CEP014 & ..........- & .....--- & 959.51 & 0.7 & NDA \\
\hline CEP016 & -.-....- & -.----- & 948.66 & 0.7 & NDA \\
\hline
\end{tabular}

NDA $=$ No Detectable Activity 


\section{HPAL ANALYSIS REPORT FORM}

FILE: 97011453

SAMPLE DESCRIPTION ANALYSIS REQUESTED RCT

HPAL 1 at CMR

Login Comments: CEP.PROJECT

Sample Date: $7 / 22 / 97$

TA: 3

Nucon Name: Kenny Espinosa

8LDG: 29

LLD (cpm): Alpha $=3$ Beta $=8$

TA: 3

Analyst: Michael Jensen MS: 6749

$\begin{array}{llccc}\begin{array}{c}\text { Sample } \\ \text { ID }\end{array} & \begin{array}{r}\text { Alpha } \\ \text { Activity } \\ \text { dpm }\end{array} & \begin{array}{c}\text { 2"sigma } \\ \text { cpm }\end{array} & \begin{array}{c}\text { Beta } \\ \text { Activity } \\ \text { dpm }\end{array} & \begin{array}{c}\text { 2"sigma } \\ \text { cpm }\end{array} \\ 1 & \text { NDA } & \text { NDA } & \text { NDA } & \text { NDA } \\ 2 & \text { NDA } & \text { NDA } & \text { NDA } & \text { NDA } \\ 3 & \text { NDA } & \text { NDA } & \text { NDA } & \text { NDA } \\ 4 & \text { NDA } & \text { NDA } & \text { NDA } & \text { NDA } \\ 5 & \text { NDA } & \text { NDA } & \text { NDA } & \text { NDA } \\ 6 & \text { NDA } & \text { NDA } & \text { NDA } & \text { NDA } \\ 7 & \text { NDA } & \text { NDA } & \text { NDA } & \text { NDA } \\ 8 & \text { NDA } & \text { NDA } & \text { NDA } & \text { NDA } \\ 9 & \text { NDA } & \text { NDA } & \text { NDA } & \text { NDA } \\ 10 & \text { NDA } & \text { NDA } & \text { NDA } & \text { NDA } \\ 11 & \text { NDA } & \text { NDA } & \text { NDA } & \text { NDA } \\ 12 & \text { NDA } & \text { NDA } & \text { NDA } & \text { NDA } \\ 13 & \text { NDA } & \text { NDA } & \text { NDA } & \text { NDA } \\ 14 & \text { NDA } & \text { NDA } & \text { NDA } & \text { NDA } \\ 15 & \text { NDA } & \text { NDA } & \text { NDA } & \text { NDA } \\ 16 & \text { NDA } & \text { NDA } & \text { NDA } & \text { NDA }\end{array}$


ESH-1 SMEAR SURVEY FORM

SAMPLE DESCRIPTION

Sample DaterTime: Z -DD\&? No. of Samples: 16

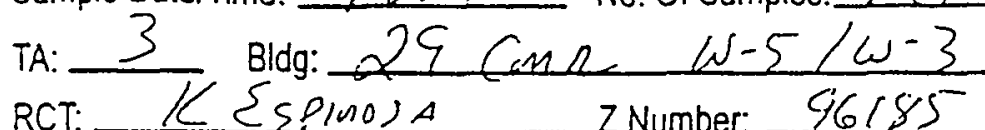

Phoneifax:

$5-1007$

SAMPLE TRACKING NUMBER

(2)

\begin{tabular}{l}
\hline PURPOSE OF SURVEY \\
$\square$ ROUTINE $\square$ PRE-JOB $\square$ POST-JOB $\square$ HOT-JOB \\
$\square$ ITEM RELEASE $\square$ OFFSITE SHIPMENT $\square$ ONSITE SHIPMENT \\
$\square$ NON-ROTINE/OTHER: \\
\hline ADDITIONAL INFORMATION: \\
$\square$ OCCUTRECI NO.: \\
$\square$ Incident No.: \\
$\square$ RWP No.:
\end{tabular}

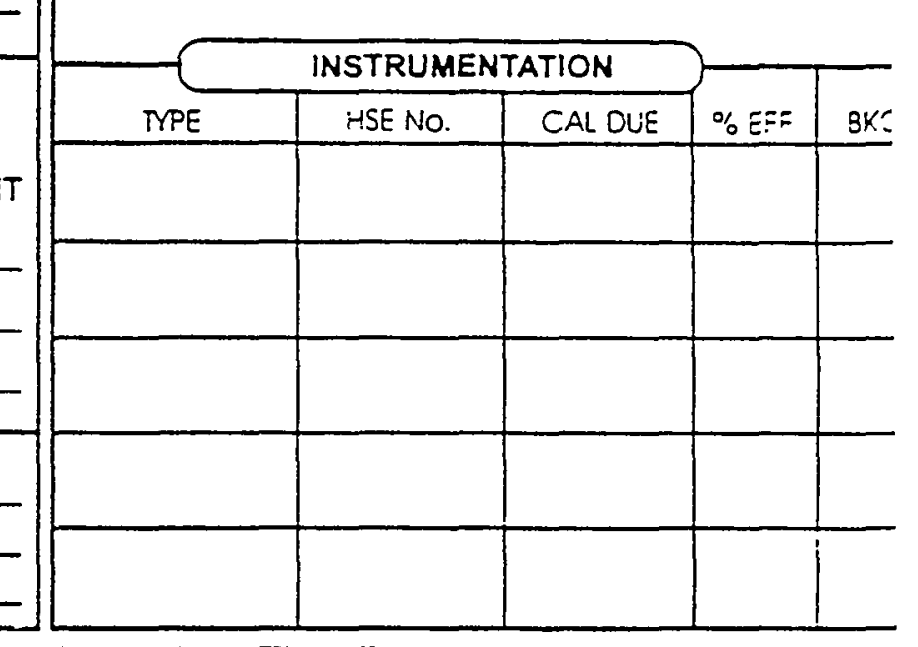

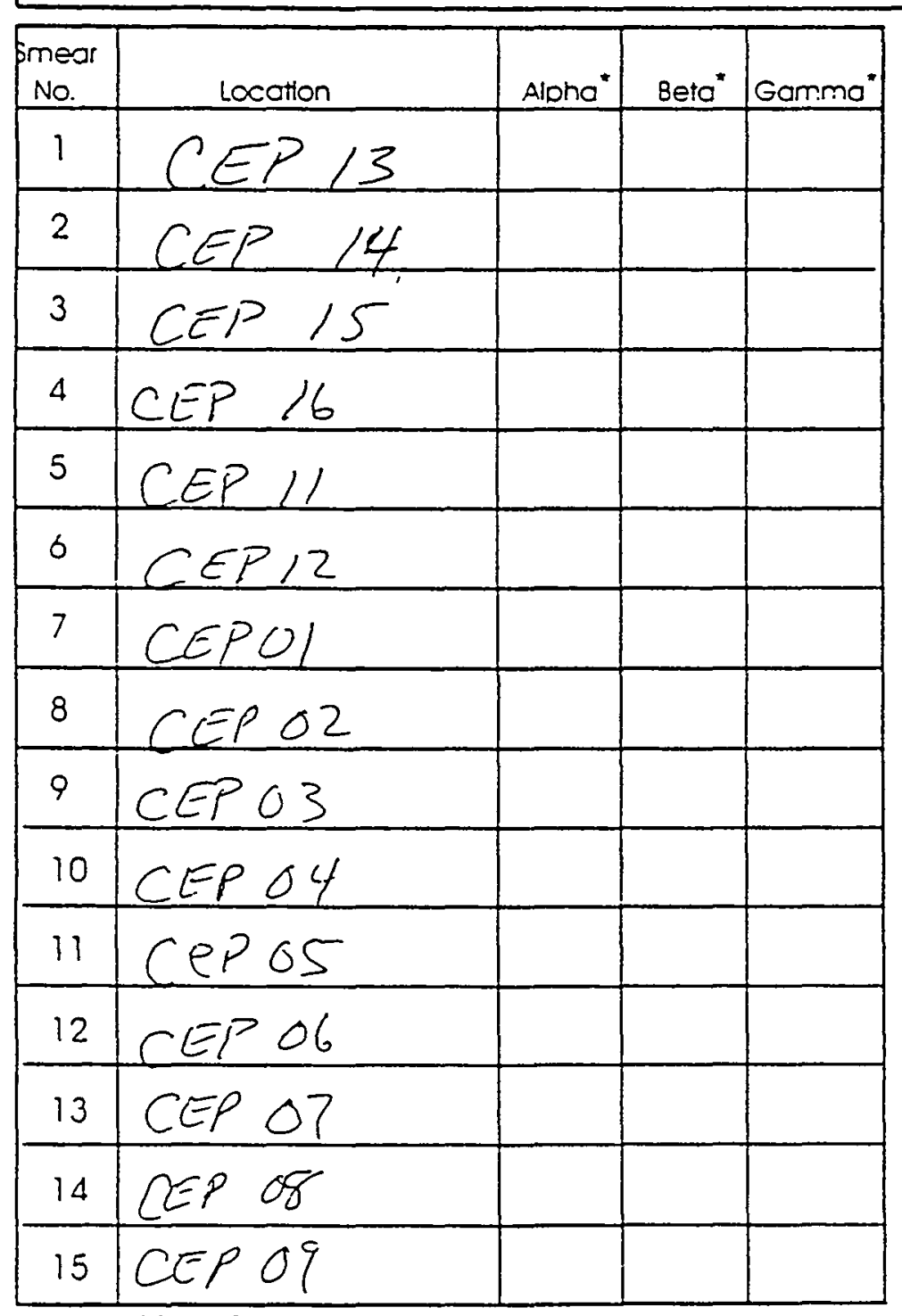

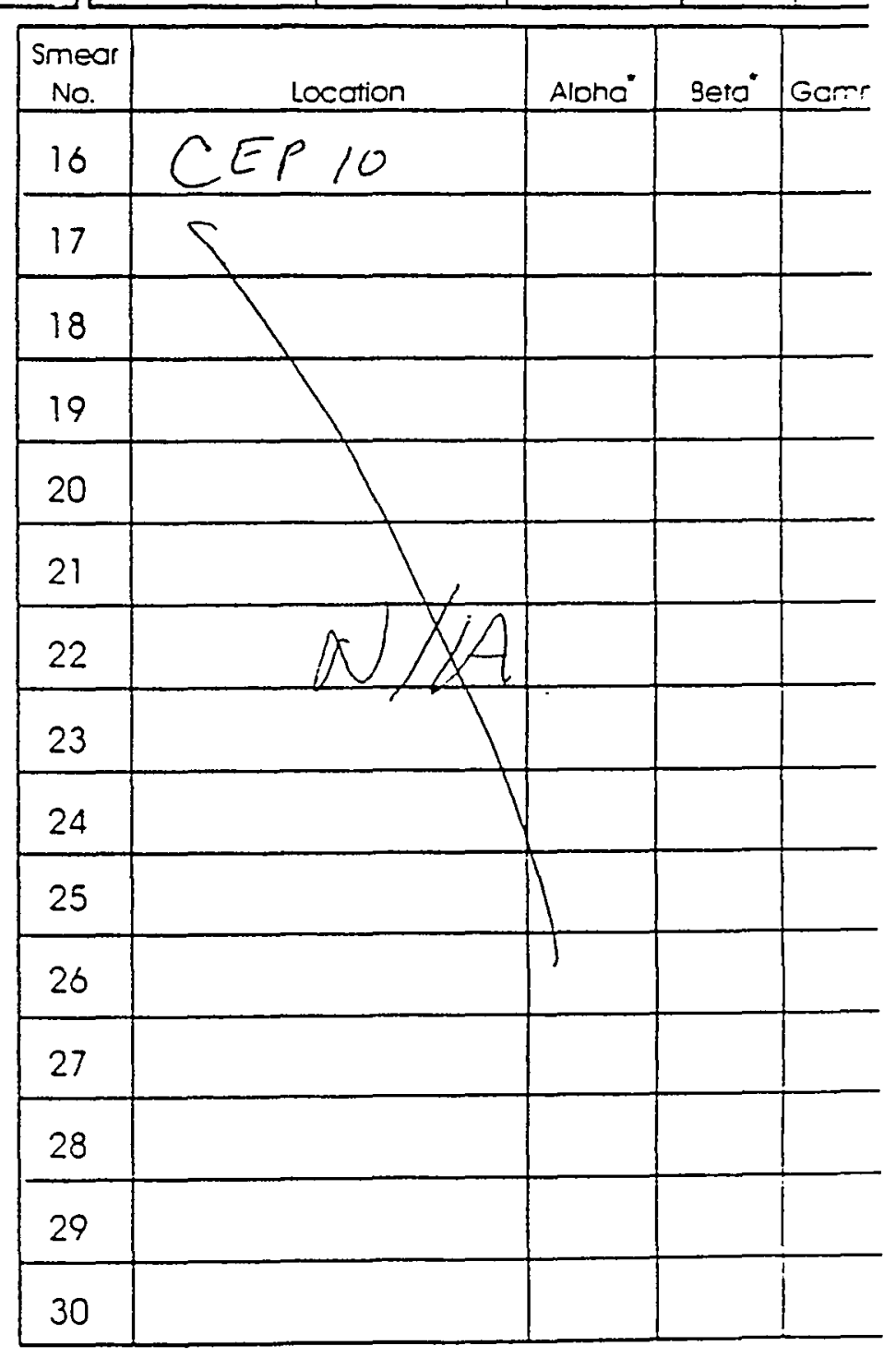


,

$+$

0 


\begin{tabular}{|c|c|c|c|c|c|c|c|c|c|c|c|c|c|c|}
\hline & & & Assigned & & as of $6 / 1 / 97$ & as of $6 / 1 / 97$ & Assigned & as of $6 / 1 / 19$ & Counts & One Std. Dev. & One Time & Count Error & $\gamma$-ray & Rel. Blas \\
\hline & & & Weiging Variance & $\mathrm{g} \mathbf{P u}$ & $\mathrm{gAm}$ in $\mathrm{PuO2}$ & g AmO2 & Weiging Variance & $\mathrm{gAM}$ in $\mathrm{AmO} 2$ & for Am & Error Counts & Count Error & for Am, RSD & $\mu \mathrm{g}$ Am loss & Am Loss Meas \\
\hline WRM\# & BlendH & gPuO2 & for $\mathrm{PuOz}(\mathrm{g} 2)$ & $87.82 \%$ & $1069 \mu \mathrm{g} \mathrm{Am} / \mathrm{g}$ Pu & weighed out & for $\mathrm{AmO} 2(\mathrm{~g} 2)$ & $78.73 \%$ & Holdup & Holdup & for $A m, R S D$ & Inc. Postion effect & & \\
\hline CEPOO1 & CEPOOIB & 0.09721 & $5.883 \mathrm{E}-10$ & 0.085354 & 0.0000912 & 0.0132 & $5.883 \mathrm{E}-10$ & 0.0103920 & 70866 & 299 & 0.004219 & 0.0440 & 5.47 & 0.070 \\
\hline CEP002 & CEP002 & 0.08968 & $5.883 \mathrm{E}-10$ & 0.078743 & 0.0000842 & 0.0125 & $5.883 \mathrm{E}-10$ & 0.0098330 & 66096 & 290 & 0.004388 & 0.0440 & 5.10 & 0.070 \\
\hline CEP003 & CEPO03 & 2.26525 & $1.323 \mathrm{E}-09$ & 1.988980 & 0.0021262 & 0.0661 & $5.883 \mathrm{E}-10$ & 0.0520700 & 444003 & 740 & 0.001667 & 0.0440 & 34.29 & 0.068 \\
\hline CEP004 & CEP004 & 2.28825 & $1.323 \mathrm{E}-09$ & 2.009175 & 0.0021478 & 0.0668 & $5.883 \mathrm{E}-10$ & 0.0526054 & 198752 & 496 & 0.002496 & 0.0440 & 15.34 & 0.068 \\
\hline CEPOOS & CEP005 & 2.27046 & $1.323 \mathrm{E}-09$ & 1.993555 & 0.0021311 & 0.1145 & $1.258 \mathrm{E}-09$ & 0.0901424 & 408645 & 712 & 0.001742 & 0.0440 & 31.56 & 0.068 \\
\hline $\begin{array}{l}\text { CEP006 } \\
\end{array}$ & CEPO06 & 2.26803 & $1.323 \mathrm{E}-09$ & 1.991421 & 0.0021288 & 0.1158 & $1.258 \mathrm{E}-09$ & 0.0911265 & 263178 & 571 & 0.002170 & 0.0440 & 20.33 & 0.068 \\
\hline CEP007 & CEP007 & 0.45051 & $1.258 \mathrm{E}-09$ & 0.395566 & 0.0004229 & 0.0691 & $5.883 \mathrm{E}-10$ & 0.0543610 & 209350 & 508 & 0.002427 & 0.0440 & 16.17 & 0.068 \\
\hline CEP008 & CEP008 & 0.47090 & $1.258 \mathrm{E}-09$ & 0.413469 & 0.0004420 & 0.0657 & $5.883 \mathrm{E}-10$ & 0.0517079 & 222826 & 525 & 0.002356 & 0.0440 & 17.21 & 0.068 \\
\hline CEPOO9 & CEPOO9 & 0.00000 & 0.00000 & 0.000000 & 0.0000000 & 0.1314 & $1.258 \mathrm{E}-09$ & 0.1034315 & 458186 & 751 & 0.001639 & 0.0440 & 35.39 & 0.068 \\
\hline \multirow{2}{*}{ CEPO10 } & CEPO10 & 0.00000 & 0.00000 & 0.000000 & 0.0000000 & 0.1268 & $1.258 \mathrm{E}-09$ & 0.0998180 & 550938 & 825 & 0.001497 & 0.0440 & 42.55 & 0.068 \\
\hline & & & & & 0.002127218 & & & & & & & & & \\
\hline & & & & & & & & & & & & & & \\
\hline & & & & & & & & & & & & & & \\
\hline \multirow{2}{*}{\multicolumn{3}{|c|}{ Variance of the fraction of Am in PuO2 }} & $1.35 \mathrm{E}-14$ & $\mathrm{~g}^{2 / \mathrm{g} 2}$ & \multicolumn{2}{|c|}{ From PuO2 Assay, 5 meas.) } & & & & & & & & \\
\hline & & & $9.39066 \mathrm{E}-04$ & $g / g$ & $9.4141 \mathrm{E}-04$ & $9.3672 \mathrm{E}-04$ & & & & & & & & \\
\hline \multicolumn{3}{|c|}{\begin{tabular}{|l|} 
Mean of the fraction of $\mathrm{Am}$ in $\mathrm{PuO} 2$ \\
Variance of the fraction of $\mathrm{Pu}$ in $\mathrm{PuO} 2$
\end{tabular}} & $9.868 \mathrm{E}-08$ & $\mathrm{~g} 2 / \mathrm{g} 2$ & \multirow{2}{*}{\multicolumn{2}{|c|}{\begin{tabular}{|l} 
From Long term PuO2 assay data) \\
(From PuO2 Assay data)
\end{tabular}}} & & & & & & & & \\
\hline \multicolumn{3}{|c|}{ Mean of the fraction of $\mathrm{Pu}$ in $\mathrm{PuO} 2$} & 0.87804 & $\mathrm{~g} / \mathrm{g}$ & & & & & & & & & & \\
\hline \multirow{2}{*}{\multicolumn{3}{|c|}{ PuO2 meas. variance $-0.02 \mathrm{~g}$}} & & & & & & & & & & & & \\
\hline & & & $5.883 \mathrm{E}-10$ & $\mathrm{~g}$ & & & & & & & & & & \\
\hline \multirow{2}{*}{\multicolumn{3}{|c|}{$\begin{array}{l}\mathrm{PuO2} \text { meas. variance }-0.20 \mathrm{~g} \\
\mathrm{Pu} 02 \text { meas. variance }-3.0 \mathrm{~g}\end{array}$}} & $1.258 \mathrm{E}-09$ & $\mathrm{~g}$ & & & $1.38273 \mathrm{E}-14$ & & & & & & & \\
\hline & & & $1.323 \mathrm{E}-09$ & 8 & & & $1.38103 \mathrm{E}-14$ & & & & & & & \\
\hline & & & & & & & & & & & & & & \\
\hline & & & & & & & & & & & & & & \\
\hline & & & & & & & & & & & & & & \\
\hline & & & & & & & & & & & & & & \\
\hline \multirow{2}{*}{\multicolumn{3}{|c|}{$\begin{array}{l}\text { Variance of the fraction of } \mathrm{Am} \text { in } \mathrm{AmO} 2 \\
\text { Mean of the fraction of } \mathrm{Am} \text { in } \mathrm{AmO2}\end{array}$}} & $1.25 \mathrm{E}-06$ & $B^{2 / 82}$ & \multicolumn{2}{|c|}{ From Am02 Assay data, 4 reps) } & & & & & & & & \\
\hline & & & 0.78727 & $g / g$ & 0.789238175 & 0.785301825 & \multicolumn{3}{|c|}{ From AmO2 Assay data, 4 reps) } & & & & & \\
\hline & & & & & & & & & & & & & & \\
\hline & & & & & & & & & & & & & & \\
\hline & & & & & & & & & & & & & & \\
\hline & & & & & & & & & & & & & & \\
\hline Rel. & is Am Meas & $100 \mathrm{cpm}$ & 0.164 & & & & & & & & & & & \\
\hline & & $500 \mathrm{cpm}$ & 0.079 & & & & & & & & & & & \\
\hline & & $800 \mathrm{cpm}$ & 0.073 & & & & & & & & & & & \\
\hline & & $1000 \mathrm{cpm}$ & 0.071 & & & & & & & & & & & \\
\hline & & $1500 \mathrm{cpm}$ & 0.070 & & & & & & & & & & & \\
\hline & & $6000 \mathrm{cpm}$ & 0.068 & & & & & & & & & & & \\
\hline & & $10000 \mathrm{cpm}$ & 0.068 & & & & & & & & & & & \\
\hline & & $16000 \mathrm{cpm}$ & 0.068 & & & & & & & & & & & \\
\hline & & $21000 \mathrm{cpm}$ & 0.068 & & & & & & & & & & & \\
\hline & & & & & & & & & & & & & & \\
\hline Count ent & ates. Min. w & as 0.044, which & included placement of & vial. Use $m$ & $\operatorname{tax}(0.044$, what is $\mathrm{s}$ & een) to be conser & vative & & & & & & & \\
\hline As Per B. & arshall: Use & -value with $4 \mathrm{~d}$, & f. $(2.776)$ to get $95 \%$ & C.I. instead of & f the generic 2.0 & & & & & & & & & \\
\hline This mak & ense from the & standpoing that & It the variance in the frt & action of Pui & in $\mathrm{PuO} 02$ is the tem & importance & $\mathrm{PuO} 2_{2}$ & & & & & & & \\
\hline
\end{tabular}




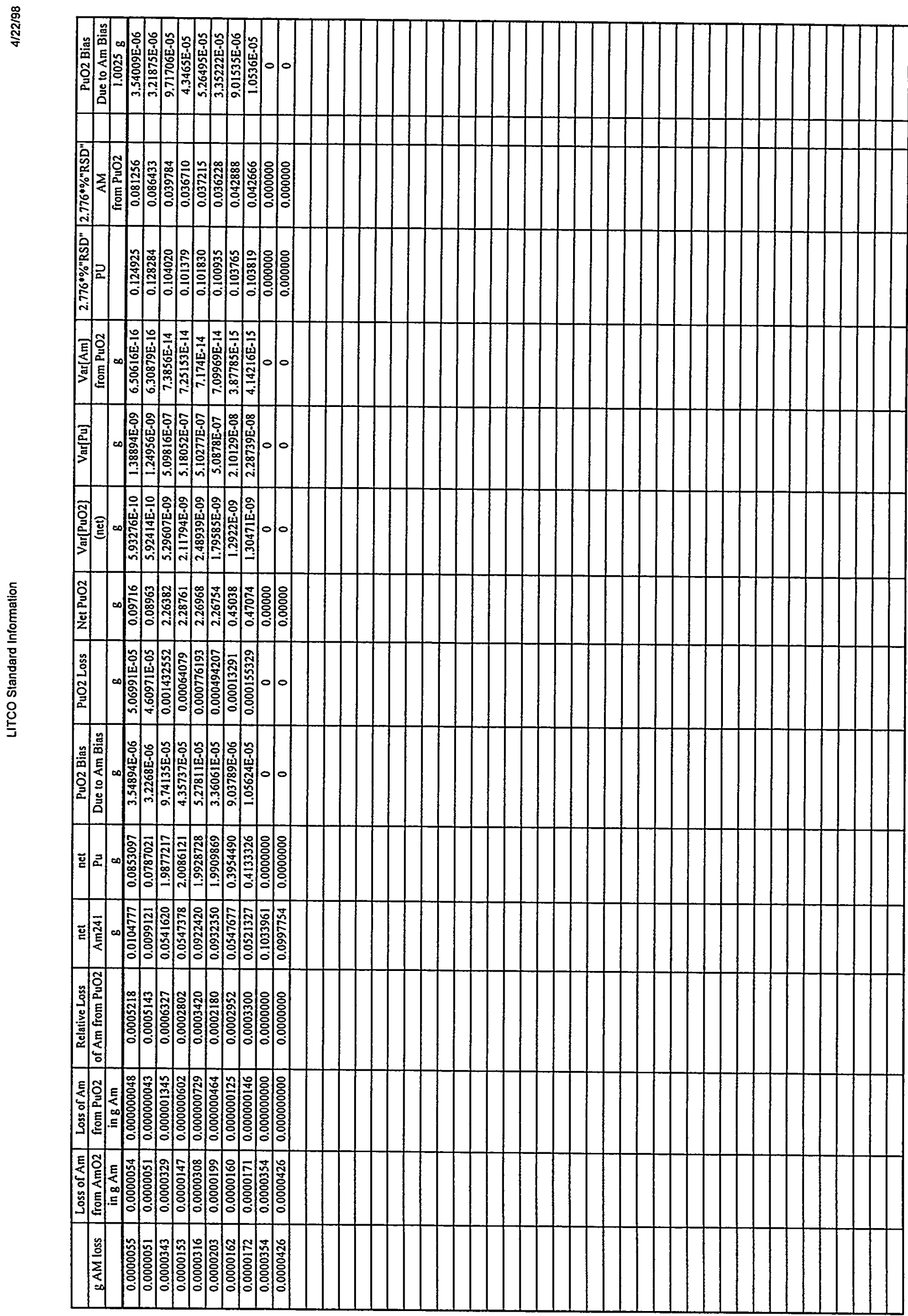




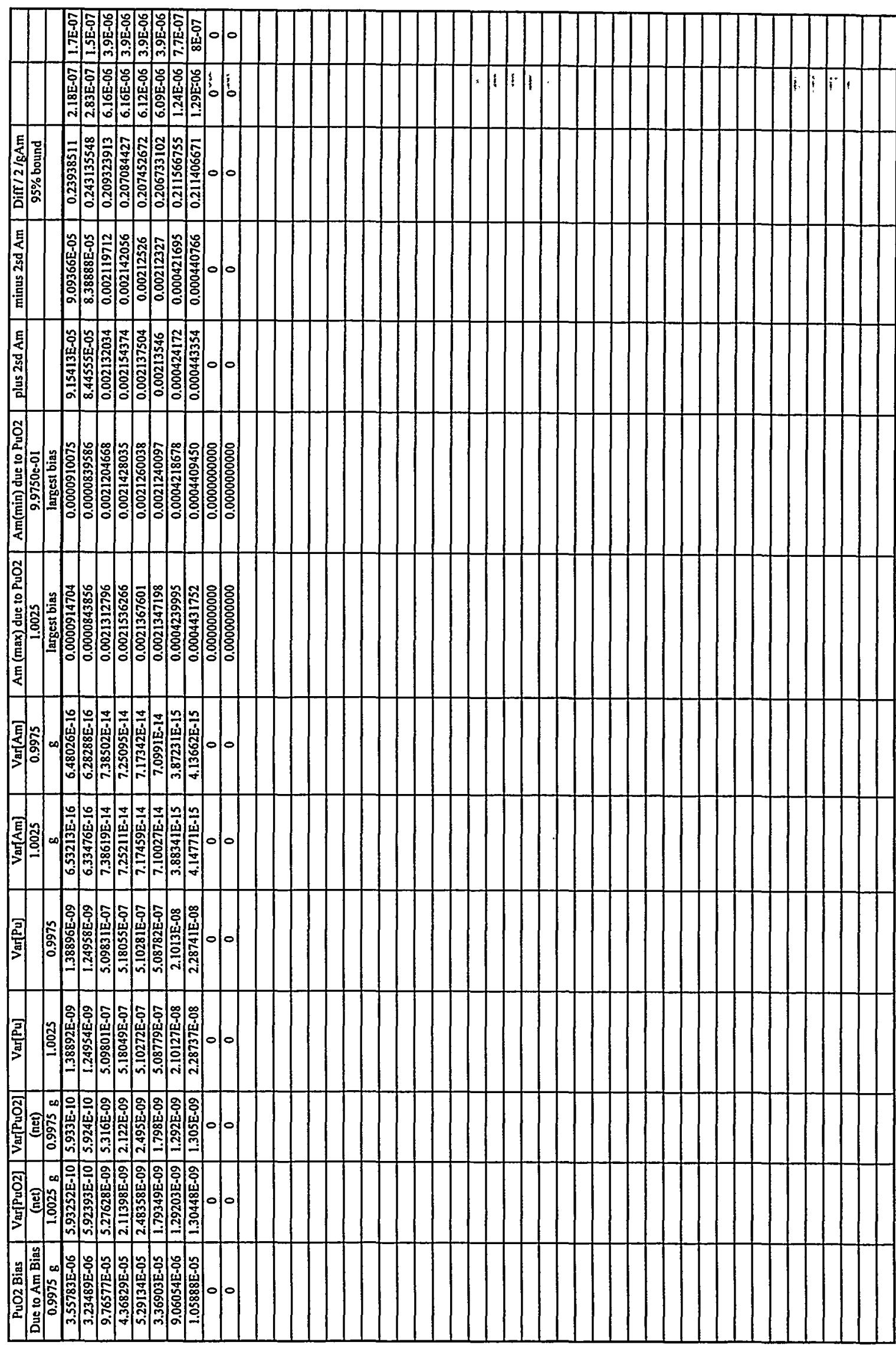




\begin{tabular}{|c|c|c|c|c|c|c|c|c|c|c|c|}
\hline Uncertainty & $\operatorname{Var}[\mathrm{Pu}]$ & Largest Pu amt & Smallest Pu ant & Approx. $95 \%$ Pu C.I. & $2.776 * \% " \mathrm{RSD}^{\prime \prime}$ & $2.776^{*} \% \%^{*} \mathrm{RS}^{\prime \prime}$ & $\operatorname{Var}[\mathrm{AM}]$ loss & $\mathrm{Var}[\mathrm{AmO} 2$ total $]$ & Total Var & Total VAR of & \\
\hline due to just & using max bias effects & Using largest bias & Using largest bias & Diff $2 *{ }^{*} \mathrm{net}^{*} 100$ & $\mathrm{PU}$ & $\mathrm{AM}$ & due to $\mathrm{AmO2}$ & $\mathrm{X}$ (Frac Am in AmO2) & of $\mathrm{Am}$ from $\mathrm{AmO} 2$ & Am from $\mathrm{AmO} 2$ and & \\
\hline biases & B & $\begin{array}{l}\text { Pius } \\
\end{array}$ & Minus & Relative $\mathrm{Cl}$ in \% & & from $\mathrm{PuO} 2$ & & & & $\mathrm{PuO} 2$ & \\
\hline 1591.396709 & $1.38896 \mathrm{E}-09$ & 0.085416335 & 0.085203171 & 0.125091593 & 0.1250916 & 0.332266533 & $5.69229 \mathrm{E}-14$ & $5.84251 \mathrm{E}-10$ & 0.00000000058 & 0.00000000058 & \\
\hline 1551.596111 & $1.24958 \mathrm{E}-09$ & 0.078803122 & 0.078601182 & 0.12845878 & 0.1284588 & 0.337472141 & $4.95042 \mathrm{E}-14$ & $5.61451 \mathrm{E}-10$ & 0.00000000056 & 0.00000000056 & \\
\hline 7191.565144 & $5.09831 \mathrm{E}-07$ & 1.989790152 & 1.985654392 & 0.104141001 & 0.1041410 & 0.290541591 & $2.10125 \mathrm{E}-12$ & $5.83458 \mathrm{E}-09$ & 0.00000000584 & 0.00000000584 & \\
\hline 7122.70837 & $5.18055 \mathrm{E}-07$ & 2.010648801 & 2.006575981 & 0.101486815 & 0.1014868 & 0.287433185 & $4.20531 \mathrm{E}-13$ & 5.94759E-09 & 0.00000000595 & 0.00000000595 & \\
\hline 4200.629674 & $5.10281 \mathrm{E}-07$ & 1.994902637 & 1.990843702 & 0.10194006 & 0.1019401 & 0.287944309 & $1.84028 \mathrm{E}-12$ & $1.71714 \mathrm{E}-08$ & 0.00000001717 & 0.00000001717 & \\
\hline 4138.04314 & $5.08782 \mathrm{E}-07$ & 1.992996802 & 1.988977454 & 0.101040539 & 0.1010405 & 0.286945545 & $7.64051 \mathrm{E}-13$ & $1.75312 \mathrm{E}-08$ & 0.00000001753 & 0.00000001753 & \\
\hline 1402.1006 & $2.1013 \mathrm{E}-08$ & 0.395859461 & 0.395038739 & 0.103878574 & 0.1038786 & 0.293654655 & 4.98419E-13 & $6.32633 \mathrm{E}-09$ & 0.00000000633 & 0.00000000633 & \\
\hline 1541.032819 & $2.28741 \mathrm{E}-08$ & 0.413761796 & 0.412903506 & 0.103933373 & 0.1039334 & 0.293432459 & $5.63734 \mathrm{E}-13$ & $5.75878 \mathrm{E}-09$ & 0.00000000576 & 0.00000000576 & \\
\hline 0 & 0 & 0 & 0 & 0 & 0.0000000 & 0 & $2.42475 E-12$ & $2.23595 \mathrm{E}-08$ & 0.00000002236 & 0.00000002236 & \\
\hline 0 & 0 & 0 & 0 & 0 & 0.0000000 & 0 & $3.50513 \mathrm{E}-12$ & $2.08782 \mathrm{E}-08$ & 0.00000002088 & 0.00000002088 & \\
\hline & & & & & & & & & & & \\
\hline & & & & & & & & & & & \\
\hline & & & & & & & & & & & \\
\hline & & & & & & & & & & & \\
\hline & & & & & & & & & & & \\
\hline & & & & & & & & & & & \\
\hline & & & & & & & & & & & \\
\hline & & & & & & & & & & & \\
\hline & & & & & & & & & & & \\
\hline & & & & & & & & & & & \\
\hline & & & & & & & & & & & \\
\hline & & & & & & & & & & & \\
\hline & & & & & & & & & & & \\
\hline & & & & & & & & & . & & \\
\hline & & & & & & & & & & & \\
\hline & & & & & & & & & & & \\
\hline & & & & & & & & & & & \\
\hline & & & & & & & & & & & \\
\hline & & & & & & & & & & & \\
\hline & & & & & & & & & & & \\
\hline & & & & & & & & & & & \\
\hline & & & & & & & & & & & \\
\hline & & & & & & & & & & & \\
\hline & & & & & & & & & & & \\
\hline & & & & & & & 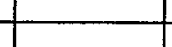 & & & & \\
\hline & & & & & & & & & & & \\
\hline & & & & & & & & & & & \\
\hline & & & & & & & & & & & \\
\hline & & & & & & & & & & & \\
\hline & & & & & & & & & & & \\
\hline & & & & & & & & & & & \\
\hline & & & & & & & & & & & \\
\hline & & & & & & & & & & & \\
\hline
\end{tabular}




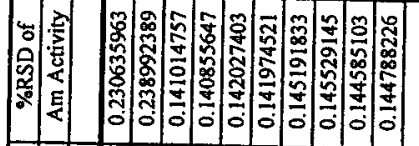

氛

눈

$\Rightarrow 4$ 年

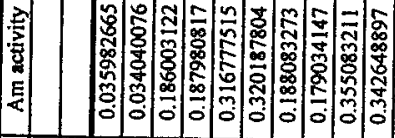

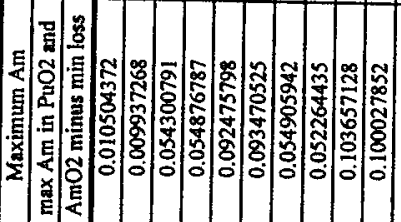

药

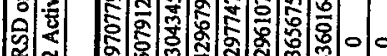

\%

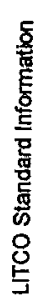

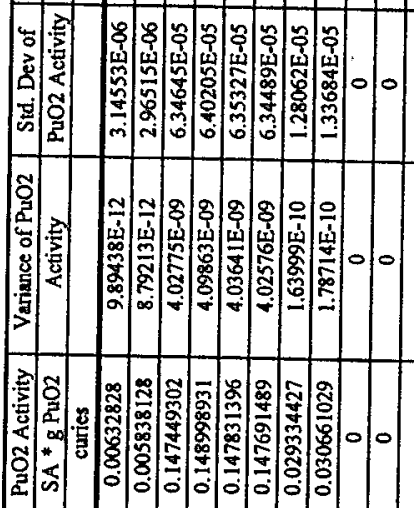

s:

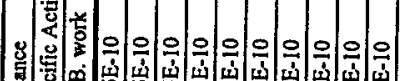

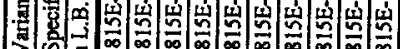

$>$ की

匀

超

-

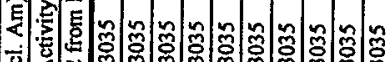

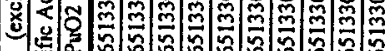

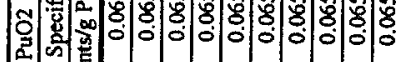
s

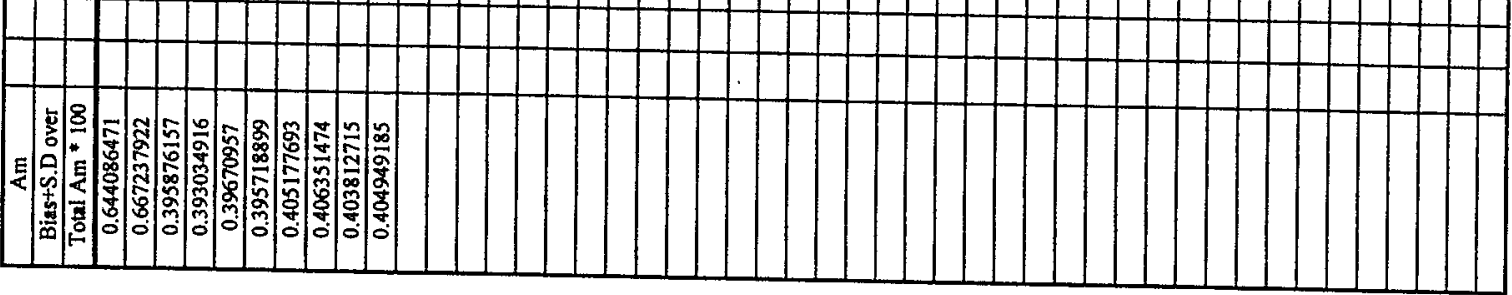




\begin{tabular}{|c|c|c|c|c|c|c|c|c|c|c|c|c|}
\hline & & as of $6 / 1 / 97$ & & net & net & net $\mathrm{Pu}$ & net Am & Pu Activity & Am Activity & PuO2 Activity & AmO2 Activity & Total Alpha Activiy \\
\hline & & $\mathrm{gAmO2}$ & Am loss & $\mathrm{Am} 241$ & $\mathrm{Pu}$ & Approx.95\% C.I. & Approx. 95\% C.I. & $\mathrm{SA} * \mathrm{gPuO2}$ & & Approx. 95\% Interval & Approx. $95 \%$ Interval & \\
\hline WRM\# & $\mathrm{gPuO2}$ & weighed out & $\mathrm{g}$ & 8 & $\mathrm{~g}$ & $\%$ & $\%$ & curies & curies & \begin{tabular}{|c|}
$\%$ \\
\end{tabular} & $\%$ & \\
\hline CEPC01 & 0.09721 & 0.0132 & 0.0000055 & 0.0104777 & 0.0853097 & 0.125091593 & 0.644086471 & 0.00632828 & 0.035982665 & 0.137988845 & 0.640245434 & 0.042310945 \\
\hline CEP002 & 0.08968 & 0.0125 & 0.0000051 & 0.0099121 & 0.0787021 & 0.12845878 & 0.667237922 & 0.005838128 & 0.034040076 & 0.140996593 & 0.663442872 & 0.039878204 \\
\hline CEP003 & 2.26525 & 0.0661 & 0.0000343 & 0.0541620 & 1.9877217 & 0.104141001 & 0.395876157 & 0.147449302 & 0.186003122 & 0.119488633 & 0.391456966 & 0.333452424 \\
\hline CEP004 & 2.28825 & 0.0668 & 0.0000153 & 0.0547378 & 2.0086121 & 0.101486815 & 0.393034916 & 0.148998931 & 0.187980817 & 0.119278973 & 0.391015276 & 0.336979749 \\
\hline CEP005 & 2.27046 & 0.1145 & 0.0000316 & 0.0922420 & 1.9928728 & 0.10194006 & 0.39670957 & 0.147831396 & 0.316777515 & 0.119305462 & 0.39426807 & 0.464608911 \\
\hline CEP006 & 2.26803 & 0.1158 & 0.0000203 & 0.0932350 & 1.9909869 & 0.101040539 & 0.395718899 & 0.147691489 & 0.320187804 & 0.119259953 & 0.39412127 & 0.467879292 \\
\hline CEP007 & 0.45051 & 0.0691 & 0.0000162 & 0.0547677 & 0.3954490 & 0.103878574 & 0.405177693 & 0.029334427 & 0.188083273 & 0.121191147 & 0.403052529 & 0.2174177 \\
\hline CEP008 & 0.47090 & 0.0657 & 0.0000172 & 0.0521327 & 0.4133326 & 0.103933373 & 0.406351474 & 0.030561029 & 0.179034147 & 0.121038151 & 0.403988906 & 0.209695176 \\
\hline CEP009 & 0.00000 & 0.1314 & 0.0000354 & 0.1033961 & 0.0000000 & 0 & 0.403812715 & 0 & 0.355083211 & 0 & 0.401368247 & 0.355083211 \\
\hline CEP010 & 0.00000 & 0.1268 & 0.0000426 & 0.0997754 & 0.0000000 & 0 & 0.404949185 & 0 & 0.342648897 & 0 & 0.401932115 & 0.342648897 \\
\hline & & & & & & & & & & & & \\
\hline & & & & & & & & & & & & \\
\hline & & & & & & & & & & & & \\
\hline & & & & & & & & & & & & \\
\hline & & & & & & & & & & & & \\
\hline & & & & & & & & & & & & \\
\hline & & & & & & & & & & & & \\
\hline & & & & & & & & & & & & \\
\hline & & & & & & & & & & & & \\
\hline & & & & & & & & & & & & \\
\hline & & & & & & & & & & & & \\
\hline & & & & & & & & & & & & \\
\hline & & & & & & & & & & & & \\
\hline & & & & & & & & & & & & \\
\hline & & & & & & & & & & & & \\
\hline & & & & & & & & & & & & \\
\hline & & & & & & & & & & & & \\
\hline & & & & & & & & & & & & \\
\hline & & & & & & & & & & & & \\
\hline & & & & & & & & & & & & \\
\hline & & & & & & & & & & & & \\
\hline & & & & & & & & & & & & \\
\hline & & & & & & & & & & & & \\
\hline & & & & & & & & & & & & \\
\hline & & & & & & & & & & & & \\
\hline & & & & & & & & & & & & \\
\hline & & & & & & & & & & & & \\
\hline & & & & & & & & & & & & \\
\hline & & & & & & & & & & & & \\
\hline & & & & & & & & & & & & \\
\hline & & & & & & & & & & & & \\
\hline
\end{tabular}


Phil Noll

COMPLETE CASE

SA uncertainty Conditioned on the SAi values

$$
S A=
$$

0.06833

$S A=F^{\star}\left\{S U M\left(F{ }^{\star} S A i\right)\right\}+F a m^{*} S A a m \quad(241$ term has BR factor)

$\mathrm{V}(\mathrm{SA})=\left(\mathrm{F}^{\wedge} 2\right)^{\star} \mathrm{V}(\mathrm{SUM})+\left(\mathrm{SUM}^{\wedge} 2\right)^{\star} \mathrm{V}(\mathrm{F})+\left(\mathrm{Fam}^{\wedge} 2\right)^{\star} \mathrm{V}(\mathrm{SAam})+\left(\mathrm{SAam}^{\wedge} 2\right)^{\star} \mathrm{V}($ Fam $)$

$V(S U M)=\operatorname{SUM}\left(V\left(F i^{*} S A i\right)\right)+2 S U M(S A i j C O V i j)$

$\mathrm{V}\left(\mathrm{Fi} i^{\star} S A i\right)=\left(F i^{\wedge} 2\right)^{\star} \mathrm{V}(\mathrm{SAi})+\left(\mathrm{Sa} \mathrm{i}^{\wedge} 2\right)^{\star} \mathrm{V}(\mathrm{Fi})$

SAijCOVij $=S A i{ }^{*} S A j{ }^{*} R H O{ }^{*} S D(F i)^{*} S D(F j)=S A{ }^{*} S A j{ }^{*} C O V i j$

Set all $\operatorname{Var}(\mathrm{SAi})$ values to $\mathbf{0 . 0}$

\begin{tabular}{|c|c|c|c|c|}
\hline & Value & $F * S A$ & s.d. & $\%$ rsd \\
\hline$\overline{f-P u}$ & 0.87804 & & 0.0003300000 & 0.0376 \\
\hline$f-238$ & 0.0001432 & 0.002454178 & 0.0000001417 & 0.0990 \\
\hline SA-238 & 17.138114 & & 0.0000000000 & 0.0000 \\
\hline$f-239$ & 0.937811 & 0.058217753 & 0.0000223400 & 0.0024 \\
\hline SA-239 & 0.062078343 & & 0.0000000000 & 0.0000 \\
\hline$f-240$ & 0.0594481 & 0.013500721 & 0.0000083800 & 0.0141 \\
\hline$S A-240$ & 0.22710097 & & 0.0000000000 & 0.0000 \\
\hline$f-241$ & 0.0020379 & 5.16425E-06 & 0.0000152800 & 0.7498 \\
\hline SA-241 & 103.4329 & & 0.0000000000 & 0.0000 \\
\hline alphaBR24 & 0.0000245 & & & \\
\hline$f-242$ & 0.0005597 & 2.21619E-06 & 0.0000028000 & 0.5003 \\
\hline SA-242 & 0.003959599 & & 0.0000000000 & 0.0000 \\
\hline f-am & 0.000938486 & 0.00322295 & 0.0000001679 & 0.0179 \\
\hline SA-am & 3.434201727 & & 0.0000000000 & 0.0000 \\
\hline & $\begin{array}{l}\text { um-noAm } \\
n \text { term }\end{array}$ & $\begin{array}{r}0.074180032 \\
0.00322295\end{array}$ & & \\
\hline
\end{tabular}

$\begin{array}{lll}\text { CoV } & \text { SDi } & \text { SDj } \\ 8-9 & 0.000004 & 0.000006 \\ 8-0 & 0.000004 & 0.000005 \\ 8-1 & 0.000004 & 0.000002 \\ 8-2 & 0.000004 & 0.000001 \\ 9-0 & 0.000006 & 0.000005 \\ 9-1 & 0.000006 & 0.000002 \\ 9-2 & 0.000006 & 0.000001 \\ 0-1 & 0.000005 & 0.000002\end{array}$

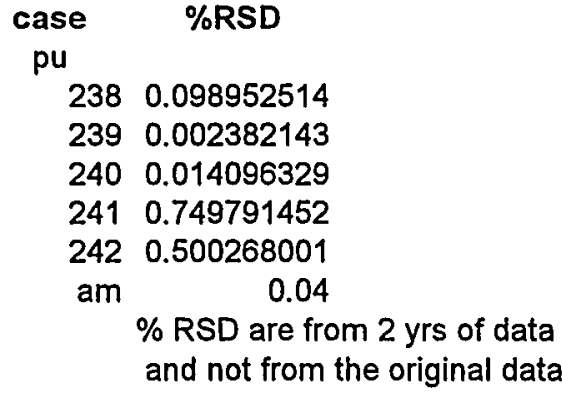




\begin{tabular}{|c|c|c|c|c|c|c|}
\hline $0-2$ & 0.000005 & 0.000001 & 1 & $5.00 E-12$ & & $4.49614 \mathrm{E}-15$ \\
\hline $1-2$ & 0.000002 & 0.000001 & 1 & $2.00 E-12$ & Inc. BR & $5.06821 \mathrm{E}-15$ \\
\hline$V$ & $\left.\left.i^{*} S A i\right)\right)+2$ & $\operatorname{cov}(i, j))$ & & $5915 \mathrm{E}-10$ & & \\
\hline
\end{tabular}

$V(S A)=\left(F^{\wedge} 2\right)^{\star} V(S U M)+\left(S^{\wedge} M^{\wedge} 2\right)^{\star} V(F)+\left(F^{\wedge} m^{\wedge} 2\right)^{\star} V(S A a m)+\left(S^{\prime} A m^{\wedge} 2\right)^{\star} V(F a m)$

$7.815 \mathrm{E}-10$

0.0000280 $S D(S A)$

\%rsd

\begin{tabular}{|lrrr|}
\hline SA Uncertainty & & SD & $\%$ RSD \\
& & $5.59 E-05$ & 0.083 \\
Approximate 95\% Confidence Bound is 2 SD or 2\%RSD & 1 sig.digit & 0.0002 & 0.003 \\
Significant Digits: 1 or 2 maximum. & 2 sig.digits & 0.00022 & 0.0032 \\
\hline
\end{tabular}

\section{ACTIVITY $=S A * W=$ Specific Activity * Weight}

SA units are "curies/(g PuO2)"

Activity $=\mathrm{SA}$ * (g PuO2) and has units "curies"

Then $\operatorname{var}(A)=\left(S A^{\wedge} 2\right)^{\star} \operatorname{var}(P u O 2)+\left(P u O 2^{\wedge} 2\right)^{\star} \operatorname{var}(S A)$

and $\% \operatorname{RSD}(A)=\operatorname{sqrt}\left(\{\% \operatorname{RSD}(S A)\}^{\wedge} 2+\{\% \operatorname{RSD}(W)\}^{\wedge} 2\right)$

$\begin{array}{ll}S A(P u)= & 0.065133036 \\ V(S A(P u)) & 7.81121 E-10 \\ S A & 0.068355986 \\ V(S A) & 7.81454 E-10\end{array}$

curies "from Pu"/gPuO2

curies "from Pu and Am"/g PuO2

$\% \operatorname{RSD}(S A)=0.041$

Wgt(PuO2) varies

$\mathrm{V}(\mathrm{PuO} 2) \quad$ varies with amount

Fraction(Pu $\quad 0.87804$

*Note: These values assume that the specific activity values for the particular isotopes are fixed.

No uncertainties were associated with the isotopic specific activity values. 


\begin{tabular}{|c|c|c|c|c|c|c|c|c|c|c|c|c|}
\hline & & & & Holdup & $\mathbf{g U}$ & Holdup & $\mathrm{DE}$ & DE & DUO2 & Blend & Blend lost to & Blend + Bottle 1 \\
\hline & & & $\mathrm{gU}$ & $\mathrm{gU}$ & in WRM & $\mathrm{UO2}$ & initial & removed & initially added & total mixed & homogeneity ck & \\
\hline WRM\# & Blend\# & gUO2 & & & & $\mathrm{g}$ & g & $\mathrm{g}$ & $\mathrm{g}$ & g & (ignore) & $\mathbf{g}$ \\
\hline CEPOII & CEP011 & 570.66000 & & 0.000000 & 0.000000 & 0.000000 & 100.990000 & 6.650600 & 571.281200 & 665.620600 & 0.150000 & 739.000000 \\
\hline CEP011B & CEP011B & 570.61000 & 499.243807 & 0.162420 & 499.081387 & 0.185638 & 113.476166 & 0.000000 & 570.413834 & 683.890000 & 0.000000 & \\
\hline CEP012 & CEP012 & 1010.37000 & 884.003024 & 0.061880 & 883.941145 & 0.070725 & 47.290000 & 0.000000 & 1139.190000 & 1186.480000 & 0.010000 & 1255.800000 \\
\hline CEPO13 & CEP013 & 1094.58000 & 957.680879 & 0.075800 & 957.605079 & 0.086636 & 47.330000 & 15.833100 & 1143.560000 & 1175.056900 & 0.100000 & 1244.360000 \\
\hline CEP014 & CEP014 & 1097.25000 & 960.016943 & 0.508640 & 959.508303 & 0.581349 & 68.800000 & 36.978600 & 1145.320000 & 1177.141400 & 0.000000 & 1246.950000 \\
\hline CEP015 & CEP015 & 1111.82000 & 972.764673 & 0.120910 & 972.643763 & 0.138194 & 47.300000 & 15.751600 & 1142.150000 & 1173.698400 & 0.000000 & 1243.060000 \\
\hline CEP016 & CEP016 & 1084.47000 & 948.835337 & 0.174780 & 948.660557 & 0.199765 & 47.330000 & 15.058700 & 1142.960000 & 1175.231300 & 0.000000 & 1248.200000 \\
\hline & & & & & & & & & & & & \\
\hline & & & & & & & & & & & & \\
\hline & & & & & & & & & & & & \\
\hline \multicolumn{3}{|c|}{ Variance of the fraction of $\mathrm{U}$ in $\mathrm{UO} 2$} & $9.68 \mathrm{E}-09$ & $\mathrm{~g} 2 / \mathrm{g} 2$ & \multicolumn{2}{|c|}{ From UO2 Assay, 5 meas.) } & & & & & & \\
\hline \multicolumn{3}{|c|}{ Mean of the fraction of $\mathrm{U}$ in $\mathrm{UO} 2$} & $8.7493 \mathrm{E}-01$ & $g / g$ & & & & & & & & \\
\hline & & & & & & & & & & & & \\
\hline & & & & & & & & & & & & \\
\hline \multicolumn{3}{|c|}{ Balances -- \%uncertainty (kind of: } & Std. Dev. & Variance & . & & & & & & . & \\
\hline \multirow[t]{6}{*}{ Balances } & 15233 & 10 & 0.0004857 & $2.35904 \mathrm{E}-07$ & & & & & & & & \\
\hline & & 200 & 0.00715 & $5.11225 \mathrm{E}-05$ & & & & & & & & \\
\hline & 16834 & 500 & 0.02952 & 0.00087143 & & & & & & & & \\
\hline & & 1000 & 0.05785 & 0.003346623 & \multicolumn{5}{|c|}{ nges to only random error effect 3rd decimal place of $\operatorname{Var}(U)$} & & & \\
\hline & 13045 & 100 & 0.009034 & $8.16132 \mathrm{E}-05$ & & & & & & & & \\
\hline & & 30 & 0.0014235 & $2.02635 \mathrm{E}-06$ & & & & & & & & \\
\hline & & & & & & & & & & & & \\
\hline & & & & & & & & & & & & \\
\hline & & & & & & & & & & & & \\
\hline \multicolumn{13}{|c|}{\begin{tabular}{|l|l|l|} 
As Per B. Marshall: Use t-value with 4 d.f. (2.776) to get $95 \%$ C.I. instead of the generic 2.0 & \\
\end{tabular}} \\
\hline \multicolumn{13}{|c|}{ This makes sense from thinking that the variance in the fraction of $\mathrm{U}$ in $\mathrm{UO} 2$ is the term of importance for $\mathrm{g} U \mathrm{U} 2$} \\
\hline & & & & & & & & & & & & \\
\hline & & & & & & & & & & & & \\
\hline \multicolumn{13}{|c|}{ Homogeneity: expressed as a standard deviation of gDUO2/gBlend, see write up } \\
\hline & & & & & & & & & & & & \\
\hline
\end{tabular}




\begin{tabular}{|c|c|c|c|c|c|c|c|c|c|c|}
\hline Blend + Bottle 1 & Blend + Bottle 2 & Bottle 2 & Blend + Bottle2 & Blend Removed & Proportion & DUO2 & Holdup & Blend in Tube & $\mathrm{U}$ in tube & Holdup \\
\hline after tube loaded & for CEP011 & Tare for CEPO11 & after CEP011 loaded & from bottle & $\mathrm{DUO} 2$ in Blend & Removed from bottle & Blend & & & Counts \\
\hline $\mathbf{g}$ & $\mathrm{g}$ & $\mathrm{g}$ & $\mathrm{g}$ & $\mathrm{g}$ & $\mathrm{g}$ & $\mathrm{g}$ & $\mathrm{g}$ & $\mathrm{g}$ & $\mathrm{g}$ & \\
\hline \multirow[t]{2}{*}{73.980000} & 735.450000 & 70.840000 & & 0.410000 & 0.858269 & 0.351890 & 0.000000 & 0.410000 & 0.307879195 & 1 \\
\hline & 754.730000 & & 70.930000 & 683.890000 & 0.834072 & 570.413834 & 0.222568 & 683.667432 & 498.9097556 & 1170.0 \\
\hline 203.490000 & & & & 1052.310000 & 0.960143 & 1010.367666 & 0.073661 & 1052.236339 & 883.9391029 & 432.0 \\
\hline 119.640000 & & & & 1124.720000 & 0.973195 & 1094.572359 & 0.089022 & 1124.630978 & 957.5983942 & 546.0 \\
\hline 119.220000 & & & & 1127.730000 & 0.972967 & 1097.244327 & 0.597501 & 1127.132499 & 959.5033393 & 3664.0 \\
\hline 100.530000 & & & & 1142.530000 & 0.973121 & 1111.819390 & 0.142011 & 1142.387989 & 972.6432292 & 871.0 \\
\hline 133.110000 & & & & 1115.090000 & 0.972540 & 1084.470152 & 0.205405 & 1114.884595 & 948.66069 & 1259.0 \\
\hline & & & & & & & & & & \\
\hline & & & & & & & & & & \\
\hline & & & & & & & & & & \\
\hline & & & & & & & & & & \\
\hline & & & & & & & & & & \\
\hline & & & & & & & & & & \\
\hline & & & & & & & & & & \\
\hline & & & & & & & & & & \\
\hline & & & & & & & & & & \\
\hline & & & & & & & & & & \\
\hline & & & & & & & & & & \\
\hline & & & & & & & & & & \\
\hline & & & & & & & & & & \\
\hline & & & & & & & & & & \\
\hline & & & & & & & & & & \\
\hline & & & & & & & & & & \\
\hline & & & & & & & & & & \\
\hline & & & & & & & & & & \\
\hline & & & & & & & & & & \\
\hline & & & & & & & & & & \\
\hline & & & & & & & & & & \\
\hline & & & & & & & & & & \\
\hline & & & & & & & & & & \\
\hline
\end{tabular}




\begin{tabular}{|c|c|c|c|c|c|c|c|}
\hline Holdup Error & Holdup & Homogeneity & Variance & Variance & Variance & Variance & Variance \\
\hline (Counts) & One time count error & Max. Variance & DE initial & DE removed & UO2 initi & Blend Total & Proportion of DUO2 in Blend \\
\hline & for U, RSD & (g) DUO2 & (g) & (g) & (g) & (g) & $(\mathrm{g})$ \\
\hline 0 & 0.000000 & 0.000109299 & $8.1613 \mathrm{E}-05$ & $5.1123 \mathrm{E}-05$ & 0.003347 & 0.003608544 & 3.89633E-08 \\
\hline 109.0 & 0.093162 & $9.74848 \mathrm{E}-05$ & 0.02234462 & 0 & 0.003347 & 0.024719468 & $8.58673 E-08$ \\
\hline 107.0 & 0.247685 & 0.000135171 & $8.1613 \mathrm{E}-05$ & $5.1123 \mathrm{E}-05$ & 0.003347 & 0.003608544 & $2.7752 \mathrm{E}-08$ \\
\hline 107.0 & 0.195971 & 0.000295565 & $8.1613 \mathrm{E}-05$ & 5.1123E-05 & 0.003347 & 0.003608544 & $9.71563 \mathrm{E}-08$ \\
\hline 121.0 & 0.033024 & 0.000295288 & $8.1613 \mathrm{E}-05$ & 5.1123E-05 & 0.003347 & 0.003608544 & $9.69556 \mathrm{E}-08$ \\
\hline 108.0 & 0.123995 & 0.000295474 & $8.1613 \mathrm{E}-05$ & 5.1123E-05 & 0.003347 & 0.003608544 & $9.71244 \mathrm{E}-08$ \\
\hline 113.0 & 0.089754 & 0.00029477 & $8.1613 \mathrm{E}-05$ & $5.1123 \mathrm{E}-05$ & 0.003347 & 0.003608544 & $9.66775 \mathrm{E}-08$ \\
\hline & & & & & & & \\
\hline & & & & & & & \\
\hline & & & & & & & \\
\hline & & & & & & & \\
\hline & & & & & & & \\
\hline & & & & & & & \\
\hline & & & & & & & \\
\hline & & & & & & & \\
\hline & & & & & & & \\
\hline & & & & & & & \\
\hline & & & & & & & \\
\hline & & & & & & & \\
\hline & & & & & & & \\
\hline & & & & & & & \\
\hline & & & & & & & \\
\hline & & & & & & & \\
\hline & & & & & & & \\
\hline & & . & & & & & \\
\hline & & & & & & & \\
\hline & & & & & & & \\
\hline & & & & & & & \\
\hline & & & & & & & \\
\hline
\end{tabular}




\begin{tabular}{|c|c|c|c|c|c|c|c|}
\hline Variance of Blend+Bottle & Variance & Variance & Variance & Variance & $\%$ RSD & Specific Activity & Combine \\
\hline Only look at random variance since (except CEP011) & Bottle Tare weigh & Blend Removed & DUO2 Removed & U in tube & $U$ in tube & & All of CEP011 \\
\hline using difference of 2 measurements to get blend removed ( $\mathrm{g}$ ) & CEP011 only (g) & $(\mathrm{g})$ & $(\mathrm{g})$ & (g) & & curies/gU & Beyond this \\
\hline $4.20993 \mathrm{E}-05$ & 8.16132E-05 & 0.000376308 & 0.000277205 & 0.000242536 & 5.058335767 & $4.04063 \mathrm{E}-07$ & Point \\
\hline 0.003346623 & 8.16132E-05 & 0.003428236 & 0.042545558 & 0.040602946 & 0.040388412 & $4.04063 \mathrm{E}-07$ & \\
\hline $4.20993 \mathrm{E}-05$ & & $4.21011 \mathrm{E}-05$ & 0.030770177 & 0.037038415 & 0.021772277 & $4.04063 \mathrm{E}-07$ & \\
\hline $4.20993 \mathrm{E}-05$ & & 0.000168397 & 0.123061688 & 0.11948852 & 0.036097712 & $4.04063 \mathrm{E}-07$ & \\
\hline $4.20993 \mathrm{E}-05$ & & 0.000168397 & 0.123465061 & 0.119959625 & 0.036096996 & $4.04063 \mathrm{E}-07$ & \\
\hline $4.20993 \mathrm{E}-05$ & & 0.000168397 & 0.126943242 & 0.123257078 & 0.036095442 & $4.04063 \mathrm{E}-07$ & \\
\hline $4.20993 \mathrm{E}-05$ & & 0.000168397 & 0.120370569 & 0.11694632 & 0.0360481 & $4.04063 \mathrm{E}-07$ & \\
\hline & & & & & & & \\
\hline & & & & & & & \\
\hline & & & & & & & \\
\hline & & & & & & & \\
\hline & & & & & & & \\
\hline & & & & & & & \\
\hline & & & & & & & \\
\hline & & & & & & & \\
\hline & & & & & & & \\
\hline & & & & & & & \\
\hline & & & & & & & \\
\hline & & & & & & & \\
\hline & & & & & & & \\
\hline & & & & & & & \\
\hline & & & & & & & \\
\hline & & & & & & & \\
\hline & & & & & & & \\
\hline & & & & & & & \\
\hline & & & & & & & \\
\hline & & & & & & & \\
\hline & & & & & & & \\
\hline & & & & & & & \\
\hline & & & & & & & \\
\hline
\end{tabular}




\begin{tabular}{|c|c|c|c|c|c|c|c|c|}
\hline $\mathrm{gU}$ & Activity & Variance & Variance & Variance & \%RSD & \%RSD & Activity: At Least $95 \%$ & gU: At Least $95 \%$ \\
\hline & & Specific Activity & grams of $U$ & Activity & of Activity & of $\mathrm{g} \mathrm{U}$ & Confidence Bound & Confidence Bound \\
\hline & Curies/gU & (Curies/gU) & $(\mathrm{gU})$ & (curies) & & & $\%$ & $\%$ \\
\hline 499.2176348 & $2.0172 \mathrm{E}-04$ & $1.24 \mathrm{E}-15$ & 0.040845482 & $3.0892 \mathrm{E}-10$ & 8.713337042 & 0.040483877 & 24.18822363 & 0.112383242 \\
\hline 883.9391029 & $3.5717 \mathrm{E}-04$ & $1.24 \mathrm{E}-1 \mathrm{~S}$ & 0.037038415 & $9.68511 \mathrm{E}-10$ & 8.713270195 & 0.021772277 & 24.18803806 & 0.060439841 \\
\hline 957.5983942 & 3.8693E-04 & $1.24 \mathrm{E}-1 \mathrm{~S}$ & 0.11948852 & $1.13666 \mathrm{E}-09$ & 8.713317767 & 0.036097712 & 24.18817012 & 0.10020725 \\
\hline 959.5033393 & $3.8770 \mathrm{E}-04$ & $1.24 \mathrm{E}-15$ & 0.119959625 & $1.14119 \mathrm{E}-09$ & 8.713317764 & 0.036096996 & 24.18817011 & 0.10020526 \\
\hline 972.6432292 & $3.9301 \mathrm{E}-04$ & $1.24 \mathrm{E}-15$ & 0.123257078 & $1.17266 \mathrm{E}-09$ & 8.713317757 & 0.036095442 & 24.18817009 & 0.100200947 \\
\hline \multirow[t]{3}{*}{948.66069} & $3.8332 \mathrm{E}-04$ & $1.24 \mathrm{E}-15$ & 0.11694632 & $1.11554 \mathrm{E}-09$ & 8.713317561 & 0.0360481 & 24.18816955 & 0.100069525 \\
\hline & & & & & & & & \\
\hline & Activity $\mathrm{mCi}$ & $+/-m \mathrm{mi}$ & & Activity $\mathrm{Bq}$ & $+/ . \mathrm{Bq}$ & & & \\
\hline CEP011 & 0.201715 & 0.048791 & & $7.4709 \mathrm{E}+06$ & $1.8071 \mathrm{E}+06$ & & & \\
\hline CEP012 & 0.357167 & 0.086392 & & $1.3228 \mathrm{E}+07$ & $3.1997 \mathrm{E}+06$ & & & \\
\hline CEP013 & 0.386930 & 0.093591 & & $1.4331 \mathrm{E}+07$ & $3.4663 \mathrm{E}+06$ & & & \\
\hline CEP014 & 0.387700 & 0.093777 & & $1.4359 \mathrm{E}+07$ & $3.4732 \mathrm{E}+06$ & & & \\
\hline CEP015 & 0.393009 & 0.095062 & & $1.4556 \mathrm{E}+07$ & $3.5208 \mathrm{E}+06$ & & & \\
\hline CEP016 & 0.383318 & 0.092718 & & $1.4197 \mathrm{E}+07$ & $3.4340 \mathrm{E}+06$ & & & \\
\hline & & & & & & & & \\
\hline & & & & & & & & \\
\hline & & & & & & & & \\
\hline & & & & & & & & \\
\hline & & & & & & & & \\
\hline & & & & & & & & \\
\hline & & & & & & & & \\
\hline & & & & & & & & \\
\hline & & & & & & & & \\
\hline & & & & & & & & \\
\hline & & & & & & & & \\
\hline & & & & & & & & \\
\hline & & & & & & & & \\
\hline & & & & & & & & \\
\hline
\end{tabular}




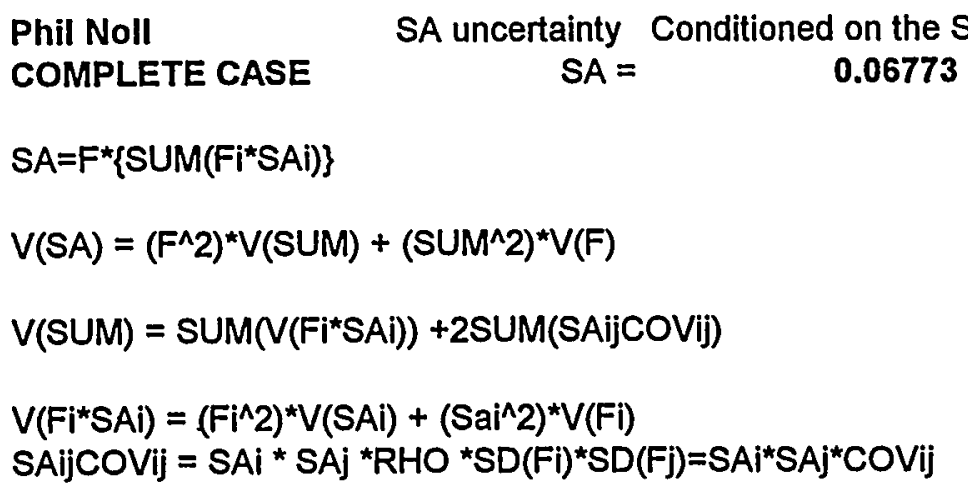

Set all $\operatorname{Var}(\mathrm{SA})$ values to $\mathbf{0 . 0}$

\begin{tabular}{lr} 
& \multicolumn{1}{c}{ Value } \\
\hline$f-U$ & 0.87493 \\
\hline$f-234$ & 0.00001 \\
$S A-234$ & $6.23 E-03$ \\
\hline$f-235$ & 0.0019 \\
$S A-235$ & $2.16 E-06$ \\
\hline$f-236$ & 0.00003 \\
SA-236 & $6.47 E-05$ \\
\hline$f-238$ & 0.99806 \\
SA-238 & $3.36 E-07$ \\
$f-233$ & 0 \\
SA-233 & $9.64 E-03$ \\
\hline
\end{tabular}

\begin{tabular}{|c|c|c|}
\hline F*SA & s.d. & \%rsd \\
\hline & 0.000220 & 0.0251 \\
\hline \multirow[t]{2}{*}{$6.2 \mathrm{E}-08$} & 0.000004 & 42.4000 \\
\hline & 0.000000 & 0.0000 \\
\hline \multirow[t]{2}{*}{ 4.1E-09 } & 0.000004 & 0.1874 \\
\hline & 0.000000 & 0.0000 \\
\hline \multirow[t]{2}{*}{ 1.9E-09 } & 0.000003 & 10.3667 \\
\hline & 0.000000 & 0.0000 \\
\hline \multirow[t]{2}{*}{$3.4 E-07$} & 0.000005 & 0.0005 \\
\hline & 0.000000 & 0.0000 \\
\hline \multirow[t]{2}{*}{0} & 0.000000 & 0.0000 \\
\hline & 0.000000 & 0.0000 \\
\hline
\end{tabular}

\begin{tabular}{|c|c|c|}
\hline cov & SDi & SDj \\
\hline $8-9$ & 0.000004 & 0.000006 \\
\hline 8-0 & 0.000004 & 0.000005 \\
\hline $8-1$ & 0.000004 & 0.000002 \\
\hline $8-2$ & 0.000004 & 0.000001 \\
\hline $9-0$ & 0.000006 & 0.000005 \\
\hline $9-1$ & 0.000006 & 0.000002 \\
\hline $9-2$ & 0.000006 & 0.000001 \\
\hline-1 & 0.000005 & 0.000002 \\
\hline
\end{tabular}

COVij

2.58E-11

2.15E-11

8.60E-12

4.30E-12

$3.00 E-11$

1.20E-11

$6.00 \mathrm{E}-12$

$1.00 \mathrm{E}-11$

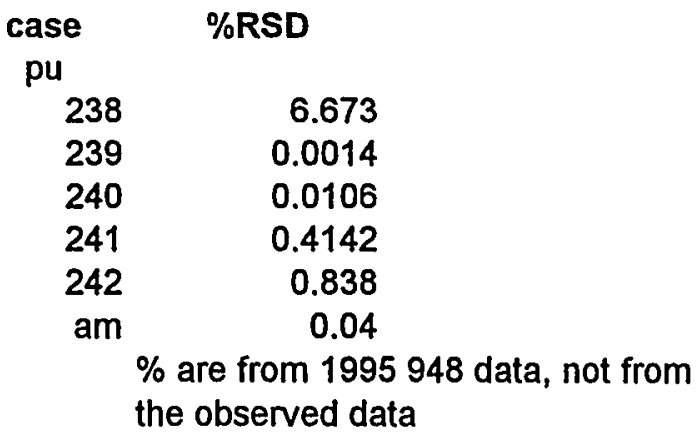

\begin{tabular}{rrr}
$V\left(F i{ }^{*} S A j\right)$ & SD(term) & \multicolumn{1}{l}{$\%$ rsd } \\
$6.97 E-16$ & $2.64 E-08$ & 6.53437 \\
$5.93 E-23$ & $7.70 E-12$ & 0.00191 \\
$4.05 E-20$ & $2.01 E-10$ & 0.04981 \\
$3.11 E-24$ & $1.76 E-12$ & 0.00044 \\
$0.00 E+00$ & $0.00 E+00$ & 0.00000 \\
$6.97 E-16$ & &
\end{tabular}

SAijCOVij

3.47482E-19

8.66508E-18

1.80149E-20

2.58233E-16

4.19947E-21

8.7308E-24

1.25151E-19

2.17718E-22 


\begin{tabular}{|c|c|c|c|}
\hline $0.000005 \quad 0.000001$ & $5.00 \mathrm{E}-12$ & $3.12086 E-18$ & \\
\hline 0.0000020 .000001 & 2.00E-12 & $\begin{array}{l}6.72786 \mathrm{E}-19 \\
2.71187 \mathrm{E}-16\end{array}$ & \\
\hline$V(S U M)=\operatorname{SUM}\left(V\left(F i^{\star} S A i\right)\right)+2 \operatorname{SUM}(\operatorname{COV}(i, j))$ & $1.23953 \mathrm{E}-15$ & & \\
\hline $\begin{array}{l}V(S A)=\left(F^{\wedge} 2\right)^{\star} V(S U M)+\left(S U M^{\wedge} 2\right)^{\star} V(F) \\
S D(S A)\end{array}$ & & & $\begin{array}{r}9.488718 E-16 \\
0.0000000\end{array}$ \\
\hline$\%$ rsd & & & 7.6235 \\
\hline
\end{tabular}

\begin{tabular}{|lrrr|}
\hline SA Uncertainty & & \\
& & SD & \%RSD \\
Approximate 95\% Confidence Bound is 2 SD or 2\%RSD & $6.16 E-08$ & 15.247 \\
Significant Digits: 1 or 2 maximum. & 1 sig.digit & 0.0002 & 0.003 \\
& 2 sig.digits & 0.00022 & 0.0032 \\
\hline
\end{tabular}

\section{ACTIVITY $=S A$ * $W=$ Specific Activity * Weight}

SA units are "curies/(g U)"

Activity $=S A$ * $(g U)$ and has units "curies"

Then $\operatorname{var}(A)=\left(S A^{\wedge} 2\right)^{\star} \operatorname{var}(U)+\left(U^{\wedge} 2\right)^{\star} \operatorname{var}(S A)$

and $\% R S D(A)=\operatorname{sqrt}\left(\{\% R S D(S A)\}^{\wedge}+\{\% R S D(M)\}^{\wedge} 2\right)$

SA $\quad 3.535 E-07$ curies "from U"/g UO2

$\begin{array}{lll}\mathrm{V}(\mathrm{SA}) & 9.489 \mathrm{E}-16 & \% \mathrm{RSD}(\mathrm{SA})=\end{array}$

Wgt(UO2) varies

$\mathrm{V}(\mathrm{UO} 2)=$ varies with amount

*Note: These values assume that the specific activity values for the particular isotopes are fixed.

No uncertainties were associated with the isotopic specific activity values. 


\begin{tabular}{|lccccc|}
\hline & \multicolumn{5}{c|}{ Total Alpha Activity in Curies } \\
& $6 / 1 / 97$ & $6 / 1 / 98$ & $6 / 1 / 99$ & $6 / 1 / 00$ & $6 / 1 / 01$ \\
\cline { 2 - 6 } CEP001 & 0.04231 & 0.04228 & 0.04225 & 0.04221 & 0.04218 \\
CEP002 & 0.03988 & 0.03985 & 0.03982 & 0.03978 & 0.03975 \\
CEP003 & 0.33345 & 0.33376 & 0.33405 & 0.33430 & 0.33452 \\
CEP004 & 0.33698 & 0.33730 & 0.33758 & 0.33783 & 0.33806 \\
CEP005 & 0.46461 & 0.46471 & 0.46479 & 0.46483 & 0.46485 \\
CEP006 & 0.46788 & 0.46798 & 0.46805 & 0.46808 & 0.46809 \\
CEP007 & 0.21742 & 0.21724 & 0.21705 & 0.21686 & 0.21666 \\
CEP008 & 0.20970 & 0.20954 & 0.20937 & 0.20920 & 0.20902 \\
CEP009 & 0.35508 & 0.35451 & 0.35395 & 0.35338 & 0.35281 \\
CEP010 & 0.34265 & 0.34210 & 0.34155 & 0.34100 & 0.34046 \\
\hline
\end{tabular}




\begin{tabular}{lccccr} 
& half-life (days) & decay const. & At. Weight & S.A. (Ci/g) & \multicolumn{1}{c}{ S.A. (mCi/g) } \\
$238 \mathrm{Pu}$ & 32010.5000000 & 0.0000217 & 238.0495530 & 17.1381141 & 17138.1140570 \\
$239 \mathrm{Pu}$ & 8800150.0000000 & 0.0000001 & 239.0521570 & 0.0620783 & 62.0783431 \\
$240 \mathrm{Pu}$ & 2395495.0000000 & 0.0000003 & 240.0538070 & 0.2271010 & 227.1009706 \\
$241 \mathrm{Pu}$ & 5237.7500000 & 0.0001323 & 241.0568450 & 0.0025341 & 2.5341056 \\
$242 \mathrm{Pu}$ & 136254500.0000000 & 0.0000000 & 242.0587370 & 0.0039596 & 3.9595993 \\
$241 \mathrm{Am}$ & 157753.0000000 & 0.0000044 & 241.0568230 & 3.4342017 & 3434.2017270
\end{tabular}

$\lambda .1 /(\lambda 2-\lambda .1)=\quad-1.0343425$

\begin{tabular}{|c|c|c|c|c|c|c|c|c|c|c|}
\hline \multicolumn{11}{|l|}{ CEPOOI } \\
\hline & \multicolumn{2}{|c|}{$6 / 1 / 97$} & \multicolumn{2}{|c|}{ 6/1/98 } & \multicolumn{2}{|c|}{$6 / 1 / 99$} & \multicolumn{2}{|c|}{$6 / 1 / 00$} & \multicolumn{2}{|c|}{$6 / 1 / 01$} \\
\hline & grams & S.A. $(\mathrm{mCi})$ & grams & S.A. (mCi) & grams & S.A. $(m C i)$ & grams & S.A. $(m \mathrm{Ci})$ & grams & S.A. $(\mathrm{mCi})$ \\
\hline •238Pu & 0.0000122 & 0.2093592 & 0.0000121 & 0.2077110 & 0.0000120 & 0.2060758 & 0.0000119 & 0.2044535 & 0.0000118 & 0.2028440 \\
\hline *239Pu & 0.0800044 & 4.9665390 & 0.0800021 & 4.9663963 & 0.0799998 & 4.9662535 & 0.0799975 & 4.9661107 & 0.0799952 & 4.9659679 \\
\hline $240 \mathrm{Pu}$ & 0.0050715 & 1.1517426 & 0.0050710 & 1.1516209 & 0.0050704 & 1.1514993 & 0.0050699 & 1.1513777 & 0.0050694 & 1.1512561 \\
\hline - $24 \mathrm{IPu}$ & 0.0001739 & 0.0004406 & 0.0001657 & 0.0004198 & 0.0001578 & 0.0004000 & 0.0001504 & 0.0003811 & 0.0001433 & 0.0003632 \\
\hline -242Pu & 0.0000477 & 0.0001891 & 0.0000477 & 0.0001891 & 0.0000477 & 0.0001891 & 0.0000477 & 0.0001891 & 0.0000477 & 0.0001891 \\
\hline -241 Am in PuO2 & 0.0000912 & 0.3133331 & 0.0000993 & 0.3409619 & 0.0001069 & 0.3672200 & 0.0001142 & 0.3921719 & 0.0001211 & 0.4158796 \\
\hline -24I Am in the AmO2 & 0.0103865 & 35.6692023 & 0.0103698 & 35.6120431 & 0.0103532 & 35.5549756 & 0.0103366 & 35.4979994 & 0.0103200 & 35.4411146 \\
\hline total $P \mathbf{L}=$ & 0.0853097 & & 0.0852986 & & 0.0852878 & & 0.0852774 & & 0.0852674 & \\
\hline cotal S.A. (Ci) $=$ & & 0.0423108 & & 0.0422793 & & 0.0422466 & & 0.0422127 & & 0.0421776 \\
\hline - less the $0.052 \%$ hold up & & & & & & & & & & \\
\hline
\end{tabular}

\begin{tabular}{|c|c|c|c|c|c|c|c|c|c|c|}
\hline \multicolumn{11}{|l|}{ CEP002 } \\
\hline & \multicolumn{2}{|c|}{$6 / 1 / 97$} & \multicolumn{2}{|c|}{ 6/1/98 } & \multicolumn{2}{|c|}{$6 / 1 / 99$} & \multicolumn{2}{|c|}{$6 / 1 / 00$} & \multicolumn{2}{|c|}{$6 / 1 / 01$} \\
\hline & grams & S.A. (mCi) & grams & S.A. $(\mathrm{mCi})$ & grams & S.A. $(\mathrm{mCi})$ & grams & S.A. (mCi) & grams & S.A. $(\mathrm{mCi})$ \\
\hline -238Pu & 0.0000113 & 0.1931465 & 0.0000112 & 0.1916260 & 0.0000111 & 0.1901174 & 0.0000110 & 0.1886207 & 0.0000109 & 0.1871358 \\
\hline *239Pu & 0.0738077 & 4.5818594 & 0.0738056 & 4.5817277 & 0.0738035 & 4.5815960 & 0.0738013 & 4.5814643 & 0.0737992 & 4.5813325 \\
\hline$\cdot 240 \mathrm{Pu}$ & 0.0046787 & 1.0625350 & 0.0046782 & 1.0624228 & 0.0046777 & 1.0623106 & 0.0046772 & 1.0621984 & 0.0046767 & 1.0620863 \\
\hline *241Pu & 0.0001604 & 0.0004064 & 0.0001528 & 0.0003873 & 0.0001456 & 0.0003690 & 0.0001388 & 0.0003516 & 0.0001322 & 0.0003350 \\
\hline $242 \mathrm{Pu}$ & 0.0000441 & 0.0001744 & 0.0000440 & 0.0001744 & 0.0000440 & 0.0001744 & 0.0000440 & 0.0001744 & 0.0000440 & 0.0001744 \\
\hline - $241 \mathrm{Am}$ in PuO2 & 0.0000842 & 0.2890636 & 0.0000916 & 0.3145524 & 0.0000986 & 0.3387766 & 0.0001054 & 0.3617959 & 0.0001117 & 0.3836672 \\
\hline -241Am in the AmO2 & 0.0098279 & 33.7510873 & 0.0098122 & 33.6970019 & 0.0097965 & 33.6430031 & 0.0097808 & 33.5890909 & 0.0097651 & 33.5352651 \\
\hline total $P u=$ & 0.0787021 & & 0.0786918 & & 0.0786819 & & 0.0786723 & & 0.0786631 & \\
\hline total S. A. $(\mathrm{Ci})=$ & & 0.0398783 & & 0.0398479 & & 0.0398163 & & 0.0397837 & & 0.0397500 \\
\hline - less the $0.051 \%$ hold up & & & & & & & & & & \\
\hline
\end{tabular}

\begin{tabular}{|c|c|c|c|c|c|c|c|c|c|c|}
\hline \multicolumn{11}{|l|}{ CEP003 } \\
\hline & \multicolumn{2}{|c|}{$6 / 1 / 97$} & \multicolumn{2}{|c|}{$6 / 1 / 98$} & \multicolumn{2}{|c|}{$6 / 1 / 99$} & \multicolumn{2}{|c|}{$6 / 1 / 00$} & \multicolumn{2}{|c|}{ 6/1/01 } \\
\hline & grams & S.A. (mCi) & grams & S.A. $(\mathrm{mCi})$ & grams & S.A. $(m C i)$ & grams & S.A. $(m C i)$ & grams & S.A. (mCi) \\
\hline -238Pu & 0.0002846 & $4.878227 i$ & 0.0002824 & 4.8398234 & 0.0002802 & 4.8017220 & 0.0002780 & 4.7639207 & 0.0002758 & 4.7264169 \\
\hline$* 239 \mathrm{Pu}$ & 1.8641073 & 115.7206910 & 1.8640537 & 115.7173642 & 1.8640001 & 115.7140374 & 1.8639465 & 115.7107108 & 1.8638929 & 115.7073842 \\
\hline $240 \mathrm{Pu}$ & 0.1181663 & 26.8356764 & 0.1181538 & 26.8328423 & 0.1181413 & 26.8300086 & 0.1181288 & 26.8271751 & 0.1181164 & 26.8243419 \\
\hline$\cdot 241 P_{u}$ & 0.0040508 & 0.0102651 & 0.0038598 & 0.0097810 & 0.0036778 & 0.0093198 & 0.0035043 & 0.0088803 & 0.0033391 & 0.0084616 \\
\hline$\cdot 242 \mathrm{Pu}$ & 0.0011125 & 0.0044052 & 0.0011125 & 0.0044052 & 0.0011125 & 0.0044051 & 0.0011125 & 0.0044051 & 0.0011125 & $0.004405 !$ \\
\hline -241Am in $\mathrm{PuO} 2$ & 0.0021259 & 7.3006596 & 0.0023133 & 7.9444113 & 0.0024915 & 8.5562237 & 0.0026608 & 9.1376054 & 0.0028216 & 9.6899939 \\
\hline *24lAm in the AmO2 & 0.0520361 & 178.7025744 & 0.0519527 & 178.4162072 & 0.0518695 & 178.1302988 & 0.0517864 & 177.8448487 & 0.0517034 & 177.5598560 \\
\hline total $P u=$ & 1.9877215 & & 1.9874622 & & 1.9872119 & & 1.9869702 & & 1.9867367 & \\
\hline total S.A. $(C i)=$ & & 0.3334525 & & 0.3337648 & & 0.3340460 & & 0.3342975 & & 0.3345209 \\
\hline * less the $0.063 \%$ hold up & & & & & & & & & & \\
\hline
\end{tabular}




\begin{tabular}{|c|c|c|c|c|c|c|c|c|c|c|}
\hline \multicolumn{11}{|l|}{ CEPOO4 } \\
\hline & \multicolumn{2}{|c|}{$6 / 1 / 97$} & \multicolumn{2}{|c|}{$6 / 1 / 98$} & \multicolumn{2}{|c|}{$6 / 1 / 99$} & \multicolumn{2}{|c|}{$6 / 1 / 00$} & \multicolumn{2}{|c|}{$6 / 1 / 01$} \\
\hline & grams & S.A. $(\mathrm{mCi})$ & grams & S.A. $(\mathrm{mCi})$ & grams & S.A. (mCi) & grams & S.A. (mCi) & grams & S.A. (mCi) \\
\hline${ }^{2} 238 \mathrm{Pu}$ & 0.0002876 & 4.9294872 & 0.0002854 & 4.8906799 & 0.0002831 & 4.8521782 & 0.0002809 & 4.8139796 & 0.0002787 & 4.7760817 \\
\hline${ }^{\circ} 239 \mathrm{Pu}$ & 1.8836985 & 116.9368832 & I.8836444 & 116.9335214 & 1.8835902 & 116.9301596 & $1.883536 !$ & 116.9267980 & 1.8834819 & 116.9234365 \\
\hline${ }^{*} 240 \mathrm{Pu}$ & 0.1194082 & 27.1177120 & 0.1193956 & 27.1148481 & 0.1193830 & 27.1119845 & 0.1193703 & 27.1091213 & 0.1193577 & 27.1062583 \\
\hline${ }^{*} 241 \mathrm{Pu}$ & 0.0040934 & 0.0103730 & 0.0039003 & 0.0098838 & 0.0037164 & 0.0094178 & 0.0035412 & 0.0089737 & 0.0033742 & 0.0085505 \\
\hline${ }^{*} 242 \mathrm{Pu}$ & 0.0011242 & 0.0044515 & 0.0011242 & 0.0044515 & 0.0011242 & 0.0044514 & 0.0011242 & 0.0044514 & 0.0011242 & 0.0044514 \\
\hline -241Am in PuO2 & 0.0021482 & 7.3773899 & 0.0023376 & 8.0279074 & 0.0025177 & 8.6461498 & 0.0026887 & 9.2336418 & 0.0028513 & 9.7918358 \\
\hline "241Am in the AmO2 & 0.0525896 & 180.6032574 & 0.0525053 & 180.3138443 & 0.0524212 & 180.0248951 & 0.0523372 & 179.7364089 & 0.0522533 & 179.4483850 \\
\hline total $\mathrm{Pu}=$ & 2.0086119 & & 2.0083498 & & 2.0080969 & & 2.0078527 & & 2.0076167 & \\
\hline total S.A. $(\mathbf{C i})=$ & & 0.3369796 & & 0.3372951 & & 0.3375792 & & 0.3378334 & & 0.3380590 \\
\hline * less the $0.028 \%$ hold up & & & & & & & & & & \\
\hline
\end{tabular}

\begin{tabular}{|c|c|c|c|c|c|c|c|c|c|c|}
\hline \multicolumn{11}{|l|}{ CEP005 } \\
\hline & \multicolumn{2}{|c|}{$6 / 1 / 97$} & \multicolumn{2}{|c|}{$6 / 1 / 98$} & \multicolumn{2}{|c|}{$6 / 1 / 99$} & \multicolumn{2}{|c|}{$6 / 1 / 00$} & \multicolumn{2}{|c|}{$6 / 1 / 01$} \\
\hline & grams & S.A. $(\mathrm{mCi})$ & grams & S.A. $(\mathrm{mCi})$ & grams & S.A. (mCi) & grams & S.A. $(\mathrm{mCi})$ & grams & S.A. (mCi) \\
\hline •238Pu & 0.0002854 & 4.8908579 & 0.0002831 & 4.8523547 & 0.0002809 & 4.8141547 & 0.0002787 & 4.7762555 & 0.0002765 & 4.7386546 \\
\hline${ }^{*} 239 \mathrm{Pu}$ & 1.8689380 & 116.0205765 & 1.8688843 & 116.0172410 & 1.8688306 & 116.0139056 & 1.8687768 & 116.0105703 & 1.8687231 & 116.0072352 \\
\hline *240Pu & 0.1184725 & 26.9052202 & 0.1184600 & 26.9023788 & 0.1184475 & 26.8995376 & 0.1184350 & 26.8966968 & 0.1184225 & 26.8938563 \\
\hline$\bullet 24 I P u$ & 0.0040613 & 0.0102917 & 0.0038698 & 0.0098064 & 0.0036873 & 0.0093440 & 0.0035134 & 0.0089034 & 0.0033477 & 0.0084835 \\
\hline$* 242 \mathrm{Pu}$ & 0.0011154 & 0.0044166 & 0.0011154 & 0.0044166 & 0.0011154 & 0.0044166 & 0.0011154 & 0.0044166 & 0.0011154 & 0.0044165 \\
\hline $241 \mathrm{Am}$ in $\mathrm{PuO} 2$ & 0.0021314 & 7.3195786 & 0.0023193 & 7.9649985 & 0.0024979 & 8.5783963 & 0.0026677 & 9.1612846 & 0.0028289 & 9.7151046 \\
\hline \multirow[t]{3}{*}{ *241Am in the AmO2 } & $0.090 \mathrm{I} 106$ & 309.4580571 & 0.0899662 & 308.9621569 & 0.0898221 & 308.4670514 & 0.0896781 & 307.9727393 & 0.0895344 & 307.4792192 \\
\hline & 1.9928726 & & 1.9926126 & & 1.9923617 & & 1.9921193 & & 1.9918852 & \\
\hline & & 0.4646090 & & 0.4647134 & & 0.4647868 & & 0.4648309 & & 0.4648470 \\
\hline * less the $0.034 \%$ hold up & & & & & & & & & & \\
\hline
\end{tabular}

\begin{tabular}{|c|c|c|c|c|c|c|c|c|c|c|}
\hline \multicolumn{11}{|l|}{ CEP006 } \\
\hline & \multicolumn{2}{|c|}{$6 / 1 / 97$} & \multicolumn{2}{|c|}{$6 / 1 / 98$} & \multicolumn{2}{|c|}{$6 / 1 / 99$} & \multicolumn{2}{|c|}{$6 / 1 / 100$} & \multicolumn{2}{|c|}{$6 / 1 / 01$} \\
\hline & grams & S.A. (mCi) & grams & S.A. $(\mathrm{mCi})$ & grams & S.A. (mCi) & grams & S.A. $(\mathrm{mCi})$ & grams & S.A. $(\mathrm{mCi})$ \\
\hline .238Pu & 0.0002851 & 4.8862306 & 0.0002829 & 4.8477639 & 0.0002806 & 4.8096000 & 0.0002784 & 4.7717366 & 0.0002762 & 4.7341713 \\
\hline .239Pu & 1.8671694 & 115.9107837 & 1.8671157 & 115.9074513 & 1.8670621 & 115.9041191 & 1.8670084 & 115.9007870 & 1.8669547 & 115.8974550 \\
\hline $240 \mathrm{Pu}$ & 0.1183604 & 26.8797590 & 0.1183479 & 26.8769203 & 0.1183354 & 26.8740818 & 0.1183229 & 26.8712437 & 0.1183104 & 26.8684058 \\
\hline -241Pu & 0.0040574 & 0.0102820 & 0.0038661 & 0.0097971 & 0.0036838 & 0.0093351 & 0.0035101 & 0.0088949 & 0.0033446 & 0.0084755 \\
\hline$\cdot 242 \mathrm{Pu}$ & 0.0011144 & 0.0044124 & 0.0011144 & 0.0044124 & 0.0011144 & 0.0044124 & 0.0011143 & 0.0044124 & 0.0011143 & 0.0044124 \\
\hline 241Am in $\mathrm{PuO} 2$ & 0.0021280 & 7.3079813 & 0.0023158 & 7.9527980 & 0.0024942 & 8.5656228 & 0.0026638 & 9.1479670 & 0.0028249 & 9.7012704 \\
\hline 241Am in the AmO2 & 0.0911070 & 312.8798167 & 0.0909610 & 312.3784332 & 0.0908152 & 311.8778532 & 0.0906697 & 311.3780753 & 0.0905244 & 310.8790983 \\
\hline total $\mathrm{Pu}=$ & 1.9909867 & & 1.9907269 & & 1.9904762 & & 1.9902341 & & 1.9900003 & \\
\hline total S.A. $(\mathrm{Ci})=$ & & 0.4678793 & & 0.4679776 & & 0.4680450 & & 0.4680831 & & 0.4680933 \\
\hline - less the $0.022 \%$ hold up & & & & & & & & & & \\
\hline
\end{tabular}




\begin{tabular}{|c|c|c|c|c|c|c|c|c|c|c|}
\hline \multicolumn{11}{|l|}{ CEP007 } \\
\hline & grams & S.A. (mCi) & grams & S.A. (mCi) & grams & S.A. (mCi) & grams & S.A. $(\mathrm{mCi})$ & grams & S.A. (mCi) \\
\hline -238Pu & 0.0000566 & 0.9704971 & 0.0000562 & 0.9628569 & 0.0000557 & 0.9552769 & 0.0000553 & 0.9477565 & 0.0000549 & 0.9402953 \\
\hline -239Pu & 0.3708564 & 23.0221522 & 0.3708458 & 23.0214903 & 0.3708351 & 23.0208285 & 0.3708244 & 23.0201667 & 0.3708138 & 23.0195049 \\
\hline $240 \mathrm{Pu}$ & 0.0235087 & 5.3388468 & 0.0235062 & 5.3382829 & 0.0235037 & 5.3377192 & 0.0235012 & 5.3371555 & 0.0234988 & 5.3365918 \\
\hline $241 \mathrm{Pu}$ & 0.0008059 & 0.0020422 & 0.0007679 & 0.0019459 & -0.0007317 & 0.0018541 & 0.0006972 & 0.0017667 & 0.0006643 & 0.0016834 \\
\hline$* 242 \mathrm{Pu}$ & 0.0002213 & 0.0008764 & 0.0002213 & 0.0008764 & 0.0002213 & 0.0008764 & 0.0002213 & 0.0008764 & 0.0002213 & 0.0008764 \\
\hline -241Am in PuO2 & 0.0004229 & 1.4524372 & 0.0004602 & 1.5805091 & 0.0004957 & 1.7022267 & 0.0005293 & 1.8178902 & 0.0005613 & 1.9277857 \\
\hline -24IAm in the AmO2 & 0.0543448 & 186.6308927 & 0.0542577 & 186.3318205 & 0.0541707 & 186.0332276 & 0.0540839 & 185.7351131 & 0.0539973 & 185.4374764 \\
\hline total $\mathrm{Pu}=$ & 0.3954490 & & 0.3953974 & & 0.3953476 & & 0.3952995 & & 0.3952530 & \\
\hline total S.A. (Ci) = & & 0.2174177 & & 0.2172378 & & 0.2170520 & & 0.2168607 & & 0.2166642 \\
\hline - less the $0.029 \%$ hold up & & & & & & & & & & \\
\hline
\end{tabular}

\begin{tabular}{|c|c|c|c|c|c|c|c|c|c|c|}
\hline \multicolumn{11}{|l|}{ CEP008 } \\
\hline & \multicolumn{2}{|c|}{$6 / 1 / 97$} & \multicolumn{2}{|c|}{$6 / 1 / 98$} & \multicolumn{2}{|c|}{$6 / 1 / 99$} & \multicolumn{2}{|c|}{$6 / 1 / 00$} & \multicolumn{2}{|c|}{$6 / 1 / 01$} \\
\hline & grams & S.A. (mCi) & grams & S.A. (mCi) & grams & S.A. (mCi) & grams & S.A. $(\mathrm{mCi})$ & grams & S.A. (mCi) \\
\hline •238Pu & 0.0000592 & 1.0143878 & 0.0000587 & 1.0064021 & 0.0000583 & 0.9984792 & 0.0000578 & 0.9906187 & 0.0000573 & 0.9828201 \\
\hline -239Pu & 0.3876279 & 24.0632952 & 0.3876167 & 24.0626034 & 0.3876056 & 24.0619117 & 0.3875944 & 24.0612199 & 0.3875833 & 24.0605282 \\
\hline -240Pu & 0.0245718 & 5.5802883 & 0.0245692 & 5.5796989 & 0.0245666 & 5.5791097 & 0.0245641 & 5.5785205 & 0.0245615 & 5.5779313 \\
\hline$\cdot 241 \mathrm{Pu}$ & 0.0008423 & 0.0021346 & 0.0008026 & 0.0020339 & 0.0007648 & 0.0019380 & 0.0007287 & 0.0018466 & 0.0006943 & 0.0017595 \\
\hline $242 P_{4}$ & 0.0002313 & 0.0009160 & 0.0002313 & 0.0009160 & 0.0002313 & 0.0009160 & 0.0002313 & 0.0009160 & 0.0002313 & 0.0009160 \\
\hline $24 \mathrm{IAm}$ in PuO2 & 0.0004421 & 1.5181198 & 0.0004810 & 1.6519835 & 0.0005181 & 1.7792056 & 0.0005533 & 1.9000999 & 0.0005867 & 2.0149652 \\
\hline \multirow[t]{3}{*}{ *24lAm in the AmO2 } & 0.0516906 & 177.5160886 & 0.0516078 & 177.2316227 & 0.0515251 & 176.9476126 & 0.0514425 & 176.6640577 & 0.0513601 & 176.3809572 \\
\hline & 0.4133326 & & 0.4132786 & & 0.4132266 & & 0.4131763 & & 0.4131278 & \\
\hline & & 0.2096952 & & 0.2095353 & & 0.2093692 & & 0.2091973 & & 0.2090199 \\
\hline - less the $0.033 \%$ hold up & & & & & & & & & & \\
\hline
\end{tabular}

\begin{tabular}{|c|c|c|c|c|c|c|c|c|c|c|}
\hline \multicolumn{11}{|l|}{ CEP009 } \\
\hline & \multicolumn{2}{|c|}{$6 / 1 / 97$} & \multicolumn{2}{|c|}{$6 / 1 / 98$} & \multicolumn{2}{|c|}{$6 / 1 / 99$} & \multicolumn{2}{|c|}{$6 / 1 / 00$} & \multicolumn{2}{|c|}{$6 / 1 / 01$} \\
\hline & grams & S.A. (mCi) & grams & S.A. (mCi) & grams & S.A. $(\mathrm{mCi})$ & grams & S.A. (mCi) & grams & S.A. (mCi) \\
\hline -238Pu & 0.0000000 & 0.0000000 & 0.0000000 & 0.0000000 & 0.0000000 & 0.0000000 & 0.0000000 & 0.0000000 & 0.0000000 & 0.0000000 \\
\hline -239Pu & 0.0000000 & 0.0000000 & 0.0000000 & 0.0000000 & 0.0000000 & 0.0000000 & 0.0000000 & 0.0000000 & 0.0000000 & 0.0000000 \\
\hline $240 \mathrm{Pu}$ & 0.0000000 & 0.0000000 & 0.0000000 & 0.0000000 & 0.0000000 & 0.0000000 & 0.0000000 & 0.0000000 & 0.0000000 & 0.0000000 \\
\hline $24 \perp \mathrm{Pu}$ & 0.0000000 & 0.0000000 & 0.0000000 & 0.0000000 & 0.0000000 & 0.0000000 & 0.0000000 & 0.0000000 & 0.0000000 & 0.0000000 \\
\hline$\cdot 242 \mathrm{Pu}$ & 0.0000000 & 0.0000000 & 0.0000000 & 0.0000000 & 0.0000000 & 0.0000000 & 0.0000000 & 0.0000000 & 0.0000000 & 0.0000000 \\
\hline -241Am in PuO2 & 0.0000000 & 0.0000000 & 0.0000000 & 0.0000000 & 0.0000000 & 0.0000000 & 0.0000000 & 0.0000000 & 0.0000000 & 0.0000000 \\
\hline -24lAm in the AmO2 & 0.1033961 & 355.0830652 & 0.1032304 & 354.5140518 & 0.1030650 & 353.9459503 & 0.1028998 & 353.3787592 & 0.1027349 & 352.8124770 \\
\hline total $P u=$ & 0.0000000 & & 0.0000000 & & 0.0000000 & & 0.0000000 & & 0.0000000 & \\
\hline total S.A. (Ci) = & & 0.3550831 & & 0.3545141 & & 0.3539460 & & 0.3533788 & & 0.3528125 \\
\hline - less the $0.034 \%$ hold up & & & & & & & & & & \\
\hline
\end{tabular}




\begin{tabular}{|c|c|c|c|c|c|c|c|c|c|c|}
\hline \multicolumn{11}{|l|}{ CEPO10 } \\
\hline & \multicolumn{2}{|c|}{$6 / 1 / 97$} & \multicolumn{2}{|c|}{$6 / 1 / 98$} & \multicolumn{2}{|c|}{$6 / 1 / 99$} & \multicolumn{2}{|c|}{$6 / 1 / 00$} & \multicolumn{2}{|c|}{$6 / 1 / 01$} \\
\hline & grams & S.A. (mCi) & grams & S.A. (mCi) & grams & S.A. (mCi) & grams & S.A. (mCi) & grams & S.A. $(\mathrm{mCi})$ \\
\hline -238Pu & 0.0000000 & 0.0000000 & 0.0000000 & 0.0000000 & 0.0000000 & 0.0000000 & 0.0000000 & 0.0000000 & 0.0000000 & 0.0000000 \\
\hline $239 \mathrm{Pu}$ & 0.0000000 & 0.0000000 & 0.0000000 & 0.0000000 & 0.0000000 & 0.0000000 & 0.0000000 & 0.0000000 & 0.0000000 & 0.0000000 \\
\hline$\cdot 240 \mathrm{Pu}$ & 0.0000000 & 0.0000000 & 0.0000000 & 0.0000000 & 0.0000000 & 0.0000000 & 0.0000000 & 0.0000000 & 0.0000000 & 0.0000000 \\
\hline • $241 \mathrm{Pu}$ & 0.0000000 & 0.0000000 & 0.0000000 & 0.0000000 & 0.0000000 & 0.0000000 & 0.0000000 & 0.0000000 & 0.0000000 & 0.0000000 \\
\hline$\cdot 242 \mathrm{Pu}$ & 0.0000000 & 0.0000000 & 0.0000000 & 0.0000000 & 0.0000000 & 0.0000000 & 0.0000000 & 0.0000000 & 0.0000000 & 0.0000000 \\
\hline "241Am in PuO2 & 0.0000000 & 0.0000000 & 0.0000000 & 0.0000000 & 0.0000000 & 0.0000000 & 0.0000000 & 0.0000000 & 0.0000000 & 0.0000000 \\
\hline \multirow[t]{3}{*}{ *24 $1 \mathrm{Am}$ in the AmO2 } & 0.0997754 & 342.6488510 & 0.0996155 & 342.0997632 & 0.0994559 & 341.5515553 & 0.0992965 & 341.0042260 & 0.0991374 & 340.4577737 \\
\hline & 0.0000000 & & 0.0000000 & & 0.0000000 & & 0.0000000 & & 0.0000000 & \\
\hline & & 0.3426489 & & 0.3420998 & & 0.3415516 & & 0.3410042 & & 0.3404578 \\
\hline - less the $0.043 \%$ hold up & & & & & & & & & & \\
\hline
\end{tabular}




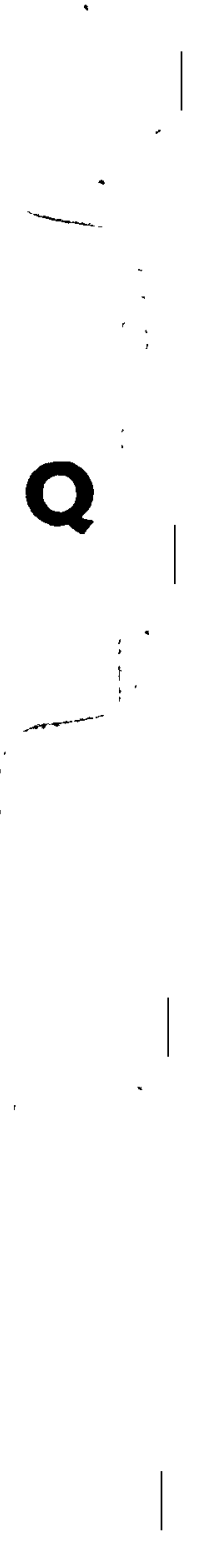




\begin{tabular}{|lllll|}
\hline $\begin{array}{l}\text { Diatomaceous Earth Weighings } \\
\text { Balance: } 13045 \text { (Certified) } \\
\text { Check Wts: Cenco Class S (Certified) }\end{array}$ & & & \\
\hline Standard Wt. & Number of Measurements & Mean & Std. Dev. & \% Uncert. \\
\hline $30 \mathrm{~g}$ & 15 & 29.99853 & $5.16 \mathrm{E}-04$ & 0.009 \\
$50 \mathrm{~g}$ & 3 & 50.001 & 0.002 & 0.014 \\
$100 \mathrm{~g}$ & 20 & 99.993 & 0.004 & 0.018 \\
\hline
\end{tabular}

\begin{tabular}{|c|c|c|c|c|}
\hline \multicolumn{5}{|c|}{$\begin{array}{l}\text { Balance: } 015233 \text { (Certified) } \\
\text { Check Wts: Not Certified }\end{array}$} \\
\hline Standard Wt. & Number of Measurements & Mean & Std. Dev. & $\%$ Uncert. \\
\hline $10 \mathrm{~g}$ & 15 & 10.00094 & $1.46 \mathrm{E}-05$ & 0.010 \\
\hline $200 \mathrm{~g}$ & 12 & 200.0143 & 4.93E-05 & 0.007 \\
\hline
\end{tabular}

\begin{tabular}{|c|c|c|c|c|}
\hline \multicolumn{5}{|c|}{$\begin{array}{l}\text { Balance: } 013599 \text { (Certified) } \\
\text { Check Wts: } 15082 \text { (Certified) }\end{array}$} \\
\hline Standard Wt. & Number of Measurements & Mean & Std. Dev. & \% Uncert. \\
\hline $10 \mathrm{mg}$ & 5 & 0.01001 & 4.47E-06 & 0.204 \\
\hline $50 \mathrm{mg}$ & 5 & 0.05002 & $5.48 \mathrm{E}-06$ & 0.062 \\
\hline $100 \mathrm{mg}$ & 10 & 0.10002 & $6.75 \mathrm{E}-06$ & 0.032 \\
\hline $1 \mathrm{~g}$ & 6 & 1.00001 & $5.16 \mathrm{E}-06$ & 0.003 \\
\hline $2 \mathrm{~g}$ & 10 & 2.00003 & $6.75 \mathrm{E}-06$ & 0.002 \\
\hline
\end{tabular}

\begin{tabular}{|lllll|}
\hline UO2 Weighings & & & \\
\hline Balance: 016834 & (Certified) \\
Check Wts: 4482,3648 (Certified) & & & & \\
\hline Standard Wt. & Number of Measurements & Mean & Std. Dev. & \% Uncert. \\
\hline $500 \mathrm{~g}$ & 41 & 499.954 & $5.91 \mathrm{E}-03$ & 0.012 \\
$1 \mathrm{~kg}$ & 38 & 999.899 & $6.49 \mathrm{E}-03$ & 0.012 \\
\hline
\end{tabular}




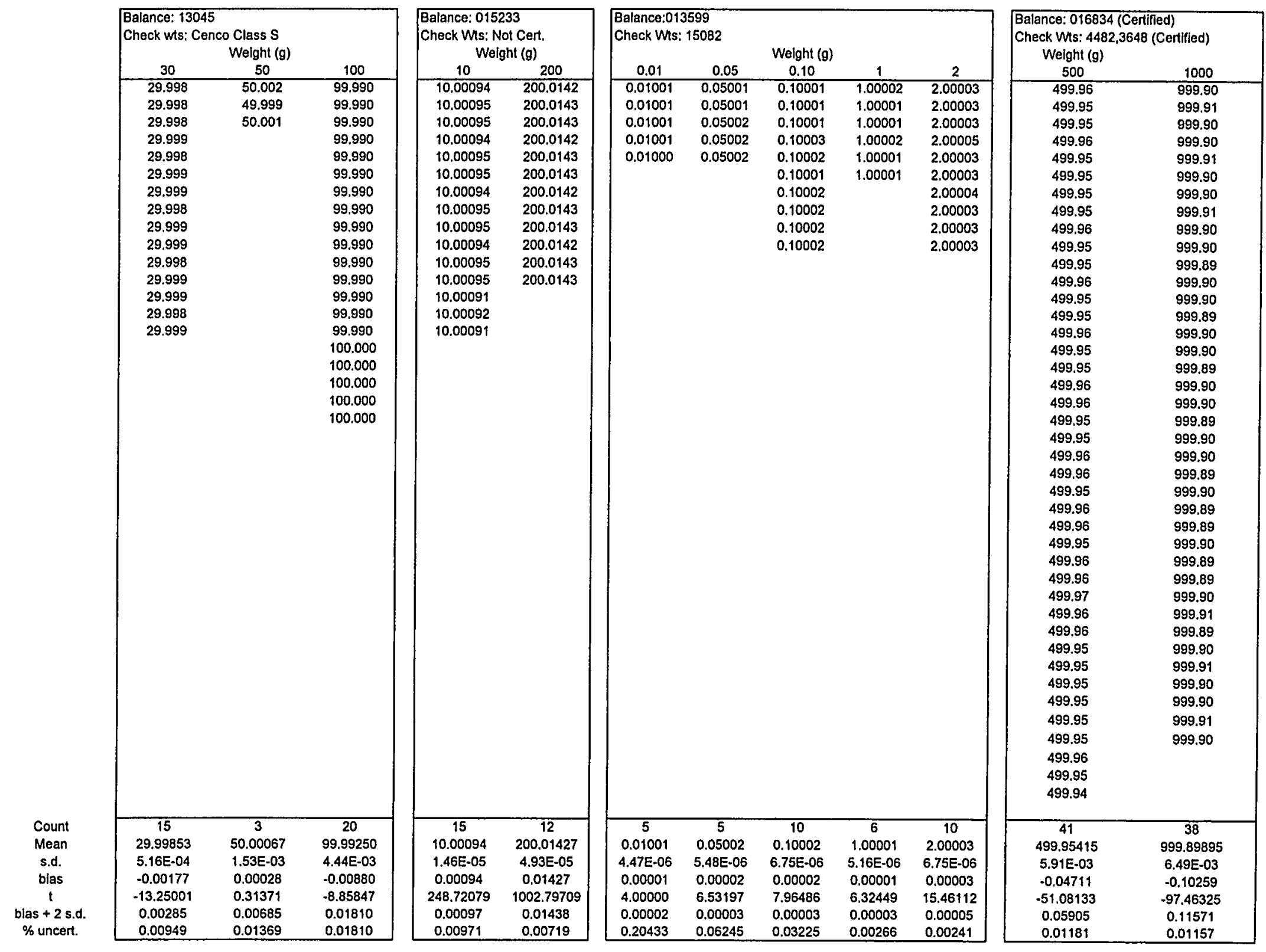




\section{Calibration Certificate}

WEIGHT SET

Mfg.:

Troemner

Serial No.: 23424

other ID:

Certified:

Expires:
NA

April 13, 1995

April 12, 1997
File No.: 15082

Calibration of the above weights was achieved in a controlled environment through the use of standards traceable to national standards.

Item Received: (X) In tolerance

( ) Out of tolerance

Item Returned: (X) In tolerance

( ) Iimited

Values reported are those that would be observed in comparing the weights to standards of density $8.0 \mathrm{~g} / \mathrm{cc}$ in local air of density $0.923 \mathrm{mg} / \mathrm{cc}$. The values reported under True Nass correction are compensated for local environment and correspond to values which would be observed in a vacuum.

Estimated uncertainties in the reported values do not exceed:

$1.5 \mathrm{ppm}$ for weights $100 \mathrm{~g}$ to $10 \mathrm{~g}$

$0.01 \mathrm{mg}$ for weights $5 \mathrm{~g}$ to $1 \mathrm{~g}$

$0.005 \mathrm{mg}$ for weights $500 \mathrm{mg}$ to $1 \mathrm{mg}$

It is expected that this item will remain within the stated uncertainty for the duration of the calibration interval, provided it is used in accordance with the operational conditions specified by the manufacturer, and provided it is not subjected to any physical damage.

Calibrated by: George perrault $/ 4$ /s:

Reviewed by:

Bernadette Salazari

Copy to:

Adrian Lovell, CST-08, G740

ESH-9 file 


\section{Calibration Certificate}

BALANCE

File No. 013559

Sartorius R200D

Property No. 901559

Location: TA-03 Bldg. CMR Rm. 5129

Certified: July 15, 1997

Expires: July 15, 1998

This instrument was calibrated on-site using equipment traceable to national standards. Under normal operating conditions, this item is expected to remain within the stated uncertainty for the duration of calibration interval.

\begin{tabular}{ll}
\multicolumn{2}{c}{ Calibration Results } \\
Instrument Received & Instrument Returned \\
{$[\mathrm{X}]$ In Tolerance } & {$[\mathrm{X}]$ In Tolerance } \\
{[] Other } & {$[$ ] Other }
\end{tabular}

It's recommended that the balance be calibrated using the internal calibration weight when there's a requirement for high accuracy measurements.

\section{Tolerance}

$+/-0.00010$ grams : 40 gram range

$+/-0.0004$ grams : 200 gram range

Calibrated by: Michael A. Salazar $\ln \theta$.

Reviewed by: Bernadette I. Salazar/8

Copy to: Donna Hofmann, CST-08, Mail Stop G740

ESH-09 File 
Standards \& Calibration Laboratory

Mail Stop D478, 657-4864

\section{Calibration Certificate}

WEIGHT SET

Manufacturer Cenco

Serial No. NA

Certified: November 06, 1997

Expires: November 06, 1999
File No. 18535

This weight set was calibrated in a controlled environment using equipment traceable to national standards. Under normal operating conditions, this item is expected to remain within the stated uncertainty for the duration of calibration interval.

Values reported are those that would be observed in comparing the weights to standards of density $8.0 \mathrm{~g} / \mathrm{cc}$ in local air of density $.924 \mathrm{mg} / \mathrm{cc}$.

Calibration Results

$\begin{array}{ll}\text { Instrument Received } & \text { Instrument Retumed } \\ {[\mathrm{X}] \text { In Tolerance }} & {[\mathrm{X}] \text { In Tolerance }} \\ \text { [] Other } & {[] \text { Other }}\end{array}$

Designation Correction Uncertainty

$\begin{array}{ccc}100 \mathrm{~g} & +1.27 & +/-0.30 \mathrm{mg} \\ 50 & +0.39 & 0.15 \\ 30 & +0.30 & 0.09 \\ 20 & -0.22 & 0.06 \\ 5 & +0.28 & 0.02 \\ 3 & -0.02 & 0.02 \\ 500 \mathrm{mg} & -0.080 & 0.01 \\ 300 & -0.005 & 0.01 \\ 100 & +0.031 & 0.01 \\ 30 & +0.020 & 0.01\end{array}$

Calibrated by: George Perrault

Reviewed by: Bernadette L. Salazar

Copy to: Donna Hofmann, CST-08, Mail Stop G740

ESH-09 File 


\section{Calibration Certificate}

BALANCE

Sartorius LC-620-D

File No. 013045

Property No. 839672

Location: TA 03 Bldg. CMR Room 5165

Certified: March 31, 1997

Expires: March 31, 1998

This instrument was calibrated on-site using equipment traceable to national standards. Under normal operating conditions, this item is expected to remain within the stated uncertainty for the duration of calibration interval.

\begin{tabular}{ll}
\multicolumn{2}{c}{ Calibration Results } \\
Instrument Received & Instrument Returned \\
{$[\mathrm{X}]$ In Tolerance } & {$[\mathrm{X}]$ In Tolerance } \\
{[] Other } & {$[$ ] Other }
\end{tabular}

\section{Tolerance}

$+/-0.003$ grams : 60 gram range

$+/-0.03$ grams : 600 gram range

Calibrated by: Christopher J. Pelchat

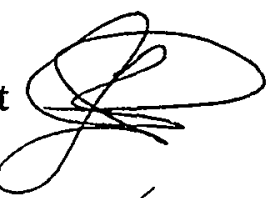

Reviewed by: Bernadette L. Salazar 8

Copy to: Adrian P. Lovell, CST-08, Mail Stop G740

ESH-09 File 
Standards \& Calibration Laboratory

Mail Stop D478, 667-4864

\section{Calibration Certificate}

$500 \mathrm{G}$ WEIGHT

File No. 4482

Manufacturer Troemner

Serial No. N/A

Other Id. N/A

Certified: June 12, 1997

Expires: June 12, 1999

This instrument was calibrated in a controlled environment using equipment traceable to national standards. Under normal operating conditions, this item is expected to remain within the stated uncertainty for the duration of calibration interval.

Values reported are those that would be observed in comparing the weights to standards of density $8.0 \mathrm{~g} / \mathrm{cc}$ in local air of density $.924 \mathrm{mg} / \mathrm{cc}$.

\begin{tabular}{ll}
\multicolumn{2}{c}{ Calibration Results } \\
Instrument Received & Instrument Returned \\
{$[\mathrm{X}]$ In Tolerance } & {$[\mathrm{X}]$ In Tolerance } \\
{[] Other } & {[] Other }
\end{tabular}

Nominal $500.0 \mathrm{~g}$
Apparent Mass

$500.00126 \mathrm{~g}$
Uncertainty

$+/-2.3 \mathrm{mg}$

Calibrated by: Christopher J. Pelchat

Copy to: Donna Hofmann, CST-08, Mail Stop G740

ESH-09 File 
Standards \& Calibration Laboratory

\section{Calibration Certificate}

1 KG WEIGHT

File No. 3648

Manufacturer Troemner

Serial No. N/A

Other Id. N/A

Certified: June 12, 1997

Expires: June 12, 1999

This instrument was calibrated in a controlled environment using equipment traceable to national standards. Under normal operating conditions, this item is expected to remain within the stated uncertainty for the duration of calibration interval.

Values reported are those that would be observed in comparing the weights to standards of density $8.0 \mathrm{~g} / \mathrm{cc}$ in local air of density $.924 \mathrm{mg} / \mathrm{cc}$.

Calibration Results

Instrument Received

$[\mathrm{X}]$ In Tolerance

Instrument Returned

[] Other

$[\mathrm{X}]$ In Tolerance

[] Other

\section{Nominal \\ $1000.0 \mathrm{~g}$}

Apparent Mass

$1000.00154 \mathrm{~g}$
Uncertainty

$+/-4.5 \mathrm{mg}$

Calibrated by: Christopher J. Pelchat

Reviewed by: Bernadette L. Salazar/8

Copy to: Donna Hofmann, CST-08, Mail Stop G740

ESH-09 File 


\section{Calibration Certificate}

BALANCE

File No. 016834

Arbor 1600

Property No. 452574

Location: TA-03 Bldg. CMR Rm. 5122

Certified: September 6, 1996

Expires: September 6,1997

This instrument was calibrated on-site using equipment traceable to national standards. Under normal operating conditions, this item is expected to remain within the stated uncertainty for the duration of calibration interval.

\begin{tabular}{|c|c|}
\hline \multicolumn{2}{|c|}{ Calibration Results } \\
\hline Instrument Received & Instrument Returned \\
\hline $\begin{array}{l}{[\mathrm{X}] \text { In Tolerance }} \\
{[] \text { Other }}\end{array}$ & $\begin{array}{l}{[\mathrm{X}] \text { In Tolerance }} \\
{[] \text { Other }}\end{array}$ \\
\hline
\end{tabular}

\section{Tolerance}

$+/-0.05$ grams

Calibrated by: Michael A. Salazar $h t$.

Reviewed by: Bernadette L. Salazar

Copy to: Adrian P. Lovell, CST-08, Mail Stop G740

ESH-09 File 


\section{Calibration Certificate}

Balance

Sartorius BP210D

File No.

015233

Serial: $N / A$

Prop. No: N/A

Other ID: TA-03 Bldg CMR Rm 5127A.

Certified: July 02, 1997

Expires: July 02,1998

Calibration of the above item(s) was achieved in a controlled environment through the use of equipment traceable to national standards. It is expected that for the duration of the calibration interval and under normal operational conditions, this item will remain within the tolerance limits specified.
Calibration
Item Received: [X] In Tolerance
Information:
Item Returned:
[X] In Tolerance
[ ] Other
[ ] Other

Tolerance: $+/-0.0005$ grams

Calibration data is available upon request.

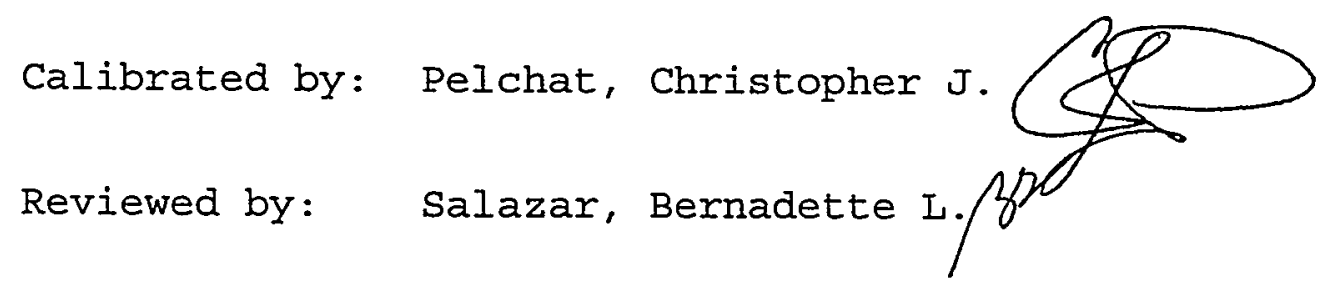

Copy to: DONNA HOFMANN, CST-08, MS G740

ESH-09 File 
$\boldsymbol{J}$ 


\title{
ZNational 通ureau of Stantarta
}

\section{Uertifirate}

\section{Standard Reference Material 4322}

\section{Alpha-Particle-Solution Standard}

\author{
Radionuclide Americium-24l \\ Source identification SRM 4322 \\ Source description Liquid in 5-mL flame-sealed \\ glass ampoule \\ Source mass Approximately 5.2 grams \\ Source composition Americium-241 in 1-molar \\ nitric acid \\ Reference time 1200 EST, 1 November 1986 \\ Radioartivity concentration \\ $38.66 \mathrm{~Bq} \mathrm{~g}^{-1}$ \\ Overall uncertainty \\ 0.81 percent (1): \\ Alpha-particle-emitting \\ None detected (2) \\ impurities (Activities at \\ reference time) \\ Measuring instrument \\ NBS $" 0.1 \pi " \alpha$ defined-solid- \\ angle counter with scintillation \\ detector \\ Half life \\ $432.2 \pm 0.5$ years

\footnotetext{
$r_{7}$ is Stantard Reference Material was prepared in the Center for Radiation Pesearch, Iorjzing Radiation Division, Radioactivity Group, Dale D. Hoppes, Grouf Leader.
}

Gaithersburg, 20899 Vorember, 1986
Stanley D. Rasberry, Chief

Office of Standard Reference Materials

$$
\text { *Notes on back }
$$




\section{NOTES}

(1) Individual uncertainties have the significance of one standard deviation of the mean, or an approximation thereof. The combined uncertainty is the individual uncertainties shown below added in quadrature. The overall uncertainty is taken to be three times the combined uncertainty. Source of uncertainty $\quad$ Uncertainty (\%)

a) alpha-particle-emission-rate measurements

b) gravimetric measurements

c) deadtime

d) background 0.03

e) detection efficiency

f) count-rate-vs-energy extrapolation to zero energy

g) half life 0.00

h) alpha-particle-emitting impurities

Combined uncertainty

Overall uncertainty

(2) The limit of detection for alpha-particle-emitting impurities is $0.004 \mathrm{as}^{-1} \mathrm{~g}^{-1}$ for energies greater than $5.60 \mathrm{MeV}$.

The material was also examined for photon-emitting impurities and none were found. The limit of detecticn for photon-emitting impurities is $0.002 \mathrm{Ys}^{-1} \mathrm{~g}^{-1}$ for energies between 90 and $1900 \mathrm{keV}$. 


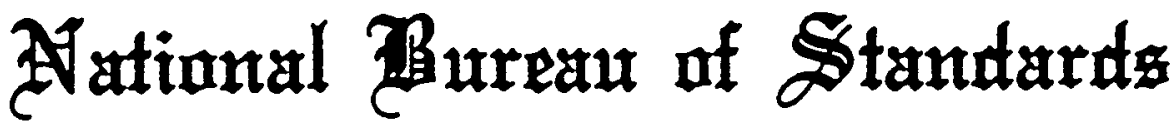

\section{Urertifitate of Ânalgæi:}

\section{Standard Reference Material 948}

\section{Plutonium Isotopic Standard}

This Standard Reference Material (SRM) is certified as an isotopic standard for use in isotopic measurements of plutonium. SRM 948 consists of approximately $250 \mathrm{mg}$ of plutonium in the form of plutonium sulfate tetrahydrate packaged in a glass microbottle.

\begin{tabular}{|c|c|c|c|c|c|}
\hline & ${ }^{238} \mathrm{Pu}$ & ${ }^{239} \mathrm{Pu}$ & ${ }^{240} \mathrm{Pu}$ & ${ }^{241} \mathrm{Pu}$ & ${ }^{242} \mathrm{Pu}$ \\
\hline Atom Percent* & $\begin{array}{r}0.010 \\
\pm 0.001\end{array}$ & $\begin{array}{r}91.736 \\
\pm 0.010\end{array}$ & $\begin{array}{c}7.922 \\
\pm 0.010\end{array}$ & $\begin{array}{r}0.299 \\
\pm 0.001\end{array}$ & $\begin{array}{r}0.0330 \\
\pm 0.0003\end{array}$ \\
\hline
\end{tabular}

* As of January 1. 1982, refer to Table I for quarterly decay-adjusted values.

The plutonium isotopic distribution was determined by thermal ionization mass spectrometry at the National Bureau of Standards (NBS) on samples from which americium and uranium were removed. Because high-purity plutonium isotopes have not been used to prepare known synthetic mixtures, the accuracy is dependent on uranium and plutonium exhibiting similar behavior. The observed mass spectrometer data were corrected for mass discrimination effects using data from the analysis of uranium isotopic SRM's that had been analyzed under similar conditions. In addition, the value for ${ }^{238} \mathrm{Pu}$ was checked by alpha-count of ${ }^{238} \mathrm{Pu}$, using the known value for ${ }^{239} \mathrm{Pu}$ as a ratio check.

SRM 948 contains uranium and americium isotopes, including growing-in daughters of plutonium that are isobaric with the plutonium isotopes. In addition, there may be radiation damage to the glass bottle and teflon cap liner tesulting in small glass slivers. Therefore, in its use, a chemical separation that provides a purified plutonium fraction : : isential to the attainment of high accuracy.

Measurements leading to the certification of this SRM were made in the Inorganic Analytical Research $\bar{\nu}:$ ision by E.L. Garner, L.A. Machlan, and W.R. Shields.

The technical and support aspects involved in the revision of this Certificate were coordinated throug: $: \therefore$. Oifice of Standard Reference Materials by T.E. Gills.

August 19, 1982

Washington, D.C. 20234

(Revision of Certificate

dated $12-3-71$ )
George A. Lrianc. 1. :::

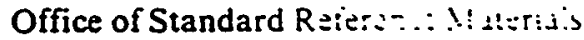

(over) 
The decay-adjusted values for the plutonium isotopic composition, in atom percent, are tabulated below in Table 1 . The half-life values, in years, used for the decay-adjustment are: ${ }^{238} \mathrm{Pu}, 87.74 ;{ }^{239} \mathrm{Pu}, 24,119 ;{ }^{240} \mathrm{Pu}, 6,560 ;{ }^{241} \mathrm{Pu}, 14.34$; and $=4$ Pu, 387,000 .

Table 1

Decay-Adjusted Plutonium Isotopic Composition

Date

January 1. 1982

April 1. 1982

July 1, 1982

October 1, 1982

January I. 1983

April I. 1983

July 1. 1983

October 1, 1983

January 1. 1984

April 1, 1984

July I, 1984

October 1. 1984

January 1. 1985

April 1. 1985

July 1. 1985

October I. 1985

January I. 1986

April 1. 1986

July 1. 1 प

October 1. 1986

959i Conlidence Limit: $\frac{{ }^{238} \mathrm{Pu}}{0.010}$

.010

.010

.010

.010

.010

.010

.010

.010

.010

.010

.010

.010

.010

.010

.010

.010

.010

.010

.010

$\pm 0.001$
Atom Percent

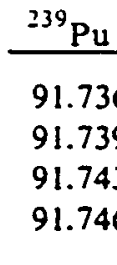

91.749

91.753

91.756

91.759

91.762

91.765

91.769

91.772

91.775

91.778

91.781

91.784
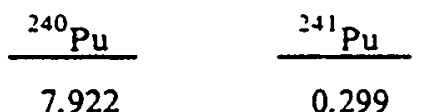

$\frac{{ }^{242} \mathrm{Pu}}{0.0330}$

7.922

7.923

7.923

.295

.292

.288

.0330

.0330

.0330

.285

.0330

7.923

7.923

7.923

7.923

.281

.278

.0330

.0330

.0330

.274

.0330

.0330

.0330

.0330

.262

.0330

.0330

.0330

.0330

91.787

91.789

91.792

91.795

$\pm 0.010$

.086334

7.924

7.924

.255

.252

.249

.0330

.0330

.0330

7.924

.243

.238

.0330

$\pm 0.001$

$\pm 0.0003$ 
U. S. Departmont of Commerce

Maurices. Stans

Secrotapy

National Standards

A. V. Aatip Director

\section{$\mathbb{U}_{\mathfrak{E r t i f i} \mathfrak{i} \mathfrak{a t e}}$}

\section{Standard Reference Material U-005 Uranium Isotopic Standard}

$\begin{array}{lcccr} & { }^{234} \mathrm{U} & 235 \mathrm{U} & 236 \mathrm{U} & { }^{238} \mathrm{U} \\ \text { Atom percent } & 0.00218 & 0.4895 & 0.00466 & 99.504 \\ & \pm .00004 & \pm .0005 & \pm .00005 & \pm .001 \\ \text { Weight percent } & 0.00214 & 0.4833 & 0.00462 & 99.510\end{array}$

The material consists of highly purified oxide, $\mathrm{U}_{3} \mathrm{O}_{8}$. The atomic weight of the material is calculated to be 238.036 using the nuclidic masses $234.0409 ; 235.0439 ; 236.0457$ and 238.0508 .

The values for ${ }^{234} \mathrm{U}$ and ${ }^{236} \mathrm{U}$ were calculated from measurements at the National Bureau of Standards. The samples were spiked with high-purity ${ }^{233} \mathrm{U}$ to approximate the ${ }^{234} \mathrm{U}$ concentration, the ratios ${ }^{233} \mathrm{U}$ to ${ }^{234} \mathrm{U}$ and ${ }^{233} \mathrm{U}$ to $236 \mathrm{U}$ were measured on a triple-filament equipped surface ionization mass spectrometer with ion-multiplier amplifier circuits.

The values for ${ }^{235} \mathrm{U}$ and ${ }^{238} \mathrm{U}$ were calculated frof musements of the ${ }^{235} \mathrm{U}$ to ${ }^{238} \mathrm{U}$ ratio made at the National Bureau of Standard on a rriole-filament, surface ionization mass spectrometer equipped with dc amplifier cucults. The observed ratios were corrected for mass discrimination effects by intefeoparison synthetic mixtures prepared at the 0.5 percent $235 \mathrm{U}$ level from high-purfy $3{ }^{3} \mathrm{~J}_{2} \mathrm{~d}^{2<38} \mathrm{U}$.

The limits indicated topic concentrations are at least as large as the 95-percent confidence limits for singl determination, and include terms for inhomogeneities in the material as welt analied error. The ${ }^{235} \mathrm{U}$ to ${ }^{238} \mathrm{U}$ ratio for this standard. 0.004919 , is known to at past porcent.

:Mass spectrometry measurements at NBS were made by E. L. Garner on solutions prepared by L. A. Machlan.

The overall direction and coordination of the technical measurements leading to certification were performed under the chairmanship of W. R. Shields.

The technical and support aspects in the preparation, certification. and issuance of this Standard Reference Material were coordinated through the Office of Standard Reference. Waterials by J. L. Hague.

Washington, D. C. 20234

W. Wayne Meinke, Chief

April 21.1969

Office of Standard Reference Materials 


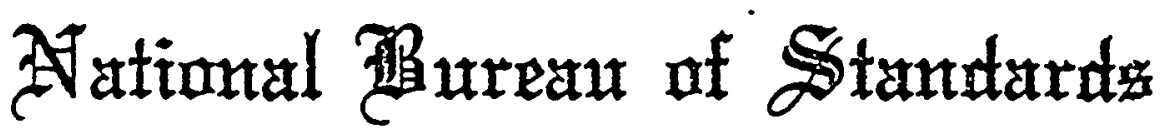

\section{Ũertifitate af Analysiz:}

\section{Standard Reference Material 949f}

\author{
Plutonium Metal
}

(In cooperation with the University of California Los Alamos

National Laboratory, Los Alamos, New Mexico)

This Standard Reference Material is certified for plutonium content and is primarily intended for use in the chemical assay of plutonium. SRM $949 \mathrm{f}$ consists of approximately 0.5 gram of plutonium metal that has been sealed in a glass tube under a reduced-pressure argon atmosphere. Each unit is identified by tube number and sample mass.

Plutonium assay, percent

99.99 (A's of October, 1980.

$[99.90-100]^{2}$ S.ee Table 2.)

Tube No.

Mass

${ }^{2}$ The uncertainty of the certified value is expressed at the $99 \%$ one-sided confidence interval

The plutonium assays were performed by the Los Alamos National Laboratory with collaborative analysis performed at the Department of Energy, New Brunswick Laboratory. The Los Alamos National Laboratory used two titrimetry methods utilizing both photometric and potentiometric end points $[1,2,3,4]$. The New Brunswick Laboratory used a controlled-potential coulometric method [5,6]. The certified value is based on the results from these two laboratories using three different methods. However, the confidence interval on the certified value is a one-sided $99 \%$ confidence interval on the mean of the potassium dichromate titrimetric method, which is $99.98-100$, expanded by the bound on the systematic error \pm 0.08 . The $99 \%$ confidence interval is based upon the potassium dichromate method because adequate systematic error bounds are available. The mean value for the potassium dichromate titrimetric method is 99.939 with a standard error on the mean of \pm 0.006 based on 16 determinations.

The americium resulting from the decay of 14.35 years plutonium-24l was approximately $21 \mu \mathrm{g} / \mathrm{g}$ as of October 1980 . The total of all detected impurities is approximately $1.15 \pm 65 \mu \mathrm{g} / \mathrm{g}$.

94. 98.85

The technical and support aspects leading to certification and issuance of this Standard Reference Material was coordinated through the Office of Standard Reference Materials by T. E. Gills.

The statistical assessment of the data for the certification of this SRM was performed by W. Liggett of the Statistical Engineering Division of the National Bureau of Standards. 
Supplemental Information

!sc:0:-2:Ana:

Pì:0.i:-a isotop:e distibuton was determined by thermal ionization mass spectrometry at the Los Alamos . National

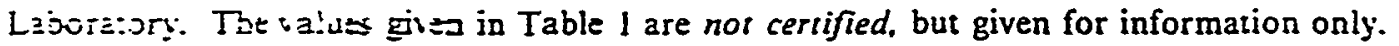

\section{Table 1}

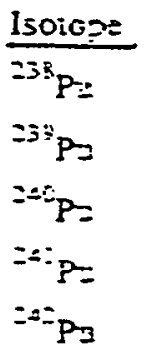

\begin{tabular}{c} 
Isotope Mass \\
\hline 238.04942 \\
239.05208 \\
240.05382 \\
241.05669 \\
24205864
\end{tabular}

Average Atom \% on October 8.1980

0.0040

97.121

2.804

0.065

0.006

Calculated Atomic Wt. 239.082

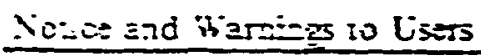

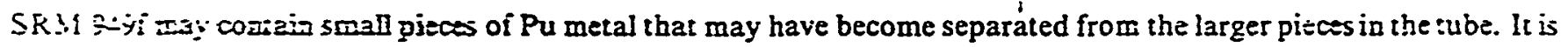

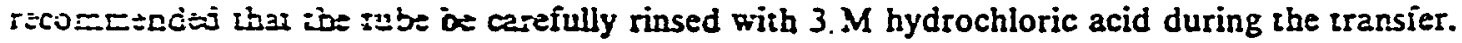

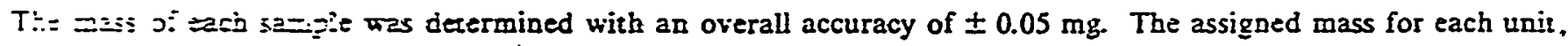

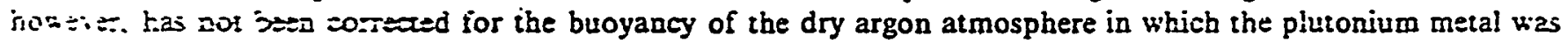

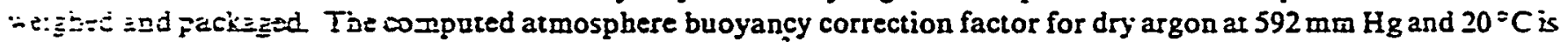

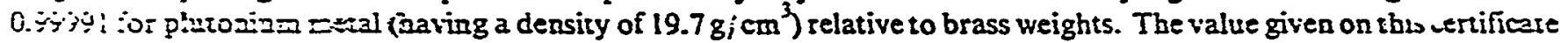
io: :ise cass of tise plunonius may be muitiplied by this factor to obtain the "true" in vacuo mass.

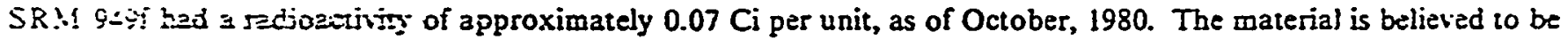

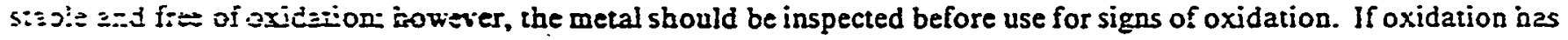

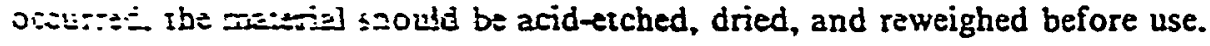

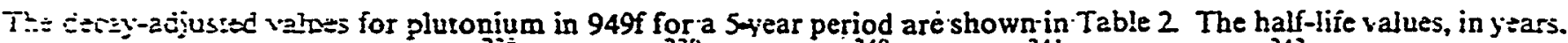

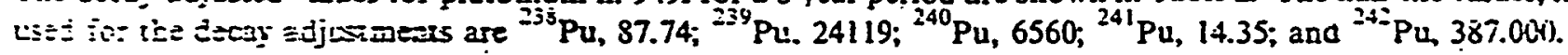

Table 2

Plutonium Assay, Percent

$\frac{1981}{99.99} \quad \frac{1981}{99.98} \cdot \frac{1982}{99.98} \quad \frac{1983}{99.97} \quad \frac{1984}{99.97}$

Resiverses

i. C. E. Calciell L. S Gill F. J. Miner, and X. E. Moody. Anal. Chem. 34 346. 1962.

2 G P.. Wiaterdizy ż a C. S. Metz, Los Alamos Scientific l.ab Report, LA 3141, 1965.

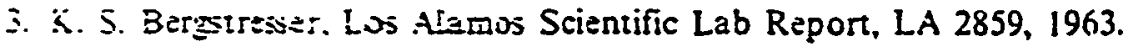

4. C. E. Pizt:- aza j. A. Baslio, Talanta, 6. 159-166, 1960.

5. ‥ K. Fivilanc. J. R. Heiss, and C. E. Pietri. Anal Chem. 50. 236-240 (1978).

6. D. D. Jacison. R. M. Ho:en. F. R. Reensch, and J. E. Rein, Anal. Chim, Acta U17 205-15(1980). 


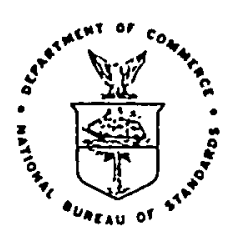

\section{National Rureau of $\$$}

\section{(Tertiffirate}

\section{Standard Reference Material 4906H-C Radioactivity Standard}

\begin{tabular}{|c|c|}
\hline Radionuclide & Plutonium-238 (1)* \\
\hline Source identification & $4906 \mathrm{H}-\mathrm{C}-9$ \\
\hline Activity & $1.674 \times 10^{3}$ \\
\hline Reference time & 1200 EST October 1, 1987 \\
\hline Overall uncertainty & 1.3 percent (2) \\
\hline $\begin{array}{r}\text { Radionuclide impurities } \\
\text { (Activity ratio at } \\
\text { reference time) }\end{array}$ & $\begin{array}{l}{ }^{241} \mathrm{Am} /{ }^{238} \mathrm{Pu}: \quad 6.5 \times 10^{-5}(3) \\
{ }^{240} \mathrm{Pu} /{ }^{238} \mathrm{Pu}: \quad<4.0 \times 10^{-5} \\
{ }^{239} \mathrm{Pu} /{ }^{238} \mathrm{Pu}:<2.4 \times 10^{-5}\end{array}$ \\
\hline Half life & $87.74 \pm 0.04$ years $(4)$ \\
\hline Measuring instrument & $" 0.8 \pi^{\prime \prime} \alpha$ counter \\
\hline
\end{tabular}

This Standard Reference Material was prepared in the Center for Radiation Research, Ionizing Radiation Division, Radioactivity Group, Dale D. Hoppes, Group Leader.

Gaithersburg, MD 20899

November, 1987
Stanley D. Rasberry, Chief Office of Standard Reference Materials 


\section{NOTES}

(1) A practically weightless source electroplated onto a 0.025 -cm-thick platinum foil $0.6 \mathrm{~cm}$ in diameter which is cemented to a stainless-steel disk $2.54 \mathrm{~cm}$ in diameter and $0.16-\mathrm{cm}$ thick.

(2) The overall uncertainty was formed by taking three times the quadratic combination of the standard deviations of the mean, or approximations thereof, for the following:
a) one standard deviation of the mean
0.10 percent
b) efficiency calibration
0.15 percent
c) count-rate vs. energy
extrapolation to zero energy 0.40 percent
d) system live time
0.05 percent

(3) An impurity search was performed at NBS using a Ge detector.

(4) NCRP Report No. 58, Second Edition, February 1985, p. 505.

(5) Defined-solid-angle counter with scintillation detector.

For further information contact J.M.R. Hutchinson at (301) 975-5543 or S.J. Bright at (301) 975-5542.

$4906 \mathrm{H}-\mathrm{C}$ 


\section{Product Description \& Measurement Certificate}

\begin{tabular}{|c|c|c|}
\hline \multirow[t]{2}{*}{ Description } & Principal radionuclide: & americium 241 (Am-24l) Product code: AMP10040 \\
\hline & Daughter Nuclide: & Batch Number: $95 / 241 / 49$ \\
\hline \multirow[t]{6}{*}{ Measurement } & Reference date: & 06 January 1987 \\
\hline & $\begin{array}{l}\text { Radioactive concentration Am-24l } \\
\text { which is equivalent to }\end{array}$ & $\begin{array}{l}4.711 \mathrm{E}+05 \text { becquerels per gram of solution } \\
1.273 \mathrm{E}+01 \text { microcuries per gram of solution }\end{array}$ \\
\hline & Mass of solution & 5.36 grams \\
\hline & Volume of solution & 5.01 millilitres \\
\hline & \multirow{2}{*}{$\begin{array}{l}\text { Total activity of Am-241 } \\
\text { which is equivalent to }\end{array}$} & $2.53 E+06$ becquerels \\
\hline & & $6.82 \mathrm{E}+01$ microcuries \\
\hline
\end{tabular}

Method of measurement (see reverse of this certificate)

Random uncertainty is: $\pm 0.1 \% \quad$ Systematic uncertainty: $\pm 0.4 \%$

Overall uncertainty in the radioactive concentration quoted above: $\pm 0.8 \%$

Overall uncertainty is defined on the reverse of this certificate.

Radionuclidic Any radioactive impurities measured are listed below, expressed as percentages

Purity

of the activity of the principle radionuclide at the reference date .

Am-241 100\%

Isolopic The elemental composition, expressed as atom per cent at the reference date .

Purity

Not Measured

Chemical Calculated weight of Am-241, 1.99E-05 grams, as $2 \mathrm{M} \mathrm{HNO3} \mathrm{solution} \mathrm{in} \mathrm{a} \mathrm{flame} \mathrm{sealed} \mathrm{glass} \mathrm{vial.}$

Composition This Tracer solutions has been produced 'carrier free'.

Physical Recommended half life of americium 241: 4.327E+02 years

Dala Principle energies of alpha emissions (MeV): $5.44312 .8 \%, 5.48685 .2 \%$

Branching ratio for alpha emission: $100.0 \%$

Calculated specific activity of americium 241: 1.268E+05 Bq per microgram Am-241.

Remarks For safety information and notes to ensure correct usage by all persons handling this radioactive Tracer solution please read the instructions accompanying the package.

AEA Technology operates a quality management system which has been independently audited and approved to ISO 9001 .

Intercomparison of measured alpha activity concentration with NPL established agreement to within $0.2 \%$. Reference, AERE R 13291 October 1988

Approved

Signatory

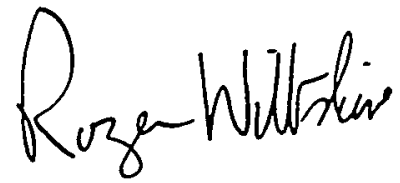

Project Ref. AE3066

Roger Wiltshire

Prepared and characterised at AEA Technology UK, world wide distribution by Isotrak, QSA Amersham International. 
The activity concentration of this batch of Tracer solutions has been measured by alpha counting accurately known weight aliquots prepared as thin sources, using a pair of absolute low geometry alpha counters. The counting efficiency of the alpha counters [ca 1:700] have been determined by accurate measurement of both the source to collimator distance and collimator aperture area. Background and dead time corrections have been applied when necessary.

The alpha particle energy spectrum data has been collected using a high resolution solid state detector operating under vacuum. The reported contribution of source activity of each nuclide has been assessed by integrating the channel contents over the expected energy range for each nuclide. Corrections for coincident alpha particle energies and low energy tailing have been applied when necessary.

Measured radionuclidic and isotopic data may be decay corrected to the reference date shown.

\section{S.I. Units of radioactivity}

The S.I. unit of radioactivity is the becquerel

$\begin{array}{lll}1 \text { becquerel }[\mathrm{Bq}]= & =1 \text { nuclear transformation per second, therefore } \\ & = & 3.7 \mathrm{E}+7 \text { becquerels exactly }\end{array}$

1 curie $[\mathrm{Ci}] \quad=\quad 3.7 \mathrm{E}+7$ becquerels exactly

Useful conversion factors are:

1 microcurie $[\mu \mathrm{Ci}]=3.7 \mathrm{E}+4 \mathrm{~Bq}=37$ kilobecquerels $[\mathrm{kBq}]$

1 millicurie $[\mathrm{mCi}]=3.7 \mathrm{E}+7 \mathrm{~Bq}=37$ megabecquerels $[\mathrm{MBq}]$

1 kilobecquerel $[\mathrm{kBq}]=27.027$ nanocuries $[\mathrm{nCi}]$

I megabecquerel $[\mathrm{MBq}]=27.027$ microcuries $[\mu \mathrm{Ci}]$

Overall uncertainty

The reported uncertainties have been estimated in accordance with the recommendations of the NAMAS document. NIS 3003, 'The Expression of Uncertainty and Confidence in Measurement for Calibrations' Edition 8 May 1995. The overall uncertainty has been calculated by combining the systematic and random uncertainties, in quadrature, and multiplying the resulting sum by the coverage factor $k=2$, providing a level of confidence of approximately $95 \%$.

References

In presenting and calculating the data a number of sources of data have used. Where possible and appropriate, data has been abstracted from the IAEA Technical Report Series, No 261, 1986 'Decay Data of the Transactinium Nuclides'.

Additional half life and decay data has been abstracted from The 8th Edition of Table of Radio Isotopes, 1986, ISBN No. 0 471-84909-X, and 'Catalogue of Alpha Particles from Radioactive Decay', W. Westmeier, A. Merklin, ISSN 0344-8402, 1985.

Atomic mass data has been taken from the 68th Edition of the Handbook of Chemistry and Physics.

One year

Avagadro's No $=\quad 365.2422$ days

$=\quad 6.02252 \mathrm{E}+23$ 


\section{Amersham}

Traceability is the ability to relate the accuracy of measurement of radionuclides to the National Institute of Standards and Technology (NIST). Traceability is achieved by participation in a Measurements Assurance Program linked to NIST and production of certified materials in accordance with a quality assurance program.

Amersham participates in measurement assurance programs conducted by NIST in cooperation with the Nuclear Energy Institute (NEI, formerly USCEA). Additionally, our production facilities and measurement laboratories operate under routinely audited quality assurance programs.

Therefore, Amersham certified standardized products meet or exceed, the NRC requirements for measurements traceable to NIST. 
Product code: QCY. 44

Solution number: $\quad R 4 / 305 / 8$

This mixed radionuclide gamma-ray reference standard consists of a solution in $4 \mathrm{M} \mathrm{HCl}$ of the nine radionuclides listed below.

Measurement

Reference time:

1200 GMT on

1 November 1994

$\because \ldots \ldots n^{\prime}$

and Accuracy

Mass of solution: 5.2477 grams Density: $1.064 \mathrm{~g} / \mathrm{ml}$ at $20^{\circ} \mathrm{C}$

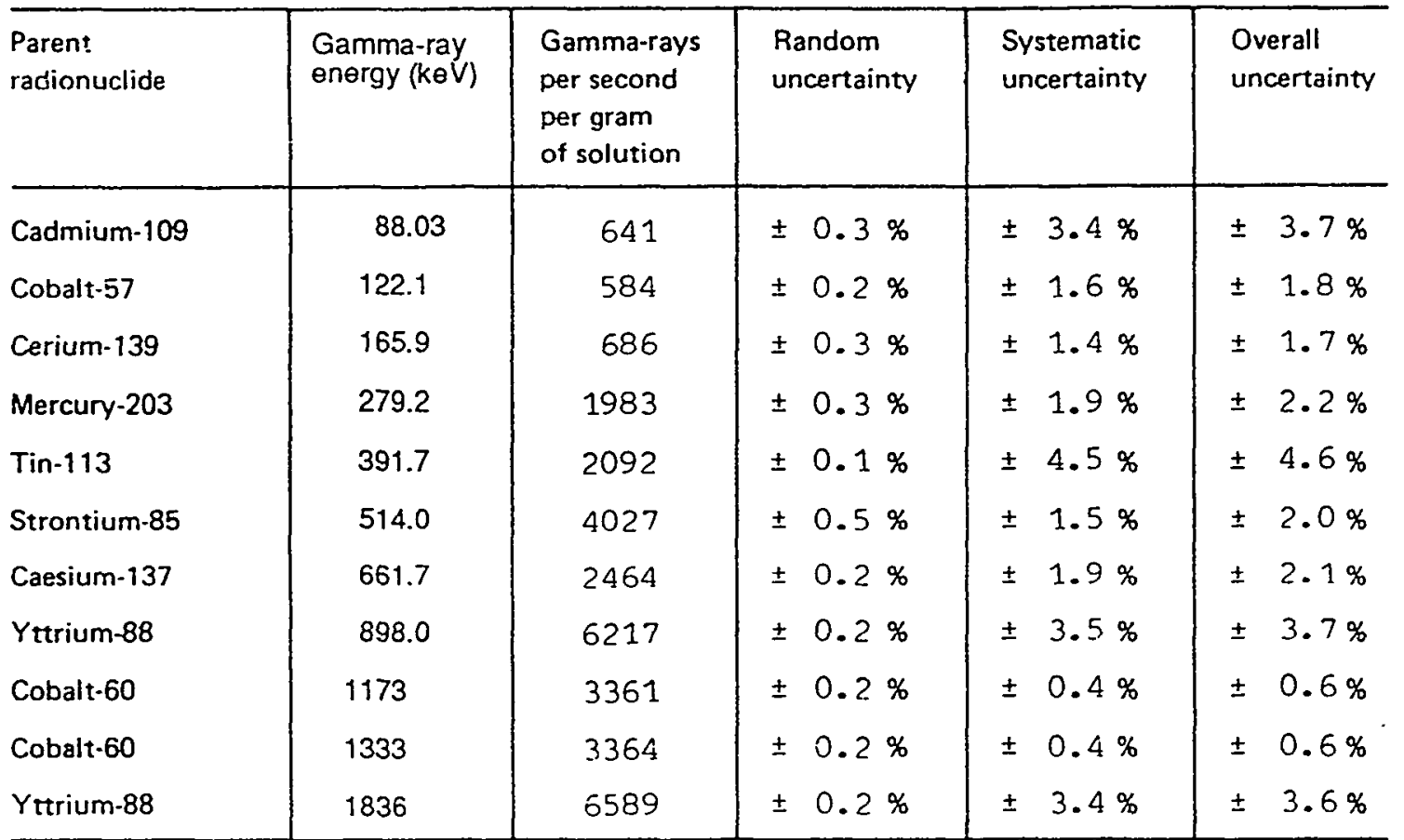

Purity

At the reference time the solution also contained the following impurities:

Iron-55 equal to 8.5 becquerels ( 0.23 nanocuries) per aram.

Hemarks Further details, including composition of the solution, methods of measurement, decay scheme assumptions, decay tables and definitions of uncertainties, are given in the data sheet accompanying this certificate.

This product meets the quality assurance requirements of NRC Regulatory Guide 4.15 for achieving explicit NIST traceability as defined in NCRP58 (1985).

Approved

Signatory

W. 1 Cas

W F Case

Page 1 of 1

Amersham

This certificate is issued in accordance with the conditions of accreditation granted by the National Measurement Accreditation Service. which has assessed the measurement capability of the laboratory and its traceability to recognised national standards and to the units of measurement realised at the corresponding national standards laboratory. Copyright of this certificate is owned jointly by the British Crown and the issuing laboratory and may not be reproduced other than in full except with the prior written approval of the Head of NAMAS and the issuing laboratory. 
Traceability is the ability to relate the accuracy of measurement of radionuclides to the National Institute of Standards and Technology (NIST). Traceability is achieved by participation in a Measurements Assurance Program linked to NIST and production of certified materials in accordance with a quality assurance program.

Amersham participates in measurement assurance programs conducted by NIST in cooperation with the Nuclear Energy Institute (NEI, formerly USCEA). Additionally, our production facilities and measurement laboratories operate under routinely audited quality assurance programs.

Therefore, Amersham certified standardized products meet or exceed, the NRC requirements for measurements traceable to NIST. 


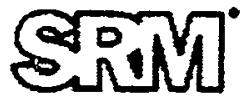

\section{Listing of SRM Certificates}

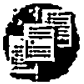

Page 1:

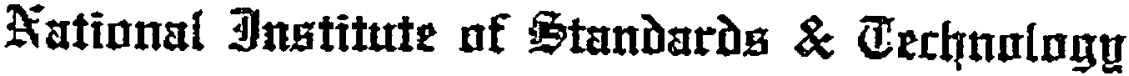

\section{UTertifitrate of Ânalugits}

\section{Standard Reference Material 89}

\section{Lead-Barium Glass}

This Standard Reference Material (SRM) is in the form of a poorder and is intended for use in evaluating chemical and instramental methods of analyses. The SRM slowly absorbs carbon dioxide and water. Therefore, the analyst must determine the loss on ignition at 900 to $1000^{\circ} \mathrm{C}$ and correct all determinations for the differenee between the value found and the original value of 0.32 weight percent. The recommended values are given below.

[All results are based on a sanple dited for one hour at 105 to $110^{\circ} \mathrm{C}$ ]

\begin{tabular}{|c|c|c|c|c|c|c|c|c|c|c|c|c|c|c|c|c|c|c|}
\hline Analysio & $\mathrm{SHO}_{2}$ & $\mathrm{PbO}$ & $x=0$ & 620 & BeO & $\mathrm{TrO}_{2}$ & $\mathrm{ZrO}_{2}$ & $\mathrm{~F} \in 2 \mathrm{O}_{3}$ & $A 4203$ & $\cos$ & $\mathrm{M}=0$ & $P: O_{5}$ & $\mathrm{Mmo}$ & $A s 203$ & $A \cup \geq O_{3}$ & $\mathrm{SO}_{3}$ & Cl & $\begin{array}{l}\text { lose } \\
\text { on } \\
\text { Ippl- } \\
\text { lion }\end{array}$ \\
\hline 1 & 36 & 250 & 38 & 5.73 & 1 & 0.011 & 0.003 & 0.048 & .181 & 0.21 & 0.029 & 0.22 & 0.089 & 39 & 0.03 & 0.031 & 0.051 & 0.30 \\
\hline 2 & 65.37 & 17.51 & 8.41 & 5.68 & 13 & 020 &.$\infty$ & .052 & .178 & 200 & .032 & 243 & .068 & .348 & .032 & .031 & .054 & $3 ?$ \\
\hline $\mathbf{3}$ & 65.28 & 1736 & 8.20 & S.SA & 149 & .011 & $\cdots$ & .044 & .130 & .21 & 0.4 & .22 & $\cdots$ & $\ldots$ & ... & $\ldots$ & $\cdots$ & 26 \\
\hline 4 & 65.42 & 17.38 & 8.30 & 5.74 & LAS & .006 & $\cdots$ & 047 & .149 & .203 & .003 & .216 & .087 & 332 & ... & .041 & .05 & 20 \\
\hline 3 & 65.38 & 17.38 & 8.19 & '5.99 & IAZ & $D 2$ & ... & .050 & .12 & .14 & 1.06 & .29 & .000 & 36 & .07 & $\ldots$ & $\ldots$ & 36 \\
\hline 6 & 65.28 & 12.41 & 8.40 & 5.62 & 1.41 & $\ldots$ & $\ldots$ & .152 & .148 & .23 & .032 & .20 & $\ldots$ & ... & $\ldots$ & $\ldots$ & $\ldots$ & 30 \\
\hline 7 & 65.26 & 1751 & 8.38 & 5.22 & 139 & $\cdots$ & $\ldots$ & ses & .18 & .1B & .09 & .24 & .081 & .383 & & $\ldots$ & $\cdots$ & 40 \\
\hline Avernges & 65.33 & 17.44 & 832 & son & 102 & 014 & .005 & .049 & .155 & .197 & .023 & 233 & .081 & 362 & .054 & .034 & .052 & 32 \\
\hline 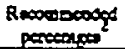 & 65.35 & 1750 & BAO & 5.70 & 1.40 & 0.01 & 0.005 & 0.049 & 0.18 & 0.21 & 0.03 & 0.23 & 0.088 & 0.36 & 0.03 & 0.03 & 0.05 & 0.32 \\
\hline
\end{tabular}

${ }^{2}$ Omirted from rerege.

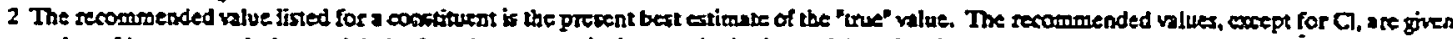
as the aride on an equivaleat weight basis and afume secichiometry in the form of the ouide jisted.

- List of Analysts

- H.B. Knowles, Burcau of Standards.

- M.O. Lamar, Nartan Co., Worcester, MA.

- P.E. Corbir, Cording Glass Works, Corning, N.Y.

- R.H. Lardin, Pittsburgb Plate Glass Co., Creighton, PA

Gaithersburg MD 20899

December 20, 1990

(Edirorial Revision of certificate dated \&-27-32)
- D.W. Moore, 3d, Libbey-Owens-Ford Glass Co., Charleston. W.V.

- R.W. Goodwin, Glass Technology Labotalory; Incandescent Lamp Departmeat of General Electric Co., Cleveland, Obio.

- The Sharp-Schurtz Co., Lancaster, Obio

Willam P. Reed, Acting Chief Standard Reference Materials Program 
Page 1:

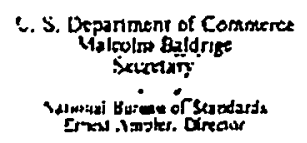

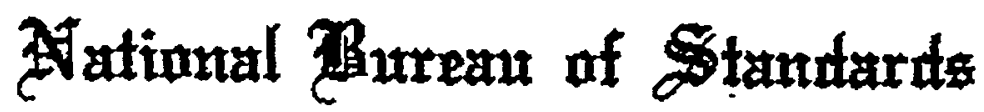

\section{Oertifitate}

\section{Standard Reference Material 91}

Opal Glass Powder

This Standard Reference Material is inteaded for use in checking chemital methods of anajysix and for calibratugg opticel emission and $x$-ray spectrometric methods of analyais.

\begin{tabular}{|c|c|}
\hline Conutituent & Percent by Weight \\
\hline $\mathrm{SiO}_{2}$ & 67.5 \\
\hline $\mathrm{CaO}$ & 10.49 \\
\hline $\mathrm{N}_{22} \mathrm{O}$ & 8.47 \\
\hline $\mathrm{Al}_{2} \mathrm{O}_{3}$ & 6.01 \\
\hline $\mathbf{F}$ & 5.73 \\
\hline $\mathrm{K}_{2} \mathrm{O}$ & 3.24 \\
\hline $\mathrm{A}_{32} \mathrm{O}_{5}$ & 0.10 \\
\hline $\mathrm{As}_{2} \mathrm{O}_{3}$ & 0.09 \\
\hline Pbo & 0.10 \\
\hline Zno & 0.08 \\
\hline $\mathrm{Fe}_{2} \mathrm{O}_{3}$ & 0.079 \\
\hline $\mathrm{P}_{2} \mathrm{O}_{5}$ & 0.023 \\
\hline $\mathrm{TiO}_{2}$ & 0.019 \\
\hline $\mathrm{Cl}$ & 0.015 \\
\hline $\mathrm{ZrO}_{2}$ & 0.009 \\
\hline
\end{tabular}

Values are based on drying the sample for one hour at $10510110^{\circ} \mathrm{C}$. The determinations of silica and fluorine followed the fusion of a 0.5-8 ample with sodium or potassium carbonate according to Hoffoan and Lundell. B.S. Jour. Research I 581 (1930). The other constiruents were determined by methods deseribed by Lundell and Hoffman. B.S. Jour. Research $\perp$, 91 (1928) and by Lundell and Knowlex, J. Am. Ceram. Soc 10.829 (1927).

Wushington, D.C. 20234

George A. Uriano, Chief

Ocsober 28. 1982

(oves) 
Page 2:

Present day procedures should follow the ASTM Standard Methods for Chemical Analysis of Soda-Line and Borosilicate Glass, C169.

$\mathrm{MnO}$ and $\mathrm{MgO}$ were baih reported to be about 0.008 . No value is given for loss on ignition because reliable tesulis could not be obtained.

Laboratories that contributed to the certification of this glass were located at:

National Bureau of Standards. Washington, D.C.

Newburgh Steel Works, Cleveiand, Ohio

Booth, Garrett, Blair, Philxdelphia, Pa.

Libby-Owens Sheet Glass Co., Charleton, W. Va.

Corning Glass Works, Corning. N.Y. 


\section{\&iㄴ}

\section{Listing of SRM Certificates}

Page 1:

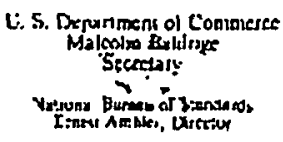

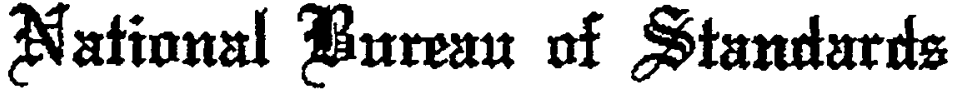

\section{(U)ertificate}

\section{Standard Reference Material 92 \\ Soda-Lime Glass Powder \\ (Low Boron)}

Thin Standard Reference Material (SRM) is intended for use in cbecking ehemical methods of determining the content of $\mathrm{B}_{2} \mathrm{O}_{\text {: in }}$ glass.

$$
\mathrm{B}_{2} \mathrm{O}_{3} \quad 0.70 \pm 0.03 \text { percent by weight }
$$

The ctertified value is the best estimate of the "true" value based on the results of a cooperaive analytical program. The ceritiled value is not expected to deviate from the "true" value by more than the stated uncertainty. A remeasurement made in 1939 confirmed that the certified value had sot changed due to aging of the powder.

This SRM should be dried for une hour at $105^{\circ} \mathrm{C}$ before making an analysis. The determination of $\mathrm{B}_{2} \mathrm{O}_{3}$ was made by the Chapis distillation method including the recovery from the residue and corsection by careful blank detcrminations.

The uverall direction and coordination of the cooperative analytical program were performed by H. B. Knowles of the Analytical Chemistry Division of the National Bureau of Standards. The laboratories that contributed to the certilucation of this glass were located at:

Pational Bureau of Standurds. Washington. D.C.

Nonou Compiny, Worchester, Mass.

Bvoth, Garrett, \& Blair, Philadelphia, Pcan.

Sharp-Schurtz Company, Lancaster, Ohio

For information unly, this soda-lime glass bas, un addition to the certified $\mathrm{B}_{2} \mathrm{O}_{3}$. the follosing approximate composition:

$\begin{array}{ll}\mathrm{SiO}_{2} & (75.0) \text { percent by weight } \\ \mathrm{Na} 2 \mathrm{O} & (13.1) \\ \mathrm{CaO}^{2} & (8.3) \\ \mathrm{R}_{2} \mathrm{O}_{2} & (1.5) \\ \mathrm{K}_{3} \mathrm{O} & (0.0) \\ \mathrm{ZnO} & (0.2) \\ \mathrm{MgO} & (0.1) \\ \text { Euss on Ignition } & (0.42)\end{array}$

Wishingion. D.C. 20234

Mlarch II. 1982

(Rtvision ot Certijicales

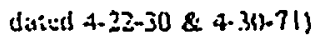

Gcorge A. Uriano. Chiel

Offic: or Standard Kef́rence Malcrials 
Page 1:

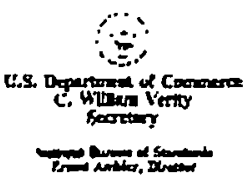

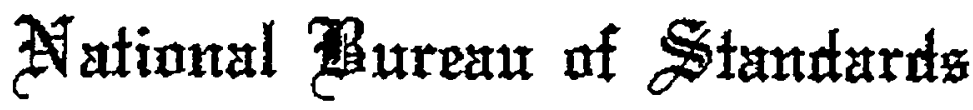

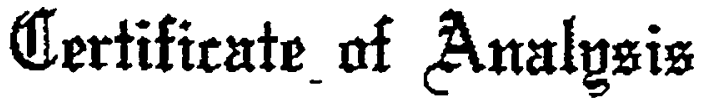

\section{Standard Reference Material 98b \\ Plastic Clay}

This Standard Reference Material (SRM) is intended for use in the determination of constituent elements in clay or material of similar matrix. SRM 98b is powdered clay that was air-dried, ball-milled, and blended to casure homogeneity.

The certified constituent elements of SRM 98b are given below in Table 1. The certified values are based on measurements made using two or more independent reliable methods or techniques. Non-certified values for constituent elements are given in Table 2 as additional information on the composition. The non-certified values should not be used for calibration or quality control. All values are based on samples that wero dried for 2 hours in a conventional oven $21140^{\circ} \mathrm{C}$ and a minimum sample size of $250 \mathrm{mg}$.

Table 1

\section{Centified Yalnes for Constituent Elements}

Element

Aluminum 5,48

Calcium bofs

Chromium ${ }^{\text {cis }}$

Irom $\cos ^{\circ}$

Litbium as

Magnerium $^{\text {b.c }}$

Content. Wh. $50^{2}$
$14.30 \pm 0.20$
$0.0759 \pm 0.0035$
$0.0119 \pm 0.0005$
$1.18 \pm 0.01$
$0.0215 \pm 0.0013$
$0.358 \pm 0.012$

Element

Manganese 2.8

Potresium bx, figi

Silicon o,i

Sodium $1, \mathrm{~d}, \mathrm{x}$

Strontium difs

Titaniumbsos
Content. Wito

$0.0116 \pm 0.0005$

$281 \pm 0.07$

$26.65 \pm 0.16$

$0.1496 \pm 0.0065$

$0.0189 \pm 0.0008$

$0.809 \pm 0.012$

\section{Mathodertectinioues:}

- Colartmetry (o-pbeannthroline)

- DC Flunmin Spectrometory

c Flame Atomis Abropption Spectrooxeloy

d Finme Emierion Spectoractry

- Grevimetry

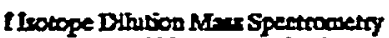

Instrunetrulal Neutron Activation Anulyxis

is Spectrophocometry

ix-rey Fiuorescence

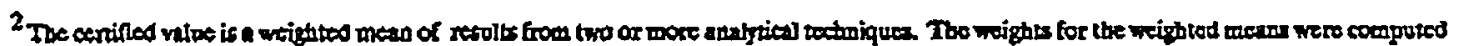

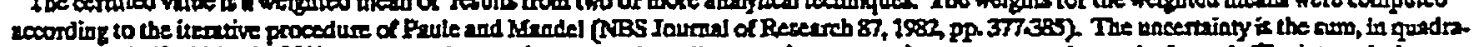

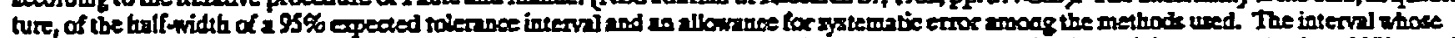

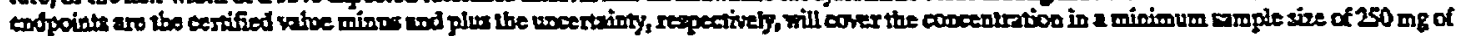
this SRM for at leal $95 \%$ of the amplex with $95 \%$ confidence. 
Page 2:

Table 2

Nop-certified Values for Constituent Elements

$\begin{array}{lclc}\text { Element } & \text { Content.Wuto } & \text { Element } & \text { Content.Wros } \\ \text { Barium } & (0.07) & \text { Rubidium } & (0.018) \\ \text { Phosphorus } & (0.03) & \text { Zinc } & (0.011) \\ & & \text { Zirconium } & (0.022)\end{array}$

Element

Contentrugets

Element

Contentureig

Antimony

(1.6)

Cexíum

(16.5)

Hafrium

Cobalt

(16.3)

Scandium

(1.3)

Tharium

Loss on Igrition (7.5 wt.\%)

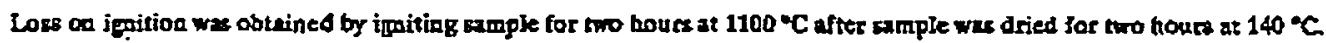

\section{Source and Preparation}

The plastic clay for SRM 98b was donated to NBS by F.J. Flanagan and J.W. Fasterman of the United States Gealogical Survey, Reston, Virginir. Approximately $220 \mathrm{~kg}$ of plastic clay was callected from the underclay of the Clarion coal bed at the Elarbison-Walker Refractories Co. plant at Clearfield, Clearfield County, PA. Tbe collected clay was air-dried and processed by the same met'iod used to prepare USGS rock standards (USGS Bulletin 1582, Flamagan 1986). After processing, the sample was delivered to NBS, whero it was again mixed in a 0.3 cubic meter " $V$ " blender for approximately 45 minures. After blending the clay was placed in polyethylene lined aluminum pails and subsequently bottled.

Howogeneity testing was performed using x-ray furorescence and instrumental activation analysis on samples randomly selected samples from cans of bulk material. There were no signiffeant differences between samples for any of the measured elements.

Chemical analyses prere perforwed in the following laboratorios:

- National Bareau of Standards, Center for Analytical Chemistry, E.S. Beary, D.A. Becker, W.A. Bowman III, T.A. Butler, KA. Brletic, J.W. Gremitich, D. Mo, J.R. Moody, and T.C. Rains.

- Mineral Constitution Laboratory, Pemsylzania State University, University Park, Penosylvania, J.B. Bodkin.

- Engeihard Corporation, Specialty Chemieal Division, Edison, New Jersey, B.P.Scibek.

- Construction Technology Laboratories, Inc., Skokic, Ilinois, H.M.Kanare.

The statistical analysis and evaluation of the data for certification was performed by $X$.R. Eberhardt and S. B. Schiller of the Statistscal Engineering Division and R.I. Watters, $f_{r}$, of the Inorganic Analytical Research Division.

The technical and support aspects involved in the preparation, certification, and issuance of this Standard Reference Material were coordinated through the Office of Standard Reference Materials by T.E. Gilts. 


\title{
Listing of SRM Certificates
}

Page 1:

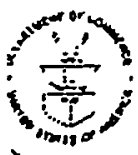

\section{Aitutiunal Innatitute uf $\$$ tandardg \& Oechnnlngu}

\section{UTertifitate}

\author{
Standard Reference Material 278
}

\section{Obsidian Rock}

This Standard Reference Material (SRM) is intended for use in evaluating the accuracy of analytical methods and instruments used in the analyzis of geological type materials. SRM 278 is a finely powdered obsidian rock. which was obtained trom Clear Lake, Newberry Crater, Oregon.

\section{Certified Values of Constiluents}

The concentrations of the constituents were determined by methods that are widely used in the field of geological analysis and have a demonstrated accuracy. The values given ase "certified" values, i.e, those values that were determined by either a definitive method, reference mathod, or by two or more independent methods, and "information" values that were determined by single or con-reference methods. The certificd values are given in Table 1.

Table 1. Certified Values of Consthtuents

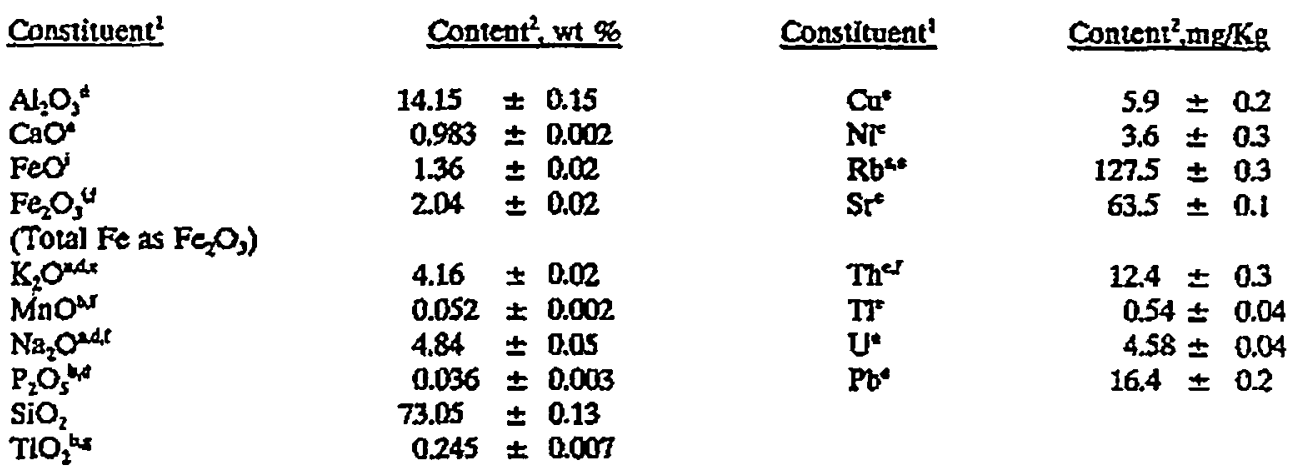

'Methods of Anatysis: codes are identified in table 2.

The estimated uncertainties of the certified values are based on judgment and represent an evaluation of the combined effects of method Imprecision, possible systematic errors among methods and material variability of $250 \mathrm{mg}$ or more (No attempt was made to derive teact statistical measures of imprecision because several methods were involved in the determination of most constituents.)

This Certificate of Anafysis has undergone editorial revision to reflect program and organizational changes at NIST and at the Department of Commerce. No attempt was made to reevaruate the certificate value or any technical daia presented in this certificate.

Gaithersburg, MD 20899

March 27, 1992

(Revision of certificate dated 8-19-81)
Willism P. Reed, Chief Stardard Reference Materials Program

(over) 
Page 2:

The overall direction and coordination of the technical measurements leading to certification werc performed in the Inorganic Analytical Research Divlsion by E.L. Garner.

The technical and support aspects intolved in the preparation, certification, and issuance of this Standard Refcrence Material were coondinated through the Standand Refcrence Materials Program by T.E. Gills. Revision of this certificaze was coordinated through the Standard Reference Materials Program by J.S. Kane.

The constituents given in Table 2 are nos centifued but are included for information only.

Table 2 Information Values

Constituent $t^{1} \quad$ Content, wt \%

$\begin{array}{ll}\mathrm{C} \text { (Total Carbos) } & (0.05) \\ \mathrm{O}_{2}^{d} & (0.01) \\ \mathrm{F}^{\mathrm{d}} & (0.05) \\ \mathrm{MgO}_{\mathrm{g}} & (0.23)\end{array}$

'Methods of Analysis:

"Atomic Absorption
'Colorimetry
'Emission Spectrometry
AGravimetry
'Isotope Dilution Mass Spectromeiry

\begin{tabular}{|c|c|}
\hline Constituent & Conlent, mg/Kg \\
\hline $\mathrm{Ba}^{\mathrm{r}}$ & $(1140)$ \\
\hline$B$ & $(25)$ \\
\hline$c e^{f}$ & $62.2)$ \\
\hline $\cot ^{t}$ & $1.5)$ \\
\hline $\mathrm{cr}$ & 6.1) \\
\hline$c s^{t}$ & $5.5)$ \\
\hline $\mathrm{Eu}^{t}$ & $0.84)$ \\
\hline Gol & $5.3)$ \\
\hline $\mathrm{Hif}^{+}$ & 8.4) \\
\hline $\mathrm{Lu}^{t}$ & $0.73)$ \\
\hline $\mathbf{s b}^{t}$ & $1.5)$ \\
\hline $\mathbf{s c}^{s}$ & $5.1)$ \\
\hline$S m^{48}$ & $5.7)$ \\
\hline Tá & $1.2)$ \\
\hline $\mathrm{Tb}^{\mathrm{E}}$ & $1.0 j$ \\
\hline $\mathbf{Y b}^{\prime}$ & $(4.5)$ \\
\hline $\mathbf{Z n}^{\varepsilon}$ & $(55)$ \\
\hline
\end{tabular}

Nentron Activation Analysis Prompt-gamma Activation Analysis "Specific Ion Electrode Potentiometry Tistimetry

ivolumetry 


\section{Preparation}

The material was processed by the Colorado School of Mines. Colorado. Approximately 350 lbs of obsidian rock were crushed, ground, and sieved to $<200$ mesh. The material was mixed in a cone blender to ensure homogencity. For homogeneity, testing and certification, samples were randomly chosen and analyeco for both major and minor constitucnts. The inhomogenejty of this material is considered to be $\leq 2 \%$ relative.

\section{Analysis}

SRM 278, a aatural glass, is hygroscopic and contains water that cannot be driven off by Jrying at lnw temperatures. This material will pick up additional water on exposure to the atmosphere. Thas, cxposure lime should be kcpt to a minimum. Furthermore, the sample should be ignited 10 a constant wcight in a mufflc furnace or over a small flame at a temperature betwcen $350-600^{\circ} \mathrm{C}$ prior to analysis. This procedurc will ensure the accurate and precise determination of $\mathrm{SiO}_{2} \mathrm{~K}_{2} \mathrm{O}_{2} \mathrm{Na}_{2} \mathrm{O}, \mathrm{AJ}_{2} \mathrm{O}_{3}$ and passibly olher major constituents.

The analysts and laboratorics cooperating in the analytical program for certification were:

- MJ. Blackman, E.L Garner, J.W. Gramlich, LA. Machlin, LJ. Moore, and R. Zeisler of the Inorganic Analytical Research Division, National Institute of Standards \& Technology.

- J.B. Bodkin, J.C. DeVine, and N.H. Suhr of the Mineral Constitution Laboratories, The Pennsylvania State University, University Park, Pennsylvania.

- S.S. Goldrich or the Department of Geology, Northern Ilinois University, DeKalb, Ininois.

- M.D. Glascock, C.C. Graham, J.R. Vogt, University of Missouri, Columbia, Missouri.

\section{Document attributes:}

SRM\# $=278$

REVISION DATE $=1992-03-27$ 


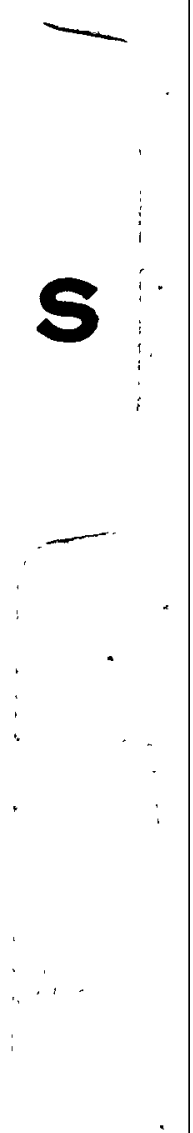




\begin{tabular}{|c|c|c|c|c|c|}
\hline \multicolumn{6}{|c|}{ NBS-948 Analyses } \\
\hline \multirow[t]{3}{*}{ instrument: VG-2 } & \multicolumn{2}{|c|}{ Total Evaporation Method } & \multicolumn{3}{|c|}{ Decay Corrected to $6 / 1 / 97$} \\
\hline & & & \multicolumn{2}{|c|}{ Weight \% } & \multirow[b]{2}{*}{242} \\
\hline & 238 & 239 & 240 & 241 & \\
\hline $3 / 28 / 95$ & 0.0108 & 91.8295 & 7.9571 & 0.1447 & 0.0342 \\
\hline $4 / 13 / 95$ & 0.0127 & 91.8282 & 7.9590 & 0.1431 & 0.0339 \\
\hline $4 / 14 / 95$ & 0.0123 & 91.8288 & 7.9576 & 0.1441 & 0.0340 \\
\hline $4 / 25 / 95$ & 0.0121 & 91.8290 & 7.9575 & 0.1449 & 0.0335 \\
\hline $4 / 26 / 95$ & 0.0121 & 91.8281 & 7.9584 & 0.1446 & 0.0339 \\
\hline $5 / 5 / 95$ & 0.0131 & 91.8252 & 7.9578 & 0.1475 & 0.0334 \\
\hline $5 / 16 / 95$ & 0.0121 & 91.8294 & 7.9582 & 0.1441 & 0.0338 \\
\hline $5 / 19 / 95$ & 0.0142 & 91.8272 & 7.9595 & 0.1434 & 0.0336 \\
\hline $5 / 24 / 95$ & 0.0109 & 91.8312 & 7.9577 & 0.1445 & 0.0337 \\
\hline $5 / 25 / 95$ & 0.0133 & 91.8280 & 7.9585 & 0.1442 & 0.0339 \\
\hline $6 / 1 / 95$ & 0.0121 & 91.8304 & 7.9577 & 0.1445 & 0.0336 \\
\hline $6 / 16 / 95$ & 0.0110 & 91.8304 & 7.9593 & 0.1445 & 0.0336 \\
\hline $6 / 20 / 95$ & 0.0109 & 91.8311 & 7.9572 & 0.1455 & 0.0341 \\
\hline $6 / 27 / 95$ & 0.0110 & 91.8288 & 7.9578 & 0.1473 & 0.0338 \\
\hline $6 / 28 / 95$ & 0.0118 & 91.8292 & 7.9570 & 0.1470 & 0.0338 \\
\hline $7 / 10 / 95$ & 0.0117 & 91.8292 & 7.9575 & 0.1471 & 0.0336 \\
\hline $7 / 11 / 95$ & 0.0134 & 91.8290 & 7.9567 & 0.1467 & 0.0333 \\
\hline $7 / 11 / 95$ & 0.0119 & 91.8272 & 7.9595 & 0.1467 & 0.0339 \\
\hline $7 / 11 / 95$ & 0.0167 & 91.8207 & 7.9591 & 0.1481 & 0.0345 \\
\hline $7 / 11 / 95$ & 0.0113 & 91.8283 & 7.9582 & 0.1474 & 0.0340 \\
\hline $7 / 11 / 95$ & 0.0138 & 91.8277 & 7.9576 & 0.1463 & 0.0338 \\
\hline Mean & 0.0123 & 91.8284 & 7.9580 & 0.1455 & 0.0338 \\
\hline Std. Dev. & 0.0014 & 0.0022 & 0.0008 & 0.0015 & 0.0003 \\
\hline$\%$ RSD & 11.4844 & 0.0024 & 0.0105 & 1.0503 & 0.8279 \\
\hline Cert. (6/1/97) & 0.0088 & 91.8576 & 7.9563 & 0.1438 & 0.0335 \\
\hline \pm & 0.0010 & 0.0100 & 0.0100 & 0.0010 & 0.0030 \\
\hline \% Deviation & 28.44689 & -0.03184 & 0.021895 & 1.221252 & 1.004675 \\
\hline
\end{tabular}




\begin{tabular}{|c|c|c|c|c|c|}
\hline \multicolumn{6}{|c|}{ NBS-948 Analyses } \\
\hline \multirow[t]{3}{*}{ Instrument: VG-2 } & \multicolumn{2}{|c|}{ Total Evaporation Method } & \multicolumn{3}{|c|}{ Decay Corrected to $6 / 1 / 97$} \\
\hline & & & \multicolumn{2}{|c|}{ Weight \% } & \multirow[b]{2}{*}{242} \\
\hline & 238 & 239 & 240 & 241 & \\
\hline $3 / 6 / 97$ & 0.0090 & 91.8515 & 7.9591 & 0.1439 & 0.0340 \\
\hline $3 / 11 / 97$ & 0.0101 & 91.8496 & 7.9604 & 0.1437 & 0.0338 \\
\hline $3 / 12 / 97$ & 0.0099 & 91.8501 & 7.9599 & 0.1440 & 0.0337 \\
\hline $3 / 14 / 97$ & 0.0092 & 91.8525 & 7.9591 & 0.1433 & 0.0337 \\
\hline $3 / 25 / 97$ & 0.0091 & 91.8499 & 7.9617 & 0.1438 & 0.0335 \\
\hline $3 / 26 / 97$ & 0.0099 & 91.8516 & 7.9596 & 0.1433 & 0.0337 \\
\hline $3 / 27 / 97$ & 0.0098 & 91.8521 & 7.9598 & 0.1427 & 0.0337 \\
\hline $3 / 28 / 97$ & 0.0105 & 91.8500 & 7.9608 & 0.1433 & 0.0335 \\
\hline $4 / 8 / 97$ & 0.0098 & 91.8519 & 7.9591 & 0.1436 & 0.0339 \\
\hline $4 / 9 / 97$ & 0.0149 & 91.8465 & 7.9596 & 0.1435 & 0.0339 \\
\hline $4 / 17 / 97$ & 0.0111 & 91.8489 & 7.9612 & 0.1439 & 0.0336 \\
\hline $4 / 24 / 97$ & 0.0128 & 91.8485 & 7.9604 & 0.1436 & 0.0336 \\
\hline $4 / 25 / 97$ & 0.0094 & 91.8526 & 7.9601 & 0.1428 & 0.0340 \\
\hline $4 / 30 / 97$ & 0.0124 & 91.8484 & 7.9606 & 0.1438 & 0.0338 \\
\hline $5 / 1 / 97$ & 0.0136 & 91.8468 & 7.9604 & 0.1443 & 0.0340 \\
\hline $5 / 2 / 97$ & 0.0096 & 91.8520 & 7.9597 & 0.1441 & 0.0338 \\
\hline $5 / 5 / 97$ & 0.0103 & 91.8498 & 7.9615 & 0.1436 & 0.0339 \\
\hline $5 / 8 / 97$ & 0.0098 & 91.8507 & 7.9616 & 0.1437 & 0.0336 \\
\hline $5 / 12 / 97$ & 0.0104 & 91.8510 & 7.9611 & 0.1435 & 0.0334 \\
\hline $5 / 15 / 97$ & 0.0097 & 91.8518 & 7.9604 & 0.1438 & 0.0338 \\
\hline Mean & 0.0106 & 91.8503 & 7.9603 & 0.1436 & 0.0338 \\
\hline Std. Dev. & 0.0016 & 0.0018 & 0.0008 & 0.0004 & 0.0002 \\
\hline$\%$ RSD & 15.1927 & 0.0020 & 0.0104 & 0.2709 & 0.5283 \\
\hline Cert. (6/1/97) & 0.0088 & 91.8576 & 7.9563 & 0.1438 & 0.0335 \\
\hline \pm & 0.0010 & 0.0100 & 0.0100 & 0.0010 & 0.0030 \\
\hline \% Deviation & 16.6151 & -0.00799 & 0.050214 & -0.09649 & 0.827802 \\
\hline
\end{tabular}




\begin{tabular}{|c|c|c|c|c|c|}
\hline \multicolumn{6}{|c|}{ NBS-U005 Analyses } \\
\hline \multirow[t]{3}{*}{ Instrument: VG-2 } & \multicolumn{2}{|c|}{ Total Evaporation Method } & \multicolumn{3}{|c|}{ Decay Corrected to 6/1/97 } \\
\hline & & & \multicolumn{2}{|c|}{ Weight \% } & \multirow[b]{2}{*}{238} \\
\hline & 233 & 234 & 235 & 236 & \\
\hline $12 / 13 / 95$ & 0.0000 & 0.0023 & 0.4839 & 0.0049 & 99.5089 \\
\hline 2/1/96 & 0.0000 & 0.0024 & 0.4834 & 0.0053 & 99.5089 \\
\hline $9 / 13 / 96$ & 0.0000 & 0.0022 & 0.4837 & 0.0048 & 99.5093 \\
\hline $10 / 11 / 96$ & 0.0000 & 0.0027 & 0.4835 & 0.0053 & 99.5085 \\
\hline $10 / 22 / 96$ & 0.0000 & 0.0025 & 0.4841 & 0.0049 & 99.5085 \\
\hline $11 / 21 / 96$ & 0.0000 & 0.0027 & 0.4847 & 0.0055 & 99.5072 \\
\hline $4 / 21 / 97$ & 0.0000 & 0.0021 & 0.4841 & 0.0049 & 99.5089 \\
\hline Mean & 0.0000 & 0.0024 & 0.4840 & 0.0050 & 99.5086 \\
\hline Std. Dev. & 0.0000 & 0.0002 & 0.0004 & 0.0003 & 0.0007 \\
\hline$\%$ RSD & 0.0000 & 9.6928 & 0.0900 & 5.3763 & 0.0007 \\
\hline Cert. (6/1/97) & 0.0000 & 0.0021 & 0.4833 & 0.0046 & 99.5099 \\
\hline \pm & 0.0000 & 0.0000 & 0.0005 & 0.0001 & 0.0010 \\
\hline \% Deviation & 0.000 & 11.533 & 0.135 & 8.788 & -0.001 \\
\hline
\end{tabular}




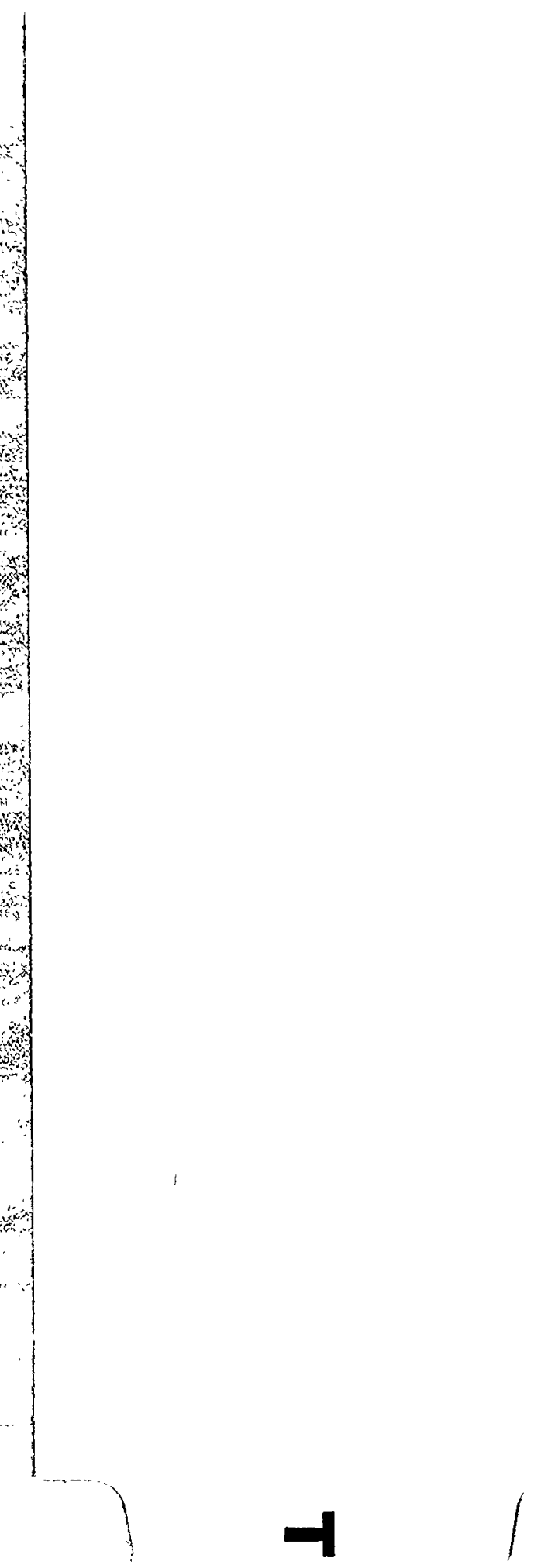


Radiochemical Analysis on Working Reference Materials (WRMs) for Capability Evaluation Project (CEP)

$$
\text { (May - August of 1997) }
$$

A Summary Report

$$
\text { by }
$$

$$
\text { Amy Wong }
$$

\section{CMR Analytical Chemistry Group, NMT-1}

May 1998 


\title{
Radiochemical Analysis on Working Reference Materials (WRMs) for Capability Evaluation Project (CEP)
}

\author{
Radiochemical Analysis of Starting Materials $\left({ }^{241} \mathrm{AmO}_{2}\right.$ and depleted uranium \\ oxide):
}

Radiochemistry team received four cuts of ${ }^{241}$ Am solutions (CST\#200023528, 17 to 25 $\mu \mathrm{g}$ each in $10-\mathrm{mL}$ diluted acid) and three cuts of depleted uranium solutions (CST\#200023526, $150 \mathrm{mg}$ each in $10 \mathrm{~mL}$ diluted acid) from the Trace Element and $\mathrm{Pu}$ Assay teams. All the initial aliquots were performed gravimetrically. The radiochemistry analyses were performed volumetrically using calibrated pipettes.

Determination of ${ }^{244} \mathrm{Cm}$ and ${ }^{252} \mathrm{Cf}$

Alpha spectroscopy analysis was performed to estimate the amounts of ${ }^{244} \mathrm{Cm}$ and ${ }^{252} \mathrm{Cf}$ levels in the starting materials ( ${ }^{241} \mathrm{Am}$ and depleted oxide) for the CEP WRMs. If there is detectable amount ( $\mu \mathrm{g} / \mathrm{g}$ level) of ${ }^{244} \mathrm{Cm}$ and ${ }^{252} \mathrm{Cf}$ in these starting materials, it will have adverse effects on the neutron and gamma based measurements of the WRMs.

Alpha spectroscopy was performed in an Oxford alpha spectroscopy system (OASIS) using surface barrier silicon detectors. The alpha spectrometers were energy calibrated with a source prepared from weapons grade $\mathrm{Pu}$ and ${ }^{244} \mathrm{Cm}$. The energy calibrations were validated with an NIST ${ }^{238} \mathrm{Pu}$ source (SRM 4906-C-9). The concentration levels of ${ }^{244} \mathrm{Cm}$ and ${ }^{252} \mathrm{Cf}$ in the ${ }^{241} \mathrm{Am}$ and depleted uranium starting materials were estimated based on the ratio of the measured region of interests (ROIs) or alpha activities, and the half-life of each isotope. This method provides a rough upper limit estimate of ${ }^{244} \mathrm{Cm}$ and ${ }^{252} \mathrm{Cf}$ concentrations.

No actual peaks were observed in the 5.7 to $7.5 \mathrm{MeV}$ region so an integrated background area (5 counts) in this energy region was used to bound ${ }^{244} \mathrm{Cm}$ and ${ }^{252} \mathrm{Cf}$ concentrations. For $\mathrm{AmO}_{2}$, the concentration of ${ }^{244} \mathrm{Cm}$ was less than $0.02 \mathrm{ppm}$ and ${ }^{252} \mathrm{Cf}$ was less than $0.003 \mathrm{ppm}$. For depleted uranium oxide, the concentration of ${ }^{244} \mathrm{Cm}$ was less than 0.001 ppm and ${ }^{252} \mathrm{Cf}$ was less than $0.001 \mathrm{ppm}$.

${ }^{241} \mathrm{Am}$ Concentration in $\mathrm{AmO}_{2}$

In additions, the concentration of ${ }^{241} \mathrm{Am}$ in the $\mathrm{AmO}_{2}$ starting material (CST\#200023528) was determined by liquid scintillation analysis and gamma-ray spectrometry. The liquid scintillation counter (Packard Tri-Carb 2200C) was calibrated using an NIST traceable Radiochemistry Primary plutonium oxide standard (PEOR3258-STD1) The NaI based 
gamma-ray spectrometer was calibrated using an NIST traceable ${ }^{241} \mathrm{Am}$ standard solution (Amersham, AMP10040, batch 95/241/49).

The amount of $241 \mathrm{Am}$ isotope within the sample was determined by radiochemical methods. Duplicated analyses were performed on each cut of sample. The total alpha activity was determined by liquid scintillation counting and ${ }^{241} \mathrm{Am}$-gamma activity was determined by gamma spectrometry.

\begin{tabular}{|c|c|c|c|c|c|}
\hline Cut & Expected, $\mu \mathrm{g}$ & $\overline{L S C}, \mu g^{*}$ & $\% \mathrm{Am}$ & Gamma, $\mu \mathrm{g}$ & \%Am \\
\hline $14 \mathrm{a}$ & 21.09 & 16.69 & 79.14 & 16.63 & 78.85 \\
\hline $14 b$ & 21.09 & 16.54 & 78.43 & 16.60 & 78.71 \\
\hline $15 \mathrm{a}$ & 17.37 & 13.83 & 79.62 & 13.77 & 79.27 \\
\hline $15 b$ & 17.37 & 13.83 & $\overline{79.62}$ & 13.91 & 80.08 \\
\hline $16 a$ & 24.33 & 19.46 & 79.98 & 19.19 & 78.87 \\
\hline $16 \mathrm{~b}$ & 24.33 & 19.19 & 78.87 & 19.28 & 79.24 \\
\hline $17 \mathrm{a}$ & 17.82 & 14.09 & 79.07 & 14.26 & 80.02 \\
\hline $17 \mathrm{~b}$ & 17.82 & 14.15 & 79.41 & 14.18 & 79.57 \\
\hline \multirow[t]{2}{*}{ 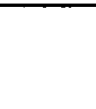 } & & AVG & $79.27 \pm 0.49$ & AVG & $79.33 \pm 0.53$ \\
\hline & & \%RSD & 0.62 & $\% \mathrm{RSD}$ & 0.66 \\
\hline
\end{tabular}

*Assume all alpha activity was due to ${ }^{241} \mathrm{Am}$.

Excellent agreement in americium concentration was obtained between LSC and gamma spectroscopy results.

Other gamma emitting radionuclides.

To determine if there were other gamma-emitting radionuclides present in the ${ }^{241} \mathrm{Am}$ and depleted uranium samples, gamma-ray analysis was performed on these samples. A high purity germanium detector was energy calibrated using an Amersham QCY.44 (NIST traceable) mixed gamma radionuclide reference solution. No noticeable peaks from other gamma-emitting radionuclides were detected by the HPGe gamma-ray measurements under the extremely high level of ${ }^{241} \mathrm{Am}$-gamma background. 


\section{DE-UO ${ }_{2}$ Blending Verification Measurements:}

Prior to loading different mass range of diatomaceous earth (DE) and depleted uranium oxide blend in the WRM, the homogeneity of these blends was verified by nondestructive gamma-ray analysis. Two different mass ranges were evaluated which included 570 and $1100 \mathrm{~g}$ of depleted uranium oxide in the blend.

Approximately $100 \mathrm{~g}$, weighed blend sample was packed into a pre-marked, constant fill height $125 \mathrm{~mL}$ Nalgene polycarbonate straight side jars. Six jars of samples were obtained from different portions of the blend. These vials were bagged out from the glovebox with one layer of plastic bags. Each sample jar was held in placed with a wooden ring and was counted on a high purity germanium detector at $8.5-\mathrm{cm}$ distance from the detector surface.

The measurement results are shown in Tables I to III. The normalized gamma-ray peak areas at $63.3,187,772$, and $1009-\mathrm{keV}$ (from the daughter nuclides of ${ }^{235} \mathrm{U},{ }^{238} \mathrm{U}$ ) are used to evaluate the homogeneity of the blend.

TABLE I. Blending Homogeneity of CEP011 ( $570 \mathrm{~g} \mathrm{UO}_{2}$ in $\left.113 \mathrm{~g} \mathrm{DE}\right)$

\begin{tabular}{|c|c|c|c|c|}
\cline { 2 - 5 } \multicolumn{1}{c|}{} & \multicolumn{4}{c|}{ normalized counts per 1200 second (ct/g/1200s) } \\
\hline Cut \# & $63.3 \mathrm{keV}$ & $186.7 \mathrm{keV}$ & $772.4 \mathrm{keV}$ & $1009 \mathrm{keV}$ \\
\hline 1 & 218.4 & 105.6 & 41.5 & 89.4 \\
\hline 2 & 223.7 & 104.7 & 41.3 & 86.7 \\
\hline 3 & 217.8 & 104.9 & 42.6 & 86.5 \\
\hline 4 & 223.6 & 105.0 & 41.2 & 86.4 \\
\hline 5 & 220.8 & 106.7 & 41.7 & 86.3 \\
\hline 6 & 216.4 & 101.7 & 41.4 & 87.2 \\
\hline \hline AVG & 220.1 & 104.8 & 41.6 & 87.1 \\
\hline STD & 3.1 & 1.7 & 0.5 & 1.2 \\
\hline \% RSD at 95\% CL & 1.47 & 1.67 & 1.31 & 1.44 \\
\hline
\end{tabular}

TABLE II. Blending Homogeneity of CEP013 $\left(\sim 1090 \mathrm{~g} \mathrm{UO}_{2}\right.$ in $\left.32 \mathrm{~g} \mathrm{DE}\right)$

\begin{tabular}{|c|c|c|c|c|}
\cline { 2 - 5 } \multicolumn{1}{c|}{} & \multicolumn{4}{c|}{ normalized counts per 1200 second (ct/g/1200s) } \\
\hline Cut \# & $63.3 \mathrm{keV}$ & $186.7 \mathrm{keV}$ & $772.4 \mathrm{keV}$ & $1009 \mathrm{keV}$ \\
\hline 1 & 214.1 & 107.7 & 49.4 & 102.3 \\
\hline 2 & 215.8 & 105.2 & 48.5 & 103.0 \\
\hline 3 & 221.3 & 108.0 & 49.1 & 104.5 \\
\hline 4 & 209.7 & 106.9 & 46.7 & 103.5 \\
\hline 5 & 212.1 & 105.0 & 47.9 & 100.4 \\
\hline 6 & 211.5 & 103.6 & 47.8 & 104.6 \\
\hline AVG & 214.1 & 106.1 & 48.2 & 103.0 \\
\hline STD & 4.1 & 1.7 & 1.0 & 1.6 \\
\hline \% RSD at 95\% CL & 2.02 & 1.71 & 2.13 & 1.60 \\
\hline
\end{tabular}


TABLE III. Blending Homogeneity of CEP014 ( $1090 \mathrm{~g} \mathrm{UO}_{2}$ in $\left.32 \mathrm{~g} \mathrm{DE}\right)$

\begin{tabular}{|c|c|c|c|c|}
\cline { 2 - 5 } \multicolumn{1}{c|}{} & \multicolumn{4}{c|}{ normalized counts per 1200 second (ct/g/1200s) } \\
\hline Cut\# & $63.3 \mathrm{keV}$ & $186.7 \mathrm{keV}$ & $772.4 \mathrm{keV}$ & $1009 \mathrm{keV}$ \\
\hline 1 & 336.3 & 169.9 & 73.7 & 158.1 \\
\hline 2 & 333.3 & 164.2 & 74.0 & 157.2 \\
\hline 3 & 338.1 & 169.1 & 73.9 & 157.5 \\
\hline 4 & 329.1 & 164.4 & 73.2 & 153.9 \\
\hline 5 & 341.7 & 165.9 & 72.9 & 154.9 \\
\hline 6 & 341.1 & 165.5 & 74.1 & 154.1 \\
\hline \hline AVG & 336.6 & 166.5 & 73.6 & 155.9 \\
\hline STD & 4.8 & 2.4 & 0.5 & 1.8 \\
\hline \% RSD at 95\% CL & 1.50 & 1.54 & 0.71 & 1.24 \\
\hline
\end{tabular}

Based on the data in Tables I to III, all the blends were very homogeneous. The uniformity of these blends had met the statement of work requirements.

\section{DE-AmO $2 / \mathrm{PuO}_{2}$ Blending Verification Measurements:}

Prior to loading plutonium oxide and americium oxide diatomaceous earth blend in the WRM, the homogeneity of a blending material was verified by non-destructive gammaray analysis. Due to relatively high radiation dose rate, only one set of blending was evaluated.

Approximately $6.3 \mathrm{~g}$ of weighed blending mix was packed into a pre-marked, constant fill height $125 \mathrm{~mL}$ Nalgene polycarbonate straight side jars. Six jars of samples were obtained from different portions of the blend. These vials were bagged out from the glovebox with two layer of plastic bags. Each sample jar was held in placed with a 2inch roll of tape on a rotating table and was counted on a high purity germanium detector at 99-cm distance from the detector surface. Due to high activity, the detector surface was covered with 4 layers of lead tape to reduce the dead time to $14 \%$.

TABLE IV. Blending Homogeneity of CEP005 ( $\sim .11 \mathrm{~g}$ of $\left.{ }^{241} \mathrm{AmO}_{2}+\sim 2.3 \mathrm{~g} \mathrm{PuO}_{2}+134 \mathrm{~g} \mathrm{DE}\right)$

\begin{tabular}{|c|c|}
\cline { 2 - 2 } \multicolumn{1}{c|}{} & normalized counts per 300 s (ct/g/300s) \\
\hline Cut \# & $59.5 \mathrm{keV}$ \\
\hline 1 & 116194 \\
\hline 2 & 116860 \\
\hline 3 & 114348 \\
\hline 4 & 119827 \\
\hline 5 & 113739 \\
\hline 6 & 116562 \\
\hline AVG & 116255 \\
\hline STD & 2154 \\
\hline \% RSD at 95\% CL & 1.94 \\
\hline
\end{tabular}


From Table IV data table, the uniformity of this americium-plutonium oxide-DE blend had met the statement of work requirements.

\section{${ }^{241}$ Am Count Rate Assessment.}

Approximately $100 \mu \mathrm{g}$ and $200 \mu \mathrm{g}$ of ${ }^{241} \mathrm{Am}$ oxide solutions were aliquoted onto health physics smears. These smears were counted at various distance in front of a high purity germanium detector. Table VI showed by increasing distance from $30 \mathrm{~cm}$ to $100 \mathrm{~cm}$, the count rate was decreased by $90 \%$. These data were used to assess the personnel exposure for ALARA purpose.

\section{TABLE IV}

\begin{tabular}{|c|c|c|c|c|c|c|c|}
\hline \multicolumn{4}{|c|}{$100 \mu \mathrm{g} \mathrm{Am}$} & \multicolumn{4}{|c|}{$200 \mu \mathrm{g} \mathrm{Am}$} \\
\hline Description & per $60 \mathrm{~s}$ & dead time & $\%$ at $30 \mathrm{~cm}$ & Description & per $60 \mathrm{~s}$ & dead time & $\begin{array}{c}\% \text { at } 30 \\
\mathrm{~cm}\end{array}$ \\
\hline$\overline{B K G}$ & 150 & & onth & $\overline{B K G}$ & 150 & & \\
\hline $\begin{array}{l}\text { At detector } \\
\text { surface }\end{array}$ & $\mathrm{NA}$ & $100 \%$ & W & At surface & NA & $100 \%$ & \\
\hline $30 \mathrm{~cm}$ & 231919 & $39 \%$ & 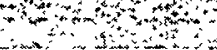 & $30 \mathrm{~cm}$ & 454702 & $39 \%$ & \\
\hline $70 \mathrm{~cm}$ & 43275 & $14 \%$ & 0.19 & $70 \mathrm{~cm}$ & 87707 & $14 \%$ & 0.19 \\
\hline $100 \mathrm{~cm}$ & 22086 & $10 \%$ & 0.10 & $100 \mathrm{~cm}$ & 43609 & $10 \%$ & 0.10 \\
\hline
\end{tabular}

\section{Determination of ${ }^{241} \mathrm{Am}$ in the ${ }^{241} \mathrm{Am}-\mathrm{Pu}-\mathrm{DE}$ Waste Items by Comparative Method}

\section{Preparation of ${ }^{241} \mathrm{Am}$ Waste Item Standards}

The same set of ${ }^{241} \mathrm{Am}$ NDA Waste Item Standards was used to calibrate the gamma-ray measurements. The standards were prepared for the NDA PDP Phase II Standard Preparation Project.

The simulated waste container was prepared into a standard by taping four cloth swipes spiked with ${ }^{241} \mathrm{Am}$ standard solution. These four cloths were arranged symmetrically around the inner wall of the blending bottle. The waste item calibration standard was prepared using the same constituents of an actual waste item; a clean blending bottle, kraft papers, Q-tips, paper funnel, and kimwipes.

The amount of activity in the high-level standard (labeled as NDA High STD, 4/97) was

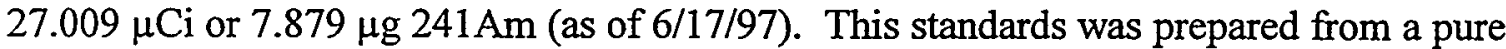
${ }^{241}$ Am standardized solution (CST\#200001684, see RC-AW-5, p.43). The CST ${ }^{241} \mathrm{Am}$ solution was standardized using calibrated liquid scintillation and gamma counters. The calibrations of these instruments were performed using NIST traceable standards. 


\section{Counting Conditions}

The amount of ${ }^{241} \mathrm{Am}$ in each of the waste items was determined by gamma-ray spectrometry using comparative method. The count rate of the ${ }^{241} \mathrm{Am} 59.5-\mathrm{keV}$ peak acquired for a waste item was compared to the total number of $59.5-\mathrm{keV}$ counts for the standard. The waste items and standard bottles were all triply bagged in order to prevent possible contamination. Each item was counted once for 1200 seconds at $45-\mathrm{cm}$ distance from the detector.

\section{$\underline{\text { Standard Measurements }}$}

The high-level americium-241 standard (NDA High STD, 4/97) was counted four times during the waste item measurements (6/17-6/18/97). The count rate is around 100,000 counts. The relative standard deviation for the four counts was $\pm 2.0 \%$.

Counting statistics of the waste item measurements

Each waste item was measured once in a fixed counting geometry similar to the standard. The counting statistics of the waste item measurements ranged from 0.15 to $0.44 \%$. The $59.5-\mathrm{keV}$ count rate (cpm) in each waste item was compared to the average normalized count rate of the waste item standards and converted to $\mu \mathrm{g}$ of ${ }^{241} \mathrm{Am}$.

Amount of americium left in the waste item

\begin{tabular}{|c|c|c|c|c|c|c|c|c|}
\hline \multicolumn{9}{|c|}{ TABLE V. Waste Item Measurements for CEP Am Waste Items (6/97):Blending Bottles (count time 1200 s) } \\
\hline & & Am241 & & Counting & Amt of Am241 in Waste Item & Total in blend & \\
\hline DATE & ID & ROI & ERR & \%ERR & $\mu$ Ci & $\mu \mathrm{g}$ & Am, mg & \%left in waste \\
\hline $6 / 17 / 97$ & CEP001-Pro & 148216 & 427 & 0.29 & 39.28 & 11.45 & 58.0 & 0.020 \\
\hline $6 / 17 / 97$ & CEP001-B & 70866 & 299 & 0.42 & 18.78 & 5.47 & 10.5 & 0.052 \\
\hline $6 / 17 / 97$ & CEP002 & 66096 & 290 & 0.44 & 17.52 & 5.10 & 9.9 & 0.051 \\
\hline $6 / 17 / 97$ & CEP003 & 444003 & 740 & 0.17 & 117.67 & 34.29 & 54.2 & 0.063 \\
\hline $6 / 17 / 97$ & CEP004 & 198572 & 496 & 0.25 & 52.62 & 15.34 & 54.8 & 0.028 \\
\hline $6 / 17 / 97$ & CEP005 & 408645 & 712 & 0.17 & 108.29 & 31.56 & 92.3 & 0.034 \\
\hline $6 / 17 / 97$ & CEP006 & 263178 & 571 & 0.22 & 69.74 & 20.33 & 93.3 & 0.022 \\
\hline $6 / 17 / 97$ & CEP007 & 209350 & 508 & 0.24 & 55.48 & 16.17 & 54.8 & 0.030 \\
\hline $6 / 18 / 97$ & CEP008 & 222826 & 525 & 0.24 & 59.05 & 17.21 & 52.2 & 0.033 \\
\hline $6 / 18 / 97$ & CEP009 & 458186 & 751 & 0.16 & 121.42 & 35.39 & 103.4 & 0.034 \\
\hline $6 / 18 / 97$ & CEP010 & 550938 & 825 & 0.15 & 146.00 & 42.55 & 99.8 & 0.043 \\
\hline $6 / 18 / 97$ & CEP005-Vial & 109957 & 373 & 0.34 & 29.14 & 8.49 & 92.3 & 0.009 \\
\hline Note: CEP001-Pro = CEP001, prototype; CEP001-B=CEP001, WRM; CEP005-Vial =CEP005, homogeneous measurement vials \\
\hline
\end{tabular}




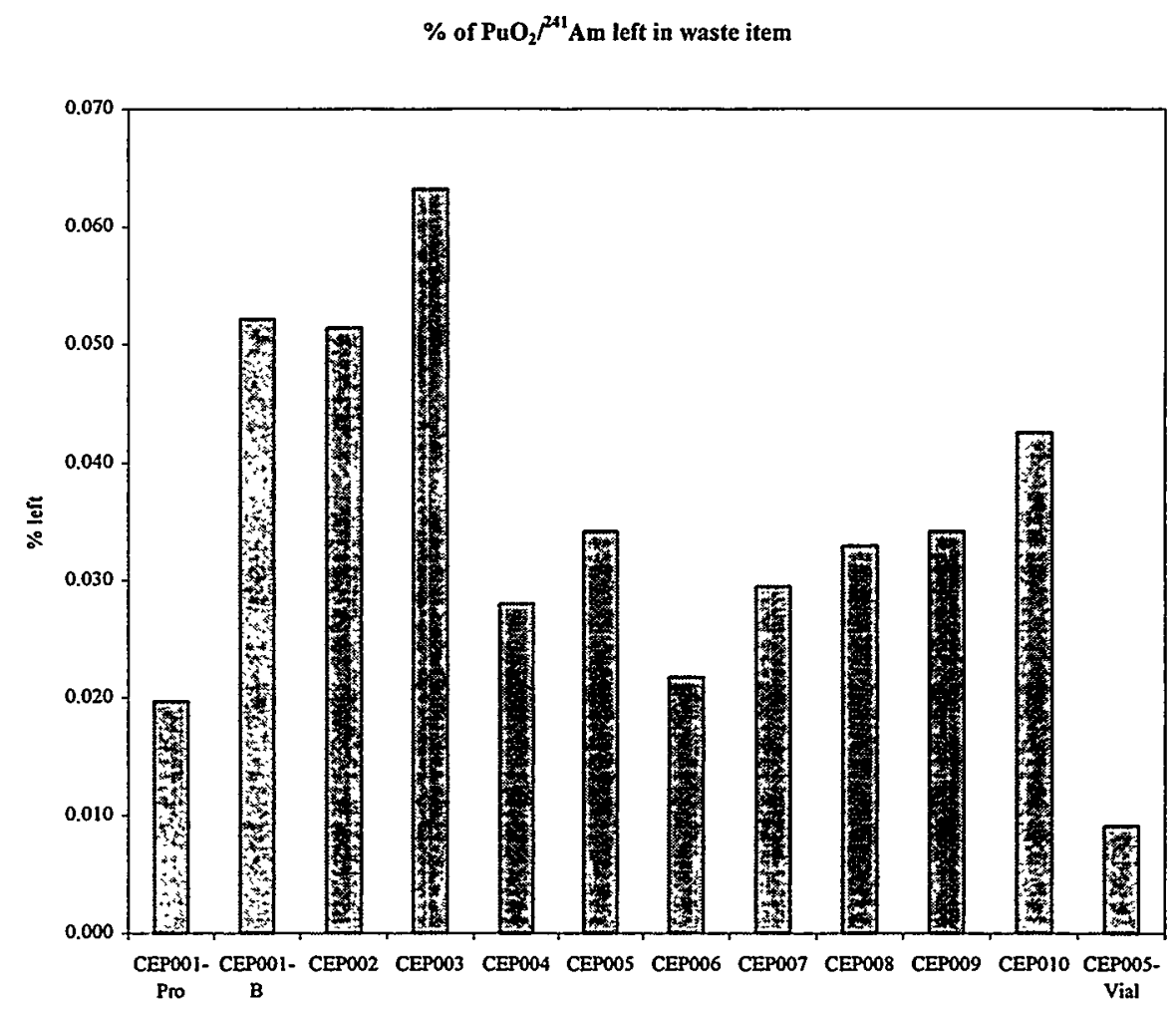

\section{Determination of Depleted Uranium in the DU-DE Waste Items by Comparative Method}

\section{Preparation of Depleted Uranium Standards}

Depleted uranium (DU) waste item standards were prepared from highly characterized depleted uranium oxide solution. A $4.8147 \mathrm{~g}$ of DU oxide $(87.493 \% \mathrm{U})$ was dissolved in $25 \mathrm{~mL}$ volumetric flask with $8 \mathrm{~N} \mathrm{NNO}_{3}$.

The simulated waste item was prepared into a standard by taping four cloth swipes spiked with depleted uranium standard solution. These four cloths were arranged symmetrically around the inner wall of the blending bottle. The waste item calibration standard was prepared using the same constituents of an actual waste item; a clean blending bottle, kraft papers, Q-tips, paper funnel, and kimwipes.

Two waste item standards were prepared. The amount of depleted uranium in the DU Standard\#1 was $168.5 \mathrm{mg}$ and in the DU Standard\#2 was $67.40 \mathrm{mg}$. 


\section{Counting Conditions}

The amount of depleted uranium in each of the waste items was determined by gammaray spectrometry using comparative method. Both ${ }^{238} U$ and ${ }^{235} U$ have long half-life which do not have good gamma-ray signatures at low concentration. Therefore the daughter radionuclide of ${ }^{238} \mathrm{U},{ }^{234} \mathrm{Th}$ (half-life $=24.1$ days) is used to quantify the amount of ${ }^{238} \mathrm{U}$ left in the waste items.

The count rate of ${ }^{234} \mathrm{Th}$ 63.3-keV peak acquired for a waste item was compared to the total number of $63.3-\mathrm{keV}$ counts for the standard. The waste items and standard bottles were all double bagged in order to prevent possible contamination. Each waste item was counted once for 10000 seconds at $25-\mathrm{cm}$ distance from the detector.

\section{$\underline{\text { Standard Measurements }}$}

Each of the DU waste item standards was counted twice times during the waste item measurements (7/11/97-7/16/97). The DU Standard \#1 had a total of $\sim 1200$ counts in 10000 seconds, and the DU standard \#2 had a total of 1400 counts in 30000 seconds. The overall counts per minute per $\mathrm{mg}$ of DU (cpm/mg DU) was $0.043 \mathrm{cpm} / \mathrm{mg} \pm 0.003$ $\mathrm{cpm} / \mathrm{mg}(\% \mathrm{RSD}=6.8 \%)$.

\section{Counting statistics of the waste item measurements}

Each waste item was measured once for 10,000 seconds. The counting statistics of the waste item measurements ranged from 3.3 to $24.8 \%$. The count rate (cpm) at $63.3 \mathrm{keV}$ of each waste item was compared to the average normalized count rate of the waste item standards and converted to $\mathrm{mg}$ of depleted uranium.

\section{Amount of depleted uranium left in the waste item}

All the measurements showed that less than $0.05 \%$ of depleted uranium was retained in all the waste items Although the counting statistics were poor for all the measurements, it was satisfied and met the criteria of the Statement of Work.

\begin{tabular}{|c|c|c|c|c|c|c|c|}
\hline \multicolumn{8}{|c|}{$\begin{array}{l}\text { TABLE VI. Waste Item Measurements for CEP Den } \\
\text { Blending Bottles (count time } 10000 \mathrm{~s} \text { ) }\end{array}$} \\
\hline & & \multicolumn{3}{|c|}{$63.32 \mathrm{keV}, 234 \mathrm{Th}$} & \multirow{2}{*}{\begin{tabular}{|c|}
$\begin{array}{c}\text { Amt of DU in waste } \\
\text { item }\end{array}$ \\
mg DU \\
\end{tabular}} & \multirow{2}{*}{$\begin{array}{c}\begin{array}{c}\text { Total in } \\
\text { blend }\end{array} \\
\text { DU, } g\end{array}$} & \multirow[b]{2}{*}{$\%$ in Waste } \\
\hline DATE & ID & Total counts & ERR & \%ERR & & & \\
\hline $7 / 11 / 97$ & CEPIIa & 1170 & 109 & 9.3 & 162.4 & 499.1 & 0.033 \\
\hline $7 / 11 / 97$ & CEP12 & 432 & 107 & 24.8 & 60.0 & 884.0 & 0.007 \\
\hline $7 / 14 / 97$ & CEP13 & 546 & 107 & 19.6 & 75.8 & 957.7 & 0.008 \\
\hline $7 / 15 / 97$ & CEP14 & 3664 & 121 & 3.3 & 508.6 & 960.0 & 0.053 \\
\hline $7 / 15 / 97$ & CEP15 & 871 & 108 & 12.4 & 120.9 & 972.8 & $\overline{0.012}$ \\
\hline $7 / 11 / 97$ & CEP16 & 1259 & 113 & 9.0 & 174.8 & 948.8 & 0.018 \\
\hline
\end{tabular}




\section{Homogeneity Evaluation of ${ }^{239} \mathrm{Pu}-{ }^{241} \mathrm{Am}-\mathrm{DE}$ Content within Each Working Reference Material:}

CEP ${ }^{239} \mathrm{Pu}-{ }^{241} \mathrm{Am}-\mathrm{DE}$ working reference materials (WRMs) were analyzed by nondestructive gamma-ray analysis on a HPGe detector. The purpose of this measurement was to provide a verification of the homogeneity of the $\mathrm{Pu}$ or/and Am content within each WRM. The homogeneity of each WRM is verified by comparing the count rate of ${ }^{239} \mathrm{Pu}$ or/and ${ }^{241} \mathrm{Am}$ peaks for the left and right segments of each WRM.

\section{Counting Geometry}

A portable HPGe photon detector was shielded with lead brick with the detector surface facing horizontally. A few lead bricks were used to create a window of $5 \mathrm{~cm}$ wide and 56 $\mathrm{cm}$ away from the detector surface. The WRM was placed horizontally inside of the lead bricks with the left or right side exposed the window opening.

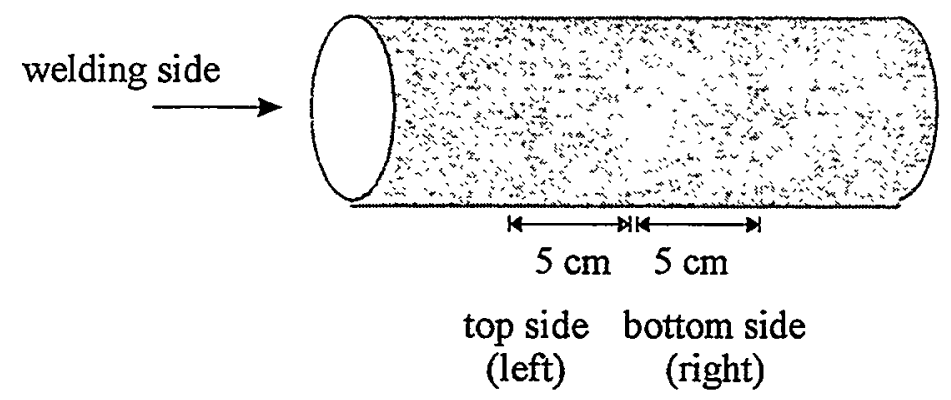

Each side of WRM was counted for 600 seconds except CEP001. The net areas of gamma-ray peaks at $59.5 \mathrm{keV}\left({ }^{241} \mathrm{Am}\right)$, and $129 \mathrm{keV}\left({ }^{239} \mathrm{Pu}\right)$ were recorded.

\section{Method of Data Analysis:}

The net areas of each gamma ray peak obtained from the left and right sides of each WRM were compared, and the deviation from the average net area was calculated. The table below showed the count ratio obtained from the left to right side of each WRM. The average left to right ratios for ${ }^{241} \mathrm{Am}$ and ${ }^{239} \mathrm{Pu}$ peaks were within $5 \%$ except for low mass Pu WRM (CEP002). This data (TABLE VI) showed that the blending materials were homogeneous distributed within each WRM. 
TABLE VI. CEP ${ }^{241}$ Am WRMs Homogeneity Measurements

\begin{tabular}{|c|c|c|c|c|c|c|c|c|c|c|c|c|}
\hline \multirow[b]{3}{*}{ WRM\# } & \multirow[b]{3}{*}{ Time (s) } & \multirow[b]{3}{*}{ Side } & \multirow[b]{3}{*}{$\mathrm{Am}, \mathrm{mg}$} & \multirow[b]{3}{*}{$\mathrm{Pu}, \mathrm{g}$} & \multicolumn{8}{|c|}{ Gamma-Ray Measurement, 600 seconds, $7 / 11 / 97,7 / 15 / 97,7 / 17 / 97$} \\
\hline & & & & & \multicolumn{4}{|c|}{$59.5 \mathrm{keV} 241 \mathrm{Am}$} & \multicolumn{4}{|c|}{$129 \mathrm{keV} 239 \mathrm{Pu}$} \\
\hline & & & & & count & $+1-$ & L/R & $\mathrm{ct} / \mathrm{mg}$ & count & $+1-$ & L/R & $\mathrm{ct} / \mathrm{g}$ \\
\hline CEP001 & 600 & $\overline{\mathrm{LL} 1}$ & 10.48 & 0.09 & 11750 & 121 & 1.000 & 1112 & 391 & 29 & & 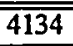 \\
\hline CEP001 & 600 & $\bar{R} 1$ & & & 12037 & 123 & & & 359 & 29 & & \\
\hline CEP001 & 600 & $\bar{L} 2$ & & & 11545 & 119 & & & 363 & 29 & & \\
\hline CEP001 & 600 & $\mathrm{R} 2$ & & & 11857 & 121 & & & 330 & 29 & & \\
\hline CEP001 & 1800 & L3 & & & 12009 & & & & 322 & & & \\
\hline CEP001 & $7200^{*}$ & CEN & & & 10911 & & & & 307 & & 0.976 & 3642 \\
\hline CEP001 & $7200^{*}$ & $\mathrm{LA}$ & & & 11512 & & & & 315 & & & \\
\hline CEP002 & 600 & $\mathrm{Ll}$ & 9.92 & 0.08 & 10808 & 116 & 1.002 & 1089 & 284 & 27 & 1.088 & 3460 \\
\hline CEP002 & 600 & $\overline{R I}$ & & & 10789 & 116 & & & 261 & 28 & & \\
\hline CEP003 & 600 & $\mathbf{L I}$ & 54.21 & 1.99 & 59368 & 270 & 0.991 & 1100 & 7181 & 97 & 1.006 & 3598 \\
\hline CEP003 & 600 & $\mathbf{R} 1$ & & & 59920 & 271 & & & 7135 & 97 & & \\
\hline CEP004 & 600 & $\mathrm{Ll}$ & 54.76 & 2.01 & 54107 & 259 & 1.006 & 985 & 7087 & 96 & 1.025 & 3484 \\
\hline CEP004 & 600 & $\bar{R} 1$ & & & 53786 & 259 & & & 6914 & 95 & & \\
\hline CEP005 & 600 & $\overline{\mathrm{Ll}}$ & 92.29 & 1.99 & 102536 & 353 & 1.000 & 1111 & 7159 & 99 & 0.983 & 3622 \\
\hline CEP005 & 600 & $\mathrm{RI}$ & & & 102559 & 353 & & & 7286 & 99 & & \\
\hline CEP006 & 600 & $\mathrm{L1}$ & 93.27 & 1.99 & 98057 & 345 & 1.045 & 1021 & 7067 & 98 & 1.004 & 3537 \\
\hline CEP006 & 600 & $\overline{\mathrm{RI}}$ & & & 92324 & 336 & & & 6899 & 98 & & \\
\hline CEP006 & 600 & $\mathrm{R2}$ & & & 95400 & 341 & & & 7172 & 90 & & \\
\hline CEP007 & 600 & $\mathrm{LI}$ & 54.79 & 0.40 & 68923 & 272 & 1.021 & 1198 & 1447 & 51 & 1.035 & 3855 \\
\hline CEP007 & 600 & $\mathrm{RI}$ & & & 68407 & 277 & & & 1459 & 51 & & \\
\hline CEP007 & 600 & $\overline{\mathrm{L} 2}$ & & & 63690 & 276 & & & 1656 & 53 & & \\
\hline CEP007 & 600 & $\overline{R 2}$ & & & 61498 & 271 & & & 1539 & 51 & & \\
\hline CEP008 & 600 & $\mathrm{Ll}$ & 52.16 & 0.41 & 58825 & 267 & 1.011 & 1128 & 1661 & 52 & 1.016 & 3883 \\
\hline CEP008 & 600 & $\overline{\mathbf{R I}}$ & & & 58401 & 266 & & & 1634 & 51 & & \\
\hline CEP008 & 600 & $\mathrm{L2}$ & & & 58637 & 266 & & & 1565 & 50 & & \\
\hline CEP008 & 600 & $\mathrm{R} 2$ & & & 58180 & 258 & & & 1607 & 52 & & \\
\hline CEP008 & 600 & $\mathrm{~L} 3$ & & & 60003 & 267 & & & 1630 & 51 & & \\
\hline CEP008 & 600 & $\overline{\mathrm{R} 3}$ & & & 58923 & 261 & & & 1539 & 52 & & \\
\hline CEP009 & 600 & $\mathrm{LI}$ & 103.45 & & 117609 & 376 & 1.018 & 1118 & \multirow{8}{*}{\multicolumn{4}{|c|}{ 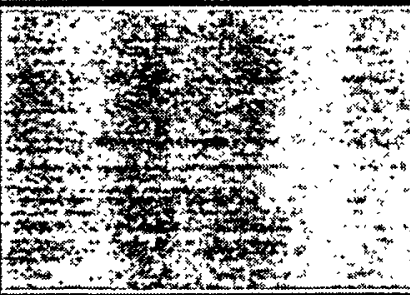 }} \\
\hline CEP009 & 600 & $L 2$ & & & 115701 & 373 & & & & & & \\
\hline CEP009 & 600 & $\mathrm{RI}$ & & & 114137 & 372 & & & & & & \\
\hline CEP009 & 600 & $\overline{\mathrm{R} 2}$ & & & 114976 & 373 & & & & & & \\
\hline CEP010 & 600 & $\overline{\mathrm{L} 1}$ & 99.83 & & 126938 & 391 & 0.999 & 1189 & & & & \\
\hline CEP010 & 600 & $\mathrm{R} 1$ & & & 125756 & 390 & & & & & & \\
\hline CEPO10 & 600 & $\mathrm{~L} 2$ & & & 110417 & 362 & & & & & & \\
\hline CEP010 & 600 & $\overline{\mathrm{R} 2}$ & & & 111864 & 363 & & & & & & \\
\hline & & & & & & & $\begin{array}{l}\text { AVG } \\
\text { STD } \\
\text { \%RSD }\end{array}$ & $\begin{array}{c}65 \\
5.89 \\
\end{array}$ & & & $\begin{array}{c}\mathrm{AVG}^{*} \\
* \\
\text { STD } \\
\% \mathrm{RSD}\end{array}$ & $\begin{array}{r}3635 \\
\\
158 \\
4.35 \\
\end{array}$ \\
\hline
\end{tabular}

*The counts in $59.5-\mathrm{keV}$ and $129-\mathrm{keV}$ peaks were expressed as $600 \mathrm{~s}$ counts.

** The short counts $(600,1800 \mathrm{~s})$ on CEP001 WRM were not included in the average of normalized 129-keV peak area due to poor peak shape and counting statistics.

\section{Verification of ${ }^{239} \mathrm{Pu}$ and ${ }^{241} \mathrm{Am}$ Content of the Working Reference Materials:}

Table VI also showed the normalized ${ }^{241} \mathrm{Am}$ and ${ }^{239} \mathrm{Pu}$ count rates (ct/g) for each WRM. The average counts per gram of ${ }^{241} \mathrm{Am}$ and ${ }^{239} \mathrm{Pu}$ were within $6 \%$. CEP001 was not included in ${ }^{239} \mathrm{Pu}$ calculation due to low $\mathrm{Pu}$ mass. 
The calculations of interest for this appendix are the uncertainties associated with the measurements of the activity and the grams of Pu and Am in each of the Working Reference Material(s) or "WRM".

\section{Activity Calculations}

Activity, in curies, has been defined as:

Activity $=$ Specific Activity $*$ Weight

or: $A=S A * W$

So, the variance of Activity can be written as:

$\operatorname{Var}(A)=S A^{2} * \operatorname{Var}(W)+W^{2} * \operatorname{Var}(S A)+\operatorname{Var}(S A) * \operatorname{Var}(W)$

Specific Activity can be written as:

$S A=F_{P u} * \sum_{i} F_{i} * S A_{i}+F_{A m} * S A_{A m}$, where

$i=P u_{238}, P u_{239}, P u_{240}, P u_{241}, P u_{242}$

$F_{i}=$ Isotope Fraction

$S A_{i}=$ Isotope Specific Activity

The branching ratio was included with the 241 , but not any others.

Variance of the Specific Activity is then:

$$
\begin{aligned}
& \operatorname{Var}(S A) \cong F_{P u}^{2} * \operatorname{Var}\left(\sum_{i} F_{i} S A_{i}\right)+\left(\sum_{i} F_{i} S A_{i}\right)^{2} * \operatorname{Var}\left(F_{P u}\right) \\
& +F_{A m}^{2} * \operatorname{Var}\left(S A_{A m}\right)+S A_{A m}^{2} * \operatorname{Var}\left(F_{A m}\right) \\
& \operatorname{Var}\left(\sum_{i} F_{i} S A_{i}\right)=\sum_{i}\left(\operatorname{Var}\left(F_{i} S A_{i}\right)\right)+2 \sum_{i \neq} \sum_{j} \operatorname{Cov}\left(F_{i} S A_{i}, F_{j} S A_{j}\right) \\
& \operatorname{Var}\left(F_{i} S A_{i}\right)=F_{i}^{2} \operatorname{Var}\left(S A_{i}\right)+S A_{i}^{2} \operatorname{Var}\left(F_{i}\right)+\operatorname{Var}\left(S A_{i}\right) * \operatorname{Var}\left(F_{i}\right)
\end{aligned}
$$

$\operatorname{Cov}\left(F_{i} S A_{i}, F_{j} S A_{j}\right) \cong \rho * S A_{i} \sqrt{\operatorname{Var}\left(F_{i}\right)} * S A_{j} \sqrt{\operatorname{Var}\left(F_{j}\right)}$

since

$$
\rho(x, y)=\operatorname{Cov}(x, y) / \sqrt{\operatorname{Var}(x) * \operatorname{Var}(y)}
$$

It is assumed that $S A_{i}$ and $S A_{j}$ are constants, so their variance is 0 . Since $p<=1$, we can get a maximum covariance value to use in deriving the variance of the Specific Acitivity by setting $\rho=1$. Using values supplied, all terms can be calculated to derive the variance for the activity due to Plutonium or Americium. 
In the activity calculations it is assumed that all Americium is in the form of $\mathrm{AmO}_{2}$. So the Am from the Plutonium was added to that of the $\mathrm{AmO}_{2}$ to do the calculations.

\section{Gram Value Uncertainties}

Each WRM has a measured amount of $\mathrm{PuO}_{2}$ put into the container that makes up the WRM.

The $\mathrm{PuO}_{2}$ is weighed and then transferred into the container for the WRM. Any $\mathrm{PuO}_{2}$ not transferred is considered in a loss term which is a count measurement calibrated to grams of Am. The "net" transferred grams of $\mathrm{PuO}_{2}$ is used to determine the amount of Pu and Am in a WRM. Using information on the fraction of $\mathrm{Pu}$ in $\mathrm{PuO}_{2}$ and the fraction of $\mathrm{Am}$ in the $\mathrm{PuO}_{2}$, the grams of $\mathrm{Am}$ and $\mathrm{Pu}$ are calculated. As equations this information is presented as:

$$
\begin{aligned}
P u & =P u O_{2(\text { net })} * \bar{F}_{P u} \\
A m & =P u O_{2(\text { net })} * \bar{F}_{A m}
\end{aligned}
$$

and:

$$
\begin{aligned}
P_{u} O_{2(\text { net })} & =\mathrm{PuO}_{2 \text { (meas) })}-\mathrm{PuO}_{2(\text { loss })} \\
& =P u O_{2(\text { meas })}-\frac{A m_{\text {(loss })}}{\bar{F}_{A m}}
\end{aligned}
$$

Where:

$P u=$ grams of $\mathrm{PU}$ in the WRM

$A m=$ grams of Am in the WRM

$\bar{F}_{P u}=$ fraction of $\mathrm{Pu}$ in the $\mathrm{PuO}_{2}$

$\bar{F}_{A m}=$ fraction of $\mathrm{Am}$ in the $\mathrm{PuO}_{2}$

$A m_{\text {(loss) }}=$ amount of Am lost during transfer

$\mathrm{PuO}_{2 \text { (meas) }}=$ amount of $\mathrm{PuO}_{2}$ measured before transfer

$\mathrm{PuO}_{2(\text { net })}=$ amount of $\mathrm{PuO}_{2}$ after loss is subtracted

The uncertainty associated with the grams of Pu in each WRM.

The variance of the Pu value, where $P u=P u O_{2(n e t)} * \bar{F}_{P u}$, can be calculated as:

$$
\operatorname{Var}[P u]=\left(\operatorname{PuO}_{2(n e)}\right)^{2} * \operatorname{Var}\left[\bar{F}_{P u}\right]+\left(\bar{F}_{P u}\right)^{2} * \operatorname{Var}\left[P u O_{2(n e t)}\right]+\operatorname{Var}\left[\bar{F}_{P u}\right] * \operatorname{Var}\left[P_{u} O_{2_{(n e)}}\right]
$$

where $\operatorname{Var}[x]$ is the variance for variable " $x$ ". 
$\mathrm{PuO}_{2 \text { (net) }}$ is the measured amount of $\mathrm{PuO}_{2}$ after the loss has been subtracted. The uncertainty in this value, " $\operatorname{Var}\left[\mathrm{PuO}_{2(\text { net })}\right]$ ", includes measurement uncertainty from the balance and uncertainty in the calculation of the loss of $\mathrm{PuO}_{2}$.

$\bar{F}_{P_{u}}$ is the relative amount of $\mathrm{Pu}$ in the $\mathrm{PuO}_{2}$. The determination of the values for $\bar{F}_{P_{u}}$ and $\operatorname{Var}\left[\bar{F}_{P_{u}}\right]$ is discussed elsewhere in the document.

All values except $\operatorname{Var}\left[\mathrm{PuO}_{2(n e t)}\right]$ come directly from current measurements and historical values (meaning values for these variables are available from existing data). $\operatorname{Var}\left[\mathrm{PuO}_{2(\text { net })}\right]$ can be found from the equation:

$\operatorname{Var}\left[P u O_{2(\text { net })}\right]=\operatorname{Var}\left[\mathrm{PuO}_{2(\text { meas })}\right]+\operatorname{Var}\left[\frac{A m_{(\text {loss })}}{\bar{F}_{A m}}\right]$

Here $\operatorname{Var}\left[\mathrm{PuO}_{2(\text { meas })}\right]$ is the balance uncertainty and $\operatorname{Var}\left[\frac{A m_{\text {(loss })}}{\bar{F}_{A m}}\right]$ is the uncertainty for the loss term. As discussed elsewhere in the document there are replicate measurements from which $\operatorname{Var}\left[\mathrm{PuO}_{2 \text { (mess) }}\right]$ can be estimated. Loss comes from a count measurement for Am, so this term includes systematic uncertainties due to the calibration of a Am standard to counts and the uncertainty of deriving the fraction of Am in the PuO2. The determination of the values for $\bar{F}_{A m}$ and $\operatorname{Var}\left[\bar{F}_{A m}\right]$ is discussed elsewhere in the document. $\operatorname{Var}\left[\frac{A m_{(\text {loss })}}{\bar{F}_{A m}}\right]$ can be approximated as:

$\operatorname{Var}\left[\frac{A m_{(\text {loss }}}{\bar{F}_{A m}}\right] \cong\left(\frac{A m_{(\text {loss })}}{\bar{F}_{A m}}\right)^{2} *\left(\frac{\operatorname{Var}\left[A m_{(\text {loss })}\right]}{\left(A m_{(\text {loss })}\right)^{2}}+\frac{\operatorname{Var}\left[\bar{F}_{A m}\right]}{\left(\bar{F}_{A m}\right)^{2}}\right)$

This can be rearranged to appear as relative standard deviations (RSD):

$\frac{\operatorname{Var}\left[\frac{A m_{(\text {loss })}}{\bar{F}_{A m}}\right]}{\left(\frac{A m_{(l o s s)}}{\bar{F}_{A m}}\right)^{2}} \cong \frac{\operatorname{Var}\left[A m_{(\text {loss })}\right]}{\left(A m_{(\text {loss })}\right)^{2}}+\frac{\operatorname{Var}\left[\bar{F}_{A m}\right]}{\left(\bar{F}_{A m}\right)^{2}}$

or:

$\left[R S D_{\text {loss }}\right]^{2} \cong\left[R S D_{A m(l o s s)}\right]^{2}+\left[R S D_{\text {assay }}\right]^{2}$ 
Looking at the value for the RSD for the Am assay:

$$
\begin{aligned}
{\left[R S D_{\text {assay }}\right]^{2} } & =\frac{\operatorname{Var}\left[\bar{F}_{A m}\right]}{\left(\bar{F}_{A m}\right)^{2}} \\
& =\frac{1.35 * 10^{-14}}{\left(8.23 * 10^{-4}\right)^{2}}=2.0 * 10^{-8}
\end{aligned}
$$

The values used in the equations presented in this appendix are discussed briefly in the last section of this appendix.

The value for the RSD of the Am measurement is a function of the amount of Am in the measurement. At present, a lower bound for this value.is of interest. From Appendix ??? (the listing of values) the counting statistics for the Am measurements will be used to estimate the RSD for the Am measurements. The nominally $30 \mathrm{mg}$ WRMs have RSD values for Am measurements ranging from $2.0 \%$ to $10 \%$. For the WRMs nominally close to $300 \mathrm{mg}$ and 3000 mg the uncertainty is considered no greater than $4.4 \%$. It is assumed that $2.0 \%$ is the lower bound for the RSD of the Am measurements, so:

$$
\begin{aligned}
{\left[R S D_{A m(\text { mos })}\right]^{2} } & =\frac{\operatorname{Var}\left[A m_{(l o s s)}\right]}{\left(A m_{(l o s s)}\right)^{2}} \\
& \geq(0.02)^{2}=4 * 10^{-4}
\end{aligned}
$$

Since $R S D_{\text {assay }}$ will be much less than $R S D_{\text {Am(neas) }}$, the value of the $R S D_{\text {assay }}$ will not affect the final result and will not be included in the calculation. So:

$$
\operatorname{Var}\left[\frac{A m_{(\text {loss })}}{\bar{F}_{A m}}\right] \equiv\left(\frac{A m_{(l o s s)}}{\bar{F}_{A m}}\right)^{2} *\left(\frac{\operatorname{Var}\left[A m_{(l o s s)}\right]}{\left(A m_{(l o s s)}\right)^{2}}\right)
$$

or:

$$
\operatorname{Var}\left[\frac{A m_{\text {(loss) }}}{\bar{F}_{A m}}\right] \cong\left[R S D_{A m(\text { loss })}\right]^{2} *\left(\frac{A m_{\text {(loss) }}}{\bar{F}_{A m}}\right)^{2}
$$

so: 


$$
\begin{aligned}
\operatorname{Var}\left[P u O_{2}\right] & =\operatorname{Var}\left[P u O_{2(\text { meas })}\right]+\operatorname{Var}\left[\frac{A m_{\text {(loss) }}}{\bar{F}_{A m}}\right] \\
& =\operatorname{Var}\left[P u O_{2(\text { mess })}\right]+\left[R S D_{A m(\text { los })}\right]^{2} *\left(\frac{A m_{(\text {loss })}}{\bar{F}_{A m}}\right)^{2} \\
& =\operatorname{Var}\left[P u O_{2 \text { (meas) })}\right]+\left(\frac{R S D_{A m(\text { loss })} * A m_{(\text {loss })}}{\bar{F}_{A m}}\right)^{2}
\end{aligned}
$$

The values for $R S D_{\text {Am(mear) }}$ vary with the specific measurement of Am. In this application, for the WRMs nominally close to $300 \mathrm{mg}$ and $3000 \mathrm{mg}$ the uncertainty is considered no greater than $4.4 \%$. For the nominally $30 \mathrm{mg}$ WRMs the counting statistics values are used which range from $2.0 \%$ to $10 \%$.

The uncertainty associated with the grams of Am from PuO2 in each WRM.

Having discussed the values for calculating the variance of the grams of $\mathrm{Pu}$, all the values to calculate the variance for the grams of Am from $\mathrm{PuO} 2$ have also been discussed. Since:

$$
A m=P_{u} O_{2(n e t)} * \bar{F}_{A m},
$$

The variance of Am is calculated as:

$$
\operatorname{Var}\left[A m_{(\text {meas })}\right]=\left(\mathrm{PuO}_{2(\text { net) }}\right)^{2} * \operatorname{Var}\left[\bar{F}_{A m}\right]+\left(\bar{F}_{A m}\right)^{2} * \operatorname{Var}\left[P u O_{2(n e t)}\right]+\operatorname{Var}\left[\bar{F}_{A m}\right] * \operatorname{Var}\left[P u O_{2(n e t)}\right]
$$

\section{Including Systematic Uncertainty in the uncertainty in Pu and Am from} PuO2 values

It is assumed that errors in developing a calibration for Am (which is needed to measure the amount of $\mathrm{PuO}_{2}$ loss) show up as a bias in the net amount of $\mathrm{PuO}_{2}$. The size of the bias changes when $\mathrm{PuO}_{2}$ is converted to grams of $\mathrm{Pu}$ using the fraction of $\mathrm{Pu}$ in $\mathrm{PuO}_{2}$. We assume that with the bias, a 95\% confidence interval on the amount of Pu would be the minimum and maximum of:

$$
\left(\mathrm{PuO} \mathrm{O}_{2} \pm \mathrm{Bias}\right) * \bar{F}_{P u} \pm 2 * \sqrt{\operatorname{Var}[\mathrm{Pu}]}
$$


This has the effect of putting a $95 \%$ confidence interval on the value of the $\mathrm{PuO}_{2}$ measurement plus the bias. This should yield a conservative or upper bound estimate of the true $95 \%$ confidence interval.

Similarly, for Americium, a 95\% confidence interval for the Am measurement is the minimum and maximum of:

$$
\left(\mathrm{PuO}_{2} \pm \mathrm{Bias}\right) * \bar{F}_{\mathrm{Am}} \pm 2 * \sqrt{\operatorname{Var}[\mathrm{Am}]}
$$

The estimated maximum bias varies with the amount of material in the WRM. For all WRMs the random uncertainty in the calibration is expected to be less than $1.6 \%$. For the WRMs nominally $30 \mathrm{mg}$, the systematic error in the calibration is expected to be less than $15 \%$. Total bias for a nominal $30 \mathrm{mg}$ WRM is expected to be less than $15 \%+2 * 1.6 \%=18 \%$ (to two significant digits). Similarly, for the nominal $300 \mathrm{mg}$ WRMs, total bias is expected to be less than $9 \%+2 * 1.6 \%=$ $12 \%$. The nominal $3000 \mathrm{mg}$ WRMs are expected to have a total bias less than $6 \%+2^{*} 1.6 \%=$ $9 \%$. These values are used in the equation above.

There is also a bias that develops in the fraction of $\mathrm{Am}$ in $\mathrm{PuO}_{2}$ measurement. The $241 \mathrm{Am}$ term relates to the 243 Am spike and there is uncertainty in this spike. There is no hard data on the size if this uncertainty. From comparisons with other measurments and expert opinion it is felt that the $243 \mathrm{Am}$ concentration has a bias of $0.25 \%$ or less. It is assumed that the value of $\bar{F}_{A m}$ has a bias of $0.25 \%$ or less with at least $95 \%$ confidence.

For the grams of Am value, this means that the uncertainty for this value is at least $0.25 \%$ since $A m=P u O_{2(n e t)} * \bar{F}_{A m}$ and the uncertainty on $\bar{F}_{A m}$ is $0.25 \%$. This is an additive error and adding $0.25 \%$ error onto the error already found would roughly give the total uncertainty. Adding this uncertainty value to the uncertainty already discussed was accomplished by finding the maximum total uncertainty using $\bar{F}_{A m}+0.25 \%$, then finding the minimum total uncertainty using $\bar{F}_{A m}-0.25 \%$. Here, total uncertainty is defined by the equation above for the $95 \%$ confidence interval. The difference between these two, the maximum and the minimum total uncertainties, gives an uncertainty bound when this $0.25 \%$ bias in $\bar{F}_{A m}$ is included. It is believed this uncertainty bound is at least $95 \%$.

For the uncertainty in the grams of $\mathrm{Pu}$, the same process is done as for Am. Using the equation above for the $95 \%$ confidence interval for the Pu measurements, the maximum total uncertainty using $\bar{F}_{A m}+0.25 \%$, and the minimum total uncertainty using $\bar{F}_{A m}-0.25 \%$ are found. The 
difference in these two values gives an uncertainty bound that is at least $95 \%$. The added effect of this bias is much less for Pu than for Am.

\section{Total Grams of Am From $\mathrm{AmO}_{2}$ and $\mathrm{PuO}_{2}$}

The total Americium in the standard comes from Plutonium oxide and Americium oxide or:

$A m_{\text {net }}=A m_{\mathrm{PuO2}}+A m_{\mathrm{AmO2}}$

$A m_{A m O 2}=A \mathrm{AO}_{2} * \bar{F}_{\mathrm{Am}_{\mathrm{AmO2}}}$ where $\bar{F}_{\mathrm{Am}_{\mathrm{AmO2}}}$ is the fraction of Am in $\mathrm{AmO}_{2}$

So :

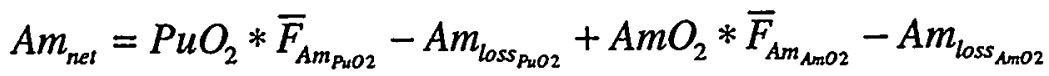

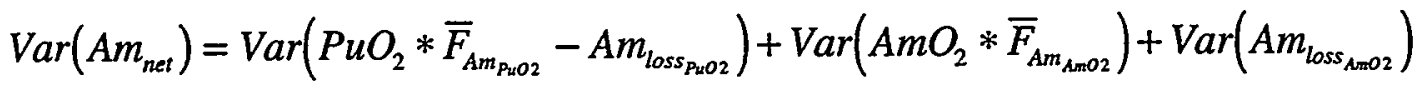

We have previously dealt with the variance of the Am from $\mathrm{PuO} 2$, so now we look at the variance of the Am from $\mathrm{AmO} 2$. , which we write as:

$\operatorname{Var}\left(A m_{A m O 2}\right)=A m O_{2}^{2} * \operatorname{Var}\left(\bar{F}_{A m}\right)+\bar{F}_{A m}{ }^{2} * \operatorname{Var}\left(A m O_{2}\right)+\operatorname{Var}\left(\bar{F}_{A m}\right) * \operatorname{Var}\left(A m O_{2}\right)$.

All these terms are availabe from the data.

Looking at the loss term, from the data we have a relative standard deviation term for the Am loss term, so we use $\operatorname{Var}\left(A m_{\text {loss }_{A m O 2}}\right)=\left(R S D_{A m} * A m_{\text {Loss }_{\text {Amo21 } 1}}\right)^{2}$. Note that uncertainty of the homogeneity of the $\mathrm{AmO}_{2}$ and $\mathrm{PuO}_{2}$ mixture add uncertainty to the Am loss term. We can write this in an equation as:

Loss $_{A m}=P_{A m O 2} * A m_{\text {Loss }_{\text {total }}}$, where $P_{\mathrm{AmO2}}$ is the proportion of Am from $\mathrm{AmO}_{2}$

So :

$$
\begin{aligned}
\operatorname{Var}\left(\operatorname{Loss}_{A m}\right)= & P_{A m O 2}{ }^{2} * \operatorname{Var}\left(A m_{\text {Loss }_{\text {toral }}}\right)+\operatorname{Var}\left(P_{A m O 2}\right) * A m_{\text {Loss }_{\text {torat }}}{ }^{2} \\
& +\operatorname{Var}\left(A m_{\text {Loss }_{\text {tocal }}}\right) * \operatorname{Var}\left(P_{A m O 2}\right)
\end{aligned}
$$

We assume that the mixture is homogeneous so that there is no uncertainty in the proportion of Am from AmO2. This last equation, when assuming homogeneity, is then the same equation above with the RSD term.

\section{More Details}

The initial measurements were made in June 1995. All assay and isotopic measurements were made current to $6 / 1 / 97$. 
The balance variabilty values came from check weighings done during the measurements. The $\mathrm{PuO}_{2}$ assay and isotopic values and uncertainties are long term uncertainties from months of checks. The $\mathrm{AmO} 2$ assay and isotopic values and uncertainties came from four replicates.

$\mathrm{PuO} \mathrm{O}_{2 \text { (meas), }} \mathrm{AmO} \mathrm{O}_{\text {(meas) }}=$ varies with each WRM

$\operatorname{Var}\left[\mathrm{PuO}_{2 \text { (meas) or }} \mathrm{AmO}_{2 \text { (meas) }}\right]=5.883 \mathrm{E}-10 \mathrm{~g}$ for $<0.10 \mathrm{~g}$ $=1.258 \mathrm{E}-09 \mathrm{~g}$ for $<1.0$ and $>0.10 \mathrm{~g}$

$=1.323 \mathrm{E}-09 \mathrm{~g}$ for $>1.0 \mathrm{~g}$

Mean of the fraction of Pu in PuO2 $=0.87804 \mathrm{~g} / \mathrm{g}$

Variance of the fraction of $\mathrm{Pu}$ in $\mathrm{PuO} 2=9.868 \mathrm{E}-08 \mathrm{~g}^{2} / \mathrm{g}^{2}$

Mean of the fraction of $\mathrm{Am}$ in $\mathrm{PuO} 2=1.35 \mathrm{E}-14 \mathrm{~g} / \mathrm{g}$

Variance of the fraction of $\mathrm{Am}$ in $\mathrm{PuO} 2=9.3907 \mathrm{E}-04 \mathrm{~g}^{2} / \mathrm{g}^{2}$

Mean of the fraction of $\mathrm{Am}$ in $\mathrm{AmO} 2=0.78727 \mathrm{~g} / \mathrm{g}$

Variance of the fraction of $A m$ in $A m O 2=1.25 E-06 g^{2} / \mathrm{g}^{2}$

Mean of the fraction of $\mathrm{Pu}$ in $\mathrm{AmO} 2$ is set at 0 .

Variance of the fraction of $\mathrm{Pu}$ in $\mathrm{AmO} 2$ is set at 0.

$A m_{(\text {loss })}=$ varies with each WRM

$R S D_{\text {Am(meas) }}=4.4 \%$ or RSD from counts, whichever is larger

Bias of $\bar{F}_{A m}=0.25 \%$

Bias of Am calibration $=6.8 \%$ for $6000 \mathrm{cpm}$ and above

$=7 \%$ for below $6000 \mathrm{cpm}$ and above $1500 \mathrm{cpm}$ 
The calculations of interest for this appendix are the uncertainties associated with the measurements of the activity and the grams of $U$ in each of the Working Reference Material(s) or "WRM".

\section{Activity Calculations}

Activity has units curies and is defined as:

Activity $=$ Specific Activity $*$ Weight

or: $A=S A * W$

So, the variance of Activity can be written as:

$\operatorname{Var}(A)=S A^{2} * \operatorname{Var}(W)+W^{2} * \operatorname{Var}(S A)+\operatorname{Var}(S A) * \operatorname{Var}(W)$

Specific Activity can be written as:

$S A=\sum_{i} F_{i} * S A_{i}$, where

$i=U_{233}, U_{234}, U_{235}, U_{236}, U_{238}$

$F_{i}=$ Isotope Fraction

$S A_{i}=$ Isotope Specific Activity

Variance of the Specific Activity is then:

$$
\begin{aligned}
& \operatorname{Var}\left(\sum_{i} F_{i} S A_{i}\right)=\sum_{i}\left(\operatorname{Var}\left(F_{i} S A_{i}\right)\right)+2 \sum_{i<} \sum_{j} \operatorname{Cov}\left(F_{i} S A_{i}, F_{j} S A_{j}\right) \\
& \operatorname{Var}\left(F_{i} S A_{i}\right)=F_{i}^{2} \operatorname{Var}\left(S A_{i}\right)+S A_{i}^{2} \operatorname{Var}\left(F_{i}\right)+\operatorname{Var}\left(S A_{i}\right) * \operatorname{Var}\left(F_{i}\right)
\end{aligned}
$$

and

$\operatorname{Cov}\left(F_{i} S A_{i}, F_{j} S A_{j}\right) \cong \rho * S A_{i} \sqrt{\operatorname{Var}\left(F_{i}\right)} * S A_{j} \sqrt{\operatorname{Var}\left(F_{j}\right)}$

since

$$
\rho(x, y)=\operatorname{Cov}(x, y) / \sqrt{\operatorname{Var}(x) * \operatorname{Var}(y)}
$$

It is assumed that $S A_{i}$ and $S A_{j}$ are constants, so their variance is 0 . Since $\rho<=1$, we can get a maximum covariance value to use in deriving the variance of the Specific Acitivity by setting $\rho=1$. Using values supplied, all terms can be calculated to derive the variance for the activity due to Uranium.

Specific Acitivity is ginfe, in terms of curies per gram of Uranium oxide. The weight term is then weight of Uranium oxide. 


\section{U Gram Value Uncertainties}

We are intersted in the gram of Uranium in each "working reference material" or WRM and the uncertainty associated with this gram value. We have developed equations to fit the procedures by which the WRMs were developed. Some knowledge of the procedures used to prepare the WRM's is assumed as no explantions are given below. A couple WRM's has procedures that were slightly different from the rest and so had terms that were defined using different weighings or may had an added term. These changes account for minute changes in the final answer, so the work below gives the information needed to determine if the uncertainties were derived in a reasonable fashion.

The amount of Uranium in each tube that is an WRM is:

$U_{\text {Tube }}=g D U O_{2 R E M} * \dddot{F}_{U}-g U_{\text {Holdup }}$

where:

$U_{\text {Tube }}=$ grams of $U$ in the Tube

$g D U O_{2 R E M}=$ grams of $D U O_{2}$ removed from the mixing bottle

$\dddot{F}_{U}=$ Fraction of Uranium in $\mathrm{DUO}_{2}$

$g U_{\text {Holdup }}=$ grams of $U$ in Holdup

So :

$$
\begin{aligned}
\operatorname{Var}\left(U_{T_{\text {Tube }}}\right) & =\operatorname{Var}\left(g D U O_{2 \text { REM }} * \dddot{F}_{U}\right)+\operatorname{Var}\left(g U_{\text {Holdup }}\right) \\
& \cong \operatorname{Var}\left(g D U O_{2 \text { REM }}\right) *\left(\dddot{F}_{U}\right)^{2}+\left(g D U O_{2 \text { REM }}\right)^{2} * \operatorname{Var}\left(\dddot{F}_{U}\right)+\operatorname{Var}\left(g U_{\text {Holdup }}\right)
\end{aligned}
$$

Note : $\dddot{F}_{U}, \operatorname{Var}\left(\dddot{F}_{U}\right)$ come from five $U$ assays

$: g U_{\text {Holdup }}, \operatorname{Var}\left(g U_{\text {Holdup }}\right)$ are sup plied with the holdup measurements

Continuing :

$g D U O_{2 R E M}=g B l e n d_{R e m} * P$

where :

$P=\frac{g \mathrm{DUO}_{2} \text { put inblend }}{g B \text { lend }}=$ proportion of $\mathrm{DUO}_{2}$ in Blend

$\operatorname{Var}\left(g D U O_{2 R E M}\right) \cong \operatorname{Var}\left(g B\right.$ lend $\left._{\mathrm{Re} m}\right) * P^{2}+\operatorname{Var}(P) *\left(g \text { Blend }_{\mathrm{Re} m}\right)^{2}$

$g$ Blend $_{\mathrm{Re} m}=g$ BlendandBottle beforeloading $-g$ BlendandBottle afferloading

$\operatorname{Var}\left(\right.$ gBlend $\left._{\mathrm{Rem}}\right) \leq \operatorname{Var}\left(\right.$ gBlendandBottle $\left._{\text {beforeloading }}\right)+\operatorname{Var}\left(\right.$ gBlendandBottle $\left._{\text {afterloading }}\right)$

$$
+2 \sqrt{\operatorname{Var}(\text { gBlendandBottle } \text { beforeloading })+\operatorname{Var}\left(\text { gBlendandBottle } e_{\text {afterloading }}\right)}
$$

where :

$\operatorname{Var}($ gBlendandBottle beforeloading $), \operatorname{Var}\left(g B\right.$ lendandBottle $\left.{ }_{\text {afferloading }}\right)$ are balance uncerta int ies 
Writing $P=\frac{X}{Y}$,

$\operatorname{Var}(P) \leq\left(\frac{X}{Y}\right)^{2} *\left(\left(\frac{\operatorname{Var}(X)}{X^{2}}\right)+\frac{\operatorname{Var}(Y)}{Y^{2}}+2 \frac{\sqrt{\operatorname{Var}(X) \operatorname{Var}(Y)}}{X Y}\right)+$ Homogeneity

where: Homogeneity is a Variance term

Here we are $u \sin g: \rho(x, y)=\frac{\operatorname{Cov}(x, y)}{\sqrt{\operatorname{Var}(x) \operatorname{Var}(y)}}$ and $-1 \leq \rho \leq 1$

Note:

$$
\begin{aligned}
\operatorname{Var}(X) & =\operatorname{Var}\left(g D U O_{2} \text { put in blend }\right)=\text { Balance uncertaint } y \\
\operatorname{Var}(Y) & =\operatorname{Var}(g B l e n d)=\operatorname{Var}\left(g D E_{\text {initial }}-g D E_{\text {removed }}+g D U O_{2}\right) \\
& \leq \operatorname{Var}\left(g D E_{\text {initial }}\right)+\operatorname{Var}\left(g D E_{\text {removed }}\right)+\operatorname{Var}\left(g D U O_{2}\right)+2 \sqrt{\operatorname{Var}\left(g D E_{\text {initial }}\right) \operatorname{Var}\left(g D E_{\text {removed }}\right)}+0
\end{aligned}
$$

where $D E$ is simply a filler

$\operatorname{Var}\left(g D E_{\text {initial }}\right), \operatorname{Var}\left(g D E_{\text {removed }}\right), \operatorname{Var}\left(g D U O_{2}\right)$ are balance uncertaint ies

Balance uncertainties come from multiple weighings of standards throughout the procedure. There are anywhere from 12 to 40 weighings of a given standard on a given balance. Uncertainties include a systematic and random error term. An approximate $95 \%$ uncertainty for the balances was defined as systematic plus two standard deviations of the random error. For the propagation of error work, one half of this $95 \%$ uncertainty bound was used as one standard deviation. This overestimates the true error, though these errors add very little to the final uncertainty, so we believe this conservative estimate is adequate.

The homgeneity estimates come from looking at six subsamples of the blend. Counts are measured at five $\mathrm{keV}$ values for each of the six subsamples. To be conservative, the $\mathrm{KeV}$ value that gives the largest distribution of counts, as measured by the standard deviation of the counts, is used for the homogeneity value. The counts per gram of blend are transformed into gDUO2 per gram of blend and expressed as a variance term. This variance term is added directly to the variance for the proportion of DUO2 in the blend. This again is conservative in that is tends to over estimate the true variance. This term is more important than the balance uncertainties, but still is a small variance term for the final uncertainty. Again, this amount of coservativeness in defining the error seems adequate.

\section{More Details}

The balance variabilty values came from check weighings done during the measurements.

The $\mathrm{UO}_{2}$ assay and isotopic values and uncertainties came from five replicates.

$\mathrm{UO}_{2 \text { (meas), }}=$ varies with each WRM

$\operatorname{Var}\left[\mathrm{UO}_{2(\text { meas })}\right]=$ Varies with balance and range of mass

Mean of the fraction of $\mathrm{U}$ in $\mathrm{UO} 2=0.87493 \mathrm{~g} / \mathrm{g}$

Variance of the fraction of $\mathrm{U}$ in $\mathrm{UO} 2=9.68-09 \mathrm{~g} / \mathrm{g}^{2}$

$U_{\text {(loss) }}=$ varies with each WRM

$R S D v($ meas $)=$ varies with each WRM 
Bias of $\bar{F}=0 . \%$

Bias of $U$ calibration $=0 \%$ for $6000 \mathrm{cpm}$ and above 


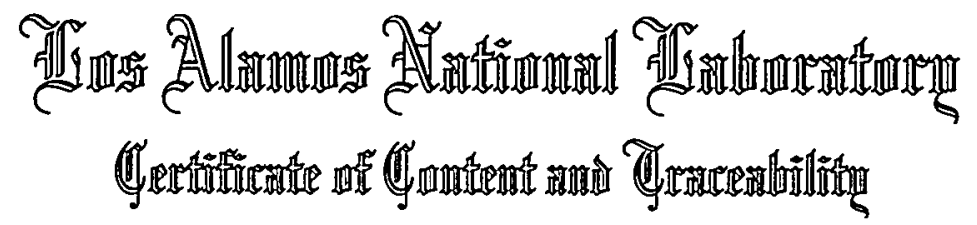

\section{Department of Energy/Idaho National Engineering and Environmental Laboratory Working Reference Material \# CEP001}

\section{$\mathrm{PuO}_{2}-\mathrm{AmO}_{2}-$ Diatomaceous Earth}

This Working Reference Material (WRM) contains high purity plutonium dioxide and americium dioxide dispersed in diatomaceous earth. Quantitative information and uncertainties on the nuclear content of this WRM are listed below. Complete information regarding the $\mathrm{Pu}$ and $\mathrm{Am}$ content, $\mathrm{Pu}$ isotopic ratios, chemical composition, elemental impurities, containment, and WRM fabrication procedure is described in the NDA CEP WRM Production Plan, LACP-98-155, and in files retained at the Idaho National Engineering and Environmental Laboratory by the Lockheed Martin Idaho Technology Co. Transuranic Waste Department and at the Los Alamos National Laboratory Analytical Chemistry Group.

\section{NUCLEAR MATERIAL CONTENT}

The nuclear material content and total alpha activity for this WRM are listed below. Also listed are overall uncertainty estimates at $95 \%$ confidence intervals (CD) for each component.

\begin{tabular}{|c|c|c|}
\hline Component & Quantity or Value & $95 \% \mathrm{CI}$ \\
\hline $\mathrm{PuO}_{2}$ in WRM & $0.09716 \mathrm{~g}$ & $\pm 0.00012 \mathrm{~g}^{(\mathrm{a})}$ \\
\hline Pu Assay & $0.87804 \mathrm{~g} \mathrm{Pu} / \mathrm{g} \mathrm{PuO}_{2}$ & $\pm 0.00036 \mathrm{~g}^{(\mathrm{b})}$ \\
\hline $\mathrm{Pu}$ in WRM & $0.08531 \mathrm{~g}$ & $\pm 0.00011 \mathrm{~g}^{(\mathrm{c})}$ \\
\hline $\mathrm{AmO}_{2}$ in $\mathrm{WRM}^{(\mathrm{d})}$ & $0.01319 \mathrm{~g}$ & $\pm 0.00009 \mathrm{~g}^{(e)}$ \\
\hline Am Assay $1^{(\mathfrak{n})}$ & $1069.5 \mu \mathrm{g} \mathrm{Am} / \mathrm{g} \mathrm{PuO}_{2}$ & $\pm 2.8 \mu \mathrm{g}^{(\mathrm{g})}$ \\
\hline Am Assay $2^{(h)}$ & $0.78727 \mathrm{~g} \mathrm{Am} / \mathrm{g} \mathrm{AmO}_{2}$ & $\pm 0.00352 \mathrm{~g}^{(\mathrm{i})}$ \\
\hline$A m$ in $W_{R M}^{(0)}$ & $0.010478 \mathrm{~g}$ & $\pm 0.00007 \mathrm{~g}^{(k)}$ \\
\hline \multicolumn{3}{|l|}{ Isotopic Weight Fraction } \\
\hline${ }^{238} \mathrm{Pu}$ & 0.000143 & $\pm 0.000018^{(1)}$ \\
\hline${ }^{239} \mathrm{Pu}$ & 0.937811 & $\pm 0.000028^{(1)}$ \\
\hline${ }^{240} \mathrm{Pu}$ & 0.059448 & $\pm 0.000010^{(1)}$ \\
\hline${ }^{241} \mathrm{Pu}$ & 0.002038 & $\pm 0.000019^{(1)}$ \\
\hline${ }^{242} \mathrm{Pu}$ & 0.000560 & $\pm 0.000003^{(1)}$ \\
\hline \multirow[t]{2}{*}{ Total $\alpha$ Activity in WRM } & $42.31 \mathrm{mCi}$ & $\pm 0.23 \mathrm{mCi}^{(\mathrm{m})}$ \\
\hline & $1.56 \mathrm{E}+09 \mathrm{~Bq}$ & $\pm 8.54 \mathrm{E}+06 \mathrm{~Bq}^{(\mathrm{m})}$ \\
\hline
\end{tabular}

All values decay corrected to 6/1/97.

Bill J. McKerley, Group Leader

Analytical Chemistry, NMT-1
Robert S. Marshall, Project Manager

NDA CEP WRM Production 


\section{MEASUREMENT METHOD AND TRACEABILITY}

The nuclear contents of this WRM were characterized and qualified using the following methods with traceability to the National Institute of Standards and Technology (formerly NBS) or New Brunswick Laboratory (NBL) standards.

$\begin{array}{cc}\text { Measurement } & \text { Measurement Method } \\ \text { Weighing } & 5 \text { place analytical balance } \\ \text { Pu Assay } & \text { Controlled Potential Coulometry } \\ \text { Am Assay } & \text { Isotope Dilution Mass Spec. } \\ \text { Pu Isotopic } & \text { Total Evaporation Mass Spec. } \\ \alpha \text { Activity } & \text { Calculated from Pu and Am mass } \\ & \text { and isotope } \alpha \text { specific activities. }\end{array}$

Reference Material

NIST traceable weights

NBL CRM 126

NIST SRM 4322B

NBS SRM 948

$T_{1 / 2}$ values are from: Firestone, Table of Isotopes, Vol. II, 8th ed., John Wiley \& Sons, New York, (1996). Atomic masses used are from: Audi \& Wapstra, The 1995 Update to the Atomic Mass Evaluation, Nuclear Physics, A595, p.409, (1995).

\section{NOTES}

Random and systematic error terms were combined and reported as $95 \%$ confidence intervals. Error terms and other notes are listed below:

(a) Balance precision, bouyancy, standard weight sets

(b) Long term precision, weighing precision and bias

(c) Above weighing and assay terms and correction for transfer loss

(d) Amount of $\mathrm{AmO}_{2}$ weighed for the WRM (does not contain the amount of Am from the decay of ${ }^{241} \mathrm{Pu}$ in the $\mathrm{PuO}_{2}$.

(e) Above weighing and assay terms and correction for transfer loss

(f) The amount of $\mathrm{Am}$ contained within the $\mathrm{PuO}_{2}$ from grow-in.

(g) Long term precision, weighing precision and bias

(h) The amount of Am contained within the $\mathrm{AmO}_{2}$

(i) Long term precision, weighing precision and bias

(j) Total amount of Am in the WRM from both the $\mathrm{AmO}_{2}$ and the $\mathrm{PuO}_{2}$

(k) Above weighing terms, Am assay terms, and corrections for transfer loss

(l) Long term precision and bias

(m) Based on propagated uncertainties on the Pu mass, ${ }^{241} \mathrm{Am}$ mass and $\mathrm{Pu}$ isotopic uncertainties listed above. It is recommended that all facilities participating in the NDA CEP program use the half-lives listed above to preclude facility to facility error terms introduced by using different half-life values. 


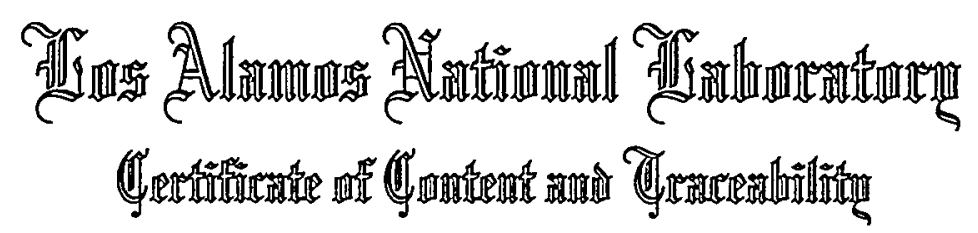

\section{Department of Energy/Idaho National Engineering and Environmental Laboratory Working Reference Material \# CEP002}

\section{$\mathrm{PuO}_{2}-\mathrm{AmO}_{2}-$ Diatomaceous Earth}

This Working Reference Material (WRM) contains high purity plutonium dioxide and americium dioxide dispersed in diatomaceous earth. Quantitative information and uncertainties on the nuclear content of this WRM are listed below. Complete information regarding the $\mathrm{Pu}$ and $\mathrm{Am}$ content, $\mathrm{Pu}$ isotopic ratios, chemical composition, elemental impurities, containment, and WRM fabrication procedure is described in the NDA CEP WRM Production Plan, LACP-98-155, and in files retained at the Idaho National Engineering and Environmental Laboratory by the Lockheed Martin Idaho Technology Co. Transuranic Waste Department and at the Los Alamos National Laboratory Analytical Chemistry Group.

\section{NUCLEAR MATERIAL CONTENT}

The nuclear material content and total alpha activity for this WRM are listed below. Also listed are overall uncertainty estimates at $95 \%$ confidence intervals $(\mathrm{CI})$ for each component.

\begin{tabular}{|c|c|c|}
\hline Component & Quantity or Value & $95 \% \mathrm{CI}$ \\
\hline $\mathrm{PuO}_{2}$ in WRM & $0.08963 \mathrm{~g}$ & $\pm 0.00012 \mathrm{~g}^{(\mathrm{a})}$ \\
\hline Pu Assay & $0.87804 \mathrm{~g} \mathrm{Pu} / \mathrm{g} \mathrm{PuO}_{2}$ & $\pm 0.00036 \mathrm{~g}^{(b)}$ \\
\hline $\mathrm{Pu}$ in WRM & $0.07870 \mathrm{~g}$ & $\pm 0.00010 \mathrm{~g}^{(c)}$ \\
\hline $\mathrm{AmO}_{2}^{-}$in $\mathrm{WRM}^{(\mathrm{d})}$ & $0.01248 \mathrm{~g}$ & $\pm 0.00008 \mathrm{~g}^{(\mathrm{e})} \quad \cdots$ \\
\hline Am Assay $1^{(\mathfrak{h})}$ & $1069.5 \mu \mathrm{g} \mathrm{Am} / \mathrm{g} \mathrm{PuO}_{2}$ & $\pm 2.8 \mu \mathrm{g}^{(\mathrm{g})}$ \\
\hline Am Assay $2^{(\mathrm{h})}$ & $0.78727 \mathrm{~g} \mathrm{Am} / \mathrm{g} \mathrm{AmO}_{2}$ & $\pm 0.00352 \mathrm{~g}^{(\mathrm{i})}$ \\
\hline$A m$ in $W_{R M}^{(j)}$ & $0.00991 \mathrm{~g}$ & $\pm 0.00007 \mathrm{~g}^{(k)}$ \\
\hline \multicolumn{3}{|l|}{ Isotopic Weight Fraction } \\
\hline${ }^{238} \mathrm{Pu}$ & 0.000143 & $\pm 0.000018^{(\mathfrak{l})}$ \\
\hline${ }^{239} \mathrm{Pu}$ & 0.937811 & $\pm 0.000028^{(1)}$ \\
\hline${ }^{240} \mathrm{Pu}$ & 0.059448 & $\pm 0.000010^{(1)}$ \\
\hline${ }^{241} \mathrm{Pu}$ & 0.002038 & $\pm 0.000019^{(1)}$ \\
\hline${ }^{242} \mathrm{Pu}$ & 0.000560 & $\pm 0.000003^{(1)}$ \\
\hline \multirow[t]{2}{*}{ Total $\alpha$ Activity in WRM } & $39.88 \mathrm{mCi}$ & $\pm 0.23 \mathrm{mCi}^{(\mathrm{m})}$ \\
\hline & $1.48 \mathrm{E}+09 \mathrm{~Bq}$ & $\pm 8.37 \mathrm{E}+06 \mathrm{~Bq}^{(\mathrm{m})}$ \\
\hline
\end{tabular}

All values decay corrected to $6 / 1 / 97$.

Bill J. McKerley, Group Leader

Analytical Chemistry, NMT-1
Robert S. Marshall, Project Manager NDA CEP WRM Production 


\section{MEASUREMENT METHOD AND TRACEABILITY}

The nuclear contents of this WRM were characterized and qualified using the following methods with traceability to the National Institute of Standards and Technology (formerly NBS) or New Brunswick Laboratory (NBL) standards.

$\begin{array}{cc}\text { Measurement } & \text { Measurement Method } \\ \text { Weighing } & 5 \text { place analytical balance } \\ \text { Pu Assay } & \text { Controlled Potential Coulometry } \\ \text { Am Assay } & \text { Isotope Dilution Mass Spec. } \\ \text { Pu Isotopic } & \text { Total Evaporation Mass Spec. } \\ \alpha \text { Activity } & \text { Calculated from Pu and Am mass } \\ & \text { and isotope } \alpha \text { specific activities. }\end{array}$

Reference Material

NIST traceable weights

NBL CRM 126

NIST SRM 4322B

NBS SRM 948

$T_{1 / 2}$ values are from: Firestone, Table of Isotopes, Vol. II, 8th ed., John Wiley \& Sons, New York, (1996). Atomic masses used are from: Audi \& Wapstra, The 1995 Update to the Atomic Mass Evaluation, Nuclear Physics, A595, p.409, (1995).

\section{NOTES}

Random and systematic error terms were combined and reported as $95 \%$ confidence intervals. Error terms and other notes are listed below:

(a) Balance precision, bouyancy, standard weight sets

(b) Long term precision, weighing precision and bias

(c) Above weighing and assay terms and correction for transfer loss

(d) Amount of $\mathrm{AmO}_{2}$ weighed for the WRM (does not contain the amount of Am from the decay of ${ }^{241} \mathrm{Pu}$ in the $\mathrm{PuO}_{2}$.

(e) Above weighing and assay terms and correction for transfer loss

(f) The amount of $\mathrm{Am}$ contained within the $\mathrm{PuO}_{2}$ from grow-in.

(g) Long term precision, weighing precision and bias

(h) The amount of Am contained within the $\mathrm{AmO}_{2}$

(i) Long term precision, weighing precision and bias

(j) Total amount of Am in the WRM from both the $\mathrm{AmO}_{2}$ and the $\mathrm{PuO}_{2}$

(k) Above weighing terms, Am assay terms, and corrections for transfer loss

(l) Long term precision and bias

(m) Based on propagated uncertainties on the Pu mass, ${ }^{241} \mathrm{Am}$ mass and Pu isotopic uncertainties listed above. It is recommended that all facilities participating in the NDA CEP program use the half-lives listed above to preclude facility to facility error terms introduced by using different half-life values. 


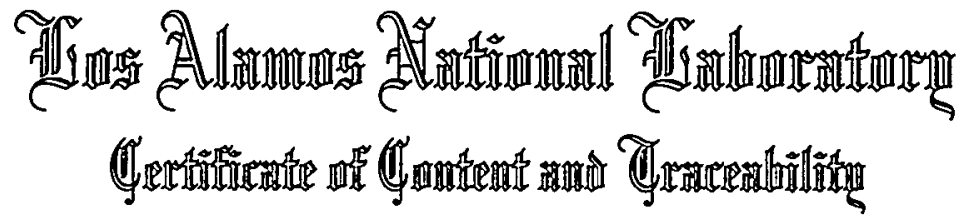

\section{Department of Energy/Idaho National Engineering and Environmental Laboratory Working Reference Material \# CEP003}

\section{$\mathrm{PuO}_{2}-\mathrm{AmO}_{2}-$ Diatomaceous Earth}

This Working Reference Material (WRM) contains high purity plutonium dioxide and americium dioxide dispersed in diatomaceous earth. Quantitative information and uncertainties on the nuclear content of this WRM are listed below. Complete information regarding the $\mathrm{Pu}$ and $\mathrm{Am}$ content, $\mathrm{Pu}$ isotopic ratios, chemical composition, elemental impurities, containment, and WRM fabrication procedure is described in the NDA CEP WRM Production Plan, LACP-98-155, and in files retained at the Idaho National Engineering and Environmental Laboratory by the Lockheed Martin Idaho Technology Co. Transuranic Waste Department and at the Los Alamos National Laboratory Analytical Chemistry Group.

\section{NUCLEAR MATERIAL CONTENT}

The nuclear material content and total alpha activity for this WRM are listed below. Also listed are overall uncertainty estimates at $\mathbf{9 5 \%}$ confidence intervals (CI) for each component.

\begin{tabular}{|c|c|c|}
\hline Component & Quantity or Value & $95 \% \mathrm{CI}$ \\
\hline $\mathrm{PuO}_{2}$ in WRM & $2.26382 \mathrm{~g}$ & $\pm 0.00236 \mathrm{~g}^{(a)}$ \\
\hline Pu Assay & 0.87804 g Pu/g PuO & $\pm 0.00036 \mathrm{~g}^{(b)}$ \\
\hline $\mathrm{Pu}$ in WRM & $1.98772 \mathrm{~g}$ & $\pm 0.00207 \mathrm{~g}^{(\mathrm{c})}$ \\
\hline $\mathrm{AmO}_{2}$ in $\mathrm{WRM}^{(\mathrm{d})}$ & $0.06610 \mathrm{~g}$ & $\pm 0.00027 \mathrm{~g}^{(e)}$ \\
\hline Am Assayl $1^{(\mathfrak{n})}$ & $1069.5 \mu \mathrm{g} \mathrm{Am} / \mathrm{g} \mathrm{PuO}_{2}$ & $\pm 2.8 \mu \mathrm{g}^{(\mathrm{B})}$ \\
\hline Am Assay2 $2^{(\mathrm{b})}$ & $0.78727 \mathrm{~g} \mathrm{Am} / \mathrm{g} \mathrm{AmO}_{2}$ & $\pm 0.00352 \mathrm{~g}^{(i)}$ \\
\hline Am in $W_{R M}^{(0)}$ & $0.04516 \mathrm{~g}$ & $\pm 0.00021 \mathrm{~g}^{(\mathrm{k})}$ \\
\hline \multicolumn{3}{|l|}{ Isotopic Weight Fraction } \\
\hline${ }^{238} \mathrm{Pu}$ & 0.000143 & $\pm 0.000018^{(1)}$ \\
\hline${ }^{239} \mathrm{Pu}$ & 0.937811 & $\pm 0.000028^{(1)}$ \\
\hline${ }^{240} \mathrm{Pu}$ & 0.059448 & $\pm 0.000010^{(1)}$ \\
\hline${ }^{241} \mathrm{Pu}$ & 0.002038 & $\pm 0.000019^{(1)}$ \\
\hline${ }^{242} \mathrm{Pu}$ & 0.000560 & $\pm 0.000003^{(1)}$ \\
\hline \multirow[t]{2}{*}{ Total $\alpha$ Activity in WRM } & $333.45 \mathrm{mCi}$ & $\pm 0.75 \mathrm{mCi}^{(\mathrm{m})}$ \\
\hline & $1.23 \mathrm{E}+10 \mathrm{~Bq}$ & $\pm 2.78 \mathrm{E}+07 \mathrm{~Bq}^{(\mathrm{m})}$ \\
\hline
\end{tabular}

All values decay corrected to 6/1/97.

Bill J. McKerley, Group Leader

Analytical Chemistry, NMT-1
Robert S. Marshall, Project Manager NDA CEP WRM Production 


\section{MEASUREMENT METHOD AND TRACEABILITY}

The nuclear contents of this WRM were characterized and qualified using the following methods with traceability to the National Institute of Standards and Technology (formerly NBS) or New Brunswick Laboratory (NBL) standards.

$\begin{array}{cc}\text { Measurement } & \text { Measurement Method } \\ \text { Weighing } & 5 \text { place analytical balance } \\ \text { Pu Assay } & \text { Controlled Potential Coulometry } \\ \text { Am Assay } & \text { Isotope Dilution Mass Spec. } \\ \text { Pu Isotopic } & \text { Total Evaporation Mass Spec. } \\ \alpha \text { Activity } & \text { Calculated from Pu and Am mass } \\ & \text { and isotope } \alpha \text { specific activities. }\end{array}$

$\underline{\text { Reference Material }}$

NIST traceable weights

NBL CRM 126

NIST SRM 4322B

NBS SRM 948

$\mathrm{T}_{1 / 2}$ values are from: Firestone, Table of Isotopes, Vol. II, 8th ed., John Wiley \& Sons, New York, (1996). Atomic masses used are from: Audi \& Wapstra, The 1995 Update to the Atomic Mass Evaluation, Nuclear Physics, A595, p.409, (1995).

\section{NOTES}

Random and systematic error terms were combined and reported as $95 \%$ confidence intervals. Error terms and other notes are listed below:

(a) Balance precision, bouyancy, standard weight sets

(b) Long term precision, weighing precision and bias

(c) Above weighing and assay terms and correction for transfer loss

(d) Amount of $\mathrm{AmO}_{2}$ weighed for the WRM (does not contain the amount of Am from the decay of ${ }^{241} \mathrm{Pu}$ in the $\mathrm{PuO}_{2}$.

(e) Above weighing and assay terms and correction for transfer loss

(f) The amount of $\mathrm{Am}$ contained within the $\mathrm{PuO}_{2}$ from grow-in.

(g) Long term precision, weighing precision and bias

(h) The amount of Am contained within the $\mathrm{AmO}_{2}$

(i) Long term precision, weighing precision and bias

(j) Total amount of $\mathrm{Am}$ in the WRM from both the $\mathrm{AmO}_{2}$ and the $\mathrm{PuO}_{2}$

(k) Above weighing terms, Am assay terms, and corrections for transfer loss

(l) Long term precision and bias

(m) Based on propagated uncertainties on the Pu mass, ${ }^{241} \mathrm{Am}$ mass and Pu isotopic uncertainties listed above. It is recommended that all facilities participating in the NDA CEP program use the half-lives listed above to preclude facility to facility error terms introduced by using different half-life values. 


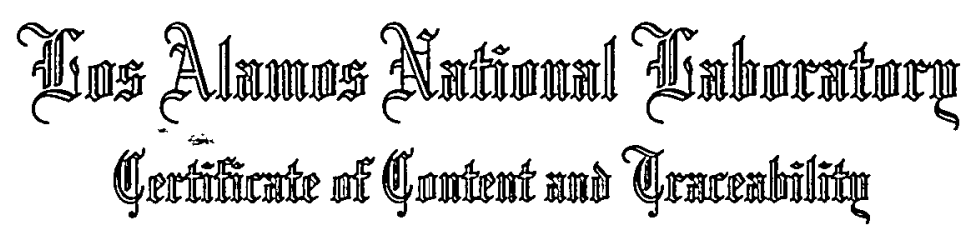

\section{Department of Energy/Idaho National Engineering and Environmental Laboratory Working Reference Material \# CEP004}

\section{$\mathrm{PuO}_{2}-\mathrm{AmO}_{2}$-Diatomaceous Earth}

This Working Reference Material (WRM) contains high purity plutonium dioxide and americium dioxide dispersed in diatomaceous earth. Quantitative information and uncertainties on the nuclear content of this WRM are listed below. Complete information regarding the $\mathrm{Pu}$ and $\mathrm{Am}$ content, $\mathrm{Pu}$ isotopic ratios, chemical composition, elemental impurities, containment, and WRM fabrication procedure is described in the NDA CEP WRM Production Plan, LACP-98-155, and in files retained at the Idaho National Engineering and Environmental Laboratory by the Lockheed Martin Idaho Technology Co. Transuranic Waste Department and at the Los Alamos National Laboratory Analytical Chemistry Group.

\section{NUCLEAR MATERIAL CONTENT}

The nuclear material content and total alpha activity for this WRM are listed below. Also listed are overall uncertainty estimates at $95 \%$ confidence intervals $(\mathrm{CI})$ for each component.

\begin{tabular}{|c|c|c|}
\hline Component & Quantity or Value & $95 \% \mathrm{CI}$ \\
\hline $\mathrm{PuO}_{2}$ in WRM & $2.28761 \mathrm{~g}$ & $\pm 0.00232 \mathrm{~g}^{(\mathrm{a})}$ \\
\hline Pu Assay & $0.87804 \mathrm{~g} \mathrm{Pu} / \mathrm{g} \mathrm{PuO}_{2}$ & $\pm 0.00036 \mathrm{~g}^{(b)}$ \\
\hline $\mathrm{Pu}$ in WRM & $2.00861 \mathrm{~g}$ & $\pm 0.00204 \mathrm{~g}^{(c)}$ \\
\hline $\mathrm{AmO}_{2}$ in $\mathrm{WRM}^{(d)}$ & $0.06680 \mathrm{~g}$ & $\pm 0.00027 \mathrm{~g}^{(e)}$ \\
\hline Am Assayl $1^{(\mathfrak{B})}$ & $1069.5 \mu \mathrm{g} \mathrm{Am} / \mathrm{g} \mathrm{PuO}_{2}$ & $\pm 2.8 \mu \mathrm{g}^{(8)}$ \\
\hline Am Assay2 $2^{(\mathfrak{h})}$ & $0.78727 \mathrm{~g} \mathrm{Am} / \mathrm{g} \mathrm{AmO}_{2}$ & $\pm 0.00352 \mathrm{~g}^{(1)}$ \\
\hline Am in $W_{R M}^{(0)}$ & $0.05474 \mathrm{~g}$ & $\pm 0.00022 \mathrm{~g}^{(k)}$ \\
\hline \multicolumn{3}{|l|}{ Isotopic Weight Fraction } \\
\hline${ }^{238} \mathrm{Pu}$ & 0.000143 & $\pm 0.000018^{(0)}$ \\
\hline${ }^{239} \mathrm{Pu}$ & 0.937811 & $\pm 0.000028^{(1)}$ \\
\hline${ }^{240} \mathrm{Pu}$ & 0.059448 & $\pm 0.000010^{(\mathrm{l})}$ \\
\hline${ }^{241} \mathrm{Pu}$ & 0.002038 & $\pm 0.000019^{(1)}$ \\
\hline${ }^{242} \mathrm{Pu}$ & 0.000560 & $\pm 0.000003^{(l)}$ \\
\hline \multirow[t]{2}{*}{ Total $\alpha$ Activity in WRM } & $336.98 \mathrm{mCi}$ & $\pm 0.76 \mathrm{mCi}^{(\mathrm{m})}$ \\
\hline & $1.25 \mathrm{E}+10 \mathrm{~Bq}$ & $\pm 2.80 \mathrm{E}+07 \mathrm{~Bq}^{(\mathrm{m})}$ \\
\hline
\end{tabular}

All values decay corrected to $6 / 1 / 97$.

Bill J. McKerley, Group Leader

Analytical Chemistry, NMT-1
Robert S. Marshall, Project Manager

NDA CEP WRM Production 


\section{MEASUREMENT METHOD AND TRACEABILITY}

The nuclear contents of this WRM were characterized and qualified using the following methods with traceability to the National Institute of Standards and Technology (formerly NBS) or New Brunswick Laboratory (NBL) standards.

$\begin{array}{cc}\text { Measurement } & \text { Measurement Method } \\ \text { Weighing } & 5 \text { place analytical balance } \\ \text { Pu Assay } & \text { Controlled Potential Coulometry } \\ \text { Am Assay } & \text { Isotope Dilution Mass Spec. } \\ \text { Pu Isotopic } & \text { Total Evaporation Mass Spec. } \\ \alpha \text { Activity } & \text { Calculated from Pu and Am mass } \\ & \text { and isotope } \alpha \text { specific activities. }\end{array}$

Reference Material

NIST traceable weights

NBL CRM 126

NIST SRM 4322B

NBS SRM 948

$T_{1 / 2}$ values are from: Firestone, Table of Isotopes, Vol. II, 8th ed., John Wiley \& Sons, New York, (1996). Atomic masses used are from: Audi \& Wapstra, The 1995 Update to the Atomic Mass Evaluation, Nuclear Physics, A595, p.409, (1995).

\section{NOTES}

Random and systematic error terms were combined and reported as $95 \%$ confidence intervals. Error terms and other notes are listed below:

(a) Balance precision, bouyancy, standard weight sets

(b) Long term precision, weighing precision and bias

(c) Above weighing and assay terms and correction for transfer loss

(d) Amount of $\mathrm{AmO}_{2}$ weighed for the WRM (does not contain the amount of Am from the decay of ${ }^{241} \mathrm{Pu}$ in the $\mathrm{PuO}_{2}$.

(e) Above weighing and assay terms and correction for transfer loss

(f) The amount of Am contained within the $\mathrm{PuO}_{2}$ from grow-in.

(g) Long term precision, weighing precision and bias

(h) The amount of Am contained within the $\mathrm{AmO}_{2}$

(i) Long term precision, weighing precision and bias

(j) Total amount of Am in the WRM from both the $\mathrm{AmO}_{2}$ and the $\mathrm{PuO}_{2}$

(k) Above weighing terms, Am assay terms, and corrections for transfer loss

(l) Long term precision and bias

(m) Based on propagated uncertainties on the Pu mass, ${ }^{241} \mathrm{Am}$ mass and $\mathrm{Pu}$ isotopic uncertainties listed above. It is recommended that all facilities participating in the NDA CEP program use the half-lives listed above to preclude facility to facility error terms introduced by using different half-life values. 


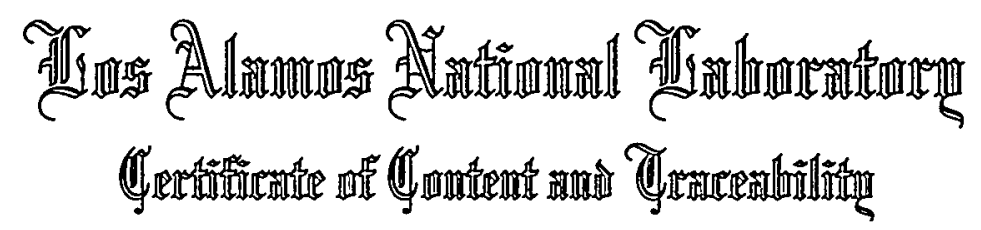

\section{Department of Energy/Idaho National Engineering and Environmental Laboratory Working Reference Material \# CEP005}

\section{$\mathrm{PuO}_{2}-\mathrm{AmO}_{2}$-Diatomaceous Earth}

This Working Reference Material (WRM) contains high purity plutonium dioxide and americium dioxide dispersed in diatomaceous earth. Quantitative information and uncertainties on the nuclear content of this WRM are listed below. Complete information regarding the $\mathrm{Pu}$ and $\mathrm{Am}$ content, $\mathrm{Pu}$ isotopic ratios, chemical composition, elemental impurities, containment, and WRM fabrication procedure is described in the NDA CEP WRM Production Plan, LACP-98-155, and in files retained at the Idaho National Engineering and Environmental Laboratory by the Lockheed Martin Idaho Technology Co. Transuranic Waste Department and at the Los Alamos National Laboratory Analytical Chemistry Group.

\section{NUCLEAR MATERIAL CONTENT}

The nuclear material content and total alpha activity for this WRM are listed below. Also listed are overall uncertainty estimates at $95 \%$ confidence intervals (CI) for each component.

\begin{tabular}{|c|c|c|}
\hline Component & Quantity or Value & $95 \% \mathrm{CI}$ \\
\hline $\mathrm{PuO}_{2}$ in WRM & $2.26968 \mathrm{~g}$ & $\pm 0.00231 \mathrm{~g}^{(a)}$ \\
\hline Pu Assay & $0.87804 \mathrm{~g} \mathrm{Pu} / \mathrm{g} \mathrm{PuO}_{2}$ & $\pm 0.00036 \mathrm{~g}^{(b)}$ \\
\hline $\mathrm{Pu}$ in WRM & $1.99287 \mathrm{~g}$ & $\pm 0.00203 \mathrm{~g}^{(c)}$ \\
\hline $\mathrm{AmO}_{2}$ in $\mathrm{WRM}^{(\mathrm{d})}$ & $0.11446 \mathrm{~g}$ & $\pm 0.00046 \mathrm{~g}^{(e)}$ \\
\hline Am Assay $1^{(\mathfrak{l})}$ & $1069.5 \mu \mathrm{g} \mathrm{Am} / \mathrm{g} \mathrm{PuO}_{2}$ & $\pm 2.8 \mu \mathrm{g}^{(\mathrm{s})}$ \\
\hline Am Assay $2^{(\mathrm{h})}$ & $0.78727 \mathrm{~g} \mathrm{Am} / \mathrm{g} \mathrm{AmO}_{2}$ & $\pm 0.00352 \mathrm{~g}^{(i)}$ \\
\hline$A m$ in $W R M^{(0)}$ & $0.09224 \mathrm{~g}$ & $\pm 0.00037 \mathrm{~g}^{(\mathrm{k})}$ \\
\hline \multicolumn{3}{|l|}{ Isotopic Weight Fraction } \\
\hline${ }^{238} \mathrm{Pu}$ & 0.000143 & $\pm 0.000018^{(\mathfrak{l})}$ \\
\hline${ }^{239} \mathrm{Pu}$ & 0.937811 & $\pm 0.000028^{(1)}$ \\
\hline${ }^{240} \mathrm{Pu}$ & 0.059448 & $\pm 0.000010^{(1)}$ \\
\hline${ }^{241} \mathrm{Pu}$ & 0.002038 & $\pm 0.000019^{(\mathfrak{l})}$ \\
\hline${ }^{242} \mathrm{Pu}$ & 0.000560 & $\pm 0.000003^{(1)}$ \\
\hline \multirow[t]{2}{*}{ Total $\alpha$ Activity in WRM } & $464.61 \mathrm{mCi}$ & $\pm 1.26 \mathrm{mCi}^{(m)}$ \\
\hline & $1.72 \mathrm{E}+10 \mathrm{~Bq}$ & $\pm 4.67 \mathrm{E}+07 \mathrm{~Bq}^{(\mathrm{m})}$ \\
\hline
\end{tabular}

All values decay corrected to $6 / 1 / 97$. 


\section{MEASUREMENT METHOD AND TRACEABILITY}

The nuclear contents of this WRM were characterized and qualified using the following methods with traceability to the National Institute of Standards and Technology (formerly NBS) or New Brunswick Laboratory (NBL) standards.
Measurement
Measurement Method
Weighing
5 place analytical balance
Pu Assay
Controlled Potential Coulometry
Am Assay
Isotope Dilution Mass Spec.
Pu Isotopic
Total Evaporation Mass Spec.
$\alpha$ Activity
Calculated from $\mathrm{Pu}$ and Am mass
and isotope $\alpha$ specific activities.

$\underline{\text { Reference Material }}$

NIST traceable weights

NBL CRM 126

NIST SRM 4322B

NBS SRM 948

$T_{1 / 2}$ values are from: Firestone, Table of Isotopes, Vol. II, 8th ed., John Wiley \& Sons, New York, (1996). Atomic masses used are from: Audi \& Wapstra, The 1995 Update to the Atomic Mass Evaluation, Nuclear Physics, A595, p.409, (1995).

\section{NOTES}

Random and systematic error terms were combined and reported as $95 \%$ confidence intervals. Error terms and other notes are listed below:

(a) Balance precision, bouyancy, standard weight sets

(b) Long term precision, weighing precision and bias

(c) Above weighing and assay terms and correction for transfer loss

(d) Amount of $\mathrm{AmO}_{2}$ weighed for the WRM (does not contain the amount of Am from the decay of ${ }^{241} \mathrm{Pu}$ in the $\mathrm{PuO}_{2}$.

(e) Above weighing and assay terms and correction for transfer loss

(f) The amount of $\mathrm{Am}$ contained within the $\mathrm{PuO}_{2}$ from grow-in.

(g) Long term precision, weighing precision and bias

(h) The amount of $\mathrm{Am}$ contained within the $\mathrm{AmO}_{2}$

(i) Long term precision, weighing precision and bias

(j) Total amount of $\mathrm{Am}$ in the WRM from both the $\mathrm{AmO}_{2}$ and the $\mathrm{PuO}_{2}$

(k) Above weighing terms, Am assay terms, and corrections for transfer loss

(l) Long term precision and bias

(m) Based on propagated uncertainties on the Pu mass, ${ }^{241} \mathrm{Am}$ mass and $\mathrm{Pu}$ isotopic uncertainties listed above. It is recommended that all facilities participating in the NDA CEP program use the half-lives listed above to preclude facility to facility error terms introduced by using different half-life values. 


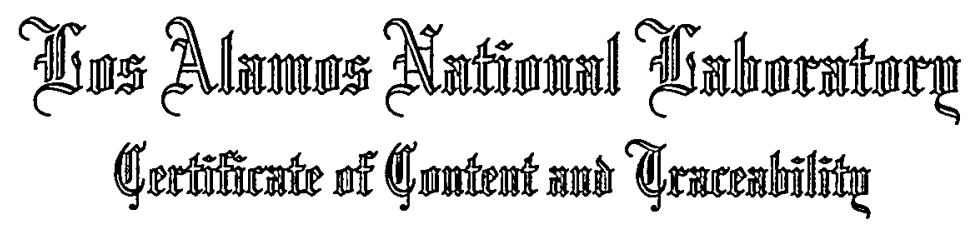

\section{Department of Energy/Idaho National Engineering and Environmental Laboratory Working Reference Material \# CEP006}

\section{$\mathrm{PuO}_{2}-\mathrm{AmO}_{2}$-Diatomaceous Earth}

This Working Reference Material (WRM) contains high purity plutonium dioxide and americium dioxide dispersed in diatomaceous earth. Quantitative information and uncertainties on the nuclear content of this WRM are listed below. Complete information regarding the $\mathrm{Pu}$ and $\mathrm{Am}$ content, $\mathrm{Pu}$ isotopic ratios, chemical composition, elemental impurities, containment, and WRM fabrication procedure is described in the NDA CEP WRM Production Plan, LACP-98-155, and in files retained at the Idaho National Engineering and Environmental Laboratory by the Lockheed Martin Idaho Technology Co. Transuranic Waste Department and at the Los Alamos National Laboratory Analytical Chemistry Group.

\section{NUCLEAR MATERIAL CONTENT}

The nuclear material content and total alpha activity for this WRM are listed below. Also listed are overall uncertainty estimates at $\mathbf{9 5 \%}$ confidence intervals (CI) for each component.

\begin{tabular}{|c|c|c|}
\hline Component & Quantity or Value & $95 \% \mathrm{CI}$ \\
\hline $\mathrm{PuO}_{2}$ in WRM & $2.26754 \mathrm{~g}$ & $\pm 0.00229 \mathrm{~g}^{(\mathrm{a})}$ \\
\hline Pu Assay & $0.87804 \mathrm{~g} \mathrm{Pu} / \mathrm{g} \mathrm{PuO}_{2}$ & $\pm 0.00036 \mathrm{~g}^{(\mathrm{b})}$ \\
\hline $\mathrm{Pu}$ in WRM & $1.99099 \mathrm{~g}$ & $\pm 0.00201 \mathrm{~g}^{(c)}$ \\
\hline $\mathrm{AmO}_{2}$ in $\mathrm{WRM}^{(\mathrm{d})}$ & $0.11573 \mathrm{~g}$ & $\pm 0.00046 \mathrm{~g}^{(e)}$ \\
\hline Am Assayl $1^{(\mathfrak{)})}$ & $1069.5 \mu \mathrm{g} \mathrm{Am} / \mathrm{g} \mathrm{PuO}_{2}$ & $\pm 2.8 \mu \mathrm{g}^{(\mathrm{g})}$ \\
\hline Am Assay2 $2^{(\mathrm{h})}$ & $0.78727 \mathrm{~g} \mathrm{Am} / \mathrm{g} \mathrm{AmO}_{2}$ & $\pm 0.00352 \mathrm{~g}^{(\mathrm{i})}$ \\
\hline Am in $W_{R M}^{(0)}$ & $0.09324 \mathrm{~g}$ & $\pm 0.00037 \mathrm{~g}^{(k)}$ \\
\hline \multicolumn{3}{|l|}{ Isotopic Weight Fraction } \\
\hline${ }^{238} \mathrm{Pu}$ & 0.000143 & $\pm 0.000018^{(\mathfrak{l})}$ \\
\hline${ }^{239} \mathrm{Pu}$ & 0.937811 & $\pm 0.000028^{(\mathfrak{l})}$ \\
\hline${ }^{240} \mathrm{Pu}$ & 0.059448 & $\pm 0.000010^{(1)}$ \\
\hline${ }^{241} \mathrm{Pu}$ & 0.002038 & $\pm 0.000019^{(1)}$ \\
\hline${ }^{242} \mathrm{Pu}$ & 0.000560 & $\pm 0.000003^{(1)}$ \\
\hline \multirow[t]{2}{*}{ Total $\alpha$ Activity in WRM } & $467.88 \mathrm{mCi}$ & $\pm 1.28 \mathrm{mCi}^{(\mathrm{m})}$ \\
\hline & $1.73 \mathrm{E}+10 \mathrm{~Bq}$ & $\pm 4.72 \mathrm{E}+07 \mathrm{~Bq}^{(\mathrm{m})}$ \\
\hline
\end{tabular}

All values decay corrected to $6 / 1 / 97$.

Bill J. McKerley, Group Leader Analytical Chemistry, NMT-1
Robert S. Marshall, Project Manager

NDA CEP WRM Production 


\section{MEASUREMENT METHOD AND TRACEABILITY}

The nuclear contents of this WRM were characterized and qualified using the following methods with traceability to the National Institute of Standards and Technology (formerly NBS) or New Brunswick Laboratory (NBL) standards.

$\begin{array}{ccc}\text { Measurement } & \text { Measurement Method } & \text { Reference Material } \\ \text { Weighing } & 5 \text { place analytical balance } & \text { NIST traceable weights } \\ \text { Pu Assay } & \text { Controlled Potential Coulometry } & \text { NBL CRM 126 } \\ \text { Am Assay } & \text { Isotope Dilution Mass Spec. } & \text { NIST SRM 4322B } \\ \text { Pu Isotopic } & \text { Total Evaporation Mass Spec. } & \text { NBS SRM 948 } \\ \alpha \text { Activity } & \text { Calculated from Pu and Am mass } & \\ & \text { and isotope } \alpha \text { specific activities. } & \end{array}$

$T_{1 / 2}$ values are from: Firestone, Table of Isotopes, Vol. II, 8th ed., John Wiley \& Sons, New York, (1996). Atomic masses used are from: Audi \& Wapstra, The 1995 Update to the Atomic Mass Evaluation, Nuclear Physics, A595, p.409, (1995).

\section{NOTES}

Random and systematic error terms were combined and reported as $95 \%$ confidence intervals. Error terms and other notes are listed below:

(a) Balance precision, bouyancy, standard weight sets

(b) Long term precision, weighing precision and bias

(c) Above weighing and assay terms and correction for transfer loss

(d) Amount of $\mathrm{AmO}_{2}$ weighed for the WRM (does not contain the amount of Am from the decay of ${ }^{241} \mathrm{Pu}$ in the $\mathrm{PuO}_{2}$.

(e) Above weighing and assay terms and correction for transfer loss

(f) The amount of Am contained within the $\mathrm{PuO}_{2}$ from grow-in.

(g) Long term precision, weighing precision and bias

(h) The amount of $\mathrm{Am}$ contained within the $\mathrm{AmO}_{2}$

(i) Long term precision, weighing precision and bias

(j) Total amount of $\mathrm{Am}$ in the WRM from both the $\mathrm{AmO}_{2}$ and the $\mathrm{PuO}_{2}$

(k) Above weighing terms, Am assay terms, and corrections for transfer loss

(l) Long term precision and bias

(m) Based on propagated uncertainties on the Pu mass, ${ }^{241} \mathrm{Am}$ mass and Pu isotopic uncertainties listed above. It is recommended that all facilities participating in the NDA CEP program use the half-lives listed above to preclude facility to facility error terms introduced by using different half-life values. 


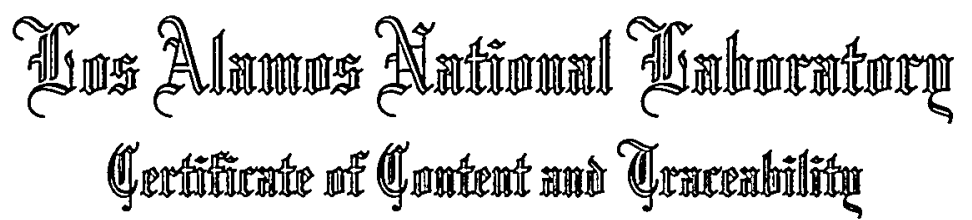

\section{Department of Energy/Idaho National Engineering and Environmental Laboratory Working Reference Material \# CEP007}

\section{$\mathrm{PuO}_{2}-\mathrm{AmO}_{2}$-Diatomaceous Earth}

This Working Reference Material (WRM) contains high purity plutonium dioxide and americium dioxide dispersed in diatomaceous earth. Quantitative information and uncertainties on the nuclear content of this WRM are listed below. Complete information regarding the $\mathrm{Pu}$ and $\mathrm{Am}$ content, $\mathrm{Pu}$ isotopic ratios, chemical composition, elemental impurities, containment, and WRM fabrication procedure is described in the NDA CEP WRM Production Plan, LACP-98-155, and in files retained at the Idaho National Engineering and Environmental Laboratory by the Lockheed Martin Idaho Technology Co. Transuranic Waste Department and at the Los Alamos National Laboratory Analytical Chemistry Group.

\section{NUCLEAR MATERIAL CONTENT}

The nuclear material content and total alpha activity for this WRM are listed below. Also listed are overall uncertainty estimates at $\mathbf{9 5 \%}$ confidence intervals $(\mathrm{CI})$ for each component.

\begin{tabular}{|c|c|c|}
\hline Component & Quantity or Value & $95 \% \mathrm{CI}$ \\
\hline $\mathrm{PuO}_{2}$ in WRM & $0.45038 \mathrm{~g}$ & $\pm 0.00047 \mathrm{~g}^{(\mathrm{a})}$ \\
\hline Pu Assay & $0.87804 \mathrm{~g} \mathrm{Pu} / \mathrm{g} \mathrm{PuO}_{2}$ & $\pm 0.00036 \mathrm{~g}^{(b)}$ \\
\hline Pu in WRM & $0.39545 \mathrm{~g}$ & $\pm 0.00041 \mathrm{~g}^{(c)}$ \\
\hline $\mathrm{AmO}_{2}$ in $\mathrm{WRM}^{(\mathrm{d})}$ & $0.06903 \mathrm{~g}$ & $\pm 0.00028 \mathrm{~g}^{(e)}$ \\
\hline Am Assay $1^{(\mathfrak{n})}$ & $1069.5 \mu \mathrm{g} \mathrm{Am} / \mathrm{g} \mathrm{PuO}_{2}$ & $\pm 2.8 \mu \mathrm{g}^{(\mathrm{B})}$ \\
\hline Am Assay2 $2^{(\mathrm{h})}$ & $0.78727 \mathrm{~g} \mathrm{Am} / \mathrm{g} \mathrm{AmO}_{2}$ & $\pm 0.00352 \mathrm{~g}^{(i)}$ \\
\hline Am in $W_{R M}^{(0)}$ & $0.05477 \mathrm{~g}$ & $\pm 0.00022 \mathrm{~g}^{(\mathrm{x})}$ \\
\hline \multicolumn{3}{|l|}{ Isotopic Weight Fraction } \\
\hline${ }^{238} \mathrm{Pu}$ & 0.000143 & $\pm 0.000018^{(1)}$ \\
\hline${ }^{239} \mathrm{Pu}$ & 0.937811 & $\pm 0.000028^{(1)}$ \\
\hline${ }^{240} \mathrm{Pu}$ & 0.059448 & $\pm 0.000010^{(1)}$ \\
\hline${ }^{241} \mathrm{Pu}$ & 0.002038 & $\pm 0.000019^{(l)}$ \\
\hline${ }^{242} \mathrm{Pu}$ & 0.000560 & $\pm 0.000003^{(1)}$ \\
\hline \multirow[t]{2}{*}{ Total $\alpha$ Activity in WRM } & $217.42 \mathrm{mCi}$ & $\pm 0.76 \mathrm{mCi}^{(\mathrm{m})}$ \\
\hline & 8.04E+9 Bq & $\pm 2.81 \mathrm{E}+07 \mathrm{~Bq}^{(\mathrm{m})}$ \\
\hline
\end{tabular}

All values decay corrected to 6/1/97.

Bill J. McKerley, Group Leader Analytical Chemistry, NMT-1
Robert S. Marshall, Project Manager NDA CEP WRM Production 


\section{MEASUREMENT METHOD AND TRACEABILITY}

The nuclear contents of this WRM were characterized and qualified using the following methods with traceability to the National Institute of Standards and Technology (formerly NBS) or New Brunswick Laboratory (NBL) standards.

$\begin{array}{cc}\text { Measurement } & \text { Measurement Method } \\ \text { Weighing } & 5 \text { place analytical balance } \\ \text { Pu Assay } & \text { Controlled Potential Coulometry } \\ \text { Am Assay } & \text { Isotope Dilution Mass Spec. } \\ \text { Pu Isotopic } & \text { Total Evaporation Mass Spec. } \\ \alpha \text { Activity } & \text { Calculated from Pu and Am mass } \\ & \text { and isotope } \alpha \text { specific activities. }\end{array}$

$\underline{\text { Reference Material }}$

NIST traceable weights

NBL CRM 126

NIST SRM 4322B

NBS SRM 948

$T_{1 / 1}$ values are from: Firestone, Table of Isotopes, Vol. II, 8th ed., John Wiley \& Sons, New York, (1996). Atomic masses used are from: Audi \& Wapstra, The 1995 Update to the Atomic Mass Evaluation, Nuclear Physics, A595, p.409, (1995).

\section{NOTES}

Random and systematic error terms were combined and reported as $95 \%$ confidence intervals. Error terms and other notes are listed below:

(a) Balance precision, bouyancy, standard weight sets

(b) Long term precision, weighing precision and bias

(c) Above weighing and assay terms and correction for transfer loss

(d) Amount of $\mathrm{AmO}_{2}$ weighed for the WRM (does not contain the amount of Am from the decay of ${ }^{241} \mathrm{Pu}$ in the $\mathrm{PuO}_{2}$.

(e) Above weighing and assay terms and correction for transfer loss

(f) The amount of $\mathrm{Am}$ contained within the $\mathrm{PuO}_{2}$ from grow-in.

(g) Long term precision, weighing precision and bias

(h) The amount of Am contained within the $\mathrm{AmO}_{2}$

(i) Long term precision, weighing precision and bias

(j) Total amount of Am in the WRM from both the $\mathrm{AmO}_{2}$ and the $\mathrm{PuO}_{2}$

(k) Above weighing terms, Am assay terms, and corrections for transfer loss

(l) Long term precision and bias

(m) Based on propagated uncertainties on the Pu mass, ${ }^{241} \mathrm{Am}$ mass and $\mathrm{Pu}$ isotopic uncertainties listed above. It is recommended that all facilities participating in the NDA CEP program use the half-lives listed above to preclude facility to facility error terms introduced by using different half-life values. 


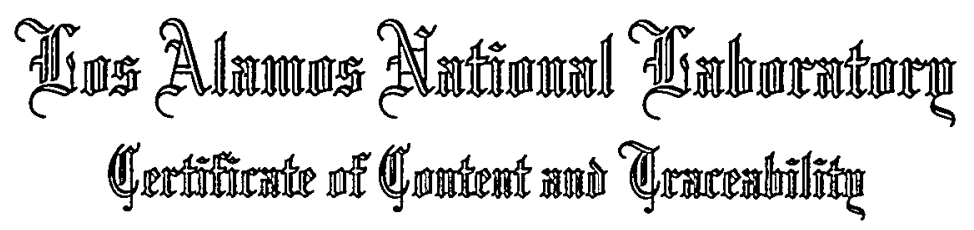

\section{Department of Energy/Idaho National Engineering and Environmental Laboratory Working Reference Material \# CEP008}

\section{$\mathrm{PuO}_{2}-\mathrm{AmO}_{2}$-Diatomaceous Earth}

This Working Reference Material (WRM) contains high purity plutonium dioxide and americium dioxide dispersed in diatomaceous earth. Quantitative information and uncertainties on the nuclear content of this WRM are listed below. Complete information regarding the $\mathrm{Pu}$ and $\mathrm{Am}$ content, $\mathrm{Pu}$ isotopic ratios, chemical composition, elemental impurities, containment, and WRM fabrication procedure is described in the NDA CEP WRM Production Plan, LACP-98-155, and in files retained at the Idaho National Engineering and Environmental Laboratory by the Lockheed Martin Idaho Technology Co. Transuranic Waste Department and at the Los Alamos National Laboratory Analytical Chemistry Group.

\section{NUCLEAR MATERIAL CONTENT}

The nuclear material content and total alpha activity for this WRM are listed below. Also listed are overall uncertainty estimates at $95 \%$ confidence intervals $(\mathrm{CI})$ for each component.

\begin{tabular}{|c|c|c|}
\hline Component & Quantity or Value & $95 \% \mathrm{CI}$ \\
\hline $\mathrm{PuO}_{2}$ in WRM & $0.47074 \mathrm{~g}$ & $\pm 0.00049 \mathrm{~g}^{(a)}$ \\
\hline Pu Assay & $0.87804 \mathrm{~g} \mathrm{Pu} / \mathrm{g} \mathrm{PuO}_{2}$ & $\pm 0.00036 \mathrm{~g}^{(b)}$ \\
\hline $\mathrm{Pu}$ in WRM & $0.41333 \mathrm{~g}$ & $\pm 0.00043 \mathrm{~g}^{(c)}$ \\
\hline $\mathrm{AmO}_{2}$ in $\mathrm{WRM}^{(\mathrm{d})}$ & $0.06566 \mathrm{~g}$ & $\pm 0.00027 \mathrm{~g}^{(e)}$ \\
\hline Am Assayl $1^{(\mathfrak{i})}$ & $1069.5 \mu \mathrm{g} \mathrm{Am} / \mathrm{g} \mathrm{PuO}_{2}$ & $\pm 2.8 \mu \mathrm{g}^{(\mathrm{g})}$ \\
\hline Am Assay $2^{(\mathrm{b})}$ & $0.78727 \mathrm{~g} \mathrm{Am} / \mathrm{g} \mathrm{AmO}_{2}$ & $\pm 0.00352 \mathrm{~g}^{(\mathrm{i})}$ \\
\hline Am in $W_{R M}^{(0)}$ & $0.05213 \mathrm{~g}$ & $\pm 0.00021 \mathrm{~g}^{(\mathrm{k})}$ \\
\hline \multicolumn{3}{|l|}{ Isotopic Weight Fraction } \\
\hline${ }^{238} \mathrm{Pu}$ & 0.000143 & $\pm 0.000018^{(1)}$ \\
\hline${ }^{239} \mathrm{Pu}$ & 0.937811 & $\pm 0.000028^{(\mathfrak{)})}$ \\
\hline${ }^{240} \mathrm{Pu}$ & 0.059448 & $\pm 0.000010^{(1)}$ \\
\hline${ }^{241} \mathrm{Pu}$ & 0.002038 & $\pm 0.000019^{(1)}$ \\
\hline${ }^{242} \mathrm{Pu}$ & 0.000560 & $\pm 0.000003^{(1)}$ \\
\hline \multirow[t]{2}{*}{ Total $\alpha$ Activity in WRM } & $209.70 \mathrm{mCi}$ & $\pm 0.73 \mathrm{mCi}^{(\mathrm{m})}$ \\
\hline & $7.76 \mathrm{E}+9 \mathrm{~Bq}$ & $\pm 2.68 \mathrm{E}+07 \mathrm{~Bq}^{(\mathrm{m})}$ \\
\hline
\end{tabular}

All values decay corrected to $6 / 1 / 97$.

Bill J. McKerley, Group Leader Analytical Chemistry, NMT-1
Robert S. Marshall, Project Manager NDA CEP WRM Production 


\section{MEASUREMENT METHOD AND TRACEABILITY}

The nuclear contents of this WRM were characterized and qualified using the following methods with traceability to the National Institute of Standards and Technology (formerly NBS) or New Brunswick Laboratory (NBL) standards.

$\begin{array}{cc}\text { Measurement } & \text { Measurement Method } \\ \text { Weighing } & 5 \text { place analytical balance } \\ \text { Pu Assay } & \text { Controlled Potential Coulometry } \\ \text { Am Assay } & \text { Isotope Dilution Mass Spec. } \\ \text { Pu Isotopic } & \text { Total Evaporation Mass Spec. } \\ \alpha \text { Activity } & \text { Calculated from Pu and Am mass } \\ & \text { and isotope } \alpha \text { specific activities. }\end{array}$

Reference Material

NIST traceable weights

NBL CRM 126

NIST SRM 4322B

NBS SRM 948

$\mathrm{T}_{1 / 2}$ values are from: Firestone, Table of Isotopes, Vol. II, 8th ed., John Wiley \& Sons, New York, (1996). Atomic masses used are from: Audi \& Wapstra, The 1995 Update to the Atomic Mass Evaluation, Nuclear Physics, A595, p.409, (1995).

\section{NOTES}

Random and systematic error terms were combined and reported as $95 \%$ confidence intervals. Error terms and other notes are listed below:

(a) Balance precision, bouyancy, standard weight sets

(b) Long term precision, weighing precision and bias

(c) Above weighing and assay terms and correction for transfer loss

(d) Amount of $\mathrm{AmO}_{2}$ weighed for the WRM (does not contain the amount of Am from the decay of ${ }^{241} \mathrm{Pu}$ in the $\mathrm{PuO}_{2}$.

(e) Above weighing and assay terms and correction for transfer loss

(f) The amount of Am contained within the $\mathrm{PuO}_{2}$ from grow-in.

(g) Long term precision, weighing precision and bias

(h) The amount of $\mathrm{Am}$ contained within the $\mathrm{AmO}_{2}$

(i) Long term precision, weighing precision and bias

(j) Total amount of Am in the WRM from both the $\mathrm{AmO}_{2}$ and the $\mathrm{PuO}_{2}$

(k) Above weighing terms, Am assay terms, and corrections for transfer loss

(l) Long term precision and bias

(m) Based on propagated uncertainties on the Pu mass, ${ }^{241} \mathrm{Am}$ mass and $\mathrm{Pu}$ isotopic uncertainties listed above. It is recommended that all facilities participating in the NDA CEP program use the half-lives listed above to preclude facility to facility error terms introduced by using different half-life values. 


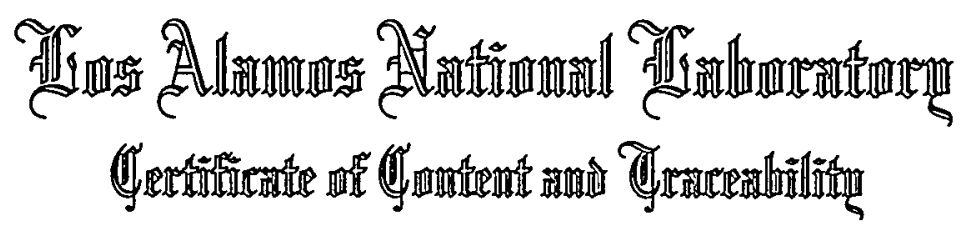

\title{
Department of Energy/Idaho National Engineering and Environmental Laboratory Working Reference Material \# CEP009
}

\author{
$\mathrm{AmO}_{2}$-Diatomaceous Earth
}

This Working Reference Material (WRM) contains high purity americium dioxide dispersed in diatomaceous earth. Quantitative information and uncertainties on the nuclear content of this WRM are listed below. Complete information regarding the Am content, chemical composition, elemental impurities, containment, and WRM fabrication procedure is described in the NDA CEP WRM Production Plan, LACP-98-155, and in files retained at the Idaho National Engineering and Environmental Laboratory by the Lockheed Martin Idaho Technology Co. Transuranic Waste Department and at the Los Alamos National Laboratory Analytical Chemistry Group.

\section{NUCLEAR MATERIAL CONTENT}

The nuclear material content and total alpha activity for this WRM are listed below. Also listed are overall uncertainty estimates at $\mathbf{9 5 \%}$ confidence intervals (CI) for each component.

\begin{tabular}{||ccc||}
\hline Component & Quantity or Value & $\underline{95 \% \mathrm{CI}}$ \\
$\mathrm{AmO}_{2}$ in $\mathrm{WRM}^{(\mathrm{a})}$ & $0.13133 \mathrm{~g}$ & $\pm 0.00053 \mathrm{~g}^{(\mathrm{b})}$ \\
$\mathrm{Am} \mathrm{Assay}^{(\mathrm{c})}$ & $0.78727 \mathrm{~g} \mathrm{Am} / \mathrm{g} \mathrm{AmO}_{2}$ & $\pm 0.00352 \mathrm{~g}^{(\mathrm{d})}$ \\
$\mathrm{Am}$ in WRM & \\
& $0.10340 \mathrm{~g}$ & $\pm 0.00042 \mathrm{~g}^{(\mathrm{s})}$ \\
Total $\alpha$ Activity in WRM & $355.08 \mathrm{mCi}$ & $\pm 1.43 \mathrm{mCi}^{(\mathrm{s})}$ \\
& $1.31 \mathrm{E}+10 \mathrm{~Bq}$ & $\pm 5.28 \mathrm{E}+07 \mathrm{~Bq}^{(\mathrm{s})}$ \\
\hline
\end{tabular}

All values decay corrected to 6/1/97.

Bill J. McKerley, Group Leader

Analytical Chemistry, NMT-1
Robert S. Marshall, Project Manager

NDA CEP WRM Production 


\section{MEASUREMENT METHOD AND TRACEABILITY}

The nuclear contents of this WRM were characterized and qualified using the following methods with traceability to the National Institute of Standards and Technology (formerly NBS) or New Brunswick Laboratory (NBL) standards.

Measurement

Weighing

Am Assay

$\alpha$ Activity
Measurement Method

5 place analytical balance

Isotope Dilution Mass Spec.

Calculated from Am mass

and isotope $\alpha$ specific activity
Reference Material

NIST traceable weights

NIST SRM 4322B

$\mathrm{T}_{1 / 2}$ value is from: Firestone, Table of Isotopes, Vol. II, 8th ed., John Wiley \& Sons, New York, (1996). Atomic mass used is from: Audi \& Wapstra, The 1995 Update to the Atomic Mass Evaluation, Nuclear Physics, A595, p.409, (1995).

\section{NOTES}

Random and systematic error terms were combined and reported as $95 \%$ confidence intervals. Error terms and other notes are listed below:

(a) Amount of $\mathrm{AmO}_{2}$ weighed for the WRM;.Balance precision, bouyancy, standard weight sets and correction for transfer loss

(b) Long term precision, weighing precision and bias

(c) Above weighing and assay terms and correction for transfer loss

(d) Long term precision and bias

(e) Total amount of Am in the WRM from the $\mathrm{AmO}_{2}$

(f) Above weighing terms, Am assay terms, and corrections for transfer loss

(g) Based on propagated uncertainties on the $\mathrm{Pu}$ mass, ${ }^{241} \mathrm{Am}$ mass and $\mathrm{Pu}$ isotopic uncertainties listed above. It is recommended that all facilities participating in the NDA CEP program use the half-lives listed above to preclude facility to facility error terms introduced by using different half-life values. 


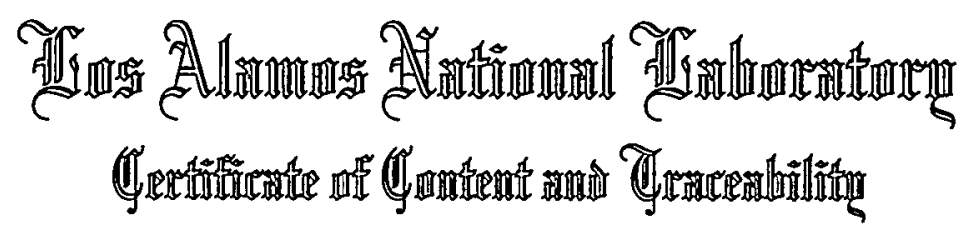

\title{
Department of Energy/Idaho National Engineering and Environmental Laboratory Working Reference Material \# CEP010
}

\author{
$\mathrm{AmO}_{2}$-Diatomaceous Earth
}

This Working Reference Material (WRM) contains high purity americium dioxide dispersed in diatomaceous earth. Quantitative information and uncertainties on the nuclear content of this WRM are listed below. Complete information regarding the Am content, chemical composition, elemental impurities, containment, and WRM fabrication procedure is described in the NDA CEP WRM Production Plan, LACP-98-155, and in files retained at the Idaho National Engineering and Environmental Laboratory by the Lockheed Martin Idaho Technology Co. Transuranic Waste Department and at the Los Alamos National Laboratory Analytical Chemistry Group.

\section{NUCLEAR MATERIAL CONTENT}

The nuclear material content and total alpha activity for this WRM are listed below. Also listed are overall uncertainty estimates at $\mathbf{9 5 \%}$ confidence intervals $(\mathrm{CI})$ for each component.

\begin{tabular}{|c|c|c|}
\hline Component & Quantity or Value & $95 \% \mathrm{CI}$ \\
\hline $\mathrm{AmO}_{2}$ in $\mathrm{WRM}^{(\mathrm{a})}$ & $0.12674 \mathrm{~g}$ & $\pm 0.00051 \mathrm{~g}^{(b)}$ \\
\hline Am Assay(c) & $0.78727 \mathrm{~g} \mathrm{Am} / \mathrm{g} \mathrm{AmO}_{2}$ & $\pm 0.00352 \mathrm{~g}^{(0)}$ \\
\hline Am in $\mathrm{WRM}^{(\boldsymbol{e})}$ & $0.099775 \mathrm{~g}$ & 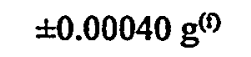 \\
\hline \multirow{2}{*}{ Total $\alpha$ Activity in WRM } & $342.65 \mathrm{mCi}$ & $\pm 1.38 \mathrm{mCi}^{(s)}$ \\
\hline & $1.27 \mathrm{E}+10 \mathrm{~Bq}$ & $\pm 5.10 \mathrm{E}+07 \mathrm{~Bq}^{(\mathrm{B})}$ \\
\hline
\end{tabular}

All values decay corrected to 6/1/97.

Bill J. McKerley, Group Leader

Analytical Chemistry, NMT-1
Robert S. Marshall, Project Manager

NDA CEP WRM Production 


\section{MEASUREMENT METHOD AND TRACEABILITY}

The nuclear contents of this WRM were characterized and qualified using the following methods with traceability to the National Institute of Standards and Technology (formerly NBS) or New Brunswick Laboratory (NBL) standards.

Measurement

Weighing

Am Assay

$\alpha$ Activity
Measurement Method

5 place analytical balance

Isotope Dilution Mass Spec.

Calculated from Am mass

and isotope $\alpha$ specific activity $\underline{\text { Reference Material }}$

NIST traceable weights

NIST SRM 4322B

$T_{1 / 2}$ value is from: Firestone, Table of Isotopes, Vol. II, 8th ed., John Wiley \& Sons, New York, (1996). Atomic mass used is from: Audi \& Wapstra, The 1995 Update to the Atomic Mass Evaluation, Nuclear Physics, A595, p.409, (1995).

\section{NOTES}

Random and systematic error terms were combined and reported as $95 \%$ confidence intervals. Error terms and other notes are listed below:

(a) Amount of $\mathrm{AmO}_{2}$ weighed for the WRM;.Balance precision, bouyancy, standard weight sets and correction for transfer loss

(b) Long term precision, weighing precision and bias

(c) Above weighing and assay terms and correction for transfer loss

(d) Long term precision and bias

(e) Total amount of Am in the WRM from the $\mathrm{AmO}_{2}$

(f) Above weighing terms, Am assay terms, and corrections for transfer loss

(g) Based on propagated uncertainties on the Pu mass, ${ }^{241} \mathrm{Am}$ mass and $\mathrm{Pu}$ isotopic uncertainties listed above. It is recommended that all facilities participating in the NDA CEP program use the half-lives listed above to preclude facility to facility error terms introduced by using different half-life values. 


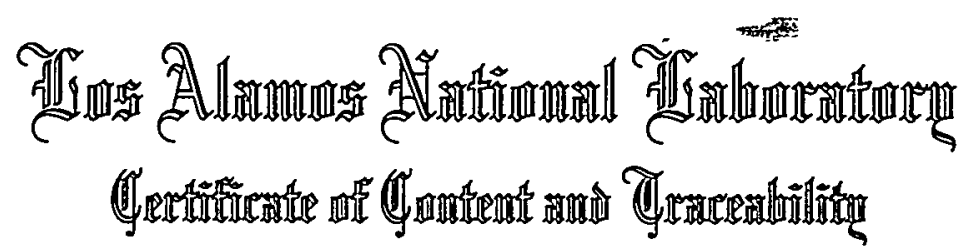

\section{Department of Energy/Idaho National Engineering and Environmental Laboratory Working Reference Material \# CEP011}

\section{$\mathrm{UO}_{2}$-Diatomaceous Earth}

This Working Reference Material (WRM) contains high purity uranium dioxide dispersed in diatomaceous earth. Quantitative information and uncertainties on the nuclear content of this WRM are listed below. Complete information regarding the $U$ content, $U$ isotopic ratios, chemical composition, elemental impurities, containment, and WRM fabrication procedure is described in the NDA CEP WRM Production Plan, LACP-98-155, and in files retained at the Idaho National Engineering and Environmental Laboratory by the Lockheed Martin Idaho Technology Co. Transuranic Waste Department and at the Los Alamos National Laboratory Analytical Chemistry Group.

\section{NUCLEAR MATERIAL CONTENT}

The nuclear material content and total alpha activity for this WRM are listed below. Also listed are overall uncertainty estimates at $95 \%$ confidence intervals (CD) for each component.

\begin{tabular}{||ccc||}
\hline Component & Quantity or Value & $25 \% \mathrm{CI}$ \\
$\mathrm{UO}_{2}$ in WRM & $570.58 \mathrm{~g}$ & $\pm 0.64 \mathrm{~g}^{(\mathrm{s})}$ \\
$\mathrm{U}$ Assay & $0.87493 \mathrm{~g} \mathrm{Pu} / \mathrm{g} \mathrm{PuO}_{2}$ & $\pm 0.00012 \mathrm{~g}^{(\mathrm{b})}$ \\
$\mathrm{U}$ in WRM & $499.22 \mathrm{~g}$ & $\pm 0.56 \mathrm{~g}^{(\mathrm{c})}$ \\
& & \\
Isotopic Weight Fraction & & \\
& & \\
${ }^{233} \mathrm{U}$ & 0.000000 & $\pm 0.000000^{(\mathrm{d})}$ \\
${ }^{234} \mathrm{U}$ & 0.000080 & $\pm 0.000005^{(\mathrm{d})}$ \\
${ }^{235} \mathrm{U}$ & 0.001902 & $\pm 0.000004^{(\mathrm{o})}$ \\
${ }^{236} \mathrm{U}$ & 0.000034 & $\pm 0.000004^{(\mathrm{o})}$ \\
${ }^{238} \mathrm{U}$ & 0.998057 & $\pm 0.000007^{(\mathrm{d})}$ \\
& & $\pm 0.05 \mathrm{mCi}^{(\mathrm{e})}$ \\
Total $\alpha$ Activity in WRM & $17.65 \mathrm{mCi}$ & $\pm 1.803 \mathrm{E}+06 \mathrm{~Bq}^{(e)}$ \\
& $6.530 \mathrm{E}+08 \mathrm{~Bq}$ & \\
\hline
\end{tabular}

All values decay corrected to 6/1/97.

Bill J. McKerley, Group Leader

Analytical Chemistry, NMT-1
Robert S. Marshall, Project Manager

NDA CEP WRM Production 


\section{MEASUREMENT METHOD AND TRACEABILITY}

The nuclear contents of this WRM were characterized and qualified using the following methods with traceability to the National Institute of Standards and Technology (formerly NBS) or New Brunswick Laboratory (NBL) standards.

$\begin{array}{cc}\text { Measurement } & \text { Measurement Method } \\ \text { Weighing } & 5 \text { place analytical balance } \\ \text { U Assay } & \text { Isotope Dilution Mass Spec. } \\ \text { U Isotopic } & \text { Total Evaporation Mass Spec. } \\ \alpha \text { Activity } & \text { Calculated from Pu and Am mass } \\ & \text { and isotope } \alpha \text { specific activities. }\end{array}$

$\underline{\text { Reference Material }}$

NIST traceable weights

NBS U005

NBS U005

$T_{1 / 2}$ values are from: Firestone, Table of Isotopes, Vol. II, 8th ed., John Wiley \& Sons, New York, (1996). Atomic masses used are from: Audi \& Wapstra, The 1995 Update to the Atomic Mass Evaluation, Nuclear Physics, A595, p.409, (1995).

\section{NOTES}

Random and systematic error terms were combined and reported as $95 \%$ confidence intervals. Error terms and other notes are listed below:

(a) Balance precision, bouyancy, standard weight sets

(b) Short term precision, weighing precision and bias

(c) Above weighing and assay terms and correction for transfer loss

(d) Short term precision and bias

(e) Based on propagated uncertainties on the $U$ mass and $U$ isotopic uncertainties listed above. It is recommended that all facilities participating in the NDA CEP program use the half-lives listed above to preclude facility to facility error terms introduced by using different half-life values. 


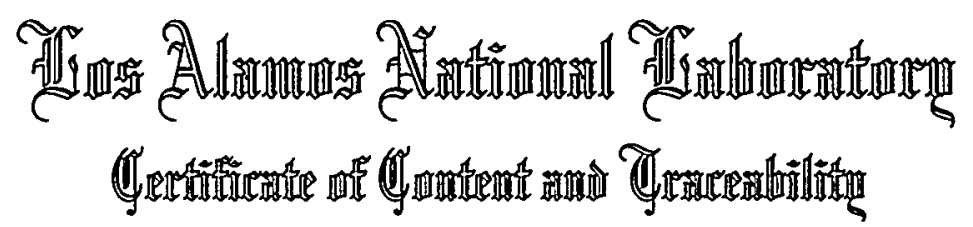

\section{Department of Energy/Idaho National Engineering and Environmental Laboratory Working Reference Material \# CEP012}

\section{UO $_{2}$-Diatomaceous Earth}

This Working Reference Material (WRM) contains high purity uranium dioxide dispersed in diatomaceous earth. Quantitative information and uncertainties on the nuclear content of this WRM are listed below. Complete information regarding the $U$ content, $U$ isotopic ratios, chemical composition, elemental impurities, containment, and WRM fabrication procedure is described in the NDA CEP WRM Production Plan, LACP-98-155, and in files retained at the Idaho National Engineering and Environmental Laboratory by the Lockheed Martin Idaho Technology Co. Transuranic Waste Department and at the Los Alamos National Laboratory Analytical Chemistry Group.

\section{NUCLEAR MATERIAL CONTENT}

The nuclear material content and total alpha activity for this WRM are listed below. Also listed are overall uncertainty estimates at $95 \%$ confidence intervals (CI) for each component.

\begin{tabular}{||ccc||}
\hline Component & Quantity or Value & $95 \% \mathrm{CI}$ \\
$\mathrm{UO}_{2}$ in WRM & $1010.30 \mathrm{~g}$ & $\pm 0.61 \mathrm{~g}^{(\mathrm{a})}$ \\
$\mathrm{U}$ Assay & $0.87493 \mathrm{~g} \mathrm{Pu} / \mathrm{g} \mathrm{PuO}_{2}$ & $\pm 0.00012 \mathrm{~g}^{(\mathrm{b})}$ \\
$\mathrm{U}$ in WRM & $883.94 \mathrm{~g}$ & $\pm 0.55 \mathrm{~g}^{(\mathrm{c})}$ \\
& & \\
Isotopic Weight Fraction & & \\
& & \\
${ }^{233} \mathrm{U}$ & 0.000000 & $\pm 0.000000^{(\mathrm{d})}$ \\
${ }^{234} \mathrm{U}$ & 0.000080 & $\pm 0.000005^{(\mathrm{d})}$ \\
${ }^{235} \mathrm{U}$ & 0.001902 & $\pm 0.000004^{(\mathrm{d})}$ \\
${ }^{236} \mathrm{U}$ & 0.000034 & $\pm 0.000004^{(\mathrm{d})}$ \\
${ }^{238} \mathrm{U}$ & 0.998057 & $\pm 0.000007^{(\mathrm{d})}$ \\
& & \\
Total $\alpha$ Activity in WRM & $31.25 \mathrm{mCi}$ & $\pm 0.08 \mathrm{mCi}^{(\mathrm{c})}$ \\
& $1.156 \mathrm{E}+10 \mathrm{~Bq}$ & $\pm 2.998 \mathrm{E}+06 \mathrm{~Bq}^{(\mathrm{c})}$ \\
\hline
\end{tabular}

All values decay corrected to $6 / 1 / 97$.

Bill J. McKerley, Group Leader Analytical Chemistry, NMT-1
Robert S. Marshall, Project Manager

NDA CEP WRM Production 
The nuclear contents of this WRM were characterized and qualified using the following methods with traceability to the National Institute of Standards and Technology (formerly NBS) or New Brunswick Laboratory (NBL) standards.

$\begin{array}{ccc}\text { Measurement } & \text { Measurement Method } & \text { Reference Material } \\ \text { Weighing } & 5 \text { place analytical balance } & \text { NIST traceable weights } \\ \text { U Assay } & \text { Isotope Dilution Mass Spec. } & \text { NBS U005 } \\ \text { U Isotopic } & \text { Total Evaporation Mass Spec. } & \text { NBS U005 } \\ \alpha \text { Activity } & \text { Calculated from Pu and Am mass } & \\ & \text { and isotope } \alpha \text { specific activities. }\end{array}$

$\mathrm{T}_{1 / 2}$ values are from: Firestone, Table of Isotopes, Vol. II, 8th ed., John Wiley \& Sons, New York, (1996). Atomic masses used are from: Audi \& Wapstra, The 1995 Update to the Atomic Mass Evaluation, Nuclear Physics, A595, p.409, (1995).

\section{NOTES}

Random and systematic error terms were combined and reported as $95 \%$ confidence intervals. Error terms and other notes are listed below:

(a) Balance precision, bouyancy, standard weight sets

(b) Short term precision, weighing precision and bias

(c) Above weighing and assay terms and correction for transfer loss

(d) Short term precision and bias

(e) Based on propagated uncertainties on the $U$ mass and $U$ isotopic uncertainties listed above. It is recommended that all facilities participating in the NDA CEP program use the half-lives listed above to preclude facility to facility error terms introduced by using different half-life values. 


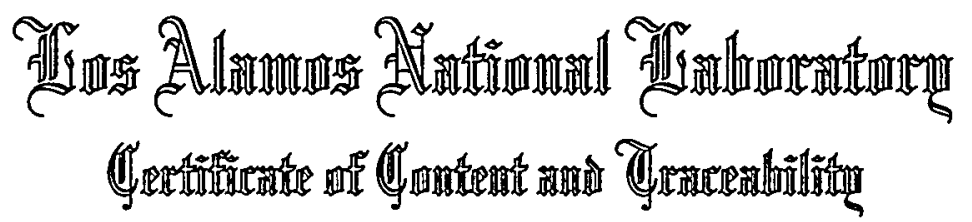

\title{
Department of Energy/Idaho National Engineering and Environmental Laboratory Working Reference Material \# CEP013
}

\author{
$\mathrm{UO}_{2}$-Diatomaceous Earth
}

This Working Reference Material (WRM) contains high purity uranium dioxide dispersed in diatomaceous earth. Quantitative information and uncertainties on the nuclear content of this WRM are listed below. Complete information regarding the $U$ content, $U$ isotopic ratios, chemical composition, elemental impurities, containment, and WRM fabrication procedure is described in the NDA CEP WRM Production Plan, LACP-98-155, and in files retained at the Idaho National Engineering and Environmental Laboratory by the Lockheed Martin Idaho Technology Co. Transuranic Waste Department and at the Los Alamos National Laboratory Analytical Chemistry Group.

\section{NUCLEAR MATERIAL CONTENT}

The nuclear material content and total alpha activity for this WRM are listed below. Also listed are overall uncertainty estimates at $\mathbf{9 5 \%}$ confidence intervals $(\mathrm{CI})$ for each component.

\begin{tabular}{||ccc||}
\hline Component & Quantity or Value & $95 \% \mathrm{CI}$ \\
$\mathrm{UO}_{2}$ in WRM & $1094.49 \mathrm{~g}$ & $\pm 1.10 \mathrm{~g}^{(\mathrm{a})}$ \\
U Assay & $0.87493 \mathrm{~g} \mathrm{Pu} / \mathrm{g} \mathrm{PuO}_{2}$ & $\pm 0.00012 \mathrm{~g}^{(\mathrm{b})}$ \\
$\mathrm{U}$ in WRM & $957.60 \mathrm{~g}$ & $\pm 0.96 \mathrm{~g}^{(\mathrm{c})}$ \\
& & \\
Isotopic Weight Fraction & & \\
& & \\
${ }^{233} \mathrm{U}$ & 0.000000 & $\pm 0.000000^{(\mathrm{d})}$ \\
${ }^{234} \mathrm{U}$ & 0.000080 & $\pm 0.000005^{(\mathrm{d})}$ \\
${ }^{235} \mathrm{U}$ & 0.001902 & $\pm 0.000004^{(\mathrm{d})}$ \\
${ }^{236} \mathrm{U}$ & 0.000034 & $\pm 0.000004^{(\mathrm{d})}$ \\
${ }^{238} \mathrm{U}$ & 0.998057 & $\pm 0.000007^{(\mathrm{d})}$ \\
& & $\pm 0.09 \mathrm{mCi}^{(\mathrm{e})}$ \\
Total $\alpha$ Activity in WRM & $33.85 \mathrm{mCi}$ & $\pm 3.399 \mathrm{E}+06 \mathrm{~Bq}^{(\mathrm{e})}$ \\
& $1.253 \mathrm{E}+09 \mathrm{~Bq}$ & \\
\hline
\end{tabular}

All values decay corrected to 6/1/97.

Bill J. McKerley, Group Leader Analytical Chemistry, NMT-1
Robert S. Marshall, Project Manager NDA CEP WRM Production 


\section{MEASUREMENT METHOD AND TRACEABILITY}

The nuclear contents of this WRM were characterized and qualified using the following methods with traceability to the National Institute of Standards and Technology (formerly NBS) or New Brunswick Laboratory (NBL) standards.

$\begin{array}{ccc}\text { Measurement } & \text { Measurement Method } & \text { Reference Material } \\ \text { Weighing } & \text { 5 place analytical balance } & \text { NIST traceable weights } \\ \text { U Assay } & \text { Isotope Dilution Mass Spec. } & \text { NBS U005 } \\ \text { U Isotopic } & \text { Total Evaporation Mass Spec. } & \text { NBS U005 } \\ \alpha \text { Activity } & \text { Calculated from Pu and Am mass } & \\ & \text { and isotope } \alpha \text { specific activities. } & \end{array}$

$T_{1 / 2}$ values are from: Firestone, Table of Isotopes, Vol. II, 8th ed., John Wiley \& Sons, New York, (1996). Atomic masses used are from: Audi \& Wapstra, The 1995 Update to the Atomic Mass Evaluation, Nuclear Physics, A595, p.409, (1995).

\section{NOTES}

Random and systematic error terms were combined and reported as $95 \%$ confidence intervals. Error terms and other notes are listed below:

(a) Balance precision, bouyancy, standard weight sets

(b) Short term precision, weighing precision and bias

(c) Above weighing and assay terms and correction for transfer loss

(d) Short term precision and bias

(e) Based on propagated uncertainties on the $U$ mass and $U$ isotopic uncertainties listed above. It is recommended that all facilities participating in the NDA CEP program use the half-lives listed above to preclude facility to facility error terms introduced by using different half-life values. 


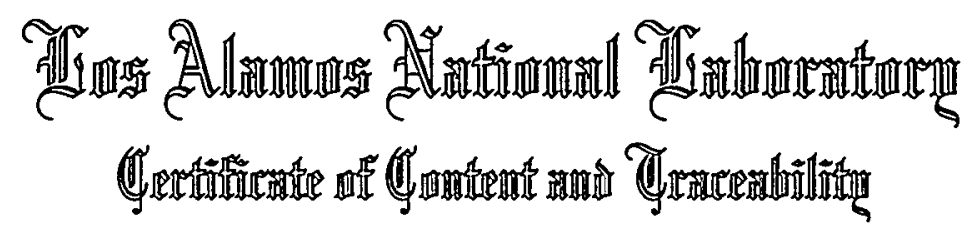

\title{
Department of Energy/Idaho National Engineering and Environmental Laboratory Working Reference Material \# CEP014
}

\author{
UO $_{2}$-Diatomaceous Earth
}

This Working Reference Material (WRM) contains high purity uranium dioxide dispersed in diatomaceous earth. Quantitative information and uncertainties on the nuclear content of this WRM are listed below. Complete information regarding the $U$ content, $U$ isotopic ratios, chemical composition, elemental impurities, containment, and WRM fabrication procedure is described in the NDA CEP WRM Production Plan, LACP-98-155, and in files retained at the Idaho National Engineering and Environmental Laboratory by the Lockheed Martin Idaho Technology Co. Transuranic Waste Department and at the Los Alamos National Laboratory Analytical Chemistry Group.

\section{NUCLEAR MATERIAL CONTENT}

The nuclear material content and total alpha activity for this WRM are listed below. Also listed are overall uncertainty estimates at $95 \%$ confidence intervals (CI) for each component.

\begin{tabular}{||ccc||}
\hline Component & Quantity or Value & $95 \% \mathrm{CI}$ \\
$\mathrm{UO}_{2}$ in WRM & $1096.66 \mathrm{~g}$ & $\pm 1.10 \mathrm{~g}^{(\mathrm{s})}$ \\
$\mathrm{U}$ Assay & $0.87493 \mathrm{~g} \mathrm{Pu} / \mathrm{g} \mathrm{PuO}_{2}$ & $\pm 0.00012 \mathrm{~g}^{(\mathrm{o})}$ \\
$\mathrm{U}$ in WRM & $959.50 \mathrm{~g}$ & $\pm 0.96 \mathrm{~g}^{(\mathrm{c})}$ \\
& & \\
Isotopic Weight Fraction & & \\
& & \\
${ }^{233} \mathrm{U}$ & 0.000000 & $\pm 0.000000^{(\mathrm{s})}$ \\
${ }^{234} \mathrm{U}$ & 0.000080 & $\pm 0.000005^{(\mathrm{d})}$ \\
${ }^{235} \mathrm{U}$ & 0.001902 & $\pm 0.000004^{(\mathrm{s})}$ \\
${ }^{236} \mathrm{U}$ & 0.000034 & $\pm 0.000004^{(\mathrm{d})}$ \\
${ }^{238} \mathrm{U}$ & 0.998057 & $\pm 0.000007^{(\mathrm{d})}$ \\
& & $\pm 0.09 \mathrm{mCi}^{(\mathrm{e})}$ \\
Total $\alpha$ Activity in WRM & $33.92 \mathrm{mCi}$ & $\pm 3.406 \mathrm{E}+06 \mathrm{~Bq}^{(\mathrm{c})}$ \\
& $1.255 \mathrm{E}+09 \mathrm{~Bq}$ & \\
\hline
\end{tabular}

All values decay corrected to 6/1/97.

Bill J. McKerley, Group Leader

Analytical Chemistry, NMT-1
Robert S. Marshall, Project Manager NDA CEP WRM Production 


\section{MEASUREMENT METHOD AND TRACEABILITY}

The nuclear contents of this WRM were characterized and qualified using the following methods with traceability to the National Institute of Standards and Technology (formerly NBS) or New Brunswick Laboratory (NBL) standards.

$\begin{array}{cc}\text { Measurement } & \text { Measurement Method } \\ \text { Weighing } & 5 \text { place analytical balance } \\ \text { U Assay } & \text { Isotope Dilution Mass Spec. } \\ \text { U Isotopic } & \text { Total Evaporation Mass Spec. } \\ \alpha \text { Activity } & \text { Calculated from Pu and Am mass } \\ & \text { and isotope } \alpha \text { specific activities. }\end{array}$

$\underline{\text { Reference Material }}$

NIST traceable weights

NBS U005

NBS U005

$T_{1 / 2}$ values are from: Firestone, Table of Isotopes, Vol. II, 8th ed., John Wiley \& Sons, New York, (1996). Atomic masses used are from: Audi \& Wapstra, The 1995 Update to the Atomic Mass Evaluation, Nuclear Physics, A595, p.409, (1995).

\section{NOTES}

Random and systematic error terms were combined and reported as $95 \%$ confidence intervals. Error terms and other notes are listed below:

(a) Balance precision, bouyancy, standard weight sets

(b) Short term precision, weighing precision and bias

(c) Above weighing and assay terms and correction for transfer loss

(d) Short term precision and bias

(e) Based on propagated uncertainties on the $U$ mass and $U$ isotopic uncertainties listed above. It is recommended that all facilities participating in the NDA CEP program use the half-lives listed above to preclude facility to facility error terms introduced by using different half-life values. 


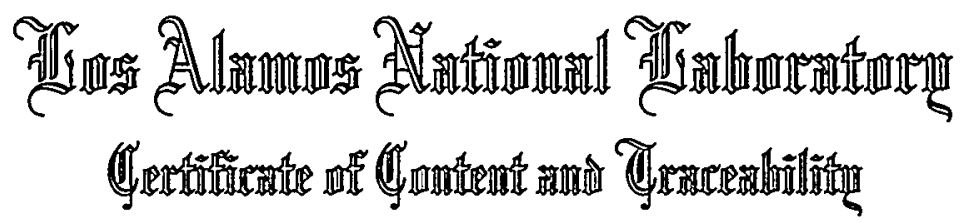

\title{
Department of Energy/Idaho National Engineering and Environmental Laboratory Working Reference Material \# CEP015
}

\author{
UO $_{2}$-Diatomaceous Earth
}

This Working Reference Material (WRM) contains high purity uranium dioxide dispersed in diatomaceous earth. Quantitative information and uncertainties on the nuclear content of this WRM are listed below. Complete information regarding the $U$ content, $U$ isotopic ratios, chemical composition, elemental impurities, containment, and WRM fabrication procedure is described in the NDA CEP WRM Production Plan, LACP-98-155, and in files retained at the Idaho National Engineering and Environmental Laboratory by the Lockheed Martin Idaho Technology Co. Transuranic Waste Department and at the Los Alamos National Laboratory Analytical Chemistry Group.

\section{NUCLEAR MATERIAL CONTENT}

The nuclear material content and total alpha activity for this WRM are listed below. Also listed are overall uncertainty estimates at $\mathbf{9 5 \%}$ confidence intervals $(\mathrm{CI})$ for each component.

\begin{tabular}{||ccc||}
\hline Component & Quantity or Value & $95 \% \mathrm{CI}$ \\
$\mathrm{UO}_{2}$ in WRM & $1111.68 \mathrm{~g}$ & $\pm 1.12 \mathrm{~g}^{(\mathrm{a})}$ \\
$\mathrm{U}$ Assay & $0.87493 \mathrm{~g} \mathrm{Pu} / \mathrm{g} \mathrm{PuO}_{2}$ & $\pm 0.00012 \mathrm{~g}^{(\mathrm{b})}$ \\
$\mathrm{U}$ in WRM & $972.64 \mathrm{~g}$ & $\pm 0.98 \mathrm{~g}^{(\mathrm{c})}$ \\
& & \\
Isotopic Weight Fraction & & \\
& & \\
${ }^{233} \mathrm{U}$ & 0.000000 & $\pm 0.000000^{(\mathrm{d})}$ \\
${ }^{234} \mathrm{U}$ & 0.000080 & $\pm 0.000005^{(\mathrm{d})}$ \\
${ }^{235} \mathrm{U}$ & 0.001902 & $\pm 0.000004^{(\mathrm{d})}$ \\
${ }^{236} \mathrm{U}$ & 0.000034 & $\pm 0.000004^{(\mathrm{d})}$ \\
${ }^{238} \mathrm{U}$ & 0.998057 & $\pm 0.000007^{(\mathrm{d})}$ \\
& & $\pm 0.09 \mathrm{mCi}^{(\mathrm{c})}$ \\
Total $\alpha$ Activity in WRM & $34.39 \mathrm{mCi}$ & $\pm 3.452 \mathrm{E}+06 \mathrm{~Bq}^{(\mathrm{e})}$ \\
\hline
\end{tabular}

All values decay corrected to $6 / 1 / 97$.

Bill J. McKerley, Group Leader Analytical Chemistry, NMT-1
Robert S. Marshall, Project Manager NDA CEP WRM Production 


\section{MEASUREMENT METHOD AND TRACEABILITY}

The nuclear contents of this WRM were characterized and qualified using the following methods with traceability to the National Institute of Standards and Technology (formerly NBS) or New Brunswick Laboratory (NBL) standards.

$\begin{array}{ccc}\text { Measurement } & \text { Measurement Method } & \text { Reference Material } \\ \text { Weighing } & 5 \text { place analytical balance } & \text { NIST traceable weights } \\ \text { U Assay } & \text { Isotope Dilution Mass Spec. } & \text { NBS U005 } \\ \text { U Isotopic } & \text { Total Evaporation Mass Spec. } & \text { NBS U005 } \\ \alpha \text { Activity } & \text { Calculated from Pu and Am mass } & \\ & \text { and isotope } \alpha \text { specific activities. } & \end{array}$

$T_{1 / 2}$ values are from: Firestone, Table of Isotopes, Vol. II, 8th ed., John Wiley \& Sons, New York, (1996). Atomic masses used are from: Audi \& Wapstra, The 1995 Update to the Atomic Mass Evaluation, Nuclear Physics, A595, p.409, (1995).

\section{NOTES}

Random and systematic error terms were combined and reported as $95 \%$ confidence intervals. Error terms and other notes are listed below:

(a) Balance precision, bouyancy, standard weight sets

(b) Short term precision, weighing precision and bias

(c) Above weighing and assay terms and correction for transfer loss

(d) Short term precision and bias

(e) Based on propagated uncertainties on the $U$ mass and $U$ isotopic uncertainties listed above. It is recommended that all facilities participating in the NDA CEP program use the half-lives listed above to preclude facility to facility error terms introduced by using different half-life values. 


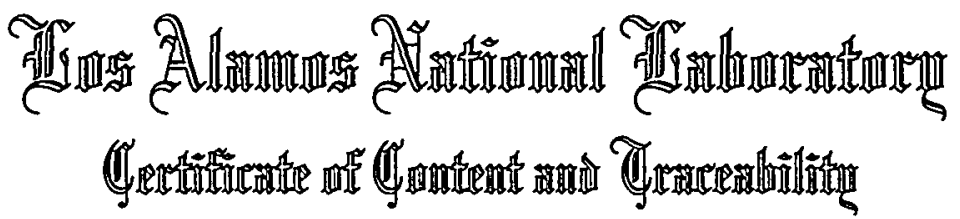

\section{Department of Energy/Idaho National Engineering and Environmental Laboratory Working Reference Material \# CEP016}

\section{UO $_{2}$-Diatomaceous Earth}

This Working Reference Material (WRM) contains high purity uranium dioxide dispersed in diatomaceous earth. Quantitative information and uncertainties on the nuclear content of this WRM are listed below. Complete information regarding the $U$ content, $U$ isotopic ratios, chemical composition, elemental impurities, containment, and WRM fabrication procedure is described in the NDA CEP WRM Production Plan, LACP-98-155, and in files retained at the Idaho National Engineering and Environmental Laboratory by the Lockheed Martin Idaho Technology Co. Transuranic Waste Department and at the Los Alamos National Laboratory Analytical Chemistry Group.

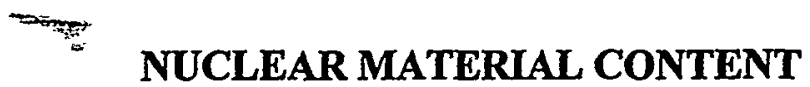

The nuclear material content and total alpha activity for this WRM are listed below. Also listed are overall uncertainty estimates at $95 \%$ confidence intervals (CI) for each component.

\begin{tabular}{||ccc||}
\hline Component & Quantity or Value & $95 \% \mathrm{CI}$ \\
$\mathrm{UO}_{2}$ in WRM & $1084.27 \mathrm{~g}$ & \\
$\mathrm{U}$ Assay & $0.87493 \mathrm{~g} \mathrm{Pu} / \mathrm{g} \mathrm{PuO}_{2}$ & $\pm 1.09 \mathrm{~g}^{(\mathrm{s})}$ \\
$\mathrm{U}$ in WRM & $948.66 \mathrm{~g}$ & $\pm 0.00012 \mathrm{~g}^{(\mathrm{b})}$ \\
& & $\pm 0.95 \mathrm{~g}^{(\mathrm{c})}$ \\
Isotopic Weight Fraction & & \\
& & \\
${ }^{233} \mathrm{U}$ & 0.000000 & $\pm 0.000000^{(\mathrm{s})}$ \\
${ }^{234} \mathrm{U}$ & 0.000080 & $\pm 0.000005^{(\mathrm{d})}$ \\
${ }^{235} \mathrm{U}$ & 0.001902 & $\pm 0.000004^{(\mathrm{d})}$ \\
${ }^{236} \mathrm{U}$ & 0.000034 & $\pm 0.000004^{(\mathrm{d})}$ \\
${ }^{238} \mathrm{U}$ & 0.998057 & $\pm 0.000007^{(\mathrm{d})}$ \\
& $33.54 \mathrm{mCi}$ & $\pm 0.09 \mathrm{mCi}^{(\mathrm{e})}$ \\
Total $\alpha$ Activity in WRM & $1.241 \mathrm{E}+09 \mathrm{~Bq}$ & $\pm 3.366 \mathrm{E}+06 \mathrm{~Bq}^{(\mathrm{e})}$ \\
\hline
\end{tabular}

All values decay corrected to $6 / 1 / 97$.

Bill J. McKerley, Group Leader Analytical Chemistry, NMT-1
Robert S. Marshall, Project Manager NDA CEP WRM Production 


\section{MEASUREMENT METHOD AND TRACEABILITY}

The nuclear contents of this WRM were characterized and qualified using the following methods with traceability to the National Institute of Standards and Technology (formerly NBS) or New Brunswick Laboratory (NBL) standards.

\section{Measurement}

Weighing

U Assay

U Isotopic

$\alpha$ Activity

\section{Measurement Method}

5 place analytical balance

Isotope Dilution Mass Spec.

Total Evaporation Mass Spec.

Calculated from $\mathrm{Pu}$ and $\mathrm{Am}$ mass

and isotope $\alpha$ specific activities. $\underline{\text { Reference Material }}$

NIST traceable weights

NBS U005

NBS U005

$T_{1 / 2}$ values are from: Firestone, Table of Isotopes, Vol. II, 8th ed., John Wiley \& Sons, New York, (1996). Atomic masses used are from: Audi \& Wapstra, The 1995 Update to the Atomic Mass Evaluation, Nuclear Physics, A595, p.409, (1995).

\section{NOTES}

Random and systematic error terms were combined and reported as $95 \%$ confidence intervals. Error terms and other notes are listed below:

(a) Balance precision, bouyancy, standard weight sets

(b) Short term precision, weighing precision and bias

(c) Above weighing and assay terms and correction for transfer loss

(d) Short term precision and bias

(e) Based on propagated uncertainties on the $U$ mass and $U$ isotopic uncertainties listed above. It is recommended that all facilities participating in the NDA CEP program use the half-lives listed above to preclude facility to facility error terms introduced by using different half-life values. 